\title{
Modelos longitudinais de grupos múltiplos multiníveis na teoria da resposta ao item : métodos de estimação e seleção estrutural sob uma perspectiva bayesiana
}

\author{
Caio Lucidius Naberezny Azevedo
}

\author{
TESE APRESENTADA \\ $\mathrm{AO}$ \\ Instituto de Matemática e Estatística \\ DA \\ Universidade De SÃo Paulo \\ PARA \\ OBTENÇÃO DO TÍTULO \\ $\mathrm{DE}$ \\ Doutor EM CiÊnCIAS
}

\author{
Área de Concentração: Estatística \\ Orientador: Prof. Dr. Dalton Francisco de Andrade \\ Co-Orientador: Prof. Dr. Carlos Alberto de Bragança Pereira
}

Durante o desenvolvimento deste trabalho o autor recebeu auxílio financeiro do $\mathrm{CNPq}$ 


\section{Modelos longitudinais de grupos múltiplos multiníveis na teoria da resposta ao item : métodos de estimação e seleção estrutural sob uma perspectiva bayesiana}

- Prof. Dr. Dalton Francisco de Andrade (orientador) - INE-UFSC.

- Prof. Dr. Carlos Alberto de Bragança Pereira (co-orientador) - IME-USP.

- Prof. Dr. Dani Gamerman - DME-UFRJ.

- Prof. Dr. Hélio dos Santos Migon - DME-UFRJ.

- Prof. Dr. Ruben Klein - CESGRANRIO. 
Dedico esta extensão da minha alma cristã-árcade, doravante Tese, à:

Deus, pela dádiva da plenitude Jesus, por nos trazer o amor Meus pais, Verônica e Hélio, pelo amor, carinho e a formação Minha esposa, Simone, pelo amor, apoio incondicional e compreensão Minha segunda mãe, Dalva, pelo amor e carinho Meus mestres, Maurício e Dalton, pelo respeito, apoio e dedicação. 
"Esperei com paciência pelo Senhor, e ele se inclinou para mim e ouviu o meu clamor. Também me tirou duma cova de destruição, dum charco de lodo; pôs os meus pés sobre uma rocha, firmou os meus passos.

Pôs na minha boca um cântico novo, um hino ao nosso Deus; muitos verão isso e temerão, e confiarão no Senhor. Bem-aventurado o homem que faz do Senhor a sua confiança, e que não atenta para os soberbos nem para os apóstatas mentirosos.

Muitas são, Senhor, Deus meu, as maravilhas que tens operado e os teus pensamentos para conosco; ninguém há que se possa comparar a ti; eu quisera anunciá-los, e manifestá-los, mas são mais do que se podem contar.

Sacrifício e oferta não desejas; abriste-me os ouvidos; holocausto e oferta de expiação pelo pecado não reclamaste.

Então disse eu: Eis aqui venho; no rolo do livro está escrito a meu respeito: Deleito-me em fazer a tua vontade, ó Deus meu; sim, a tua lei está dentro do meu coração.

Tenho proclamado boas-novas de justiça na grande congregação; eis que não retive os meus lábios; Não ocultei dentro do meu coração a tua justiça; apregoei a tua fidelidade e a tua salvação; não escondi da grande congregação a tua benignidade e a tua verdade.

Não detenhas para comigo, Senhor a tua compaixão; a tua benignidade e a tua fidelidade sempre me guardem.

Pois males sem número me têm rodeado; as minhas iniqüidades me têm alcançado, de modo que não posso ver; são mais numerosas do que os cabelos da minha cabeça, pelo que desfalece o meu coração.

Digna-te, Senhor, livra-me; Senhor, apressa-te em meu auxílio. Sejam à uma envergonhados e confundidos os que buscam a minha vida para destruí-la; tornem atrás e confundam-se os que me desejam o mal.

Desolados sejam em razão da sua afronta os que me dizem: Ah! Ah! Regozijem-se e alegrem-se em ti todos os que te buscam. Digam continuamente os que amam a tua salvação: Engrandecido seja o Senhor. Eu, na verdade, sou pobre e necessitado, mas o Senhor cuida de mim. Tu és o meu auxílio e o meu libertador; não te detenhas, ó Deus meu." 
"E também os soldados o escarneciam, chegando-se a ele, e apresentando-lhe vinagre. E dizendo: Se tu és o Rei dos Judeus, salva-te a ti mesmo. E também por cima dele, estava um título, escrito em letras gregas, romanas, e hebraicas: ESTE É O REI DOS JUDEUS. E um dos malfeitores que estavam pendurados blasfemava dele, dizendo: Se tu és o Cristo, salva-te a ti mesmo, e a nós.

Respondendo, porém, o outro, repreendia-o, dizendo: Tu nem ainda temes a Deus, estando na mesma condenação? E nós, na verdade, com justiça, porque recebemos o que os nossos feitos mereciam; mas este nenhum mal fez. E disse a Jesus: Senhor, lembra-te de mim, quando entrares no teu reino. E disse-lhe Jesus: Em verdade te digo que hoje estarás comigo no Paraíso. "

Lucas, $23,36-43$

"A consciência masculina tem sido comparada ao Sol, e a feminina à Lua. Ao meio dia, vê-se tudo com seus contornos nítidos e uma coisa se diferencia claramente da outra.

Mas ninguém consegue ficar muito tempo sob esse Sol quente e brilhante. Sem o frio, a umidade e a escuridão, a vista e a paisagem em breve se tornam insuportáveis, a terra seca e não pode produzir vida.

É assim que fica a vida do homem sem a influência da fertilidade feminina sobre ele. Sem o relacionamento com o seu mundo interior, um homem pode focalizar as coisas, mas falta-lhe imaginação; ele pode perseguir metas, mas vai faltar-lhe emoção; é capaz de lutar pelo poder, porém incapaz de ser criativo, porque não consegue produzir nova vida fora de si mesmo. Somente a profícua união do princípio Yin com o princípio Yang podem estimular sua energia, impedir sua consciência de se tornar estéril e sua força masculina de minguar."

Reverendo John A. Sanford 
"Não é fácil escrever.

É duro quebrar rochas.

Voam faíscas e lascas como aços espelhados.

Mas já que se há de escrever, que ao menos não se esmaguem com palavras as entrelinhas."

Clarice Lispector

"Até cortar os próprios defeitos pode ser perigoso. Nunca se sabe qual deles sustenta nosso edifício inteiro."

Clarice Lispector

"Perco a consciência, mas não importa, encontro a maior serenidade na alucinação. É curioso como não sei dizer quem sou. Quer dizer, sei-o bem, mas não posso dizer. Sobretudo tenho medo de dizer, porque no momento em que tento falar, não só não exprimo o que sinto como o que sinto se transforma lentamente no que eu digo."

Clarice Lispector

"Tenho pensamentos que, se pudesse revelá-los e fazê-los viver, acrescentariam nova luminosidade às estrelas, nova beleza ao mundo e maior amor ao coração dos homens. "

Fernando Pessoa 
Para minha Mãe, Verônica

"Mãe...São três letras apenas As desse nome bendito: Também o céu tem três letras E nelas cabe o infinito Para louvar a nossa mãe, Todo bem que se disser Nunca há de ser tão grande Como o bem que ela nos quer Palavra tão pequenina, Bem sabem os lábios meus Que és do tamanho do céu E apenas menor que Deus! ”

Mário Quintana 
Para minha esposa, Simone

"Eu quero olhar ao meu redor e ver além do que meus olhos podem ver Além do céu além do mar e ter certeza de que vou te encontrar. Olha pra mim. Nosso rumo certo fica em outra direção Há tempos eu sei que eu não sei viver sem teu carinho Não me deixe esquecer de todas nossas vidas sempre juntos E o futuro é aprender a ler aquilo que não está escrito São pequenos sinais nas nuvens nas estrelas Quanta coisa amor vimos se perder, e quantas coisas encontramos pra alegrar o coração Nessas horas eu chego acreditar, que certas vezes o melhor é se entregar à ilusão Mais um pouco e a dor vai embora vamos brincar a noite inteira e rir de tudo outra vez Fecha os olhos, me dê a mão que a chuva logo passa e o Sol volta a brilhar Eu quero olhar ao meu redor, e ver alé do que meus olhos podem ver Além do céu além do mar e ter certeza de que vou te encontrar"

Marcelo Bonfá

"Quem diz que Amor é falso ou enganoso, ligeiro, ingrato, vão, desconhecido, Sem falta lhe terá bem merecido

Que lhe seja cruel ou rigoroso. Amor é brando, é doce e é piedoso; Quem o contrário diz não seja crido:

Seja por cego e apaixonado tido, $\mathrm{E}$ aos homens e inda aos deuses odioso.

Se males faz Amor, em mi se vêem; Em mim mostrando todo o seu rigor, Ao mundo quis mostrar quanto podia.

Mas todas suas iras são de amor; Todos estes seus males são um bem, Que eu por todo outro bem não trocaria." 


\section{Agradecimentos}

Este segmento da nossa existência não teria tomado vida sem a ajuda de algumas pessoas. Elas, diretamente ou indiretamente, contribuíram para que os afluentes de nossas pesquisas desaguassem no mar da ciência. Dessa forma, gostaríamos de expressar nossos agradecimentos à:

Deus, criador, arquiteto do universo e essência da vida, pela dádiva da existência e pela construção do universo e do paraíso. Por nos conceder a todos o privilégio de ao menos poder tentar transformar o mundo no esboço do Paraíso.

À Jesus por ter-nos mostrado o caminho para a redenção, salvação e vida eterna, através do amor e do perdão. Pelo exemplo de perseverança em sua fé, no respeito pela vida e pelos valiosíssimos ensinamentos.

À meus pais, Verônica e Hélio, por todo o amor e carinho imensuráveis, pelos sacríficos feitos em nome dos filhos, pelo esforço em nos dar uma ótima educação: intelectual, moral e espiritual. Principalmente à minha mãe pelo apoio incondicional, pelas palvras e atitudes de amor que nos fizeram chegar até aqui e acreditar que os limites existem para serem superados. Por ter cudiado de mim em todos os momentos da minha vida, por ter me oferecido o abrigo e proteção de seu útero de sua alma maternas. Mais uma etapa vencida juntos, minha mãezinha.

À minha esposa, Simone, pelo amor, incentivo, apoio e compreensão nessa longa jornada. Por ter me ajudado a concretizar vários sonhos, dentre os quais a conclusão do nosso Doutorado. Por ter apoiado nosso estágio na Holanda, emocional e logisticamente. Por ter me ajudado a resgatar minha inspiração, coragem e fé. Por compartilhar sua essência comigo e unir-se à mim em busca da plenitude do amor e da longevidade da união.

À minha segunda mãe, Dalva, por ter cuidado de mim com empenho materno, pela dedicação, amor e carinho, desde minha infância até os dias de hoje. Por me tratar com imensa atenção e nos ter apoiado em todas nossas empreitadas.

Aos nossos irmãos, André e Elisângela, pelo amor, carinho e as brincadeiras fraternas. Pelo apoio e força nos momentos difíceis. 
À tia Paula, pelo amor ofertado, por toda ajuda e abrigo oferecidos durante todo Doutorado e por ter me acolhido como a um filho.

Ao nosso eterno mestre, amigo, pai e orientador, Prof. João Maurício, pelo incentivo, apoio e o amor despendido. Por ter me ajudado em momentos difícies da minha vida. Por ser, em parte, responsável, pelo meu caráter e personalidade, desde a graduação. Pelo respeito e confiança que sempre teve por nós e por acreditar em nossa dedicação.

Ao nosso amigo, pai e orientador, Prof. Dalton, pelo incentivo, paciência, apoio, confiança e amizade. Pela excelente orientação de todos os trabalhos que fizemos sob sua supervisão. Pelas palavras de carinho e segurança. Por acreditar em nosso esforço, por toda ajuda, desde a graduação, no âmbito acadêmico e pessoal. Por ter me acolhido diversas vezes em seu lar e por me oferecer carinho paterno.

Ao nosso co-orientador Prof. Carlos Alberto Bragança Pereira, pelo incentivo e apoio constantes e também as conversas bayesianas. Pelos conselhos e oportunidades.

Ao Prof. Dr. Jean-Paul Fox, da Universidade de Twente, Holanda, pela receptividade, respeito e apoio. Por ter me permitido conviver com sua família e pela hospitalidade oferecida. Pelas conversas decisivas para o surgimento dos Capítulos 3 e 4 e também por todo apoio logístico.

Ao nosso grande irmão Juvêncio, pela amizade, respeito e ajuda. Pelas brincadeiras e frases inesquecíveis, pelas conversas, discussões que ajudaram muito na Tese, pelo apoio emocional e pela partilha intelectual.

Aos nossos amigos Alexandre, Rafael, Michel e Fred, pela ajuda, principalmente quando estávamos além do oceano atlântico, pelo respeito, partilha e brincadeiras. Pelos artigos enviados e dúvidas solucionadas sobre a parte computacional.

Ao Prof. e amigo Héliton Tavares, pela ajuda fundamental no trabalho, apoio e amizade. Pelo respeito e incentivo e por acreditar em nosso trabalho.

Aos nossos amigos Gilberto e Ronald, pelas conversas sobre a TRI, as discussões fundamentais para o desenvolvimento do trabalho. Pela amizade, o apoio e o incentivo.

Aos amigos e colegas de graduação do DEMA/UFC e também de pós-graduação do IME/USP, pelas discussões, ajuda e os momentos de descontração. Em especial : aos amigos da UFC - Andrea, Agnaldo, Patrícia, Eveline, Jurandir e Gleydson; aos colegas do IME/USP - Elier, Paulo Tadeu, Tatiene, Kelly, Raydonal, Marcos e Daniela, Luz Mery, Jesus, David, Lílian, Domingo, Adrylaine, Said e Nélio; as amigas da sala 250 - Patrícia, Hilde, Fernanda Ester, Fernanda, Andreia e Maite.

A todos os professors e funcionários do Departamento de Estatística e Matemática Aplicada da Universidade Federal do Ceará (DEMA/UFC), pela formação proporcionada, ajuda e apoio. Em especial à: Welliandre, Manoel, Ana Maria, Márgeri e Luiza. 
Ao Prof. Júlio Singer pela amizade, ajuda, incentivo e as conversas longitudinais. Pelo apoio e a preocupação a nós ofertada.

A todos os professores do Departamento de Estatística do Instituto de Matemática e Estatística da Universidade de São Paulo (IME/USP), pela agradável convivência, amizade, os cafés e os congressos. Em especial à: Antônio Carlos, Beth Kira, Márcia Branco, Rinaldo Artes, Sílvia Ferrari e Cecília, por toda a ajuda e carinho.

Aos nossos amigos da Holanda, por me presentearem com um ambiente familiar, repleto de descontração, ternura e valiosas discussões científicas. Em especial a Oksana, Sascha e Emily, por partilharem sua família comigo, a Elger Abrahemse pela grande amizade, as viagens pela Holanda e memoráveis brincadeiras e a Khalid Naveed, pelo companheirismo, brincadeiras, passeios na neve e discussões sobre a TRI.

Aos amigos, Regina Albanese e Olímpio, pela receptividade, carinho e amizade. Pelas conversas e apoio, os almoços e por toda a cordialidade com que me trataram.

Aos membros da banca Prof. Hélio Migon, Prof. Dani Gamerman, Prof. Ruben Klein e Prof. Carlos Alberto Bragança Pereira, pelos valiosos comentários, sugestões, críticas e incentivos.

Aos Prof. Heleno pelo apoio na reta final e por ter aceitado o convite para compor a banca.

A Profa. Rosângela Loschi por ter aceitado o convite de participar da banca de nossa Tese.

Aos amigos que ficaram no Ceará nos apoiando : César, Yuri, Ximenes e Léo, pela amizade, brincadeiras e respeito.

Aos colegas cruspianos, Adriando e João Batista, pela grande ajuda e acolhimento.

Aos meus conterrâneos cearenses e ao estado do Ceará, por terem me proporcionado uma maravilohsa convivência durante quase toda a minha vida na terra da luz, por fazerem parte da minha história e da praia onde nasci e por me ajudar a construir parte dos alicerces da minha existência.

Ao povo e ao estado de São Paulo, por me proporcionar um grande aprendizado de vida, pelo ambiente cosmopolita e pela multipluralidade cultural presentes nesse estado.

Ao povo Holandês e a Holanda, pela calorosa recepção, pelas feiras nos fins-de-semana, por recuarem o mar com os diques e assim nos proporcionar mais terras a se conhecer, por serem um exemplo de organização e aproveitamento, e por terem fundado minha terra natal, a lindíssima cidade de Fortaleza.

Ao $\mathrm{CNPq}$ pelo apoio financeiro durante toda a graduação, mestrado, doutorado e doutorado sanduíche.

E, por fim, a todos aqueles, que por quaisquer motivos, não mencionei por fazerem parte desta etapa de nossa vida. 



\section{Resumo}

No presente trabalho propomos uma estrutura bayesiana, através de um esquema de dados aumentados, para analisar modelos longitudinais com grupos mútiplos (MLGMTRI) na Teoria da Resposta ao Item (TRI). Tal estrutura consiste na tríade : modelagem, métodos de estimação e métodos de diagnóstico para a classe de MLGMTRI. Na parte de modelagem, explorou-se as estruturas multivariada e multinível, com o intuito de representar a hierarquia existente em dados longitudinais com grupos múltiplos. Esta abordagem permite considerar várias classes de submodelos como: modelos de grupos múltiplos e modelos longitudinais de um único grupo. Estudamos alguns aspectos positivos e negativos de cada uma das supracitadas abordagens. A modelagem multivariada permite representar de forma direta estruturas de dependência, além de possibilitar que várias delas sejam facilmente incorporadas no processo de estimação. Isso permite considerar, por exemplo, uma matriz não estruturada e assim, obter indícios da forma mais apropriada para a estrutura de dependência. Por outro lado, a modelagem multinível propicia uma interpretação mais direta, obtenção de condicionais completas univariadas, fácil inclusão de informações adicionais, incorporação de fontes de dependência intra e entre unidades amostrais, dentre outras. Com relação aos métodos de estimação, desenvolvemos um procedimento baseado nas simulações de Monte Carlo via cadeias de Markov (MCMC). Mostramos que as distribuições condicionais completas possuem forma analítica conhecida e, além disso, são fáceis de se amostrar. Tal abordagem, apesar de demandar grande esforço computacional, contorna diversos problemas encontrados em outros procedimentos como: limitação no número de grupos envolvidos, quantidade de condições de avaliação, escolha de estruturas de dependência, assimetria dos traços latentes, imputação de dados, dentre outras. Além disso, através da metodologia MCMC, desenvolvemos uma estrutura de seleção de matrizes de covariâncias, através de um esquema de Monte Carlo via Cadeias de Markov de Saltos Reversíveis (RJMCMC). Estudos de simulação indicam que o modelo, o método de estimação e o método de seleção produzem resultados bastante satisfatórios. Também, robustez à escolha de prioris e valores iniciais foi observada. Os métodos de estimação desenvolvidos podem ser estendidos para diversas situações de interesse de um modo bem direto. Algumas das técnicas de diagnóstico estudadas permitem avaliar a qualidade do ajuste do modelo de um modo global. Outras medidas fornecem indícios de violação de suposições específicas, como ausência de normalidade para os traços latentes. Tal metodologia fornece meios concretos de se avaliar a qualidade do instrumento de medida (prova, questionário etc). Finalmente, a análise de um conjunto de dados real, utilizando-se alguns dos 
modelos abordados no presente trabalho, ilustra o potencial da tríade desenvolvida além de indicar um ganho na utilização dos modelos longitudinais da TRI na análise de ensaios educacionais com medidas repetidas em deterimento a suposição de independência.

Palavras-chave: Teorida da resposta ao item, dados longitudinais, grupos múltiplos, modelos multiníveis, inferência bayesiana, algoritmos MCMC, métodos de diagnostico. 


\section{Abstract}

In this work we proposed a bayesian framework, by using an augmented data scheme, to analyze longitudinal multiple groups models (LMGMIRT) in the Item Response Theory (IRT). Such framework consists in the following set : modelling, estimation methods and diagnostic tools to the LMGMIRT. Concerning the modelling, we exploited multivariate and multilevel structures in order to represent the hierarchical nature of the longitudinal multiple groupos model. This approach allows to consider several submodels such that: multiple groups and longitudinal one group models. We studied some positive and negative aspects of both above mentioned approches. The multivariate modelling allows to represent, in a straightforward way, many dependence structures. Furthermore it possibilities that many of them can be easily considered in the estimation process. This allows, for example, to consider an unstructured covariance matrix and, then, it allows to obtain information about the most appropritate dependece structure. On the other hand, the multilevel modelling permits to obtain: more straightforward interpretations of the model, the construction of univariate full conditional distributions, an easy way to include auxiliary information, the incorporation of within and between subjects (groups) sources of variability, among others. Concerning the estimation methods, we developed a procedure based on Monte Carlo Markov Chain (MCMC) simulation. We showed that the full conditional distributions are known and easy to sample from. Even though such approach demands a considerable amount of time it circumvents many problems such that: limitation in the number of groups that can be considered, the limitation in the number of instants of observation, the choice of covariance matrices, latent trait asymmetry, data imputation, among others. Furthermore, within the MCMC metodology, we developed a procedure to select covariance matrices, by using the so called Reversible Jump MCMC (RJMCMC). Simulation studies show that the model, the estimation method and the model selection procedure produce reasonable results. Also, the studies indicate that the developed metodology presents robustness concerning prior choice and different initial values choice. It is possible to extent the developed estimation methods to other situations in a straightforward way. Some diagnostics techniques that were studied allow to assess the model fit, in a global sense. Others techniques give directions toward the departing from some specific assumptions as the latent trait normality. Such methodology also provides ways to assess the quality of the test or questionaire used to measure the latent traits. Finally, by analyzing a real data set, using some of the models that were developed, it was possible to verify the potential of the methodology considered in this work. Furthermore, the results of 
this analysis indicate advantages in using longitudinal IRT models to model educational repeated measurement data instead of to assume independence.

Keywords: Item response theory, multiple groups, multilevel models, bayesian inference, MCMC algorithms, diagnostic methods. 


\section{Prólogo}

Apesar de termos tentado minimizar a quantidade de erros, eventualmente, algumas fórmulas podem conter imprecisões. Portanto, sugerimos que o leitor revise os resultados que pretende utilizar. Os programas desenvolvidos, embora não tenham versão amigável para o usuário, podem ser utilizados sem grandes problemas. Qualquer material de interesse pode ser solicitado via e-mail : cnaber@gmail.com. Sugestões, críticas e comentários são totalmente bem-vindos. Assumimos toda e qualquer responsabilidade acerca das referidas imprecisões e erros. 



\section{Conteúdo}

Agradecimentos vii

Resumo

\begin{tabular}{lll}
\hline Abstract & xiii
\end{tabular}

Prólogo

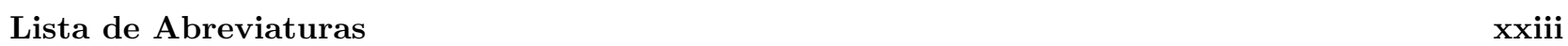

$\begin{array}{lll}\text { Lista de símbolos } & \text { xxv }\end{array}$

Lista de Figuras $\quad$ xxvii

$\begin{array}{ll}\text { Lista de Tabelas } & \text { xxxi }\end{array}$

\begin{tabular}{lll}
\hline & Introdução & 1
\end{tabular}

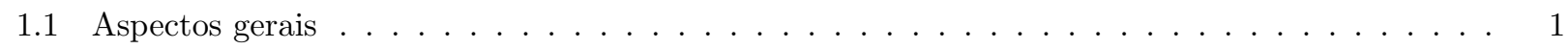

1.2 Revisão sobre modelos de resposta ao item $\ldots \ldots \ldots \ldots \ldots \ldots \ldots \ldots$

1.3 Modelos longitudinais de resposta ao item $\ldots \ldots \ldots \ldots \ldots \ldots \ldots \ldots$

1.4 Estrutura hierárquica de dados $\ldots \ldots \ldots \ldots \ldots \ldots \ldots \ldots \ldots$

1.5 Desconsideração de estruturas longitudinais $\ldots \ldots \ldots \ldots \ldots \ldots$ 
1.6 Desconsideração de estruturas multiníveis $\ldots \ldots \ldots \ldots \ldots \ldots$

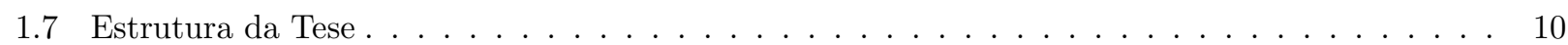

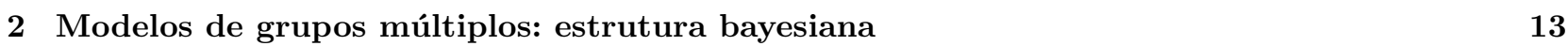

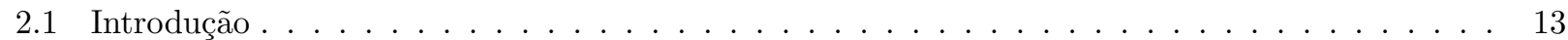

2.2 Considerações para a modelagem $\ldots \ldots \ldots \ldots \ldots \ldots \ldots$

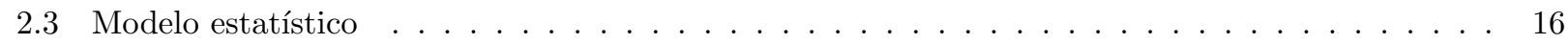

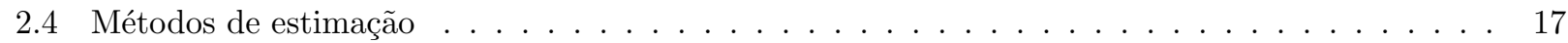

2.5 Verossimilhança de dados aumentados $\ldots \ldots \ldots \ldots \ldots$

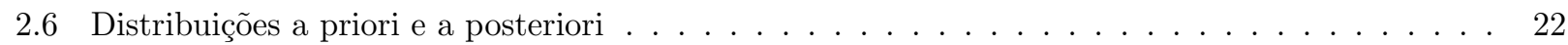

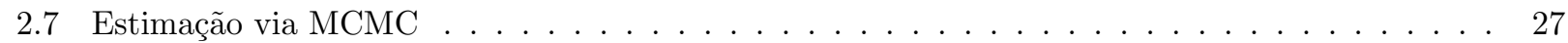

2.7 .1 Agrupamento no algoritmo MCMC $\ldots \ldots \ldots \ldots \ldots \ldots \ldots$. . . . . . . . . . . . . 32

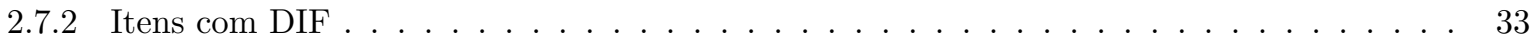

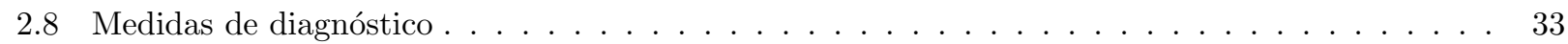

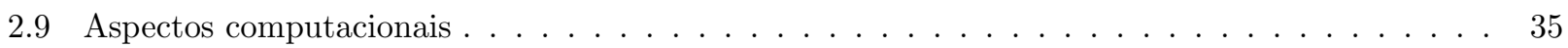

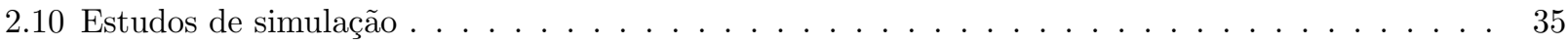

2.10 .1 Análise de sensibilidade $\ldots \ldots \ldots \ldots \ldots$

2.10 .2 Estudo de replicação $\ldots \ldots \ldots \ldots \ldots$. . . . . . . . . . . . . . . 42

2.10 .3 Estudo de acompanhamento $\ldots \ldots \ldots \ldots \ldots$. . . . . . . . . . . . . 47

2.11 Análise de dados reais $\ldots \ldots \ldots \ldots \ldots \ldots \ldots \ldots \ldots$

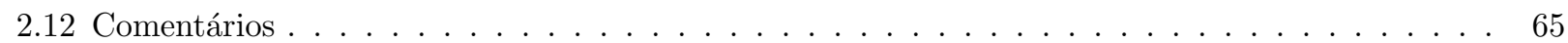

\begin{tabular}{|lll}
\hline 3 & Modelo longitudinal: estrutura bayesiana multivariada & 67
\end{tabular}

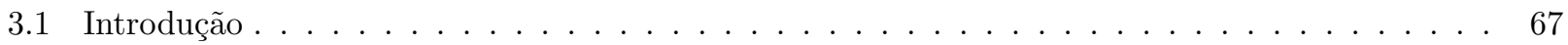

3.2 Modelo estatístico $\ldots \ldots \ldots \ldots \ldots \ldots$

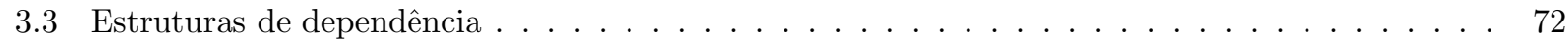

3.4 Verossimilhança de dados aumentados $\ldots \ldots \ldots \ldots \ldots \ldots \ldots$. . . . . . . . . . . . 74 
3.5 Estimação MCMC $\ldots \ldots \ldots \ldots \ldots \ldots \ldots \ldots \ldots \ldots \ldots \ldots$

3.5 .1 Dados faltantes $\ldots \ldots \ldots \ldots \ldots \ldots \ldots \ldots$

3.5 .2 Agrupamento no algoritmo MCMC $\ldots \ldots \ldots \ldots \ldots \ldots \ldots$

3.5 .3 Itens com DRIFT $\ldots \ldots \ldots \ldots \ldots \ldots \ldots \ldots \ldots$

$3.6 \quad$ Aspectos computacionais $\ldots \ldots \ldots \ldots \ldots \ldots \ldots$

3.7 Estudos de simulação $\ldots \ldots \ldots \ldots \ldots \ldots$

3.7 .1 Análise de sensibilidade $\ldots \ldots \ldots \ldots \ldots \ldots$

3.7 .2 Estudo de replicação $\ldots \ldots \ldots \ldots$. . . . . . . . . . . . . . . . . 93

3.7 .3 Estudo de acompanhamento $\ldots \ldots \ldots \ldots \ldots \ldots \ldots \ldots$

3.8 Análise de dados reais $\ldots \ldots \ldots$. . . . . . . . . . . . . . . . . . . . . . . . . . . 104

3.9 Comentários . . . . . . . . . . . . . . . . . . . . . . . . . . . . . 114

4 Modelo longitudinal com grupos múltiplos: abordagem multivariada bayesiana 115

4.1 Introdução . . . . . . . . . . . . . . . . . . . . . . . . . . 115

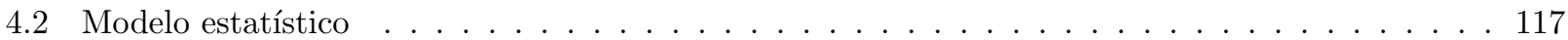

4.3 Verossimilhança de dados aumentados $\ldots \ldots \ldots \ldots \ldots \ldots$

4.4 Estruturas de covariância ． . . . . . . . . . . . . . . . . . . . . . . . . . . 120

4.4 .1 Matriz uniforme heterocedástica . . . . . . . . . . . . . . . . . . . . . . . . . . 121

4.4 .2 Toeplitz heterogênea $\ldots \ldots \ldots$. . . . . . . . . . . . . . . . . . . 122

4.4 .3 Matriz Hankel . . . . . . . . . . . . . . . . . . . . . . . . . . . . . . . . . . 122

$4.4 .4 \quad$ Matriz auto-regressiva com média móvel heterocedástica de ordem 1 . . . . . . . . . . . 123

4.4 .5 Matriz de ante-dependência . . . . . . . . . . . . . . . . . . . . . 124

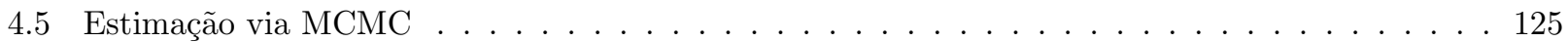

4.6 Seleção de estruturas de covariância via RJMCMC ～. . . . . . . . . . . . . . . . . . . . 130

4.7 Estudos de simulação $\ldots \ldots \ldots \ldots \ldots$. . . . . . . . . . . . . . . . . . . . 134

$4.7 .1 \quad$ Análise longitudinal com grupos múltiplos . . . . . . . . . . . . . . . . . . . . . . . 134

4.7 .2 Estudo de seleção de modelos através da metodologia RJMCMC $\ldots \ldots$. . . . . . . . 140 
4.8 Análise de dados reais $\ldots \ldots \ldots \ldots \ldots \ldots \ldots \ldots$

4.9 Comentários . . . . . . . . . . . . . . . . . . . . . . . . . . . . . . . . . . . . . . . . . . . . . 149

5 Modelo longidutinal com grupos múltiplos : estrutura multinível bayesiana $\quad 151$

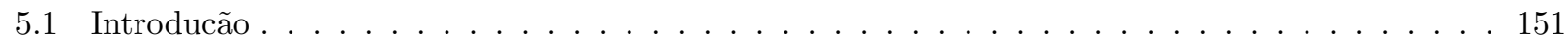

5.2 Modelos multiníveis homocedásticos f . . . . . . . . . . . . . . . . . . . . . . 153

5.2 .1 Matrizes uniforme e Hankel $\ldots \ldots \ldots \ldots$. . . . . . . . . . . . . . 154

5.3 Modelos para séries temporais estacionárias $\ldots \ldots \ldots \ldots \ldots \ldots \ldots$

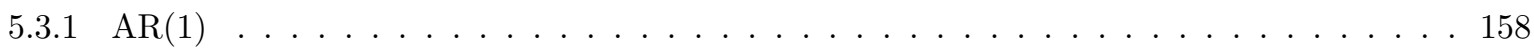

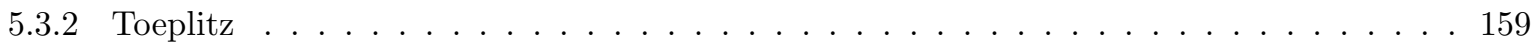

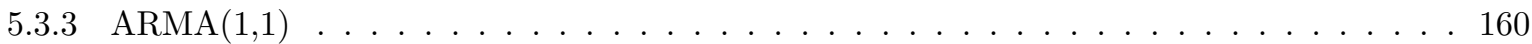

5.4 Modelos multiníveis heterocedásticos $\ldots \ldots \ldots \ldots$. . . . . . . . . . . . . . . . . 162

5.4 .1 Matriz Hankel . . . . . . . . . . . . . . . . . . . . . . . . . . . . . 162

5.4 .2 Matriz uniforme $\ldots \ldots \ldots \ldots \ldots \ldots \ldots \ldots \ldots$

5.5 Modelos de séries temporais não estacionários ～. . . . . . . . . . . . . . . . . . . . . . . . 164

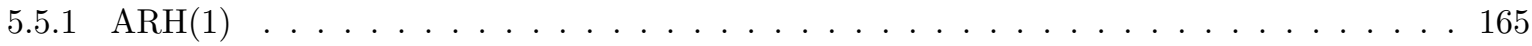

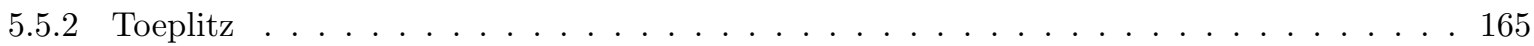

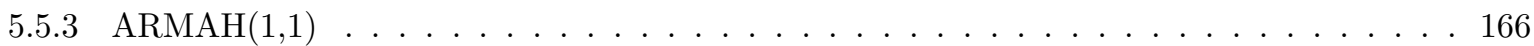

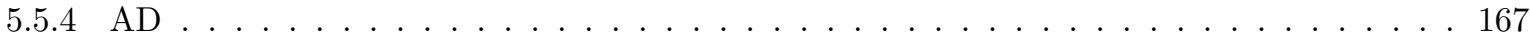

5.6 Verossimilhança de dados aumentados $\ldots \ldots \ldots \ldots$. . . . . . . . . . . . . 169

5.7 Estimação MCMC para modelos multiníveis homocedásticos e estacionários ～. . . . . . . . . . 170

5.8 Estimação MCMC para modelos multiníveis heterocedásticos e não estacionários ～. . . . . . . 180

5.9 Estudos de simulação $\ldots \ldots \ldots \ldots$. . . . . . . . . . . . . . . . . . . 195

5.10 Análise de dados reais $\ldots \ldots \ldots \ldots \ldots \ldots \ldots \ldots \ldots$

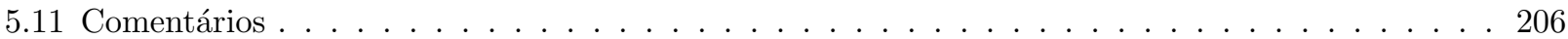

6 Comentários e sugestões para futuras pesquisas 207 


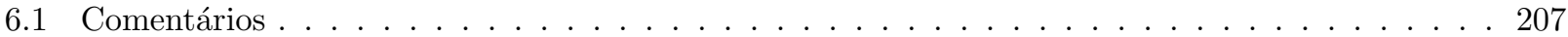

6.2 Sugestões para futuras pesquisas $\ldots \ldots \ldots \ldots \ldots \ldots$. . . . . . . . . . . . . . 207

6.2 .1 Inclusão do parâmetro de acerto casual ～. . . . . . . . . . . . . . . . . 207

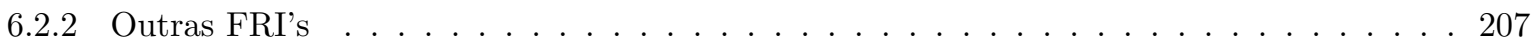

6.2 .3 Distribuições assimétricas $\ldots \ldots \ldots \ldots \ldots \ldots \ldots \ldots$

6.2 .4 Distribuições não-paramétricas ～. . . . . . . . . . . . . . . . . . . . 208

6.2 .5 Outros métodos de estimação $\ldots \ldots \ldots$. . . . . . . . . . . . . . . . 208

6.2 .6 Medidas de diagnóstico $\ldots \ldots \ldots \ldots \ldots \ldots$

6.2 .7 Construção de testes de hipótese $\ldots \ldots \ldots$. . . . . . . . . . . . . . . 209

6.2 .8 Utilização de estruturas dos modelos dinâmicos e modelos com erros nas variáveis . . . . 209

6.2.9 Comparação da abordagem multivariada com a multinível para o modelo longitudinal . 209

6.2 .10 Comparação do modelo longitudinal com o modelo de grupos múltiplos . . . . . . . . . . 209

6.2 .11 Modelos multiníveis com dependência intra grupos . . . . . . . . . . . . . . . . 210

6.2 .12 Modelos de curvas de crescimento . . . . . . . . . . . . . . . . . . . . . . . . . . . 210

6.2 .13 Outras matrizes de covariância . . . . . . . . . . . . . . . . . 210

6.2 .14 Recursos computacionais $\ldots \ldots \ldots \ldots \ldots \ldots \ldots \ldots$

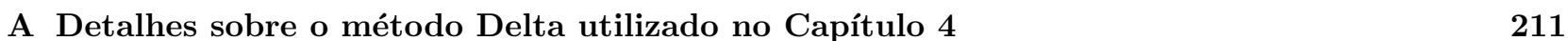

B Desenvolvimentos relacionados aos modelos de séries temporais estacionárias 213

B.1 Estrutura AR1 . . . . . . . . . . . . . . . . . . . . . . . . . . . . . 213

B.2 Estrutura Toeplitz . . . . . . . . . . . . . . . . . . . . . . . . . . . . . 214

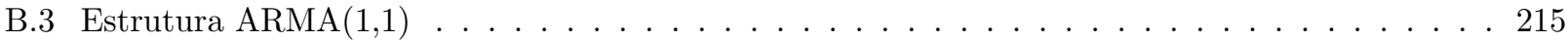

C Desenvolvimentos relacionados aos modelos de séries temporais não estacionárias 219

C.1 Estruturas ARH(1) . . . . . . . . . . . . . . . . . . . . . . . . . . . . . . . 219

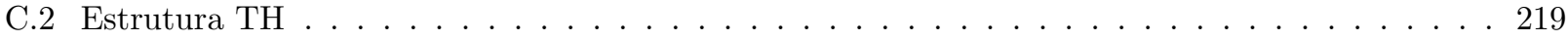

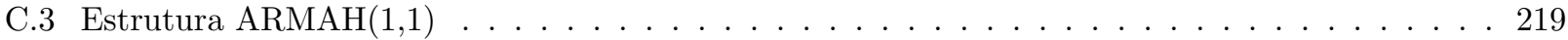


C.4 Estrutura AD . . . . . . . . . . . . . . . . . . . . . . . . . . 219

\begin{tabular}{|l|l}
\hline Referências Bibliográficas & 221
\end{tabular}

\begin{tabular}{ll}
\hline Referências Bibliográficas & 221
\end{tabular} 


\section{Lista de Abreviaturas}

TRI Teoria da Resposta ao Item.

TCM Teoria Clássica de Medidas .

FRI Função de resposta ao item.

MRI Modelos de resposta ao item .

MGM Modelo de grupos múltiplos.

MLONG Modelo longitudinal (da TRI).

MLGMTRI Modelo longitudinal de grupos múltplos (da TRI).

MCMC Monte Carlo via cadeias de Markov (Monte Carlo Markov Chain).

RJMCMC Monte Carlo via cadeias de Markov com saltos reversíveis

(Reversible Jumps Monte Carlo Markov Chain).

DIF Funcionamento diferenciado do item (Differential item functioning).

MST Modelos de séries temporais.

MSTE Modelos de séries temporais estacionárias.

AST Análise de séries temporais.

ABP Abordagem bayesiana plena.

Var Variância.

VQ Vício quadrático.

EP Erro-padrão.

Corr Correlação linear de Pearson.

REQM Raiz quadrada do erro quadrático médio. 



\section{Lista de símbolos}

$\begin{array}{ll}Y & \text { resposta a testes. } \\ Z & \text { variável aumentada. } \\ V & \text { variável indicadora de resposta. } \\ \theta & \text { traço latente. } \\ a & \text { parâmetro de discriminação. } \\ b & \text { parâmetro de dificuldade. } \\ \theta & \text { traço latente. } \\ \boldsymbol{\zeta} & \text { vetor com os parâmetros do item (discriminação, dificuldade). } \\ \mu_{\theta} & \text { média populacional dos traços latentes (escalar). } \\ \boldsymbol{\mu}_{\theta} & \text { médias populacionais dos traços latentes (vetor). } \\ \psi_{\theta} & \text { variância populacional dos traços latentes (escalar). } \\ \boldsymbol{\psi}_{\theta} & \text { variâncias populacionais dos traços latentes (vetor). } \\ \boldsymbol{\Psi}_{\theta} & \text { matriz de covariâncias populacionais dos traços latentes. } \\ \boldsymbol{\Omega}_{\theta} & \text { matriz de correlações populacionais dos traços latentes. } \\ \rho_{\theta} & \text { correlação populacional dos traços latentes. } \\ \tau & \text { efeitos aleatórios dos traços latentes. } \\ \sigma^{2} & \text { variância populacional dos efeitos aleatórios dos traços latentes. } \\ X \perp Y & \text { variáveis aleatórias X e Y mutuamente independentes. } \\ X \sim D(\vartheta) & \text { variável aleatória X segue uma distribuição D indexada pelos parâmetros } \vartheta . \\ N(\mu, \psi) & \text { distribuição normal univariada com média } \mu \text { e variância } \psi . \\ N_{T}(\boldsymbol{\mu}, \Psi) & \text { distribuição normal T-variada com vetor de médias } \mu \text { e matriz de covariâncias } \boldsymbol{\Psi} . \\ I G(\nu, \kappa) & \text { distribuição gama inversa com parâmetros } \nu \text { e } \kappa . \\ I G(\nu, W) & \text { distribuição Wishart inversa com parâmetros } \nu \text { e } \boldsymbol{W} . \\ & \end{array}$





\section{Lista de Figuras}

$1.1 \quad$ Inter-relação entre os MGM, MLONG e multivariado $\ldots \ldots \ldots \ldots \ldots$

1.2 Diagrama de influência de um MRI monótono $\ldots \ldots \ldots \ldots \ldots \ldots$

1.3 Grafo ilustrativo da hierarquia de alguns MRI $\ldots \ldots \ldots \ldots \ldots \ldots$

1.4 Grafo ilustrativo da interleção das modelagens estudadas . . . . . . . . . . . . . . . . . . . 11

2.1 Diagrama de influência do modelo de grupos múltiplos bayesiano via dados aumentados (MMGBDA) 24

2.2 Gráfico de duas prioris para o parâmetro de discriminação e uma verossimilhança artifical . . . 26

2.3 Gráficos de dispersão entre os valores dos parâmetros de discriminação e suas estimativas :

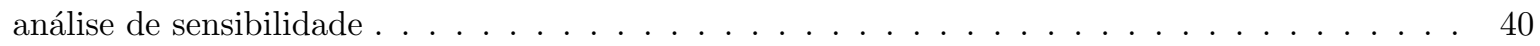

2.4 Gráficos de dispersão entre os valores dos parâmetros de dificuldade e suas estimativas : análise

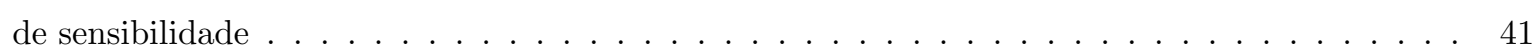

2.5 Gráficos de dispersão entre os valores dos verdadeiros parâmetros e as respectivas estimativas

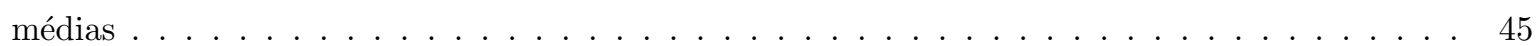

$2.6 \quad$ Perfil das estimativas dos parâmetros populacionais ao longo das replicações . . . . . . . . . . . 46

2.7 Valores simulados, dos parâmetros dos itens 4 e 33, para diferentes valores iniciais : estudo de

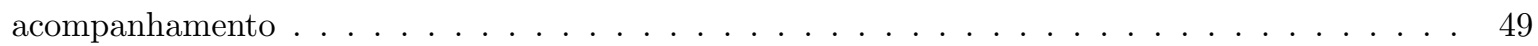

2.8 Valores simulados, dos parâmetros populacionais, para diferentes valores iniciais : estudo de

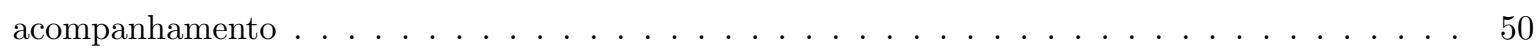

2.9 Auto-correlacao dos parâmetros populacionais : estudo de acompanhamento . . . . . . . . . . 51

2.10 Auto-correlacao dos parâmetros dos itens 4 e 33 : estudo de acompanhamento . . . . . . . . . 52

2.11 Histogramas e densidades das amostras válidas dos parâmetros selecionados . . . . . . . . . . 53 
2.12 Desidades conjuntas das amostras válidas para os parâmetros selecionados . . . . . . . . . . . . 54

2.13 Escores preditos, observados e IC's simétricos de $95 \%$. . . . . . . . . . . . . 57

2.14 Densidade dos resíduos dos traços latentes $\ldots \ldots \ldots \ldots \ldots \ldots$. . . . . . . . . . . 58

2.15 Gráficos de quantis normal-normal dos resíduos dos traços latentes . . . . . . . . . . . . . . . 59

2.16 Box-plot das estimativas dos parâmetros dos itens e populacionais $\ldots \ldots \ldots$. . . . . . . 62

2.17 Estimativas e IC's simétricos de $95 \%$ para os parâmetros dos itens e populacionais . . . . . . . 63

2.18 Comparação das densidades dos parâmetros populacionais $\ldots \ldots \ldots$. . . . . . . . . . . . 64

$3.1 \quad$ Estrutura do modelo longitudinal para os traços latentes $\ldots \ldots \ldots \ldots$. . . . . . . . . 72

3.2 Diagrama de influência do modelo longitudinal bayesiano $\ldots \ldots \ldots \ldots \ldots$

3.3 Gráficos de dispersão entre os valores do parâmetros de discriminação e suas estimativas : análise

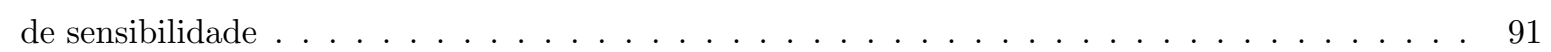

3.4 Gráficos de dispersão entre os valores do parâmetros de dificuldade e suas estimativas : análise

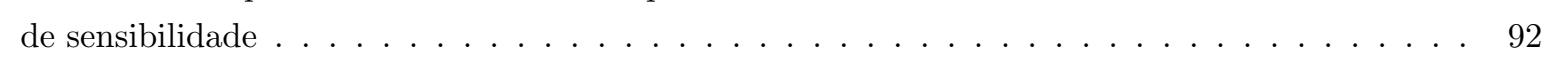

3.5 Gráficos de dispersão entre os valores dos verdadeiros parâmetros e as respectivas estimativas

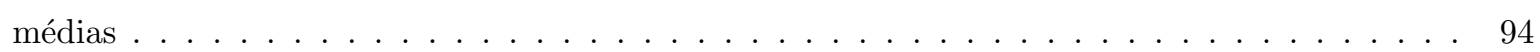

3.6 Valores simulados dos parâmetros dos itens 4 e 33 obtidos a partir de diferentes valores iniciais

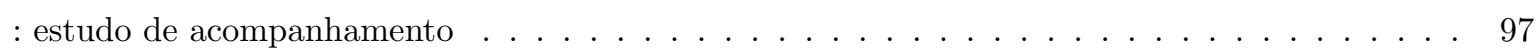

3.7 Valores simulados dos parâmetros populacionais para diferentes valores iniciais : estudo de acom-

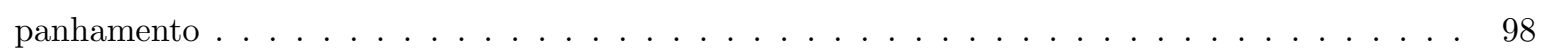

$3.8 \quad$ Auto-correlacao dos parâmetros populacionais : estudo de acompanhamento . . . . . . . . . . 99

$3.9 \quad$ Auto-correlacao dos parâmetros dos itens 4 e 33 : estudo de acompanhamento . . . . . . . . . . 100

3.10 Histogramas e densidades das amostras válidas dos parâmetros populacionais . . . . . . . . . 101

3.11 Histogramas e densidades das amostras válidas dos parâmetros dos itens selecionados . . . . . 102

3.12 Densidades conjuntas das amostras válidas para os parâmetros selecionados . . . . . . . . . 103

3.13 Escores preditos, observados e IC's simétricos de $95 \%$. . . . . . . . . . . . . . 106

3.14 Densidade dos resíduos dos traços latentes . . . . . . . . . . . . . . . . . . 107

3.15 Gráficos de quantis normal-normal dos resíduos dos traços latentes $\ldots \ldots$. . . . . . . . . 108 
3.16 Box-plot das estimativas dos parâmetros dos itens e populacionais . . . . . . . . . . . . . . 111

3.17 Estimativas e IC's simétricos de $95 \%$ para os parâmetros dos itens e populacionais . . . . . . . 112

3.18 Comparação das densidades dos parâmetros populacionais . . . . . . . . . . . . . . . . . . . . 113

$4.1 \quad$ Esquema do algoritmo RJMCMC considerando dois modelos . . . . . . . . . . . . . . . . . . . 131

4.2 Estimativas do estudo de replicação : estudo longitudinal de grupos múltiplos . . . . . . . . . . 139

4.3 Estimativas do estudo de replicação : situação 1 . . . . . . . . . . . . . . . . . . . . . . . . . . . 143

4.4 Estimativas do estudo de replicação : situação 2 . . . . . . . . . . . . . . . . . . . . . . . . . . . 144

4.5 Estimativas do estudo de replicação : situação 3 . . . . . . . . . . . . . . . . . . . . . . . . . . . 145

4.6 Estimativas dos parâmetros dos itens via RJMCMC e sem RJMCMC : dados reais . . . . . . . 148

5.1 Médias das estimativas do estudo de replicação . . . . . . . . . . . . . . . . . . . . . . . . . 197

$5.2 \quad$ Escores preditos, observados e respectivos IC's simétricos de $95 \%$. . . . . . . . . . . . . . . . . 199

5.3 Densidade dos resíduos dos traços latentes . . . . . . . . . . . . . . . . . . . . . . . 200

5.4 Gráfico de quantis normal-normal dos resíduos dos traços latentes. . . . . . . . . . . . . . . . . 201

5.5 Box-plot das estimativas dos parâmetros dos itens e populacionais . . . . . . . . . . . . . . . . 204

$5.6 \quad$ Estimativas e IC's de $95 \%$ dos parâmetros dos itens e populacionais . . . . . . . . . . . . . . . 205 



\section{Lista de Tabelas}

$2.1 \quad$ Prioris escolhidas para a análise de sensibilidade $\ldots \ldots \ldots \ldots \ldots$

2.2 Resultados da estimação dos traços latentes : análise de sensibilidade . . . . . . . . . . . . . . 39

2.3 Resultados da estimação dos parâmetros dos itens : análise de sensibilidade ～. . . . . . . . . 39

2.4 Resultados da estimação dos parâmetros populacionais : análise de sensibilidade $\ldots . . . \ldots$

2.5 Resultados da estimação dos traços latentes e dos parâmetros dos itens : estudo de replicação . 44

$2.6 \quad$ Resultados da estimação dos parâmetros populacionais : estudo de replicação . . . . . . . . . . 44

$2.7 \quad$ Parâmetros dos itens e resultados para o estudo de acompanhamento . . . . . . . . . . . . . . 48

2.8 Resultados para a estimação dos parâmetros populacionais : estudo de acompanhamento . . . . 49

2.9 Descrição das estruturas dos testes $\ldots \ldots \ldots \ldots \ldots \ldots \ldots \ldots \ldots \ldots$

2.10 Resultados dos parâmetros dos itens : análise de dados reais . . . . . . . . . . . . . . . 60

2.11 Estatística descritivas das estimativas dos parâmetros dos itens . . . . . . . . . . . . . 61

2.12 Resultados das estimativas dos parâmetros populacionais : análise de dados reais . . . . . . . 61

3.1 Prioris escolhidas para a análise de sensibilidade $\ldots \ldots \ldots \ldots$. . . . . . . . . 90

3.2 Resultados da estimação dos traços latentes : análise de sensibilidade . . . . . . . . . . . . . 90

3.3 Resultados da estimação dos parâmetros dos itens : análise de sensibilidade . . . . . . . . . . 90

3.4 Resultados da estimação dos parâmetros populacionais : análise de sensibilidade . . . . . . . . 91

3.5 Resultados da estimação dos traços latentes e dos parâmetros dos itens : estudo de replicação . 93

3.6 Resultados da estimação dos parâmetros populacionais : estudo de replicação . . . . . . . . . . 94

3.7 Parâmetros dos itens e resultados do o estudo de acompanhamento . . . . . . . . . . . . . . 96 
3.8 Resultados da estimação dos parâmetros populacionais : estudo de acompanhamento . . . . . . 96

3.9 Resultados dos parâmetros dos itens : análise de dados reais $\ldots \ldots \ldots$. . . . . . . . . . . 109

3.10 Estatística descritivas das estimativas dos parâmetros dos itens ～. . . . . . . . . . . . . . 110

3.11 Resultados das estimativas dos parâmetros populacionais : análise de dados reais . . . . . . . 110

4.1 Parâmetros dos itens e estimativas para o estudo longitudinal de grupos múltiplos _ . . . . . . 136

4.2 Resultados da estimação dos traços latentes e dos parâmetros dos itens : estudo de replicação longitudinal de grupos múltiplos $\ldots \ldots \ldots \ldots \ldots \ldots \ldots$

4.3 Resultados da estimação dos parâmetros populacionais (média e variância) : estudo de replicação

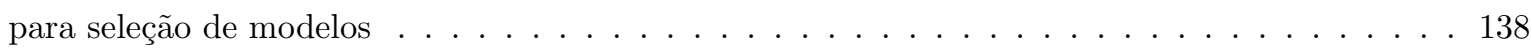

4.4 Proporção de visitas a cada modelo $\ldots \ldots \ldots$. . . . . . . . . . . . . . . . . . . 141

4.5 Resultados da estimação dos traços latentes e dos parâmetros dos itens : estudo de replicação para seleção de modelos $\ldots \ldots \ldots \ldots$. . . . . . . . . . . . . . . . . . 141

4.6 Resultados da estimação dos parâmetros populacionais : estudo de replicação para seleção de modelos . . . . . . . . . . . . . . . . . . . . . . . . 142

4.7 Estimativas dos parâmetros dos itens via RJMCMC $\ldots \ldots \ldots \ldots$. . . . . . . . . . . 147

5.1 Resultados da estimação dos traços latentes e dos parâmetros dos itens : estudo de replicação . 196

5.2 Resultados da estimação dos parâmetros populacionais : estudo de replicação ～. . . . . . . . 196

$5.3 \quad$ Resultados dos parâmetros dos itens : análise de dados reais . . . . . . . . . . . . . . . . . . 202

5.4 Estatística descritivas das estimativas dos parâmetros dos itens . . . . . . . . . . . . . . 203

5.5 Resultados das estimativas dos parâmetros populacionais : análise de dados reais . . . . . . . . 204

5.6 Comparação entre as abordagens multinível e multivariada $\ldots \ldots$. . . . . . . . . . . 206 


\section{Capítulo 1}

\section{Introdução}

\subsection{Aspectos gerais}

Em muitas áreas de pesquisa é bastante comum encontrar conjuntos de dados que estão relacionados com variáveis não observáveis diretamente. Exemplos são os resultados de um teste de Matemática, veja Bazán et al. (2004), onde se tem interesse em medir o conhecimento de indivíduos, nos estudos de qualidade de vida (QDV), onde um questionário é aplicado com o intuito de medir algum índice de QDV, veja Douglas (1999), ou mesmo em pesquisas psiquiátricas nas quais se intenciona analisar o grau de depressão de indivíduos, veja Kessler et al. (2002). O nível de conhecimento, o índice de QDV e o grau de depressão são exemplos de variáveis latentes, veja Bartholomew and Knott (1980), por exemplo. Isto é, não é possível observá-las diretamente, mas somente os resultados dos testes pertinentes. Então, faz-se necessário considerar modelos que levem estas características em consideração. Isto é, modelos que representem de modo satisfatório o relacionamento entre as variáveis observáveis (respostas aos questionários) e as variáveis não-observáveis (traços latentes). Uma das classes de modelos mais utilizadas que consideram tal relacionamento é a Teoria da Resposta ao Item (TRI). De uma forma geral, a TRI é baseada em conjuntos de modelos desenvolvidos para estudar o relacionamento entre as características não observáveis dos indivíduos, também chamadas de traços latentes, algumas características dos instrumentos de medida (testes ou questionários), e as respostas dos indivíduos a esses testes. Mais concretamente, os modelos de resposta ao item (MRI), representam a probabilidade de um indivíduo obter um certo escore (pontuação) em determinado item, condicionada aos traços latentes e as características desse item (parâmetros). Originalmente, a TRI foi desenvolvida para suprir algumas deficiências da chamada Teoria Clássica de Medidas (TCM), veja Vianna (1978), no contexto de avaliação educacional. No entanto, nos últimos anos, têm sido conduzidas muitas aplicações desta teoria em outras áreas como : genética, veja Tavares et al. (2004), qualidade de vida, veja Douglas (1999), pesquisas clínicas, veja Hendryx et al. (1992), dentre outras. Para uma discussão ampla a respeito da TRI e dos aspectos relacionados à ela sugerimos a leitura de Hambleton and Swaminathan (1985), Hambleton et al. (1991), Lord (1980), Lord and Novick (1968) e Andrade et al. (2000). Entretanto, uma breve revisão da estrutura dos MRI será apresentada na próxima seção. 
Na medida em que a TRI foi sendo aplicada em vários campos de pesquisa e também devido ao surgimento de planejamentos mais complexos, foi sendo verificada a necessidade de desenvolvimento de MRI que pudessem levar em consideração as diversas características desses estudos. Dessa forma muitas propostas têm sido estudadas tais como, os Modelos Multidimensionais, veja Nojosa (2001), os quais assumem que é necessário mais de um traço latente para modelar apropriadamente as probabilidades de resposta, Modelos Mutivariados, veja Matos (2001), que consideram estruturas de dependência dos traços latentes medidos em diferentes áreas de conhecimento e Modelos longitudinais (MLONG), veja Tavares (2001), que modelam dependências longitudinais dos traços latentes. Estas e outras classes de modelos permitem aplicar a TRI em um grande número de situações e também conduzem à obtenção de resultados mais confiáveis. Outro ponto importante é o fato de que muitos MRI podem ser analisados como membros de outras classes de modelos estatísticos. Por exemplo, a família de modelos de Rasch pertencem à classe dos Modelos Lineares Generalizados Mistos (MLGM), veja Rijmen et al. (2003). Isto permite usar métodos de estimação e diagnósticos ou mesmo pacotes computacionais desenvolvidos para os MLGM no ajuste de modelos de Rasch. Além disso, informações adicionais podem ser incluídas, para os traços latentes e parâmetros dos itens utilizando a estrutura dos MLGM. Do mesmo modo, estruturas de dependência e fontes de variabilidade extra podem ser modeladas.

Por outro lado, estudar as classes de MRI sob uma visão mais ampla, pode trazer benefícios significativos. Por exemplo, pode-se desenvolver métodos de estimação e diagnósticos para tais classes mais gerais e particularizar os resultados para MRI de interesse. Ainda, os MRI podem ser combinados com outras classes de modelos para criar estruturas mais amplas. Neste sentido, trabalhos como os de Kamata (1998), que estuda os modelos de Rasch através de uma estrutura linear hierárquica generalizada,veja Lee and Nelder (1996), Rijmen et al. (2003), que analisam alguns MRI sob a estrutura dos modelos não-lineares mixtos (MNLM), veja também Davidian and Giltinam (1995), e Fox (2001), que apresenta uma abordagem multinível para os traços latentes no modelo de grupos múltiplos homocedástico, veja Bock and Zimowski (1997), permitem não só obter um desenvolvimento mais amplo de métodos de estimação e diagnóstico mas também utilizar técnicas específicas disponíveis para tais modelos.

Notadamente, na área de avaliação educacional, existe um interessante crescente na aplicação de dois tipos de estudo : múltiplos grupos e longitudinal. O primeiro se caracteriza pela existência de grupos de indivíduos que possuem, em certo sentido, características diferentes. É necessário pois, levar em consideração tais diferenças, as quais podem, por exemplo, induzir comportamentos distintos dos traços latentes e do modelo de resposta ao item empregado. Um outro ponto importante diz respeito ao fato de que, na presença de diferentes grupos, é necessário as vezes aplicar um teste diferente para cada grupo. Isto ocorre, por exemplo, quando se tem interesse em comparar séries distintas. O segundo tipo de estudo se caracteriza quando o mesmo grupo de indivíduos é acompanhado ao longo do tempo, submetido a um teste em cada condição temporal, por exemplo. Isto induz, possivelmente, uma estrutura de dependência entre os resultados, uma vez que os mesmos indivíduos são submetidos a tais testes. De modo igual ao caso de múltiplos grupos, se faz necesário a aplicação de testes diferentes, neste caso, em cada condição de avaliação.

Azevedo, Caio L. N.

IME/USP 
Um outro ponto importante é o fato de que os Modelos Multivariados, veja Matos (2001), podem ser obtidos como um caso particular dos MLONG. Isto ocorre quando consideramos as médias em cada tempo iguais a zero e uma matriz de covariância não estruturada (com os elementos da diagonal principal iguais a 1), veja Matos (2001). Na verdade, o MGM também pode ser visto como um caso particular dos MLONG. Isto se verifica quando consideramos uma matriz de covariâncias diagonal, veja Tavares (2001). Uma visão geral de como os modelos longitudinais, multivariados e de múltiplos grupos se relacionam está ilustado na Figura 1.1 . Setas indicam que o modelo no final da mesma corresponde a um caso particular daquele que está no começo. Linhas tracejadas indicam que os modelos podem ser combinados entre si e dessa forma gerar classes mais amplas de modelos.

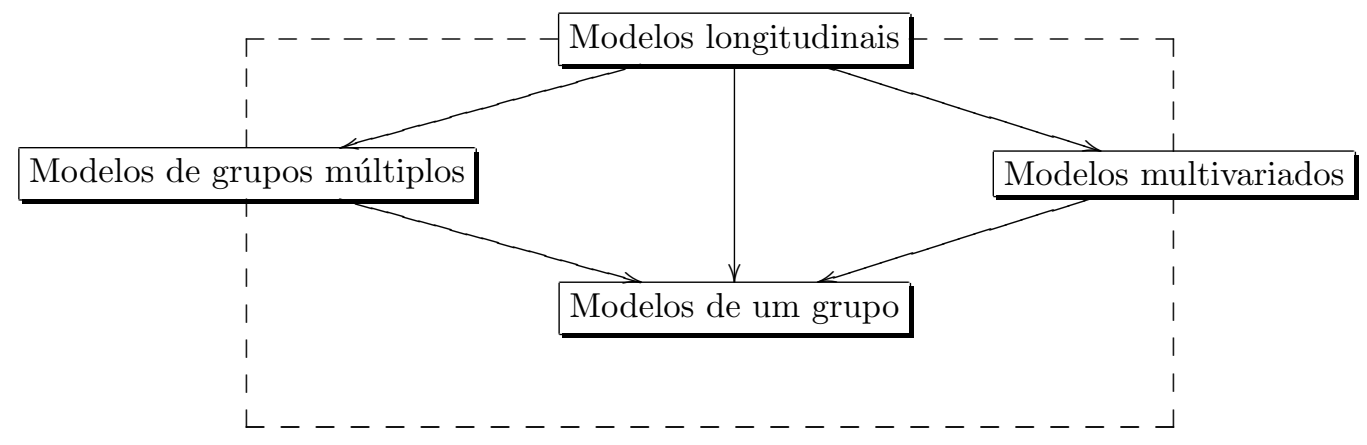

Figura 1.1: Inter-relação entre os MGM, MLONG e multivariado

Ambas situações expostas nos parágrafos anteriores devem ser analisadas apropriadamente de modo a ser possível se levar em consideração as características supracitadas. Em nosso trabalho temos particular interesse em duas classes de MRI e uma classe de modelagem adicional. Com relação ao primeiro, nos concentraremos nos modelos de múltiplos grupos e longitudinais. Com relação ao segundo aspecto, nos concentraremos na modelagem multinível.

Os MGM consitutem um grande avanço em questões como a equalização, veja Kolen and Brennan (2004) e estudos de funcionamento diferencial do item (DIF), veja calves (2006). Por outro lado, os MLONG possibilitam a obtenção de resultados mais refinados uma vez que permitem modelar a dependência dos resultados de diferentes avaliações aplicadas ao longo do tempo nos mesmos indivíduos, veja Tavares (2001). Um outro aspecto é que tal modelagem permite avaliar o desgaste do item ao longo do tempo (DRIFT), veja Bock et al. (1998).

Embora muito se tenha estudado a respeito dos MGM, ainda existem alguns pontos não explorados. Apesar da existência de pacotes computacionais para o ajuste do modelo através de métodos de máxima verossimilhança, veja Bock and Zimowski (1997), pouco, ou quase nada, existe no desenvolvimento de métodos de 
estimação bayesianos através da metodologia de MCMC, veja Gilks et al. (1996). Além disso, não existem estudos para avaliar estimativas dos parâmetros em situações com diferentes testes para cada população.

No contexto longitudinal, nos últimos anos, alguns modelos têm sido propostos para estudos envolvendo respostas binárias ou policotômicas. Por exemplo, Gibbons and Hedeker (1997) propuseram um modelo probito/logístico de três níveis parea analisar dados longitudinais agrupados, permitindo a inclusão de covariáveis em diferentes níveis, e o ajuste do modelo através do método de máxima verossimilhança marginal, veja Bock and Aitkin (1981). Este modelo pertence à família de Rasch, na medida em que considera apenas o parâmetro de dificuldade do item. O'Brien and Dunson (2004) desenvolveram um modelo de regressão logístico bayesiano para analisar dados dicotômicos e policotômicos longitudinais com a possibilidade de inclusão de covariáveis. Para o ajuste do modelo, desenvolveram uma abordagem de MCMC através de um esquema de dados aumentados considerando a distribuição t-Student para modelar os dados aumentados. No entanto, nem efeitos aleatórios nem parâmetros de discriminação, por exemplo, foram considerados na modelagem. Pastor and Beretvas (2006) propuseram um modelo de Rasch de três níveis para dados longitudinais que permite avaliar mudanças nos traços latentes e possíveis mudanças no comportamento dos itens, ao longo do tempo. Para o ajuste os autores consideraram o pacote comercial HLM®, veja Raundebush et al. (2004).

Devido ao elevado número de parâmetros, diferentes distribuições dos traços latentes envolvidas e estruturas de dependência (no caso do MLONG), é relativamente complicado o ajuste tanto de MGM quanto do MLONG. Dessa forma, faz-se necessário a utilização de métodos de estimação que levem em consideração todas as suas características. Apesar do método de estimação de máxima verossimilhança marginal (MVM), veja Bock and Aitkin (1981), ser amplamente utilizado, estar disponível em programas computacionais bem desenvolvidos e de produzir, em geral, bons resultados, possui algumas limitações. Basicamente estas dizem respeito aos procedimentos numéricos necessários para a implementação de tal método, veja Baker and Kim (2004) e Azevedo (2003). A versão bayesiana do método de MVM, conhecida por moda marginal a posteriori (MMAP), vide Mislevy (1986), constitui um aperfeiçoamento razoável de seu correspondente frequentista, mas padece de similares limitações. Por outro lado, a estrutura de análise bayesiana plena, ou seja, aquele que se propõe ao cálculo da distribuição a posteriori e não se limita somente à obtenção de algumas quantidades pontuais, possui muitas vantagens, notadamente os procedimentos conduzidos através de algoritmos do tipo MCMC. Primeiro, incorporam facilmente aspectos como espaços paramétricos restritos, dados omissos, estruturas de dependência, veja Baker and Kim (2004), Patz and Junker (1999b) and Patz and Junker (1999b). Segundo, análise de resíduos, veja Albert and Chib (1995), e outras medidas de diagnóstico, vide Fox (2001) e Chaloner and Brant (1988), são facilmente calculadas. Terceiro, na abordagem bayesiana estruturas hierárquicas podem ser especificadas para levar em consideração o comportamento aleatório dos traços latentes e de outros efeitos aleatórios de interesse.

Na próxima seção apresentaremos uma breve revisão dos modelos de resposta ao item.

Azevedo, Caio L. N.

IME/USP 


\subsection{Revisão sobre modelos de resposta ao item}

De uma forma geral, os modelos de resposta ao item podem ser caracterizados por :

- Uma variável resposta, possivelmente um vetor, $(\boldsymbol{Y})$ o qual é adimitido seguir uma distribuição de Bernoulli, univariada ou multivariada, veja Gelman et al. (2004). No primeiro caso temos que a variável resposta é dicotômica ou dicotomizada enquanto que no segundo caso tal variável é de natureza policotômica, veja van der Linden and Hambleton (1997), Capítulo 1. Vale a pena salientar também a existência dos MRI para resposta contínua, veja Mellenbergh (1994).

- Um conjunto de traços latentes $(\boldsymbol{\theta})$ o qual está sendo medido pelo teste em questão e que pode ser unidimensional ou multidimensional, veja McDonald (1997).

- Um conjunto de parâmetros dos itens $(\boldsymbol{\zeta})$ que caracterizam o intrumento de medida (teste, questionário etc).

- Um conjunto de parâmetros populacionais $\left(\boldsymbol{\eta}_{\boldsymbol{\theta}}\right)$ que caracterizam a distribuição dos traços latentes.

- Uma função de ligação $(\Phi)$, denominada de Função de Resposta ao Item (FRI), que estabelece a relação entre as respostas dos indivíduos aos itens e os traços latentes, veja van der Linden and Hambleton (1997), Capítulo 5. A FRI especifica a probabilidade de um indivíduo obter um certo escore em um determinado item. Além disso, ela pode ter um comportamento monótono ou não, veja van der Linden and Hambleton (1997), Capítulo 5.

- Um conjunto de parâmetros $(\phi)$ que caracterizam a FRI e ajudam a definir o comportamente da probailidade de resposta, veja Bazán (2005).

Então, uma estrutura geral para um MRI monótono é,

$$
\begin{aligned}
\boldsymbol{Y} & \sim B_{M}(\boldsymbol{P}), \\
\boldsymbol{P}=\boldsymbol{P}(\boldsymbol{Y}=\boldsymbol{y} \mid \boldsymbol{\theta}, \boldsymbol{\zeta}, \boldsymbol{\phi}) & =\sum_{l=1}^{L} \prod_{h=1}^{H} \Phi_{l h}(\boldsymbol{\theta}, \boldsymbol{\zeta}, \boldsymbol{\phi}) \\
\boldsymbol{\theta} & \sim D\left(\boldsymbol{\eta}_{\theta}\right),
\end{aligned}
$$

em que $B_{M}(\boldsymbol{P})$ denota uma distribuição de Bernoulli multivariada de dimensão $M$, $\phi_{l h}$ são funções de distribuição acumuladas, e. g. normal, logística, normal assimétrica, e complemento log-log, $D$ representa uma distribuição de probabilidade conveniente, e $H$ e $L$ dizem respeito ao número de FRI necessárias para se modelar de modo satisfatório as probabilidades de resposta. Em outras palavras, um MRI monótono pode ser 
representado através de uma função de ligação composta, veja Skrondal and Rabe-Hesketh (2004), página 32, para exemplos de função de ligação composta. Um diagrama de influência para tal modelo é apresentado na Figura 1.2

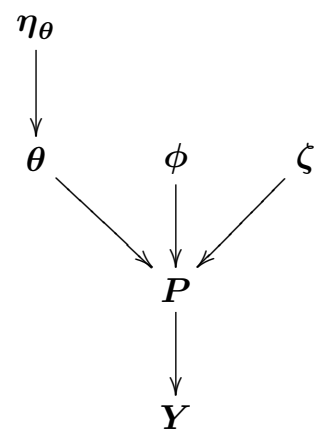

Figura 1.2: Diagrama de influência de um MRI monótono

Desta forma, diferentes escolhas para as componentes apresentadas na Figura 1.2 levam a diferentes classes de MRI. De acordo com o que foi dito na Seção anterior, nosso interesse maior irá residir na estrutura do traço latente. Naturalmente, a estrutura apresentada na Figura 1.2 pode ser ampliada afim de contemplar mais componentes, e.g., regressores para os traços latentes, vide Mislevy (1987) e Fox (2001). Na próxima seção discutiremos tópicos relacionados aos modelos longitudinais da TRI, uma classe onde diferentes estruturas de dependência podem ser consideradas.

\subsection{Modelos longitudinais de resposta ao item}

Modelos longitudinais de resposta ao item não são uma classe tão recente de modelos. Além dos trabalhos relacionados citados na Seção 1.1. outros, no contexto da TRI, merecem citação. Conoway (1990), propôs um modelo de Rasch longitudinal para estudar dados de painel ("panel data"), e utilizou a abordagem de máxima versossimilhança marginal (MVM), veja Bock and Aitkin (1981), para estimar os parâmetros. Eid (1996) definiu um modelo longitudinal para análise fatorial confirmatória para dados de resposta ao item policotômicos. O programa computacional LISCOMP, veja Muthén (1988) foi utilizado para analisar os dados em questão. Douglas (1999) analisou dados oriundos de um estudo longitudinal de qualidade de vida através de uma estrutura híbrida composta pelo modelo de Cox, veja Cox (1972), e o modelo de resposta gradual, veja Samejima (1969). O autor desenvolveu um esquema de simulação de MCMC com saltos de MetropolisHastings, veja Chib and Greenberg (1995). Andrade and Tavares (2005) consideraram um modelo logístico de 3 parâmetros longitudinal, para itens dicotômicos ou dicotomizados, e estudaram algumas escolhas para modelar a matriz de covariância. Eles desenvolveram uma extensão do método de MVM para ajustar o modelo. Mais recentemente, Liu and Hedeker (2006) consideraram uma modelo de 3 níveis longitudinal para respostas 
ordinais com o intuito de analisar dados agrupados considerando a inclusão de covariáveis. Eles propuseram uma algoritmo escore de Fisher para a estimação dos parâmetros do modelo.

A despeito dessas e outras abordagens, algumas extensões não foram desenvolvidas : métodos de estimação mais apropriados (no sentido de considerar todas as características do modelo sem padecer dos problemas do número de dimensões envolvidas), medidas de diagnóstico apropriadas, inclusão de certos tipos de informação auxiliares, outras FRI como o modelo de 2 e 3 parâmetros com ligação probito, ou o modelo de resposta nominal, distribuições para os traços latentes diferentes da normal simétrica, escolha de estruturas de covariância apropriadas. No presente trabalho atenção será dada em explorar alguns dos tópicos citados.

\subsection{Estrutura hierárquica de dados}

Em muitas áreas de pesquisa é bastante comum a presença de estruturas hierárquicas de dados. Estas se caracterizam quando unidades amostrais formam grupos de unidades amostrais os quais, por sua vez, podem ou não formar outros grupos. Neste tipo de estrutura, unidades que pertencem ao mesmos grupos tendem a apresentar algum tipo de associação entre si ou fontes de variabilidade extras. Isto é devido ao fato de que unidades amostrais que pertencem aos mesmo grupos tendem a apresentar mais similaridades do que unidades que pertencem a diferentes grupos. Estimativas viesadas e inferências incorretas podem ser obtidas quando a estrutura hierárquica é ignorada. Os modelos que levam em consideração tal tipo de estrutura são chamados de modelos multiníveis ou modelos hierárquicos. Referências importantes são Goldstein (2003), Raudenbush and Bryk (2001) e Nátis (2000).

Planejamentos longitudinais apresentam uma estrutra hierárquica natural na medida en que as condições de avaliação (tempo) produzem observações dentro de cada indivíduo. Respostas de um mesmo indivíduo tendem a ser mais correlacionadas do que respostas de diferentes indivíduos.

No contexto da TRI, Fox (2001) apresenta uma modelagem multinível para modelos de múltiplos grupos homocedástico. O intuito desta modelagem é permitir que similaridades entre indivíduos que pertençam aos mesmos grupos possam ser consideradas no modelo. Isto é feito através de uma modelagem multinível de 2 níveis sendo o primeiro nível, aluno e o segundo, escola. Tal abordagem deu margem a algumas questões interessantes :Fox and Glas (2001) apresentam um procedimento de estimação bayesiana via MCMC, Fox (2003) desenvolveu um procedimento de ajuste via algoritmo EM estocástico, veja Celeux and Diebolt (1985), Fox and Glas (2003) consideram covariáveis medidas com erro para os traços latentes e Fox (2005) consideram extensões para respostas policotômicas.

De uma forma geral, pode-se dizer que a estrutura multinível, no contexto da TRI, é uma modelagme auxiliar que permite, por exemplo, representar MRI de forma mais conveniente ou, adicionar de forma apropriada, informações de interesse. No presente trabalho utilizaremos estruturas multiníveis para representar estudos longitudinais. A Figura 1.4 apresenta um esquema que relaciona os MLTRI, MGM e os modelos multiníveis.

Azevedo, Caio L. N.

IME/USP 
Setas sólidas indicam que o modelo no final dessa carrega em si a estrutura do modelo que está no começo. Setas tracejadas indicam que o modelo no final dela pode ser representado ou extendido pelo modelo que está no começo de tal seta.

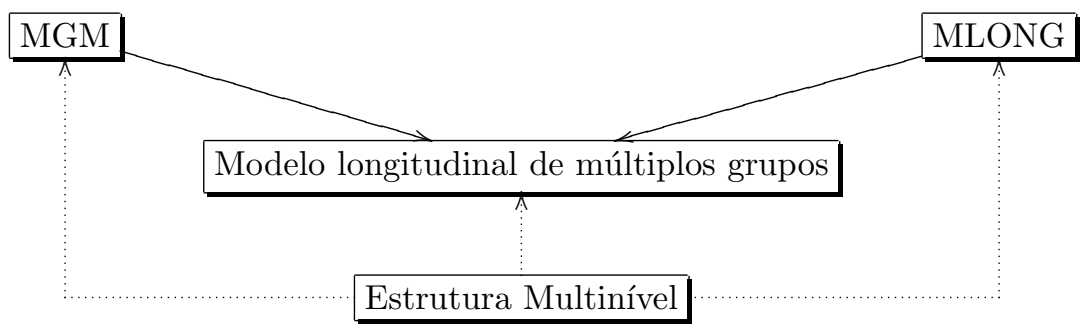

Figura 1.3: Grafo ilustrativo da hierarquia de alguns MRI

Para a leitura das duas próximas seções sugerirmos antes o leitor verificar o índice de símbolos no começo do presente trabalho.

\subsection{Desconsideração de estruturas longitudinais}

Para dar alguma motivação no estudo de modelos longitudinais na TRI apresentaremos um exemplo bem simples. Como descrito em Andrade and Tavares (2005), considere um conjunto de indivíduos estudados ao longo de instantes de avaliação. Além disso, suponha que os traços latentes desses indivíduos apresentam a mesma correlação não importa a distância entre as observações. Retornaremos à questão da modelagem da estrutura de dependência e da estimação do modelo com detalhes em Capítulos posteriores. Se considerarmos o esquema de dados aumentados proposto por Albert (1992), atribuírmos uma priori normal multivariada para os traços latentes e utilizarmos a forma analítica da matriz de covariância em questão, veja Tavares (2001) teremos a seguinte distribuição condicional completa para os traços latentes:

$$
\theta_{j t} \sim N_{T}\left(\widehat{\psi}_{\theta_{j t}} \widehat{\theta}_{j t}, \widehat{\psi}_{\theta_{j t}}\right)
$$

em que $\widehat{\psi}_{\theta_{j t}}=v^{-1}\left[\frac{1}{\left(1-\rho_{\theta}^{*}\right) \psi_{\theta}^{*}}\left(1-\frac{\rho_{\theta}^{*}}{1+(T-1) \rho_{\theta}^{*}}\right)\right], \widehat{\theta}_{j t}=\sum_{i=1}^{I} z_{i j t} a_{i}+\sum_{i=1}^{I} a_{i} b_{i}+\mu_{\theta}, v=\sum_{i=1}^{I} a_{i}^{2}, \psi_{\theta}^{*}=\psi_{\theta}+v^{-1}$ and $\rho_{\theta}^{*}=\rho_{\theta} \psi_{\theta}^{*}$. Entretanto, se considerarmos uma estrutura diagonal uniforme para a matriz de covariância da distribuição a priori, o que equivale a considerar que os traços latentes são independentes, teremos

Azevedo, Caio L. N.

IME/USP 


$$
\theta_{j t} \sim N_{T}\left(\tilde{\psi}_{\theta_{j t}} \widehat{\theta}_{j t}, \tilde{\psi}_{\theta_{j t}}\right)
$$

em que $\tilde{\psi}_{j t}=\left(v+\psi_{\theta}\right)^{-1} \mathrm{e} \widehat{\theta}_{j t}$ permanece o mesmo. Isto é, distribuições condicionais completas diferentes seriam obtidas consoante a escolha ou não de uma estrutura de dependência. Em outras palavras, o procedimento de MCMC baseado em diferentes suposições poderiam produzir diferentes estimativas e, consequemente, diferentes resultados. Desta forma, a inferência baseada no modelo de independência poderia ver viesada. Semelhantes comentários podem ser aplicados à outros métodos de estimação. Nosso objetivo com tal exemplo é o de ilustrar que estruturas de dependência (longitudinal) têm influência no processo de inferência.

\subsection{Desconsideração de estruturas multiníveis}

Nesta seção apresentaremos um simples exemplo com relação a se ignorar uma estrutura hierárquica na TRI. Suponha que, induzido ou por uma estrutura hierárquica ou por delineamento longitudinal, o modelo populacional para os traços latentes seja dado por

$$
\begin{aligned}
\theta_{j t} \mid \tau & \sim N\left(\mu_{\theta}+\tau, \psi_{\theta}\right) \\
\tau & \sim N\left(0, \sigma^{2}\right) .
\end{aligned}
$$

Neste caso, a distribuição condicional completa para o traço latente de um determinado indivíduo, é dada por

$$
\theta_{j t} \sim N_{T}\left(\widehat{\psi}_{\theta_{j t}} \widehat{\theta}_{j t}, \widehat{\psi}_{\theta_{j t}}\right)
$$

em que $\widehat{\psi}_{\theta_{j t}}=\left(v+\psi_{\theta}\right)^{-1}$ e $\widehat{\theta}_{j t}=\sum_{i=1}^{I} z_{i j t} a_{i}+\sum_{i=1}^{I} a_{i} b_{i}+\mu_{\theta}+\tau$. No entanto, se não considerarmos $\tau$ em 1.1], isto é, na distribuição dos traços latentes, a distribuição condicional completa será a mesma obtida para o caso em que admite-se uma matriz de covariância uniforme, exposta na Seção 1.5 . Neste caso, ignorar a estrutura multinível pode levar a conclusões equivocadas.

Azevedo, Caio L. N.

IME/USP 


\subsection{Estrutura da Tese}

Sucintamente, os aspectos da TRI que serão abordados no presente trabalho são :

- Elevado número de parâmetros.

- Falta de identificabilidade.

- Dificuldades na estimação dos parâmetros.

- Dificuldades na verificação do ajuste dos modelos.

- Ausência de metodologias apropriadas para a seleção de modelos não encaixados.

O objetivo principal do presente trabalho é desenvolver, sob uma perspectiva bayesiana, uma estrutura geral para os modelos de múltiplos grupos e longitudinais. Tal estrutura corresponde a modelagens, métodos de estimação e mecanismos de diagnóstico que serão desenvolvidos com o intuito de solucionar os problemas mencioandos no começo da presente seção. No Capítulo 1 apresentamos uma revisão sobre alguns dos modelos da TRI, métodos de ajuste e diagnóstico, fornecemos motivação para o estudo do problema e expusemos algumas questões em aberto. No Capítulo 2 discutiremos uma abordagem bayesiana via dados aumentados para o modelo de múltiplos grupos. Desenvolveremos uma metodologia via MCMC para o ajuste do modelo bem como algumas medidas de diagnóstico. No Capítulo 3 desenvolveremos uma abordagem de dados aumentados bayesiana, sob uma perspectiva multivariada, para o modelo longitudinal. De modo semelhante ao Capítulo 2, proporemos um mecanismo de ajuste via MCMC bem como algumas medidas de diagnóstico. O Capítulo 3 pode ser visto como uma extensão do Capítulo 2 no sentido ilustrado na Figura 1.1. O Capítulo 4 pode ser considerado como uma extensão natural dos Capítulo 2 e 3 na medida em que propõe uma modelagem conjunta para dados longitudinais oriundos de múltiplos grupos. Esta abordagem também apresenta uma fundamentação multivariada. Bem como seus antecessores, nele desenvolveremos mecanismo de estimação MCMC e, além disso, discutiremos sobre escolha de modelos. No Capítulo 5 apresentaremos uma alternativa às modelagens dos capítulos anteriores. Nele exporemos o caso longitudinal, de um ou mais grupos, sob uma estrutura multinível e apresentaremos as vantagens dessa metodologia. Também discutiremos o procedimento de MCMC e algumas medidas de diagnóstico pertinentes. Finalmente no Capítulo 6 apresentaremos algumas conclusões e comentários bem como algumas sugestões para futuras pesquisas. A Figura 1.7 ilustra como as diferentes modelagnes estudadas no presente trabalho se interelacionam. A setas tracejadas e pontilhadas apenas diferenciam entre as abordagens multivariada e multinível.

Azevedo, Caio L. N.

$\mathrm{IME} / \mathrm{USP}$ 


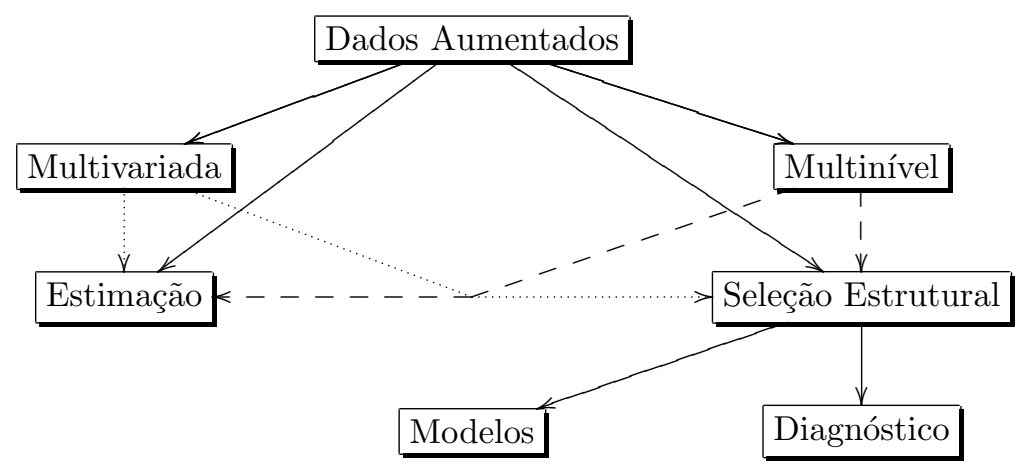

Figura 1.4: Grafo ilustrativo da interleção das modelagens estudadas

Azevedo, Caio L. N. 



\section{Capítulo 2}

\section{Modelos de grupos múltiplos: estrutura bayesiana}

\subsection{Introdução}

Frequentemente, em muitos estudos científicos, dentre eles avaliações na área educacional, existe um interesse em estudar indivíduos oriundos de diferentes grupos ou populaçõeł* Estes, por sua vez, comumente, apresentam diferentes características, próprias de cada um desses grupos. Por exemplo, poder-se-ía avaliar o conhecimento em Matemática de estudantes oriundos de escolas públicas e privadas, ou, acompanhar indíces de qualidade de vida em homens e mulheres. Tais grupos podem ser caracterizados, de uma forma geral, por diferentes sexos, regiões demográficas, indivíduos classificados em pesquisas anteriores, diferentes tratamentos (comum em planejamento de experimentos) dentre outras possibilidades. Em Bock and Zimowski (1997) é possivel encontrar alguns exemplos de situações que ilustram a existência de grupos múltiplos, na área educacional. Em muitos desses estudos também é comum o interesse em se estudar variáveis latentes, como o conhecimento ou nível de depressão.

As diferentes características das populações envolvidas no estudo podem induzir comportamentos distintos na distribuição dos traços latentes, das respostas aos testes ou mesmo na FRI mais apropriada para a modelagem. Com relação aos traços latentes, as distribuições, não só em termos de parâmetros mas também em termos de forma, poderiam ser específicas para cada população. Com relação à FRI poder-se-ía observar DIF para alguns itens. Dessa forma, faz-se necessário um modelo que possa levar em consideração a heterogeneidade, ou seja, as particulares características, desses grupos.

No Contexto da TRI, uma proposta nesse sentido foi apresentada por Mislevy (1983) que modelou possíveis diferenças entre os grupos através da consideração de médias e variâncias particulares (para cada grupo) dos traços latentes. Verdadeiramente, este trabalho forneceu uma modelagem bem estruturada para a questão de grupos múltiplos na TRI. Mislevy (1984) desenvolveu uma estimação não-paramétrica de máxima verossimilhança para a estimação das densidades latentes de diversos grupos no contexto da TRI. Mislevy (1985) apresentou um procedimento de estimação via algoritmo EM, vide Dempster et al. (1977), para estimar

\footnotetext{
* Usaremos indistintamente a nomeclatura "grupo" ou "população" para nos referirmos a uma amostra de indivíduos ou a população como um todo
} 
as médias e variâncias de variáveis latentes em um modelo de resposta discreta (ao item). Baseado no conceito de imputação múltipla, Mislevy (1991) discute a estimação dos parâmetros populacionais de uma distribuição de variável latente sem a necessidade de estimação dos valores individuais dos mesmos. Através da inclusão de informações adicionais a respeito dos indivíduos, tal como sexo, grau de escolaridade etc, o autor mostra que tais estimativas fornecem resultados mais precisos do que aqueles baseados nas estimativas individuais dos traços latentes. Recentemente, Bock and Zimowski (1997) desenvolveram o assim chamado modelo de grupos múltiplos (MGM) o qual representa uma unificação de algumas das propostas citadas anteriormente. Mais especificamente, propuseram extensões dos modelos para um único grupo, atribuindo distribuições gaussianas com parâmetros específicos para cada população. Neste trabalho, os autores desenvolvem uma extensão da abordagem de MVM para um único grupo, proposta por Bock and Aitkin (1981) e também discutem a estimação das densidades latentes baseada nesse algoritmo de estimação. Dessa forma, pode-se estimar conjuntamente os parâmetros dos itens e os parâmetros populacionais (os parâmetros que caracterizam a distribuição dos traços latentes).

O MGM, como citado em Bock and Zimowski (1997), oferece uma abordagem unificada a algumas situações de interesse, notadamente na área educacional, como : funcionamento diferencial do item, desgate dos parâmetros dos itens, equalização de grupos não-equivalentes, equalização vertical, testes em dois estágios e avaliação de matrizes de competência educacionais. Além disso, tal modelagem permite conduzir o processo de equalização, vide Kolen and Brennan (2004), em concomitância com o ajuste do modelo. Este expediente possibilita a obtenção de resultados mais precisos do que quando se emprega métodos de equalização a posteriori, vide Kolen and Brennan (2004). Resultados empíricos obtidos por Andrade (1999) evidenciam tal superioridade. Um outro aspecto é o fato de que resultados provenientes de testes distintos, com itens comuns, podem ser analisados de maneira mais apropriada através de tal modelagem. Em geral, considera-se o MGM quando aos grupos são apresentados diferentes testes, veja Andrade et al. (2000) ou Valle (1999), por exemplo.

Apesar de adequadamente estruturado, bastante utilizado e da existência de pacotes computacionais que permitem utilizar o MGM, como o BILOG-MG e o Parscale, vide Zimowski et al. (1996), não existe uma abordagem bayesiana plena para o ajuste do modelo. Ou seja, metodologias que consideram o cálculo das distribuições a posteriori de interesse. Mais especificamente, não existe nenhuma técnica que se utilize de algoritmos do tipo MCMC para tal ajuste. Apenas, pelo que nos consta, Béguin and Glas (2001) apresentaram um esquema do amostrador de Gibbs sem, no entanto, se aprofundar em estudos de simulação ou análise de dados reais. Por conseguinte, metodologias de diagnóstico bayesiana também não se encontram disponíveis. O objetivo deste Capítulo é o de desenvolver uma modelagem bayesiana geral para o MGM via dados aumentados. Além disso desenvolveremos uma metodologia bayesiana de ajuste baseada no algoritmo do amostrador de Gibbs ("Gibbs Sampling") e medidas de diagnóstico pertinentes.

Na Seção 2.1 apresentamos uma introdução e revisão de aspectos concernentes ao MGM. Na Seção 2.2 
apresentaremos algumas considerações sobre a modelagem enquanto que na Seção 2.3 o modelo propriamente dito. A Seção 2.4 apresentará uma breve discussão sobre métodos de estimação na TRI e a abordagem utilizada em nosso trabalho. A Seção 2.5 discutitá a construção da verossimilhança de forma adequada e a Seção 2.6 apresentará uma discussão de escolha de prioris. A Seção 2.7 apresentará o desenvolvimento do algoritmo MCMC, a Seção 2.8 discutirá alguns aspectos relacionados a medidas de diagnóstico, a Seção 2.9 aborda alguns aspectos computacionais, a Seção 2.10 apresentará estudos de simulação enquanto que a Seção 2.11 apresentará uma análise de dados reais. Finalmente, na Seção 2.12 exporemos algumas conclusões e comentários sobre o presente Capítulo.

As contribuições do presente capítulo são :

1. Desenvolvimento da abordagem de dados aumentados para o modelo probito de 2 parâmetros de grupos múltiplos.

2. Desenvolvimento e implementação computacional do amostrador de Gibbs para o modelo do item 1).

3. Extensão do amostrador de Gibbs mencionado no item 2) para considerar o agrupamento na simulação dos parâmetros populacionais e também modelar DIF dos itens.

4. Desenvolvimento e implementação computacional de algumas medidas de diagnóstico para avaliar a qualidade do ajuste do modelo descrito no item 1) ajustado através do procedimento descrito no item $2)$.

5. Estudo de simulação :

(a) Sensibilidade do modelo e do método de estimação à escolha de prioris.

(b) Estudo do comportamento das cadeias de Markov, geradas pelo algoritmo de Gibbs descrito no item 2 , no que concerne as autocorrelações, influência da escolha de valores iniciais e comportamento das distribuições a posteriori.

(c) Consistência dos estimadores.

6. Aplicação da metodologia a um conjunto de dados reais.

O presente capítulo é uma generalização do trabalho de Albert (1992).

\subsection{Considerações para a modelagem}

Consoante ao que foi dito no começo deste capítulo, utilizaremos o termo grupo para nos refirir, de modo indistinto à uma população ou à uma amostra dela extraída. Caso se trate de uma amostra, consideraremos que a mesma foi selecionada segundo um esquema de Amostra Aleatório Simples sem reposição, veja Cochran 
(2001). Contudo, a população de origem será considerada infinitamente grande, do modo que, o procedimento equivale à uma amostragem aleatória simples com reposição. Portanto, o tamanho da população não irá interferir no processo de inferência. Atribuiremos uma distribuição de probabilidade contínua $d_{\theta_{k}}$ para representar o comportamento dos traços latentes. A cada um desses grupos será aplicado um teste, os quais podem ou não compartilhar itens segundo alguma disposição conveniente, vide Andrade et al. (2000). Naturalmente o caso em que os testes são exatamente os mesmos está contemplado.

Uma outra questão é que existem muitas possibilidades de se definir uma população. Por exemplo, é possível considerar que elas são diferentes conjuntos de escolas, públicas e privadas, ou mesmo que cada escola, por si só, é uma população. Esta última abordagem foi utilizada por Fox (2001) no contexto multinível. Neste sentido tem-se muitos grupos com não muitos indivíduos alocados neles. No nosso trabalho, por outro lado, consideraremos poucos grupos com muitos indivíduos. Entretanto, nossos desenvolvimentos também se aplicam ao caso citado primeiramente.

\subsection{Modelo estatístico}

De acordo com o processo exposto na seção anterior temos $K$ grupos, compostos cada um de $n_{k}$ indivíduos, $n=\sum_{k=1}^{K} n_{k}$ no total, os quais serão submetidos a testes com $I_{k}$ itens cada. Esses itens são escolhidos adequamente de um conjunto total de $I$ itens.

Antes de definir o modelo introduziremos algumas notações úteis : $\theta_{j k}$ é o traço latente do indivíduo $j$ $\left(j=1, \ldots, n_{k},\right)$ pertencente à grupo $k(k=1, \ldots, K), \boldsymbol{\theta}_{. k}=\left(\theta_{j 1}, \ldots, \theta_{j K}\right)^{t}$ é o vetor dos traços latentes dos indivíduos do grupo $k$ e $\boldsymbol{\theta}_{. .}=\left(\boldsymbol{\theta}_{.1}, \ldots, \boldsymbol{\theta}_{. K}\right)^{t}$ é o vetor de todos os traços latentes; $Y_{i j k}$ é o escore do indivíduo $j$, do grupo $k$ no item $i(i=1, \ldots, I), \boldsymbol{Y}_{. j k}=\left(Y_{1 j k}, \ldots, Y_{I j k}\right)^{t}$ é o vetor dos escores em todos os itens do indivíduo $j$ do grupo $k, \boldsymbol{Y}_{. . k}=\left(\boldsymbol{Y}_{.1 t}^{t}, \ldots, \boldsymbol{Y}_{. n_{k} t}^{t}\right)^{t}$ é o vetor de todas as respostas de todos os indivíduos do grupo $k, \boldsymbol{Y}_{\ldots}=\left(\boldsymbol{Y}_{.1}^{t}, \ldots, \boldsymbol{Y}_{. n_{k} .}^{t}\right)^{t}$ é o vetor com os conjuntos de respostas dos indivíduos e $\left(y_{i j k}, \boldsymbol{y}_{. j k}^{t}, \boldsymbol{y}_{. . k}^{t}, \boldsymbol{y}_{\ldots .}^{t}\right)^{t}$ são os respectivos valores observados; $\boldsymbol{\zeta}_{i}$ é o vetor de parâmetros de item $i, \boldsymbol{\zeta}=\left(\boldsymbol{\zeta}_{1}^{t}, \ldots, \boldsymbol{\zeta}_{I}^{t}\right)^{t}$ é o vetor com todos

os parâmetros de todos os itens, $\boldsymbol{\eta}_{\theta_{k}}$ é o vetor de parâmetros populacionais do grupo $k$ e $\boldsymbol{\eta}_{\boldsymbol{\theta}}=\left(\boldsymbol{\eta}_{\theta_{1}}^{t}, \ldots, \boldsymbol{\eta}_{\theta_{K}}^{t}\right)^{t}$ é o vetor com os parâmetros populacionais de todos os grupos.

Portanto, o modelo probito de 2 parâmetros de grupos múltiplos (MP2PMG) é dado por

\section{Modelo de resposta ao item (parte funcional)}

$$
Y_{i j k} \mid\left(\theta_{j k}, \boldsymbol{\zeta}_{i}\right) \sim B\left(P_{i j k}\right)
$$

Azevedo, Caio L. N.

$\mathrm{IME} / \mathrm{USP}$ 


$$
P_{i j k}=P\left(Y_{i j k}=1 \mid \theta_{j k}, \boldsymbol{\zeta}_{i}\right)=\Phi\left(a_{i} \theta_{j k}-b_{i}\right),
$$

\section{Distribuição latente (parte estrutural)}

$$
\theta_{j k} \mid \boldsymbol{\eta}_{\theta_{k}} \sim N\left(\mu_{\theta_{k}}, \psi_{\theta_{k}}\right),
$$

em que $\boldsymbol{\zeta}_{i}=\left(a_{i}, b_{i}\right)^{t}$ e $\boldsymbol{\eta}_{\theta_{k}}=\left(\mu_{\theta_{k}}, \psi_{\theta_{k}}\right)^{t}$. É digno de nota que 2.1 é uma reparametrização do modelo original probito de 2 parâmetros, veja Baker and Kim (2004). Na equação (2.1) o parâmetro $b$ representa $b=a b^{*}$, em que $b^{*}$ é o parâmetro de dificuldade original. Além disso, de uma forma em geral, a parte 2.2 do modelo

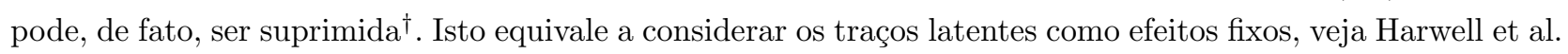
(1988). Entrentanto, em termos do ajuste do modelo via MCMC, a mesma se faz necessária. Tais comentários são válidos para todo o desenvolvimento desta Tese.

Com relação a distribuição dada em 2.2 algumas escolhas têm sido consideradas na literatura: normal padrão, Bock and Aitkin (1981), mistura finitas de normais, Mislevy (1986), normal multivariada, Tavares (2001) e normal assimétrica, Bazán (2005). Além disso, uma representação não-paramétrica é possível dividindo-se a densidade latente em um conjunto finito de pontos. Neste sentido algumas referências importantes são Bock and Aitkin (1981) e Mislevy (1984). A suposição de normalidade nos desenvolvimentos apresentados aqui é baseada em dois pontos. Primeiro, em algumas situações é razoável a escolha de tal modelo para representar o comportamento dos traços latentes ou mesmo, tal modelo pode se mostrar robusto, veja Azevedo and Andrade (2007). Segundo, as estruturas de outras distribuições de interesse, e.g. normal assimétrica, t e t-assimétrica, podem ser facilmente desenvolvidas a partir da estrutura da distribuição normal, através de alguma representação estocástica conveniente.

\subsection{Métodos de estimação}

Sem dúvida, um dos aspectos mais importantes com respeito a aplicação da TRI nos últimos anos, tem sido o desenvolvimentos de métodos de estimação apropriados. Existe uma vasta literatura com respeito a esse segmento. Por exemplo, Baker and Kim (2004) mostram diferentes métodos e apresentam uma visão geral sobre a história desse tópico. Azevedo (2003) discute alguns aspectos de relevância e apresenta alguns procedimentos alternativos aos usuais. Recomendamos a leitura de ambos para um aprofundamento no assunto.

$\dagger$ No sentido de não ser atribuir distribuição de probabilidade aos traços latentes. Isto equivale a tratá-los como efeitos fixos.

Azevedo, Caio L. N.

IME/USP 
Nesta seção discutiremos, brevemente, os principais métodos utilizados. De uma forma em geral, podemos dizer que existem três grandes problemas com relação ao ajuste de um MRI : a falta de identificabilidade, o grande número de parâmetros (que aumenta com o aumento do tamanho da amostra) e a complexidade das FRI. Dessa forma, procedimentos de estimação conjunta dos parâmetros, num contexto frequentista, podem não produzir estimativas consistentes, veja Baker and Kim (2004). Isto, inclusive, pode ocorrer com certos procedimentos bayesianos, veja Lord (1986). Em alternativa à essa abordagem alguns trabalhos foram desenvolvidos. Bock and Lieberman (1970) consideraram a obtenção da verossimilhança marginal, através da integração dos traços latentes, daí a nomenclatura máxima verossimilhança marginal (MVM). Contudo, tal procedimento exige a maximização de tal verossimilhança (marginal) conjuntamente com relação aos parâmetros dos itens, o que torna este método limitado para testes com mais do que 15 itens. Na tentativa de solucionar tal problema, Bock and Aitkin (1981) consideraram a utilização de um pseudo algoritmo EM, vide Dempster et al. (1977), implementado através das quantidades assim chamadas de dados artificiais. Nesta abordagem os parâmetros dos itens são estimados individualmente, a menos das quantidades artificiais, o que torna tal método potencialmente aplicável em um número razoável de situações. Além disso, algumas medidas de ajuste foram desenvolvidas com base nos resultados obtidos por este método, vide Zimowski et al. (1996). Mislevy (1986) desenvolveu um paralelo bayesiano da abordagem de MVM no sentido de que ele atribuiu prioris para os parâmetros dos itens e para os traços latentes. Note-se que, neste caso, a priori para os traços latentes, apesar de ser utilizada na construção da verossimilhança marginal, é atribuída através de argumentos bayesianos e não embasada em suposições de amostragem, veja Andrade et al. (2000). Com relação a estimação dos parâmetros dos itens tal método é conhecido como Moda Marginal a Posteriori (MMAP). Para a estimação dos traços latentes Mislevy (1986) sugere a utilização da média ou da moda a posteriori. Por outro lado, Mislevy and Stocking (1989) sugerem com maior ênfase, esperança a posteriori. Esses métodos são conduzidos em duas etapas no sentido de que primeiro se estima os parâmetros dos itens.Então, de posse de tais estimativas, estima-se os traços latentes através de uma verossimilhança do tipo perfilada, Fraser and Reid (1989). Mais detalhes sugerimos a leitura das referências supracitadas.

No contexto da TRI, a abordagem bayesiana plena (ABP), baseada em métodos de MCMC, veja Gilks et al. (1996), iniciou-se com o trabalho de Albert (1992). Em uma ABP via MCMC, as distribuições a posteriori, conjuntas e marginais, dos parâmetros de interesse são obtidas, de modo empírico, ao invés de meras estimativas pontuais, como nas abordagens discutidas anteriormente. Neste trabalho, Albert utilizou um esquema de dados aumentados, veja Tanner and Wong (1987) e Johnson and Albert (1999) por exemplo, no modelo probito de 2 parâmetros (para um único grupo), veja Baker and Kim (2004), desenvolvendo um esquema direto de simulação através do amostrador de Gibbs, vide Gilks et al. (1996). Este procedimento permite que modelos complexos sejam ajustados sem a necessidade da utilização de métodos numéricos de integração ou de maximização de funções. Modelos como os longitudinais, veja Tavares (2001), ou multivariados, veja Matos (2001), necessitam se utilizar de métodos de integração numérica para a implementação da abordagem via verossimilhança marginal. Apesar de métodos de quadratura adaptativa, vide Schilling and Bock (2005) e Gander and Gautschi (2000), 
poderem ser utilizados, tal abordagem, principalmente na ausência de normalidade simétrica, pode não produzir bons resultados, mesmo que seja possível de obtê-los. Dessa forma, a utilização de algoritmo do tipo MCMC é uma alternativa bastante útil principalmente no ajuste de modelos complexos.

Outros trabalhos que utilizam a metodologia de dados aumentados com MCMC na TRI, são Bazán (2005), Béguin and Glas (2001), Fox and Glas (2001), Fox and Glas (2003) e Sahu (2002). Uma vez que a verossimilhança, para a abordagem de dados aumentados, requer especial atenção, apresenta-la-emos na próxima seção com detalhes.

\subsection{Verossimilhança de dados aumentados}

É sabido que a verossimilhança desempenha papel fundamental em qualquer análise estatística, vide Cordeiro (1992). Na inferência bayesiana, ela é a responsável pela ligação entre a priori e a posteriori. Qualquer que seja a verossimilhança considerada na análise, é necessário lançar mão de algumas suposições de forma a permitir sua construção de modo conveniente. Com relação à modelagem proposta no presente capítulo e que se assume, em geral, para a grande maioria dos MRI, tais suposições são

- As informações necessárias para modelar a probabilidade de resposta são somente os traços latentes e os parâmetros dos itens.

- Apenas uma dimensão do traço latente é necessária para se modelar tal probabilidade (unidimensionalidade).

- O tempo disponível para se responder o teste é suficiente.

- Dado omissos ("missing data") são gerados por uma mecanismo de não-reposta não-informativo, veja Little and Rubin (2002).

As duas primeiras suposições estão associadas à correta especificação do modelo (2.1). Além disso, elas implicam que as respostas de cada indivíduo, aos diferentes itens, são condicionalmente independentes dado os traços latentes e os parâmetros dos itens. Em outras palavras, nenhuma outra informação é necessária para o cálculo de tais probabilidades. As duas últimas garantem que o mecanismo gerador dos dados faltantes possui distribuição ignorável. Tal estrutura é conhecida como MAR ("missing at random"),veja Little and Rubin (2002). Dessa forma, ela pode ser desconsidereda na análise, sem se alterar, de modo significativo, os resultados.

A razão para utilizarmos o esquema de dados aumentados é que este permite obter distribuições condicionais completas, veja Gamerman and Lopes (2006) por exemplo, com forma funcional mais simples, vide Albert (1992). Além disso, ao se considerar um esquema de dados aumentados, introduzimos um modelo mais geral. Um tercerio aspecto é que tal abordagem permite construir mecanismos de ajuste do modelo de modo mais 
direto, veja Fox (2001). A idéia geral por trás do esquema de dados aumentados é definir um conjunto de variáveis não-observáveis baseado nos dados observados (respostas ao itens). Mais especificamente, o objetivo é o de utilizar a verossimilhança gerada por esses dados aumentados ao invés da verossimilhança original. Isto se traduz, por sua vez, em utilizar a distribuição condicional das variáveis aumentadadas dada as variáveis observadas e os parâmetros, vide Tanner and Wong (1987). O processo de inferência então é baseado na verossimilhança aumentada e não mais na verossimilhança original, vide Tanner and Wong (1987). No presente contexto, utilizando a FRI dada em (2.1), as variáveis aumentadas são, essencialmente, as mesmas definidas por Albert (1992). Estas são dadas por

$$
Z_{i j k} \mid\left(\theta_{j k}, \boldsymbol{\zeta}_{i}, y_{i j k}\right)= \begin{cases}N\left(a_{i} \theta_{j k}-b_{i}, 1\right) \mathbb{1}_{\left(z_{i j k} \geq 0\right)}, & \text { se } Y_{i j k}=1, \\ N\left(a_{i} \theta_{j k}-b_{i}, 1\right) \mathbb{1}_{\left(z_{i j k}<0\right)}, & \text { se } Y_{i j k}=0,\end{cases}
$$

em que $\mathbb{1}_{\left(z_{j i k} \geq 0\right)}$ é a função indicadora usual, isto é, é igual a 1 se o argumento for verdadeiro e 0 caso contrário. As suposições descritas anteriormente garantem que estas variáveis são mutuamente independentes, condicionadas aos traços latentes, aos parâmetros dos itens e as respostas.

Note que se escrevermos

$$
Y_{i j k}=\mathbb{1}_{\left(z_{i j k} \geq 0\right)}
$$

vem que

$$
\begin{aligned}
P\left(Y_{i j k}=1 \mid \theta_{j k}, \boldsymbol{\zeta}_{i}\right) & =P\left(\mathbb{1}_{\left(z_{i j k} \geq 0\right)}=1 \mid \theta_{j k}, \boldsymbol{\zeta}_{i}\right)=P\left(Z_{i j k} \geq 0 \mid \theta_{j k}, \boldsymbol{\zeta}_{i}\right) \\
& =\Phi\left(a_{i} \theta_{j k}-b_{i}\right),
\end{aligned}
$$

o qual é o mesmo modelo dado em 2.1. A última igualdade em 2.5 segue da propriedade de simetria da normal simétrica padrão. Dessa forma, as verossimilhanças dos dados aumentados condicionado aos dados observados e aquela oriunda somente dos dados observados são equivalentes. Entretanto, inferências baseadas nelas podem ser diferentes sendo esperado resultados próximos por conta da relação expressa em (2.5). Chamamos atenção para o fato de que as notações relacionadas aos dados aumentados são equivalentes àquelas definidas para os dados observados no começo da Seção 2.3 .

É bastante usual, na presença de várias populações, aplicar-se testes diferentes mas com itens em comum. Esse tipo de situação gera o que Tavares (2001) nomeou de ausência de resposta pelo planejamento. 
Os dados omissos gerados por esse mecanismo são não-informativos, ou seja, são regidos por mecanismos de ausência por acaso MAR, veja Little and Rubin (2002). Portanto, tal mecanismo não é relevante para o processo de inferência. Além disso, os indivíduos podem não responder aos itens por outros motivos, como "stress", falta de tempo, negligência etc. No entanto, não importa o motivo da ausência de resposta, ele será considerado como MAR. Sendo assim, definiremos um conjunto de variáveis observáveis, que denotam se, para determinado indivíduo, observou-se resposta ou não para determinado item. Estas são dadas por:

$$
V_{i j k}= \begin{cases}1, & \text { se para o item } i \text { foi observada resposta do indivíduo } j \text { pertencente ao grupo } k \\ 0, & \text { caso contrário. }\end{cases}
$$

De modo similar às variáveis aumentadas, as variáveis indicadoras de resposta são condicionalmente independentes, entre indivíduos, itens e populações, dado os parâmetros que regem sua distribuição de probabilidade. Em outras palavras,

$$
p\left(\boldsymbol{v}_{\ldots} \mid \boldsymbol{\delta}\right)=\prod_{k=1}^{K} \prod_{j=1}^{n_{k}} \prod_{i=1}^{I} p\left(v_{i j k} \mid \boldsymbol{\delta}\right)
$$

Posto os argumentos acima, temos que a verossimilhança é dada por

$$
\begin{aligned}
& L\left(\boldsymbol{\theta}_{\ldots}, \boldsymbol{\zeta}, \boldsymbol{\eta}_{\theta}, \boldsymbol{\delta} \mid \boldsymbol{z}_{\ldots,}, \boldsymbol{y}_{\ldots,}, \boldsymbol{v}_{\ldots}\right) \propto p\left(\boldsymbol{v}_{\ldots,}, \boldsymbol{z}_{\ldots} \mid \boldsymbol{\theta}_{\ldots}, \boldsymbol{\zeta}, \boldsymbol{\eta}_{\theta}, \boldsymbol{\delta}, \boldsymbol{y}_{\ldots}\right) \\
& =p\left(\boldsymbol{v}_{\ldots} \mid \boldsymbol{z}_{\ldots}, \boldsymbol{\theta}_{\ldots .}, \boldsymbol{\zeta}, \boldsymbol{\eta}_{\theta}, \boldsymbol{\delta}, \boldsymbol{y}_{\ldots}\right) p\left(\boldsymbol{z}_{\ldots} \mid \boldsymbol{\theta}_{\ldots,}, \boldsymbol{\zeta}, \boldsymbol{\eta}_{\theta}, \boldsymbol{\delta}, \boldsymbol{y}_{\ldots}\right) \\
& =p\left(\boldsymbol{v}_{\ldots} \mid \boldsymbol{\delta}\right) p\left(\boldsymbol{z}_{\ldots} \mid \boldsymbol{\theta}_{. .}, \boldsymbol{\zeta}, \boldsymbol{y}_{\ldots}\right) \\
& \propto p\left(\boldsymbol{z}_{\ldots} \mid \boldsymbol{\theta}_{. .}, \boldsymbol{\zeta}, \boldsymbol{y}_{\ldots}\right) \\
& \propto \prod_{k=1}^{K} \prod_{j=1}^{n_{k}} \prod_{i \in I_{j k}} \exp \left\{-0.5\left(z_{i j k}-a_{i} \theta_{j k}+b_{i}\right)^{2}\right\} \mathbb{1}_{\left(z_{i j k}, y_{i j k}\right)},
\end{aligned}
$$

em que $I_{j k}$ é o conjunto de itens apresentados ao indivíduo $j$ da população $k$ e $\mathbb{1}_{\left(z_{i j k}, y_{i j k}\right)}$ representa a função indicadora $\mathbb{1}_{\left(Y_{i j k}=0, Z_{i j k}<0\right)}+\mathbb{1}_{\left(Y_{i j k}=1, Z_{i j k} \geq 0\right)}$. Note que 2.7 vem do fato de que $\boldsymbol{\eta}_{\theta}$ depende somente da distribuição de $\boldsymbol{\theta}_{\text {... }}$. Além disso 2.8 segue do fato de que $\boldsymbol{V}_{\text {... }}$ é regido por um processo MAR.

Por outro lado, podemos redefinir a estrutura dada por (2.1) e 2.2 em termos dos dados aumentados (2.3), tal como

Azevedo, Caio L. N.

IME/USP 


$$
\begin{aligned}
Z_{i j k} \mid y_{i j k} & =a_{i} \theta_{j k}-b_{i}+\xi_{i j k}^{(Z)} \\
\theta_{j k} & =\mu_{\theta_{j k}}+\xi_{j k}^{(\theta)}
\end{aligned}
$$

em que $\xi_{i j k}^{(Z)} \sim N(0,1)$, mutuamente independentes e independentes de $\xi_{j k}^{(\theta)} \sim N\left(0, \psi_{\theta_{k}}\right)$. Liu and Hedeker (2006), por exemplo, utilizaram uma estrutura similar à (2.10) para apresentar o modelo desenvolvido no trabalho deles. Podemos notar, então, que o modelo estabelecido em 2.10 pode ser visto como um MRI contínuo ou mesmo, um modelo de regressão no qual as variáveis resposta seguem distribuição normal truncada. Isto é, nossos desenvolvimentos também se aplicam em tais casos.

\subsection{Distribuições a priori e a posteriori}

A essência inferencial dos métodos de análise bayesiana reside na distribuição a posteriori, vide Bernardo and Smith (2000), Paulino et al. (2003) e Gelman et al. (2004). A mesma é obtida a partir de operações probabilísticas envolvendo a verossimilhança e a distribuição a priori. Esta última, por sua vez, reflete o conhecimento a priori (de um especialista) sobre o problema ou mesmo o grau de incerteza a respeito das quantidades desconhecidas do modelo.

Particurlamente, no contexto da TRI, muitos estudos têm sido conduzidos a respeito da escolha de prioris mais adequadas. Muitas questões como a falta de identificabilidade, espaços paramétricos restritos, amostras pequenas, dentre outros, podem ser, se não resolvidas na sua totalidade, pelo menos parcialmente tratadas, através da escolha conveniente de prioris. Com relação aos parâmetros dos itens, Gifford and Swaminathan (1990) estudaram o efeito de escolhas de prioris para os modelos logísticos de um, dois e três parâmetros (1PL, 2PL e 3PL, respectivamente), veja Baker and Kim (2004), através do procedimento de estimação bayesiana conjunta, vide Baker and Kim (2004). Eles mostram que, dependendo da escolha das prioris e do tamanho da amostra (número de respondentes), diferentes resultados podem ser obtidos. Harwell and Janosky (1991), usando o modelo 2PL e o método MMAP, observaram que com poucos indivíduos e/ou variâncias pequenas para as prioris dos parâmetros dos itens, os resultados também são afetados por diferentes escolhas. Kim et al. (1994) considerando o uso de um procedimento bayesiano hierárquico, vide Paulino et al. (2003), para estimar os hiperparâmetros dos parâmetros dos itens, mostraram que pode se obter um refinamento das estimativas dos parâmetros de interesse. Resultados semelhantes foram obtidos por Mislevy (1986) através de uma abordagem um pouco diferente. Baker (1998) mostrou, através de estudos de simulação que, para a escolha de certas prioris não-informativas (impróprias), o método de MVM pode produzir resultados mais acurados que a abordagem de MCMC. Os resultados de Patz and Junker (1999b) e Patz and Junker (1999a), utilizando os modelos 2LP e 3LP, indicam que, mesmo para tamanhos de amostra razoáveis, a escolha de prioris pode produzir resultados diferentes. Swaminathan et al. (2003) mostraram que, para tamanhos amostrais 
pequenos, prioris convenientes podem refinar a acurácia das estimativas, especialmente para modelos mais complexos. Ghosh et al. (2002) discutem a existência das distribuições a posteriori, para o modelo de Rasch, sob a escolha de prioris não-informativas impróprias. Eles provaram que algumas escolhas podem conduzir a posterioris impróprias. Resultado semelhante é demonstrado em Albert and Ghosh (2000) para o modelo probito e logístico de 2 parâmetros. Sahu (2002), para o modelo probito de 3 parâmetros, também encontrou estimativas diferentes e mesmo resultados instáveis para diferentes escolhas de prioris

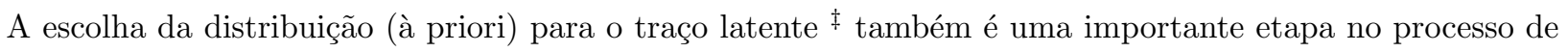
estimação dos MRI. Escolhas adequadas permitem não só resolver (parcial ou totalmente) os problemas de falta de identificabilidade, mas também acomodar características inerentes ao estudo como por exemplo dependência longitudinal, vide Andrade and Tavares (2005) e assimetria, vide Bazán (2005). No presente trabalho, como estabelecido anteriormente, consideraremos uma distribuição normal simétrica. A escolha de hiperprioris para os parâmetros populacionais também podem afetar os resultados, principalmente para procedimentos via algoritmos MCMC, veja Gelman (2006). A escolha das prioris (excluindo os traços latentes) será baseada na garantia de obtenção de posterioris próprias e também na pertinência à família de modelos de conjugação condicional, veja Gelman (2006).

A nossa abordagem será baseada na seguinte forma geral da priori conjunta,

$$
p\left(\left(\boldsymbol{\zeta}, \boldsymbol{\eta}_{\boldsymbol{\theta}}\right) \mid\left(\boldsymbol{\eta}_{\boldsymbol{\zeta}}, \boldsymbol{\eta}_{\boldsymbol{\eta}}\right)\right)=\left\{\prod_{i=1}^{I} p\left(\boldsymbol{\zeta}_{i} \mid \boldsymbol{\eta}_{\boldsymbol{\zeta}_{i}}\right)\right\}\left\{\prod_{k=1}^{K} p\left(\boldsymbol{\eta}_{\boldsymbol{\theta}_{k}} \mid \boldsymbol{\eta}_{\boldsymbol{\eta}_{k}}\right)\right\}
$$

em que $\boldsymbol{\eta}_{\boldsymbol{\zeta}}=\left(\boldsymbol{\eta}_{\zeta_{1}}^{t}, \ldots, \boldsymbol{\eta}_{\zeta_{I}}^{t}\right)^{t}$ e $\boldsymbol{\eta}_{\boldsymbol{\eta}}=\left(\boldsymbol{\eta}_{\boldsymbol{\eta}_{1}}^{t}, \ldots, \boldsymbol{\eta}_{\boldsymbol{\eta}_{K}}^{t}\right)^{t}$. Isto significa que estamos admitindo independência a priori entre os itens e os parâmetros de diferentes populações, o que faz sentido em termos práticos. Se, por outro lado, considerarmos que os hiperparâmetros em 2.12 são os mesmos para todas as prioris, $\boldsymbol{\eta}_{\zeta}=\left(\boldsymbol{\eta}_{\zeta}^{t}, \ldots, \boldsymbol{\eta}_{\zeta}^{t}\right)^{t}$ e $\boldsymbol{\eta}_{\boldsymbol{\eta}}=\left(\boldsymbol{\eta}_{\boldsymbol{\eta}}^{t}, \ldots, \boldsymbol{\eta}_{\boldsymbol{\eta}}^{t}\right)^{t}$, isto é,

$$
p\left(\boldsymbol{\zeta}, \boldsymbol{\eta}_{\boldsymbol{\theta}}\right)=\left\{\prod_{i=1}^{I} p\left(\boldsymbol{\zeta}_{i} \mid \boldsymbol{\eta}_{\boldsymbol{\zeta}}\right)\right\}\left\{\prod_{k=1}^{K} p\left(\boldsymbol{\eta}_{\theta_{k}} \mid \boldsymbol{\eta}_{\boldsymbol{\eta}}\right)\right\}
$$

assumimos que os parâmetros são permutáveis, veja Bernardo and Smith (2000). Contudo, algum tipo de dependência pode ser considerado para os parâmetros de um mesmo item, bem como para os parâmetros de uma mesma população.

$\ddagger$ É possível também se atribuir uma distribuição de probabilidade para os traços latentes utilizando argumentos probabilísticos, o que ocorre para o caso da estimação de MVM, veja Andrade et al. (2000) e Baker and Kim (2004), por exemplo.

Azevedo, Caio L. N.

$\mathrm{IME} / \mathrm{USP}$ 
O passo seguinte à escolha das prioris, é a construção das posterioris. Utilizando $(2.9)$ e $(2.13)$ temos que a mesma é dada por,

$$
\begin{aligned}
p\left(\boldsymbol{z}_{\ldots}, \boldsymbol{\theta}_{. .}, \boldsymbol{\zeta}, \boldsymbol{\eta}_{\theta} \mid \boldsymbol{y}_{\ldots}\right)= & \left\{\prod_{k=1}^{K} \prod_{j=1}^{n_{k}} \prod_{i} p\left(z_{i j k} \mid \theta_{j k}, \boldsymbol{\zeta}_{i}, y_{i j k}\right)\right\}\left\{\prod_{k=1}^{K} \prod_{j=1}^{n_{k}} p\left(\theta_{j k} \mid \boldsymbol{\eta}_{\theta_{k}}\right)\right\} \\
& \left\{\prod_{i=1}^{I} p\left(\boldsymbol{\zeta}_{i}\right)\right\}\left\{\prod_{k=1}^{K} p\left(\boldsymbol{\eta}_{\theta_{k}}\right)\right\},
\end{aligned}
$$

em que

$$
\begin{aligned}
p\left(\boldsymbol{\zeta}_{i}\right) & =p\left(\boldsymbol{\zeta}_{i} \mid \boldsymbol{\eta}_{\boldsymbol{\zeta}}\right), \\
p\left(\boldsymbol{\eta}_{\theta_{k}}\right) & =p\left(\boldsymbol{\eta}_{\theta_{k}} \mid \boldsymbol{\eta}_{\boldsymbol{\eta}}\right),
\end{aligned}
$$

Um diagrama de influência para representar o MGM, através do esquema de dados aumentados proposto, sob uma estrutura bayesiana, é mostrado na Figura 2.1. As linhas tracejadas representam o fato de que $Y \mid Z \perp(\theta, \boldsymbol{\zeta})$, ou seja, as respostas são estatisticamente independentes dos traços latentes e dos parâmetros dos itens, condicionadas as variáveis aumentadas. Com efeito, basta conhecermos o sinal da variável aumentada para determinar a resposta do indivíduo ao item.

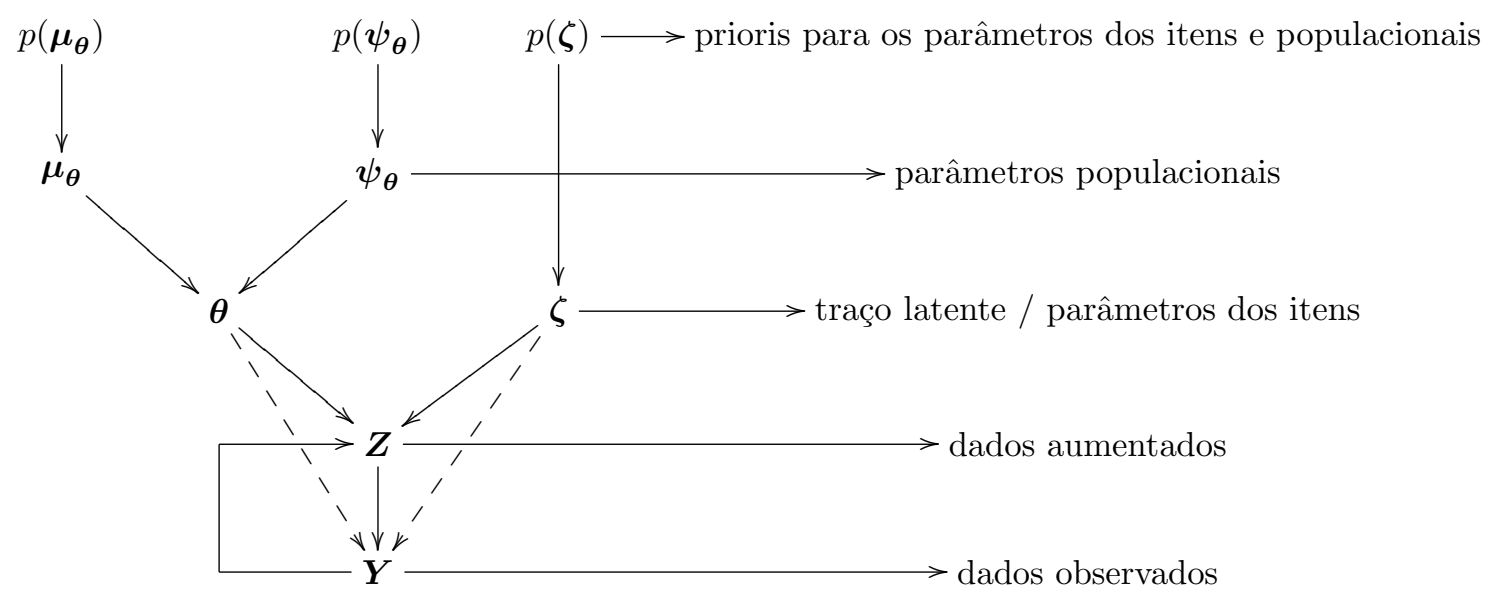

Figura 2.1: Diagrama de influência do modelo de grupos múltiplos bayesiano via dados aumentados (MMGBDA)

Azevedo, Caio L. N.

IME/USP 
Com relação aos parâmetros dos itens, duas escolhas têm disso consideradas na literatura : normal multivariada (com $a_{i}>0$ ) e não-informativas, as quais são dadas, respectivamente, por

$$
p\left(\boldsymbol{\zeta}_{i}\right) \propto \exp \left[-0.5\left(\boldsymbol{\zeta}_{i}-\boldsymbol{\mu}_{\zeta}\right)^{t} \boldsymbol{\Psi}_{\boldsymbol{\zeta}}^{-1}\left(\boldsymbol{\zeta}_{i}-\boldsymbol{\mu}_{\zeta}\right)\right] \mathbb{1}_{\left(a_{i}>0\right)}
$$

e

$$
p\left(\boldsymbol{\zeta}_{i}\right) \propto \mathbb{1}_{\left(\boldsymbol{\zeta}_{i} \in A_{\zeta_{i}}\right)}
$$

em que $A_{\zeta_{i}}$ representa algum conjunto que torna a priori própria (para garantir uma distribuição própria), por exemplo $A_{\zeta_{i}}=\left\{a_{i} \in(0,100), b_{i} \in(-200,200)\right\}$. Certo cuidado deve ser tomado quando se escolhe, por exemplo, média a priori 0 para o parâmetro de discriminação. Isso pode causar um conflito entre a verossimilhança e a priori, como ilustra a Figura 2.2. Percebemos que, quanto mais próximo de zero for a média da priori para o parâmetro de discriminação, maior poderá ser a distância entre ela e a verossimilhança. Isto pode prejudicar o procedimento de estimação uma vez que ambas tenderiam a direções opostas.

Uma escolha natural para os parâmetros populacionais, uma vez que o modelo normal foi atribuído para os traços latentes, é a assim chamada distribuição normal-qui-quadrado escalonada, veja Gelman et al. (2004), cuja densidade é dada por

$$
p\left(\boldsymbol{\eta}_{\theta_{k}}\right)=p\left(\mu_{\theta_{k}} \mid \psi_{\theta_{k}}\right) p\left(\psi_{\theta_{k}}\right) \propto \psi_{\theta_{k}}^{-1 / 2}\left(\psi_{\theta_{k}}\right)^{-\left(v_{0} / 2+1\right)} \exp \left(-\frac{1}{2 \psi_{\theta_{k}}}\left[v_{0} \psi_{0}+\kappa_{0}\left(\mu_{\theta_{k}}-\mu_{0}\right)^{2}\right]\right),
$$

em que $\left(\mu_{0}, \psi_{0}, \kappa_{0}, v_{0}\right)^{t}$ são hiperparâmetros associados. Isto implica que estamos assumindo uma dependência a priori entre os parâmetros de uma mesma população. No entanto, se for mais razoável considerar tais parâmetros independentes, uma escolha apropriada é a distribuição normal para a média e gama inversa para a variância, ou seja,

$$
p\left(\mu_{\theta_{k}}, \psi_{\theta_{k}}\right)=p\left(\mu_{\theta_{k}}\right) p\left(\psi_{\theta_{k}}\right) \propto \exp \left[-\frac{1}{2 \psi_{0}}\left(\mu_{\theta_{k}}-\mu_{0}\right)^{2}\right] \psi_{\theta_{k}}^{-v_{0} / 2-1} \exp \left(-\frac{\kappa_{0}}{2 \psi_{\theta_{k}}}\right)
$$

em que $\left(\mu_{0}, \psi_{0}, \kappa_{0}, v_{0}\right)^{t}$ são os hiperparâmetros associados. Se ainda não houver nenhum conhecimento a priori

Azevedo, Caio L. N.

IME/USP 


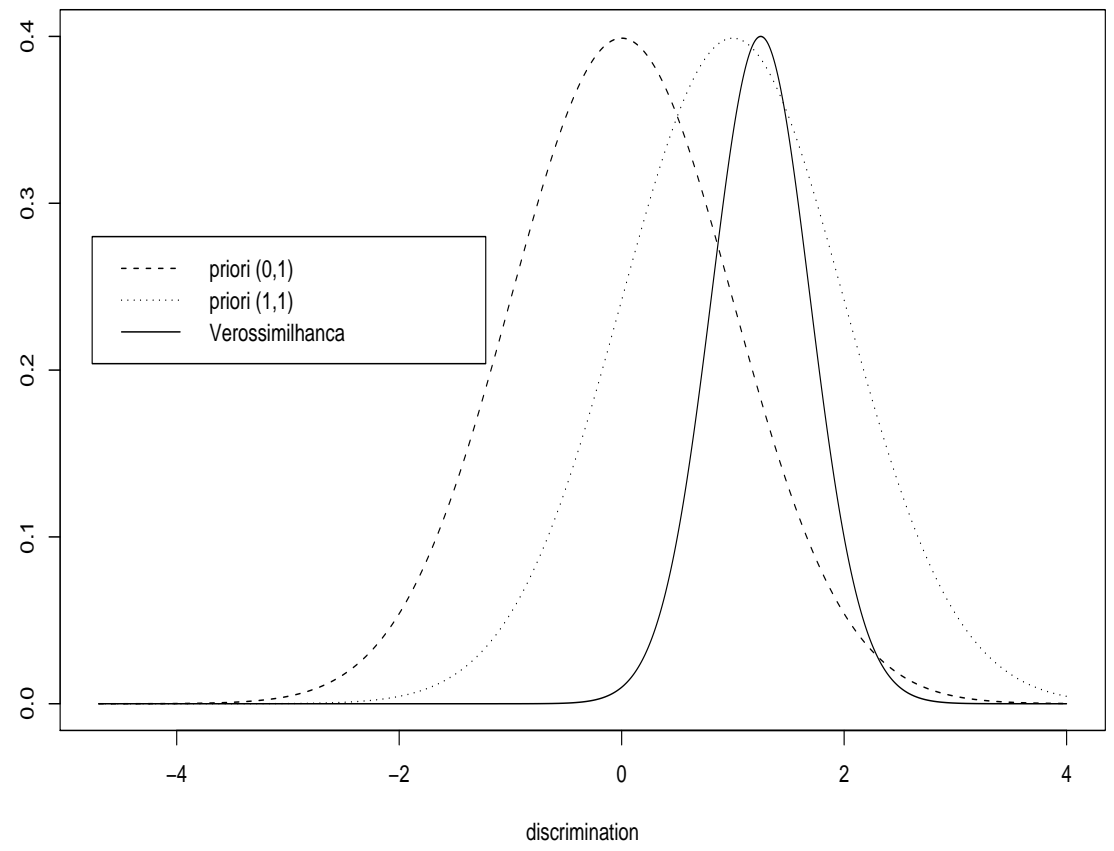

Figura 2.2: Gráfico de duas prioris para o parâmetro de discriminação e uma verossimilhança artifical

sobre os parâmetros populacionais, uma escolha natural é a priori de Jeffrey's, veja Gelman et al. (2004), que é obtida tomando-se $\left(\psi_{0}, \kappa_{0}, v_{0}\right)^{t} \rightarrow(0,0,0)^{t}$ em 2.17 ou 2.18, isto é,

$$
p\left(\mu_{\theta_{k}}, \psi_{\theta_{k}}\right) \propto \psi_{\theta_{k}}^{-1}
$$

No entanto, é necessário ter cautela no que tange a escolha de prioris impróprias, como a considerada em 2.19). As prioris definidas em 2.17), 2.18 e 2.19) conduzem à distribuições condicionais completas com forma conhecida. Mais ainda, elas levam à famílias de distribuições condicionalmente conjugadas, veja Gelman (2006).

Dessa forma, considerando a verossimilhança descrita em (2.9) as prioris dadas em 2.2, 2.15) e 2.18, temos que a distribuição a posteriori definida em (2.14), torna-se :

Azevedo, Caio L. N.

IME/USP 


$$
\begin{aligned}
p\left(\boldsymbol{z}_{\ldots,}, \boldsymbol{\theta}_{. .}, \boldsymbol{\zeta}, \boldsymbol{\eta}_{\theta} \mid \boldsymbol{y}_{\ldots}\right) & \propto\left\{\prod_{k=1}^{K} \prod_{j=1}^{n_{k}} \prod_{i \in I_{j k}} \exp \left\{-0.5\left(z_{i j k}-a_{i} \theta_{j k}+b_{i}\right)^{2}\right\} \mathbb{1}_{\left(z_{i j k}, y_{i j k}\right)}\right\} \\
& \times \prod_{j=1}^{n_{k}}\left\{\exp \left\{-\frac{1}{\psi_{\theta_{k}}}\left(\theta_{j k}-\mu_{\theta_{k}}\right)^{2}\right\}\right\} \psi_{\theta_{k}}^{-n_{k} / 2} \\
& \times\left\{\prod_{k=1}^{K} \exp \left(-\frac{1}{\psi_{\theta_{0}}}\left(\mu_{\theta_{k}}-\mu_{0}\right)^{2}\right)\right\}\left\{\prod_{k=1}^{K} \psi_{\theta_{k}}^{-v_{0} / 2-1} \exp \left(-\frac{\kappa_{0}}{2 \psi_{\theta_{k}}}\right)\right\} \\
& \times \prod_{i=1}^{I} \exp \left\{-0.5\left(\boldsymbol{\zeta}_{i}-\boldsymbol{\mu}_{\zeta}\right)^{t} \boldsymbol{\Psi}_{\boldsymbol{\zeta}}^{-1}\left(\boldsymbol{\zeta}_{i}-\boldsymbol{\mu}_{\boldsymbol{\zeta}}\right)\right\} \mathbb{1}_{\left(a_{i}>0\right)}
\end{aligned}
$$

Devido a forma intratável da função (2.20), no sentido de se obter de modo análitico as distribuições a posteriori de interesse, precisamos utilizar algoritmos de simulação dinâmica, veja Gamerman and Lopes (2006), por exemplo. Na próxima seção apresentaremos uma estrutura do amostrador de Gibbs para o modelo proposto.

\subsection{Estimação via MCMC}

As características dos MRI levam à necessidade de se utilizar métodos de estimação que considerem tais particularidades. Nos MRI, é extremamente complicado, ou mesmo impossível, obter-se de forma explícita as distribuições a posteriori de interesse. Isso dificulta a aplicação da ABP. Os métodos de simulação de Monte Carlo via cadeias de Markov (MCMC \$3 vão ao encontro de tal necessidade. No contexto bayesiano, os métodos MCMC permitem obter, de forma empírica, a estrutura de distribuições a posteriori conjuntas e marginais. Isso é conduzido através de simulações iterativas das, assim chamadas, distribuições condicionais completas. Estas fazem, por sua vez, o papel das funções de transição, responsáveis pelas mudanças de estados nas cadeias de Markov de interesse. Para a compreensão de tais métodos sugerimos a leitura de Gilks et al. (1996), Gamerman and Lopes (2006) e Robert and Casella (2005), por exemplo. A abordagem utilizada no presente capítulo se baseia na estrutura do amostrador de Gibbs, vide Geman et al. (1993).

De acordo com o densenvolvimento da Seção 2.6. uma estrutura de simulação de MCMC, via dados aumentados, para o MGM, é descrito no resultado que se segue.

$\S$ Sigla que representa a expressão em inglês Monte Carlo Markov Chain.

Azevedo, Caio L. N.

IME/USP 
Resultado 2.7.1. Considerando a posteriori definida em (2.20) e denotando por (.) o conjunto de todos os outros parâmetros, os passos do algoritmo do amostrador de Gibbs para os MGM são:

- Passo 1 : Simular as variáveis não observáveis utilizando $Z_{i j k} \mid(.) \sim N\left(a_{i} \theta_{j k}-b_{i}, 1\right) \mathbb{1}_{\left(y_{i j k}, z_{i j k}\right)}$, de forma mutuamente independente.

- Passo 2 : Simular os traços latentes utilizando $\theta_{j k} \mid(.) \sim N\left(\widehat{\psi}_{\theta_{j k}} \widehat{\theta}_{j k}, \widehat{\psi}_{\theta_{j k}}\right)$, mutuamente independentes, em que

$$
\begin{aligned}
\widehat{\theta}_{j k} & =\sum_{i \in I_{j k}} z_{i j k} a_{i}+\sum_{i \in I_{j k}} a_{i} b_{i}+\frac{\mu_{\theta_{k}}}{\psi_{\theta_{k}}}, \\
\widehat{\psi}_{\theta_{j k}} & =\left(\frac{1}{\psi_{\theta_{k}}}+\sum_{i \in I_{j k}} a_{i}^{2}\right)^{-1} .
\end{aligned}
$$

- Passo 3 : Simular os parâmetros dos itens através de $\boldsymbol{\zeta}_{i} \mid(.) \sim N\left(\widehat{\boldsymbol{\Psi}}_{\zeta_{i}} \widehat{\boldsymbol{\zeta}}_{i}, \widehat{\boldsymbol{\Psi}}_{\boldsymbol{\zeta}_{i}}\right)$, de forma mutuamente independente, em que

$$
\begin{aligned}
\widehat{\boldsymbol{\zeta}}_{i} & =\boldsymbol{H}_{i . .}^{t} \boldsymbol{z}_{i . .}+\boldsymbol{\Psi}_{\boldsymbol{\zeta}}^{-1} \boldsymbol{\mu}_{\boldsymbol{\zeta}}, \\
\widehat{\boldsymbol{\Psi}}_{\boldsymbol{\zeta}_{i}} & =\left(\boldsymbol{H}_{i . .}^{t} \boldsymbol{H}_{i . .}+\boldsymbol{\Psi}_{\boldsymbol{\zeta}}^{-1}\right)^{-1}, \\
\boldsymbol{H}_{i . .} & =[\boldsymbol{\theta}-\mathbf{1}] \bullet \mathbb{1}_{i},
\end{aligned}
$$

$\mathbb{1}_{i}$ é uma matriz indicadora de dimensão $n \times 2$ cuja linhas assumem o valor do vetor com 0 's ou 1's consoante o indivíduo $j$ da população $k$ responde ou não ao item $i$ e $\bullet$ denota o produto de Hadamard, o qual multiplica de forma pontual os elementos correspondentes de matrizes de mesma dimensão, vide Horn and Johnson (1991). Em cada iteração. We forem simulados valores negativos para o parâmetro $a$ esses serão descartados e novos valores gerados.

- Passo 4 : Simular as médias populacionais através de $\mu_{\theta_{k}} \mid(.) \sim N\left(\widehat{\psi}_{\mu_{k}} \widehat{\mu}_{\theta_{k}}, \widehat{\psi}_{\mu_{k}}\right)$, de forma mutuamente independente, em que

$$
\begin{aligned}
\widehat{\mu}_{\theta_{k}} & =\sum_{j=1}^{n_{k}} \frac{\theta_{j k}}{\psi_{\theta_{k}}}+\frac{\mu_{0}}{\psi_{0}}, \\
\widehat{\psi}_{\mu_{k}} & =\left(\frac{n_{k}}{\psi_{\theta_{k}}}+\frac{1}{\psi_{0}}\right)^{-1} .
\end{aligned}
$$

Azevedo, Caio L. N.

IME/USP 
- Passo 5 : Simular as variâncias populacionais $\psi_{\theta_{k}} \mid(.) \sim I G\left(\widehat{v}_{k}, \widehat{\kappa}_{k}\right)$, de forma mutuamente independente, em que

$$
\begin{aligned}
\widehat{v}_{k} & =\frac{n_{k}+v_{0}}{2}, \\
\widehat{\kappa}_{k} & =\frac{\sum_{j=1}^{n_{k}}\left(\theta_{j k}-\mu_{\theta_{k}}\right)^{2}+\kappa_{0}}{2},
\end{aligned}
$$

e $I G\left(\widehat{v}_{k}, \widehat{\kappa}_{k}\right)$ representa uma distribuição gama inversa com parâmetros $\left(\widehat{v}_{t}, \widehat{\kappa}_{k}\right)^{t}$.

\section{Demonstração do Resultado 2.7.1:}

O Passo 1 do Resultado 2.7.1 segue diretamente de 2.3. Para provar o Passo 2, note que,

$$
\begin{aligned}
p\left(\theta_{j k} \mid(.)\right) & \propto p\left(\boldsymbol{z}_{. j k} \mid \theta_{j k}, \boldsymbol{\zeta}_{i}, \boldsymbol{y}_{. j k}\right) p\left(\theta_{j k} \mid \boldsymbol{\eta}_{\theta_{k}}\right) \\
& \propto \exp \left(-\frac{1}{2} \sum_{i \in I_{j k}}\left(z_{i j k}-a_{i} \theta_{j t}+b_{i}\right)^{2}\right) \exp \left(-\frac{1}{2 \psi_{\theta_{k}}}\left(\theta_{j k}-\mu_{\theta_{k}}\right)^{2}\right) .
\end{aligned}
$$

Analisando 2.22 concluí-se que este representa um modelo de regressão com variável resposta $Z_{i j k}+b_{i}$, variável explicativa $a_{i}$, inclinação $\theta_{j k}$ e distribuição a priori normal (vide Fox (2001), pag. 36). Utilizando as propriedades de conjugação do modelo normal com priori normal, o resultado segue. Um argumento similar pode ser aplicado as médias populacionais, notando-se que,

$$
\begin{aligned}
p\left(\mu_{\theta_{k}} \mid(.)\right) & \propto\left\{\prod_{j=1}^{n_{k}} p\left(\boldsymbol{\theta}_{. k} \mid \boldsymbol{\eta}_{\theta_{k}}\right)\right\} p\left(\mu_{\theta_{k}}\right) \\
& \propto \exp \left(-\frac{1}{2 \psi_{\theta_{k}}} \sum_{j=1}^{n_{k}}\left(\theta_{j k}-\mu_{\theta_{k}}\right)^{2}\right) \exp \left(-\frac{1}{2 \psi_{0}}\left(\mu_{\theta_{k}}-\mu_{0}\right)^{2}\right),
\end{aligned}
$$

dessa forma, o Passo 4 segue. Com relação aos parâmetros dos itens, podemos notar que o seguinte modelo linear, condicionado as variáveis aumentadas e aos traços latentes, é válido

Azevedo, Caio L. N.

IME/USP 


$$
\boldsymbol{Z}_{i . .}=\boldsymbol{H}_{i . .} \boldsymbol{\zeta}_{i}+\boldsymbol{\xi}_{i . .}^{(\boldsymbol{Z})},
$$

em que $\boldsymbol{H}_{i . .}$ é dado por 2.21, e $\boldsymbol{\xi}_{i .}^{(\boldsymbol{Z})} \sim N_{n}\left(\mathbf{0}_{n}, \boldsymbol{I}_{n}\right)$. Considerando a priori 2.15 temos que,

$$
\begin{aligned}
p\left(\boldsymbol{\zeta}_{i} \mid(.)\right) & \propto p\left(\boldsymbol{z}_{i . .} \mid \theta_{j k}, \boldsymbol{\zeta}_{i}, \boldsymbol{y}_{. j k}\right) p\left(\boldsymbol{\zeta}_{i}\right) \\
\propto & \exp \left[-\frac{1}{2} \sum_{i \in I_{j k}}\left(z_{i j k}-a_{i} \theta_{j k}+b_{i}\right)^{2}\right] \\
& \times \exp \left[-0.5\left(\boldsymbol{\zeta}_{i}-\boldsymbol{\mu}_{\zeta}\right)^{t} \boldsymbol{\Psi}_{\boldsymbol{\zeta}}^{-1}\left(\boldsymbol{\zeta}_{i}-\boldsymbol{\mu}_{\zeta}\right)\right] \mathbb{1}_{\left(a_{i}>0\right)} .
\end{aligned}
$$

Note-se que no modelo acima, os indivíduos que não respondem a determinado item, devem ser excluídos para a obtenção da distribuição condicional completa. Dessa forma, depois de alguma álgebra o resultado segue.

Finalmente, com relação ao Passo 5, podemos observar que,

$$
\begin{aligned}
p\left(\psi_{\theta_{k}} \mid(.)\right) & \propto\left\{\prod_{j=1}^{n_{k}} p\left(\boldsymbol{\theta}_{. k} \mid \boldsymbol{\eta}_{\boldsymbol{\theta}_{k}}\right)\right\} p\left(\psi_{\theta_{k}}\right) \\
& \propto \exp \left(-\frac{1}{2 \psi_{\theta_{k}}} \sum_{j=1}^{n_{k}}\left(\theta_{j k}-\mu_{\theta_{k}}\right)^{2}\right) \psi_{\theta_{k}}^{-v_{0} / 2-1} \exp \left(-\frac{\kappa_{0}}{2 \psi_{\theta_{k}}}\right)
\end{aligned}
$$

então, utilizando as propriedadas de conjugação do modelo normal com a distribuição gama inversa, o Passo 5 é obtido.

\section{Q.E.D.}

Apesar de termos utilizado um determinado conjunto de prioris, outras podem ser facilmente acomodadas como, por exemplo, as do tipo não informativas, equações 2.16) e 2.19). Outro aspecto importante, diz respeito a não-identificabilidade dos MRI, anteriormente mencionada. Para o caso do MGM, uma forma usual é fixar os parâmetros de uma determinada população, chamada então de população referência, e estimar os demais parâmetros do modelo. Dessa forma, todas as estimativas estarão associadas à escala de tal população, veja Andrade et al. (2000) e Tavares (2001). Em termos de priori, tal restrição equivale (tomando-se a população nomeadamente população 1 , como a de referência) à

Azevedo, Caio L. N.

IME/USP 


$$
p\left(\mu_{\theta_{1}}=0\right)=1 \text { e } p\left(\psi_{\theta_{1}}=1\right)=1 .
$$

Por outro lado, podemos reescalonar os traços latentes de tal população, em cada iteração, e estimar os respectivos hiperparâmetros. Apesar de tal solução se constituir em artifício "Ad hoc", ela pode ser útil quando a fixação de parâmetros trouxer complicações à obtenção das distribuições condicionais completas. Este é o caso, por exemplo, quando se considera modelos de regressão para os traços latentes. Além disso, em estudos de simulação, este expediente elimina a necessidade de equalização das estimativas com os verdadeiros valores, veja Baker (1990). Com efeito, utilizaremos este mecanismo de identificabilidade em todo o presente trabalho.

Existem quatro pontos bastante importantes relacionados aos métodos MCMC. Primeiro, a ordem em que os passos são conduzidos podem influenciar na convergência do processo. Roberts and Sahu (1997) sugerem que a ordem deve ser mantida fixa ao longo de todo o processo e, em nosso trabalho, seguimos ordem similar ao trabalho de Fox (2001). O segundo diz respeito aos valores iniciais. Se tais valores forem muito distantes dos verdadeiros, a convergência pode se tornar lenta. Especialmente, se o processo apresentar autocorrelações elevadas, veja Chen et al. (2000). Para o modelo de um único grupo, algumas sugestões têm sido propostas na literatura, vide Baker and Kim (2004), Andrade et al. (2000) e Tucker (1946). É possível considerar a relação entre os parâmetros da TRI e os da Teoria Clássica de Medidas, bem como as estimativas obtidas através de programas comerciais, como o BILOG-MG ${ }^{\circledR}$. Em nosso trabalho, utilizaremos o seguinte esquema :

1. Utilizar a abordagem de Tavares and Andrade (2006) para calcular os valores iniciais das médias populacionais, digamos $\widehat{\boldsymbol{\mu}}_{\boldsymbol{\theta}}^{(0)}=\left(\widehat{\mu}_{\theta_{1}}^{(0)}, \ldots, \widehat{\mu}_{\theta_{k}}^{(0)}\right)^{t}$, baseado na diferença entre as proporções de respostas corretas aos itens comuns.

2. Calcular os escores padronizados, digamos $\widehat{Y}_{. j k}$, para cada grupo, e então calcular $\widehat{\theta}_{j k}^{(0)}=\widehat{Y}_{. j k}+\widehat{\mu}_{\theta_{k}}^{(0)}$.

3. Fixar todos os parâmetros de discriminação e todas as variâncias populacionais iguais à 1 .

4. Fixar todos os parâmetros de dificuldade iguais à 0 .

Um terceiro aspecto diz respeito a presença de autocorrelação. Este problema tende a tornar a convergência do processo de simulação lento ou mesmo contribuir para a obtenção de estimativas imprecisas, veja Chen et al. (2000). Sendo assim, é necessário gerar um número razoável de valores e considerar um espaçamento adequado quando da seleção destes. Ou seja, a partir do valor considerado como aquecimento (burn-in) da cadeia, devemos reter, para fins de inferência, por exemplo, apenas de 20 em 20 valores.

O quarto aspecto diz respeito a verificação da convergência do processo de simulação. É de extrema importância avaliar se os valores gerados, a partir de um certo ponto (burn-in) correspondem a valores simulados 
da distribuição a posteriori. A geração de várias cadeias, a partir de diferentes valores iniciais, a visualização das médias ergódiga: T] e a estatística de Geweke, são ferramentas importantes na avaliação da convergência. Para maiores detalhes vide Gilks et al. (1996), Gamerman and Lopes (2006), Robert and Casella (2005), Cowles and Carlin (1996) e Cowles and Carlin (1996).

\subsubsection{Agrupamento no algoritmo MCMC}

De acordo com a literatura, os procedimentos baseados na simulação MCMC, muito freqüentemente, produzem amostras altamente correlacionadas. Isto pode prejudicar o processo de convergência levando a necessidade da simulação de um número muito elevado de valores. Ou ainda, pode comprometer a convergência do processo se os valores simulados de alguns parâmetros ficarem restritos a certas regiões do espaço paramétrico, como as caudas da distribuição, veja Chen et al. (2000), por exemplo. Uma das formas de contornar esse problema consiste na simulação simultânea de conjuntos de parâmetros que apresentem alta correlação ente si, veja Gamerman and Lopes (2006), por exemplo. No caso do modelo proposto, uma alternativa seria considerar a distribuição conjunta dos parâmetros $\boldsymbol{\eta}_{\theta_{k}}=\left(\mu_{\theta_{k}}, \psi_{\theta_{k}}\right)^{t}, k=1, \ldots, K$. Em outras palavras, substituir os passos 4 e 5 do Resultado 2.7.1 por um único, qual seja :

Passo 4 : Considerar a priori 2.17) e simular $\boldsymbol{\eta}_{\theta_{k}}$ através de

$$
p\left(\boldsymbol{\eta}_{\theta_{k}} \mid(.)\right) \propto \psi_{\theta_{k}}^{-1 / 2}\left(\psi_{\theta_{k}}\right)^{-\left(\widehat{v}_{0} / 2+1\right)} \exp \left(-\frac{1}{2 \psi_{\theta_{k}}}\left[\widehat{v}_{0} \widehat{\psi}_{0}+\widehat{\kappa}_{0}\left(\mu_{\theta_{k}}-\widehat{\mu}_{0}\right)^{2}\right]\right)
$$

em que

$$
\begin{aligned}
\widehat{\mu}_{k} & =\frac{\kappa_{0}}{\kappa_{0}+n_{k}} \mu_{0}+\frac{n_{k}}{\kappa_{0}+n_{k}} \bar{\theta}_{. k} \\
\widehat{\psi}_{k} & =\frac{1}{v_{0}+n_{k}}\left[v_{0} \sqrt{\psi_{0}}+\sum_{j=1}^{k}\left(\theta_{j k}-\bar{\theta}_{. k}\right)^{2}+\frac{\kappa_{0} n_{k}}{\kappa_{0}+n_{k}}\left(\theta_{. k}-\mu_{0}\right)^{2}\right] \\
\widehat{\kappa}_{k} & =\kappa_{0}+n_{k} \\
\widehat{v}_{k} & =v_{0}+n_{k} \\
\bar{\theta}_{. k} & =\frac{1}{n_{k}} \sum_{j=1}^{n_{k}} \theta_{j k} .
\end{aligned}
$$

ฯ São as médias calculadas considerando-se todos os valores simulados em cada iteração.

Azevedo, Caio L. N.

IME/USP 
Dessa forma a simulação seria realizada conjuntamente para os parâmetros populacionais $\boldsymbol{\eta}_{\theta_{k}}$ o que poderia diminuir a autocorrelação de tais parâmetros, veja Subseção 2.10 .3 .

\subsubsection{Itens com DIF}

Uma das suposições mais importantes da TRI, principalmente na área educacional, é a inexistência de DIF! Isto implica que os itens funcionam da mesma forma, para todos os grupos equivalentes aos quais ele for apresentado. Ou seja, as estimativas dos parâmetros associados a este item, obtidas a partir dos resultados dos diferentes grupos, devem ser bastante próximas. Portanto, veririficar a possível existência de tal comportamento é de relevante importância. À luz dessa idéia, uma abordagem para verificar a existência de DIF seria considerar um modelo de dados aumentados mais geral, que se traduz em:

$$
\begin{aligned}
Z_{i j k} \mid y_{i j k} & =\left(a_{i}+\alpha_{i k} \mathbb{1}_{i k}\right) \theta_{j k}-\left(b_{i}+\delta_{i k} \mathbb{1}_{i k}\right)+\xi_{i j k}^{(Z)} \\
\theta_{j k} & =\mu_{\theta_{j k}}+\xi_{j k}^{(\theta)}
\end{aligned}
$$

em que

$$
\mathbb{1}_{i k}=\left\{\begin{array}{ll}
1, & \text { se o item } i \text { foi apresentado à população } k, k=2,3, \ldots, K \\
0, & \text { caso contrário. }
\end{array} .\right.
$$

Note que os parâmetros $\left(\delta_{i k}, \alpha_{i k}\right)$ só seriam considerados para os itens aplicados em duas ou mais populações. Dessa forma, não existiria $D I F$ para os itens cujos parâmetros acima fossem iguais à 0 .

\subsection{Medidas de diagnóstico}

Sem dúvida, um importante aspecto na utilização de modelos estatísticos e em particular, nos MRI, é a avaliação da qualidade do ajuste. Embora nos primórdios da TRI, esse aspecto tenha sido pouco estudado, nos últimos anos tem-se dado bastante atenção a este tópico. Alguns trabalhos nessa linha são Fox (2004), Hoijtink and Molenaar (1997), Béguin and Glas (2001) e Sinharay et al. (2006).

No presente capítulo e nos próximos, utilizaremos as seguintes ferramente para avaliar a qualidade do ajuste dos modelos propostos :

|| Sigla em inglês que representa a expressão "Differential Item Functioning"

Azevedo, Caio L. N.

IME/USP 
1. distribuição preditiva dos escores, veja Béguin and Glas (2001),

2. p-valor baseado na discrepância entre os escores observados e preditos pelo modelo, veja Berkhof et al. (2001) e Horra and Rodríguez-Bernal (1999),

3. resíduos bayesianos para os traços latentes, veja Fox (2001)

Discutiremos brevemente os itens acima. Seja $\boldsymbol{Y}^{\text {obs }}$ a matriz de respostas observadas e $\boldsymbol{Y}^{\text {rep }}$ uma matriz de respostas geradas a partir da distribuição preditiva, veja Paulino et al. (2003), ou seja

$$
p\left(\boldsymbol{Y}^{r e p} \mid \boldsymbol{Y}^{o b s}\right)=\int p\left(\boldsymbol{Y}^{r e p} \mid \boldsymbol{\vartheta}\right) p\left(\boldsymbol{\vartheta} \mid \boldsymbol{Y}^{o b s}\right) d \boldsymbol{\vartheta}
$$

em que $\vartheta$ representa os parâmetros envolvidos no modelo. Definindo uma media de discrepância adequada $D(., \boldsymbol{\vartheta})$, por exemplo a diferença entre os escores observados e preditos, o p-valor preditivo a posteriori é dado por

$$
\begin{aligned}
p_{D} & =\mathbb{P}\left(D\left(\boldsymbol{Y}^{r e p}, \boldsymbol{\vartheta}\right) \geq D\left(\boldsymbol{Y}^{o b s}, \boldsymbol{\vartheta}\right) \mid\left(\boldsymbol{Y}^{o b s}, H_{0}\right)\right) \\
& =\iint \mathbb{1}_{D\left(\boldsymbol{Y}^{r e p}, \boldsymbol{\vartheta}\right) \geq D\left(\boldsymbol{Y}^{\text {obs }}, \boldsymbol{\vartheta}\right)} p\left(\boldsymbol{Y}^{r e p} \mid \boldsymbol{\vartheta}\right) p\left(\boldsymbol{\vartheta} \mid \boldsymbol{Y}^{o b s}\right) d y^{r e p} d \boldsymbol{\vartheta}
\end{aligned}
$$

No presente trabalho, a medida de discrepância adotada será

$$
D_{E}=\sum_{l=1}^{L}\left(n_{l}^{(o b s)}-n_{l}^{(r e p)}\right)^{2}
$$

em que $L$ é o número de escores possíveis no teste, $n_{l}^{(o b s)}$ é o número de indivíduos com escore na classe $l$ e $n_{l}^{(r e p)}$ é o número de indvíduos com escore na classe $l$ predito pelo modelo.

Os resíduos bayesianos para os traços latentes são seus valores padronizados, ou seja

$$
r_{\theta_{j k}}=\frac{\theta_{j k}-\mu_{\theta_{k}}}{\sqrt{\psi_{\theta_{k}}}}
$$

Os mecanismos de diagnóstico apresentados acima foram utilizados em outros modelos da TRI. Eles mostram desempenho razoável em fornecer subsíduos referentes a qualidade de ajuste do modelo. Para uma maior 
discussão a respeito de medidas de diagnóstico nos MRI sugerirmos a leitura de Stern and Sinharay (2005), Sinharay (2006), Sinharay et al. (2006), Fox (2004) e Fox and Glas (2005), por exemplo.

\subsection{Aspectos computacionais}

A aplicação da TRI tornar-se-ía impossível sem a existência de plataformas computacionais adequadas. Para os métodos de MVM e MMAP existem pacotes computacionais comerciais adequadamente documentados. Para modelos dicotômicos, de uma ou mais de uma população, dois dos mais utilizados são o Bilog ${ }^{\circledR}$ e Bilog-MG ${ }^{\circledR}$, respectivamente. Para modelos policotômicos, existem bons programas como o Multilog ${ }^{\circledR}$ e o Parscale ${ }^{\circledR}$, os quais, de forma similar, possuem implementados as versões de uma e mais de uma população. Para detalhes consulte http://www.ssicentral.com/ e Andrade et al. (2000). Entretanto, para abordagens via MCMC, não existem pacotes disponíveis. A biblioteca computacional MCMCpack, desenvolvida para a linguagem $\mathrm{R}^{\circledR}$, (veja www.r-project.org) é uma ferramente poderosa para ajuste de alguns MRI (não incluí modelos de grupos múltiplos, longitudinais e policotômicos, por exemplo). Ela utiliza um código desenvolvido em linguagem $\mathrm{C}++{ }^{\circledR}$, o qual faz uso de uma biblioteca chamada Scythe Statistical Library, veja http://scythe.wustl.edu/, a qual possui implementadas inúmeras funções de geração de números aleatórios, de probabilidade e estatística. Outra biblioteca também desenvolvida para o programa $\mathrm{R}^{\circledR}$ é o UMACS (Universal Markov Chain Sampler). Esta permite que esquemas de MCMC sejam facilmente implementados apenas fornecendo o mecanismo de simulação das distribuições condicionais completas. O pacote Winbugs ${ }^{\circledR}$ (http://www.mrc-bsu.cam.ac.uk/bugs/winbugs/contents.shtml) permite que simulações MCMC sejam implementadas fornecendo apenas a verossimilhança e as prioris. Entretanto modificações na estrutura de simulação, por vezes, são complicadas e também a utilização de grandes bancos de dados.

Uma outra alternativa é a construção plena de todo o algoritmo desenvolvido. Para isso, podemos utilizar linguagens como $\mathrm{C}++{ }^{\circledR}, \mathrm{R}^{\circledR}$ ou Ox ${ }^{\circledR}$ (http://www.doornik.com/products.html\#Ox) por exemplo. Em nosso trabalho, desenvolvemos programas nas linguagens $\mathrm{R}^{\circledR}$ e Ox ${ }^{\circledR}$. Contudo, para efeito de análise, apenas as rotinas em $\mathrm{Ox}{ }^{\circledR}$ foram utilizadas devido à sua maior velocidade de processamento em relação ao programa $R^{\circledR}$. Para a construção de gráficos e manipulação de alguns resultados, desenvolvemos algumas rotinas em $\mathrm{R}^{\mathrm{R}}$.

\subsection{Estudos de simulação}

Nesta seção conduziremos alguns estudos apropriados de simulação com o intuito de verificar a acurácia do modelo e do método de estimação. Uma vez que estamos utilizando uma metodologia bayesiana via MCMC, três estudos de simulação serão conduzidos para avaliar o desempenho do método de estimação e do modelo. Nós os chamaremos de análise de sensibilidade, replicação e estudo de acompanhamento. Na análise de sensibilidade verificaremos a robustez do modelo com relação à escolha de prioris. No estudo de replicação verificaremos a

Azevedo, Caio L. N.

IME/USP 
consistência dos estimadores e no estudo de acompanhamento verificaremos, com mais detalhes, a convergência e auto-correlação das cadeias geradas pelo procedimento MCMC desenvolvido.

Para tal, consideraremos a seguinte situação : em três grupos (nomeadamente 1, 2 e 3) aplicaremos três diferentes testes (nomeadamente 1, 2 e 3), com 24 itens cada, de tal forma que os testes 1 e 2 têm 6 itens em comum e o mesmo ocorre com os testes 2 e 3, sendo outros 6 itens diferentes. Dessa forma, teremos um conjunto total de 60 itens, veja Tabela 2.7. Os traços latentes foram gerados, de forma independente, a partir de distribuições normais com médias $\boldsymbol{\mu}_{\theta}=(0,1,2)^{t}$ e variâncias $\boldsymbol{\psi}_{\theta}=(1,0.9,0.95)^{t}$ para os grupos 1, 2 e 3 respectivamente. Escolheu-se usar o mesmo tamanho amostral para cada um dos grupos igual à $\boldsymbol{n}=(1000,1000,1000)^{t}$. Seguindo DeMars 2003), para assegurar que as estimativas fiquem na mesma métrica dos valores simulados, veja Baker (1990) para detalhes, aplicou-se uma transformação aos traços latentes simulados de sorte que tivessem exatamente as médias e variâncias desejadas. Isto foi obtido através de:

$$
\theta_{j k}^{* *}=\sqrt{\psi_{\theta_{k}}} s_{\theta_{k}}^{-1}\left(\theta_{j k}^{*}-\bar{\theta}_{k}\right)+\mu_{\theta_{k}}
$$

em que $\theta_{j k}^{*}$ são os traços latentes simulados e $\bar{\theta}_{k}$ e $s_{\theta_{k}}$ são a média e o desvio-padrão amostrais dos traços latentes simulados, respectivamente. Este expediente será utilizado em todo trabalho.

\subsubsection{Análise de sensibilidade}

Existem diversas formas de verificar a qualidade do ajuste de um modelo. É possivél utilizar metodologias como análise residual, testes de hipótese e estatística de ajuste como o AIC e BIC, veja Huber-Carol et al. (2002) e Atkinson and Riani (2000), por exemplo. Na estrutura de análise bayesiana existem, de igual modo, diversos mecanismos. Um deles consiste em verificar a sensibilidade do modelo à escolha de diferentes prioris. Um segundo, é baseado na capacidade do modelo de reproduzir os dados observados utilizando a distribuição preditiva, veja Stern and Sinharay (2005) and Gelman et al. (2004), por exemplo. Nesta subseção nós consideraremos o estudo de sensibilidade às prioris para verificar o ajuste do modelo. As diferentes prioris serão consideradas para os parâmetros dos itens e para as variâncias, pois estes tendem a apresentar mais complicações para a estimação. Para os demais parâmetros manteremos as mesmas prioris. Com relação ao traços latentes, como dito anteriormente, assumiremos a priori (2.2). Para as médias consideramos $\mu_{\theta_{k}} \sim N(0,2)$. Ou seja, assumimos, a priori, que as médias são iguais (lembrando que a escala do traço latente é completamente arbitrária) e que elas podem variar até (K-1) desvios padrões com relação à 0 . As prioris para os parâmetros dos itens e variância são aquelas consideradas em 2.15) e 2.18), respectivamente. Com relação aos parâmetros dos itens, utilizaremos dois conjuntos de valores para o vetor de médias e para a matriz de covariâncias, mantendo esta diagonal, ou seja, independência a priori. Para as variâncias escolhemos uma priori informativa e outra não informativa (imprópria). Os valores se encontram na Tabela 2.1. O vetor de médias $(0,0)$ e $(1,0)$

Azevedo, Caio L. N.

IME/USP 
estão associados aos trabalhos de Johnson and Albert (1999) e Albert and Ghosh (2000), respectivamente. Com relação ao parâmetro de discriminação o valor 0 permite que a verrosimilhança tenhar uma maior influência nas estimativas enquanto que o valor 1 indica que, em média, esperamos que os itens apresentem um boa discriminação. $\mathrm{O}$ valor 0 para o parâmetro de dificuldade indica que em média, espera-se que os itens tenham dificuldade em torno do valor médio dos traços latentes, o que é razoável para um teste. Com relação às variâncias das prioris do parâmetros dos itens, os valores para as dificuldades permitem que elas possam variar razoavelmente, o que é esperado, uma vez que os testes podem diferir bastante entre si. Por outro lado, lembremos que a discriminação tem de ser positiva (ao menos no que se refere ao conhecimento), não muito elevada e nem baixa demais. Dessa forma, a variâncias escolhidas, associadas ao fato da truncagem à esquerda do valor 0 , permitem tal comportamento. Com relação às variâncias populacionais, utilizamos uma priori que resulta em média 1 e variância $10(4,2 ; 2,2)$, e uma não informativa, obtida tomando-se $\left(\nu_{0}, \kappa_{0}\right)=(0,0)^{t}$, em 2.15. Tal escolhe permite considerar crenças a priori diferentes, mas não diametralmente opostas.

Com os valores definidos acima, geramos um único conjunto de respostas e com este procedemos à estimação via MCMC. Devido à análise de convergência e de autocorrelação, vide a subseção 2.10.3, definiu-se o valor de aquecimento ("burn-in") como sendo B $=16000$, genando um total de 26000 valores e considerando, a partir da quantidade B, somente os valores com espaçamento da ordem de 30. Dessa forma, para a estimação das distribuições a posteriori, reteve-se um conjunto total de 334 valores simulados para cada um dos parâmetros do modelo. Tal procedimento foi repetido para cada um dos conjuntos de prioris.

Com o intuito de avaliar a acurácia dos resultados, para cada priori, e compará-los entre si utilizamos as seguintes estatísticas:

- Corr : a correlação entre os verdadeiros valores e suas respectivas estimativas.

- Mvício : a média do vício das estimativas, ou seja

$$
\text { Mvício }=\frac{\sum_{l=1}^{L}\left(\widehat{\vartheta}_{l}-\vartheta_{l}\right)^{2}}{L},
$$

em que $\vartheta$ representa algum parâmetro, e. g., o traço latente ou um parâmetro do item, $\widehat{\vartheta}$ sua respectiva estimativa e $L$ é o número de parâmetros, e. g. $n=1000$.

- MEP : a média do erros-padrão associados as estimativas de cada parâmetro.

- REQM : a raiz quadrada (positiva) da soma do Mvício com a média das variâncias associadas as estimativas de cada parâmetro.

Azevedo, Caio L. N.

IME/USP 
As Tabelas 2.2 2.3 e 2.4 e as Figuras 2.3 e 2.4 apresentam os resultados da análise de sensibilidade. Podemos perceber que as correlações e os erros-padrão apresentam-se razoavelmente próximos entre si para todos os conjuntos de prioris envolvidas. Entretanto, notamos uma diferença, bem pequena, com relação ao vício e, consequentemente, com relação ao REQM. Essa diferença deve-se, muito possivelmente, aos parâmetros de um único item, os quais não foram muito bem estimados para algumas prioris, vide Figuras 2.3 e 2.4. Este parâmetro apresenta tanto os valores da discriminação quanto da dificuldade original elevados e, portanto, também da dificuldade transformada, vide Tabela 2.7. Os valores para os parâmetros populacionais, para todas as prioris, mostram-se próximos dos verdadeiros valores. Com exceção da priori 6 , as estimativas das variâncias para a população 3 são maiores do que as da população 2, tal como os verdadeiros valores. Os melhores resultados, com relação as médias populacionais, são obtidos com as prioris 1 e 2. Enquanto que para as variâncias populacionais, os melhores resultados são obtidos com as prioris 3,5 e 7 . Adotando-se o REQM como critério de otimalidade, tanto para os resultados referentes aos traços latentes e quanto para os parâmetros dos itens, nota-se o seguinte : as prioris 4 e 8 apresentam os melhores resultados para as traços latentes enquanto que as prioris 1 e 5 apresentam os melhores resultados para os parâmetros dos itens. Podemos concluir então que, apesar das prioris mais informativas apresentarem um tênue desempenho melhor, todas produziram estimativas comparáveis. Sendo assim, o método de estimação/modelo apresentam robustez com relação à tal escolha. Salientamos, no entanto, que tal conclusão se restringe à classe de prioris abordadas. Resultados significativamente diferentes poderiam ser obtidos sob a escolha, por exemplo, de priois impróprias ou extremamente informativas para os parâmetros dos itens. Além disso, apesar da robustez ter-se verificado, isso não torna os resultados obtidos através de análises bayesianas equivalentes aos resultados da inferência clássica, veja Baker (1998), Kim (2001) e Wollack et al. (2002), por exemplo.

Tabela 2.1: Prioris escolhidas para a análise de sensibilidade

\begin{tabular}{lrrr}
\hline \hline \multirow{2}{*}{ Priori } & \multicolumn{3}{c}{ Hiperparâmetros } \\
\cline { 2 - 4 } & $\boldsymbol{\mu}_{\boldsymbol{\zeta}}$ & \multicolumn{1}{c}{$\boldsymbol{\Psi}_{\boldsymbol{\zeta}}$} & $\left(\nu_{0}, \tau_{0}\right)^{t}$ \\
\hline 1 & $(1,0)$ & $(0,5 ; 3)$ & $(0,0)$ \\
2 & $(1,0)$ & $(1 ; 6)$ & $(0,0)$ \\
3 & $(0,0)$ & $(3 ; 3)$ & $(0,0)$ \\
4 & $(0,0)$ & $(6,6)$ & $(0,0)$ \\
5 & $(1,0)$ & $(0,5 ; 3)$ & $(4,2 ; 2,2)$ \\
6 & $(1,0)$ & $(1 ; 6)$ & $(4,2 ; 2,2)$ \\
7 & $(0,0)$ & $(3 ; 3)$ & $(4,2 ; 2,2)$ \\
8 & $(0,0)$ & $(6,6)$ & $(4,2 ; 2,2)$ \\
\hline \hline
\end{tabular}

Azevedo, Caio L. N.

$\mathrm{IME} / \mathrm{USP}$ 
Tabela 2.2: Resultados da estimação dos traços latentes : análise de sensibilidade

\begin{tabular}{lrrrr}
\hline \hline \multirow{2}{*}{ Priori } & \multicolumn{4}{c}{ Estatística } \\
\cline { 2 - 5 } & Corr & MEP & Mvício & REQM \\
\hline$(1,0)(0,5 ; 3)(0,0)$ & 0,971 & 0,306 & 0,094 & 0,436 \\
$(1,0)(1 ; 6)(0,0)$ & 0,971 & 0,299 & 0,094 & 0,431 \\
$(0,0)(3 ; 3)(0,0)$ & 0,971 & 0,302 & 0,094 & 0,433 \\
$(0,0)(6,6)(0,0)$ & 0,971 & 0,295 & 0,094 & 0,428 \\
$(1,0)(0,5 ; 3)(4,2 ; 2,2)$ & 0,971 & 0,300 & 0,093 & 0,431 \\
$(1,0)(1 ; 6)(4,2 ; 2,2)$ & 0,971 & 0,294 & 0,095 & 0,429 \\
$(0,0)(3 ; 3)(4,2 ; 2,2)$ & 0,971 & 0,299 & 0,093 & 0,431 \\
$(0,0)(6,6)(4,2 ; 2,2)$ & 0,971 & 0,294 & 0,095 & 0,428 \\
\hline \hline
\end{tabular}

Tabela 2.3: Resultados da estimação dos parâmetros dos itens : análise de sensibilidade

\begin{tabular}{|c|c|c|c|c|c|c|c|c|}
\hline \multirow[t]{3}{*}{ Priori } & \multicolumn{8}{|c|}{ Par. do item } \\
\hline & \multicolumn{4}{|c|}{ Disc. } & \multicolumn{4}{|c|}{ Diff. } \\
\hline & Corr & MEP & Mvício & REQM & Corr & MEP & Mvício & REQM \\
\hline$(1,0)(0,5 ; 3)(0,0)$ & 0,934 & 0,094 & 0,006 & 0,126 & 0,996 & 0,122 & 0,017 & 0,196 \\
\hline$(1,0)(1 ; 6)(0,0)$ & 0,920 & 0,099 & 0,008 & 0,138 & 0,993 & 0,128 & 0,035 & 0,246 \\
\hline$(0,0)(3 ; 3)(0,0)$ & 0,929 & 0,099 & 0,006 & 0,132 & 0,996 & 0,124 & 0,021 & 0,210 \\
\hline$(0,0)(6,6)(0,0)$ & 0,920 & 0,098 & 0,009 & 0,139 & 0,995 & 0,126 & 0,028 & 0,226 \\
\hline$(1,0)(0,5 ; 3)(4,2 ; 2,2)$ & 0,929 & 0,093 & 0,006 & 0,126 & 0,996 & 0,120 & 0,018 & 0,195 \\
\hline$(1,0)(1 ; 6)(4,2 ; 2,2)$ & 0,912 & 0,101 & 0,010 & 0,146 & 0,994 & 0,128 & 0,034 & 0,242 \\
\hline$(0,0)(3 ; 3)(4,2 ; 2,2)$ & 0,930 & 0,096 & 0,006 & 0,128 & 0,996 & 0,125 & 0,019 & 0,206 \\
\hline$(0,0)(6,6)(4,2 ; 2,2)$ & 0,910 & 0,100 & 0,010 & 0,147 & 0,993 & 0,129 & 0,041 & 0,260 \\
\hline
\end{tabular}

Tabela 2.4: Resultados da estimação dos parâmetros populacionais : análise de sensibilidade

\begin{tabular}{lcccccccc}
\hline \multirow{2}{*}{ Prior } & \multicolumn{7}{c}{ Parâmetros Populacionais } \\
\cline { 2 - 9 } & \multicolumn{2}{c}{$\mu_{\theta_{2}}$} & \multicolumn{2}{c}{$\mu_{\theta_{3}}$} & $\psi_{\theta_{2}}$ & $\psi_{\theta_{3}}$ \\
\cline { 2 - 9 } & Est. & EP & Est. & EP & Est. & EP & Est. & EP \\
\hline$(1,0)(0,5 ; 3)(0,0)$ & 1,012 & 0,046 & 2,026 & 0,079 & 0,938 & 0,089 & 1,015 & 0,118 \\
$(1,0)(1 ; 6)(0,0)$ & 1,005 & 0,049 & 1,988 & 0,086 & 0,904 & 0,086 & 0,917 & 0,109 \\
$(0,0)(3 ; 3)(0,0)$ & 0,992 & 0,047 & 1,968 & 0,081 & 0,900 & 0,084 & 0,965 & 0,118 \\
$(0,0)(6,6)(0,0)$ & 0,995 & 0,048 & 1,962 & 0,074 & 0,869 & 0,080 & 0,879 & 0,104 \\
$(1,0)(0,5 ; 3)(4,2 ; 2,2)$ & 0,992 & 0,046 & 1,977 & 0,073 & 0,902 & 0,076 & 0,952 & 0,090 \\
$(1,0)(1 ; 6)(4,2 ; 2,2)$ & 0,993 & 0,046 & 1,942 & 0,075 & 0,863 & 0,083 & 0,861 & 0,103 \\
$(0,0)(3 ; 3)(4,2 ; 2,2)$ & 0,992 & 0,043 & 1,973 & 0,073 & 0,897 & 0,072 & 0,945 & 0,106 \\
$(0,0)(6,6)(4,2 ; 2,2)$ & 0,990 & 0,046 & 1,947 & 0,075 & 0,865 & 0,078 & 0,871 & 0,099 \\
\hline \hline
\end{tabular}



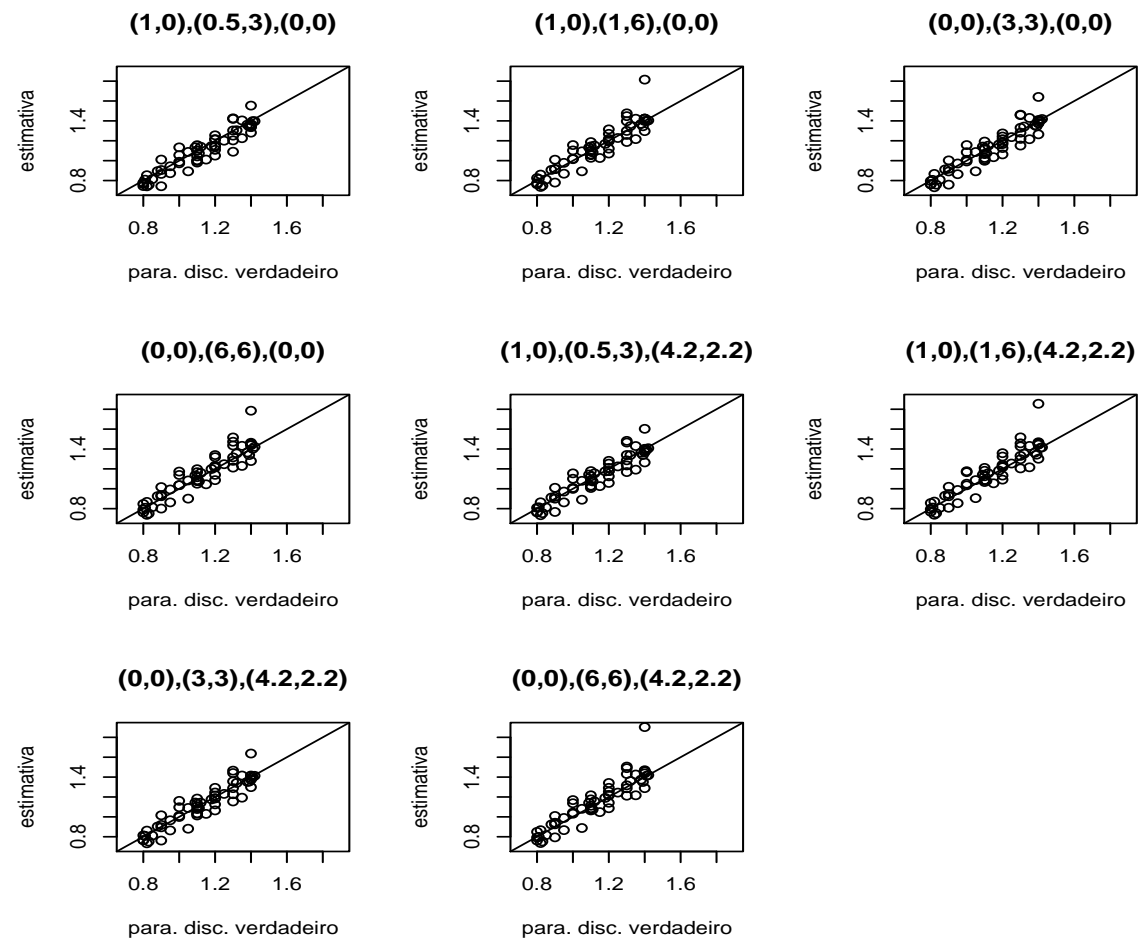

Figura 2.3: Gráficos de dispersão entre os valores dos parâmetros de discriminação e suas estimativas : análise de sensibilidade

Azevedo, Caio L. N. 

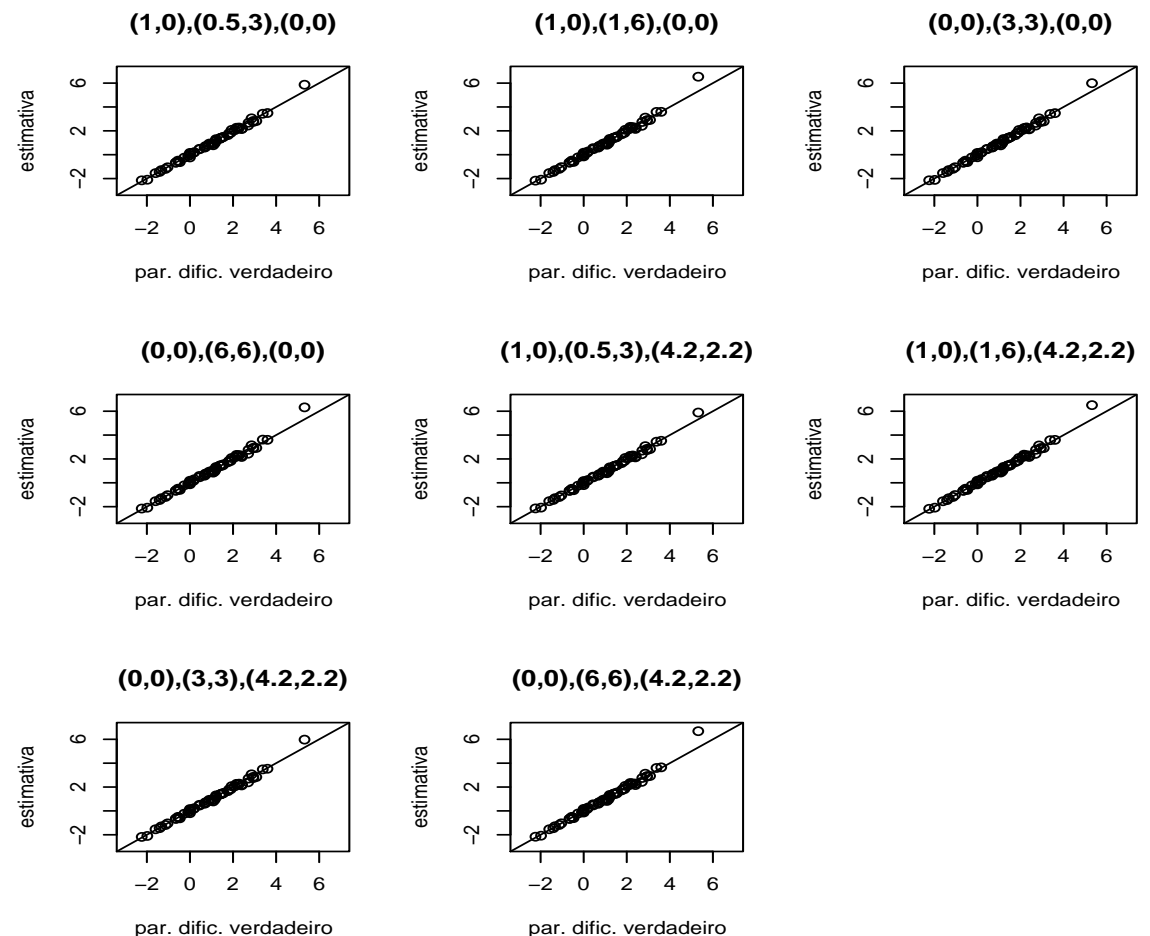

Figura 2.4: Gráficos de dispersão entre os valores dos parâmetros de dificuldade e suas estimativas : análise de sensibilidade

Azevedo, Caio L. N. 


\subsubsection{Estudo de replicação}

De uma forma em geral, um método de estimação produz estimativas consistentes se os valores esperados dos estimadores associados a tal método tenderem para o verdadeiro valor do parâmetro e se as respectivas variâncias tenderem à 0. Espera-se, dessa forma, observar vícios e variâncias de magnitudes desprezíveis. Esta subseção diz respeito a um estudo com o objetivo de verificar tal propriedade do método de estimação desenvolvido, veja também Harwell et al. (1996). Considerando os resultados da subseção anterior, no qual não se encontrou diferença significativa nos resultados para as prioris em questão, optou-se por adotar a priori 1. Ela é informativa para os parâmetros dos itens, embora permita que eles variem num intervalo razoável em termos práticos, mas não fornece nenhuma informação a respeito das variâncias. Isto nos poupa da escolha dos hiperparâmetros mais adequados para tais parâmetros. Com estrutura igual aquela explicitada na subseção anterior, gerou-se um conjunto de $\mathrm{R}=10$ réplicas. Em cada réplica, portanto, obteve-se um conjunto de estimativas para todos os parâmetros. Com as estimativas obtidas em cada réplica, analisaremos os resultados

da seguinte forma : considerando $\vartheta$ um parâmetro de interesse e $\widehat{\vartheta}_{r}$ a estimativa associada à réplica $r$, temos a seguinte relação:

$$
\underbrace{\frac{1}{R} \sum_{r=1}^{R}\left(\vartheta-\widehat{\vartheta}_{r}\right)^{2}}_{\text {EQM }}=\underbrace{(\vartheta-\widehat{\bar{\vartheta}})^{2}}_{\text {Vício }}+\underbrace{\frac{1}{R} \sum_{r=1}^{R}\left(\widehat{\bar{\vartheta}}-\widehat{\vartheta}_{r}\right)^{2}}_{\text {Variância }}
$$

em que

$\widehat{\bar{\vartheta}}=\frac{1}{R} \sum_{r=1}^{R} \widehat{\vartheta_{r}}, \mathrm{EQM}=$ erro quadrático médio.

Dessa forma, através da relação dada em (2.26) e da correlação entre as estimativas e os verdadeiros valores, consideraremos as seguintes estatísticas para analisar os resultados:

- Corr : é a correlação entre a média das estimativas obtidas em cada réplica e os verdadeiros valores, ou seja:

$$
\text { Corr }=\operatorname{correlação}(\widehat{\bar{\vartheta}}, \vartheta)
$$

- MEP : é a média dos erros-padrão obtidas em cada estimativa.

- VQ : é o vício quadrático das estimativas, veja o segundo termo de (2.26).

- Var : é o variância entre as estimativas obtidas em cada réplica, veja o terceiro termo de (2.26). 
- REQM : é a raiz quadrada do EQM das estimativas, veja o primeiro termo de 2.26 .

Note que, como temos vários traços latentes e parâmetros dos itens para estimar, cada estatística será obtida como a média entre os diferentes valores dos parâmetros. Por exemplo, para o traços latentes, a equação 2.26), se converte em :

$$
\frac{1}{n} \frac{1}{R} \sum_{j=1}^{n} \sum_{r=1}^{R}\left(\vartheta-\widehat{\vartheta}_{j r}\right)^{2}=\frac{1}{n} \sum_{j=1}^{n}\left(\vartheta_{j}-\widehat{\bar{\vartheta}}_{j}\right)^{2}+\frac{1}{n} \frac{1}{R} \sum_{r=1}^{R}\left(\widehat{\bar{\vartheta}}_{j}-\widehat{\vartheta}_{j r}\right)^{2},
$$

em que

$$
\widehat{\bar{\vartheta}}=\frac{1}{n} \frac{1}{R} \sum_{r=1}^{R} \widehat{\vartheta}_{j r} \text { e } \widehat{\bar{\vartheta}}_{j}=\frac{1}{R} \sum_{r=1}^{R} \widehat{\vartheta}_{j r}
$$

Pelos resultados, de uma forma em geral, notamos que o algoritmo de Gibbs gerou estimativas bastante satisfatórias, veja as Tabelas 2.5 e 2.6 e as Figuras 2.5 e 2.6. Com exceção da variância da população 3, todos os parâmetros foram bem estimados. As respectivas estimativas médias apresentam-se próximas dos verdadeiros valores. Podemos perceber que existe uma variação maior entre as estimativas de cada réplica do que em considerando suas médias. No entanto ambas variabilidades se mostram pequenas. Isso significa que, apesar de exister diferenças entre as estimativas obtidas em cada réplica e os respectivos valores verdadeiros, em média, tais estimativas apresentam pequenos vícios. Além disso, elas tendem a não diferir muito entre si. Percebemos que as correlações são bem altas, que a média das estimativas são próximas dos verdadeiros valores e que a variabilidade entre as estimativas é pequena. Dessa forma, podemos concluir que as estimativas possuem vício desprezível e variam muito pouco em torno dos verdadeiros valores. Além disso, desenvolvemos uma metodologia de seleção de estruturas de covariância através de procedimento de estimação RJMCMC. Tal expediente, unido ao ajuste de um modelo de grupos múltiplos, isto é, que considera independência entre os traços latentes, se constitui em uma ferramente útil para se escolher a estrutura de dependência mais conveniente. Apesar de não terem sido apresentados, os métodos de avaliação do ajuste de modelos desenvolvidos nos capítulos anteriores podem ser facilmente estendidos. Os resultados dos estudos de simulação mostraram o desempenho bastante satisfatório da modelagem e método de estimação proprostos. Na análise de dados reais ficou evidenciada a garnde utilidade do desenvolvimento considerado no presenta capítulo.

Azevedo, Caio L. N.

IME/USP 
Tabela 2.5: Resultados da estimação dos traços latentes e dos parâmetros dos itens : estudo de replicação

\begin{tabular}{lccccr}
\hline \hline \multirow{2}{*}{ Parâmetro } & \multicolumn{5}{c}{ Estatística } \\
\cline { 2 - 6 } & Corr & MEP & VQ & Var & REQM \\
\hline Traço latente & 0,995 & 0,301 & 0,019 & 0,090 & 0,331 \\
Discriminação & 0,984 & 0,095 & 0,001 & 0,008 & 0,095 \\
Dificuldade & 0,999 & 0,122 & 0,004 & 0,017 & 0,145 \\
\hline \hline
\end{tabular}

Tabela 2.6: Resultados da estimação dos parâmetros populacionais : estudo de replicação

\begin{tabular}{lrrrrr}
\hline \hline \multirow{2}{*}{ Parâmetro } & \multicolumn{5}{c}{ Estatística } \\
\cline { 2 - 6 } & M. Est. & MEP & VQ & Var & REQM \\
\hline$\mu_{\theta_{2}}$ & 0,997 & 0,045 & $<0,001$ & $<0,001$ & 0,020 \\
$\mu_{\theta_{3}}$ & 1,995 & 0,076 & $<0,001$ & 0,002 & 0,040 \\
$\psi_{\theta_{2}}$ & 0,906 & 0,078 & $<0,001$ & 0,002 & 0,043 \\
$\psi_{\theta_{3}}$ & 0,998 & 0,111 & 0,002 & 0,004 & 0,081 \\
\hline \hline
\end{tabular}

Azevedo, Caio L. N. 

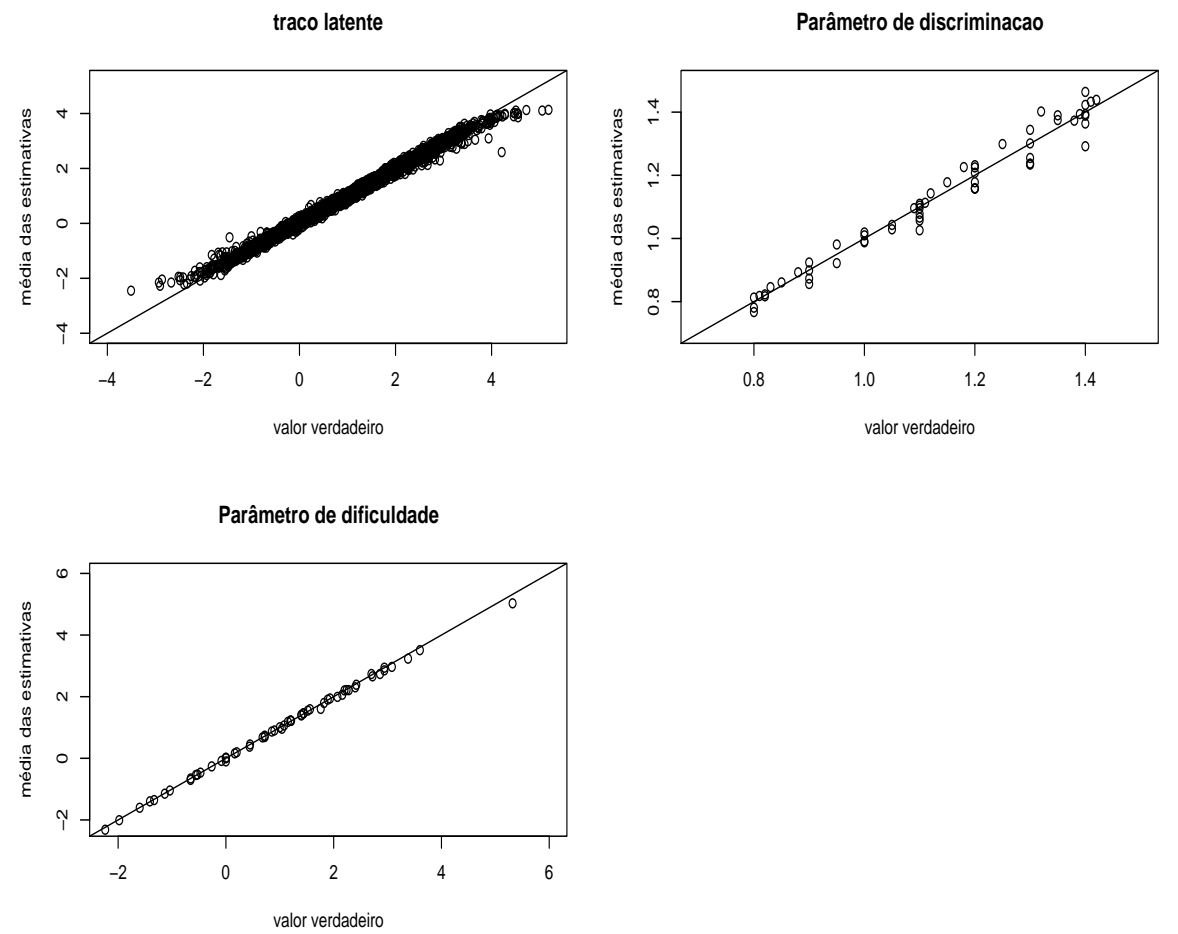

Figura 2.5: Gráficos de dispersão entre os valores dos verdadeiros parâmetros e as respectivas estimativas médias 

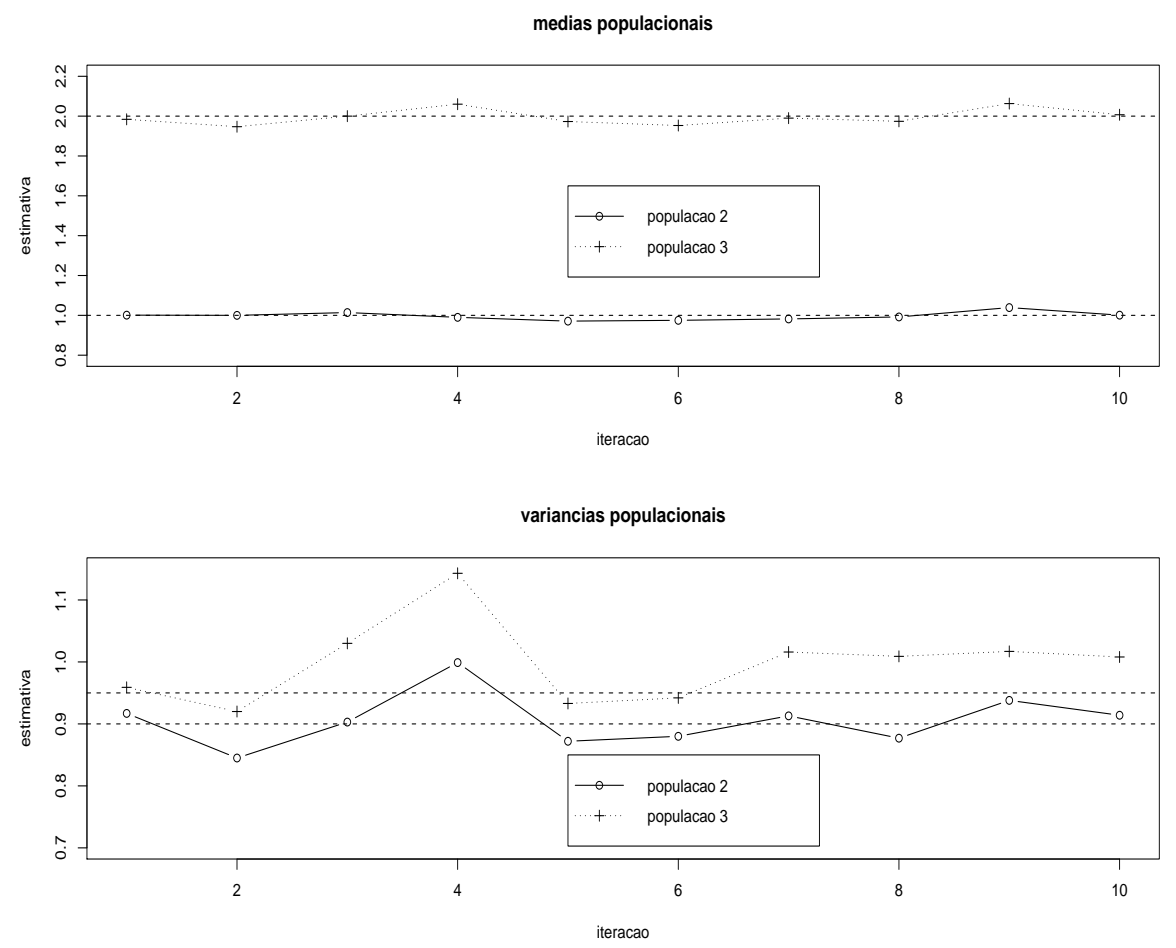

Figura 2.6: Perfil das estimativas dos parâmetros populacionais ao longo das replicações 


\subsubsection{Estudo de acompanhamento}

Nesta subseção analisaremos o comportamento do procedimento MCMC, no que concerne à convergência, autocorrelação e sensibilidade com relação à escolha de valores iniciais, com um único conjunto de respostas simuladas. O esquema é o mesmo descrito na Seção 2.10 com as prioris utilizadas na subseção 2.10 .2

As Tabelas 2.7 e 2.8 apresentam as estimativas, os erros-padrão, os intervalos de credibilidade (IC) com caudas iguais e os HPD's ${ }^{* *}$, com $95 \%$ de confiança, para os parâmetros dos itens e populacionais, respectivamente, veja Paulino et al. (2003). Os HPD's foram calculados utilizando-se a técnica descrita em Chen and Shao (1999). Podemos ver que as estimativas estão bem próximas dos verdadeiros valores. Os IC's e os HPD's contêm todos os verdadeiros valores, à exceção dos parâmetros de discriminação dos itens 9 , 33 e 38 e dos parâmetros de dificuldade dos itens 9 e 33. Isto reforça a boa qualidade dos resultados obtidos. Salientamos que, o fato das estimativas de alguns parâmetros populacionais não se apresentarem tão próximos dos verdadeiros valores, é provavelmente devido à flutuações amostrais e não da qualidade do método de estimação, veja as seções 2.10 .1 e 2.10 .2 .

Os gráficos de médias ergódigas e de valores simulados indicaram que a convergência ocorreu em até 16000 iterações. Acompanhando-se as médias e as variâncias dos valores simulados, a cada 1000 iterações após o aquecimento da cadeia, verificou-se que estes se apresentaram bastante próximos. Com efeito, as estatísticas de Geweke para todos os parâmetros, apresentaram-se não significativas. Por isso adotamos tal valor como burn-in.

As Figuras $2.7 \mathrm{e} 2.8$ apresentam os valores simulados, obtidos a partir de diferentes valores iniciais, retidos a cada 30 iterações, desde o início, para os parâmetros populacionais e os parâmetros de dois itens escolhidos aos acaso. Nota-se claramente que, as diferentes escolhas de valores iniciais, não alteram, de forma significativa, os resultados.

As Figuras 2.9 e 2.10 apresentam as autocorrelações, calculadas a partir da amostra pós aquecimento, com e sem espaçamento, para os parâmetros citados no parágrafo anterior. Notamos que, apesar de haver autocorrelações significativas mesmo com defasagens superiores a 50, o espaçamento de tamanho 30 parece diminuir substancialmente a magnitude delas. Isto indica que a amostra obtida com tal espaçamento é, praticamente, não correlacionada.

A Figura 2.11 apresenta os histogramas e as densidades estimadas, a partir da amostra gerada, para os parâmetros supracitados. Eles indicam que as distribuições apresentam um comportamento simétrico. Em termos práticos, isso implica que utilizar a média, mediana ou a moda, como estimativa, é praticamente indiferente. A Figura 2.12 apresenta as curvas de nível das distribuições conjuntas, entre os parâmetros dos itens e os parâmetros populacionais. Percebe-se uma certa dependência positiva entre os parâmetros populacionais do grupo 3 e também entre os parâmetros do item 33. Observamos uma dependência negativa para os parâmetros

** Sigla da expressão em inglês "Highest Posterior Density"

Azevedo, Caio L. N.

IME/USP 
do item 4 e uma aparente independência entre os parâmetros populacionais do grupo 2. A dependência encontrada nos parâmetros populacionais poderia ajudar a explicar a magnitude das autocorrelações apresentadas na Figura 2.9.

Tabela 2.7: Parâmetros dos itens e resultados para o estudo de acompanhamento

\begin{tabular}{|c|c|c|c|c|c|c|c|c|c|c|c|}
\hline \multirow[t]{2}{*}{ Teste } & \multirow[t]{2}{*}{ Item } & \multicolumn{2}{|c|}{ Val. verd. } & \multicolumn{8}{|c|}{ Estimativas } \\
\hline & & a & b & Est. & EP & $\begin{array}{c}a \\
\text { CI }(95 \%)\end{array}$ & HPD $(95 \%)$ & Est. & EPP & $\frac{b}{\mathrm{CI}(95 \%)}$ & $4 P$ (95\%) \\
\hline 1 & 1 & 0,80 & $-1,60$ & 0,768 & 0,082 & 0,$620 ; 0,941$ & 0,$611 ; 0,921$ & $-1,483$ & 0,079 & {$[-1,639 ;-1,335$} & {$[-1,617 ;-1,326$} \\
\hline 1 & 2 & 1,10 & $-1,98$ & 0,926 & 0,096 & 0,$742 ; 1,118$ & 0,$760 ; 1,126$ & $-1,962$ & 0,111 & {$[-2,161 ;-1,757$} & {$[-2,165 ;-1,765$} \\
\hline 1 & 3 & 1,40 & $-2,24$ & 1,411 & 0,144 & 1,$117 ; 1,697$ & 1,$107 ; 1,679$ & $-2,212$ & 0,161 & $-2,544 ;-1,902$ & $-2,505 ;-1,886$ \\
\hline 1 & 4 & 0,81 & $-1,13$ & 0,875 & 0,072 & 0,$734 ; 1,014$ & 0,$720 ; 0,992$ & $-1,194$ & 0,064 & $-1,309 ;-1,064$ & $-1,315 ;-1,071$ \\
\hline 1 & 5 & 1,11 & $-1,33$ & 1,137 & 0,094 & 0,$955 ; 1,323$ & 0,$943 ; 1,304$ & $-1,389$ & 0,090 & $-1,550 ;-1,211$ & $-1,553 ;-1,223$ \\
\hline 1 & 6 & 1,41 & $-1,41$ & 1,362 & 0,106 & 1,$182 ; 1,576$ & 1,$182 ; 1,576$ & $-1,422$ & 0,094 & $-1,604 ;-1,238$ & $-1,579 ;-1,223$ \\
\hline 1 & 7 & 0,82 & $-0,66$ & 0,840 & 0,061 & 0,$729 ; 0,970$ & 0,$738 ; 0,972$ & $-0,624$ & 0,047 & $-0,711 ;-0,539$ & $-0,708 ;-0,536$ \\
\hline 1 & 8 & 1,09 & $-0,65$ & 0,995 & 0,069 & 0,$850 ; 1,129$ & 0,$838 ; 1,110$ & $-0,567$ & 0,049 & $-0,659 ;-0,466$ & $-0,659 ;-0,466$ \\
\hline 1 & 9 & 1,39 & $-0,56$ & 1,639 & 0,116 & 1,$415 ; 1,889$ & 1,$438 ; 1,899$ & $-0,694$ & 0,069 & {$[-0,844 ;-0,565$} & $-0,844 ;-0,565$ \\
\hline 1 & 10 & 0,83 & $-0,08$ & 0,745 & 0,055 & 0,$620 ; 0,852$ & 0,$617 ; 0,845$ & $-0,041$ & 0,045 & {$[-0,133 ; 0,044$} & {$[-0,133 ; 0,044$} \\
\hline 1 & 11 & 0,90 & 0,90 & 0,919 & 0,070 & 0,$789 ; 1,055$ & 0,$788 ; 1,049$ & 0,971 & 0,062 & {$[0,861 ; 1,084$} & {$[0,861 ; 1,084$} \\
\hline 1 & 12 & 1,20 & 1,44 & 1,287 & 0,110 & 1,$074 ; 1,531$ & 1,$035 ; 1,487$ & 1,529 & 0,103 & 1,$329 ; 1,718$ & 1,$329 ; 1,718$ \\
\hline 1 & 13 & 1,38 & 1,93 & 1,235 & 0,105 & 1,$007 ; 1,438$ & 1,$021 ; 1,448$ & 1,774 & 0,102 & 1,$583 ; 1,964$ & 1,$580 ; 1,959$ \\
\hline 1 & 14 & 0,95 & 1,52 & 0,974 & 0,088 & 0,$795 ; 1,143$ & 0,$787 ; 1,134$ & 1,541 & 0,084 & 1,$382 ; 1,709$ & 1,$402 ; 1,726$ \\
\hline 1 & 15 & 1,05 & 1,89 & 1,121 & 0,110 & 0,$925 ; 1,337$ & 0,$934 ; 1,342$ & 1,868 & 0,119 & 1,$642 ; 2,095$ & 1,$658 ; 2,098$ \\
\hline 1 & 16 & 1,35 & 2,70 & 1,379 & 0,165 & 1,$085 ; 1,753$ & 1,$071 ; 1,719$ & 2,775 & 0,214 & 2,$441 ; 3,260$ & 2,$441 ; 3,260$ \\
\hline 1 & 17 & 0,85 & 0,68 & 0,856 & 0,065 & 0,$737 ; 0,995$ & 0,$736 ; 0,991$ & 0,642 & 0,054 & {$[0,543 ; 0,748$} & 0,$557 ; 0,753$ \\
\hline 1 & 18 & 1,05 & 0,00 & 0,968 & 0,065 & 0,$851 ; 1,093$ & 0,$850 ; 1,083$ & 0,030 & 0,044 & $-0,060 ; 0,134$ & $-0,064 ; 0,128$ \\
\hline $1-2$ & 19 & 1,35 & 0,00 & 1,445 & 0,074 & 1,$301 ; 1,589$ & 1,$307 ; 1,590$ & 0,052 & 0,045 & $-0,037 ; 0,135$ & $-0,021 ; 0,144$ \\
\hline $1-2$ & 20 & 0,82 & 0,16 & 0,883 & 0,044 & 0,$799 ; 0,973$ & 0,$791 ; 0,965$ & 0,197 & 0,037 & {$[0,129 ; 0,263$} & {$[0,129 ; 0,262$} \\
\hline $1-2$ & 21 & 1,12 & 0,45 & 1,154 & 0,057 & 1,$047 ; 1,281$ & 1,$055 ; 1,287$ & 0,445 & 0,046 & 0,$363 ; 0,540$ & 0,$363 ; 0,540$ \\
\hline $1-2$ & 22 & 1,42 & 0,85 & 1,423 & 0,070 & 1,$295 ; 1,556$ & 1,$295 ; 1,556$ & 0,903 & 0,059 & 0,$778 ; 1,013$ & 0,$792 ; 1,018$ \\
\hline $1-2$ & 23 & 0,90 & 0,72 & 0,997 & 0,052 & 0,$899 ; 1,093$ & 0,$904 ; 1,093$ & 0,754 & 0,046 & 0,$665 ; 0,836$ & 0,$661 ; 0,827$ \\
\hline $1-2$ & 24 & 1,20 & 1,20 & 1,119 & 0,059 & 1,$010 ; 1,239$ & 1,$006 ; 1,228$ & 1,144 & 0,057 & 1,$027 ; 1,248$ & {$[1,042 ; 1,256$} \\
\hline 2 & 25 & 1,30 & $-1,04$ & 1,487 & 0,182 & 1,$159 ; 1,867$ & 1,$140 ; 1,841$ & $-0,929$ & 0,094 & {$[-1,108 ;-0,728$} & {$[-1,108 ;-0,755$} \\
\hline 2 & 26 & 0,88 & $-0,53$ & 0,945 & 0,088 & 0,$800 ; 1,113$ & 0,$800 ; 1,113$ & $-0,459$ & 0,077 & {$[-0,605 ;-0,318$} & $-0,607 ;-0,320$ \\
\hline 2 & 27 & 1,18 & $-0,47$ & 1,217 & 0,109 & 1,$012 ; 1,447$ & 0,$995 ; 1,413$ & $-0,428$ & 0,081 & $-0,578 ;-0,288$ & $-0,583 ;-0,299$ \\
\hline 2 & 28 & 1,32 & $-0,26$ & 1,370 & 0,115 & 1,$171 ; 1,579$ & 1,$157 ; 1,555$ & $-0,186$ & 0,083 & {$[-0,348 ;-0,021$} & $-0,349 ;-0,026$ \\
\hline 2 & 29 & 1,00 & 0,00 & 1,020 & 0,076 & 0,$872 ; 1,165$ & 0,$865 ; 1,155$ & 0,044 & 0,069 & {$[-0,102 ; 0,181$} & {$[-0,091 ; 0,183$} \\
\hline 2 & 30 & 1,20 & 2,40 & 1,266 & 0,105 & 1,$077 ; 1,457$ & 1,$076 ; 1,441$ & 2,492 & 0,159 & {$[2,182 ; 2,791$} & {$[2,173 ; 2,779$} \\
\hline 2 & 31 & 1,30 & 2,86 & 1,268 & 0,121 & 1,$035 ; 1,520$ & 1,$051 ; 1,527$ & 2,789 & 0,195 & 2,$406 ; 3,192$ & 2,$404 ; 3,169$ \\
\hline 2 & 32 & 0,95 & 2,28 & 0,998 & 0,094 & 0,$837 ; 1,202$ & 0,$828 ; 1,186$ & 2,271 & 0,144 & 2,$013 ; 2,583$ & 2,$003 ; 2,552$ \\
\hline 2 & 33 & 1,25 & 1,00 & 1,475 & 0,101 & 1,$286 ; 1,670$ & 1,$290 ; 1,672$ & 1,237 & 0,104 & 1,$049 ; 1,439$ & 1,$028 ; 1,412$ \\
\hline 2 & 34 & 1,15 & 1,15 & 1,211 & 0,095 & 1,$028 ; 1,380$ & 1,$051 ; 1,397$ & 1,199 & 0,106 & 1,$018 ; 1,426$ & 0,$989 ; 1,380$ \\
\hline 2 & 35 & 1,00 & 1,20 & 1,141 & 0,085 & 0,$987 ; 1,315$ & 0,$975 ; 1,293$ & 1,312 & 0,100 & 1,$121 ; 1,497$ & 1,$117 ; 1,483$ \\
\hline 2 & 36 & 1,10 & 1,21 & 1,206 & 0,090 & 1,$024 ; 1,400$ & 1,$010 ; 1,379$ & 1,357 & 0,106 & 1,$161 ; 1,609$ & 1,$141 ; 1,552$ \\
\hline $2-3$ & 37 & 1,20 & 1,56 & 1,278 & 0,075 & 1,$146 ; 1,442$ & 1,$146 ; 1,442$ & 1,609 & 0,102 & 1,$415 ; 1,815$ & 1,$415 ; 1,815$ \\
\hline $2-3$ & 38 & 1,30 & 1,82 & 1,462 & 0,088 & 1,$309 ; 1,637$ & 1,$306 ; 1,630$ & 1,981 & 0,123 & 1,$755 ; 2,246$ & 1,$753 ; 2,238$ \\
\hline $2-3$ & 39 & 1,40 & 2,24 & 1,549 & 0,090 & 1,$373 ; 1,718$ & 1,$388 ; 1,725$ & 2,345 & 0,130 & 2,$075 ; 2,595$ & 2,$063 ; 2,574$ \\
\hline $2-3$ & 40 & 0,80 & 1,44 & 0,815 & 0,050 & 0,$712 ; 0,923$ & 0,$722 ; 0,926$ & 1,414 & 0,078 & 1,$266 ; 1,562$ & 1,$265 ; 1,554$ \\
\hline $2-3$ & 41 & 1,10 & 2,20 & 1,117 & 0,060 & 1,$010 ; 1,234$ & 1,$003 ; 1,222$ & 2,128 & 0,096 & 1,$955 ; 2,317$ & 1,$938 ; 2,298$ \\
\hline $2-3$ & 42 & 1,40 & 2,94 & 1,547 & 0,102 & 1,$359 ; 1,755$ & 1,$350 ; 1,738$ & 3,125 & 0,168 & {$[2,810 ; 3,449$} & {$[2,809 ; 3,444$} \\
\hline 3 & 43 & 1,30 & 0,00 & 1,384 & 0,172 & 1,$067 ; 1,728$ & 1,$022 ; 1,671$ & 0,049 & 0,185 & $-0,279 ; 0,432$ & $-0,300 ; 0,359$ \\
\hline 3 & 44 & 1,00 & 0,20 & 0,915 & 0,107 & 0,$714 ; 1,125$ & 0,$726 ; 1,135$ & $-0,034$ & 0,150 & $-0,311 ; 0,233$ & $-0,311 ; 0,233$ \\
\hline 3 & 45 & 1,10 & 0,44 & 0,947 & 0,099 & 0,$762 ; 1,138$ & 0,$757 ; 1,128$ & 0,203 & 0,136 & $-0,090 ; 0,473$ & $-0,054 ; 0,491$ \\
\hline 3 & 46 & 1,20 & 0,72 & 1,168 & 0,118 & 0,$964 ; 1,382$ & 0,$951 ; 1,367$ & 0,601 & 0,162 & {$[0,300 ; 0,920$} & {$[0,316 ; 0,930$} \\
\hline 3 & 47 & 1,30 & 1,04 & 1,266 & 0,112 & 1,$051 ; 1,498$ & 1,$050 ; 1,494$ & 0,887 & 0,166 & 0,$558 ; 1,239$ & 0,$554 ; 1,220$ \\
\hline 3 & 48 & 1,40 & 1,40 & 1,472 & 0,133 & 1,$198 ; 1,731$ & 1,$195 ; 1,722$ & 1,434 & 0,196 & 1,$056 ; 1,822$ & 1,$001 ; 1,752$ \\
\hline 3 & 49 & 0,90 & 1,08 & 0,895 & 0,082 & 0,$751 ; 1,080$ & 0,$746 ; 1,073$ & 0,932 & 0,131 & 0,$681 ; 1,222$ & 0,$672 ; 1,184$ \\
\hline 3 & 50 & 1,00 & 1,40 & 0,942 & 0,083 & 0,$788 ; 1,101$ & 0,$793 ; 1,103$ & 1,193 & 0,144 & 0,$928 ; 1,496$ & 0,$892 ; 1,437$ \\
\hline 3 & 51 & 1,10 & 1,76 & 1,015 & 0,081 & 0,$864 ; 1,177$ & 0,$869 ; 1,178$ & 1,591 & 0,147 & 1,$329 ; 1,856$ & 1,$350 ; 1,874$ \\
\hline 3 & 52 & 1,20 & 2,16 & 1,397 & 0,112 & 1,$192 ; 1,618$ & 1,$192 ; 1,618$ & 2,339 & 0,200 & 1,$940 ; 2,710$ & 1,$918 ; 2,684$ \\
\hline 3 & 53 & 0,80 & 2,72 & 0,702 & 0,071 & 0,$577 ; 0,850$ & 0,$576 ; 0,846$ & 2,411 & 0,169 & 2,$107 ; 2,768$ & 2,$144 ; 2,785$ \\
\hline 3 & 54 & 1,10 & 2,42 & 1,067 & 0,087 & 0,$901 ; 1,247$ & 0,$894 ; 1,223$ & 2,275 & 0,163 & 1,$945 ; 2,599$ & 1,$938 ; 2,582$ \\
\hline 3 & 55 & 1,40 & 2,94 & 1,427 & 0,115 & 1,$196 ; 1,658$ & 1,$218 ; 1,669$ & 2,874 & 0,206 & 2,$468 ; 3,280$ & 2,$450 ; 3,249$ \\
\hline 3 & 56 & 0,90 & 2,07 & 0,923 & 0,078 & 0,$779 ; 1,078$ & 0,$778 ; 1,060$ & 2,014 & 0,146 & 1,$728 ; 2,321$ & 1,$724 ; 2,308$ \\
\hline 3 & 57 & 1,20 & 3,60 & 1,394 & 0,129 & 1,$136 ; 1,695$ & 1,$129 ; 1,660$ & 3,962 & 0,292 & 3,$374 ; 4,614$ & 3,$313 ; 4,515$ \\
\hline 3 & 58 & 1,30 & 3,38 & 1,352 & 0,111 & 1,$149 ; 1,567$ & 1,$115 ; 1,532$ & 3,413 & 0,227 & 2,$992 ; 3,868$ & 2,$980 ; 3,846$ \\
\hline 3 & 59 & 1,10 & $\begin{array}{l}3,00 \\
3,08\end{array}$ & $\begin{array}{l}1,002 \\
1,098\end{array}$ & 0,100 & 0,$902 ; 1,279$ & 0,$934 ; 1,294$ & 2,942 & 0,208 & {$[2,554 ; 3,364$} & 2,$484 ; 3,283$ \\
\hline 3 & 60 & 1,40 & 5,32 & 1,363 & 0,145 & 1,$104 ; 1,677$ & 1,$104 ; 1,677$ & 4,953 & 0,419 & {$[4,213 ; 5,894$} & 4,$137 ; 5,772$ \\
\hline
\end{tabular}

Azevedo, Caio L. N.

IME/USP 
Tabela 2.8: Resultados para a estimação dos parâmetros populacionais : estudo de acompanhamento

\begin{tabular}{lcccc}
\hline \hline Parâmetro & Est. & EP & IC(95\%) & HPD(95\%) \\
\hline$\mu_{\theta_{2}}$ & 0,987 & 0,044 & {$[0,912 ; 1,066]$} & {$[0,912 ; 1,066]$} \\
$\mu_{\theta_{3}}$ & 1,912 & 0,068 & {$[1,795 ; 2,065]$} & {$[1,790 ; 2,055]$} \\
$\psi_{\theta_{2}}$ & 0,833 & 0,063 & {$[0,697 ; 0,972]$} & {$[0,687 ; 0,949]$} \\
$\psi_{\theta_{3}}$ & 0,903 & 0,097 & {$[0,752 ; 1,102]$} & {$[0,722 ; 1,065]$} \\
\hline \hline
\end{tabular}
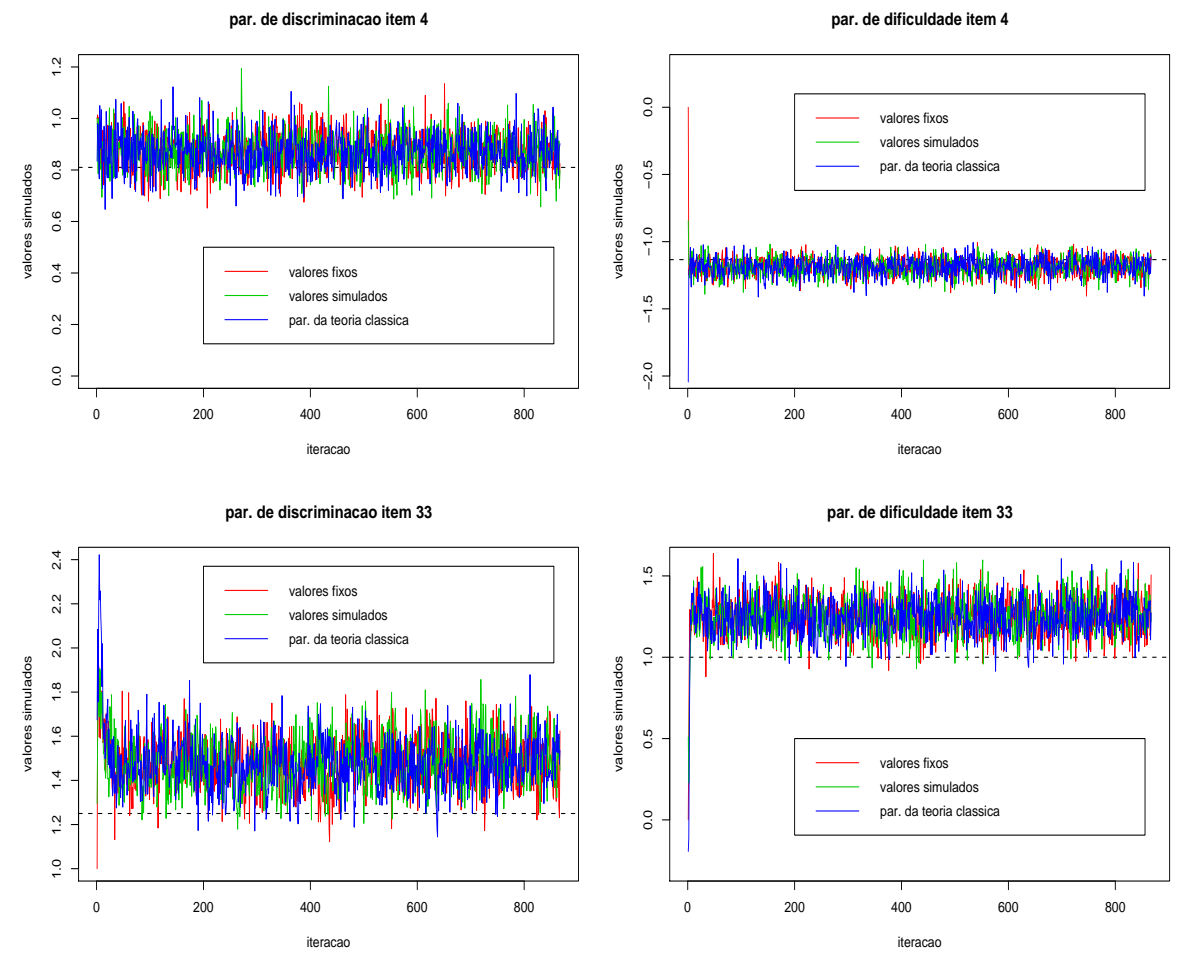

Figura 2.7: Valores simulados, dos parâmetros dos itens 4 e 33, para diferentes valores iniciais : estudo de acompanhamento

Azevedo, Caio L. N.

IME/USP 

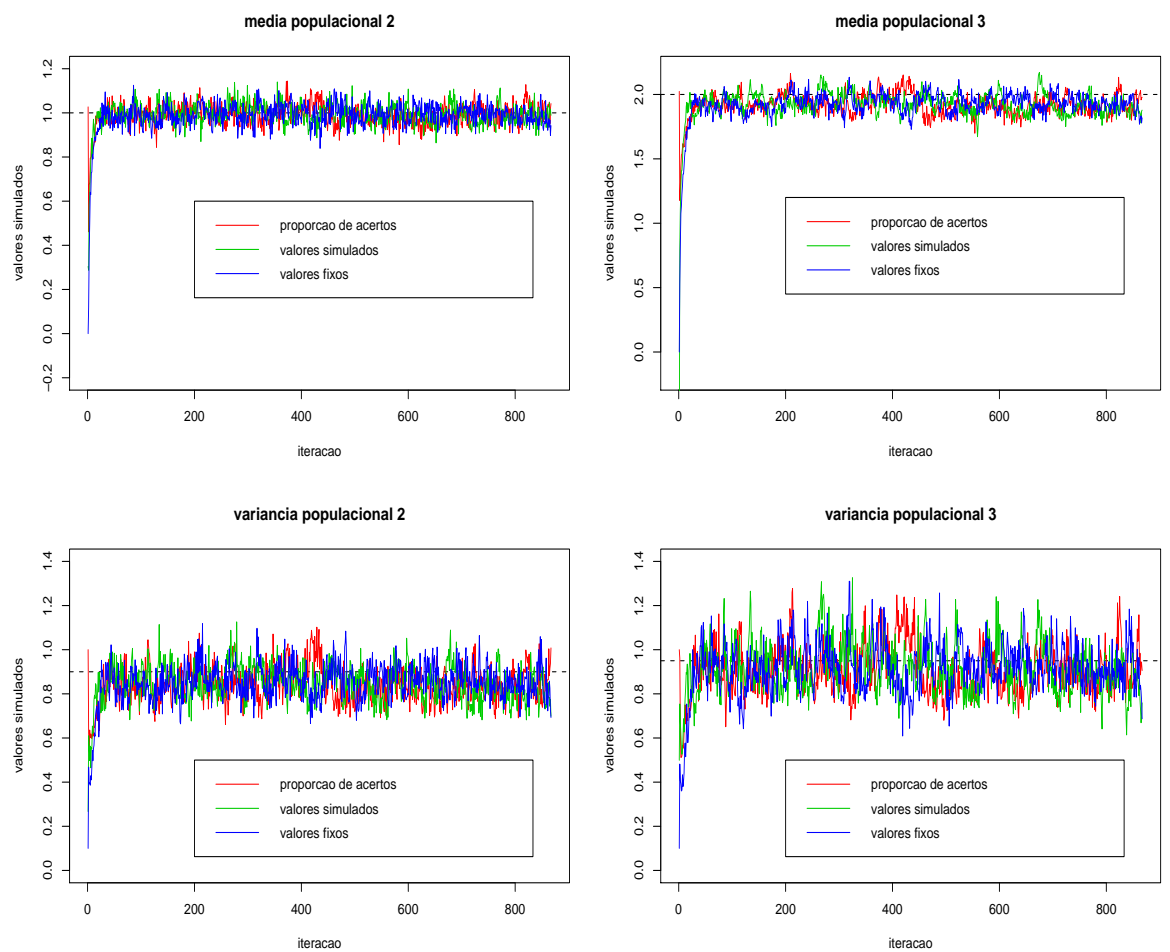

Figura 2.8: Valores simulados, dos parâmetros populacionais, para diferentes valores iniciais : estudo de acompanhamento 

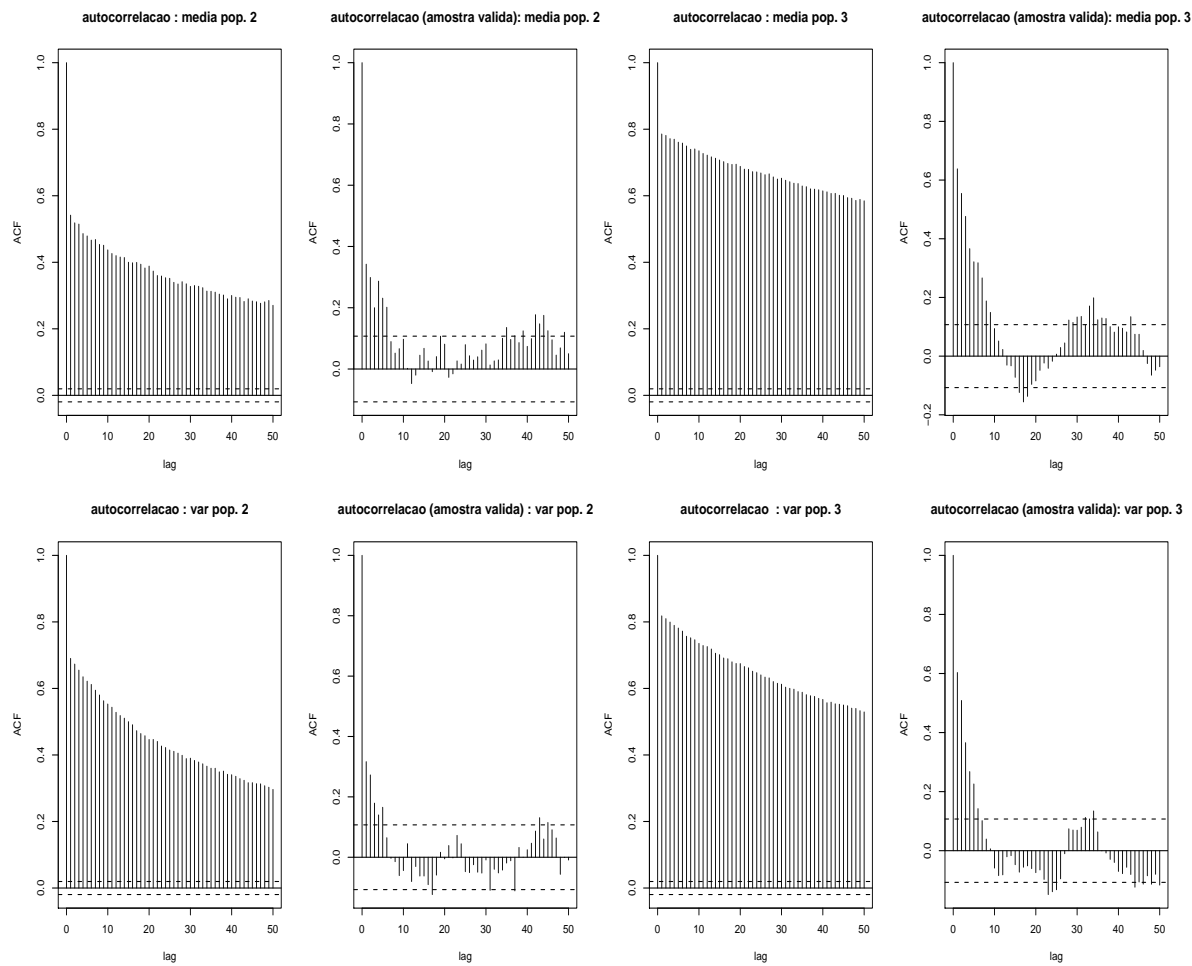

Figura 2.9: Auto-correlacao dos parâmetros populacionais : estudo de acompanhamento 

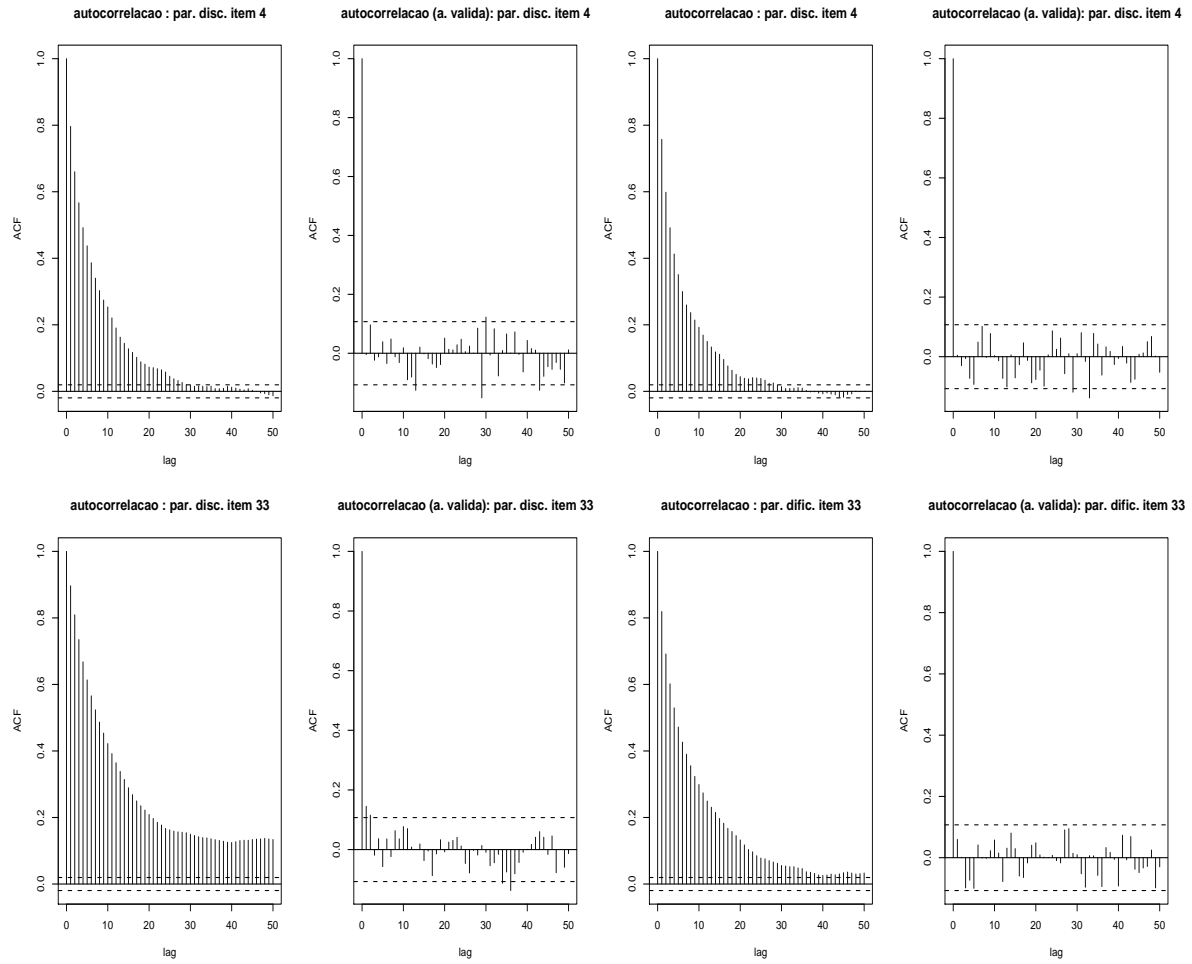

Figura 2.10: Auto-correlacao dos parâmetros dos itens 4 e 33 : estudo de acompanhamento 

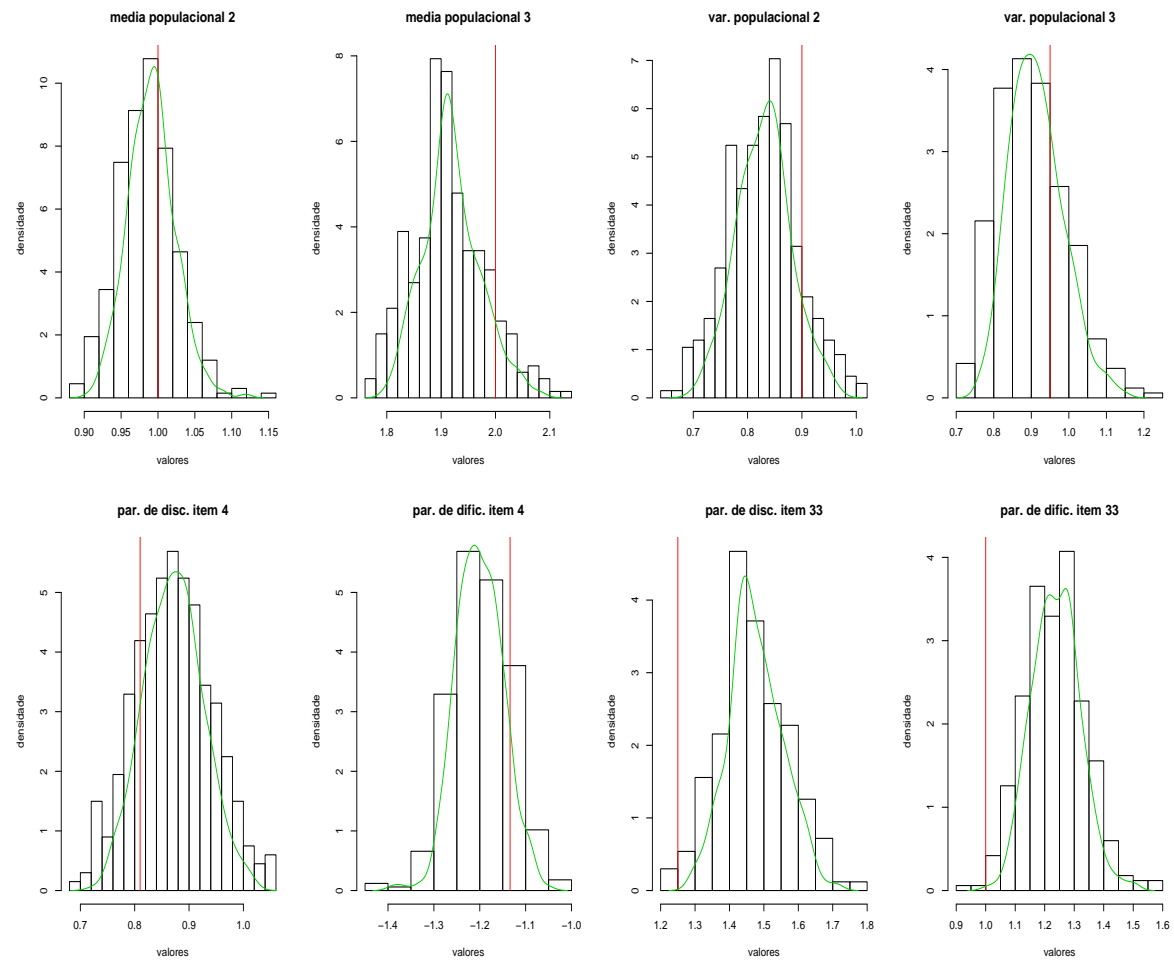

Figura 2.11: Histogramas e densidades das amostras válidas dos parâmetros selecionados

Azevedo, Caio L. N. 

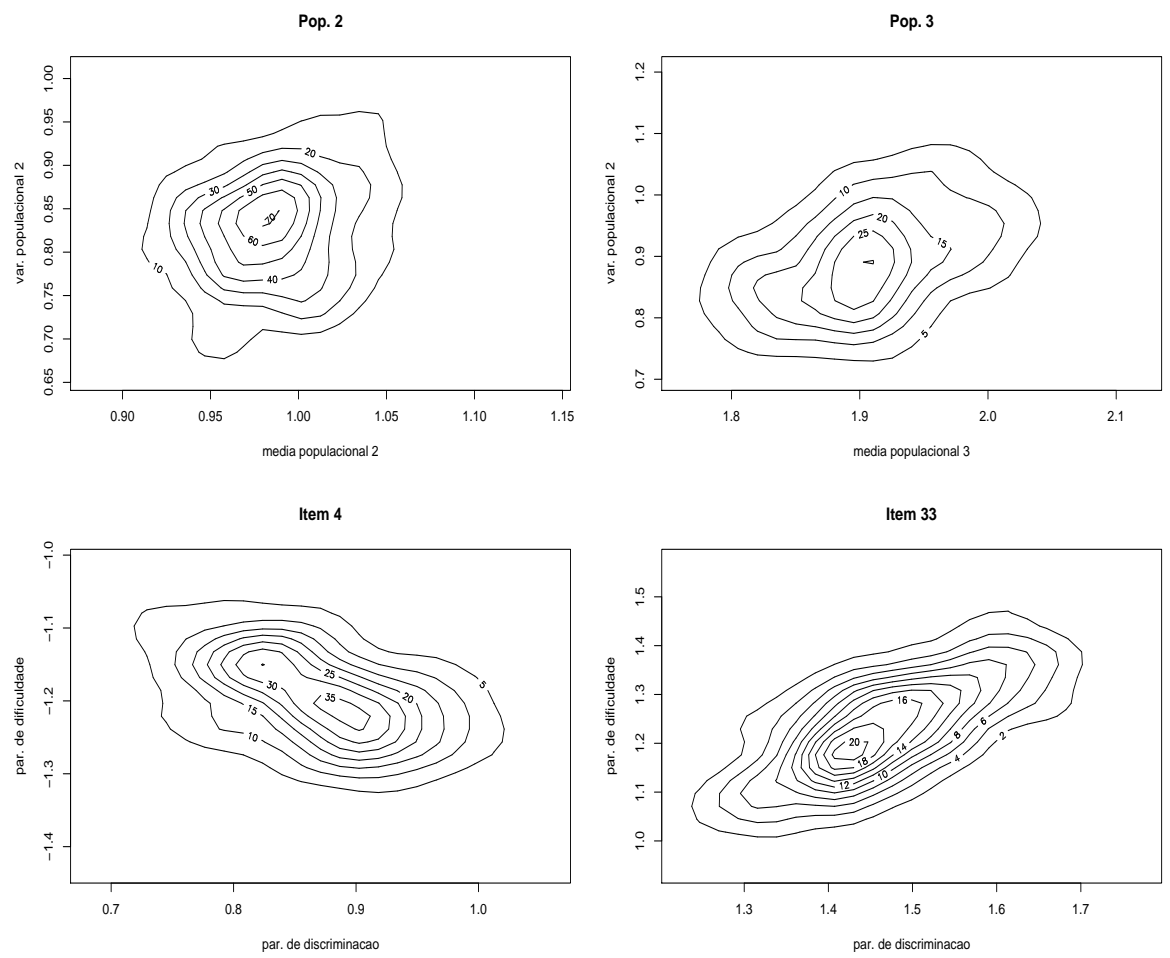

Figura 2.12: Desidades conjuntas das amostras válidas para os parâmetros selecionados 


\subsection{Análise de dados reais}

Nesta seção, com o objetivo de ilustrar o uso da metodologia proposta e explorar algumas de suas importantes características, analisaremos um conjunto de dados reais.

Os dados em questão constituem uma parte da pesquisa relacionado ao Programa de Desenvolvimento Escolar (PDE) conduzido pelo Instituto Nacional de Pesquisas Educacionais (INEP), veja (http://www.inep.gov.br/). Uma descrição bem detalhada dos dados pode ser encontrada em de Araújo (2003). Sucintamente, este estudo consiste em um planejamento longitudinal, para avaliar o conhecimento de crianças em Matemática e Português, realizado durante 5 anos através da aplicações de seis testes distintos, mas com itens comuns. O conjunto de dados analisado compreende as três primeiras avaliações, com relação aos resultados de Matemática, e foram utilizados os itens que permanceram de acordo com a análise anteriormente feita, gerando um total de 94 itens. A descrição da estrutura dos testes, com o número de itens em cada um e em comum, pode ser encontrada na Tabela 2.9. Além disso, apenas os indivíduos que participaram das 6 avaliações foram considerados. Nos estudos de simulação utilizamos 1000 indivíduos por grupo e 60 itens. Como o número de itens na análise real é de 94 , o que gera uma razão de $(94 / 60 \approx 1,5)$, optamos por também considerar tal razão no número de indivíduos, para efeito de comparação com os resultados das simulações. Portanto, uma amostra aleatória simples sem reposição de 1500 indivíduos foi retirada. No total temos então, um conjunto de 1500 respondentes (em três instantes de avaliação, considerados aqui como 3 grupos independentes) e um total de 94 itens.

Tabela 2.9: Descrição das estruturas dos testes

\begin{tabular}{cc}
\hline \hline Teste & \# de itens \\
\hline 1 & 23 \\
2 & 26 \\
3 & 31 \\
1,2 & 5 \\
1,3 & 0 \\
2,3 & 4 \\
$1,2,3$ & 5 \\
\hline \hline
\end{tabular}

Para a análise de tal conjunto de dados utilizamos a priori de número 1, vide Tabela 2.1. Além disso, todos os critérios definidos na seção anterior, foram utilizados, inclusive com relação à convergência e o tamanho da amostra válida.

Salientamos que, por se tratar de um conjunto de dados real e, portanto, a interpretação dos parâmetros tem uma importância maior do que num estudo de simulação, analisaremos os parâmetros de dificuldade originais ao invés dos transformados, veja equação 2.1. Procedendo-se uma análise prévia, a fim de avaliar os itens 
da prova, detectou-se que alguns deles apresentaram parâmetro de discriminação (a), abaixo do valor 0,4, o equivalente à 0,68 na escala logística, vide Andrade et al. (2000). Isto representa uma discriminação muito baixa de acordo com a literatura. Dessa forma, tais item foram retirados, mantendo-se um total de 73 itens com 24, 34 e 30, itens nos Testes 1, 2 e 3 respectivamente, sendo que nenhum dos itens retirados era comum a dois ou mais testes. Considerando-se este conjunto reduzido de itens rodou-se outra análise a qual acusou a presença de 3 itens com discriminação abaixo de 0,4. No entanto, optamos por deixar tais itens pois seus valores foram próximos de 0,4 .

O p-valor bayesiano, utilizando-se a medida de discrepância 2.25), referente ao ajuste deste modelo foi $\mathrm{p}=$ 0,4611, o que indica um bom ajuste. A Figura 2.13 apresenta os resultados referentes a distribuição dos escores, com os respectivos valores preditos pelo modelo e IC's de $95 \%$. Podemos verificar que, para todos os 3 grupos, os escores observados encontram-se próximos dos preditos e, para a maioria dos valores, dentro dos intervalos de credibilidade. Isto reforça o parecer pelo ajuste razoável do modelo. As Figuras 2.14 e 2.15 apresentam, respectivamente, as densidades das distribuições dos resíduos dos traços latentes e os gráficos de quantis normal-normal associados. Nota-se que a suposição de normalidade parece não ser violada. Debruçando-se sobre os comentários anteriores concluímos que, o modelo se ajustou razoavelmente bem aos dados.

A Tabela 2.10 apresenta os resultados referentes aos parâmetos de discriminação e de dificuldade (originais), enquanto que a Tabela 2.11 apresenta algumas medidas resumo referente à elas. Podemos observar que a maioria dos itens, veja Figuras 2.16 e 2.17, se posiciona abaixo da média da escala $(0,1)$, com relação ao parâmetro de dificuldade. Levando-se em consideração que as médias foram positivas, veja Tabela 2.12 podemos concluir que os testes, de um modo em geral, foram fáceis para as populações envolvidas. De modo semelhante, os parâmetros de discriminação ficaram abaixo do valor 0,6 (o equivalente à 1,02 na escala logística), veja Figuras 2.16 e 2.17 Este valor representa uma discriminação razoável. Dessa forma, podemos afirmar que o teste foi, em geral, pouco discriminativo. Por outro lado, pelo elevado CV e o valores mínimo e máximo dos parâmetros de dificuldade, podemos notar que os itens estão bem distribuídos ao longo da escala da habilidade. Isto é uma boa característica para o teste. É digno de nota que, as conclusões poderiam ser outras se usássemos, por exemplo, o modelo probito de 3 parâmetros, veja Baker and Kim (2004). Com efeito, a inserção do parâmetro de acerto ao acaso tende a elever os valores das estimativas dos parâmetros de discriminação, de um modo em geral. Podemos notar ainda, através da Figura 2.17, que os parâmetros, discriminação e dificuldade, de alguns itens, apresentam-se, estatisticamente, iguais. Através de uma pequena modificação do Passo 3 do Resultado 2.7.1. veja Seção 2.12, poderíamos estimar tais parâmetros com a restrição de igualdade entre esses. Isto, por outro lado, poderia levar a uma maior precisão nas estimativas, haja vista a diminuição no número de parâmetros.

A Tabela 2.12 apresenta os resultados referentes aos parâmetros populacionais. Podemos notar que as médias apresentam-se significativamente diferentes entre si, com uma tendência crescente ao longo do tempo. Do contrário, parece que, apesar das estimativas das variâncias terem se apresentado diferentes, os HPD's sugerem

Azevedo, Caio L. N.

$\mathrm{IME} / \mathrm{USP}$ 
uma aparente homocesdaticidade. Mais concretamente, podemos utilizar a função de distribuição acumulada empírica $\left(\widehat{F}_{X}(x)=\right.$ proporção de valores observados da variável aleatória $X$ menores que $\mathrm{x}$ ), veja Rohatgi and Saleh (1994), calculada com base nas amostras de 334 valores gerados, da distribuição conjunta $\left(\psi_{\theta_{2}}, \psi_{\theta_{3}}\right)^{t}$. Através dela obtemos que $1-\widehat{F}_{\psi_{\theta_{2}}}(1)=0,9760$ e $1-\widehat{F}_{\psi_{\theta_{3}}}(1)=0$, 7814. Estes valores sugerem uma alta probabilidade de que as variâncias do segundo e terceiro grupos (instantes) sejam ambas diferentes de 1. Além disso, a área sob a curva definida pela interseção das densidades a posteriori das duas variâncias, veja Figura 2.17, é giual à 0,6138. Estes resultados sugerem que um modelo em que as variâncias dos grupos $2 \mathrm{e}$ 3 fossem iguais entre si porém não necessariamentes iguais a 1 poderia ser ajustado. De fato, nesse modelo essa variância comum seria estimada com maior precisão e poder-se-í-a verificar, com menor incerteza, se um modelo homocedástico global seria preferível.
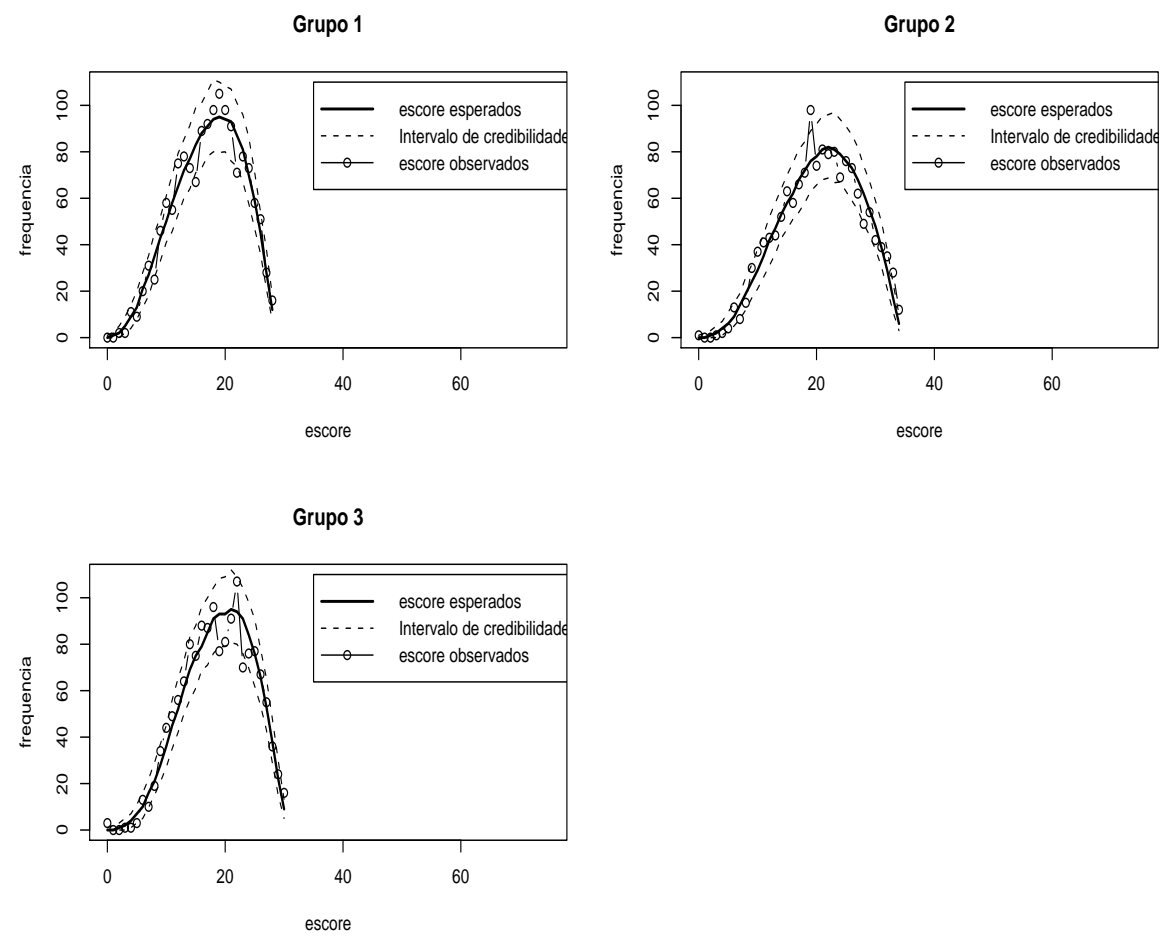

Figura 2.13: Escores preditos, observados e IC's simétricos de 95\%

Azevedo, Caio L. N. 

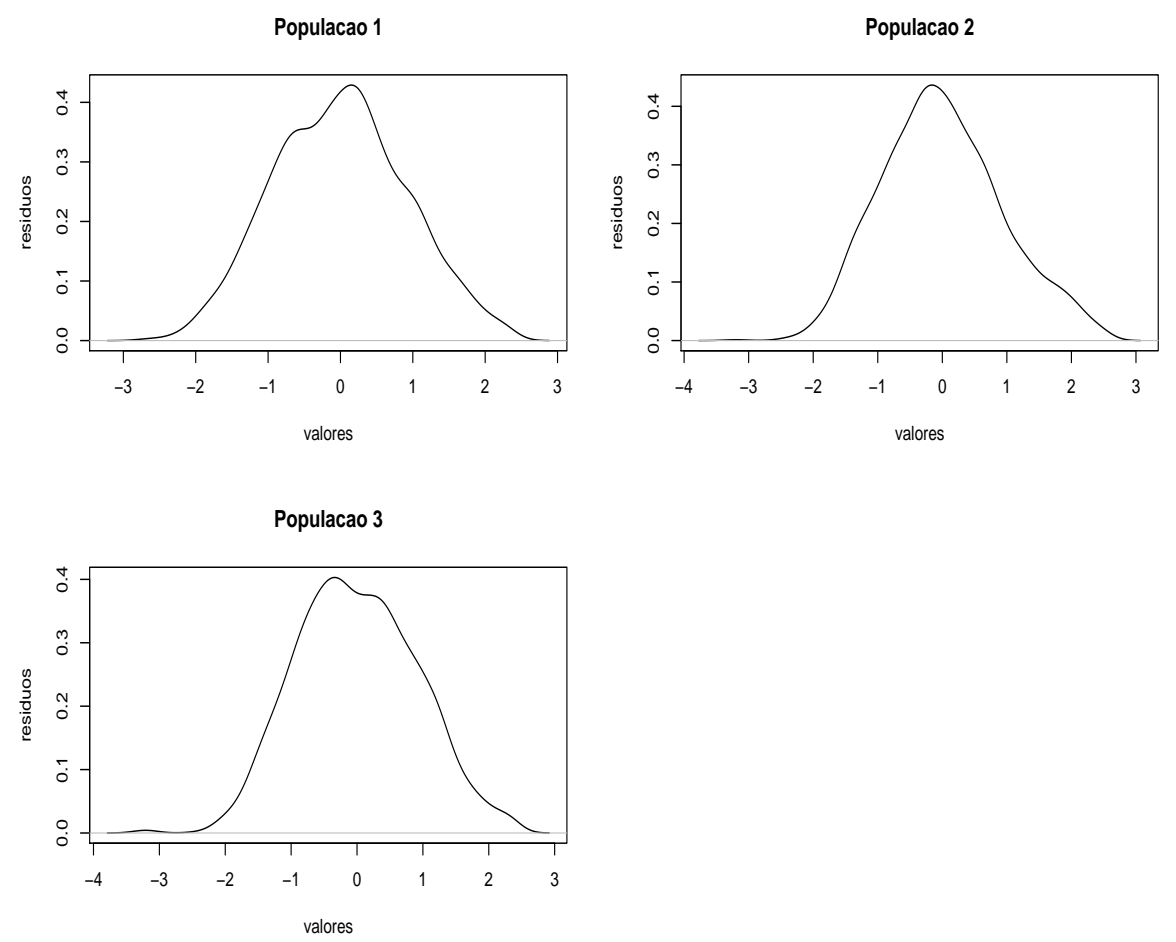

Figura 2.14: Densidade dos resíduos dos traços latentes

Azevedo, Caio L. N. 

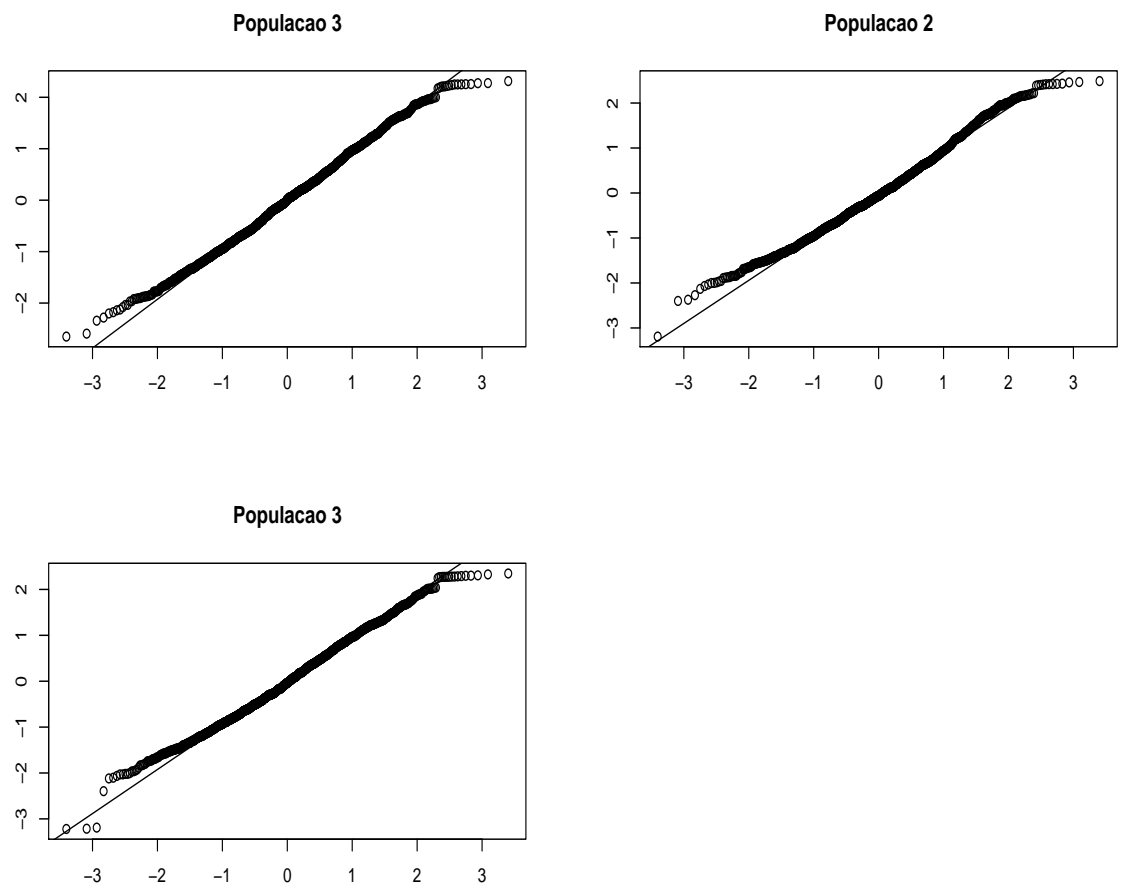

Figura 2.15: Gráficos de quantis normal-normal dos resíduos dos traços latentes 
Tabela 2.10: Resultados dos parâmetros dos itens : análise de dados reais

\begin{tabular}{|c|c|c|c|c|c|c|c|c|c|}
\hline \multirow[t]{3}{*}{ Teste } & \multirow[t]{3}{*}{ Item } & \multicolumn{8}{|c|}{ Estimativas } \\
\hline & & \multicolumn{4}{|c|}{$\mathbf{a}$} & \multicolumn{4}{|c|}{$\mathbf{b}^{*}$} \\
\hline & & Est. & EP & CI (95\%) & HPD(95\%) & Est. & EP & CI (95\%) & HPD(95\%) \\
\hline 1 & 101 & 0,425 & 0,040 & 0,$349 ; 0,496$ & 0,$347 ; 0,489$ & $-0,428$ & 0,007 & $-0,619 ;-0,284]$ & {$[-0,576 ;-0,256$} \\
\hline 1 & 102 & 0,416 & 0,045 & 0,$341 ; 0,507$ & 0,$341 ; 0,507$ & $-0,925$ & 0,015 & $-1,151 ;-0,725$ & $-1,151 ;-0,725$ \\
\hline 1 & 103 & 0,626 & 0,047 & 0,$544 ; 0,733$ & 0,$544 ; 0,733$ & $-0,925$ & 0,007 & $-1,083 ;-0,786$ & $-1,084 ;-0,789$ \\
\hline $1-2$ & 104 & 0,538 & 0,030 & 0,$480 ; 0,597$ & 0,$483 ; 0,599$ & $-0,618$ & 0,003 & $-0,726 ;-0,511$ & $-0,729 ;-0,522$ \\
\hline 1 & 106 & 0,412 & 0,043 & 0,$321 ; 0,488$ & 0,$320 ; 0,485$ & $-1,441$ & 0,026 & $-1,820 ;-1,183$ & $-1,797 ;-1,172$ \\
\hline 1 & 108 & 0,408 & 0,044 & 0,$323 ; 0,505$ & 0,$322 ; 0,495$ & $-1,752$ & 0,036 & $-2,210 ;-1,416$ & $-2,145 ;-1,403$ \\
\hline $1-2-3$ & 109 & 0,740 & 0,035 & 0,$678 ; 0,809$ & 0,$678 ; 0,809$ & $-0,865$ & 0,002 & $-0,959 ;-0,770$ & $-0,972 ;-0,786$ \\
\hline $1-2$ & 110 & 0,654 & 0,035 & 0,$588 ; 0,723$ & 0,$589 ; 0,724$ & $-0,446$ & 0,002 & $-0,541 ;-0,358$ & $-0,526 ;-0,353$ \\
\hline 1 & 111 & 0,538 & 0,052 & 0,$448 ; 0,652$ & 0,$444 ; 0,643$ & $-1,580$ & 0,022 & $-1,878 ;-1,338$ & $-1,861 ;-1,326$ \\
\hline $1-2-3$ & 114 & 0,520 & 0,025 & 0,$470 ; 0,573$ & 0,$469 ; 0,569$ & $-0,403$ & 0,002 & $-0,497 ;-0,304$ & $-0,499 ;-0,311$ \\
\hline 1 & 116 & 0,756 & 0,052 & 0,$660 ; 0,855$ & 0,$663 ; 0,856$ & $-0,998$ & 0,005 & $-1,133 ;-0,883$ & $-1,118 ;-0,875$ \\
\hline 1 & 117 & 0,548 & 0,041 & 0,$466 ; 0,618$ & 0,$472 ; 0,619$ & 0,044 & 0,004 & {$[-0,079 ; 0,162]$} & {$[-0,079 ; 0,162$} \\
\hline 1 & 118 & 0,539 & 0,046 & 0,$461 ; 0,635$ & 0,$459 ; 0,628$ & $-0,549$ & 0,006 & $-0,704 ;-0,410$ & $-0,692 ;-0,407$ \\
\hline $1-2-3$ & 119 & 0,408 & 0,026 & 0,$362 ; 0,456$ & 0,$360 ; 0,453$ & $-0,862$ & 0,006 & $-1,025 ;-0,723$ & $-1,025 ;-0,723$ \\
\hline 1 & 120 & 0,442 & 0,042 & 0,$365 ; 0,526$ & 0,$373 ; 0,529$ & $-0,639$ & 0,009 & $-0,845 ;-0,476$ & $-0,807 ;-0,456$ \\
\hline 1 & 121 & 0,522 & 0,050 & 0,$439 ; 0,620$ & 0,$433 ; 0,608$ & $-1,771$ & 0,027 & $-2,087 ;-1,484$ & $-2,071 ;-1,484$ \\
\hline $1-2$ & 122 & 0,668 & 0,034 & 0,$594 ; 0,735$ & 0,$609 ; 0,742$ & 0,279 & 0,002 & {$[0,203 ; 0,361]$} & {$[0,202 ; 0,359$} \\
\hline $1-2-3$ & 124 & 0,681 & 0,030 & 0,$624 ; 0,745$ & 0,$619 ; 0,734$ & 0,018 & 0,001 & {$[-0,047 ; 0,074]$} & {$[-0,042 ; 0,078$} \\
\hline 1 & 125 & 0,790 & 0,058 & 0,$676 ; 0,906$ & 0,$687 ; 0,916$ & $-1,001$ & 0,004 & $-1,154 ;-0,873$ & $-1,161 ;-0,886$ \\
\hline $1-2$ & 126 & 0,726 & 0,036 & 0,$654 ; 0,805$ & 0,$651 ; 0,798$ & $-0,369$ & 0,001 & $-0,452 ;-0,289$ & $-0,444 ;-0,284$ \\
\hline 1 & 127 & 0,617 & 0,042 & 0,$530 ; 0,709$ & 0,$542 ; 0,717$ & 0,033 & 0,003 & {$[-0,073 ; 0,142]$} & {$[-0,064 ; 0,147$} \\
\hline $1-2-3$ & 128 & 0,679 & 0,028 & 0,$629 ; 0,732$ & 0,$629 ; 0,732$ & 0,064 & 0,001 & {$[0,005 ; 0,136]$} & {$[0,005 ; 0,133$} \\
\hline 1 & 129 & 0,852 & 0,053 & 0,$747 ; 0,953$ & 0,$747 ; 0,953$ & $-0,150$ & 0,002 & {$[-0,233 ;-0,062]$} & {$[-0,232 ;-0,061$} \\
\hline 1 & 130 & 0,395 & 0,039 & 0,$318 ; 0,468$ & 0,$324 ; 0,473$ & $-0,152$ & 0,008 & {$[-0,295 ; 0,019$} & {$[-0,294 ; 0,019$} \\
\hline 1 & 132 & 0,476 & 0,039 & 0,$393 ; 0,567$ & 0,$386 ; 0,553$ & $-0,008$ & 0,005 & {$[-0,128 ; 0,128]$} & {$[-0,132 ; 0,123$} \\
\hline $1-2$ & 134 & 0,604 & 0,038 & 0,$532 ; 0,681$ & 0,$529 ; 0,673$ & $-1,756$ & 0,011 & {$[-1,959 ;-1,549$} & $-1,957 ;-1,549$ \\
\hline 1 & 135 & 0,953 & 0,064 & 0,$829 ; 1,084$ & 0,$828 ; 1,071$ & $-0,537$ & 0,002 & $-0,627 ;-0,463$ & $-0,621 ;-0,459$ \\
\hline 1 & 136 & 0,424 & 0,038 & 0,$343 ; 0,504$ & 0,$349 ; 0,506$ & $-0,300$ & 0,007 & $-0,463 ;-0,158$ & $-0,460 ;-0,156$ \\
\hline 2 & 203 & 0,491 & 0,040 & 0,$414 ; 0,569$ & 0,$413 ; 0,561$ & $-0,027$ & 0,005 & {$[-0,198 ; 0,119$} & {$[-0,183 ; 0,122$} \\
\hline $2-3$ & 204 & 0,400 & 0,029 & 0,$334 ; 0,464$ & 0,$332 ; 0,453$ & $-1,615$ & 0,023 & {$[-2,033 ;-1,329]$} & {$[-1,938 ;-1,303$} \\
\hline 2 & 207 & 0,714 & 0,053 & 0,$618 ; 0,823$ & 0,$617 ; 0,819$ & 0,091 & 0,003 & {$[-0,002 ; 0,214]$} & {$[-0,003 ; 0,210$} \\
\hline 2 & 208 & 0,619 & 0,047 & 0,$536 ; 0,722$ & 0,$536 ; 0,722$ & 1,498 & 0,011 & {$[1,299 ; 1,702]$} & {$[1,299 ; 1,698$} \\
\hline 2 & 209 & 0,621 & 0,051 & 0,$523 ; 0,725$ & 0,$528 ; 0,729$ & $-1,092$ & 0,011 & $-1,319 ;-0,907$ & $-1,288 ;-0,879$ \\
\hline 2 & 210 & 0,572 & 0,044 & 0,$485 ; 0,669$ & 0,$480 ; 0,662$ & $-0,261$ & 0,006 & $-0,404 ;-0,135$ & $-0,404 ;-0,142$ \\
\hline 2 & 214 & 0,458 & 0,040 & 0,$383 ; 0,544$ & 0,$379 ; 0,531$ & 1,832 & 0,023 & {$[1,570 ; 2,144$} & {$[1,542 ; 2,084$} \\
\hline 2 & 215 & 0,407 & 0,039 & 0,$329 ; 0,496$ & 0,$320 ; 0,483$ & 1,399 & 0,020 & {$[1,153 ; 1,677]$} & {$[1,123 ; 1,623$} \\
\hline 2 & 216 & 0,623 & 0,061 & 0,$508 ; 0,736$ & 0,$507 ; 0,731$ & $-1,966$ & 0,038 & {$[-2,347 ;-1,613]$} & $-2,334 ;-1,607$ \\
\hline $2-3$ & 218 & 0,663 & 0,040 & 0,$578 ; 0,740$ & 0,$582 ; 0,742$ & $-1,059$ & 0,007 & {$[-1,226 ;-0,879$} & $-1,206 ;-0,874$ \\
\hline $2-3$ & 219 & 0,510 & 0,030 & 0,$450 ; 0,578$ & 0,$451 ; 0,578$ & $-0,117$ & 0,004 & {$[-0,243 ; 0,004]$} & {$[-0,246 ; 0,000$} \\
\hline 2 & 220 & 0,407 & 0,038 & 0,$333 ; 0,487$ & 0,$341 ; 0,490$ & 1,594 & 0,021 & {$[1,325 ; 1,907$} & {$[1,325 ; 1,907$} \\
\hline 2 & 221 & 0,501 & 0,041 & 0,$420 ; 0,582$ & 0,$419 ; 0,578$ & $-0,089$ & 0,006 & {$[-0,252 ; 0,072]$} & {$[-0,236 ; 0,075$} \\
\hline 2 & 222 & 0,749 & 0,064 & 0,$639 ; 0,879$ & 0,$633 ; 0,867$ & $-1,460$ & 0,015 & {$[-1,700 ;-1,227]$} & {$[-1,704 ;-1,247$} \\
\hline $2-3$ & 223 & 0,745 & 0,040 & 0,$676 ; 0,817$ & 0,$676 ; 0,817$ & 0,512 & 0,002 & {$[0,427 ; 0,601$} & {$[0,431 ; 0,602$} \\
\hline 2 & 225 & 0,737 & 0,069 & 0,$607 ; 0,895$ & 0,$584 ; 0,851$ & $-1,632$ & 0,017 & $-1,941 ;-1,358$ & $-1,947 ;-1,368$ \\
\hline 2 & 226 & 0,466 & 0,042 & 0,$380 ; 0,554$ & 0,$392 ; 0,557$ & $-0,466$ & 0,009 & $-0,674 ;-0,287$ & $-0,654 ;-0,269$ \\
\hline 2 & 227 & 0,412 & 0,037 & 0,$344 ; 0,488$ & 0,$337 ; 0,479$ & 1,109 & 0,012 & {$[0,885 ; 1,355]$} & {$[0,864 ; 1,305$} \\
\hline 2 & 228 & 0,603 & 0,043 & 0,$519 ; 0,690$ & 0,$518 ; 0,689$ & 0,620 & 0,005 & {$[0,475 ; 0,776]$} & {$[0,465 ; 0,755$} \\
\hline 2 & 229 & 0,817 & 0,072 & 0,$693 ; 0,966$ & 0,$693 ; 0,956$ & $-1,590$ & 0,015 & $-1,847 ;-1,378$ & $-1,838 ;-1,371$ \\
\hline 2 & 233 & 0,543 & 0,047 & 0,$451 ; 0,627$ & 0,$449 ; 0,623$ & $-0,607$ & 0,008 & $-0,798 ;-0,459$ & $-0,802 ;-0,481$ \\
\hline 2 & 234 & 0,930 & 0,061 & 0,$824 ; 1,042$ & 0,$821 ; 1,037$ & $-0,410$ & 0,003 & $-0,509 ;-0,311]$ & $-0,513 ;-0,317$ \\
\hline 2 & 236 & 0,745 & 0,060 & 0,$639 ; 0,858$ & 0,$637 ; 0,852$ & $-0,850$ & 0,006 & $-1,004 ;-0,714]$ & $-0,993 ;-0,711$ \\
\hline 2 & 240 & 0,573 & 0,046 & 0,$487 ; 0,661$ & 0,$487 ; 0,660$ & $-0,943$ & 0,010 & $-1,165 ;-0,763$ & $-1,134 ;-0,756$ \\
\hline
\end{tabular}

Azevedo, Caio L. N. 
Continuação da Tabela 2.10

\begin{tabular}{|c|c|c|c|c|c|c|c|c|c|}
\hline \multirow[t]{3}{*}{ Teste } & \multirow[t]{3}{*}{ Item } & \multicolumn{8}{|c|}{ Estimativas } \\
\hline & & \multicolumn{4}{|c|}{$\mathbf{a}$} & \multicolumn{4}{|c|}{$\mathbf{b}^{*}$} \\
\hline & & Est. & EP & CI (95\%) & HPD(95\%) & Est. & EP & CI $(95 \%)$ & HPD(95\%) \\
\hline 3 & 303 & 0,444 & 0,048 & 0,$347 ; 0,531$ & 0,$364 ; 0,543$ & $-1,100$ & 0,042 & {$[-1,553 ;-0,769$} & {$[-1,477 ;-0,743$} \\
\hline 3 & 308 & 0,465 & 0,042 & 0,$386 ; 0,550$ & 0,$393 ; 0,553$ & 1,330 & 0,010 & {$[1,128 ; 1,511$} & {$[1,127 ; 1,503$} \\
\hline 3 & 309 & 0,510 & 0,048 & 0,$423 ; 0,611$ & 0,$425 ; 0,612$ & $-0,750$ & 0,021 & {$[-1,038 ;-0,472$} & {$[-1,021 ;-0,470$} \\
\hline 3 & 312 & 0,442 & 0,043 & 0,$358 ; 0,524$ & 0,$355 ; 0,520$ & 0,201 & 0,010 & {$[0,019 ; 0,398$} & {$[0,010 ; 0,386$} \\
\hline 3 & 315 & 0,475 & 0,045 & 0,$393 ; 0,566$ & 0,$396 ; 0,569$ & 0,963 & 0,008 & {$[0,785 ; 1,136$} & {$[0,791 ; 1,137$} \\
\hline 3 & 316 & 0,807 & 0,072 & 0,$656 ; 0,962$ & 0,$655 ; 0,942$ & $-0,852$ & 0,014 & {$[-1,120 ;-0,648$} & {$[-1,088 ;-0,619$} \\
\hline 3 & 317 & 0,576 & 0,046 & 0,$487 ; 0,664$ & 0,$500 ; 0,670$ & 0,697 & 0,006 & {$[0,550 ; 0,845$} & {$[0,562 ; 0,849$} \\
\hline 3 & 318 & 0,386 & 0,039 & 0,$303 ; 0,463$ & 0,$298 ; 0,453$ & 0,973 & 0,010 & 0,$789 ; 1,189$ & 0,$769 ; 1,139$ \\
\hline 3 & 319 & 0,543 & 0,046 & {$[0,4620,627$} & {$[0,4620,625$} & 0,885 & 0,006 & {$[0,7331,021$} & {$[0,7221,009$} \\
\hline 3 & 324 & 0,591 & 0,050 & $0,496 \quad 0,697$ & $0,496 \quad 0,697$ & $-0,345$ & 0,010 & $-0,556-0,174$ & $-0,556-0,174$ \\
\hline 3 & 326 & 0,476 & 0,049 & $0,3930,561$ & $0,3930,561$ & $-0,128$ & 0,012 & {$\left[\begin{array}{ll}-0,348 & 0,072\end{array}\right.$} & {$\left[\begin{array}{ll}-0,338 & 0,076\end{array}\right.$} \\
\hline 3 & 330 & 0,488 & 0,045 & $0,401 \quad 0,575$ & $0,3960,566$ & 0,752 & 0,006 & {$\left[\begin{array}{ll}0,582 & 0,905\end{array}\right.$} & {$\left[\begin{array}{ll}0,573 & 0,891\end{array}\right.$} \\
\hline 3 & 331 & 0,512 & 0,050 & $0,4130,614$ & $0,408 \quad 0,603$ & $-0,574$ & 0,019 & {$[-0,864-0,334$} & {$\left[\begin{array}{lll}-0,850 & -0,332\end{array}\right.$} \\
\hline 3 & 332 & 0,634 & 0,050 & $\begin{array}{lll}0,537 & 0,734\end{array}$ & $0,5430,736$ & 0,532 & 0,004 & {$\left[\begin{array}{lll}0,396 & 0,664\end{array}\right.$} & {$\left[\begin{array}{lll}0,388 & 0,643\end{array}\right.$} \\
\hline 3 & 334 & 0,494 & 0,046 & $0,4060,585$ & $0,3970,568$ & $-0,345$ & 0,013 & {$[-0,584-0,137$} & $-0,597-0,153$ \\
\hline 3 & 335 & 0,627 & 0,051 & $0,5270,737$ & $0,5250,727$ & 0,543 & 0,004 & {$\left[\begin{array}{lll}0,416 & 0,672\end{array}\right.$} & {$\left[\begin{array}{lll}0,416 & 0,672\end{array}\right.$} \\
\hline 3 & 336 & 0,426 & 0,043 & $0,350 \quad 0,512$ & $0,341 \quad 0,499$ & 0,531 & 0,009 & $0,351 \quad 0,714$ & $0,3510,714$ \\
\hline 3 & 337 & 0,633 & 0,052 & $0,540 \quad 0,735$ & $0,5350,729$ & 1,313 & 0,007 & {$\left[\begin{array}{lll}1,160 & 1,468\end{array}\right.$} & {$\left[\begin{array}{ll}1,152 & 1,457\end{array}\right.$} \\
\hline 3 & 338 & 0,622 & 0,051 & $0,5350,733$ & $0,5340,732$ & 0,043 & 0,007 & {$\left[\begin{array}{lll}-0,112 & 0,198\end{array}\right.$} & {$\left[\begin{array}{lll}-0,117 & 0,183\end{array}\right.$} \\
\hline 3 & 339 & 0,616 & 0,052 & $0,5230,715$ & $0,5320,717$ & 0,769 & 0,004 & {$\left[\begin{array}{ll}0,641 & 0,904\end{array}\right.$} & {$\left[\begin{array}{ll}0,640 & 0,903\end{array}\right.$} \\
\hline 3 & 340 & 0,380 & 0,040 & $0,2970,460$ & {$[0,3030,461]$} & 1,358 & 0,013 & {$[1,1191,605$} & $1,1441,609$ \\
\hline
\end{tabular}

Tabela 2.11: Estatística descritivas das estimativas dos parâmetros dos itens

\begin{tabular}{lrr}
\hline \hline Estatística & Disc. (a) & Dif. Ori. (b*) \\
\hline Média & 0,573 & $-0,230$ \\
Mediana & 0,543 & $-0,345$ \\
Desvio-Padrão & 0,137 & 0,925 \\
CV(\%) & 23,973 & 402,815 \\
Mínimo & 0,380 & $-1,966$ \\
Máximo & 0,953 & 1,832 \\
Assimetria & 0,676 & 0,237 \\
\hline \hline
\end{tabular}

Tabela 2.12: Resultados das estimativas dos parâmetros populacionais : análise de dados reais

\begin{tabular}{lcccc}
\hline \hline Parâmetro & Est. & EP & $\mathbf{I C}(\mathbf{9 5 \%})$ & $\mathbf{H P D}(\mathbf{9 5 \%})$ \\
\hline$\mu_{\theta_{2}}$ & 0,264 & 0,038 & {$[0,189 ; 0,341]$} & {$[0,197 ; 0,345]$} \\
$\mu_{\theta_{3}}$ & 0,820 & 0,050 & {$[0,722 ; 0,916]$} & {$[0,728 ; 0,918]$} \\
$\psi_{\theta_{2}}$ & 1,152 & 0,078 & {$[1,000 ; 1,321]$} & {$[1,010 ; 1,324]$} \\
$\psi_{\theta_{3}}$ & 1,071 & 0,090 & {$[0,904 ; 1,252]$} & {$[0,912 ; 1,256]$} \\
\hline \hline
\end{tabular}

Azevedo, Caio L. N.

IME/USP 

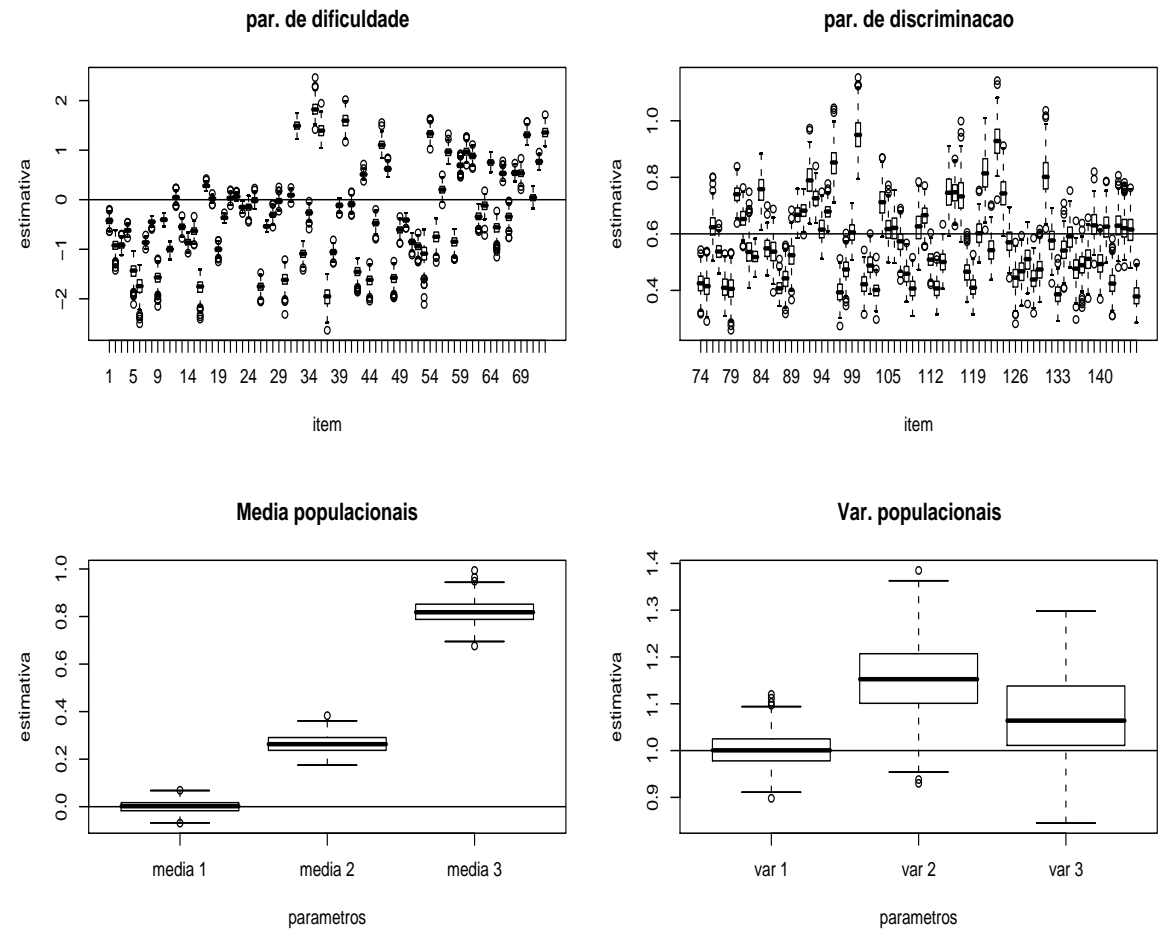

Figura 2.16: Box-plot das estimativas dos parâmetros dos itens e populacionais 

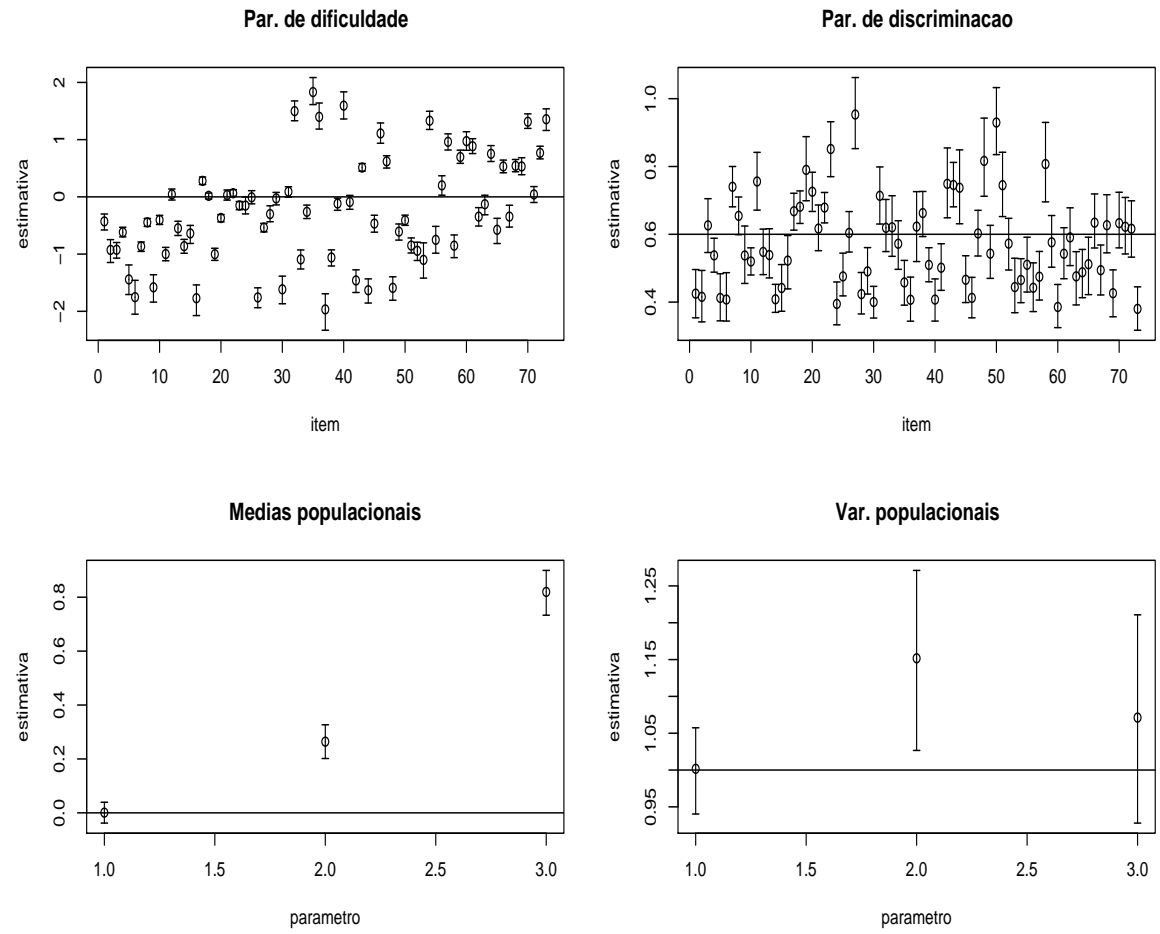

Figura 2.17: Estimativas e IC's simétricos de $95 \%$ para os parâmetros dos itens e populacionais 

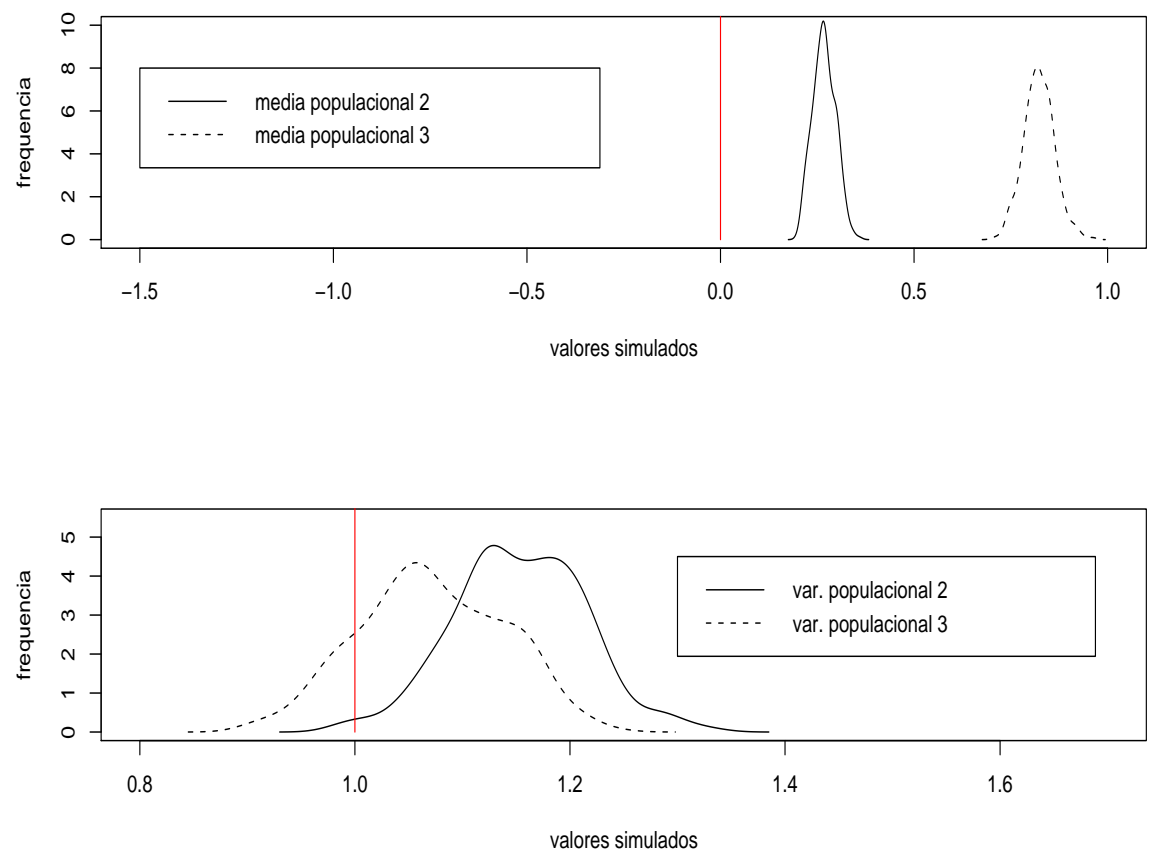

Figura 2.18: Comparação das densidades dos parâmetros populacionais 


\subsection{Comentários}

No presente Capítulo apresentamos uma estrutura de dados aumentados bayesiana para o modelo probito de 2 parâmetros. Propomos um mecanismo de estimação baseado no amostrador de Gibbs que equivale a uma extensão do trabalho de Albert (1992) e, em certo sentido, um caso particular da abordagem de Béguin and Glas (2001). A abordagem proposta suporta dados faltantes gerados através de mecanismos MAR e pode ser estendida para situações mais complexas como o modelo de 3 parâmetros e modelos multiníveis. Conduzimos três estudos de simulação que indicaram uma consistência das estimativas e uma robustez à escolha de prioris, para os parâmetros dos itens e variâncias populacionais. Além disso, a análise de dados reais ilustra o potencial de análise da modelagem/método de estimação propostos. Eventuais afastamentos das suposições usuais como normalidade dos traços latentes ou DIF podem ser facilmente incorporados na modelagem e ajustadas através da abordagem MCMC. Além disso um amplo conjunto de mecanismos de diagnósticos podem ser calculados através de distribuições condicionais completas específicas. Outro aspecto diz respeito à diminuição no número de parâmetros e a inserção de tal restrição no processo de estimação. Tomemos como exemplo os parâmetros dos itens. Se concluíssemos que existem subconjuntos de itens com parâmetros com valores iguais, poderíamos modificar o Passo 3 do Resultados 2.7.1, de modo à incluir tais restrições. Mais concretamente, denotando por $\boldsymbol{A}_{\boldsymbol{\zeta}}$ uma matriz $r \times 2 I$, em que $r$ é o número de restrições de interesse, o Passo 3 em questão se traduziria em :

Simular os parâmetros dos itens restritors $\boldsymbol{\zeta}^{*}=\boldsymbol{A}_{\boldsymbol{\zeta}} \boldsymbol{\zeta}$, através de $\boldsymbol{\zeta}^{*} N_{r}\left(\boldsymbol{A}_{\boldsymbol{\zeta}}\left(\widehat{\boldsymbol{\Psi}}_{\boldsymbol{\zeta}} \widehat{\boldsymbol{\zeta}}\right), \boldsymbol{A}_{\boldsymbol{\zeta}}\left(\widehat{\boldsymbol{\Psi}}_{\boldsymbol{\zeta}}\right) \boldsymbol{A}_{\boldsymbol{\zeta}}^{t}\right)$, em que

$$
\begin{array}{r}
\widehat{\boldsymbol{\zeta}}=\left(\widehat{\boldsymbol{\zeta}}_{1}^{t}, \ldots, \widehat{\boldsymbol{\zeta}}_{I}^{t}\right)^{t} \\
\widehat{\boldsymbol{\Psi}}_{\boldsymbol{\zeta}}=\bigoplus_{i=1}^{I} \widehat{\Psi}_{\zeta_{i}}
\end{array}
$$

O mesmo raciocínio se aplica aos parâmetros populacionais $\boldsymbol{\eta}_{\theta}$. 



\section{Capítulo 3}

\section{Modelo longitudinal: estrutura bayesiana multivariada}

\subsection{Introdução}

Medidas repetidas, veja Singer and Andrade (2000), são caracterizadas quando unidades amostrais são estudadas ao longo de diferentes condições de avaliação. Estas condições podem ser: diferentes tempos, distâncias ou profundidades no solo, por exemplo. Em cada instante podem ser medidas uma ou mais variáveis. O primeiro e segundo casos caracterizam, respectivamente, os estudos univariados e multivariados de medidas respetidas. Quando tais condições não podem ser aleatorizadas entre si, tais experimentos são ditos longitudinais. Mesmo quando tal condição de avaliação é o tempo, estes estudos diferem-se daqueles chamados séries temporais. No primeiro, muitas unidades amostrais são estudadas ao longo de poucos instantes. No segundo, poucas unidades amostrais são acompanhadas durante muitos instantes de tempo.

Dentro desse contexto, pode se ter o interesse em estudar o comportamento de variáveis latentes (conhecimento, predisposição genética, qualidade de vida) tal como nos exemplos citados no Capítulo 1. Em termos de avaliação educacional, uma situação que se encaixa neste perfil, é aquela referente ao conjunto de dados do Capítulo 2. Lembremos que tal conjunto é oriundo de um estudo longitudinal o qual consistiu na avaliação de alunos ao longo de várias séries. Neste exemplo em particular, intenciona-se avaliar os traços latentes ao longo das séries. Por exemplo, poder-se-ía estar interessado em avaliar se houve ganho de conhecimento ao longo do tempo.

Devido a natureza dos estudos longitudinais, no que diz respeito a obtenção de medidas nos mesmos indivíduos, espera-se observar algum tipo de dependência. É sabido, ademais, que ingorar-se tais estruturas pode trazer algum tipo de viés para os resultados. Senão em termos de estimativas pontuais, ao menos em termos de estimativas intervalares (erros-padrão). Isto, por outro lado, pode ser especialmente prejudicial em aspectos como análise de diagnóstico e seleção de modelos. Tais estruturas de dependência podem, condicionado à natureza das variáveis resposta, serem cabalmente traduzidas em termos de estruturas de covariâncias, e, consequentemente de correlação, apropriadas.

Existe uma extensa literatura a respeito de experimentos (dados) longitudinais, a qual inclui modelos apropri- 
ados, métodos de estimação e mecanismos de diagnóstico. Dentre outros, podemos citar Hedeker and Gibbons (2006), Molenberghs and Verbeke, Nobre (2004) e da Rocha (2004). Com relação ao estudo de séries temporais, recomenda-se a leitura de Hamilton (1994). A literatura existente, entretanto, de uma forma geral, concerne a situações em que a estrutura de dependência recai, essencialmente, na variável resposta. Entretanto, no caso da TRI, esperamos observar dependência nos traços latentes dos indivíduos, devido as propriedades de indepedência condicional, ver Andrade et al. (2000) e Tavares (2001). Com relação à modelagem pertinente, algumas idéias têm sido propostas na literatura. Entretanto, muitas questões permanecem em aberto.

Dentro do contexto da TRI, Tavares (2001) introduziu o modelo logístico de 3 parâmetros com estrutura longitudinal para os traços latentes. O autor considerou uma estrutura normal multivariada para modelar a dependência longitudinal. Por simplicidade, utilizaremos o termo MLONG (definido no Capítulo 1) para denominar todas as classes de modelos longitudinais na TRI. Como dito anteriormente, várias questões de interesse surgem a partir de tal estrutura : distribuições de probabilidade (para os traços latente e demais variáveis aleatórias envolvidas), escolha de estruturas de dependência, vide da Rocha (2004), curvas de crescimento, vide Geisser (1980), covariáveis dependentes no tempo, dentre outras. No presente Capítulo introduziremos o modelo probito de 2 parâmetros sob normalidade multivariada para representar as probabilidades de resposta e incluir estruturas de dependência longitudinais para os traços latentes. Ademais, um esquema de dados aumentados e um método de simulação da classe MCMC, mais especificamente uma estrutura do amostrador de Gibbs, veja Geman et al. (1993), serão propostos. Com relação à estrutura dos traços latentes utilizaremos abordagem semelhante a Tiao and Zellner (1964). No entanto, diferentemente deste trabalho, no qual se considera uma matriz de covariâncias não estruturada, escolheremos estruturas mais parcimoniosas, vide Singer and Andrade (2000) e da Rocha (2004). Isto é, procuraremos representar a dependência longitudinal utilizando o menor número de parâmetros possível sem comprometer o ajuste do modelo.

A estrutura geral do presente Capítulo é a seguinte : estudaremos uma única população ao longo de $T$ instantes de avaliação considerando um único grupo. Como na Seção 2.2, o termo "grupo" pode representar tanto uma população quanto uma amostra. Independentemente da situação em questão, tal grupo será selecionado no primeiro instante do estudo. Apesar do processo de seleção ser feito no dito instante, admiteremos ser possível a eliminação ("drop-out") de indivíduos. O caso de possíveis inclusões não será objeto de estudo, embora algum comentário a respeito seja feito mais adiante. Assumiremos uma distribuição $\boldsymbol{d}_{\boldsymbol{\theta}}$ para representar o comportamento dos traços latentes.

Um outro ponto importante é que, a menos que se mencionado o contrário, consideraremos as condições de avaliação como igualmente espaçadas, ou pelo menos, que seja possível redefiní-las como tal.

O presente capítulo está organizado da seguinte forma : A presente seção introduziu o problema a ser estudado. Na Seção 3.2 apresentaremos o modelo estatístico. A Seção 3.3 discute alguns aspectos relacionados à estruturas de covariância. A Seção 3.4 aborda a construção da verossimilhança de dados aumentados. Na Seção 3.5 desenvolveremos o algoritmo de Gibbs para o modelo em estudo. Nas Subseões 3.5.1 e 3.5 .2 apresen-

Azevedo, Caio L. N.

$\mathrm{IME} / \mathrm{USP}$ 
taremos, respectivamente, a extensão da algoritmo do amostrador de Gibbs de modo considerar a eliminação e a inclusão de indivíduos e o agrupamento na simulação de alguns parâmetros populacionais. Na subseção 3.5.3 trataremos da modelagem de DRIFT. Na Seção 3.6 discutiremos alguns aspectos computacionais. Na Seção 3.7 conduziremos alguns estudos de simulação para avaliar o desempenho do método de estimação e do modelo em questão. Na Seção 3.8 apresentaremos uma análise de dados reais e finalmente, na Seção 3.9 . apresentaremos algumas discussões.

As contribuições do presente capítulo são :

1. Desenvolvimento da abordagem de dados aumentados para o modelo probito de 2 parâmetros longitudinal.

2. Desenvolvimento e implementação computacional do amostrador de Gibbs para o modelo do item 1).

3. Extensão do amostrador de Gibbs mencionado no item 2) para considerar o agrupamento na simulação dos parâmetros populacionais e também modelar DRIFT dos itens.

4. Extesão do amostrador de Gibbs mencionado no item 2) para considerar eliminação ou inclusão de indivíduos.

5. Desenvolvimento e implementação computacional de algumas medidas de diagnóstico para avaliar a qualidade do ajuste do modelo descrito no item 1) ajustado através do procedimento descrito no item 2).

6. Estudo de simulação :

(a) Sensibilidade do modelo e do método de estimação à escolha de prioris.

(b) Estudo do comportamento das cadeias de Markov, geradas pelo algoritmo de Gibbs descrito no item 2, no que concerne as autocorrelações, valores iniciais e comportamento das distribuições a posteriori.

(c) Consistência dos estimadores.

7. Aplicação da metodologia a um conjunto de dados longitudinais reais.

\subsection{Modelo estatístico}

De acordo com o processo exposto na seção anterior temos um único grupo de respondentes avaliados em $T$ condições de avaliação distintas. Em cada instante $t$ aplica-se um teste com $I_{t}$ itens selecionados de um conjunto total de $I$ itens. Tais testes partilham de alguma estrutura adequada de itens comuns a fim de permitir o processo de equalização, veja Kolen and Brennan (2004).

Azevedo, Caio L. N.

IME/USP 
Antes de definir o modelo, adotaremos algumas notações : $\theta_{j t}$ é o traço latente do indivíduo $j(j=1, \ldots, n$, na condição de avaliação $t(t=1, \ldots, T), \boldsymbol{\theta}_{j}=\left(\theta_{j 1}, \ldots, \theta_{j T}\right)^{t}$ é o vetor de traços latentes do indivíduo j e $\boldsymbol{\theta}_{. .}=\left(\boldsymbol{\theta}_{1}, \ldots, \boldsymbol{\theta}_{n} .\right)^{t}$ é o vetor de traços latentes de todos os indivíduos; $Y_{i j t}$, é o escore do indivíduo $j$ no item $i$, na condição de avaliação $t, \boldsymbol{Y}_{. j t}=\left(Y_{1 j t}, \ldots, Y_{I j t}\right)^{t}$, é o vetor de escores em todos os itens do indivíduo $j$ na condição de avaliação $t, \boldsymbol{Y}_{. j} .=\left(\boldsymbol{Y}_{1 j t}^{t}, \ldots, \boldsymbol{Y}_{I j t}^{t}\right)^{t}$, é o vetor de todas as respostas do indivíduo $j, \boldsymbol{Y}_{\ldots}=\left(\boldsymbol{Y}_{.1 .}^{t}, \ldots, \boldsymbol{Y}_{. n .}^{t}\right)^{t}$, é o vetor com todas as respostas de todos os indivíduos e $\left(y_{i j t}, \boldsymbol{y}_{. j t}^{t}, \boldsymbol{y}_{. j .}^{t}, \boldsymbol{y}_{\ldots}^{t}\right)^{t}$ os respectivos valores observados; $\boldsymbol{\eta}_{\boldsymbol{\theta}}$ representa os parâmetros da distribuição dos traços latentes enquanto que $\boldsymbol{\zeta}_{i}$ e $\boldsymbol{\zeta}$ são como definidos no Capítulo 2.

O modelo de 2 parâmetros probito longitudinal (M2PPLG) é dado por

Modelo de resposta ao Item (parte funcional)

$$
\begin{gathered}
Y_{i j t} \mid\left(\theta_{j t}, \boldsymbol{\zeta}_{i}\right) \sim B\left(P_{i j t}\right), \\
P_{i j t}=P\left(Y_{i j t}=1 \mid \theta_{j t}, \boldsymbol{\zeta}_{i}\right)=\Phi\left(a_{i} \theta_{j t}-b_{i}\right),
\end{gathered}
$$

Distribuição Latente (parte estrutural)

$$
\boldsymbol{\theta}_{j .} \mid \boldsymbol{\eta}_{\boldsymbol{\theta}} \sim N_{T}\left(\boldsymbol{\mu}_{\boldsymbol{\theta}}, \boldsymbol{\Psi}_{\boldsymbol{\theta}}\right)
$$

em que

$$
\boldsymbol{\mu}_{\boldsymbol{\theta}}=\left[\begin{array}{c}
\mu_{\theta_{1}} \\
\mu_{\theta_{2}} \\
\vdots \\
\mu_{\boldsymbol{\theta}_{T}}
\end{array}\right], \boldsymbol{\Psi}_{\boldsymbol{\theta}}=\left[\begin{array}{cccc}
\psi_{11(\boldsymbol{\theta})} & \psi_{12(\boldsymbol{\theta})} & \ldots & \psi_{1 T(\boldsymbol{\theta})} \\
\psi_{21(\boldsymbol{\theta})} & \psi_{22(\boldsymbol{\theta})} & \ldots & \psi_{2 T(\boldsymbol{\theta})} \\
\vdots & \vdots & \ddots & \vdots \\
\psi_{1 T(\boldsymbol{\theta})} & \psi_{2 T(\boldsymbol{\theta})} & \ldots & \psi_{T T(\boldsymbol{\theta})}
\end{array}\right]
$$

Azevedo, Caio L. N. 
$\boldsymbol{\eta}_{\boldsymbol{\theta}}=\left(\boldsymbol{\mu}_{\boldsymbol{\theta}}^{t}, v\left(\Psi_{\boldsymbol{\theta}}\right)^{t}\right)^{t}, v\left(\Psi_{\boldsymbol{\theta}}\right)=\operatorname{vecd}\left(\Psi_{\boldsymbol{\theta}}\right), \operatorname{vecd}($.$) representa os elementos diferentes de \boldsymbol{\Psi}_{\boldsymbol{\theta}}, \Phi$ é a distribuição acumulada da normal padrão e $N_{T}\left(\boldsymbol{\mu}_{\boldsymbol{\theta}}, \boldsymbol{\Psi}_{\boldsymbol{\theta}}\right)$ representa a distribuição normal multivariada de dimensão $T$, com vetor de médias $\boldsymbol{\mu}_{\boldsymbol{\theta}}$ e matriz de covariâncias $\boldsymbol{\Psi}_{\boldsymbol{\theta}}$. Isto significa que consideramos uma estrutura de dependência para os traços latentes do mesmo indivíduo, embora, entre indivíduos, permaneça a independência. A representação (3.2) pode ser escrita tal como em Tiao and Zellner (1964), ou seja,

$$
\Theta=\mathbf{1}_{n} \otimes \boldsymbol{\mu}_{\boldsymbol{\theta}}^{t}+\boldsymbol{\xi}^{(\Theta)},
$$

em que,

$$
\boldsymbol{\Theta}=\left[\begin{array}{ccc}
\theta_{11} & \ldots & \theta_{1 T} \\
\vdots & \ddots & \vdots \\
\theta_{n 1} & \ldots & \theta_{n 1}
\end{array}\right] \quad \mathbf{1}_{n}=\left[\begin{array}{c}
1 \\
1 \\
\vdots \\
1
\end{array}\right], \boldsymbol{\xi}^{(\boldsymbol{\Theta})}=\left[\begin{array}{ccc}
\xi_{11}^{(\boldsymbol{\Theta})} & \ldots & \xi_{1 T}^{(\boldsymbol{\Theta})} \\
\vdots & \ddots & \vdots \\
\xi_{n 1}^{(\boldsymbol{\Theta})} & \ldots & \xi_{n 1}^{(\boldsymbol{\Theta})}
\end{array}\right]
$$

$\otimes$ representa o produto de Kronecker à direita, veja Magnus and Neudecker (1999), ou seja, cada elemento da primeira matriz é multiplicado por toda a segunda matriz.

Uma representação gráfica do modelo 3.4 é apresentada na Figura 3.1

A especificação apresentada em (3.4) é útil para considerar diferentes matrizes de covariância. Entretanto, para considerar estruturas de regressão para média, desenvolver métodos de estimação e diagnóstico, é mais conveniente considerá-la em sua forma vetorizada, ou seja,

$$
\begin{aligned}
\operatorname{vec}\left(\boldsymbol{\Theta}^{t}\right) & =\left(\mathbf{1}_{n} \otimes 1\right) \operatorname{vec}\left(\boldsymbol{\mu}_{\boldsymbol{\theta}}\right)+\operatorname{vec}\left(\boldsymbol{\xi}^{(\boldsymbol{\Theta})^{t}}\right) \\
\boldsymbol{\theta}_{. .} & =\mathbf{1}_{n} \otimes \boldsymbol{\mu}_{\boldsymbol{\theta}}+\boldsymbol{\xi}_{. .}^{(\boldsymbol{\theta})}
\end{aligned}
$$

em que, $\boldsymbol{\theta}_{. .}=\operatorname{vec}\left(\boldsymbol{\Theta}^{t}\right) \sim N_{n T}\left(\boldsymbol{\mu}_{\boldsymbol{\theta}}^{*}, \boldsymbol{\Psi}_{\theta}^{*}\right), \boldsymbol{\mu}_{\boldsymbol{\theta}}^{*}=\mathbf{1}_{n} \otimes \boldsymbol{\mu}_{\boldsymbol{\theta}}, \boldsymbol{\Psi}_{\boldsymbol{\theta}}^{*}=\boldsymbol{I}_{n} \otimes \boldsymbol{\Psi}_{\theta}, \boldsymbol{\xi}_{. .}^{(\boldsymbol{\theta})}=\operatorname{vec}\left(\boldsymbol{\xi}^{(\boldsymbol{\Theta})^{t}}\right)=\left(\xi_{11}, \ldots, \xi_{n_{T} T}\right)^{t}$ e vec é o operador vec, o qual transforma uma matriz em um vetor, concantenando as colunas da mesma, veja Magnus and Neudecker (1999). 


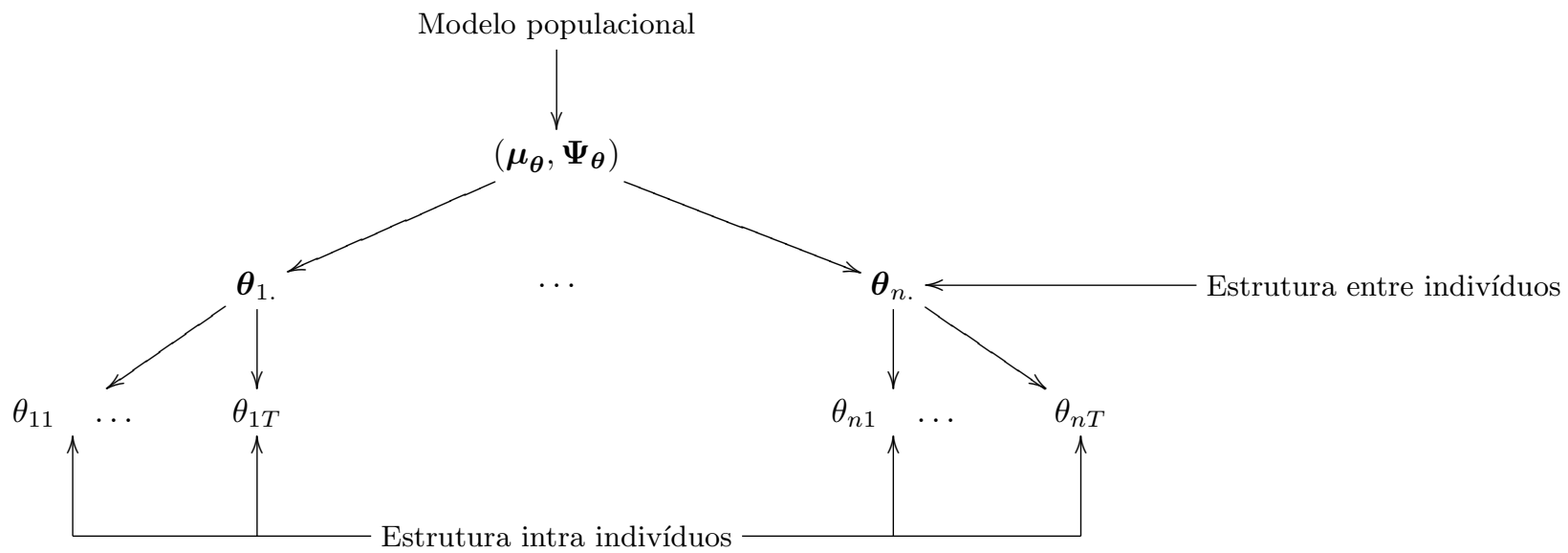

Figura 3.1: Estrutura do modelo longitudinal para os traços latentes

\subsection{Estruturas de dependência}

Uma das etapas mais importantes na análise de dados longitudinais é a escolha de uma estrutura de covariância apropriada. Em outras palavras, aquela que mais satisfatoriamente modela a estrutura de dependência dos dados, veja da Rocha (2004). Existe uma extensa literatura sobre este tópico, não somente no que concerne à diferentes modelos de estruturas de covariância mas também com relação à métodos de seleção apropriados. Sugerimos a leitura de da Rocha (2004) e Hedeker and Gibbons (2006) e as referências contidas neles, para maiores detalhes.

De uma forma em geral, uma matriz de covariâncias apropriada precisa incorporar o planejamento utilizado para coletar os dados bem como o mecanismo gerador das observações, como ressalta da Rocha (2004). De acordo com Diggle et al. (2002), veja também da Rocha (2004), a estrutura de dependência precisa ser flexível o suficiente para incluir três fontes de variação :

- A variação devida aos efeitos aleatórios, quando as unidades amostrais constituem uma amostra aleatória da população.

- A variação que pode ser explicada pela correlação serial, na qual se espera observar correlações de magnitudes maiores para pares de observações mais próximas.

- A variação devida a erros de medida.

Azevedo, Caio L. N.

IME/USP 
Particuralmente no MLONG, os traços latentes são variáveis não observáveis e, dessa forma, a escolha da estrutura de dependência mais apropriada torna-se um tanto mais complicada. Uma abordagem conveniente é a utilização do MGM, (o qual supõe independência) para se explorar, de modo descritivo, candidatas a estruturas de covariância apropriadas (escores). Uma outra forma seria a utilização das respostas observadas. Retornaremos a este ponto nos próximos Capítulos.

Para os desenvolvimentos do presente Capítulo, adotaremos a estrutura conhecida como autoregressiva heterogênea de ordem 1, doravante denotada por $\operatorname{ARH}(1)\left(\psi_{\theta}, \rho_{\theta}\right)$, ou simplesmente ARH(1), veja da Rocha (2004) ou Singer and Andrade (2000). Tal estrutura é dada por

$$
\mathbf{\Psi}_{\boldsymbol{\theta}}=\left[\begin{array}{ccccc}
\psi_{\theta_{1}} & \sqrt{\psi_{\theta_{1}}} \sqrt{\psi_{\theta_{2}}} \rho_{\theta} & \sqrt{\psi_{\theta_{1}}} \sqrt{\psi_{\theta_{3}}} \rho_{\theta}^{2} & \cdots & \sqrt{\psi_{\theta_{1}}} \sqrt{\psi_{\theta_{T}}} \rho_{\theta}^{T-1} \\
\sqrt{\psi_{\theta_{1}}} \sqrt{\psi_{\theta_{2}}} \rho_{\theta} & \psi_{\theta_{2}} & \sqrt{\psi_{\theta_{2}}} \sqrt{\psi_{\theta_{3}}} \rho_{\theta} & \cdots & \sqrt{\psi_{\theta_{2}}} \sqrt{\psi_{\theta_{T}}} \rho_{\theta}^{T-2} \\
\sqrt{\psi_{\theta_{1}}} \sqrt{\psi_{\theta_{3}}} \rho_{\theta}^{2} & \sqrt{\psi_{\theta_{2}}} \sqrt{\psi_{\theta_{3}}} \rho_{\theta} & \psi_{\theta_{3}} & \cdots & \sqrt{\psi_{\theta_{3}}} \sqrt{\psi_{\theta_{T}}} \rho_{\theta}^{T-3} \\
\vdots & \vdots & \vdots & \ddots & \vdots \\
\sqrt{\psi_{\theta_{1}}} \sqrt{\psi_{\theta_{T}}} \rho_{\theta}^{T-1} & \sqrt{\psi_{\theta_{2}}} \sqrt{\psi_{\theta_{T}}} \rho_{\theta}^{T-2} & \sqrt{\psi_{\theta_{3}}} \sqrt{\psi_{\theta_{T}}} \rho_{\theta}^{T-3} & \cdots & \psi_{\theta_{t}}
\end{array}\right],
$$

e a correspondente matriz de correlações por,

$$
\boldsymbol{\Omega}_{\boldsymbol{\theta}}=\left[\begin{array}{ccccc}
1 & \rho_{\theta} & \rho_{\theta}^{2} & \ldots & \rho_{\theta}^{T-1} \\
\rho_{\theta} & 1 & \rho_{\theta}^{2} & \ldots & \rho_{\theta}^{T-2} \\
\rho_{\theta} & \rho_{\theta}^{1} & 1 & \ldots & \rho_{\theta}^{T-3} \\
\vdots & \vdots & \vdots & \ddots & \vdots \\
\rho_{\theta}^{T-1} & \rho_{\theta}^{T-2} & \rho_{\theta}^{T-3} & \ldots & 1
\end{array}\right]
$$

em que $\boldsymbol{\psi}_{\boldsymbol{\theta}}=\left(\psi_{\theta_{1}}, \ldots, \psi_{\theta_{T}}\right)^{t}, \psi_{\theta_{t}} \in(0, \infty)$ e $\rho_{\theta} \in(-1,1)$. Note que as correlações decrescem com o tempo e também é a mesma para pares de pontos equidistantes. Além disso, podemos notar que as variâncias podem diferir ao longo do tempo. Um ponto bastante interessante, em se definir um parâmetro associado a correlação, é o fato de que obtemos uma estimativa direta para tal característica. Isto, por sua vez, permite obter resultados mais acurados do que, por exemplo, estimar a estrutura de dependência baseando-se somente nas correlações amostrais dos traços latentes (utilizando-se o MGM). Um outro aspecto é o fato de que a correlação não depende da métrica adotada, como coloca Matos (2001) pag. 37, isto é, dispomos de uma medida de dependência, sob uma estrutura normal multivariada, a qual não depende da métrica adotada.

Azevedo, Caio L. N.

IME/USP 


\subsection{Verossimilhança de dados aumentados}

As suposições para a construção da verossimilhança são, basicamente, as mesmas estabelecidas na Seção 2.5 . Elas implicam que, apesar de se esperar observar dependência entre os traços latentes dos mesmos indivíduos, as respostas aos itens, condicionada aos traços latentes e aos parâmetros dos itens, são independentes entre os itens e ao longo dos tempos (testes). Esta última suposição foi denominada de independência temporal, por Tavares (2001). Esta suposição é bastante razoável, uma vez que se espera que as informações contidas nas respostas aos testes anteriores se reflitam no comportamento dos traços latentes e não diretamente nas respostas dos testes futuros.

Com efeito, as variáveis aumentadas e indicadoras de respostas são dadas respectivamente por

$$
Z_{i j t} \mid\left(\theta_{j t}, \boldsymbol{\zeta}_{i}, y_{i j t}\right)= \begin{cases}N\left(a_{i} \theta_{j t}-b_{i}, 1\right) \mathbb{1}_{\left(z_{i j t} \geq 0\right)}, & \text { se } Y_{i j t}=1 \\ N\left(a_{i} \theta_{j t}-b_{i}, 1\right) \mathbb{1}_{\left(z_{i j t}<0\right)}, & \text { se } Y_{i j t}=0\end{cases}
$$

e

$$
V_{i j t}= \begin{cases}1, & \text { se para o item } i \text { foi observada resposta do indivíduo } j \text { no tempo } t \\ 0, & \text { caso contrário. }\end{cases}
$$

Salientamos que, a matriz indicadora definida pela equação 3.9 , não contempla a eliminação ou a inclusão de indivíduos. Estes casos serão discutidos na Seção 2.5. Para outros detalhes relacionados a eliminação e inclusão de indivíduos veja Little and Rubin (2002) ou Schafer (1997), por exemplo. De qualquer forma, a estrutura de dados faltantes será considerada como oriunda de um processo MAR e, dessa forma, poderemos desconsiderar o mecanismo gerador de não observância das respostas do processo de inferência, sem comprometer este último.

À semelhança do modelo de grupos múltiplos, a verossimilhança do modelo longitudinal se traduz em

$$
\begin{aligned}
L\left(\boldsymbol{\theta}_{. .}, \boldsymbol{\zeta}, \boldsymbol{\eta}_{\boldsymbol{\theta}}, \boldsymbol{\delta} \mid \boldsymbol{z}_{\ldots}, \boldsymbol{y}_{\ldots}, \boldsymbol{v}_{\ldots}\right) & \propto p\left(\boldsymbol{v}_{\ldots}, \boldsymbol{z}_{\ldots} \mid \boldsymbol{\theta}_{\ldots}, \boldsymbol{\zeta}, \boldsymbol{\eta}_{\boldsymbol{\theta}}, \boldsymbol{\delta}, \boldsymbol{y}_{\ldots}\right) \\
& =p\left(\boldsymbol{v}_{\ldots} \mid \boldsymbol{z}_{\ldots}, \boldsymbol{\theta}_{. .}, \boldsymbol{\zeta}, \boldsymbol{\eta}_{\theta}, \boldsymbol{\delta}, \boldsymbol{y}_{\ldots}\right) p\left(\boldsymbol{z}_{\ldots} \mid \boldsymbol{\theta}_{. .}, \boldsymbol{\zeta}, \boldsymbol{\eta}_{\theta}, \boldsymbol{\delta}, \boldsymbol{y}_{\ldots}\right) \\
& =p\left(\boldsymbol{v}_{\ldots} \mid \boldsymbol{\delta}\right) p\left(\boldsymbol{z}_{\ldots} \mid \boldsymbol{\theta} . ., \boldsymbol{\zeta}, \boldsymbol{y}_{\ldots}\right) \\
& \propto p\left(\boldsymbol{z}_{\ldots} \mid \boldsymbol{\theta}_{. .}, \boldsymbol{\zeta}, \boldsymbol{y}_{\ldots}\right) \\
& \propto \prod_{t=1}^{T} \prod_{j=1}^{n} \prod_{i \in I_{j t}} \exp \left\{-0.5\left(z_{i j t}-a_{i} \theta_{j t}+b_{i}\right)^{2}\right\} \mathbb{1}_{\left(z_{i j t}, y_{i j t}\right)},
\end{aligned}
$$

Azevedo, Caio L. N.

IME/USP 
em que $I_{j t}$ é o conjunto de itens respondidos pelo indivíduo $j$ no tempo $t$. Tal como para o MGM, a equação (3.10) vem do fato de que $\boldsymbol{\eta}_{\boldsymbol{\theta}}$ depende somente da distribuição $\boldsymbol{\theta} .$. . Além disso, 3.11 segue do fato de que $\boldsymbol{V} \ldots$ segue um processo MAR.

Em termos de dados aumentados, a estrutura considerada de (3.1) a (3.3), pode ser representada através do seguinte modelo multinível

$$
\begin{aligned}
\boldsymbol{Z}_{i j .} \mid \boldsymbol{y}_{i j .} & =\boldsymbol{D}_{a_{i}} \boldsymbol{\theta}_{j .}-b_{i} \mathbf{1}_{T}+\boldsymbol{\xi}_{i j .}^{(Z)} \\
\boldsymbol{\theta}_{j .} & =\boldsymbol{\mu}_{\boldsymbol{\theta}}+\boldsymbol{\xi}_{j .}^{(\theta)}
\end{aligned}
$$

em que $\boldsymbol{\xi}_{i j .}^{(Z)} \sim N_{T}\left(\mathbf{0}, \boldsymbol{I}_{T}\right)$ são mutuamente independentes de $\boldsymbol{\xi}_{j .}^{(\theta)} \sim N_{T}\left(\mathbf{0}, \boldsymbol{\Psi}_{\boldsymbol{\theta}}\right)$ e $\boldsymbol{D}_{a_{i}}=a_{i} \boldsymbol{I}_{T}$. À semelhança do Capítulo 2, os desenvolvimentos apresentados neste Capítulo aplicam-se à MRI contínuos bem como a modelos de regressão multivariados com resposta normal truncada.

Um diagrama de influência do modelo é apresentado na Figura 3.2. As linhas tracejadas representam o fato de que $Y \mid Z \perp(\theta, \boldsymbol{\zeta})$, ou seja, as respostas são estatisticamente independentes dos traços latentes e dos parâmetros dos itens, condicionadas as variáveis aumentadas. Com efeito, basta conhecermos o sinal da variável aumentada para determinar a resposta do indivíduo ao item.

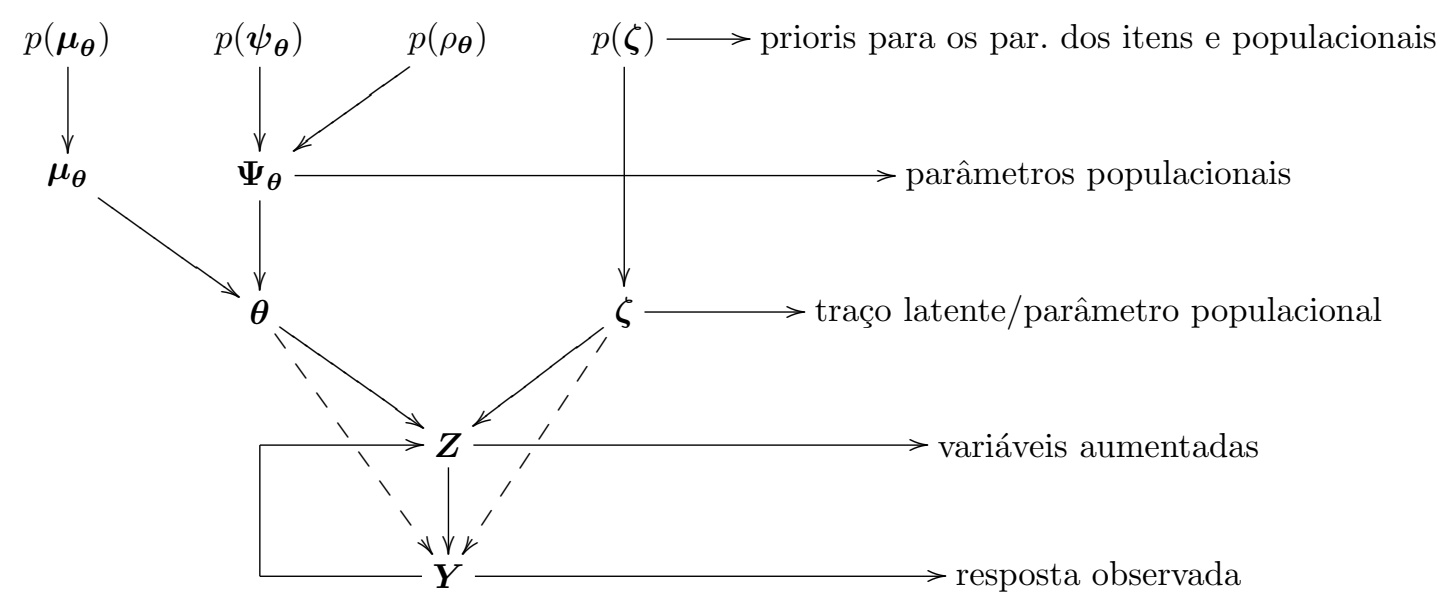

Figura 3.2: Diagrama de influência do modelo longitudinal bayesiano

Azevedo, Caio L. N.

$\mathrm{IME} / \mathrm{USP}$ 


\subsection{Estimação MCMC}

Existem muitos trabalhos na literatura a respeito de métodos de estimação via MCMC em modelos probito longitudinais e multivariados. Chib and Greenberg (1998) estudaram métodos de estimação para modelos probito multivariados com respostas binárias desenvolvendo um algoritmo MCMC com saltos de MetropolisHastings. Chib and Carlin (1999) desenvolveram diferentes algoritmos de MCMC para ajustar modelos de resposta binária longitudinais (pertencentes à classe de modelos lineares generalizados mistos). Tais algoritmos diferem entre si em complexidade de implementação e velocidade de convergência. Imai and van Dyk (2005) desenvolveram um esquema de MCMC que apresenta razoável velocidade de convergência. McCulloh et al. (2000) propôs uma esquema de amostrador de Gibbs conveniente na presença de matrizes de covariância com restrições de identificabilidade.

O esquema de simulação MCMC para o modelo longitudinal usará parte da estrutura daquele desenvolvido para o MGM, veja Resultado 2.7.1. Com efeito, em termos paramétricos, a principal diferença reside na adição de parâmetros de correlação. No caso da Matriz $\operatorname{ARH}(1)$, estes se resumem ao parâmetro $\rho_{\theta}$. Entretanto, notemos que estamos na presença de distribuições multivariadas e matrizes de parâmetros. Com efeito, os parâmetros populacionais se traduzem pelo vetor de médias e a matriz de covariâncias. Sendo assim, métodos apropriados se fazem necessários para contemplar tal estrutura.

Adotando-se o usual expediente de identificabildiade para modelos longitudinais na TRI, vide Tavares (2001), ou seja, fixar $\mu_{\theta_{1}}=0$ e $\psi_{\theta_{1}}=1$, teríamos uma matriz de covariâncias com o elemento da primeira linha e coluna igual à 1. Na verdade, isto também ocorre caso e padronize os traços latentes do primeiro tempo, procedimento que utilizamos no presente trabalho. Isto torna complicado a atribuição de prioris (que levem em consideração tal restrição) e, conseqüentemente, a obtenção da respectiva posteriori, veja McCulloh et al. (2000). Além disso, em se considerando diretamente os parâmetros $\left(\psi_{\boldsymbol{\theta}}, \rho_{\theta}\right)$, a obtenção de condicionais completas, com forma análitica conhecida, tornar-se-ía impossível. Um terceiro aspecto é o fato de que em algumas matrizes, frequentemente consideradas em estudos longitudinais, as covariâncias são funcionalmente dependentes. Isto é, dependem de parâmetros comuns. Dessa forma utilizaremos uma adaptação da abordagem proposta McCulloh et al. (2000). Tal abordagem consiste em uma decomposição da matriz de covariâncias original baseada em propriedades da distribuição normal multivariada. Ela resolve o problema da atribuição de prioris com restrições

de identificabilidade e, em nosso caso, levará a distribuições condicionais completas com forma conhecida. Para explicar tal adaptação definamos as seguintes partições para a estrutura dos traços latentes

$$
\begin{aligned}
& \boldsymbol{\theta}_{j .}=\left(\theta_{j 1}, \theta_{j 2}, \ldots, \theta_{j T}\right)^{t}=\left(\theta_{j 1}, \boldsymbol{\theta}_{j .}^{(T-1)}\right),^{t} \\
& \boldsymbol{\mu}_{\boldsymbol{\theta}}=\left(\mu_{\theta_{1}}, \mu_{\theta_{2}}, \ldots, \mu_{\theta_{T}}\right)^{t}=\left(\mu_{\theta_{1}}, \boldsymbol{\mu}_{\boldsymbol{\theta}}^{(T-1)}\right),^{t}
\end{aligned}
$$

Azevedo, Caio L. N.

IME/USP 


$$
\boldsymbol{\Psi}_{\boldsymbol{\theta}}=\left[\begin{array}{cc}
\psi_{\theta_{1}} & \boldsymbol{\psi}_{\boldsymbol{\theta}}^{t(T-1)} \\
\boldsymbol{\psi}_{\boldsymbol{\theta}}^{(T-1)} & \boldsymbol{\Psi}_{\boldsymbol{\theta}}^{(T-1)}
\end{array}\right]
$$

em que $\boldsymbol{\theta}_{j .}^{(T-1)}=\left(\theta_{j 2}, \ldots, \theta_{j T}\right)^{t}, \boldsymbol{\mu}_{\boldsymbol{\theta}}^{(T-1)}=\left(\mu_{\theta_{2}}, \ldots, \mu_{\theta_{T}}\right)^{t}, \boldsymbol{\psi}_{\boldsymbol{\theta}}^{(T-1)}=\left(\psi_{12(\boldsymbol{\theta})}, \ldots, \psi_{1 T(\boldsymbol{\theta})}\right)^{t}$

e

$$
\mathbf{\Psi}_{\boldsymbol{\theta}}^{(T-1)}=\left[\begin{array}{ccc}
\psi_{22(\boldsymbol{\theta})} & \ldots & \psi_{2 T(\boldsymbol{\theta})} \\
\vdots & \ddots & \vdots \\
\psi_{2 T(\boldsymbol{\theta})} & \ldots & \psi_{T T(\boldsymbol{\theta})}
\end{array}\right]
$$

Por outro lado, utilizando algumas propriedades da distribuição normal multivariada, veja Rencher (2002) por exemplo, temos que

$$
\boldsymbol{\theta}_{j .}^{(T-1)} \mid \theta_{j 1} \sim N_{(T-1)}\left(\boldsymbol{\mu}_{\boldsymbol{\theta}(T-1)}, \boldsymbol{\Psi}_{\boldsymbol{\theta}(T-1)}\right)
$$

em que $\boldsymbol{\mu}_{\boldsymbol{\theta}(T-1)}=\boldsymbol{\mu}_{\boldsymbol{\theta}}^{(T-1)}+\psi_{\theta_{1}}^{-1} \boldsymbol{\psi}_{\boldsymbol{\theta}}^{(T-1)}\left(\theta_{j 1}-\mu_{\theta_{1}}\right)$ e $\boldsymbol{\Psi}_{\boldsymbol{\theta}(T-1)}=\boldsymbol{\Psi}_{\boldsymbol{\theta}}^{(T-1)}-\psi_{\theta_{1}}^{-1} \boldsymbol{\psi}_{\boldsymbol{\theta}}^{(T-1)} \boldsymbol{\psi}_{\boldsymbol{\theta}}^{t(T-1)}$. Isto é equivalente à,

$$
\boldsymbol{\theta}_{j .}^{(T-1)} \mid \theta_{j 1}=\boldsymbol{\mu}_{\boldsymbol{\theta}}^{(T-1)}+\psi_{\theta_{1}}^{-1} \boldsymbol{\psi}_{\boldsymbol{\theta}}^{(T-1)}\left(\theta_{j 1}-\mu_{\theta_{1}}\right)+\boldsymbol{\xi}_{j .}^{(\boldsymbol{\theta})(T-1)},
$$

em que $\boldsymbol{\xi}_{j}^{\boldsymbol{\theta}(T-1)} \sim N_{(T-1)}\left(\mathbf{0}_{(T-1)}, \boldsymbol{\Psi}_{\boldsymbol{\theta}(T-1)}\right)$. Em outras palavras, condicionalmente em $\theta_{j 1}$, para cada $\boldsymbol{\theta}_{j}^{(T-1)}$, (3.18) define um modelo de regressão linear multivariado com variável explicativa $\left(\theta_{j 1}-\mu_{\theta_{1}}\right)$, intercepto $\boldsymbol{\mu}_{\boldsymbol{\theta}}^{(T-1)}$ e coeficiente angular $\boldsymbol{\psi}_{\boldsymbol{\theta}}^{(T-1)}$. Então, o vetor $\boldsymbol{\psi}_{\boldsymbol{\theta}}^{(T-1)}$ é o coeficiente de um modelo de regressão linear multivariada o que torna a obtenção de sua respectiva distribuição condicional completa mais simples. Além disso, a matriz $\boldsymbol{\Psi}_{\boldsymbol{\theta}(T-1)}$ apresenta uma forma próxima a de uma matriz não-estruturada, sem restrições de identificabilidade, veja da Rocha (2004). Ou seja, podemos utilizar abordagens padrão para estimar seus elementos, veja Gelman et al. (2004).

Contudo, para efeito de estimação, é preferível eliminar a variância populacional do primeiro instante do vetor $\boldsymbol{\psi}_{\boldsymbol{\theta}}^{(T-1)}$, ou seja, 


$$
\boldsymbol{\theta}_{j .}^{(T-1)} \mid \theta_{j 1}=\boldsymbol{\mu}_{\boldsymbol{\theta}}^{(T-1)}+\psi_{\theta_{1}}^{-1 / 2} \boldsymbol{\psi}_{\boldsymbol{\theta}(T-1)}\left(\theta_{j 1}-\mu_{\theta_{1}}\right)+\boldsymbol{\xi}_{j}^{(\boldsymbol{\theta})(T-1)},
$$

em que

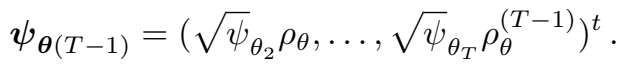

Dessa forma, os parâmetros

$$
\left(\boldsymbol{\psi}_{\boldsymbol{\theta}(T-1)}^{t}, \boldsymbol{\Psi}_{\boldsymbol{\theta}(T-1)}^{t}\right)^{t}
$$

definem uma transformação um a um da matriz de covariâncias $\boldsymbol{\Psi}_{\boldsymbol{\theta}}$. Assim, a estimação dos parâmetros populacionais $\left(\boldsymbol{\psi}_{\boldsymbol{\theta}}, \rho_{\theta}\right)$ será conduzida através da estimação dos parâmetros (3.21). Estes são, por sua vez, parâmetros de um modelo de regressão multivariada bayesiana, sem restrições na matriz de covariâncias, veja Tiao and Zellner (1964), para os quais abordagens padrão podem ser utilizadas.

O passo seguinte consiste na escolha de prioris adequadas. Posto o modelo (3.19), a escolha de prioris que levem a famílias de conjugação condicional, veja Gelman (2006), torna-se direta. De acordo com este modelo, os parâmetros de interesse passam a ser $\left(\boldsymbol{\mu}_{\boldsymbol{\theta}}^{t}, \psi_{\theta_{1}}, \boldsymbol{\psi}_{\boldsymbol{\theta}(T-1)}^{t}, \boldsymbol{\Psi}_{\boldsymbol{\theta}(T-1)}^{t}\right)^{t}$. Dessa forma, tais prioris se traduzem em

$$
\begin{aligned}
\boldsymbol{\mu}_{\boldsymbol{\theta}} & \sim N_{T}\left(\boldsymbol{\mu}_{0}, \boldsymbol{\Psi}_{0}\right), \\
\psi_{\theta_{1}} & \sim I G\left(\nu_{0}, \kappa_{0}\right), \\
\boldsymbol{\psi}_{\boldsymbol{\theta}(T-1)} & \sim N_{T-1}\left(\boldsymbol{\mu}_{\boldsymbol{\psi}}, \boldsymbol{\Psi}_{\boldsymbol{\psi}}\right), \\
\boldsymbol{\Psi}_{\boldsymbol{\theta}(T-1)} & \sim I W_{T-1}\left(\nu \boldsymbol{\Psi}, \boldsymbol{\Psi}_{\boldsymbol{\Psi}}\right),
\end{aligned}
$$

em que $I W_{T-1}\left(\nu_{\Psi}, \mathbf{\Psi}_{\mathbf{\Psi}}\right)$ representa uma distribuição inversa-Wishart de dimensão T-1, com graus de liberdade $\nu_{\Psi}$ e matriz de dispersão $\Psi_{\Psi}$, veja Gelman et al. (2004).

De modo semelhante, para introduzir convenientemente a restrição $\mu_{\theta_{1}}=0$, é útil utilizar a distribuição 3.17, para simular o vetor $\boldsymbol{\mu}_{\boldsymbol{\theta}}^{(T-1)}$. Além disso, a decomposição:

Azevedo, Caio L. N.

IME/USP 


$$
p(\boldsymbol{\theta} \mid \boldsymbol{\eta})=p\left(\boldsymbol{\theta}_{j .}^{(T-1)} \mid \boldsymbol{\eta}_{\boldsymbol{\theta}}\right) p\left(\theta_{j 1} \mid \boldsymbol{\eta}_{\theta_{1}}\right)
$$

é apropriada para simular o vetor $\left(\mu_{\theta_{1}}, \psi_{\theta_{1}}\right)$.

Dessa forma, considerando a verossimilhança (3.12), as prioris (3.2), 2.15), 3.22, (3.23, (3.24) e (3.25), temos que a distribuição a posteriori é dada por :

$$
\begin{aligned}
& p\left(\boldsymbol{z}_{\ldots}, \boldsymbol{\theta}_{. .}, \boldsymbol{\zeta}, \boldsymbol{\mu}_{\boldsymbol{\theta}}, \boldsymbol{\psi}_{\boldsymbol{\theta}(T-1)}, \boldsymbol{\Psi}_{\boldsymbol{\theta}(T-1)}\right) \propto\left\{\prod_{t=1}^{T} \prod_{j=1}^{n} \prod_{i \in I_{j t}} \exp \left\{-0.5\left(z_{i j t}-a_{i} \theta_{j t}+b_{i}\right)^{2}\right\} \mathbb{1}_{\left(z_{i j t}, y_{i j t}\right)}\right\} \\
& \times\left\{\prod_{j=1}^{n} \exp \left\{-0.5\left(\boldsymbol{\theta}_{j .}^{(T-1)}-\boldsymbol{\mu}_{\theta(T-1)}\right)^{t} \boldsymbol{\Psi}_{\boldsymbol{\theta}(T-1)}^{-1}\left(\boldsymbol{\theta}_{j .}^{(T-1)}-\boldsymbol{\mu}_{\theta(T-1)}\right)\right\}\right\} \\
& \times\left\{\left|\boldsymbol{\Psi}_{\boldsymbol{\theta}(T-1)}\right|^{-n / 2}\right\} \\
& \times\left\{\prod_{j=1}^{n} \exp \left\{-\frac{1}{2 \psi_{\theta_{1}}}\left(\theta_{j 1}-\mu_{\theta_{1}}\right)^{2}\right\}\right\}\left\{\psi_{\theta_{1}}^{-n / 2}\right\} \\
& \times \exp \left\{-0.5\left(\boldsymbol{\mu}_{\boldsymbol{\theta}(T-1)}-\boldsymbol{\mu}_{0}\right)^{t} \boldsymbol{\Psi}_{0}^{-1}\left(\boldsymbol{\mu}_{\boldsymbol{\theta}(T-1)}-\boldsymbol{\mu}_{0}\right)\right\} \\
& \times \quad \exp \left\{-\frac{1}{2 \psi_{0}}\left(\mu_{\theta_{1}}-\mu_{0}\right)^{2}\right\} \\
& \times\left|\Psi_{\boldsymbol{\theta}(T-1)}\right|^{-(n+\nu \Psi+T) / 2} \exp \left\{-\operatorname{tr}\left(\boldsymbol{\Psi}_{\boldsymbol{\Psi}} \boldsymbol{\Psi}_{\boldsymbol{\theta}(T-1)}^{-1}\right) / 2\right\} \\
& \times \exp \left\{-0.5\left(\boldsymbol{\psi}_{\boldsymbol{\theta}(T-1)}-\boldsymbol{\mu}_{\boldsymbol{\psi}}\right)^{t} \boldsymbol{\Psi}_{\boldsymbol{\psi}}\left(\boldsymbol{\psi}_{\boldsymbol{\theta}(T-1)}-\boldsymbol{\mu}_{\boldsymbol{\psi}}\right)\right\} \\
& \times \psi_{\theta_{1}}^{-\left(\nu_{0} / 2+1\right)} \exp \left\{-\frac{\kappa_{0}}{2 \psi_{\theta_{1}}}\right\} \\
& \times \prod_{i=1}^{I} \exp \left\{-0.5\left(\boldsymbol{\zeta}_{i}-\boldsymbol{\mu}_{\boldsymbol{\zeta}}\right)^{t} \boldsymbol{\Psi}_{\boldsymbol{\zeta}}^{-1}\left(\boldsymbol{\zeta}_{i}-\boldsymbol{\mu}_{\boldsymbol{\zeta}}\right)\right\} \mathbb{1}_{\left(a_{i}>0\right)}
\end{aligned}
$$

Note que, no desenvolvimento da abordagem acima, nenhuma forma específica para a matriz $\boldsymbol{\Psi}_{\boldsymbol{\theta}}$ foi estipulada. A única restrição é a de que $\psi_{\theta_{1}}=1 \mathrm{ou}$, de modo equivalente, de que devemos optar pelo reescalonamento dos traços latentes no tempo 1, em cada iteração MCMC. Então podemos estabelecer o seguinte resultado: 
Resultado 3.5.1. Considerando a posteriori dada em (3.26) e denotando por (.) o conjunto de todos os outros parâmetros, os passos para amostragem de Gibbs para o MLONG são dados por:

- Passo 1 : Simular os dados aumentados através do Passo 1 do Resultado 2.7.1.

- Passo 2 : Simular os traços latentes, de forma independente entre os indivíduos, através de,

$$
\boldsymbol{\theta}_{j} \mid(.) \sim N_{T}\left(\widehat{\boldsymbol{\Psi}}_{\boldsymbol{\theta}_{j}} \widehat{\boldsymbol{\theta}}_{j}, \widehat{\boldsymbol{\Psi}}_{\boldsymbol{\theta}_{j}}\right)
$$

em que

$$
\begin{aligned}
\widehat{\boldsymbol{\theta}}_{j} & =\sum_{i \in I_{j t}} a_{i} b_{i} \mathbf{1}_{T}+\sum_{i \in I_{j t}} a_{i} \boldsymbol{z}_{i j .}+\boldsymbol{\Psi}_{\boldsymbol{\theta}}^{-1} \boldsymbol{\mu}_{\boldsymbol{\theta}}, \\
\widehat{\boldsymbol{\Psi}}_{\boldsymbol{\theta}_{j}} & =\left(\sum_{i \in I_{j t}} a_{i}^{2} \boldsymbol{I}_{T}+\boldsymbol{\Psi}_{\boldsymbol{\theta}}^{-1}\right)^{-1},
\end{aligned}
$$

e $\boldsymbol{z}_{i j .}=\left(z_{i j 1}, \ldots, z_{i j T}\right)^{t}$.

- Passo 3 : Simular os parâmetros dos itens através de $\boldsymbol{\zeta}_{i} \mid($.$) utilizando o Passo 3$ do Resultado 2.7.1.

- Passo 4 : Simular as médias populacionais através de

$$
\begin{aligned}
\mu_{\theta_{1}} \mid(.) & \sim N\left(\widetilde{\mu}_{\theta_{1}}, \widehat{\psi}_{\mu}\right), \\
\boldsymbol{\mu}_{\boldsymbol{\theta}}^{(T-1)} \mid\left(\mu_{\theta_{1}},(.)\right) & \sim N_{T}\left(\widetilde{\boldsymbol{\mu}}_{\boldsymbol{\theta}(T-1)}, \widehat{\Psi}_{\boldsymbol{\mu}_{(T-1)}}\right),
\end{aligned}
$$

em que 


$$
\begin{aligned}
\widehat{\boldsymbol{\mu}}_{\boldsymbol{\theta}} & =\boldsymbol{\Psi}_{\boldsymbol{\theta}}^{-1} \sum_{j=1}^{n} \boldsymbol{\theta}_{j .}+\boldsymbol{\Psi}_{0}^{-1} \boldsymbol{\mu}_{\boldsymbol{\theta}}=\left(\widehat{\mu}_{\theta_{1}}, \widehat{\mu}_{\theta_{2}}, \ldots, \widehat{\mu}_{\theta_{T}}\right)^{t}=\left(\widehat{\mu}_{\theta_{1}}, \widehat{\boldsymbol{\mu}}_{\boldsymbol{\theta}}^{(T-1)}\right)^{t}, \\
\widehat{\boldsymbol{\Psi}}_{\boldsymbol{\mu}} & =\left(n \boldsymbol{\Psi}_{\boldsymbol{\theta}}^{-1}+\boldsymbol{\Psi}_{\boldsymbol{\mu}}^{-1}\right)^{-1}=\left[\begin{array}{cc}
\widehat{\psi}_{\mu} & \widehat{\boldsymbol{\psi}}_{\boldsymbol{\mu}}^{t(T-1)} \\
\widehat{\boldsymbol{\psi}}_{\boldsymbol{\mu}}^{(T-1)} & \widehat{\boldsymbol{\Psi}}_{\boldsymbol{\mu}}^{(T-1)}
\end{array}\right], \\
\widetilde{\boldsymbol{\mu}}_{\boldsymbol{\theta}} & =\widehat{\boldsymbol{\Psi}}_{\boldsymbol{\mu}} \widehat{\boldsymbol{\mu}}_{\boldsymbol{\theta}}=\left(\widetilde{\mu}_{\theta_{1}}, \widetilde{\mu}_{\theta_{2}}, \ldots, \widetilde{\mu}_{\theta_{T}}\right)^{t}=\left(\widetilde{\mu}_{\theta_{1}}, \widetilde{\boldsymbol{\mu}}_{\boldsymbol{\theta}}^{(T-1)}\right)^{t}, \\
\widetilde{\boldsymbol{\mu}}_{\boldsymbol{\theta}(T-1)} & =\widetilde{\boldsymbol{\mu}}_{\boldsymbol{\theta}}^{(T-1)}+\widehat{\psi}_{\mu}^{-1} \widehat{\boldsymbol{\psi}}_{\boldsymbol{\mu}}^{(T-1)}\left(\mu_{\theta_{1}}-\widetilde{\mu}_{\theta_{1}}\right), \\
\widehat{\boldsymbol{\Psi}}_{\boldsymbol{\mu}(T-1)} & =\widehat{\boldsymbol{\Psi}}_{\boldsymbol{\mu}}^{(T-1)}-\widehat{\psi}_{\mu}^{-1} \widehat{\boldsymbol{\psi}}_{\boldsymbol{\mu}}^{(T-1)} \widehat{\boldsymbol{\psi}}_{\boldsymbol{\mu}}^{t(T-1)} .
\end{aligned}
$$

- Passo 5 : Simular a variância populacional do primeiro instante através de $\psi_{\theta_{1}} \mid(.) \sim I G\left(\widehat{v}_{0}, \widehat{\kappa}_{0}\right)$, em que

$$
\begin{aligned}
\widehat{v}_{1} & =\frac{n+v_{0}}{2}, \\
\widehat{\kappa}_{1} & =\frac{\sum_{j=1}^{n}\left(\theta_{j 1}-\mu_{\theta_{1}}\right)^{2}+\kappa_{0}}{2} .
\end{aligned}
$$

- Passo 6 : Simular o vetor de covariâncias através de $\boldsymbol{\psi}_{\boldsymbol{\theta}(T-1)} \sim N_{T-1}\left(\widehat{\boldsymbol{\Psi}}_{\psi} \widehat{\boldsymbol{\psi}}_{\boldsymbol{\psi}}, \widehat{\boldsymbol{\Psi}}_{\boldsymbol{\psi}}\right)$, em que

$$
\begin{aligned}
\widehat{\boldsymbol{\psi}}_{\boldsymbol{\psi}} & =\psi_{\theta_{1}}^{-1 / 2} \boldsymbol{\Psi}_{\boldsymbol{\theta}(T-1)}^{-1} \sum_{j=1}^{n}\left(\boldsymbol{\theta}_{j .}^{(T-1)}-\boldsymbol{\mu}_{\boldsymbol{\theta}}^{(T-1)}\right)\left(\theta_{j 1}-\mu_{\theta_{1}}\right)+\boldsymbol{\Psi}_{\boldsymbol{\psi}}^{-1} \boldsymbol{\mu}_{\boldsymbol{\psi}} \\
\widehat{\boldsymbol{\Psi}}_{\boldsymbol{\psi}} & =\left(\psi_{\theta_{1}}^{-1} \boldsymbol{\Psi}_{\boldsymbol{\theta}(T-1)}^{-1} \sum_{j=1}^{n}\left(\theta_{j 1}-\mu_{\theta_{1}}\right)^{2}+\boldsymbol{\Psi}_{\boldsymbol{\psi}}^{-1}\right)^{-1}
\end{aligned}
$$

- Passo 7 : Simular a sub-matriz de covariâncias através de $\boldsymbol{\Psi}_{\boldsymbol{\theta}(T-1)} \sim I W_{T-1}\left(\widehat{\nu}_{\boldsymbol{\Psi}}, \widehat{\boldsymbol{\Psi}}_{\boldsymbol{\Psi}}\right)$, em que

$$
\begin{aligned}
\widehat{\nu}_{\boldsymbol{\Psi}} & =n+\nu_{\boldsymbol{\Psi}} \\
\widehat{\boldsymbol{\Psi}}_{\boldsymbol{\Psi}} & =\boldsymbol{\Psi}_{\boldsymbol{\Psi}}+\sum_{j=1}^{n}\left(\boldsymbol{\theta}_{j .}^{(T-1)}-\boldsymbol{\mu}_{\boldsymbol{\theta}(T-1)}\right)\left(\boldsymbol{\theta}_{j .}^{(T-1)}-\boldsymbol{\mu}_{\boldsymbol{\theta}(T-1)}\right)^{t} .
\end{aligned}
$$

- Passo 8 : Calcular a matriz de covariâncias original através de 3.15 e $\boldsymbol{\Psi}_{\boldsymbol{\theta}}^{(T-1)}=\boldsymbol{\Psi}_{\boldsymbol{\theta}(T-1)}+\boldsymbol{\psi}_{\boldsymbol{\theta}(T-1)} \boldsymbol{\psi}_{\boldsymbol{\theta}(T-1)}^{t}$.

- Passo 9 : Calcular as variâncias populacionais através de 


$$
\left(\psi_{\theta_{2}}, \ldots, \psi_{\theta_{T}}\right)^{t}=\boldsymbol{\psi}_{\boldsymbol{\theta}(T-1)}^{*}=\operatorname{Diag}\left(\boldsymbol{\Psi}_{\boldsymbol{\theta}(T-1)}+\boldsymbol{\psi}_{\boldsymbol{\theta}(T-1)} \boldsymbol{\psi}_{\boldsymbol{\theta}(T-1)}^{t}\right)
$$

em que Diag é o operador que extrai a diagonal principal de uma matriz quadradra.

- Passo 10 : Calcular a correlação populacional através de

$$
\rho_{\theta}=\frac{1}{T-1} \mathbf{1}_{T-1}^{t}\left(\boldsymbol{\psi}_{\boldsymbol{\theta}(T-1)} \bullet\left(\boldsymbol{\psi}_{\boldsymbol{\theta}(T-1)}^{*}\right)^{-1 / 2}\right)^{1 / t}
$$

em que $\boldsymbol{\psi}_{\boldsymbol{\theta}(T-1)}^{*}$ é dado em 3.27$)$.

\section{Demonstração do Resultado 3.5.1:}

A prova dos Passos 1 e 3, do Resultado 3.5.1. são dadas no Resultado 2.7.1. Com relação ao Passo 2, observemos que

$$
\begin{aligned}
p\left(\boldsymbol{\theta}_{j .} \mid(.)\right) \propto & \left\{\prod_{i=1}^{I} p\left(\boldsymbol{z}_{i j .} \mid \boldsymbol{\theta}_{j .}, \boldsymbol{\zeta}_{i}, \boldsymbol{y}_{i j .}, \boldsymbol{v}_{i j .}\right)\right\} p\left(\boldsymbol{\theta}_{j .} \mid \boldsymbol{\eta}_{\boldsymbol{\theta}}\right) \\
\propto & \exp \left\{-0.5 \sum_{i \in I_{j t}}\left(\boldsymbol{z}_{i j .}-a_{i} \boldsymbol{\theta}_{j .}+\mathbf{1}_{T} b_{i}\right)^{t} \boldsymbol{I}_{T}\right. \\
& \left.\left(\boldsymbol{z}_{i j .}-a_{i} \boldsymbol{\theta}_{j .}+\mathbf{1}_{T} b_{i}\right)\right\} \exp \left\{-0.5\left(\boldsymbol{\theta}_{j .}-\boldsymbol{\mu}_{\boldsymbol{\theta}}\right) \mathbf{\Psi}_{\boldsymbol{\theta}}^{-1}\left(\boldsymbol{\theta}_{j .}-\boldsymbol{\mu}_{\boldsymbol{\theta}}\right)\right\} .
\end{aligned}
$$

Analisando 3.29 notamos de que se trata de um modelo de regressão multivariado com vetor de respostas $\boldsymbol{Z}_{i j .}+\mathbf{1}_{T} b_{i}$ e variáveis explicativas $a_{i}$ e $\boldsymbol{\theta}_{j}$. no papel de coeficiente de regressão. Combinado com uma distribuição priori normal multivariada para $\boldsymbol{\theta}_{j}$, o resultado segue, pela conjugação do modelo normal.

Para o vetor de média, Passo 4, o desenvolvimento é similar ao dos traços latentes, observando que 


$$
\begin{aligned}
p\left(\boldsymbol{\mu}_{\boldsymbol{\theta}} \mid(.)\right) & \propto p\left(\boldsymbol{\theta} . . \mid \boldsymbol{\eta}_{\boldsymbol{\theta}}\right) p\left(\boldsymbol{\mu}_{\boldsymbol{\theta}}\right) \\
& \propto \exp \left\{-0.5 \sum_{j=1}^{n}\left(\boldsymbol{\theta}_{j .}-\boldsymbol{\mu}_{\boldsymbol{\theta}}\right) \Psi_{\boldsymbol{\theta}}^{-1}\left(\boldsymbol{\theta}_{j .}-\boldsymbol{\mu}_{\boldsymbol{\theta}}\right)\right\} \\
& \times \exp \left\{\left(\boldsymbol{\mu}_{\boldsymbol{\theta}}-\boldsymbol{\mu}_{0}\right) \boldsymbol{\Psi}_{0}^{-1}\left(\boldsymbol{\mu}_{\boldsymbol{\theta}}-\boldsymbol{\mu}_{0}\right)\right\}
\end{aligned}
$$

Utilizando novamente a conjugação dos modelos normais, juntamente com propriedades da distribuição normal multivariada, veja Rencher (2002), o resultado segue.

O Passo 5 segue do Passo 5 do resultado 2.7.1. Com relação ao Passo 6, temos de (3.17) e (3.24), que

$$
\begin{aligned}
p\left(\boldsymbol{\psi}_{\boldsymbol{\theta}(T-1)} \mid(.)\right) \propto & \left\{\prod_{j=1}^{n} p\left(\boldsymbol{\theta}_{j .} \mid \theta_{j 1}, \boldsymbol{\eta}_{\boldsymbol{\theta}}\right)\right\} p\left(\boldsymbol{\psi}_{\boldsymbol{\theta}(T-1)}\right) \\
& \exp \left\{-0.5 \sum_{j=1}^{n}\left[\boldsymbol{\theta}_{j .}^{(T-1)}-\boldsymbol{\mu}_{\boldsymbol{\theta}}^{(T-1)}-\psi_{\theta_{1}}^{-1 / 2} \boldsymbol{\psi}_{\boldsymbol{\theta}(T-1)}\left(\theta_{j 1}-\mu_{\theta_{1}}\right)\right]^{t} \boldsymbol{\Psi}_{\boldsymbol{\theta}(T-1)}^{-1}\right. \\
& \left.\times\left[\boldsymbol{\theta}_{j .}^{(T-1)}-\boldsymbol{\mu}_{\boldsymbol{\theta}}^{(T-1)}-\psi_{\theta_{1}}^{-1 / 2} \boldsymbol{\psi}_{\boldsymbol{\theta}(T-1)}\left(\theta_{j 1}-\mu_{\theta_{1}}\right)\right]\right\} \\
& \exp \left\{-0.5\left(\boldsymbol{\psi}_{\theta(T-1)}-\boldsymbol{\mu}_{\boldsymbol{\psi}}\right)^{t} \boldsymbol{\Psi}_{\boldsymbol{\psi}}^{-1}\left(\boldsymbol{\psi}_{\theta(T-1)}-\boldsymbol{\mu}_{\boldsymbol{\psi}}\right)\right\},
\end{aligned}
$$

e o resultado segue, novamente, da conjugação do modelo normal multivariado com priori normal multivarida.

Finalmente, para o Passo 7, temos, de (3.17), com a priori 3.25$)$, que

$$
\begin{aligned}
p\left(\mathbf{\Psi}_{\boldsymbol{\theta}}^{(T-1)} \mid(.)\right) \propto & \exp \left\{-0.5 \operatorname{tr}\left[\left(\boldsymbol{\Psi}_{\boldsymbol{\theta}(T-1)}\right)^{-1} \sum_{j=1}^{n}\left(\boldsymbol{\theta}_{j .}^{(T-1)}-\boldsymbol{\mu}_{\boldsymbol{\theta}(T-1)}\right)^{t}\left(\boldsymbol{\theta}_{j .}^{(T-1)}-\boldsymbol{\mu}_{\boldsymbol{\theta}(T-1)}\right)\right.\right. \\
& \left.\left.\times\left(\theta_{j 1}-\mu_{\theta_{1}}\right)^{2}\right]\right\}\left|\boldsymbol{\Psi}_{\boldsymbol{\theta}(T-1)}\right|^{-n / 2}, \\
& \exp \left\{-0.5 \operatorname{tr}\left[\boldsymbol{\Psi}_{\Psi} \mathbf{\Psi}_{\theta(T-1)}^{-1}\right]\right\}\left|\boldsymbol{\Psi}_{\boldsymbol{\theta}(T-1)}\right|^{\nu_{\Psi}+T+1},
\end{aligned}
$$

em que $\operatorname{tr}$ representa o traço de uma matriz e os resultado segue diretamente da conjugação do modelo normal multivariado com a priori Inversa-Wishart, veja Gelman et al. (2004).

Q.E.D.

Azevedo, Caio L. N.

IME/USP 
Podemos notar que o Resultado 3.5.1 apresenta uma estrutura geral de estimação no sentido de não considerarmos restrições estruturais para a matriz $\Psi_{\boldsymbol{\theta}}$. Apesar de poder se reter os parâmetros consoante a matriz de covariâncias, veja o Resultado 4.5.1 no Capítulo 4, o algoritmo fornece a estimativa de $\boldsymbol{\Psi}_{\boldsymbol{\theta}}$ considerando a mesma como não-estruturada. Isto é bastante útil para se ter uma idéia sobre a forma mais conveniente da estrutura de dependência.

\subsubsection{Dados faltantes}

Embora o modelo, da forma como foi desenvolvido, permita a não-observância de algumas respostas por indivíduo, ele não considera a exclusão de indivíduos ("drop-outs") e nem sua inclusão. Fatores associados a exclusão poderiam ser : repetência, desistência, não observância de algumas restrições (escore mínimo por exemplo), dentre outros. Fatores associados a inclusão seriam : necessidade de estudo de mais indivíduos, repetência de alunos de séries mais avançadas, dentre outros. Nesta seção apresentaremos uma abordagem que permite a análise de ambos os casos. Mais especificamente, como a estimação dos traços latente é necessária, há que se considerar em que instantes tais indivíduos foram observados. Devido à flexibilidade do modelo normal multivariado, podemos considerar as distribuições condicionais completas correspondentes somente àqueles tempos em que os indivíduos participaram do estudo. Sendo assim, somente seriam simulados valores para os traços latentes correspondentes à tais instantes. Por outro lado, também podemos gerar valores dos traços latentes para os tempos não observados, através da distribuição condicional de tais tempos, dado os instantes observados, veja Douglas (1999). Isso equivale a considerar um processo de imputação de dados, veja Little and Rubin (2002). Contudo, qualquer que seja a escolha para a análise desse tipo de dados faltantes, o processo continuará sendo considerado como MAR, veja Little and Rubin (2002). Ademais, isso não interfere nas distribuições condicionais completas dos outros parâmetros, uma vez que, basta considerarmos os traços latentes de que dispomos.

Com o intuito de considerar a proposta acima, no procedimento MCMC propriamente dito, exploraremos os dois casos em separado. Mais concretamente, apresentaremos, primeiramente, a proprosta sem imputação e, sem seguida, sua correspodente com o supracitado processo de imputação.

\section{Sem imputação}

- Passo 1: Simular os dados aumentados tal como no Passo 1 do Resultado 3.5.1 somente para os traços latentes observados.

- Passo 2 : Simular os traços latentes, independentemente para cada indivíduo, através de

$$
\boldsymbol{\theta}_{j .} \mid(.) \sim N_{T_{j}}\left(\boldsymbol{A}_{\theta_{j}} \widehat{\boldsymbol{\Psi}}_{\boldsymbol{\theta}_{j}} \widehat{\boldsymbol{\theta}}_{j}, \boldsymbol{A}_{\theta_{j}} \widehat{\boldsymbol{\Psi}}_{\boldsymbol{\theta}_{j}} \boldsymbol{A}_{\theta_{j}}^{t}\right)
$$

Azevedo, Caio L. N.

IME/USP 
em que $\boldsymbol{A}_{\theta_{j}}$ é uma matriz $T_{j} \times T\left(T_{j} \leq T\right)$, cujas linhas indicam em que instantes o indivíduo $j$ foi observado e $T_{j}$ é o número de instantes em que o indivíduo $j$ foi observado.

- Passo 3 : Simular os parâmetros dos itens tal como no Passo 3 do Resultado 3.5.1

- Passo 4 : Simular as médias populacionais tal como no Passo 4 do Resultado 3.5.1. com a seguinte modificação

$$
\begin{aligned}
\widehat{\boldsymbol{\mu}}_{\boldsymbol{\theta}} & =\boldsymbol{\Psi}_{\boldsymbol{\theta}}^{-1} \sum_{j=1}^{n}\left(\boldsymbol{\theta}_{j} . \boldsymbol{A}_{\theta_{j}}^{t}\right)+\boldsymbol{\Psi}_{0}^{-1} \boldsymbol{\mu}_{0}, \\
\widehat{\Psi}_{0} & =\left(\boldsymbol{D}_{\boldsymbol{n}} \boldsymbol{\Psi}_{\boldsymbol{\theta}}^{-1}+\boldsymbol{\Psi}_{0}^{-1}\right)^{-1}
\end{aligned}
$$

em que $\boldsymbol{D}_{\boldsymbol{n}}=\operatorname{diag}\left(n_{1}, n_{2}, \ldots, n_{T}\right)^{t}$ e $n_{t}$ é o número de indivíduos observados no instante $t$.

- Passo 5 : Simular a variância populacional do primeiro instante tal como no Passo 5 do Resultado 3.5.1.

- Passo 6 : Simular o vetor de covariâncias através de no Passo 7 do Resultado 3.5.1. com a seguinte modificação

$$
\widehat{\boldsymbol{\psi}}_{\boldsymbol{\psi}}=\psi_{\theta_{1}}^{-1 / 2} \boldsymbol{\Psi}_{\boldsymbol{\theta}(T-1)}^{-1} \sum_{j=1}^{n}\left[\boldsymbol{A}_{\theta_{j}}^{t}\left(\boldsymbol{\theta}_{j .}^{(T-1)}-\boldsymbol{\mu}_{\boldsymbol{\theta}}^{(T-1)}\right)\right]\left(\theta_{j 1}-\mu_{\theta_{1}}\right)+\boldsymbol{\Psi}_{\boldsymbol{\psi}}^{-1} \boldsymbol{\mu}_{\boldsymbol{\psi}}
$$

- Passo 7 : Simular a sub-matriz de covariâncias através do Passo 7 do Resultado 3.5.1 com a seguinte modificação:

$$
\widehat{\boldsymbol{\Psi}}_{\boldsymbol{\Psi}}=\boldsymbol{\Psi}_{\boldsymbol{\Psi}}+\sum_{j=1}^{n}\left[\boldsymbol{A}_{\theta_{j}}^{t}\left(\boldsymbol{\theta}_{j .}^{(T-1)}-\boldsymbol{\mu}_{\boldsymbol{\theta}(T-1)}\right)\left(\boldsymbol{\theta}_{j .}^{(T-1)}-\boldsymbol{\mu}_{\boldsymbol{\theta}(T-1)}\right) \boldsymbol{A}_{\theta_{j}}\right] .
$$

- Demais passos : Permanecem os mesmos pois dizem respeito somente ao cálculo dos parâmetros de interesse.

Azevedo, Caio L. N.

IME/USP 


\section{Com imputação}

- Passos 1 e 2 : Proceder exatamente como os Passo 1 do Resultado 3.5.1 e o Passo 2 descrito anteriormente (sem imputação).

- Passo 3 : Simular o vetor de traços latentes, para os instantes não observados, através de

$$
\boldsymbol{\theta}_{j .}^{(F)} \mid\left((.), \boldsymbol{\theta}_{j .}^{(O)}\right) \sim N_{T-T_{j}}\left(\widetilde{\boldsymbol{\theta}}_{j .}^{(F)}, \widetilde{\boldsymbol{\Psi}}_{\boldsymbol{\theta}_{j}}^{(F)}\right)
$$

em que

$$
\begin{aligned}
\widetilde{\boldsymbol{\theta}}_{j .}^{(F)} & =\widehat{\boldsymbol{\theta}}_{j .}^{(F)}+\widehat{\boldsymbol{\Psi}}_{\boldsymbol{\theta}_{j}}^{(O, F)-1} \widehat{\mathbf{\Psi}}_{\boldsymbol{\theta}_{j}}^{(O)}\left(\boldsymbol{\theta}_{j .}^{(0)}-\widehat{\boldsymbol{\theta}}_{j .}^{(O)}\right), \\
\widetilde{\boldsymbol{\Psi}}_{j .}^{(F)} & =\widehat{\boldsymbol{\Psi}}_{j .}^{(F)}-\widehat{\boldsymbol{\Psi}}_{\boldsymbol{\theta}_{j}}^{(F, O)} \widehat{\boldsymbol{\Psi}}_{\boldsymbol{\theta}_{j}}^{(O)-1} \widehat{\boldsymbol{\Psi}}_{\boldsymbol{\theta}_{j}}^{(O, F)}, \\
\left(\begin{array}{c}
\boldsymbol{\theta}_{j .}^{(O)} \\
\boldsymbol{\theta}_{j .}^{(F)}
\end{array}\right) & \sim N_{T}\left[\left(\begin{array}{l}
\widetilde{\boldsymbol{\theta}}_{j .}^{(O)} \\
\widetilde{\boldsymbol{\theta}}_{j .}^{(F)}
\end{array}\right),\left(\begin{array}{ll}
\widehat{\boldsymbol{\Psi}}_{\boldsymbol{\theta}_{j}}^{(O)} & \widehat{\boldsymbol{\Psi}}_{\boldsymbol{\theta}_{j}}^{(O, F)} \\
\widehat{\boldsymbol{\Psi}}_{\boldsymbol{\theta}_{j}}^{(F, O)} & \widehat{\boldsymbol{\Psi}}_{\boldsymbol{\theta}_{j}}^{(F)}
\end{array}\right)\right],
\end{aligned}
$$

$\widehat{\boldsymbol{\Psi}}_{\boldsymbol{\theta}_{j}}^{(O, F)}=\widehat{\boldsymbol{\Psi}}_{\boldsymbol{\theta}_{j}}^{(F, 0) t}, \widehat{\boldsymbol{\theta}}_{j}^{(\cdot)}$ é a partição correspondente do vetor $\widehat{\boldsymbol{\Psi}}_{\boldsymbol{\theta}_{j}} \widehat{\boldsymbol{\theta}}_{j}$ e $\widehat{\boldsymbol{\Psi}}_{\boldsymbol{\theta}_{j}}^{(.)}$é a partição correspondente da matriz $\widehat{\mathbf{\Psi}}_{\boldsymbol{\theta}_{j}}$.

- Passos 4 a 10 : Proceder exatamente como nos Passos de 4 a 10 do Resultado 3.5.1

Podemos notar que, ao se optar pelo processo de imputação descrito acima, embora se tenha necessidade de simular valores através da distribuição condicional (3.30), não há modificações nas distribuições condicionais completas restantes. Por outro lado, ao se optar pela não imputação, há a necessidade de se modificar algumas distribuições condicionais completas. De qualquer forma, para se obter preditores com bom desempenho, no processo de imputação, é necessário ter observarções em mais instantes do que aqueles em que o respondente não foi observado. Mais detalhes a respeito de métodos de imputação podem ser encontrados em Little and Rubin (2002), Efron (1994) e Liu (1995), por exemplo. 


\subsubsection{Agrupamento no algoritmo MCMC}

Sabidamente, as amostras geradas pelos métodos de MCMC costumam apresentar autocorrelações bastante elevadas. Isto leva a necessidade, muitas vezes, de se gerar muitos valores a fim de se obter amostras representativas das distribuições a posteriori de interesse, Chen et al. (2000) e Gamerman and Lopes (2006). Uma das técnicas mais utilizadas para se obter cadeias com autocorrelações menores, consiste em se proceder amostragens por blocos. Este mecanismo se baseia em simular, de modo simultâneo, parâmetros que apresentem correlações elevadas entre si, veja Roberts and Sahu (1997). O modelo descrito em (3.19) induz uma correlação natural no vetor de parâmetros $\boldsymbol{\beta}_{\boldsymbol{\eta}}=\left(\boldsymbol{\mu}_{\boldsymbol{\theta}}^{t(T-1)}, \boldsymbol{\psi}_{\boldsymbol{\theta}(T-1)}^{t}\right)^{t}$, pois estes são coeficientes de um modelo de regressão (multivariado). Portanto, uma modificação natural no Resultado 3.5.1 seria a execução simultânea dos Passos 4 e 6. Mais concretamente, considerando a distribuição a priori,

$$
\boldsymbol{\beta}_{\boldsymbol{\eta}} \sim N_{2(T-1)}\left(\boldsymbol{\beta}_{0(\boldsymbol{\eta})}, \boldsymbol{\Psi}_{0(\boldsymbol{\mu}, \boldsymbol{\psi})}\right)
$$

teríamos que os Passos 4 e 6 traduzir-se-iam num único, tal como se segue:

Passo substituto :Simular $\boldsymbol{\beta}_{\boldsymbol{\eta}} \sim N_{2(T-1)}\left(\widetilde{\boldsymbol{\beta}}_{0(\boldsymbol{\eta})}, \widehat{\boldsymbol{\Psi}}_{0(\boldsymbol{\eta})}\right)$, em que

$$
\begin{aligned}
\widetilde{\boldsymbol{\beta}}_{0(\boldsymbol{\eta})} & =\widehat{\boldsymbol{\Psi}}_{0(\boldsymbol{\eta})} \widehat{\boldsymbol{\beta}}_{0(\boldsymbol{\eta})}, \\
\widehat{\boldsymbol{\beta}}_{0(\boldsymbol{\eta})} & =\boldsymbol{W} \boldsymbol{\theta}_{.}^{(T-1)}+\boldsymbol{\Psi}_{0(\boldsymbol{\mu}, \boldsymbol{\psi})}^{-1} \boldsymbol{\beta}_{0(\boldsymbol{\eta})}, \\
\widehat{\boldsymbol{\Psi}}_{0(\boldsymbol{\eta})} & =\left(\boldsymbol{W}^{t} \boldsymbol{W}+\boldsymbol{\Psi}_{0(\boldsymbol{\eta})}^{-1}\right)^{-1},
\end{aligned}
$$

$\mathrm{e}$

$$
\boldsymbol{\theta}_{. .}^{(T-1)}=\left[\begin{array}{c}
\boldsymbol{\theta}_{1 .}^{(T-1)} \\
\boldsymbol{\theta}_{2 .}^{(T-1)} \\
\vdots \\
\boldsymbol{\theta}_{n .}^{(T-1)}
\end{array}\right], \boldsymbol{W}=\left[\begin{array}{cc}
1 & \psi_{\theta_{1}}^{-1 / 2}\left(\theta_{11}-\mu_{\theta_{1}}\right) \\
1 & \psi_{\theta_{1}}^{-1 / 2}\left(\theta_{11}-\mu_{\theta_{1}}\right) \\
\vdots & \vdots \\
1 & \psi_{\theta_{1}}^{-1 / 2}\left(\theta_{11}-\mu_{\theta_{1}}\right)
\end{array}\right]
$$

A demonstração segue diretamente do desenvolvimento do Passo 4 do Resultado 3.5.1.

Azevedo, Caio L. N.

IME/USP 


\subsubsection{Itens com DRIFT}

Um dos aspectos relacionados ao fato de se utilizar o mesmo item ao longo de uma sequência de testes longitudinais é o fato de que o mesmo pode apresentar um certo desgaste em sua utilização. Tal comportamento é conhecido com "DRIFT" ’ veja Bock et al. (1998). À semelhança da seção 2.7.2. na qual tratamos da presença de itens com DIF, a abordagem no presente caso seria considerar uma variação do modelo (3.14), ou seja,

$$
\begin{aligned}
\boldsymbol{Z}_{i j .} \mid \boldsymbol{y}_{i j .} & =\left(\boldsymbol{D}_{a_{i t}}+\boldsymbol{D}_{\alpha_{i t}} \mathbb{1}_{i t}\right) \boldsymbol{\theta}_{j .}-\left(b_{i}+\delta_{i t} \mathbb{1}_{i t}\right) \mathbf{1}_{T}+\boldsymbol{\xi}_{i j .}^{(Z)} \\
\boldsymbol{\theta}_{j .} & =\boldsymbol{\mu}_{\theta_{j .}}+\boldsymbol{\xi}_{j .}^{(\theta)}
\end{aligned}
$$

em que

$$
\mathbb{1}_{i t}= \begin{cases}1, & \text { se o item } i \text { foi apresentado à população no instante } t, t=2,3, \ldots, T \\ 0, & \text { caso contrário. }\end{cases}
$$

\subsection{Aspectos computacionais}

Pelo que sabemos, não existem pacotes, nem comerciais e nem gratuitos, que ajustem modelos longitudinais de resposta ao item. Isto se deve, provavelmente, a escassez de desenvolvimentos de métodos de estimação nessa área. Alguns autores desenvolveram rotinas pessoais. Tavares (2001) desenvolveu, utilizando o pacote Ox ${ }^{\circledR}$, uma extensão da abordagem de MVM proposto por Bock and Aitkin (1981). Pastor and Beretvas (2006) utilizaram o programa HLM ${ }^{\circledR}$, veja Raundebush et al. (2004), para analisar dados longitudinais via modelo de Rasch. Douglas (1999) desenvolveu rotinas em $\mathrm{C}++{ }^{\mathrm{B}}$ para analisar o modelo longitudinal proposto por ele. Da mesma forma que para o MGM, utilizamos o programa Ox ${ }^{\circledR}$ para rodar as análises e o programa $\mathrm{R}^{\circledR}$, para a interface gráfica.

\subsection{Estudos de simulação}

Nesta seção conduziremos estudos de simulação apropriados. Estes visam avaliar o comportamento do método de estimação e do modelo. A estrura geral, em termos de tipos de simulação e valores de parâmetros é exatamente aquela apresentada na Seção 2.10. Adicionalmente, consideraremos o valor 0, 8 para o parâmetro de correlação $\left(\rho_{\theta}\right)$. Este valor induz uma correlação relativamente elevada entre os traços latentes.

\footnotetext{
* Tal termo admite algumas traduções para a língua portuguesa, contudo, a mais apropriada seria tendência. Neste caso, uma tendência ao desgaste.
}

Azevedo, Caio L. N.

IME/USP 
Da mesma forma que na Seção 2.10, asseguramos a métrica das estimativas, através da seguinte transformação:

$$
\boldsymbol{\theta}_{j k .}^{* *}=\operatorname{Chol}\left(\boldsymbol{\Psi}_{\theta_{k}}\right) \operatorname{Chol}\left(\boldsymbol{S}_{\boldsymbol{\theta}_{k}}\right)^{-1}\left(\boldsymbol{\theta}_{j k .}^{*}-\overline{\boldsymbol{\theta}}_{k}\right)+\boldsymbol{\mu}_{\boldsymbol{\theta}_{k}}
$$

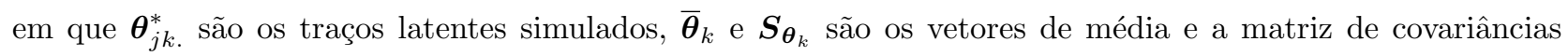
amostrais dos traços latentes simulados, respectivamente, e Chol representa a decomposição de Cholesky de uma matriz positiva definida, veja Magnus and Neudecker (1999).

\subsubsection{Análise de sensibilidade}

Nesta subseção avaliaremos o comportamento do modelo/método de estimação, com relação à escolha de algumas prioris. Analogamente à subseção 2.10.1, consideraremos mudanças nas prioris dos parâmetros dos itens e da estrutura de covariância. A escolha para os parâmetros dos itens é a mesma expressa na Tabela 2.1 . Com relação a estrutura de covariância adotaremos duas escolhas, seguindo a abordagem de McCulloh et al. (2000). Esta consiste em tomar a seguinte estrutura de hiperparâmetros, veja equações (3.24) e (3.25),

$$
\begin{aligned}
\boldsymbol{\mu}_{\boldsymbol{\psi}} & =\mathbf{0}_{T-1}, \boldsymbol{\Psi}_{\boldsymbol{\psi}}=\tau \boldsymbol{I}_{T-1} \mathrm{e} \\
\boldsymbol{\Psi}_{\boldsymbol{\Psi}} & =\left(\nu_{\boldsymbol{\Psi}}-T+1\right)\left(\boldsymbol{I}-\boldsymbol{\Psi}_{\boldsymbol{\psi}}\right)
\end{aligned}
$$

Dessa forma a escolha recaí nos hiperparâmetros $\left(\nu_{\Psi}, \tau\right)^{t}$. Optamos por utilizar dois conjuntos de prioris, um não-informativo (imprópria) e outro informativo de acordo com a sugestão de McCulloh et al. (2000). Tais valores se encontram na Tabela 3.1 . O valor $(0,0)$ indica priori imprópria.

As Tabelas $3.1 \mathrm{e} 3.2$ apresentam as estatísticas referentes as estimativas dos traços latentes e dos parâmetros, respectivamente, de cada uma das combinações das prioris. Podemos notar, claramente, que os valores das estatísticas são, praticamente, os mesmos. Isso indica uma certa robustez à escolha de prioris. Os resultados das Tabelas 3.3 e 3.4 reforçam a conjectura de robustez. Embora as estimativas das médias do instante 3, tenham sido um pocuo diferentes, os respectivos erros-padrão sugerem que elas não são significativamente diferentes. Dessa forma, mesmo considerando classes de prioris razoavelmente diferentes, observamos um comportamento robusto com relação à escolha das mesmas. Comentários semelhantes aos da Seção 2.10.1, e referências contidas nela, também se aplicam na presente seção, com relação a robustez, veja também comentários no início da Seção 3.7.2. Principalmente por se tratar de um modelo mais complexo, escolhas adequadas de prioris podem levar a resultados mais acurados, apesar da robustez verificada dentro da classe de prioris considerada.

Azevedo, Caio L. N.

IME/USP 
Tabela 3.1: Prioris escolhidas para a análise de sensibilidade

\begin{tabular}{lrrr}
\hline \hline \multirow{2}{*}{ Priori } & \multicolumn{3}{c}{ Hiperparâmetros } \\
\cline { 2 - 4 } & $\boldsymbol{\mu}_{\boldsymbol{\psi}}$ & \multicolumn{1}{c}{$\boldsymbol{\Psi}_{\boldsymbol{\psi}}$} & $\left(\nu_{\boldsymbol{\Psi}}, \tau\right)^{t}$ \\
\hline 1 & $(1,0)$ & $(1 / 2 ; 3)$ & $(0,0)$ \\
2 & $(1,0)$ & $(1 ; 6)$ & $(0,0)$ \\
3 & $(0,0)$ & $(3 ; 3)$ & $(0,0)$ \\
4 & $(0,0)$ & $(6,6)$ & $(0,0)$ \\
5 & $(1,0)$ & $(1 / 2 ; 3)$ & $(5 ; 1 / 8)$ \\
6 & $(1,0)$ & $(1 ; 6)$ & $(5 ; 1 / 8)$ \\
7 & $(0,0)$ & $(3 ; 3)$ & $(5 ; 1 / 8)$ \\
8 & $(0,0)$ & $(6,6)$ & $(5 ; 1 / 8)$ \\
\hline \hline
\end{tabular}

Tabela 3.2: Resultados da estimação dos traços latentes : análise de sensibilidade

\begin{tabular}{lrrrr}
\hline \hline \multirow{2}{*}{ Priori } & \multicolumn{4}{c}{ Estatística } \\
\cline { 2 - 5 } & Corr & MEP & Mvício & REQM \\
\hline$(1 ; 0)(0,5 ; 3)(5 ; 1 / 8)$ & 0,977 & 0,278 & 0,076 & 0,155 \\
$(1 ; 0)(1 ; 6)(5 ; 1 / 8)$ & 0,977 & 0,272 & 0,075 & 0,151 \\
$(0 ; 0)(3 ; 3)(5 ; 1 / 8)$ & 0,976 & 0,280 & 0,076 & 0,157 \\
$(0 ; 0)(6 ; 6)(5 ; 1 / 8)$ & 0,977 & 0,271 & 0,076 & 0,151 \\
$(1 ; 0)(0,5 ; 3)(0 ; 0)$ & 0,977 & 0,269 & 0,077 & 0,152 \\
$(1 ; 0)(1 ; 6)(0 ; 0)$ & 0,977 & 0,265 & 0,079 & 0,151 \\
$(0 ; 0)(3 ; 3)(0 ; 0)$ & 0,977 & 0,272 & 0,077 & 0,153 \\
$(0 ; 0)(6 ; 6)(0 ; 0)$ & 0,977 & 0,272 & 0,076 & 0,152 \\
\hline \hline
\end{tabular}

Tabela 3.3: Resultados da estimação dos parâmetros dos itens : análise de sensibilidade

\begin{tabular}{lrrrrrrrr}
\hline \hline \multirow{2}{*}{ Priori } & \multicolumn{9}{c}{ Par. do item } \\
\cline { 2 - 9 } & \multicolumn{9}{c}{ Disc. } & \multicolumn{4}{c}{ Diff. } \\
\cline { 2 - 9 } & Corr & MEP & Mvício & REQM & Corr & MEP & Mvício & REQM \\
\hline$(1 ; 0)(0,5 ; 3)(5 ; 1 / 8)$ & 0,941 & 0,093 & 0,007 & 0,017 & 0,997 & 0,121 & 0,019 & 0,040 \\
$(1 ; 0)(1 ; 6)(5 ; 1 / 8)$ & 0,939 & 0,095 & 0,009 & 0,019 & 0,996 & 0,126 & 0,025 & 0,049 \\
$(0 ; 0)(3 ; 3)(5 ; 1 / 8)$ & 0,931 & 0,095 & 0,009 & 0,019 & 0,996 & 0,122 & 0,023 & 0,044 \\
$(0 ; 0)(6 ; 6)(5 ; 1 / 8)$ & 0,939 & 0,098 & 0,011 & 0,021 & 0,996 & 0,126 & 0,027 & 0,050 \\
$(1 ; 0)(0,5 ; 3)(0 ; 0)$ & 0,938 & 0,099 & 0,012 & 0,023 & 0,995 & 0,128 & 0,031 & 0,057 \\
$(1 ; 0)(1 ; 6)(0 ; 0)$ & 0,944 & 0,096 & 0,012 & 0,022 & 0,996 & 0,126 & 0,025 & 0,048 \\
$(0 ; 0)(3 ; 3)(0 ; 0)$ & 0,942 & 0,105 & 0,011 & 0,024 & 0,996 & 0,128 & 0,026 & 0,050 \\
$(0 ; 0)(6 ; 6)(0 ; 0)$ & 0,940 & 0,100 & 0,010 & 0,022 & 0,996 & 0,127 & 0,028 & 0,053 \\
\hline \hline
\end{tabular}


Tabela 3.4: Resultados da estimação dos parâmetros populacionais : análise de sensibilidade

\begin{tabular}{|c|c|c|c|c|c|c|c|c|c|c|}
\hline \multirow[t]{3}{*}{ Priori } & \multicolumn{8}{|c|}{ Parâmetros populacionais } & & \\
\hline & \multicolumn{2}{|c|}{$\mu_{\theta_{2}}$} & \multicolumn{2}{|c|}{$\mu_{\theta_{3}}$} & \multicolumn{2}{|c|}{$\psi_{\theta_{2}}$} & \multicolumn{2}{|c|}{$\psi_{\theta_{3}}$} & \multicolumn{2}{|c|}{$\rho_{\theta}$} \\
\hline & Est. & EP & Est. & EP & Est. & EP & Est. & EP & Est. & EP \\
\hline$(1 ; 0)(0,5 ; 3)(5 ; 1 / 8)$ & 0,945 & 0,047 & 1,990 & 0,080 & 0,894 & 0,080 & 1,024 & 0,120 & 0,810 & 0,012 \\
\hline$(1 ; 0)(1 ; 6)(5 ; 1 / 8)$ & 0,946 & 0,043 & 1,971 & 0,063 & 0,869 & 0,064 & 0,951 & 0,096 & 0,810 & 0,011 \\
\hline$(0 ; 0)(3 ; 3)(5 ; 1 / 8)$ & 0,948 & 0,043 & 2,008 & 0,077 & 0,905 & 0,077 & 1,054 & 0,119 & 0,809 & 0,013 \\
\hline$(0 ; 0)(6 ; 6)(5 ; 1 / 8)$ & 0,943 & 0,045 & 1,959 & 0,072 & 0,858 & 0,074 & 0,927 & 0,103 & 0,809 & 0,011 \\
\hline$(1 ; 0)(0,5 ; 3)(0 ; 0)$ & 0,935 & 0,043 & 1,941 & 0,074 & 0,840 & 0,077 & 0,916 & 0,107 & 0,813 & 0,012 \\
\hline$(1 ; 0)(1 ; 6)(0 ; 0)$ & 0,928 & 0,042 & 1,921 & 0,065 & 0,822 & 0,065 & 0,881 & 0,094 & 0,812 & 0,012 \\
\hline$(0 ; 0)(3 ; 3)(0 ; 0)$ & 0,934 & 0,047 & 1,934 & 0,094 & 0,839 & 0,093 & 0,914 & 0,130 & 0,813 & 0,012 \\
\hline$(0 ; 0)(6 ; 6)(0 ; 0)$ & 0,942 & 0,045 & 1,956 & 0,080 & 0,853 & 0,077 & 0,938 & 0,122 & 0,813 & 0,012 \\
\hline
\end{tabular}

$(1,0),(0.5,3),(5,1 / 8)$

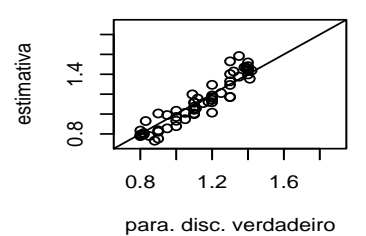

$(0,0),(6,6),(5,1 / 8)$

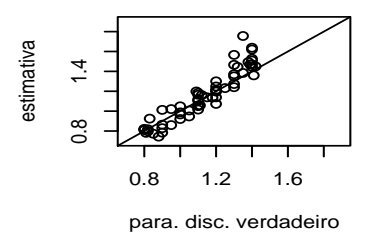

$(0,0),(3,3),(0,0)$

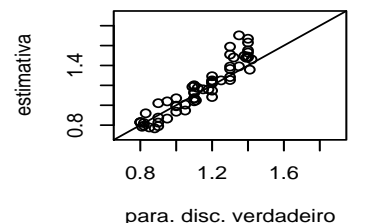

$(0,0),(1,6),(5,1 / 8)$

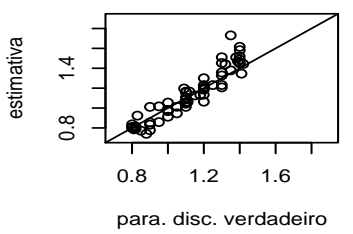

$(1,0),(0.5,3),(0,0)$

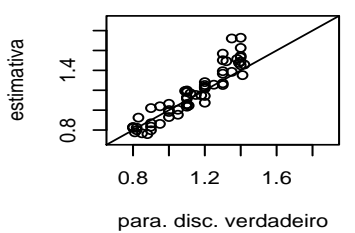

$(0,0),(6,6),(0,0)$

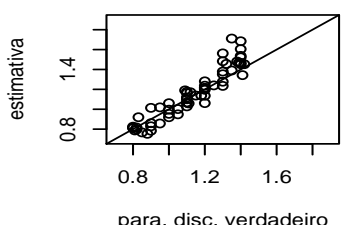

$(0,0),(3,3),(5,1 / 8)$

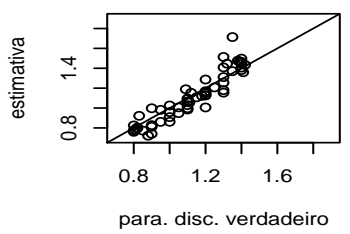

$(0,0),(1,6),(0,0)$

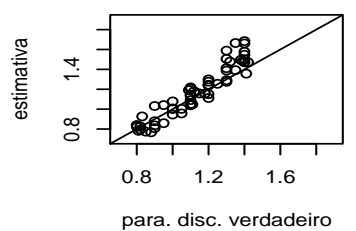

para. disc. verdadeiro

Figura 3.3: Gráficos de dispersão entre os valores do parâmetros de discriminação e suas estimativas : análise de sensibilidade

Azevedo, Caio L. N.

IME/USP 

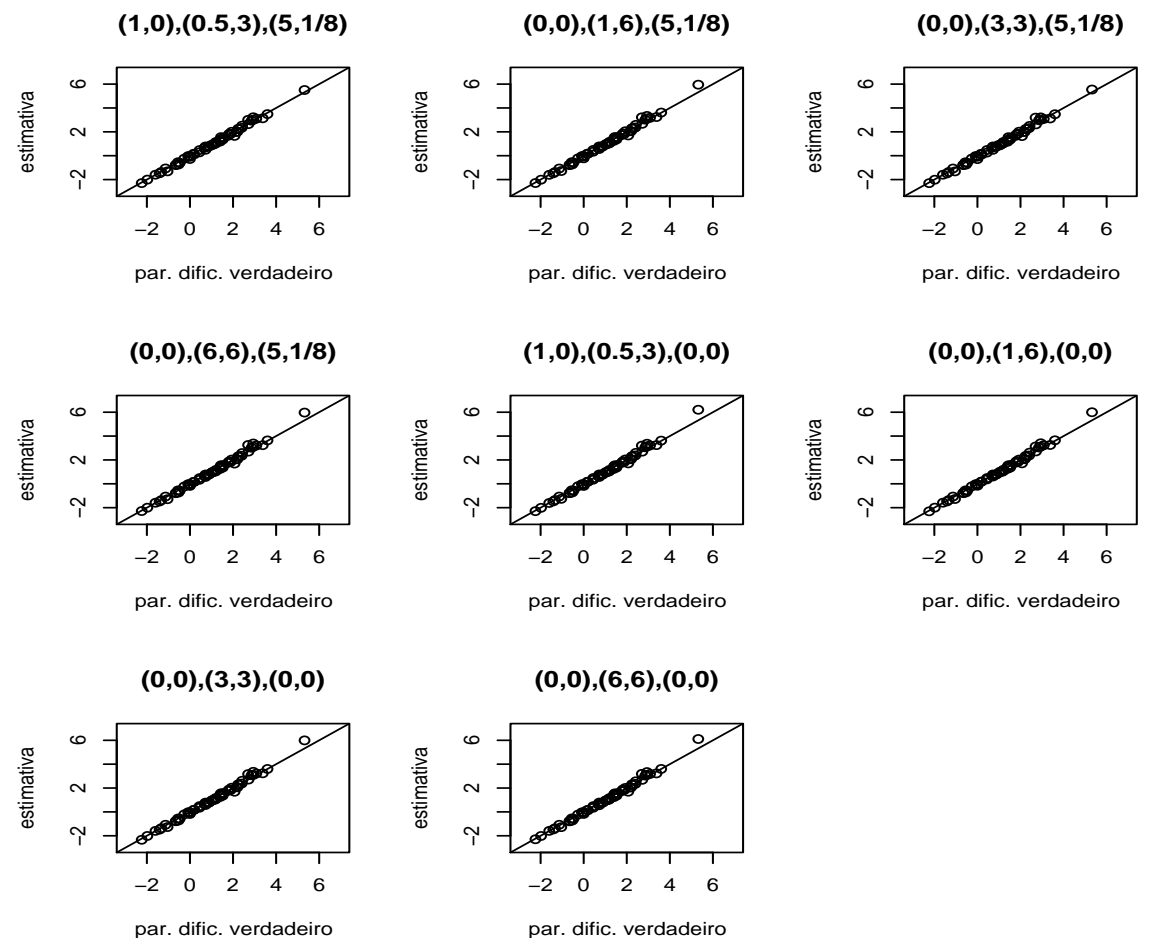

Figura 3.4: Gráficos de dispersão entre os valores do parâmetros de dificuldade e suas estimativas : análise de sensibilidade

Azevedo, Caio L. N.

IME/USP 


\subsubsection{Estudo de replicação}

Em princípio, de acordo com os resultados da seção anterior, que indica uma equivalência nos resultados utilizando diferentes prioris, escolhemos a priori número 1. Entretanto, conduzindo-se estudos de replicação com a mesma, notamos que os parâmetros populacionais tendem a ser subestimados. Dessa forma, escolheu-se a priori de número 5. Ela permite uma variação razoável tanto dos parâmetros dos itens quanto dos parâmetros de covariância.

A referida subestimação pode ser explicada por dois motivos : primeiro, a complexidade da estrutura longitudinal, possivelmente, exige uma tamanho de amostra maior do que o considerado (1000 indivíduos) para que as distribuições a posteriori tenham um comportamento mais estável; segundo, a literatura afirma que a robustez quanto a prioris pode não ocorrer quando se compara prioris próprias com impróprias, veja Paulino et al. (2003). Além disso, o estudo de robustez é mais ilustrativo se considerado com replicações. Tal expediente não foi considerado devido a demanda computacional do algoritmo do amostrador de Gibbs. Isto, no entanto, pode ser cabalmente resolvido implementando-se a metodologia desenvolvida em uma linguagem mais rápida como o $\mathrm{C}++{ }^{\circledR}$, por exemplo.

A Tabela 3.5 apresenta os resultados referentes à estimação dos traços latentes e dos parâmetros dos itens. Os resultados indicam que as estimativas foram bastante satisfatórias, alta correlação e valores baixos para as outras estatísticas. Dessa forma, podemos concluir que as estimativas possuem vício desprezível e variam muito pouco em torno dos verdadeiros valores. A Tabela 3.6 indica que as estimativas dos parâmetros populacionais foram próximas dos verdadeiros valores, à exceção da variância do terceiro instante, à semelhança do Capítulo 2 .

Tabela 3.5: Resultados da estimação dos traços latentes e dos parâmetros dos itens : estudo de replicação

\begin{tabular}{lccccr}
\hline \hline \multirow{2}{*}{ Parâmetro } & \multicolumn{5}{c}{ Estatística } \\
\cline { 2 - 6 } & Corr & MEP & Vq & Var & REQM \\
\hline Traço latente & 0,994 & 0,280 & 0,022 & 0,080 & 0,319 \\
Discriminação & 0,983 & 0,094 & 0,001 & 0,010 & 0,105 \\
Dificuldade & 0,999 & 0,121 & 0,004 & 0,020 & 0,154 \\
\hline \hline
\end{tabular}

Azevedo, Caio L. N.

IME/USP 
Tabela 3.6: Resultados da estimação dos parâmetros populacionais : estudo de replicação

\begin{tabular}{lrrrrr}
\hline \hline \multirow{2}{*}{ Parâmetro } & \multicolumn{5}{c}{ Estatística } \\
\cline { 2 - 6 } & M. Est. & \multicolumn{1}{c}{ MEP } & \multicolumn{1}{c}{ VQ } & \multicolumn{1}{c}{ Var } & REQM \\
\hline$\mu_{\theta_{2}}$ & 0,994 & 0,046 & $<0,001$ & $<0,001$ & 0,026 \\
$\mu_{\theta_{3}}$ & 1,998 & 0,079 & 0,002 & 0,002 & 0,063 \\
$\psi_{\theta_{2}}$ & 0,896 & 0,079 & 0,003 & 0,003 & 0,076 \\
$\psi_{\theta_{3}}$ & 1,001 & 0,110 & 0,007 & 0,005 & 0,113 \\
$\rho_{\theta}$ & 0,797 & 0,012 & $<0,001$ & $<0,001$ & 0,008 \\
\hline \hline
\end{tabular}
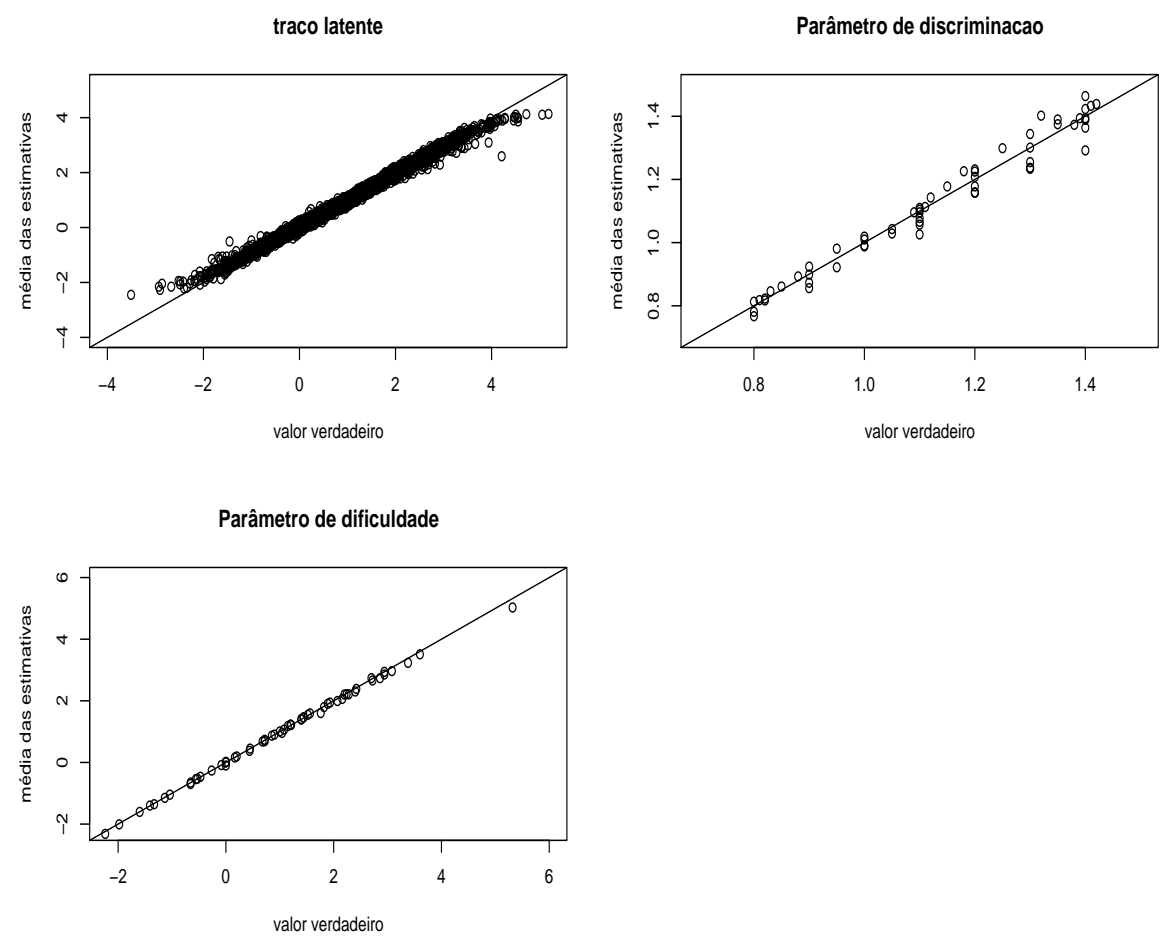

Figura 3.5: Gráficos de dispersão entre os valores dos verdadeiros parâmetros e as respectivas estimativas médias 


\subsubsection{Estudo de acompanhamento}

Os resultados descritos nesta subseção referem-se aos parâmetros dos itens 4 e 33 bem como aos parâmetros populacionais, salvo menção ao contrário.

A Tabela 3.7 apresenta as estimativas, IC's e HPD's relacionados aos parâmetros dos itens. Podemos observar que as estimativas estão bem próximas dos verdadeiros valores e além disso, os HPD's contêm praticamente todos os verdadeiros valores, à exceção dos itens 14, 31 e 43. A Tabela 3.8 apresenta tais resultados para os parâmetros populacionais. Percebemos que as estimativas foram bem próximas dos verdadeiros valores assim como os HPD's contêm os verdadeiros valores. Os resultados indicam que as estimativas foram bem satisfatórias.

As Figuras 3.6 e 3.7 apresentam os valores gerados, a cada 30 iterações, obtidos a partir de diferentes valores iniciais. As figuras indicam que diferentes valores iniciais não interferem no comportamento das cadeias.

As Figuras 3.8 e 3.9 , apresentam as autocorrelações considerando as amostras totais e as amostras válidas. Pecebemos que os parâmetros populacionais apresentaram os maiores valores, com exceção do parâmetro de correlação que apresentou os menores. Isto, provavelmente, se deve ao fato de que tal parâmetro é estimado como a média dos parâmetros de covariância, veja equação (3.28), o que permite que os valores simulados percorram mais livremente o espaço paramétrico.

As Figuras 3.10 e 3.11 apresentam os histogramas e as densidades estimadas, a partir das amostras geradas, para os parâmetros supracitados. Eles indicam que as distribuições apresentam um comportamento simétrico. A Figura 2.12 apresenta as curvas de nível das distribuições conjuntas, entre os parâmetros dos itens e os parâmetros populacionais. Percebe-se uma certa dependência positiva entre os parâmetros populacionais do grupo 3 e uma certa independência entre os demais pares de parâmetros.

Azevedo, Caio L. N.

IME/USP 
Tabela 3.7: Parâmetros dos itens e resultados do o estudo de acompanhamento

\begin{tabular}{|c|c|c|c|c|c|c|c|c|c|c|c|}
\hline \multirow[t]{3}{*}{ Teste } & \multirow[t]{3}{*}{ Item } & \multicolumn{2}{|c|}{ Val. verd. } & \multicolumn{8}{|c|}{ Estimativas } \\
\hline & & $a$ & 1 & & & $\mathrm{a}$ & & & & $\mathrm{b}$ & \\
\hline & & & & Est. & EP & CI (95\%) & HPD(95\%) & Est. & EP & CI (95\%) & HPD(95\%) \\
\hline 1 & 1 & 0,80 & $-1,60$ & 0,903 & 0,085 & {$[0,738 ; 1,090]$} & {$[0,737 ; 1,059]$} & $-1,629$ & 0,086 & {$[-1,803 ;-1,464]$} & {$[-1,803 ;-1,464$} \\
\hline 1 & 2 & 1,10 & $-1,98$ & 1,126 & 0,113 & {$[0,891 ; 1,363]$} & 1,371 & $-2,031$ & 0,128 & {$[-2,290 ;-1,787]$} & {$[-2,259 ;-1,763$} \\
\hline 1 & 3 & 1,40 & $-2,24$ & 1,425 & 0,150 & $1,162 ; 1,782]$ & $; 1,716$ & $-2,228$ & 0,163 & $-2,612 ;-1,949$ & $-2,528 ;-1,934$ \\
\hline 1 & 4 & 0,81 & $-1,13$ & 0,866 & 0,071 & $0,725 ; 1,002]$ & 0,$722 ; 0,992$ & $-1,115$ & 0,065 & $-1,259 ;-0,983$ & $-1,264 ;-0,988$ \\
\hline 1 & 5 & 1,11 & $-1,33$ & 1,153 & 0,100 & {$[0,963 ; 1,366]$} & 0,$961 ; 1,339$ & $-1,396$ & 0,088 & $-1,565 ;-1,249$ & $-1,555 ;-1,247$ \\
\hline 1 & 6 & 1,41 & $-1,41$ & 1,390 & 0,112 & $1,201 ; 1,635]$ & 1,$187 ; 1,593$ & $-1,387$ & 0,089 & $-1,586 ;-1,212$ & $-1,590 ;-1,229$ \\
\hline 1 & 7 & 0,82 & $-0,66$ & 0,881 & 0,065 & 0,$756 ; 1,009$ & 0,$771 ; 1,019$ & $-0,631$ & 0,052 & $-0,740 ;-0,532$ & $-0,740 ;-0,532$ \\
\hline 1 & 8 & 1,09 & $-0,65$ & 1,101 & 0,077 & $0,942 ; 1,252]$ & $; 1,265$ & $-0,609$ & 0,057 & $-0,723 ;-0,511$ & $-0,714 ;-0,510$ \\
\hline 1 & 9 & 1,39 & $-0,56$ & 1,355 & 0,099 & {$[1,169 ; 1,561]$} & 1,$165 ; 1,532$ & $-0,560$ & 0,056 & $-0,656 ;-0,430$ & $-0,661 ;-0,436$ \\
\hline 1 & 10 & 0,83 & $-0,08$ & 0,939 & 0,067 & $0,809 ; 1,067]$ & 0,$804 ; 1,055$ & $-0,087$ & 0,045 & $-0,180 ;-0,001$ & $-0,180 ;-0,001$ \\
\hline 1 & 11 & 0,90 & 0,90 & 0,871 & 0,066 & $0,743 ; 1,002]$ & 0,$758 ; 1,009$ & 0,848 & 0,054 & {$[0,743 ; 0,949$} & {$[0,750 ; 0,955$} \\
\hline 1 & 12 & 1,20 & 1,44 & 1,196 & 0,094 & {$[1,015 ; 1,401]$} & 1,$011 ; 1,374$ & 1,471 & 0,086 & 1,$332 ; 1,645$ & 1,$330 ; 1,641$ \\
\hline 1 & 13 & 1,38 & 1,93 & 1,440 & 0,136 & {$[1,202 ;] 1,700$} & 1,$201 ; 1,689$ & 2,013 & 0,141 & 1,$724 ; 2,295$ & 1,$756 ; 2,306$ \\
\hline 1 & 14 & 0,95 & 1,52 & 1,069 & 0,098 & {$[0,904 ; 1,283]$} & 0,$904 ; 1,283$ & 1,700 & 0,100 & 1,$515 ; 1,916$ & 1,$526 ; 1,921$ \\
\hline 1 & 15 & 1,05 & 1,89 & 1,191 & 0,104 & 0,$997 ; 1,389$ & 1,372 & 1,950 & 0,118 & 1,$726 ; 2,199$ & 1,$722 ; 2,180$ \\
\hline 1 & 16 & 1,35 & 2,70 & 1,383 & 0,161 & 1,$080 ; 1,750$ & 1,$069 ; 1,707$ & 2,532 & 0,207 & 2,$167 ; 3,006$ & 2,$161 ; 2,980$ \\
\hline 1 & 17 & 0,85 & 0,68 & 0,781 & 0,058 & $0,664 ; 0,894]$ & 0,$663 ; 0,888$ & 0,748 & 0,053 & {$[0,661 ; 0,847]$} & {$[0,657 ; 0,834$} \\
\hline 1 & 18 & 1,05 & 0,00 & 1,054 & 0,069 & {$[0,915 ; 1,184]$} & 1,176 & $-0,010$ & 0,047 & {$[-0,108 ; 0,074]$} & $-0,104 ; 0,076$ \\
\hline $1-2$ & 19 & 1,35 & 0,00 & 1,456 & 0,068 & $1,330 ; 1,591]$ & 1,$330 ; 1,591$ & $-0,010$ & 0,042 & $-0,095 ; 0,074$ & $-0,090 ; 0,078$ \\
\hline $1-2$ & 20 & 0,82 & 0,16 & 0,780 & 0,038 & {$[0,704 ; 0,851]$} & 0,$703 ; 0,843$ & 0,156 & 0,034 & {$[0,092 ; 0,224]$} & {$[0,092 ; 0,224$} \\
\hline $1-2$ & 21 & 1,12 & 0,45 & 1,173 & 0,056 & $1,069 ; 1,298]$ & 1,$064 ; 1,286$ & 0,465 & 0,041 & 0,$383 ; 0,554$ & 0,$395 ; 0,558$ \\
\hline $1-2$ & 22 & 1,42 & 0,85 & 1,450 & 0,069 & 1,$335 ; 1,574$ & 1,563 & 0,764 & 0,055 & 0,$669 ; 0,869$ & 0,$674 ; 0,872$ \\
\hline $1-2$ & 23 & 0,90 & 0,72 & 0,909 & 0,043 & 0,$827 ; 1,002$ & 0,$822 ; 0,989$ & 0,760 & 0,045 & 0,$685 ; 0,856$ & 0,$682 ; 0,845$ \\
\hline $1-2$ & 24 & 1,20 & 1,20 & 1,220 & 0,062 & 1,$115 ; 1,348$ & 1,$109 ; 1,340$ & 1,216 & 0,058 & {$[1,102 ; 1,329$} & {$[1,099 ; 1,321$} \\
\hline 2 & 25 & 1,30 & $-1,04$ & 1,413 & 0,172 & 1,$100 ; 1,816$ & 1,753 & $-1,182$ & 0,093 & {$[-1,380 ;-0,999$} & $-1,365 ;-0,988$ \\
\hline 2 & 26 & 0,88 & $-0,53$ & 1,020 & 0,097 & 0,$842 ; 1,209$ & $; 1,201$ & $-0,530$ & 0,077 & $-0,669 ;-0,371$ & $-0,659 ;-0,370$ \\
\hline 2 & 27 & 1,18 & $-0,47$ & 1,215 & 0,103 & 1,$007 ; 1,419$ & $; 1,400$ & $-0,475$ & 0,075 & $-0,627 ;-0,341$ & $-0,624 ;-0,340$ \\
\hline 2 & 28 & 1,32 & $-0,26$ & 1,475 & 0,126 & 1,$225 ; 1,698$ & 1,698 & $-0,282$ & 0,085 & $-0,453 ;-0,099$ & $-0,466 ;-0,123$ \\
\hline 2 & 29 & 1,00 & 0,00 & 0,979 & 0,081 & 0,$833 ; 1,143$ & 0,$823 ; 1,115$ & 0,060 & 0,071 & {$[-0,096 ; 0,206$} & {$[-0,062 ; 0,219$} \\
\hline 2 & 30 & 1,20 & 2,40 & 1,222 & 0,100 & 1,$045 ; 1,445$ & 1,$064 ; 1,445$ & 2,322 & 0,141 & {$[2,067 ; 2,617$} & {$[2,091 ; 2,630$} \\
\hline 2 & 31 & 1,30 & 2,86 & 1,134 & 0,100 & 0,$944 ; 1,329$ & 0,$956 ; 1,337$ & 2,539 & 0,157 & 2,$256 ; 2,841$ & 2,$272 ; 2,847$ \\
\hline 2 & 32 & 0,95 & 2,28 & 0,913 & 0,085 & 0,$745 ; 1,078$ & 1,078 & 2,168 & 0,127 & 1,$918 ; 2,420$ & 1,$911 ; 2,407$ \\
\hline 2 & 33 & 1,25 & 1,00 & 1,292 & 0,093 & 1,$106 ; 1,476$ & 1,$122 ; 1,483$ & 1,065 & 0,092 & 0,$865 ; 1,259$ & 0,$893 ; 1,282$ \\
\hline 2 & 34 & 1,15 & 1,15 & 1,143 & 0,085 & 0,$979 ; 1,348$ & 0,$952 ; 1,293$ & 1,082 & 0,090 & 0,$920 ; 1,273$ & 0,$918 ; 1,262$ \\
\hline 2 & 35 & 1,00 & 1,20 & 0,985 & 0,077 & 0,$850 ; 1,152$ & 1,139 & 1,106 & 0,092 & 0,$919 ; 1,272$ & 0,$926 ; 1,275$ \\
\hline 2 & 36 & 1,10 & 1,21 & 1,127 & 0,083 & 0,$966 ; 1,317$ & 0,$951 ; 1,270$ & 1,196 & 0,093 & 1,$019 ; 1,392$ & 1,$019 ; 1,375$ \\
\hline $2-3$ & 37 & 1,20 & 1,56 & 1,181 & 0,072 & 1,$043 ; 1,332$ & 1,$043 ; 1,317$ & 1,485 & 0,089 & 1,$313 ; 1,663$ & 1,$313 ; 1,653$ \\
\hline $2-3$ & 38 & 1,30 & 1,82 & 1,279 & 0,075 & 1,$135 ; 1,429$ & 1,$132 ; 1,420$ & 1,701 & 0,098 & 1,$515 ; 1,890$ & 1,$523 ; 1,897$ \\
\hline $2-3$ & 39 & 1,40 & 2,24 & 1,430 & 0,085 & 1,$295 ; 1,604$ & 1,$289 ; 1,596$ & 2,243 & 0,112 & 2,$040 ; 2,485$ & 2,$028 ; 2,457$ \\
\hline $2-3$ & 40 & 0,80 & 1,44 & 0,790 & 0,043 & 0,$694 ; 0,876$ & 0,$701 ; 0,881$ & 1,389 & 0,070 & $1,241 ; 1,532]$ & 1,$262 ; 1,538$ \\
\hline $2-3$ & 41 & 1,10 & 2,20 & 1,143 & 0,066 & 1,$023 ; 1,287$ & 1,$012 ; 1,273$ & 2,275 & 0,096 & 2,$108 ; 2,490$ & 2,$107 ; 2,475$ \\
\hline $2-3$ & 42 & 1,40 & 2,94 & 1,412 & 0,087 & 1,$247 ; 1,597$ & 1,591 & 2,874 & 0,133 & {$[2,622 ; 3,153]$} & {$[2,622 ; 3,153$} \\
\hline 3 & 43 & 1,30 & 0,00 & 1,062 & 0,136 & 0,$808 ; 1,335$ & 1,305 & $-0,406$ & 0,155 & {$[-0,710 ;-0,082]$} & {$[-0,695 ;-0,082$} \\
\hline 3 & 44 & 1,00 & 0,20 & 1,144 & 0,117 & 0,$935 ; 1,406$ & 0,$919 ; 1,370$ & 0,299 & 0,153 & {$[0,020 ; 0,633]$} & {$[0,000 ; 0,587$} \\
\hline 3 & 45 & 1,10 & 0,44 & 1,045 & 0,104 & 0,$846 ; 1,274$ & 0,$857 ; 1,283$ & 0,448 & 0,147 & 0,$176 ; 0,735$ & 0,$179 ; 0,735$ \\
\hline 3 & 46 & 1,20 & 0,72 & 1,150 & 0,110 & 0,$935 ; 1,401$ & 0,$933 ; 1,368$ & 0,583 & 0,149 & 0,$294 ; 0,930$ & 0,$270 ; 0,894$ \\
\hline 3 & 47 & 1,30 & 1,04 & 1,336 & 0,114 & 1,$119 ; 1,556$ & 1,$118 ; 1,545$ & 1,005 & 0,164 & 0,$697 ; 1,336$ & 0,$695 ; 1,320$ \\
\hline 3 & 48 & 1,40 & 1,40 & 1,471 & 0,131 & 1,$230 ; 1,749$ & 1,$219 ; 1,719$ & 1,423 & 0,189 & 1,$051 ; 1,803$ & 1,$068 ; 1,809$ \\
\hline 3 & 49 & 0,90 & 1,08 & 0,967 & 0,083 & 0,$805 ; 1,111$ & 0,$805 ; 1,111$ & 1,145 & 0,138 & 0,$874 ; 1,413$ & 0,$894 ; 1,424$ \\
\hline 3 & 50 & 1,00 & 1,40 & 0,927 & 0,074 & 0,$797 ; 1,070$ & 1,054 & 1,226 & 0,137 & 0,$969 ; 1,517$ & 0,$941 ; 1,450$ \\
\hline 3 & 51 & 1,10 & 1,76 & 1,106 & 0,088 & 0,$940 ; 1,274$ & 0,$947 ; 1,274$ & 1,724 & 0,150 & 1,$467 ; 2,043$ & 1,$458 ; 2,009$ \\
\hline 3 & 52 & 1,20 & 2,16 & 1,200 & 0,096 & 1,$018 ; 1,402$ & 1,$021 ; 1,403$ & 2,110 & 0,171 & 1,$822 ; 2,519$ & 1,$786 ; 2,446$ \\
\hline 3 & 53 & 0,80 & 2,72 & 0,713 & 0,070 & 0,$586 ; 0,869$ & 0,$596 ; 0,871$ & 2,476 & 0,163 & 2,$162 ; 2,856$ & 2,$135 ; 2,800$ \\
\hline 3 & 54 & 1,10 & 2,42 & 1,049 & 0,080 & 0,$895 ; 1,221$ & 0,$906 ; 1,225$ & 2,241 & 0,163 & 1,$894 ; 2,589$ & 1,$850 ; 2,513$ \\
\hline 3 & 55 & 1,40 & 2,94 & 1,345 & 0,109 & 1,$154 ; 1,559$ & 1,$153 ; 1,551$ & 2,805 & 0,214 & 2,$433 ; 3,201$ & 2,$433 ; 3,201$ \\
\hline 3 & 56 & 0,90 & 2,07 & 0,969 & 0,079 & 0,$829 ; 1,131$ & 0,$819 ; 1,120$ & 2,224 & 0,155 & 1,$911 ; 2,525$ & 1,$929 ; 2,527$ \\
\hline 3 & 57 & 1,20 & 3,60 & 1,160 & 0,107 & 0,$963 ; 1,379$ & 0,$976 ; 1,387$ & 3,536 & 0,259 & 3,$076 ; 4,052$ & 3,$071 ; 4,016$ \\
\hline 3 & 58 & 1,30 & 3,38 & 1,338 & 0,103 & 1,$139 ; 1,559$ & 1,$159 ; 1,565$ & 3,517 & 0,224 & 3,$086 ; 3,995$ & 3,$039 ; 3,924$ \\
\hline 3 & 59 & 1,10 & 3,08 & 1,020 & 0,088 & 0,$864 ; 1,190$ & 0,$855 ; 1,179$ & 2,836 & 0,193 & 2,$485 ; 3,200$ & 2,$502 ; 3,214$ \\
\hline 3 & 60 & 1,40 & 5,32 & 1,288 & 0,152 & 0,$971 ; 1,620$ & 1,$046 ; 1,662$ & 5,012 & 0,432 & 4,$178 ; 5,950$ & 4,$211 ; 5,951$ \\
\hline
\end{tabular}

Tabela 3.8: Resultados da estimação dos parâmetros populacionais : estudo de acompanhamento

\begin{tabular}{lcccc}
\hline \hline Parâmetro & Est. & EP & IC(95\%) & HPD(95\%) \\
\hline$\mu_{\theta_{2}}$ & 0,983 & 0,044 & {$[0,902 ; 1,052]$} & {$[0,901 ; 1,050]$} \\
$\mu_{\theta_{3}}$ & 1,974 & 0,071 & {$[1,829 ; 2,089]$} & {$[1,829 ; 2,089]$} \\
$\psi_{\theta_{2}}$ & 0,863 & 0,075 & {$[0,731 ; 1,005]$} & {$[0,726 ; 0,981]$} \\
$\psi_{\theta_{3}}$ & 1,014 & 0,104 & {$[0,836 ; 1,227]$} & {$[0,814 ; 1,202]$} \\
$\rho_{\theta}$ & 0,802 & 0,012 & {$[0,779 ; 0,825]$} & {$[0,784 ; 0,829]$} \\
\hline \hline
\end{tabular}

Azevedo, Caio L. N. 

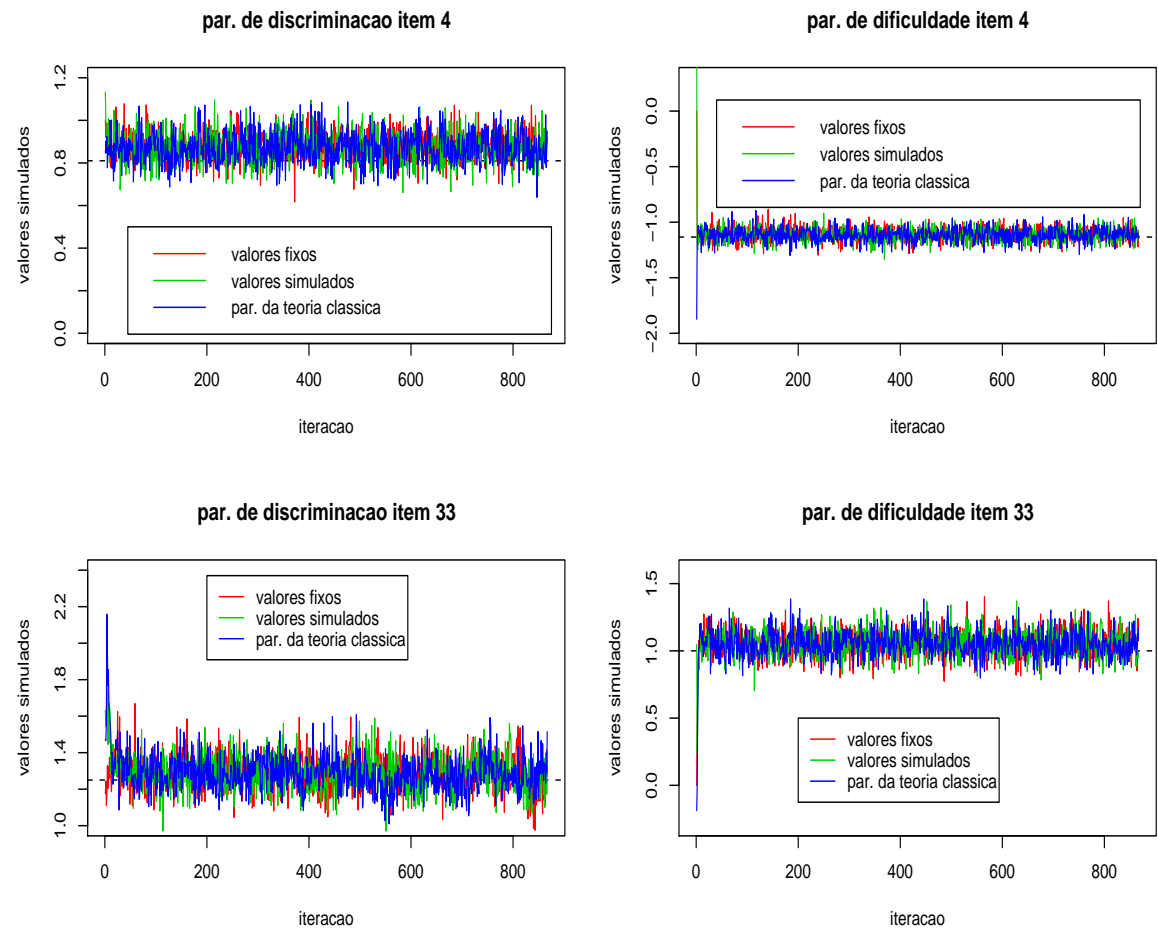

Figura 3.6: Valores simulados dos parâmetros dos itens 4 e 33 obtidos a partir de diferentes valores iniciais : estudo de acompanhamento

Azevedo, Caio L. N.

IME/USP 
media populacional 2

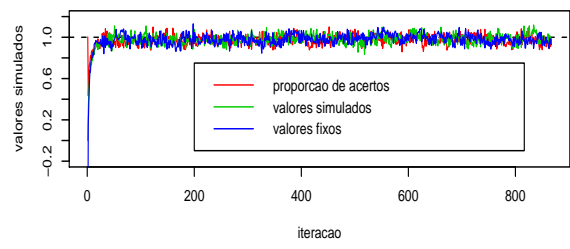

variancia populacional 2

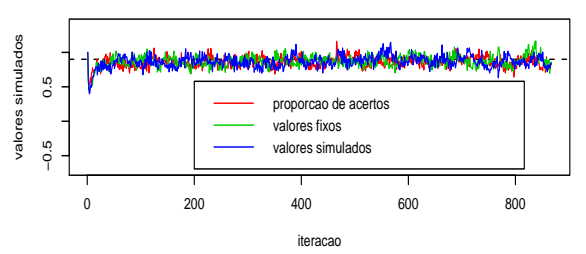

par. de correlacao

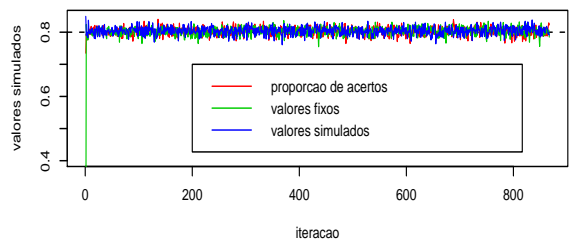

media populacional 3

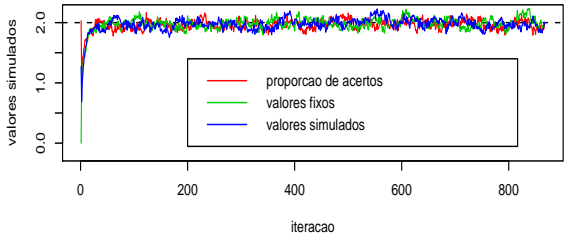

variancia populacional 3

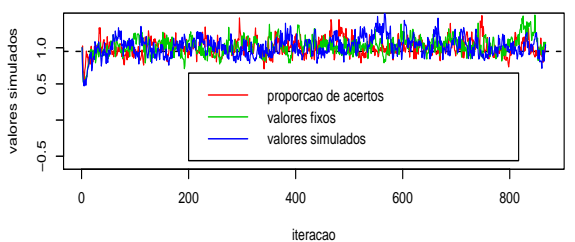

Figura 3.7: Valores simulados dos parâmetros populacionais para diferentes valores iniciais : estudo de acompanhamento 

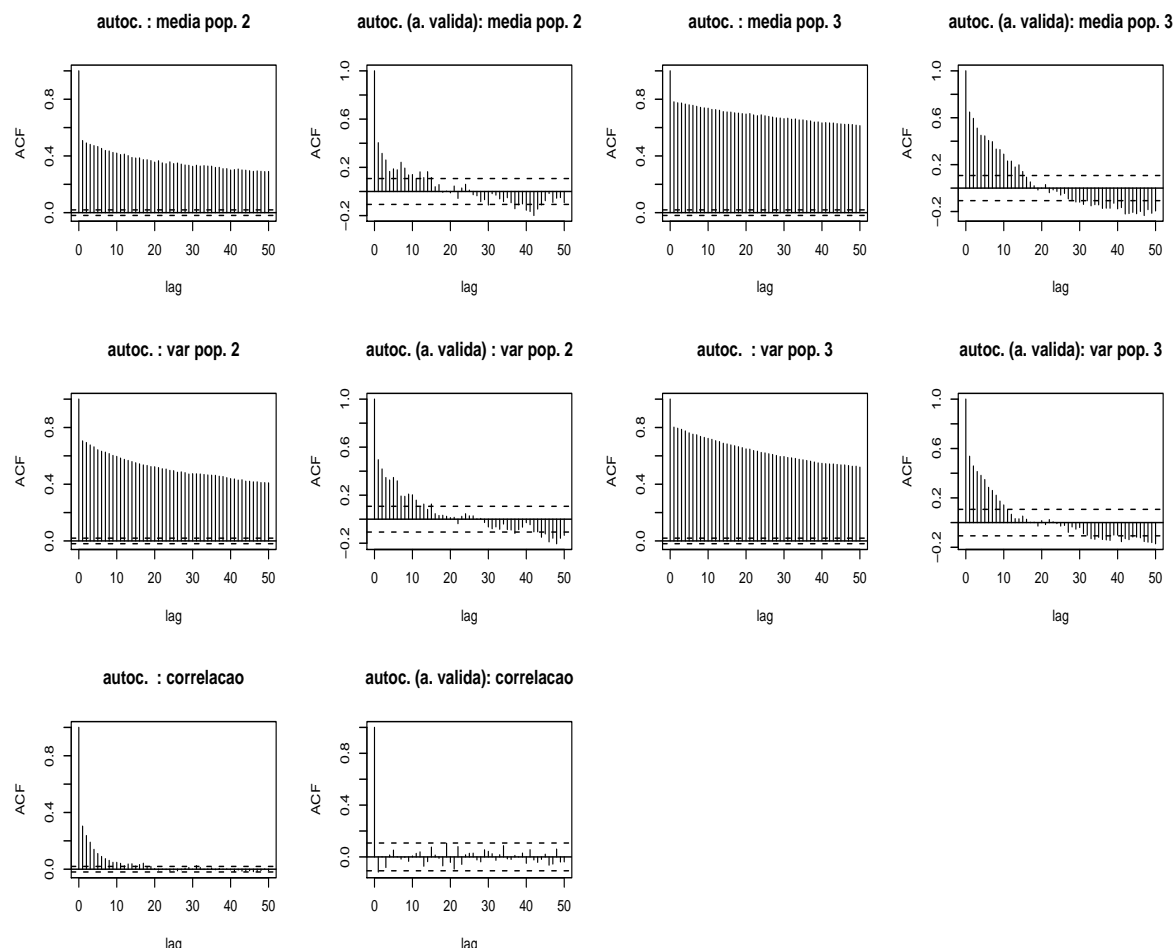

lag

Figura 3.8: Auto-correlacao dos parâmetros populacionais : estudo de acompanhamento 

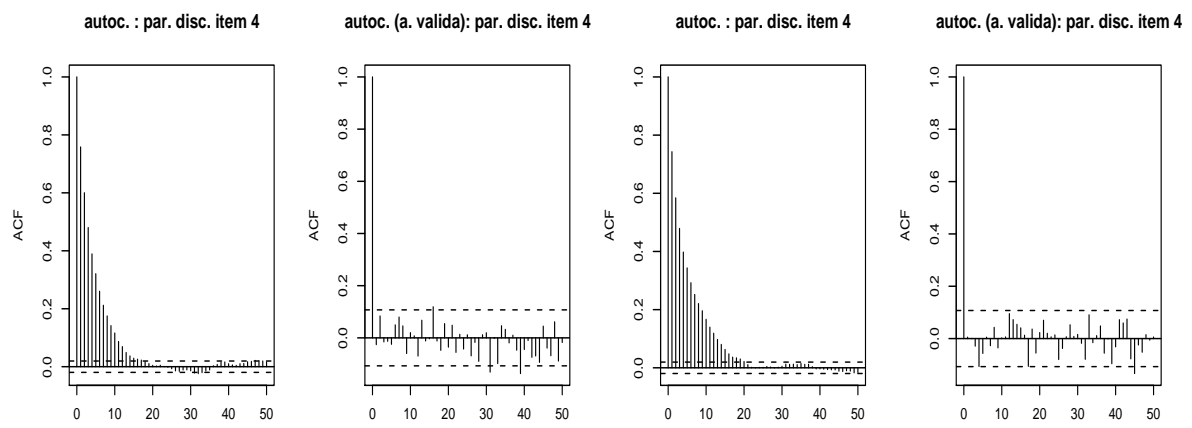

lag

lag

lag
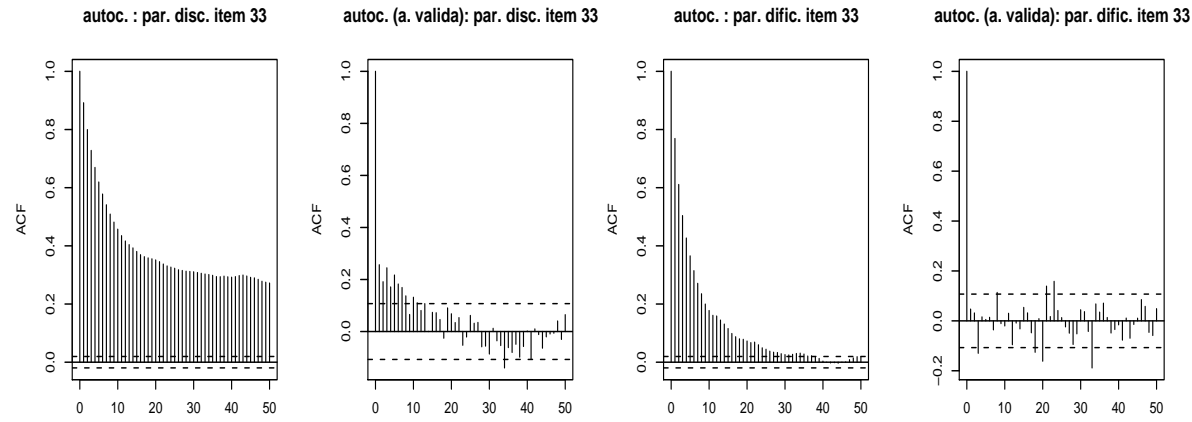

lag

lag

Figura 3.9: Auto-correlacao dos parâmetros dos itens 4 e 33 : estudo de acompanhamento 

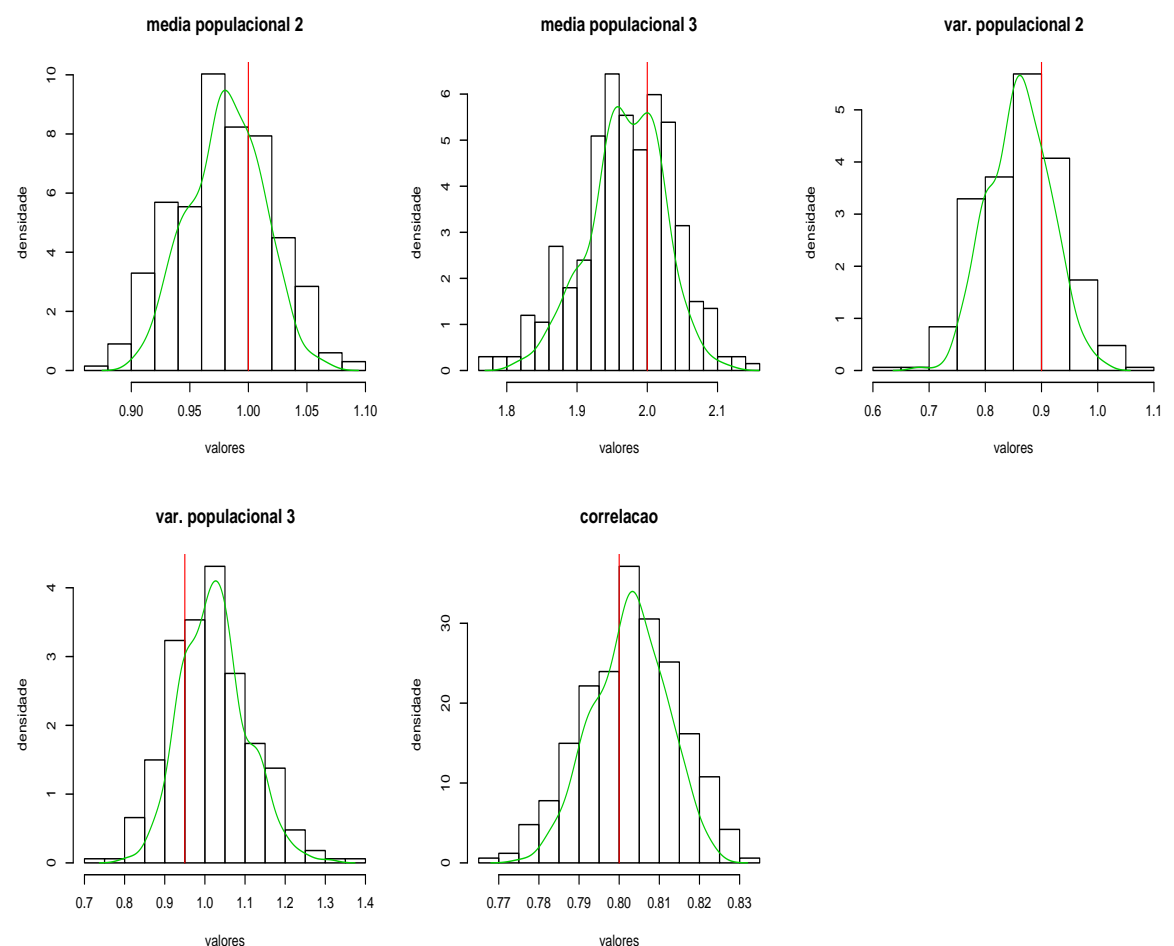

Figura 3.10: Histogramas e densidades das amostras válidas dos parâmetros populacionais

Azevedo, Caio L. N. 

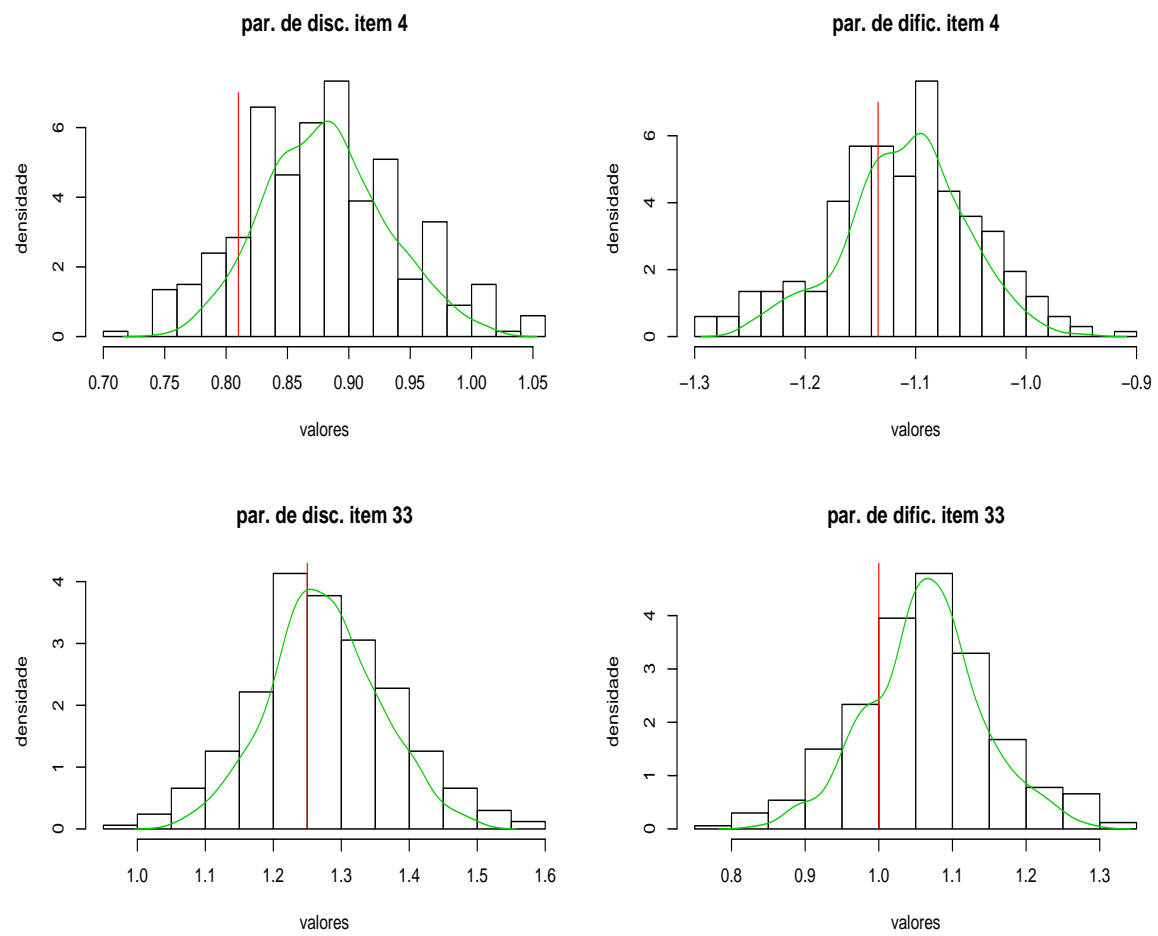

Figura 3.11: Histogramas e densidades das amostras válidas dos parâmetros dos itens selecionados 

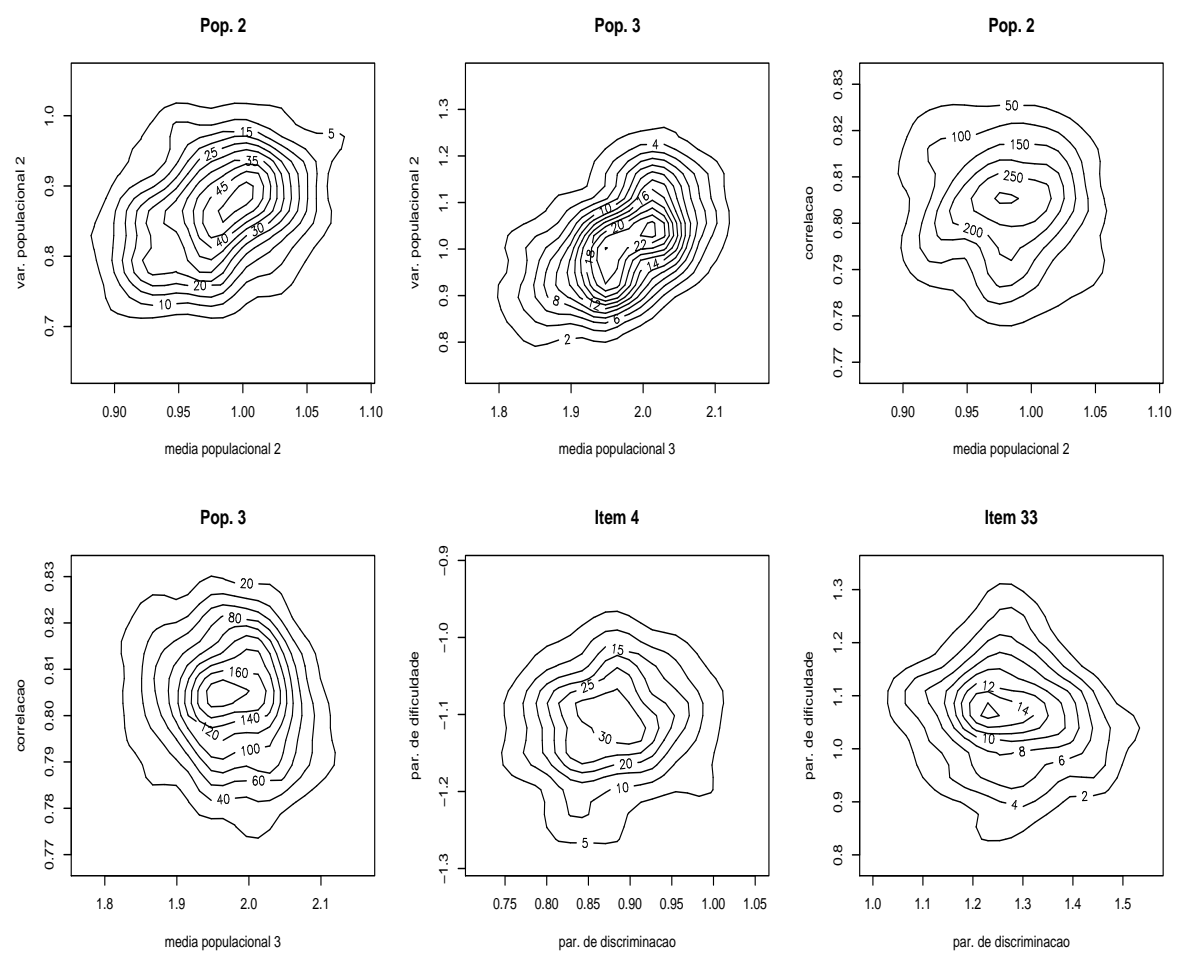

Figura 3.12: Densidades conjuntas das amostras válidas para os parâmetros selecionados 


\subsection{Análise de dados reais}

Os dados em questão correspondem exatamente àqueles descritos na Seção 2.11. Na medida em que estamos utilizando um outro modelo e, dessa forma, podemos obter resultados distintos, começaremos considerando o conjunto total de 94 itens.

Primeiramente, apresentaremos algumas características estimadas a partir do modelo de grupos múltiplos. A matriz dada em (3.31) apresenta as variâncias na diagona principal, as correlações acima dela e as covariâncias abaixo, todas calculadas a partir das estimativas dos traços latentes, com exceção das variâncias que foram obtidas pelo procedimento MCMC através dos parâmetros populacionais diretamente, veja Tabela 2.12.

$$
\left[\begin{array}{lll}
1,000 & 0,723 & 0,629 \\
0,659 & 1,152 & 0,681 \\
0,540 & 0,641 & 1,071
\end{array}\right]
$$

As variâncias que foram calculadas através das estimativas dos traços latentes foram diferentes destas e, seguindo Mislevy (1991), utilizaremos aqueles valores ao invés destes. É digno de nota que tal comportamento também ocorreu nos estudos de simulação. Acreditamos que existem, basicamente, três fatores que explicam isso : as estimativas obtidas através dos preditores (estimativas) dos traços latentes são menos precisas do que àquelas obtidas através dos parâmetros populacionais como demonstrado em Mislevy (1991); segundo, como as estimativas obtidas via MCMC são baseadas em simulações que dependem, por sua vez, dos resultados de outras simulações, espera-se uma flutuação amostral decorrente disso; terceiro, como o MGM não considera uma possível dependência existente entre os traços latentes do mesmo indivíduo e, portanto, utiliza menos informação, espera-se obter uma precisão menor nos resultados. Contudo, o mais importante é observar uma correlação positiva decrescente entre os traços latentes, que parece não ser a mesma para pares de tempos equidistantes, o que indicaria uma não estacionariedade, veja Hamilton (1994). Com efeito, testes de hipótese para nulidade das correlações geraram p-valores menores do que 0,001. Isto sugere a existência de dependência entre os traços latentes dos mesmos indivíduos. Portanto, um modelo que contemple tal estrutura seria preferível ao modelo que supõe independência.

Dessa maneira, ajustou-se via MCMC o modelo descrito neste capítulo, considerando a priori de número 5 com as mesmas escolhas definidas nas subseções anteriores acerca das cadeias geradas. Esta análise detectou a presença de 23 itens com o valor do parâmetro de discriminação abaixo de 0,4, um a mais do que fora acusado pelo ajuste do MGM. Dessa forma, tais itens foram retirados, ficando-se com um total de 72 itens. A análise com esse conjunto detectou a presença de apenas um item com valor da discriminação abaixo de 0,4 e optou-se por deixá-lo.

Azevedo, Caio L. N.

IME/USP 
O p-valor bayesiano, utilizando-se a medida de discrepância (2.25), referente ao ajuste deste modelo foi $\mathrm{p}=0,4281$, praticamente o mesmo daquele obtido pelo MGM, valor que indica um bom ajuste do modelo. A Figura 3.13 apresenta os resultados referentes a distribuição dos escores, com os respectivos valores preditos pelo modelo e IC's de 95\%. Praticamente é o mesmo comportamento da Figura 2.13 , o que indicaria que não houve uma melhora significativa, de uma forma global, no ajuste do modelo, pelo fato de ter-se incorporado a estrutura de dependência. Podemos verificar que, para todos os 3 grupos, os escores observados encontram-se próximos dos preditos e, para a maioria dos valores, dentro dos intervalos de credibilidade. Isto reforça o parecer pelo ajuste razoável do modelo. As Figuras 3.14 e 3.15 apresentam, respectivamente, as densidades das distribuições dos resíduos dos traços latentes e os gráficos de quantis normal-normal associados. Nota-se que a suposição de normalidade parece não ser violada. De modo semelhante, parece não haver diferenças perceptíveis entre estes gráficos e as Figuras 2.14 e 2.15. que são seus correspondentes no ajuste utilizando-se o MGM. Assim, podemos concluir que o modelo se ajustou de modo satisfatório aos dados.

A Tabela 3.9 apresenta os resultados referentes aos parâmetos de discriminação e de dificuldade (originais), enquanto que a Tabela 3.10 apresenta algumas medidas resumo referente à elas. As conclusões são essencialmente as mesmas as que foram construídas na análise da seção 2.11 Ou seja, o teste parece ter sido fácil para a população envolvida no estudo, com um baixo poder de discriminação, em geral. Novamente, essas conclusões dizem respeito à um modelo que, embora considere a estrutura de dependência nos traços latentes, claramente existente, não incorpora o parâmetro de acerto acaso. Portanto, dado que o teste possui uma estrutura de múltipla escolha, um parecer mais efetivo sobre a qualidade do teste passa, necesseriamente, pelo o uso do modelo de 3 parâmetros, ou de resposta nominal, veja Baker and Kim (2004).

Com relação aos parâmetros populacionais, percebemos que houve uma mudança (significativa) em relação ao MGM. Tal mudança diz respeito ao fato de que o ajuste do MLONG sugere uma homocedasticidade plena e não só entre as variâncias dos dois últimos instantes, veja os comentários na seção 2.11. Com efeito, a área comum entre as duas densidades, no caso do modelo longitudinal, calculada através da função de distribuição acumulada empírica, veja Rohatgi and Saleh (1994) foi de 0,7395, relativamente maior do que a área encontrada na seção 2.11, que foi de 0,6138 . No que diz respeito as médias, a mesma tendência positiva crescente foi detectada, o que mostra uma ganho significativo no conhecimento dos indivíduos ao longo do tempo. Além disso, a correlação, entre dois tempos consecutivos, foi significativamente alta $\widehat{\rho}_{\theta}=0,865(0,009)$, o que indica que existe uma forte dependência entre os traços latentes dos mesmos indivíduos. Ademais, esta estimativa foi bem diferente do valor encontrado através do MGM, veja a matriz dada em (3.31), a qual foi de 0,723 . Isto reforça o ganho em se utilizar o MLONG ao invés do MGM, para analisar os dados do estudo longitudinal.

Azevedo, Caio L. N.

IME/USP 

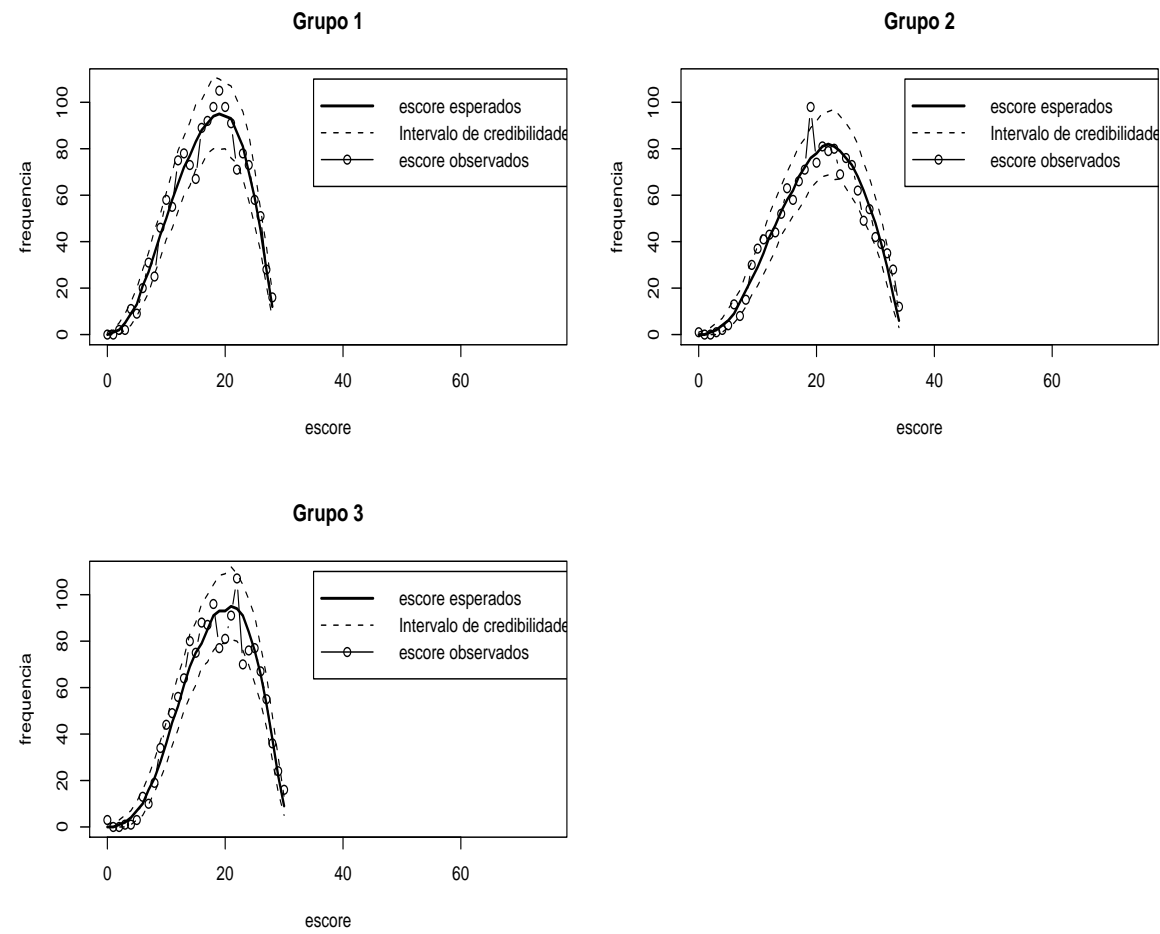

Figura 3.13: Escores preditos, observados e IC's simétricos de $95 \%$

Azevedo, Caio L. N. 

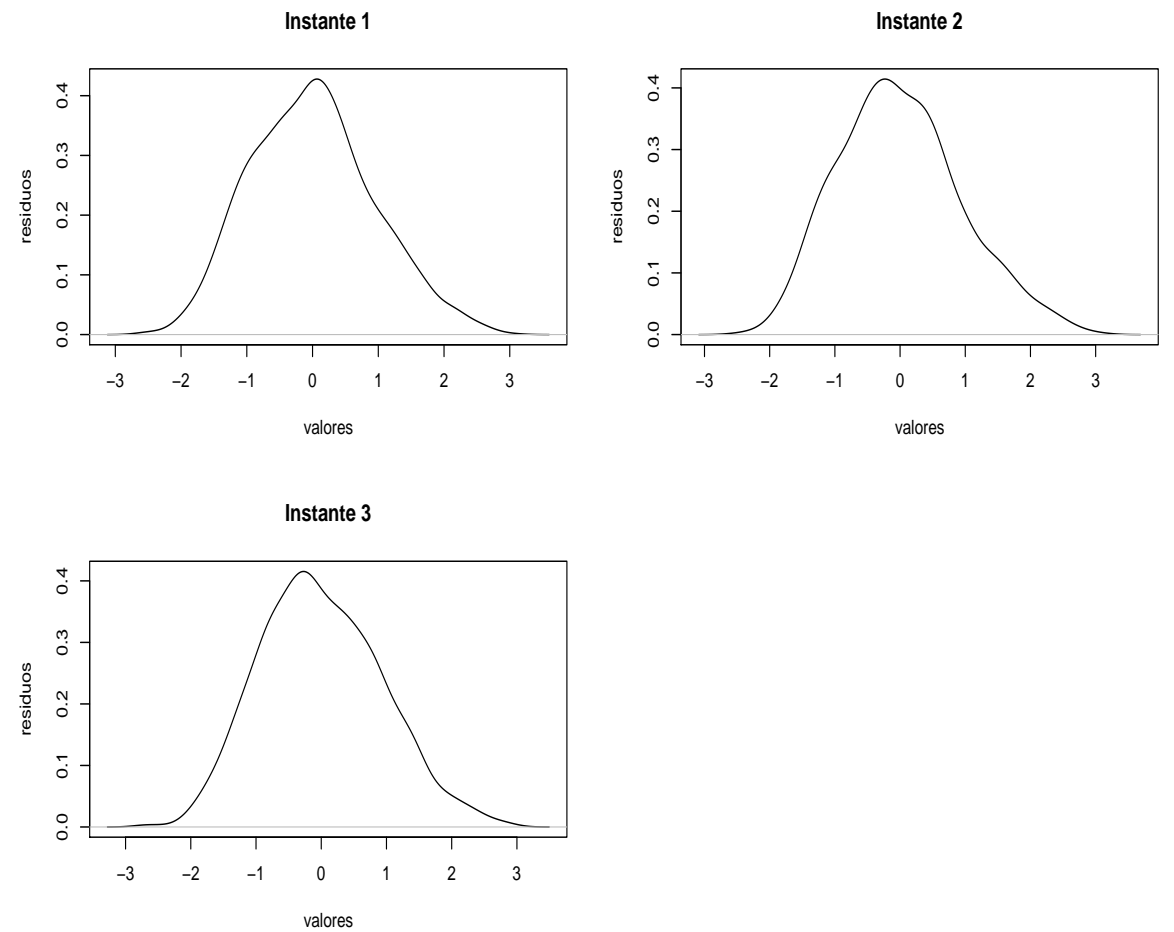

Figura 3.14: Densidade dos resíduos dos traços latentes

Azevedo, Caio L. N. 

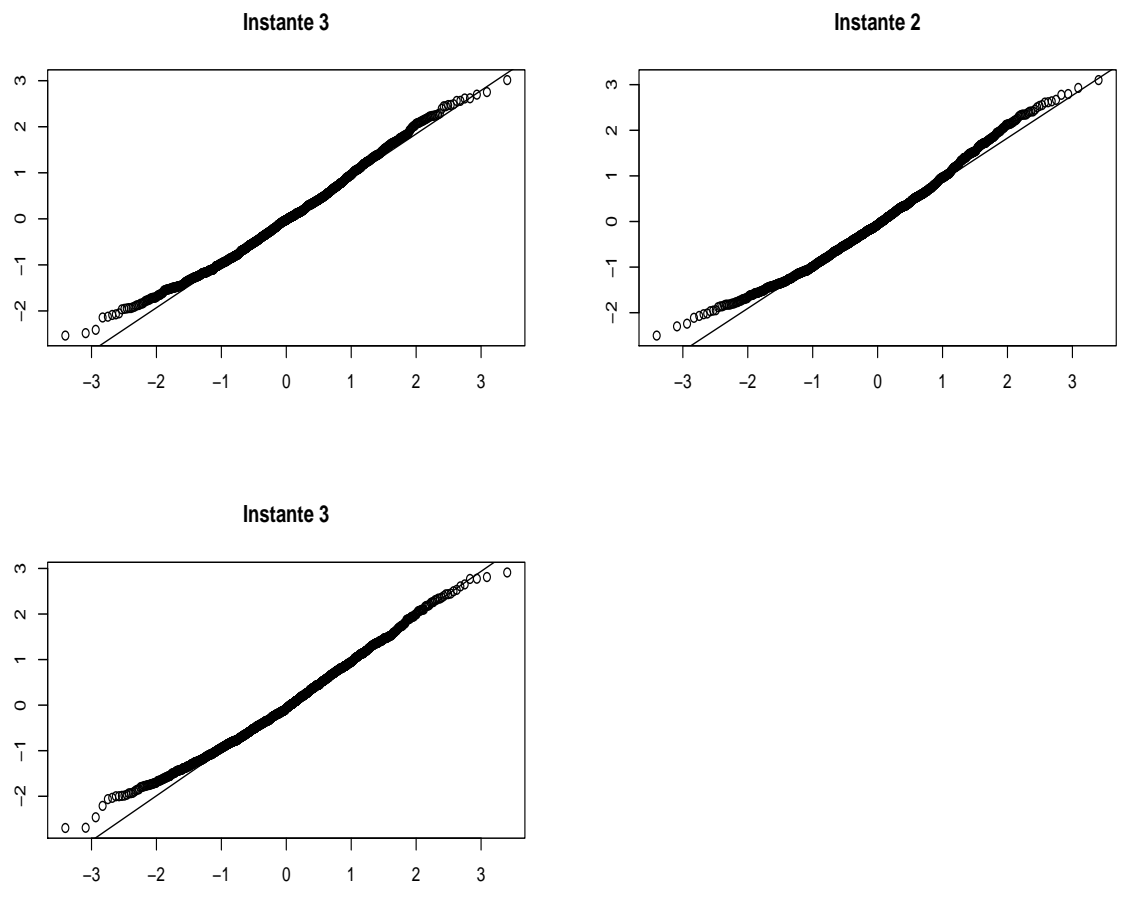

Figura 3.15: Gráficos de quantis normal-normal dos resíduos dos traços latentes 
Tabela 3.9: Resultados dos parâmetros dos itens : análise de dados reais

\begin{tabular}{|c|c|c|c|c|c|c|c|c|c|}
\hline \multirow[t]{3}{*}{ Teste } & \multirow[t]{3}{*}{ Item } & \multicolumn{8}{|c|}{ Estimativas } \\
\hline & & \multicolumn{4}{|c|}{ a } & \multicolumn{4}{|c|}{$\mathbf{b}^{*}$} \\
\hline & & Est. & EP & CI (95\%) & HPD(95\%) & Est. & EP & CI (95\%) & HPD(95\%) \\
\hline 1 & 101 & 0,414 & 0,039 & 0,$339 ; 0,488$ & {$[0,335 ; 0,481]$} & $-0,438$ & 0,084 & {$[-0,610 ;-0,283]$} & {$[-0,600 ;-0,274$} \\
\hline 1 & 102 & 0,447 & 0,043 & 0,$366 ; 0,539$ & 0,$356 ; 0,520$ & $-0,868$ & 0,103 & {$[-1,088 ;-0,681]$} & $-1,064 ;-0,666$ \\
\hline 1 & 103 & 0,651 & 0,049 & 0,$555 ; 0,736$ & 0,$555 ; 0,736$ & $-0,891$ & 0,077 & $-1,056 ;-0,756$ & $-1,033 ;-0,752$ \\
\hline $1-2$ & 104 & 0,571 & 0,031 & 0,$514 ; 0,633$ & 0,$520 ; 0,635$ & $-0,593$ & 0,052 & $-0,696 ;-0,496$ & $-0,693 ;-0,495$ \\
\hline 1 & 106 & 0,424 & 0,043 & 0,$344 ; 0,501$ & 0,$350 ; 0,503$ & $-1,415$ & 0,158 & $-1,794 ;-1,156$ & $-1,755 ;-1,146$ \\
\hline 1 & 108 & 0,420 & 0,042 & 0,$334 ; 0,505$ & 0,$336 ; 0,506$ & $-1,702$ & 0,171 & $-2,080 ;-1,385$ & $-2,005 ;-1,340$ \\
\hline $1-2-3$ & 109 & 0,787 & 0,037 & 0,$715 ; 0,857$ & 0,$712 ; 0,853$ & $-0,833$ & 0,049 & $-0,930 ;-0,743$ & $-0,934 ;-0,747$ \\
\hline $1-2$ & 110 & 0,697 & 0,035 & 0,$633 ; 0,768$ & 0,$637 ; 0,769$ & $-0,435$ & 0,043 & $-0,521 ;-0,352$ & $-0,520 ;-0,351$ \\
\hline 1 & 111 & 0,569 & 0,050 & 0,$464 ; 0,670$ & 0,$491 ; 0,678$ & $-1,513$ & 0,119 & $-1,756 ;-1,290$ & $-1,726 ;-1,273$ \\
\hline $1-2-3$ & 114 & 0,550 & 0,026 & 0,$493 ; 0,597$ & 0,$502 ; 0,600$ & $-0,396$ & 0,048 & $-0,491 ;-0,304$ & $-0,479 ;-0,302$ \\
\hline 1 & 116 & 0,741 & 0,052 & 0,$645 ; 0,847$ & 0,$655 ; 0,856$ & $-1,009$ & 0,066 & $-1,159 ;-0,883$ & $-1,174 ;-0,902$ \\
\hline 1 & 117 & 0,524 & 0,040 & 0,$453 ; 0,614$ & 0,$451 ; 0,604$ & 0,038 & 0,067 & {$[-0,088 ; 0,166$} & {$[-0,099 ; 0,153$} \\
\hline $1-2-3$ & 118 & 0,551 & 0,043 & 0,$466 ; 0,636$ & 0,$471 ; 0,637$ & $-0,548$ & 0,070 & $-0,706 ;-0,424$ & $-0,680 ;-0,404$ \\
\hline 1 & 119 & 0,448 & 0,026 & 0,$393 ; 0,499$ & 0,$398 ; 0,499$ & $-0,791$ & 0,069 & $-0,953 ;-0,670$ & $-0,934 ;-0,666$ \\
\hline 1 & 120 & 0,431 & 0,043 & 0,$348 ; 0,521$ & 0,$342 ; 0,510$ & $-0,668$ & 0,095 & $-0,841 ;-0,493$ & $-0,841 ;-0,493$ \\
\hline $1-2$ & 121 & 0,501 & 0,047 & 0,$415 ; 0,591$ & 0,$417 ; 0,592$ & $-1,830$ & 0,166 & $-2,199 ;-1,528$ & $-2,159 ;-1,523$ \\
\hline $1-2-3$ & 122 & 0,689 & 0,034 & 0,$624 ; 0,758$ & 0,$630 ; 0,763$ & 0,253 & 0,042 & {$[0,170 ; 0,332$} & {$[0,179 ; 0,338$} \\
\hline 1 & 124 & 0,715 & 0,028 & 0,$663 ; 0,769$ & 0,$663 ; 0,768$ & 0,001 & 0,036 & {$[-0,071 ; 0,060$} & {$[-0,067 ; 0,061$} \\
\hline $1-2$ & 125 & 0,772 & 0,056 & 0,$666 ; 0,881$ & 0,$666 ; 0,881$ & $-1,021$ & 0,069 & $-1,182 ;-0,898$ & $-1,159 ;-0,886$ \\
\hline 1 & 126 & 0,754 & 0,034 & 0,$681 ; 0,818$ & 0,$687 ; 0,821$ & $-0,370$ & 0,039 & $-0,448 ;-0,298$ & $-0,440 ;-0,296$ \\
\hline $1-2-3$ & 127 & 0,608 & 0,041 & 0,$533 ; 0,690$ & 0,$534 ; 0,691$ & 0,030 & 0,054 & {$[-0,082 ; 0,143$} & {$[-0,084 ; 0,133$} \\
\hline 1 & 128 & 0,722 & 0,031 & 0,$667 ; 0,783$ & 0,$667 ; 0,782$ & 0,045 & 0,033 & {$[-0,017 ; 0,110$} & {$[-0,020 ; 0,105$} \\
\hline 1 & 129 & 0,794 & 0,052 & 0,$685 ; 0,895$ & 0,$680 ; 0,888$ & $-0,163$ & 0,046 & $-0,253 ;-0,076$ & $-0,253 ;-0,079$ \\
\hline 1 & 132 & 0,509 & 0,041 & 0,$429 ; 0,588$ & 0,$439 ; 0,595$ & $-0,018$ & 0,071 & {$[-0,159 ; 0,122$} & {$[-0,131 ; 0,130$} \\
\hline $1-2$ & 134 & 0,585 & 0,041 & 0,$511 ; 0,668$ & 0,$508 ; 0,661$ & $-1,805$ & 0,125 & $-2,068 ;-1,574$ & $-2,046 ;-1,561$ \\
\hline 1 & 135 & 0,911 & 0,054 & 0,$808 ; 1,017$ & 0,$821 ; 1,022$ & $-0,560$ & 0,048 & $-0,655 ;-0,473$ & $-0,659 ;-0,478$ \\
\hline 1 & 136 & 0,431 & 0,038 & 0,$359 ; 0,500$ & 0,$355 ; 0,494$ & $-0,297$ & 0,082 & $-0,462 ;-0,136$ & $-0,441 ;-0,124$ \\
\hline 2 & 203 & 0,546 & 0,047 & 0,$462 ; 0,640$ & 0,$467 ; 0,641$ & $-0,037$ & 0,069 & {$[-0,166 ; 0,106$} & {$[-0,174 ; 0,083$} \\
\hline $2-3$ & 204 & 0,427 & 0,033 & 0,$363 ; 0,499$ & 0,$360 ; 0,489$ & $-1,525$ & 0,155 & $-1,833 ;-1,235$ & $-1,816 ;-1,227$ \\
\hline 2 & 207 & 0,752 & 0,052 & 0,$652 ; 0,863$ & 0,$660 ; 0,867$ & 0,074 & 0,056 & {$[-0,023 ; 0,202$} & {$[-0,033 ; 0,187$} \\
\hline 2 & 208 & 0,675 & 0,049 & 0,$584 ; 0,777$ & 0,$568 ; 0,751$ & 1,370 & 0,097 & {$[1,186 ; 1,551$} & {$[1,207 ; 1,560$} \\
\hline 2 & 209 & 0,677 & 0,055 & 0,$575 ; 0,790$ & 0,$576 ; 0,791$ & $-1,021$ & 0,098 & $-1,246 ;-0,837$ & $-1,227 ;-0,837$ \\
\hline 2 & 210 & 0,610 & 0,045 & 0,$526 ; 0,705$ & 0,$522 ; 0,699$ & $-0,253$ & 0,070 & $-0,399 ;-0,123$ & $-0,393 ;-0,120$ \\
\hline 2 & 214 & 0,505 & 0,040 & 0,$429 ; 0,580$ & 0,$431 ; 0,582$ & 1,671 & 0,132 & {$[1,444 ; 1,944$} & {$[1,443 ; 1,936$} \\
\hline 2 & 215 & 0,442 & 0,041 & 0,$363 ; 0,526$ & 0,$360 ; 0,519$ & 1,284 & 0,129 & {$[1,068 ; 1,577$} & {$[1,061 ; 1,563$} \\
\hline 2 & 216 & 0,646 & 0,064 & 0,$520 ; 0,780$ & 0,$514 ; 0,764$ & $-1,900$ & 0,172 & $-2,273 ;-1,599$ & $-2,283 ;-1,622$ \\
\hline $2-3$ & 218 & 0,703 & 0,045 & 0,$613 ; 0,796$ & 0,$624 ; 0,798$ & $-1,017$ & 0,081 & $-1,195 ;-0,866$ & $-1,195 ;-0,866$ \\
\hline $2-3$ & 219 & 0,539 & 0,035 & 0,$469 ; 0,607$ & 0,$477 ; 0,611$ & $-0,126$ & 0,056 & $-0,240 ;-0,013$ & $-0,249 ;-0,033$ \\
\hline 2 & 220 & 0,444 & 0,041 & 0,$367 ; 0,534$ & 0,$356 ; 0,517$ & 1,462 & 0,140 & {$[1,205 ; 1,773$} & {$[1,169 ; 1,721$} \\
\hline 2 & 221 & 0,539 & 0,042 & 0,$463 ; 0,620$ & 0,$465 ; 0,621$ & $-0,096$ & 0,075 & {$[-0,260 ; 0,040$} & {$[-0,263 ; 0,032$} \\
\hline 2 & 222 & 0,751 & 0,062 & 0,$640 ; 0,867$ & 0,$639 ; 0,864$ & $-1,442$ & 0,115 & {$[-1,665 ;-1,242$} & {$[-1,665 ;-1,242$} \\
\hline $2-3$ & 223 & 0,784 & 0,039 & 0,$709 ; 0,856$ & 0,$715 ; 0,861$ & 0,467 & 0,044 & {$[0,388 ; 0,559$} & {$[0,385 ; 0,556$} \\
\hline 2 & 225 & 0,737 & 0,071 & 0,$608 ; 0,873$ & 0,$605 ; 0,867$ & $-1,624$ & 0,156 & $-1,937 ;-1,358$ & $-1,917 ;-1,350$ \\
\hline 2 & 226 & 0,481 & 0,044 & 0,$410 ; 0,566$ & 0,$410 ; 0,566$ & $-0,465$ & 0,092 & $-0,668 ;-0,295$ & $-0,640 ;-0,270$ \\
\hline 2 & 227 & 0,456 & 0,043 & 0,$368 ; 0,542$ & 0,$376 ; 0,545$ & 1,005 & 0,105 & {$[0,824 ; 1,219$} & {$[0,824 ; 1,219$} \\
\hline 2 & 228 & 0,659 & 0,050 & 0,$560 ; 0,764$ & 0,$559 ; 0,749$ & 0,556 & 0,066 & {$[0,437 ; 0,698$} & {$[0,433 ; 0,692$} \\
\hline 2 & 229 & 0,869 & 0,078 & 0,$718 ; 1,031$ & 0,$704 ; 1,013$ & $-1,509$ & 0,115 & $-1,756 ;-1,306$ & {$[-1,760 ;-1,316$} \\
\hline 2 & 233 & 0,575 & 0,046 & 0,$494 ; 0,664$ & 0,$494 ; 0,664$ & $-0,580$ & 0,087 & $-0,754 ;-0,423$ & $-0,748 ;-0,421$ \\
\hline 2 & 234 & 0,957 & 0,065 & 0,$825 ; 1,084$ & 0,$819 ; 1,062$ & $-0,404$ & 0,054 & $-0,510 ;-0,284$ & $-0,515 ;-0,311$ \\
\hline 2 & 236 & 0,748 & 0,057 & 0,$651 ; 0,864$ & 0,$644 ; 0,846$ & $-0,852$ & 0,077 & $-1,009 ;-0,712$ & $-0,992 ;-0,704$ \\
\hline 2 & 240 & 0,577 & 0,049 & 0,$483 ; 0,675$ & 0,$492 ; 0,683$ & $-0,937$ & 0,109 & $-1,162 ;-0,756$ & $-1,155 ;-0,753$ \\
\hline
\end{tabular}

Azevedo, Caio L. N. 
Continuação da Tabela 3.9

\begin{tabular}{|c|c|c|c|c|c|c|c|c|c|}
\hline \multirow[t]{3}{*}{ Teste } & \multirow[t]{3}{*}{ Item } & \multicolumn{8}{|c|}{ Estimativas } \\
\hline & & \multicolumn{4}{|c|}{$\mathbf{a}$} & \multicolumn{4}{|c|}{$\mathrm{b}^{*}$} \\
\hline & & Est. & EP & CI (95\%) & HPD(95\%) & Est. & EP & CI (95\%) & HPD $(95 \%)$ \\
\hline 3 & 303 & 0,477 & 0,051 & 0,$378 ; 0,581$ & 0,$376 ; 0,568$ & $-1,039$ & 0,176 & {$[-1,379 ;-0,742$} & {$[-1,379 ;-0,742$} \\
\hline 3 & 308 & 0,507 & 0,043 & 0,$425 ; 0,597$ & 0,$422 ; 0,589$ & 1,213 & 0,091 & {$[1,048 ; 1,407$} & {$[1,054 ; 1,407$} \\
\hline 3 & 309 & 0,552 & 0,054 & 0,$449 ; 0,658$ & 0,$455 ; 0,658$ & $-0,703$ & 0,135 & {$[-0,977 ;-0,467$} & $-0,981 ;-0,485$ \\
\hline 3 & 312 & 0,490 & 0,045 & 0,$409 ; 0,586$ & 0,$401 ; 0,576$ & 0,191 & 0,084 & {$[0,014 ; 0,347$} & {$[0,014 ; 0,347$} \\
\hline 3 & 315 & 0,518 & 0,046 & 0,$435 ; 0,615$ & 0,$433 ; 0,606$ & 0,888 & 0,082 & {$[0,741 ; 1,063$} & {$[0,747 ; 1,066$} \\
\hline 3 & 316 & 0,897 & 0,081 & 0,$747 ; 1,082$ & 0,$760 ; 1,083$ & $-0,774$ & 0,105 & {$[-0,990 ;-0,577$} & {$[-0,993 ;-0,585$} \\
\hline 3 & 317 & 0,589 & 0,050 & 0,$488 ; 0,700$ & 0,$484 ; 0,682$ & 0,633 & 0,072 & {$[0,492 ; 0,781$} & {$[0,511 ; 0,789$} \\
\hline 3 & 318 & 0,417 & 0,043 & 0,$336 ; 0,504$ & 0,$339 ; 0,505$ & 0,897 & 0,088 & 0,$721 ; 1,084$ & 0,$709 ; 1,063$ \\
\hline 3 & 319 & 0,574 & 0,050 & {$\left[\begin{array}{lll}0,484 & 0,669\end{array}\right.$} & {$\left[\begin{array}{lll}0,485 & 0,671\end{array}\right.$} & 0,807 & 0,075 & {$\left[\begin{array}{lll}0,666 & 0,943\end{array}\right.$} & {$\left[\begin{array}{ll}0,672 & 0,943\end{array}\right.$} \\
\hline 3 & 324 & 0,663 & 0,059 & {$\left[\begin{array}{ll}0,547 & 0,777\end{array}\right.$} & {$\left[\begin{array}{lll}0,547 & 0,777\end{array}\right.$} & $-0,302$ & 0,090 & $-0,484-0,131$ & $-0,500-0,155$ \\
\hline 3 & 326 & 0,496 & 0,051 & $0,388 \quad 0,588$ & $0,407 \quad 0,602$ & $-0,147$ & 0,111 & {$[-0,377 \quad 0,046$} & {$\left[\begin{array}{ll}-0,377 & 0,032\end{array}\right.$} \\
\hline 3 & 330 & 0,513 & 0,046 & $0,4170,602$ & $0,4170,602$ & 0,680 & 0,080 & {$\left[\begin{array}{lll}0,538 & 0,843\end{array}\right.$} & {$\left[\begin{array}{lll}0,539 & 0,844\end{array}\right.$} \\
\hline 3 & 331 & 0,526 & 0,050 & $0,4390,627$ & $0,437 \quad 0,623$ & $-0,586$ & 0,128 & {$[-0,864-0,357$} & $-0,823-0,342$ \\
\hline 3 & 332 & 0,655 & 0,052 & $0,5570,768$ & $0,544 \quad 0,748$ & 0,475 & 0,068 & {$[0,3340,616$} & {$\left[\begin{array}{ll}0,333 & 0,603\end{array}\right.$} \\
\hline 3 & 334 & 0,494 & 0,049 & $0,410 \quad 0,595$ & $0,407 \quad 0,589$ & $-0,398$ & 0,111 & {$\left[\begin{array}{lll}-0,617 & -0,188\end{array}\right.$} & {$[-0,570-0,155$} \\
\hline 3 & 335 & 0,634 & 0,052 & $0,5410,734$ & $0,5300,719$ & 0,490 & 0,067 & {$\left[\begin{array}{lll}0,356 & 0,620\end{array}\right.$} & {$\left[\begin{array}{lll}0,356 & 0,620\end{array}\right.$} \\
\hline 3 & 336 & 0,448 & 0,046 & $0,358 \quad 0,549$ & $0,351 \quad 0,537$ & 0,477 & 0,086 & $0,3030,643$ & $0,2940,616$ \\
\hline 3 & 337 & 0,652 & 0,049 & $0,5630,749$ & $0,5620,741$ & 1,231 & 0,078 & {$[1,0731,378$} & {$[1,0861,386$} \\
\hline 3 & 338 & 0,624 & 0,054 & $0,518 \quad 0,741$ & $0,5120,730$ & 0,003 & 0,076 & {$\left[\begin{array}{lll}-0,151 & 0,134\end{array}\right.$} & {$\left[\begin{array}{lll}-0,136 & 0,145\end{array}\right.$} \\
\hline 3 & 339 & 0,643 & 0,052 & $0,5330,742$ & $0,5190,723$ & 0,707 & 0,068 & {$\left[\begin{array}{lll}0,574 & 0,833\end{array}\right.$} & {$[0,5740,833$} \\
\hline 3 & 340 & 0,393 & 0,041 & $0,3180,478$ & {$[0,3150,469$} & 1,279 & 0,119 & {$\left[\begin{array}{ll}1,058 & 1,514\end{array}\right.$} & $1,0551,500$ \\
\hline
\end{tabular}

Tabela 3.10: Estatística descritivas das estimativas dos parâmetros dos itens

\begin{tabular}{lrr}
\hline \hline Estatística & Disc. (a) & Dif. Ori. $\left(\mathbf{b}^{*}\right)$ \\
\hline Média & 0,598 & $-0,245$ \\
Mediana & 0,575 & $-0,336$ \\
Desvio padrão & 0,135 & 0,887 \\
CV(\%) & 22,500 & 361,202 \\
Mínimo & 0,393 & $-1,900$ \\
Máximo & 0,957 & 1,671 \\
Assimetria & 0,579 & 0,181 \\
\hline \hline
\end{tabular}

Tabela 3.11: Resultados das estimativas dos parâmetros populacionais : análise de dados reais

\begin{tabular}{lcccc}
\hline \hline Parâmetro & Est. & EP & $\mathbf{I C ( 9 5 \% )}$ & $\mathbf{H P D ( 9 5 \% )}$ \\
\hline$\mu_{\theta_{2}}$ & 0,234 & 0,040 & {$[0,156 ; 0,314]$} & {$[0,166 ; 0,319]$} \\
$\mu_{\theta_{3}}$ & 0,756 & 0,049 & {$[0,665 ; 0,858]$} & {$[0,660 ; 0,844]$} \\
$\psi_{\theta_{2}}$ & 1,021 & 0,082 & {$[0,880 ; 1,188]$} & {$[0,876 ; 1,177]$} \\
$\psi_{\theta_{2}}$ & 0,963 & 0,086 & {$[0,805 ; 1,143]$} & {$[0,790 ; 1,108]$} \\
$\rho_{\theta}$ & 0,865 & 0,009 & {$[0,848 ; 0,882]$} & {$[0,850 ; 0,883]$} \\
\hline \hline
\end{tabular}

Azevedo, Caio L. N. 


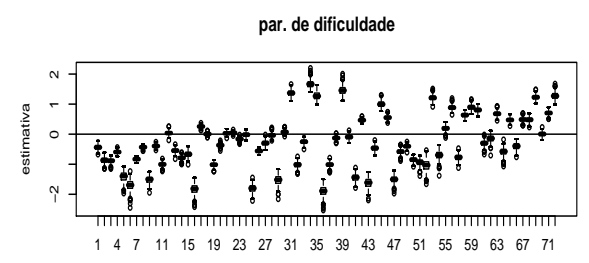

iten

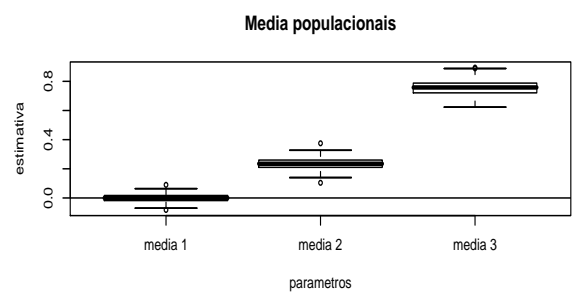

Par. de correlacao

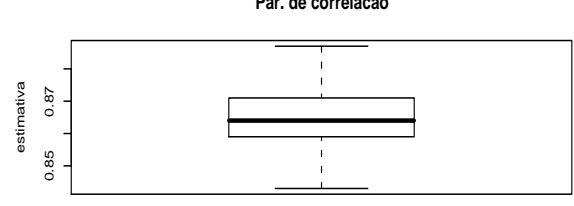

correlacao par. de discriminacao

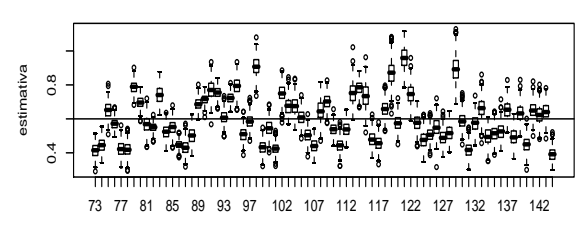

item

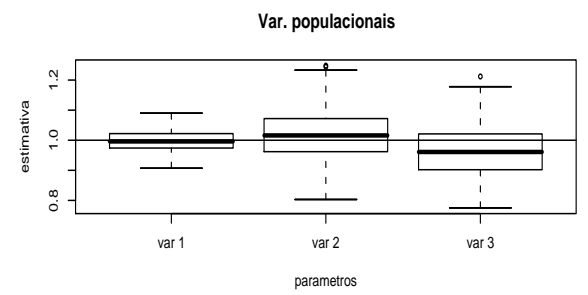

Figura 3.16: Box-plot das estimativas dos parâmetros dos itens e populacionais 

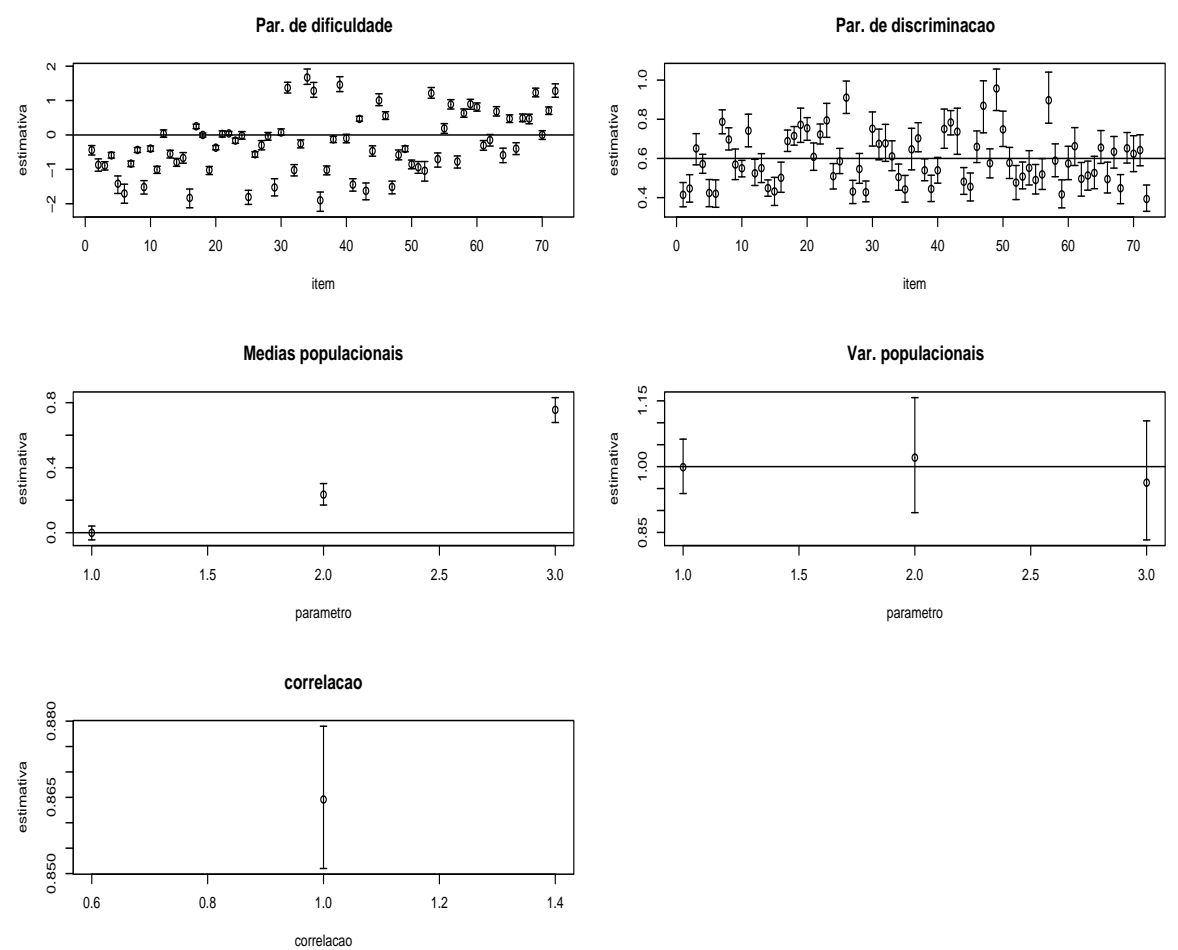

Figura 3.17: Estimativas e IC's simétricos de 95\% para os parâmetros dos itens e populacionais 

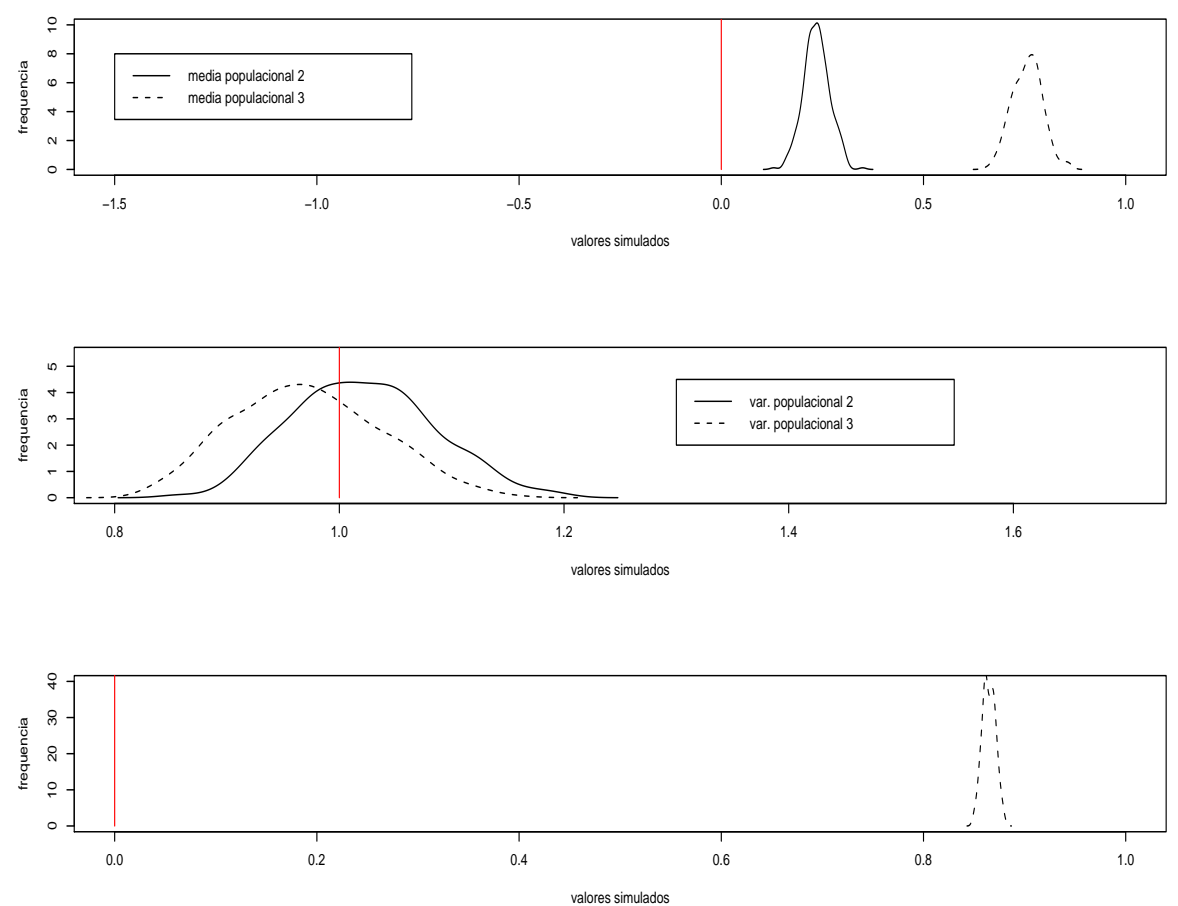

Figura 3.18: Comparação das densidades dos parâmetros populacionais 


\subsection{Comentários}

No presente Capítulo apresentamos uma estrutura de análise bayesiana via dados aumentados para o modelo probito de 2 parâmetros da TRI. Esta estrutura compreende um algoritmo de Gibbs para simulação MCMC e alguns métodos de diagnóstico para a validação do modelo. A metodologia de estimação proposta é bastante flexível pois permite considerar um número virtualmente infinito de instantes de avaliação bem como diversas estrutras de covariâncias : estacionárioas ou não, homocedásticas, heterocedásticas etc. Com efeito, nenhuma estrutura é imposta à $\boldsymbol{\Psi}_{\boldsymbol{\theta}}$ na construção do algoritmo do amostrador de Gibbs. Os métodos de diagnóstico permitem inferir sobre o ajuste geral do modelo e do afastamento da suposição de normalidade para os traços latentes. As simulações indicaram não só consistência dos estimadores como também uma certa robustez à escolha de prioris. Contudo, deve-se ter um certo cuidado com a escolha de prioris impróprias. Na análise de dados reais verificou-se que existe uma ganho nos resultados ao se modelar a estrutura de dependência em detrimento à utilização da modelagem de independência. Notadamente, este ganho se observa na melhor acurácia das estimativas dos parâmetros populacionais.

Azevedo, Caio L. N. 


\section{Capítulo 4}

\section{Modelo longitudinal com grupos múltiplos: abordagem multivariada bayesiana}

\subsection{Introdução}

Freqüentemente, em muitos estudos de caráter científico que envolvem a análise de variáveis latentes (conhecimento, qualidade de vida, grau de depressão) tem-se o interesse em acompanhar indivíduos pertencentes à diferentes grupos, ao longo de várias condições de avaliação. Por exemplo, a avaliação de estudantes de escolas públicas e privadas ao longo de diferentes séries. O estudo da qualidade de vida de homes e mulheres ao longo de algumas semanas. Para se analisar tais conjuntos de dados, poder-se-ía considerar as combinações grupo/tempo como sendo populações independentes. A partir desse pressuposto seria possível utilizar metodologias de equalização a posteriori ou utilizar o MGM, veja Kolen and Brennan (2004) e Bock and Zimowski (1997). Entretanto, não importa qual das duas abordagens mencionadas se adote, não se considerará estruturas de dependência induzidas pelas medidas feitas em mesmos indivíduos. Dessa forma, estar-se-ía negligenciando informações potencialmente importantes. Além disso, a análise conjunta (longitudinal com grupos múltiplos) permite equalizar os resultados em concomitância com o ajuste do modelos

No presente capítulo proporemos uma extensão dos modelos desenvolvidos nos dois capítulos anteriores. Em outras palavras, consideraremos uma estrutura de análise para dados longitudinais com grupos múltiplos. A presente abordagem difere do Capítulo 7 de Tavares (2001), na medida que utilizaremos uma estrutura bayesiana via dados aumentados, tal como nos capítulos 2 e 3 . Além disso, consideraremos algumas questões de potencial interesse.

Um desses aspectos diz respeito ao processo de equalização. Isto ocorre porque é necessário equalizar os resultados dos testes entre e intra populações, veja Tavares (2001). Um outro aspecto concerne à melhor forma de garantir a identificabilidade do modelo. Ou seja, o número mínimo de restrições necessárias para se obter tal característica, veja Rivers (2003). Além disso, a escolha de estruturas de covariância e a modelagem dos vetores de médias (curvas de crescimento) são igualmente importantes. Tais características são relevantes 
não só por permitirem representar de forma mais apropriada o planejamento em questão, mas também por levar à redução do número de parâmetros envolvidos.

Salientamos que, proceder a equalização em concomitância com o ajuste do modelo, permite obter resultados mais confiáveis, veja Kolen and Brennan (2004) e Andrade (1999). Além disso, comparações de interesse intra e entre populações podem ser feitas utilizando-se mais informações, em relação à se considerar a equalização a posteriori.

A estrutura aqui apresentada é uma união daquelas apresentadas nos capítulos 2 e 3. Note-se que quaisquer uma das duas estruturas é um caso particular desta aqui considerada. Mais concretamente, estudaremos $k$ grupos em $T$ condições de avaliação aplicando-se $T$ testes (possivelmente) diferentes. Alguns destes testes devem ter alguns itens em comum para permitir o processo de equalização. É possível que alguns grupos não sejam considerados em todos os instantes assim como particulares subgrupos de indivíduos. Novamente, utilizaremos a denominação grupo para nos referirmos, indistintamente, à uma amostra ou a uma população de indivíduos. Utilizaremos uma distribuição (multivariada) $d_{\boldsymbol{\theta}_{k}}$ para representar o comportamento dos traços latentes.

Na Seção 4.1 apresentamos uma introdução ao problema em questão e pontos de interesse. Na Seção 4.2 apresentaremos o modelo estatístico longitudinal de grupos múltiplos. Na Seção 4.3 construiremos a verossimilhança de dados aumentados. A Seção 4.4 apresentará as matrizes de covariâncias de interesse. Na Seção 4.5 desenvolveremos um algoritmo de Gibbs para o ajuste do modelo proposto. A Seção 4.6 tratará do estudo de um mecanismo de seleção de matrizes de covariância. Na Seção 4.7 consideraremos um estudo de simulação para avaliar a metodologia proposta. A Seção 4.8 versará sobre a análise de um conjunto de dados reais. Finalmente, na Seção 4.9 apresentaremos alguns comentários pertinentes.

As contribuições do presente capítulo são :

1. Desenvolvimento da abordagem de dados aumentados para o modelo probito de 2 parâmetros longitudinal com grupos múltiplos.

2. Estudo de algumas estruturas de covariância importantes na análise de dados longitudinais.

3. Desenvolvimento e implementação computacional do amostrador de Gibbs para o modelo do item 1).

4. Extensão do amostrador de Gibbs mencionado no item 2) para considerar a seleção de estruturas de covariância em concomitância ao ajuste do modelo e respectiva implementação computacional.

5. Estudo de simulação :

(a) Consistência dos estimadores.

(b) Capacidade de seleção da correta estrutura de covariância do procedimento mencionado no item 4).

6. Aplicação da metodologia a um conjunto de dados reais.

Azevedo, Caio L. N.

IME/USP 


\subsection{Modelo estatístico}

De acordo com o estabelecido na seção anterior, temos um conjunto total de $n=\sum_{k=1}^{K} n_{k}$ indivíduos, em que $n_{k}$ é o número de indivíduos do grupo $k$. A cada um desses grupo, no instante $t$ é aplicado um teste com $I_{t}$ itens extraídos de um conjunto total de $I$ itens.

Algumas notações se seguem : seja $\theta_{j k t}$ o traço latente do respondente $j j=1, \ldots, n_{k}$, da população $k$, $k=1, \ldots, K$ no instante $t, t=1, \ldots, T, \boldsymbol{\theta}_{j k} .=\left(\theta_{j k 1}, \ldots, \theta_{j k T}\right)^{t}$ o vetor de traços latentes do indivíduo $j$, da população $k, \boldsymbol{\theta}_{. k t}=\left(\theta_{1 k t}, \ldots, \theta_{n_{k} k t}\right)^{t}$ o vetor dos traços latentes de todos os indivíduos da população $k$, no instante $t, \boldsymbol{\theta}_{. k .}=\left(\boldsymbol{\theta}_{. k 1}, \ldots, \boldsymbol{\theta}_{. k T}\right)^{t}$ o vetor dos vetores de traços latentes de todos os indivíduos da população $k$ e $\boldsymbol{\theta}_{. .}=\left(\boldsymbol{\theta}_{1}, \ldots, \boldsymbol{\theta}_{n}\right)^{t}$ o vetor de todos os traços latentes; $Y_{i j k t}$, o escore do indivíduo $j$ da população $k$ no item $i$, no instante $t, \boldsymbol{Y}_{. j k t}=\left(Y_{1 j k t}, \ldots, Y_{I j k t}\right)^{t}$, o vetor de escores em todos os itens do indvíduo $j$, da população $k$ no instante $t, \boldsymbol{Y}_{. j k}=\left(\boldsymbol{Y}_{1 j t}^{t}, \ldots, \boldsymbol{Y}_{I j t}^{t}\right)^{t}$, o vetor de todas as respostas do indivíduo $j$ da população $k, \boldsymbol{Y}_{\ldots .}=\left(\boldsymbol{Y}_{.1 . .}, \ldots, \boldsymbol{Y}_{. n . .}\right)^{t}$, o vetor com todas as respostas de todos os indivíduos e $\left(y_{i j t}, \boldsymbol{y}_{. j k t}^{t}, \boldsymbol{y}_{. j k .}^{t}, \boldsymbol{y}_{\ldots .}^{t}\right)^{t}$ os respectivos valores observados. Seja também $\boldsymbol{\zeta}_{i}$ o vetor de parâmetros do item $i, \boldsymbol{\zeta}=\left(\boldsymbol{\zeta}_{1}^{t}, \ldots, \boldsymbol{\zeta}_{I}^{t}\right)^{t}$, o vetor com todos os parâmetros de todos os itens, $\boldsymbol{\eta}_{\boldsymbol{\theta}_{k}}$ o conjunto dos parâmetros populacionais da população $k \mathrm{e}$ $\boldsymbol{\eta}_{\boldsymbol{\theta}}=\left(\boldsymbol{\eta}_{\boldsymbol{\theta}_{1}}^{t}, \ldots, \boldsymbol{\eta}_{\boldsymbol{\theta}_{K}}^{t}\right)^{t}$ o vetor com todos os parâmetros populacionais.

O modelo probito de 2 parâmetros longitudinal de grupos múltiplos (MP2PLMG) é dado por

\section{Modelo de Resposta ao Item (parte funcional)}

$$
\begin{aligned}
Y_{i j k t} \mid\left(\theta_{j k t}, \boldsymbol{\zeta}_{i}\right) & \sim B\left(P_{i j k t}\right), \\
P_{i j k t}=P\left(Y_{i j k t}=1 \mid \theta_{j k t}, \boldsymbol{\zeta}_{i}\right) & =\Phi\left(a_{i} \theta_{j k t}-b_{i}\right),
\end{aligned}
$$

\section{Distribuição latente (parte estrutural)}

$$
\boldsymbol{\theta}_{j k .} \mid \boldsymbol{\eta}_{\boldsymbol{\theta}_{k}} \sim N_{T}\left(\boldsymbol{\mu}_{\boldsymbol{\theta}_{k}}, \boldsymbol{\Psi}_{\boldsymbol{\theta}_{k}}\right)
$$

em que 


$$
\boldsymbol{\mu}_{\boldsymbol{\theta}_{k}}=\left[\begin{array}{c}
\mu_{\theta_{K 1}} \\
\mu_{\theta_{K 2}} \\
\vdots \\
\mu_{\boldsymbol{\theta}_{K T}}
\end{array}\right], \boldsymbol{\Psi}_{\boldsymbol{\theta}}=\left[\begin{array}{cccc}
\psi_{k 11(\boldsymbol{\theta})} & \psi_{k 12(\boldsymbol{\theta})} & \ldots & \psi_{k 1 T(\boldsymbol{\theta})} \\
\psi_{k 21(\boldsymbol{\theta})} & \psi_{k 22(\boldsymbol{\theta})} & \ldots & \psi_{k 2 T(\boldsymbol{\theta})} \\
\vdots & \vdots & \ddots & \vdots \\
\psi_{k 1 T(\boldsymbol{\theta})} & \psi_{k 2 T(\boldsymbol{\theta})} & \ldots & \psi_{k T T(\boldsymbol{\theta})}
\end{array}\right]
$$

e as definições seguem aquelas descritas para a equação (3.3). Da mesma forma, podemos definir a estrutura (4.2) utilizando um modelo de regressão multivariada, veja (3.5), ou através da abordagem vetorial descrita em (3.4). Nesta última teremos

$$
\boldsymbol{\theta} \ldots=\mathbf{1}_{n} \otimes \boldsymbol{\mu}_{\boldsymbol{\theta}}+\boldsymbol{\xi}_{\ldots}^{(\boldsymbol{\theta})}
$$

em que $\boldsymbol{\xi}_{\ldots} \sim N_{n T}\left(\mathbf{0}_{n T}, \boldsymbol{\Psi}_{\boldsymbol{\theta}}^{* *}\right), \boldsymbol{\Psi}_{\boldsymbol{\theta}}^{* *}=\bigoplus_{k=1}^{K} \boldsymbol{\Psi}_{\boldsymbol{\theta}_{k}}^{*}, \boldsymbol{\Psi}_{\boldsymbol{\theta}_{k}}^{*}=\boldsymbol{I}_{n_{k}} \otimes \boldsymbol{\Psi}_{\boldsymbol{\theta}_{k}}$ e $\bigoplus_{k=1}^{K}$ é o operador soma direta, que cria uma matriz bloco diagonal com as matrizes de seu argumento nos respectivos blocos. Mais concretamente,

$$
\boldsymbol{\theta}_{\ldots}=\left[\begin{array}{c}
\boldsymbol{\theta}_{.1 .} \\
\boldsymbol{\theta}_{.2 .} \\
\vdots \\
\boldsymbol{\theta}_{. K .}
\end{array}\right], \boldsymbol{\mu}_{\boldsymbol{\theta}}=\left[\begin{array}{c}
\boldsymbol{\mu}_{\boldsymbol{\theta}_{1}} \\
\boldsymbol{\mu}_{\boldsymbol{\theta}_{2}} \\
\vdots \\
\boldsymbol{\mu}_{\boldsymbol{\theta}_{K}}
\end{array}\right], \boldsymbol{\mu}_{\boldsymbol{\theta}_{k}}=\left[\begin{array}{c}
\mu_{\theta_{K 1}} \\
\mu_{\theta_{K 2}} \\
\vdots \\
\mu_{\theta_{K T}}
\end{array}\right], \boldsymbol{\Psi}_{\boldsymbol{\theta}}^{* *}=\left[\begin{array}{cccc}
\boldsymbol{\Psi}_{\boldsymbol{\theta}_{1}} & \mathbf{0} & \ldots & \mathbf{0} \\
\mathbf{0} & \boldsymbol{\Psi}_{\boldsymbol{\theta}_{2}} & \ldots & \mathbf{0} \\
\vdots & \vdots & \ddots & \vdots \\
\mathbf{0} & \mathbf{0} & \ldots & \boldsymbol{\Psi}_{\boldsymbol{\theta}_{K}}
\end{array}\right]
$$

Se assumirmos os mesmos parâmetros populacionais para as diferentes populações, teremos

$$
\boldsymbol{\mu}_{\boldsymbol{\theta}}=\mathbf{1}_{n} \otimes \boldsymbol{\mu}_{\boldsymbol{\theta}_{1}} \text { and } \boldsymbol{\Psi}_{\boldsymbol{\theta}_{k}}^{*}=\boldsymbol{I}_{n} \otimes \boldsymbol{\Psi}_{\boldsymbol{\theta}_{1}}
$$

em que $\boldsymbol{\mu}_{\boldsymbol{\theta}_{1}}$ e $\boldsymbol{\Psi}_{\boldsymbol{\theta}_{1}}$ são os parâmetros populacionais comuns.

\subsection{Verossimilhança de dados aumentados}

Basicamente, a verossimilhança tem a mesma estrutura dos capítulos anteriores. Mais concretamente, ela é uma junção das duas referidas. As suposições vêm da união daquelas descritas nas seções $2.5 \mathrm{e} 3.4$. Com efeito os dados aumentados são dados por:

Azevedo, Caio L. N.

IME/USP 


$$
Z_{i j k t} \mid\left(\theta_{j k t}, \boldsymbol{\zeta}_{i}, y_{j k t}\right)= \begin{cases}N\left(a_{i} \theta_{j k t}-b_{i}, 1\right) \mathbb{1}_{\left(z_{i j k t} \geq 0\right)}, & \text { if } Y_{i j k t}=1 \\ N\left(a_{i} \theta_{j k t}-b_{i}, 1\right) \mathbb{1}_{\left(z_{i j k t}<0\right)}, & \text { if } Y_{i j k t}=0\end{cases}
$$

Da mesma forma, as variáveis indicadoras se traduzem por

$$
V_{i j k t}=\left\{\begin{array}{l}
1, \quad \text { se para o item } i \text { foi observada a resposta do indivíduo } j, \text { da população } k \\
\text { no tempo } t . \\
0, \quad \text { caso contrário. }
\end{array}\right.
$$

Ambos os conjuntos de variáveis aleatórias são mutuamente independentes em relação aos indivíduos, itens, grupos e tempo. Novamente, assumiremos que as variáveis definidas em (4.4) são regidas por um mecanismo MAR, veja Little and Rubin (2002) ou Schafer (1997), por exemplo. Reiteramos o fato de que tal matriz contempla a eliminação/inclusão de indivíduos e ou grupos, completamente.

Então, de 4.3 e 4.4, temos que a verossimilhança é dada por

$$
\begin{aligned}
& L\left(\boldsymbol{\theta}_{\ldots,}, \boldsymbol{\zeta}, \boldsymbol{\eta}_{\boldsymbol{\theta}}, \boldsymbol{\delta} \mid \boldsymbol{z}_{\ldots .}, \boldsymbol{y}_{\ldots .}, \boldsymbol{v}_{\ldots .}\right) \propto p\left(\boldsymbol{v}_{\ldots .}, \boldsymbol{z}_{\ldots} \mid \boldsymbol{\theta}_{\ldots,}, \boldsymbol{\zeta}, \boldsymbol{\eta}_{\boldsymbol{\theta}}, \boldsymbol{\delta}, \boldsymbol{y}_{\ldots}\right) \\
& =p\left(\boldsymbol{v}_{\ldots .} \mid \boldsymbol{z}_{\ldots .}, \boldsymbol{\theta}_{\ldots,}, \boldsymbol{\zeta}, \boldsymbol{\eta}_{\boldsymbol{\theta}}, \boldsymbol{\delta}, \boldsymbol{y}_{\ldots .}\right) p\left(\boldsymbol{z}_{\ldots .} \mid \boldsymbol{\theta}_{\ldots,}, \boldsymbol{\zeta}, \boldsymbol{\eta}_{\boldsymbol{\theta}}, \boldsymbol{\delta}, \boldsymbol{y}_{\ldots}\right) \\
& =p\left(\boldsymbol{v}_{\ldots} \mid \boldsymbol{\delta}\right) p\left(\boldsymbol{z}_{\ldots .} \mid \boldsymbol{\theta}_{\ldots,}, \boldsymbol{\zeta}, \boldsymbol{y}_{\ldots .}\right) \\
& \propto p\left(\boldsymbol{z}_{\ldots .} \mid \boldsymbol{\theta} \ldots, \boldsymbol{\zeta}, \boldsymbol{y}_{\ldots} \ldots\right) \\
& \propto \prod_{k=1}^{K} \prod_{t=1}^{T} \prod_{j=1}^{n_{k}} \prod_{i \in I_{j k t}} \exp \left\{-0.5\left(z_{i j k t}-a_{i} \theta_{j k t}+b_{i}\right)^{2}\right\} \\
& \times \mathbb{1}_{\left(z_{i j k t}, y_{i j k t}\right)} \text {, }
\end{aligned}
$$

em que $I_{j k t}$ representa o conjunto de itens apresentados ao indivíduo $j$, da população $k$ no instante $t$. Novamente 4.5) segue do fato de que $\boldsymbol{\eta}_{\boldsymbol{\theta}}$ depende apenas da distribuição de $\boldsymbol{\theta}_{\ldots}$ e 4.6. vem do fato de que $\boldsymbol{V} \ldots$ segue um processo MAR.

Além disso, podemos reformular 4.1] e 4.2 em termos de dados aumentados de tal forma que 


$$
\begin{aligned}
\boldsymbol{Z}_{i j k .} & =\boldsymbol{D}_{a_{i}} \boldsymbol{\theta}_{j k .}+b_{i} \mathbf{1}_{T}+\boldsymbol{\xi}_{i j k}^{(Z)} \\
\boldsymbol{\theta}_{j k .} & =\boldsymbol{\mu}_{\boldsymbol{\theta}_{k}}+\boldsymbol{\xi}_{j}^{(\theta)}
\end{aligned}
$$

Comentários semelhantes àqueles feitos nos capítulos anteriores para os modelos 2.11) e (3.14), também se aplicam aqui.

\subsection{Estruturas de covariância}

No capítulo 3 consideramos uma estrutura de covariância autoregressiva heterogênea de ordem 1, nomeadamente $\mathrm{ARH}(1)$, vide (3.6), para representar a dependência longitudinal. Esta matriz é bastante útil quando temos variâncias (possivelmente) diferentes, correlações que decaem com o aumento da distância entre as medições e quando tais decaimento dependem apenas da distância e não dos valores dos tempos, propriamente. Entretanto, outras estruturas podem ser mais realísticas do que esta, dependendo do tipo de estudo e do comportamento do conjunto de dados. Dessa forma, é de interesse considerar outras matrizes que podem vir a ser mais apropriadas. Existem várias possibilidades descritas na literatura, veja Andrade and Tavares (2005), Singer and Andrade (2000), Diggle et al. (2002) e da Rocha (2004), por exemplo. Um outro aspecto diz respeito à utilização de métodos de escolha da matriz mais apropriada. Com efeito, este é um dos aspectos mais importantes na análise de dados longitudinais. Este ponto será retomado mais adiante.

Nas próximas subseções apresentaremos algumas das estruturas utilizadas em dados longitudinais bem com algumas de suas características mais importantes. Todas elas consideram heterocedasticidade, isto é, variâncias possivelmente diferentes. No entanto, antes disso, iremos apresentar a extensão da matriz ARH(1), para o caso em que temos várias populações envolvidas. Com efeito, tal matriz para a população $k$, tem a seguinte estrutura:

$$
\boldsymbol{\Psi}_{\boldsymbol{\theta}_{k}}=\left[\begin{array}{ccccc}
\psi_{\theta_{k 1}} & \sqrt{\psi_{\theta_{k 1}}} \sqrt{\psi_{\theta_{k 2}}} \rho_{\theta_{k}} & \sqrt{\psi_{\theta_{k 1}}} \sqrt{\psi_{\theta_{k 3}}} \rho_{\theta_{k}}^{2} & \cdots & \sqrt{\psi_{\theta_{k 1}}} \sqrt{\psi_{\theta_{k T}}} \rho_{\theta_{\theta_{k}}}^{T-1} \\
\sqrt{\psi_{\theta_{k 1}}} \sqrt{\psi_{\theta_{k 2}}} \rho_{\theta_{k}} & \psi_{\theta_{k 2}} & \sqrt{\psi_{\theta_{k 2}}} \sqrt{\psi_{\theta_{k 3}}} \rho_{\theta_{k}} & \cdots & \sqrt{\psi_{\theta_{k 2}}} \sqrt{\psi_{\theta_{k T}}} \rho_{\theta_{k}}^{T-2} \\
\sqrt{\psi_{\theta_{k 1}}} \sqrt{\psi_{\theta_{k 3}}} \rho_{\theta_{k}}^{2} & \sqrt{\psi_{\theta_{k 2}}} \sqrt{\psi_{\theta_{k 3}}} \rho_{\theta_{k}} & \psi_{\theta_{k 3}} & \cdots & \sqrt{\psi_{\theta_{k 3}}} \sqrt{\psi_{\theta_{k T}}} \rho_{\theta_{k}}^{T-3} \\
\vdots & \vdots & \vdots & \ddots & \vdots \\
\sqrt{\psi_{\theta_{k 1}} \sqrt{\psi_{\theta_{k T}}} \rho_{\theta_{k}}^{T-1}} & \sqrt{\psi_{\theta_{k 2}}} \sqrt{\psi_{\theta_{k T}}} \rho_{\theta_{k}}^{T-2} & \sqrt{\psi_{\theta_{k 3}}} \sqrt{\psi_{\theta_{k T}}} \rho_{\theta_{k}}^{T-3} & \cdots & \psi_{\theta_{k t}}
\end{array}\right]
$$

e a correspondente matriz de correlações é dada por: 


$$
\boldsymbol{\Omega}_{\boldsymbol{\theta}}=\left[\begin{array}{ccccc}
1 & \rho_{\theta_{k}} & \rho_{\theta_{k}}^{2} & \ldots & \rho_{\theta_{k}}^{T-1} \\
\rho_{\theta_{k}} & 1 & \rho_{\theta_{k}}^{2} & \ldots & \rho_{\theta_{k}}^{T-2} \\
\rho_{\theta_{k}} & \rho_{\theta_{k}}^{1} & 1 & \ldots & \rho_{\theta_{k}}^{T-3} \\
\vdots & \vdots & \vdots & \ddots & \vdots \\
\rho_{\theta_{k}}^{T-1} & \rho_{\theta_{k}}^{T-2} & \rho_{\theta_{k}}^{T-3} & \ldots & 1
\end{array}\right]
$$

Doravante, utilizaremos a seguinte notação : $\operatorname{ARH1}\left(\boldsymbol{\psi}_{\boldsymbol{\theta}_{k}}, \rho_{\theta_{k}}\right)$ representa uma estrutura AutoRegressiva Heterogênea de ordem 1, caracterizada pelos parâmetros $\left(\boldsymbol{\psi}_{\boldsymbol{\theta}_{k}}, \rho_{\theta_{k}}\right)^{t}$ referentes à população $k$. No entanto, por questões de praticidade, utilizaremos a notação $\mathrm{ARH}(1)$, com o mesmo significado.

\subsubsection{Matriz uniforme heterocedástica}

Esta estrutura, também conhecida como de simetria composta, nomeadamente $U H\left(\boldsymbol{\psi}_{\boldsymbol{\theta}_{k}}, \rho_{\theta_{k}}\right)$, em que $\psi_{\boldsymbol{\theta}_{k}}=$ $\left(\psi_{\theta_{k 1}}, \ldots, \boldsymbol{\psi}_{\theta_{k t}}\right)^{t}$, assume que as correlações são constantes ao longo do tempo, não importando a distância entre os instantes. Sua forma é mais simples do que a estrutura ARH(1) porém, ambas apresentam o mesmo número de parâmetros. Sua forma é dada por

$$
\boldsymbol{\Psi}_{\boldsymbol{\theta}_{k}}=\left[\begin{array}{ccccc}
\psi_{\theta_{k 1}} & \sqrt{\psi_{\theta_{k 1}}} \sqrt{\psi_{\theta_{k 2}}} \rho_{\theta_{k}} & \sqrt{\psi_{\theta_{k 1}}} \sqrt{\psi_{\theta_{k 3}}} \rho_{\theta_{k}} & \ldots & \sqrt{\psi_{\theta_{k 1}}} \sqrt{\psi_{\theta_{k T}}} \rho_{\theta_{k}} \\
\sqrt{\psi_{\theta_{k 1}}} \sqrt{\psi_{\theta_{k 2}}} \rho_{\theta} & \psi_{\theta_{k 2}} & \sqrt{\psi_{\theta_{k 2}}} \sqrt{\psi_{\theta_{k 3}}} \rho_{\theta_{k}} & \ldots & \sqrt{\psi_{\theta_{k 2}}} \sqrt{\psi_{\theta_{k T}}} \rho_{\theta_{k}} \\
\sqrt{\psi_{\theta_{k 1}}} \sqrt{\psi_{\theta_{k 3}}} \rho_{\theta} & \sqrt{\psi_{\theta_{k 2}}} \sqrt{\psi_{\theta_{k 3}}} \rho_{\theta_{k}} & \psi_{\theta_{k 3}} & \ldots & \sqrt{\psi_{\theta_{k 3}}} \sqrt{\psi_{\theta_{k T}}} \rho_{\theta_{k}} \\
\vdots & \vdots & \vdots & \ddots & \vdots \\
\sqrt{\psi_{\theta_{k 1}}} \sqrt{\psi_{\theta_{k T}}} \rho_{\theta_{k}} & \sqrt{\psi_{\theta_{k 2}}} \sqrt{\psi_{\theta_{k T}}} \rho_{\theta_{k}} & \sqrt{\psi_{\theta_{k 3}}} \sqrt{\psi_{\theta_{k T}}} \rho_{\theta_{k}} & \ldots & \psi_{\theta_{k T}}
\end{array}\right]
$$

e a respectiva matriz de correlações por:

$$
\boldsymbol{\Omega}_{\boldsymbol{\theta}_{k}}=\left[\begin{array}{ccccc}
1 & \rho_{\theta_{k}} & \rho_{\theta_{k}} & \ldots & \rho_{\theta_{k}} \\
\rho_{\theta_{k}} & 1 & \rho_{\theta_{k}} & \ldots & \rho_{\theta_{k}} \\
\rho_{\theta_{k}} & \rho_{\theta_{k}} & 1 & \ldots & \rho_{\theta_{k}} \\
\vdots & \vdots & \vdots & \ddots & \vdots \\
\rho_{\theta_{k}} & \rho_{\theta_{k}} & \ldots & \rho_{\theta_{k}} & 1
\end{array}\right]
$$

Azevedo, Caio L. N. 


\subsubsection{Toeplitz heterogênea}

Esta estrutura, doravante $T H\left(\boldsymbol{\psi}_{\boldsymbol{\theta}_{k}}, \rho_{\theta_{k}}\right)$, em que $\boldsymbol{\psi}_{\boldsymbol{\theta}_{k}}=\left(\psi_{\theta_{k 1}}, \ldots, \psi_{\theta_{k t}}\right)^{t}$, é um caso particular da estrutura $U H$ na medida que considera dependência apenas entre as medidas tomadas em instantes adjacentes, isto é

$$
\mathbf{\Psi}_{\boldsymbol{\theta}_{k}}=\left[\begin{array}{ccccc}
\psi_{\theta_{k 1}} & \sqrt{\psi_{\theta_{k 1}}} \sqrt{\psi_{\theta_{k 2}}} \rho_{\theta_{k}} & 0 & \ldots & 0 \\
\sqrt{\psi_{\theta_{k 1}}} \sqrt{\psi_{\theta_{k 2}}} \rho_{\theta_{k}} & \psi_{\theta_{2 k}} & \sqrt{\psi_{\theta_{2 k}}} \sqrt{\psi_{\theta_{3 k}}} \rho_{\theta_{k}} & \ldots & 0 \\
0 & \sqrt{\psi_{\theta_{2 k}}} \sqrt{\psi_{\theta_{3 k}}} \rho_{\theta_{k}} & \psi_{\theta_{3 k}} & \ldots & 0 \\
\vdots & \vdots & \vdots & \ddots & \vdots \\
0 & 0 & 0 & \ldots & \psi_{\theta_{k T}}
\end{array}\right],
$$

com a seguinte matriz de correlações:

$$
\boldsymbol{\Omega}_{\boldsymbol{\theta}_{k}}=\left[\begin{array}{ccccc}
1 & \rho_{\theta_{k}} & 0 & \ldots & 0 \\
\rho_{\theta_{k}} & 1 & \rho_{\theta_{k}} & \ldots & 0 \\
0 & \rho_{\theta_{k}} & 1 & \ldots & 0 \\
\vdots & \vdots & \vdots & \ddots & \vdots \\
0 & 0 & \ldots & 0 & 1
\end{array}\right]
$$

Esta matriz é adequada quando as correlações decaem muito rapidamente ou mesmo quando as medições forem feitas muito distantes entre si. Um importante aspecto concernente à esta estrutura diz respeito aos valores de $\rho_{\theta_{k}}$ para os quais a mesma é positiva definida, veja Graybill (2001) e Tavares (2001). Dependendo da dimensão da matriz, tal restrição é uma função meramente do tempo, não tendo relação direta com o vetor $\boldsymbol{\psi}_{\boldsymbol{\theta}_{k}}$, veja Tavares (2001). Apesar disto se constituir em uma limitação do uso desta matriz, pode-se contornar tal problema aplicando-se filtros na simulação MCMC ou mesmo prioris bem restritas em função do tempo, por exemplo.

\subsubsection{Matriz Hankel}

Esta estrutura, nomeadamente $H\left(\boldsymbol{\psi}_{\boldsymbol{\theta}_{k}}, \psi_{\theta_{k}}\right)$, em que $\boldsymbol{\psi}_{\boldsymbol{\theta}_{k}}=\left(\psi_{\theta_{k 1}}, \ldots, \psi_{\theta_{k t}}\right)^{t}$, é similar à matriz UH. Entretanto, as covariâncias são iguais, ao invés das correlações. Isso permite que estas possam variar entre os tempos. Sua forma é dada por:

Azevedo, Caio L. N.

IME/USP 


$$
\boldsymbol{\Psi}_{\boldsymbol{\theta}_{k}}=\left[\begin{array}{ccccc}
\psi_{\theta_{k 1}} & \psi_{\theta_{k}} & \psi_{\theta_{k}} & \ldots & \psi_{\theta_{k}} \\
\psi_{\theta_{k}} & \psi_{\theta_{k 2}} & \psi_{\theta_{k}} & \cdots & \psi_{\theta_{k}} \\
\psi_{\theta_{k}} & \psi_{\theta_{k}} & \psi_{\theta_{k 3}} & \ldots & \psi_{\theta_{k}} \\
\vdots & \vdots & \vdots & \ddots & \vdots \\
\psi_{\theta_{k}} & \psi_{\theta_{k}} & \psi_{\theta_{k}} & \ddots & \psi_{\theta_{k T}}
\end{array}\right]
$$

com a correspondente matriz de correlações dada por:

$$
\boldsymbol{\Omega}_{\boldsymbol{\theta}_{k}}=\left[\begin{array}{ccccc}
1 & \psi_{\theta_{k}} / \sqrt{\psi_{\theta_{k 1}} \psi_{\theta_{k 2}}} & \psi_{\theta_{k}} / \sqrt{\psi_{\theta_{k 1}} \psi_{\theta_{k 3}}} & \ldots & \psi_{\theta_{k}} / \sqrt{\psi_{\theta_{k 1}} \psi_{\theta_{k T}}} \\
\psi_{\theta_{k}} / \sqrt{\psi_{\theta_{k 1}} \psi_{\theta_{k 2}}} & 1 & \psi_{\theta_{k}} / \sqrt{\psi_{\theta_{k 2}} \psi_{\theta_{k 3}}} & \ldots & \psi_{\theta_{k}} / \sqrt{\psi_{\theta_{k 2}} \psi_{\theta_{k T}}} \\
\psi_{\theta_{k}} / \sqrt{\psi_{\theta_{k 1}} \psi_{\theta_{k 3}}} & \psi_{\theta_{k}} / \sqrt{\psi_{\theta_{k 2}} \psi_{\theta_{k 3}}} & 1 & \vdots & \psi_{\theta_{k}} / \sqrt{\psi_{\theta_{k 3}} \psi_{\theta_{k T}}} \\
\vdots & \vdots & \vdots & \ldots & \vdots \\
\psi_{\theta_{k}} / \sqrt{\psi_{\theta_{k 1}} \psi_{\theta_{k T}}} & \psi_{\theta_{k}} / \sqrt{\psi_{\theta_{k 2}} \psi_{\theta_{k T}}} & \psi_{\theta_{k}} / \sqrt{\psi_{\theta_{k 3}} \psi_{\theta_{k T}}} & \ldots & 1
\end{array}\right]
$$

Note-se que esta matriz é parametrizada pelas covariâncias $\psi_{\theta_{k}}, k=1, \ldots, K$, ao invés da correlação. Isto induz uma parametrização diferente das outras matrizes estudadas.

\subsubsection{Matriz auto-regressiva com média móvel heterocedástica de ordem 1}

Esta matriz, doravante $\operatorname{ARMAH}(1,1)\left(\psi_{\boldsymbol{\theta}_{k}}, \gamma_{\theta_{k}}, \rho_{\theta_{k}}\right)$, em que $\boldsymbol{\psi}_{\boldsymbol{\theta}_{k}}=\left(\psi_{\theta_{k 1}}, \ldots, \psi_{\theta_{k t}}\right)^{t}$, é uma extensão do modelo $A R H(1)$, veja 4.9), na medida em que incorpora uma parâmetro $\gamma_{\theta_{k}}$, para flexibilizar a modelagem das correlações entre os instantes. Sua estrutura é dada por

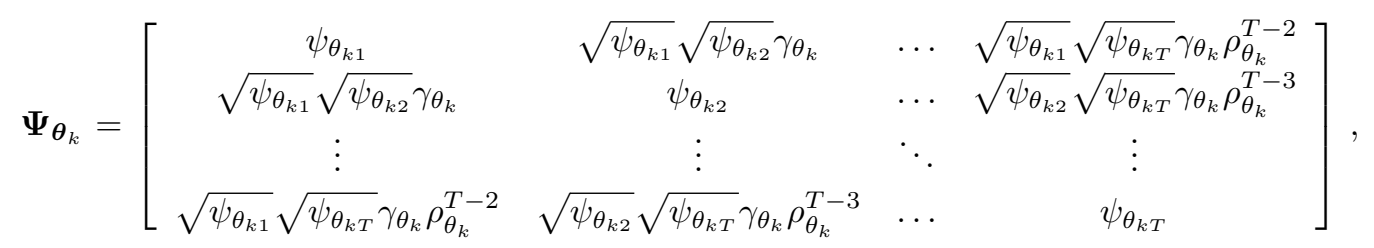

com a seguinte matriz de correlações:

Azevedo, Caio L. N.

IME/USP 


$$
\boldsymbol{\Omega}_{\boldsymbol{\theta}_{k}}=\left[\begin{array}{cccc}
1 & \gamma_{\theta_{k}} & \ldots & \gamma_{\theta_{k}} \rho_{\theta}^{T-2} \\
\gamma_{\theta_{k}} & 1 & \ldots & \gamma_{\theta_{k}} \rho_{\theta_{k}}^{T-3} \\
\vdots & \vdots & \ddots & \vdots \\
\gamma_{\theta_{k}} \rho_{\theta_{k}}^{T-2} & \gamma_{\theta_{k}} \rho_{\theta_{k}}^{T-3} & \ldots & 1
\end{array}\right]
$$

\subsubsection{Matriz de ante-dependência}

Esta matriz, representada por $A D\left(\boldsymbol{\psi}_{\boldsymbol{\theta}_{k}}, \boldsymbol{\rho}_{\boldsymbol{\theta}_{k}}\right)$, em que $\boldsymbol{\psi}_{\boldsymbol{\theta}_{k}}=\left(\psi_{\theta_{k 1}}, \ldots, \psi_{\theta_{k t}}\right)^{t}$ e $\boldsymbol{\rho}_{\boldsymbol{\theta}_{k}}=\left(\rho_{\theta_{k 1}}, \ldots, \rho_{\theta_{k(T-1)}}\right)^{t}$, é útil quando os instantes não são igualmente espaçados e também quando há heterogeneidade nos dados, veja Nunez-Anton and Zimmerman (2000). Sua estrutura é dada por:

$$
\mathbf{\Psi}_{\boldsymbol{\theta}_{k}}=\left[\begin{array}{cccc}
\psi_{\theta_{k 1}} & \sqrt{\psi_{\theta_{k 1}}} \sqrt{\psi_{\theta_{k 2}}} \rho_{\theta_{k 1}} & \cdots & \sqrt{\psi_{\theta_{k 1}}} \sqrt{\psi_{\theta_{k T}}} \prod_{t=1}^{T-1} \rho_{\theta_{k t}} \\
\sqrt{\psi_{\theta_{k 1}}} \sqrt{\psi_{\theta_{k 2}}} \rho_{\theta_{k 1}} & \psi_{\theta_{k 2}} & \cdots & \sqrt{\psi_{\theta_{k 2}}} \sqrt{\psi_{\theta_{k T}}} \prod_{t=2}^{T-1} \rho_{\theta_{k t}} \\
\vdots & \vdots & \ddots & \vdots \\
\sqrt{\psi_{\theta_{k 1}}} \sqrt{\psi_{\theta_{k T}}} \prod_{t=1}^{T-1} \rho_{\theta_{k t}} & \sqrt{\psi_{\theta_{k 2}}} \sqrt{\psi_{\theta_{k T}}} \prod_{t=2}^{T-1} \rho_{\theta_{k t}} & \cdots & \psi_{\theta_{k T}}
\end{array}\right],
$$

e a correspondente matriz de correlações dada por:

$$
\boldsymbol{\Omega}_{\boldsymbol{\theta}}=\left[\begin{array}{cccc}
1 & \rho_{\theta_{k 1}} & \cdots & \prod_{t=1}^{T-1} \rho_{\theta_{k t}} \\
\rho_{\theta_{k 1}} & 1 & \cdots & \prod_{t=2}^{T-1} \rho_{\theta_{k t}} \\
\vdots & \vdots & \ddots & \vdots \\
\prod_{t=1}^{T-1} \rho_{\theta_{k t}} & \prod_{t=2}^{T-1} \rho_{\theta_{k t}} & \cdots & 1
\end{array}\right]
$$

Notemos que as matrizes TH e AD permitem que as correlações dependam dos tempos em si e não só da distância entre as medidas. Isto torna tais modelos não estacionários (veja mais detalhes na Seção 5.3 .).

Azevedo, Caio L. N.

IME/USP 


\subsection{Estimação via MCMC}

Nesta seção apresentaremos extensões da estrutura proposta no Resultado 3.5.1 com o intuito de considerar as matrizes de covariância descritas nas subseções anteriores. Essencialmente, aquele algoritmo se aplica à qualquer que seja a forma da matriz de covariâncias, na medida em que não é imposta nenhuma estrutura à matriz $\boldsymbol{\Psi}_{\boldsymbol{\theta}}$. A única diferença reside nos parâmetros que se necessita dela extrair. Dessa forma, apenas apresentaremos o modo pelo qual tais parâmetros devem ser calculados. Isto equivale a inserir pequenas mudanças nos Passo 10 e a eventual inserção de um passo adicional consoante a matriz adotada. Tais modificações e/ou inserções serão apresentadas individualmente com relação à cada matriz anteriormente descrita. Entretanto, antes de apresentar tais modificações, estenderemos o Resultados 3.5.1 (que se utiliza da matriz ARH(1)), para o caso em que temos um estudo longitudinal com várias populações. Antes, notemos que, da verossimilhança (4.7) e das prioris 4.2 , 2.15, 3.22, 3.23, 3.24 e 3.25, temos que a distribuição a posteriori é dada por:

$$
\begin{aligned}
p\left(\boldsymbol{z}_{\ldots .}, \boldsymbol{\theta} \ldots, \boldsymbol{\zeta}, \boldsymbol{\mu}_{\boldsymbol{\theta}}, \boldsymbol{\psi}_{\boldsymbol{\theta}(T-1)}, \boldsymbol{\Psi}_{\boldsymbol{\theta}(T-1)}\right) & \propto\left\{\prod_{k=1}^{K} \prod_{t=1}^{T} \prod_{j=1}^{n_{k}} \prod_{i \in I_{j k t}} \exp \left\{-0.5\left(z_{i j k t}-a_{i} \theta_{j k t}+b_{i}\right)^{2}\right\} \mathbb{1}_{\left(z_{i j k t}, y_{i j k t}\right)}\right\} \\
& \times\left\{\prod_{k=1}^{K} \prod_{j=1}^{n_{k}} \exp \left\{-0.5\left(\boldsymbol{\theta}_{j k}^{(T-1)}-\boldsymbol{\mu}_{\theta(T-1)_{k}}\right)^{t} \boldsymbol{\Psi}_{\boldsymbol{\theta}(T-1)_{k}}^{-1}\left(\boldsymbol{\theta}_{j k}^{(T-1)}-\boldsymbol{\mu}_{\theta(T-1)_{k}}\right)\right\}\right\} \\
& \times\left\{\prod_{k=1}^{k}\left|\boldsymbol{\Psi}_{\boldsymbol{\theta}(T-1)_{k}}\right|^{-n_{k} / 2}\right\} \\
& \times\left\{\prod_{k=1}^{K} \prod_{j=1}^{n_{k}} \exp \left\{-\frac{1}{2 \psi_{\theta_{k 1}}}\left(\theta_{j k 1}-\mu_{\theta_{k 1}}\right)^{2}\right\}\right\}\left\{\prod_{k=1}^{K} \psi_{\theta_{k 1}}^{-n_{k} / 2}\right\} \\
& \times \prod_{k=1}^{K} \exp \left\{-0.5\left(\boldsymbol{\mu}_{\boldsymbol{\theta}(T-1)_{k}}-\boldsymbol{\mu}_{0}\right)^{t} \boldsymbol{\Psi}_{0}^{-1}\left(\boldsymbol{\mu}_{\boldsymbol{\theta}(T-1)_{k}}-\boldsymbol{\mu}_{0}\right)\right\} \\
& \times\left\{\prod_{k=1}^{K} \exp \left\{-\frac{1}{2 \psi_{0}}\left(\mu_{\theta_{k 1}}-\mu_{0}\right)^{2}\right\}\right\}\left\{\prod_{k=1}^{K} \psi_{\theta_{k 1}}^{-\left(\nu_{0} / 2+1\right)} \exp \left\{-\frac{\kappa_{0}}{2 \psi_{\theta_{k 1}}}\right\}\right\} \\
& \times \prod_{k=1}^{K}\left\{\left|\boldsymbol{\Psi}_{\boldsymbol{\theta}(T-1)_{k}}\right|^{-\left(n_{k}+\nu \Psi+T\right) / 2} \exp \left\{-\operatorname{tr}\left(\boldsymbol{\Psi}_{\boldsymbol{\Psi}} \boldsymbol{\Psi}_{\boldsymbol{\theta}(T-1)_{k}}^{-1}\right) / 2\right\}\right\} \\
& \times \prod_{k=1}^{K} \exp \left\{-0.5\left(\boldsymbol{\psi}_{\boldsymbol{\theta}(T-1)_{k}}-\boldsymbol{\mu}_{\boldsymbol{\psi}}\right)^{t} \boldsymbol{\Psi}_{\boldsymbol{\psi}}\left(\boldsymbol{\psi}_{\boldsymbol{\theta}(T-1)_{k}}-\boldsymbol{\mu}_{\boldsymbol{\psi}}\right)\right\} \\
& \times \prod_{i=1}^{I} \exp \left\{-0.5\left(\boldsymbol{\zeta}_{i}-\boldsymbol{\mu}_{\boldsymbol{\zeta}}\right)^{t} \boldsymbol{\Psi}_{\boldsymbol{\zeta}}^{-1}\left(\boldsymbol{\zeta}_{i}-\boldsymbol{\mu}_{\boldsymbol{\zeta}}\right)\right\} \mathbb{1}_{\left(a_{i}>0\right)}
\end{aligned}
$$

Azevedo, Caio L. N. 
Podemos então estabelecer o seguinte resultado :

Resultado 4.5.1. Considerando a posteriori definida em 4.15) edenotando por (.) o conjunto de todos os outros parâmetros, os passos do amostrador de Gibbs para o modelo MLONGMG são dados por:

Para cada população $(k=1, \ldots, K)$, de forma mutuamente independete, execute os seguintes passos:

- Passo 1 : Simular as variáveis aumentadas não observáveis $Z_{i j k t}$, mutuamente independentes, utilizando o esquema do Passo 1 do Resultado 3.5.1.

- Passo 2 : Simular os traços latentes, mutuamente independente, em relação aos indivíduos e grupos, através de,

$$
\boldsymbol{\theta}_{j k .} \mid(.) \sim N_{T}\left(\widehat{\boldsymbol{\Psi}}_{\boldsymbol{\theta}_{j k}} \widehat{\boldsymbol{\theta}}_{j k}, \widehat{\boldsymbol{\Psi}}_{\boldsymbol{\theta}_{j k}}\right)
$$

em que

$$
\begin{aligned}
\widehat{\boldsymbol{\theta}}_{j k} & =\sum_{i \in I_{j k t}} a_{i} b_{i} \mathbf{1}_{T}+\sum_{i \in I_{j k t}} a_{i} \boldsymbol{z}_{i j k .}+\boldsymbol{\Psi}_{\boldsymbol{\theta}_{j k}}^{-1} \boldsymbol{\mu}_{\boldsymbol{\theta}_{k}} \\
\widehat{\boldsymbol{\Psi}}_{\boldsymbol{\theta}_{j}} & =\left(\sum_{i \in I_{j k t}} a_{i}^{2} \boldsymbol{I}_{T}+\boldsymbol{\Psi}_{\boldsymbol{\theta}_{k}}^{-1}\right)^{-1},
\end{aligned}
$$

$\boldsymbol{I}_{T}$ é uma matriz identidade de ordem $T$ e $\boldsymbol{z}_{i j k .}=\left(z_{i j k 1}, \ldots, z_{i j k T}\right),{ }^{t}$.

- Passo 3 : Simular os parâmetros dos itens através de $\boldsymbol{\zeta}_{i} \mid($.$) utilizando-se o esquema do Passo 3$ do Resultado 3.5 .1 e $\left(\boldsymbol{Z}_{\ldots .}^{t}, \boldsymbol{\theta}_{\ldots}^{t}\right)^{t}$, obtidos nos Passos 1 e 2 anteriormente descritos.

- Passo 4 : Simular as médias populacionais longitudinais através de

$$
\begin{aligned}
\mu_{\theta_{k 1}} \mid(.) & \sim N\left(\widetilde{\mu}_{\theta_{k 1}}, \widehat{\psi}_{\mu_{k}}\right) \\
\boldsymbol{\mu}_{\boldsymbol{\theta}_{k}}^{(T-1)} \mid\left(\mu_{\theta_{k 1}},(.)\right) & \sim N_{T}\left(\widetilde{\boldsymbol{\mu}}_{\boldsymbol{\theta}(T-1)_{k}}, \widehat{\Psi}_{\boldsymbol{\mu}_{(T-1)_{k}}}\right)
\end{aligned}
$$

em que 


$$
\begin{aligned}
\widehat{\boldsymbol{\mu}}_{\boldsymbol{\theta}_{k}} & =\boldsymbol{\Psi}_{\boldsymbol{\theta}_{k}}^{-1} \sum_{j=1}^{n_{k}} \boldsymbol{\theta}_{j k}+\boldsymbol{\Psi}_{k 0}^{-1} \boldsymbol{\mu}_{\boldsymbol{\theta}_{k}}=\left(\widehat{\mu}_{\theta_{k 1}}, \widehat{\mu}_{\theta_{k 2}}, \ldots, \widehat{\mu}_{\theta_{k T}}\right)^{t}=\left(\widehat{\mu}_{\theta_{k 1}}, \widehat{\boldsymbol{\mu}}_{\boldsymbol{\theta}}^{(T-1)_{k}}\right)^{t}, \\
\widehat{\boldsymbol{\Psi}}_{\boldsymbol{\mu}_{k}} & =\left(n_{k} \boldsymbol{\Psi}_{\boldsymbol{\theta}_{k}}^{-1}+\boldsymbol{\Psi}_{\boldsymbol{\mu}_{k}}^{-1}\right)^{-1}=\left[\begin{array}{cc}
\widehat{\psi}_{\mu_{k}} & \widehat{\boldsymbol{\psi}}_{\boldsymbol{\mu}_{k}}^{t(T-1)} \\
\widehat{\boldsymbol{\psi}}_{\boldsymbol{\mu}_{k}}^{(T-1)} & \widehat{\boldsymbol{\Psi}}_{\boldsymbol{\mu}_{k}}^{(T-1)}
\end{array}\right], \\
\widetilde{\boldsymbol{\mu}}_{\boldsymbol{\theta}_{k}} & =\widehat{\boldsymbol{\Psi}}_{\boldsymbol{\mu}_{k}} \widehat{\boldsymbol{\mu}}_{\boldsymbol{\theta}_{k}}=\left(\widetilde{\mu}_{\theta_{k 1} 1}, \widetilde{\mu}_{\theta_{k 2}}, \ldots, \widetilde{\mu}_{\theta_{k T}}\right)^{t}=\left(\widetilde{\mu}_{\theta_{k 1}}, \widetilde{\boldsymbol{\mu}}_{\boldsymbol{\theta}_{k}}^{(T-1)}\right)^{t}, \\
\widetilde{\boldsymbol{\mu}}_{\boldsymbol{\theta}(T-1)_{k}} & =\widetilde{\boldsymbol{\mu}}_{\boldsymbol{\theta}_{k}}^{(T-1)}+\widehat{\psi}_{\mu_{k}}^{-1} \widehat{\boldsymbol{\psi}}_{\boldsymbol{\mu}_{k}}^{(T-1)}\left(\mu_{\theta_{k 1}}-\widetilde{\mu}_{\theta_{k 1}}\right), \\
\widehat{\boldsymbol{\Psi}}_{\boldsymbol{\mu}(T-1)_{k}} & =\widehat{\boldsymbol{\Psi}}_{\boldsymbol{\mu}_{k}}^{(T-1)}-\widehat{\psi}_{\boldsymbol{\mu}_{k}}^{-1} \widehat{\boldsymbol{\psi}}_{\boldsymbol{\mu}_{k}}^{(T-1)} \widehat{\boldsymbol{\psi}}_{\boldsymbol{\mu}_{k}}^{t(T-1)} .
\end{aligned}
$$

- Passo 5 : Simular a variância populacional do primeiro instante através de $\psi_{\theta_{k 1}} \mid(.) \sim I G\left(\widehat{v}_{0_{k}}, \widehat{\kappa}_{0_{k}}\right)$, em que

$$
\begin{aligned}
\widehat{v}_{0_{k}} & =\frac{n_{k}+v_{0_{k}}}{2} \\
\widehat{\kappa}_{0_{k}} & =\frac{\sum_{j=1}^{n_{k}}\left(\theta_{j k 1}-\mu_{\theta_{k 1}}\right)^{2}+\kappa_{0_{k}}}{2} .
\end{aligned}
$$

- Passo 6 : Simular o vetor de covariâncias através de $\boldsymbol{\psi}_{\boldsymbol{\theta}(T-1)_{k}} \mid(.) \sim N_{T-1}\left(\widehat{\boldsymbol{\Psi}}_{\boldsymbol{\psi}_{k}} \widehat{\boldsymbol{\psi}}_{\boldsymbol{\psi}_{k}}, \widehat{\boldsymbol{\Psi}}_{\boldsymbol{\psi}_{k}}\right)$, em que

$$
\begin{aligned}
\widehat{\boldsymbol{\psi}}_{\boldsymbol{\psi}_{k}} & =\psi_{\boldsymbol{\theta}_{k 1}}^{-1 / 2} \boldsymbol{\Psi}_{\boldsymbol{\theta}(T-1)_{k}}^{-1} \sum_{j=1}^{n_{k}}\left(\boldsymbol{\theta}_{j k .}^{(T-1)}-\boldsymbol{\mu}_{\boldsymbol{\theta}_{k}}^{(T-1)}\right)\left(\theta_{j k 1}-\mu_{\theta_{k 1}}\right)+\boldsymbol{\Psi}_{\boldsymbol{\psi}}^{-1} \boldsymbol{\mu}_{\boldsymbol{\psi}_{k}} \\
\widehat{\boldsymbol{\Psi}}_{\boldsymbol{\psi}_{k}} & =\left(\psi_{\theta_{k 1}}^{-1} \boldsymbol{\Psi}_{\boldsymbol{\theta}(T-1)_{k}}^{-1} \sum_{j=1}^{n_{k}}\left(\theta_{j k 1}-\mu_{\theta_{k 1}}\right)^{2}+\boldsymbol{\Psi}_{\boldsymbol{\psi}_{k}}^{-1}\right)^{-1}
\end{aligned}
$$

- Passo 7 : Simular a sub-matriz de covariâncias através de $\boldsymbol{\Psi}_{\boldsymbol{\theta}(T-1)_{k}} \mid(.) \sim I W_{T-1}\left(\widehat{\nu}_{\boldsymbol{\Psi}_{k}}, \widehat{\boldsymbol{\Psi}}_{\boldsymbol{\Psi}_{k}}\right)$, em que

$$
\begin{aligned}
\widehat{\nu}_{\mathbf{\Psi}_{k}} & =n_{k}+\nu_{\mathbf{\Psi}_{k}}, \\
\widehat{\boldsymbol{\Psi}}_{\boldsymbol{\Psi}_{k}} & =\boldsymbol{\Psi}_{\boldsymbol{\Psi}_{k}}+\sum_{j=1}^{n_{k}}\left(\boldsymbol{\theta}_{j k}^{(T-1)}-\boldsymbol{\mu}_{\boldsymbol{\theta}(T-1)_{k}}\right)\left(\boldsymbol{\theta}_{j k .}^{(T-1)}-\boldsymbol{\mu}_{\boldsymbol{\theta}(T-1)_{k}}\right)^{t} .
\end{aligned}
$$


- Passo 8 : Calcular a matriz de covariâncias original através de 3.15 e $\boldsymbol{\Psi}_{\boldsymbol{\theta}_{k}}^{(T-1)}=\boldsymbol{\Psi}_{\boldsymbol{\theta}(T-1)_{k}}+\boldsymbol{\psi}_{\boldsymbol{\theta}(T-1)_{k}} \boldsymbol{\psi}_{\boldsymbol{\theta}(T-1)_{k}}^{t}$.

- Passo 9 : Calcular as variâncias populacionais através de

$$
\left(\psi_{\theta_{k 2}}, \ldots, \psi_{\theta_{k T}}\right)^{t}=\boldsymbol{\psi}_{\boldsymbol{\theta}(T-1)_{k}}^{*}=\operatorname{Diag}\left(\boldsymbol{\Psi}_{\boldsymbol{\theta}(T-1)_{k}}+\boldsymbol{\psi}_{\boldsymbol{\theta}(T-1)_{k}} \boldsymbol{\psi}_{\boldsymbol{\theta}(T-1)_{k}}^{t}\right)
$$

em que Diag é o operador que extrai a diagonal principal de uma matriz quadradra.

- Passo 10 : Calcular a correlação populacional através de

$$
\rho_{\theta_{k}}=\frac{1}{T-1} \sum_{t=1}^{T-1}\left(\boldsymbol{\psi}_{\boldsymbol{\theta}(T-1)_{k}} \bullet\left(\boldsymbol{\psi}_{\boldsymbol{\theta}(T-1)_{k}}^{*}\right)^{-1 / 2}\right)^{1 / t}
$$

em que $\boldsymbol{\psi}_{\boldsymbol{\theta}(T-1)_{k}}^{*}$ é dado em 4.16.

\section{Demonstração do Resultado 4.5.1:}

A demonstração é análoga ao Resultado 3.5.1 e, portanto, a mesma será omitida.

Q.E.D.

Como dito anteriormente o Resultado 3.5.1 e o Resultado 4.5.1 são válidos para quaisquer matrizes de covariância. A única restrição é que tal(is) matriz(es) seja(m) positiva(s) definida(s). Contudo, essa é uma suposição amplamente aceita na literatura. Dessa forma, o algoritmo de Gibbs para modelos longitudinas com as matrizes apresentadas na Seção 4.4, têm apenas que serem modificados no que concerne ao cálculo dos parâmetros de dependência. Ou seja, das (co)variâncias e das correlações. Mais concretamente devemos considerar as seguintes modificações nos passos referentes ao cálculo de tais parâmetros

Azevedo, Caio L. N.

IME/USP 


\section{Uniforme Heterogênea}

- Passo 10 : Calcular a correlação populacional através de

$$
\rho_{\theta_{k}}=\frac{1}{T-1} \mathbf{1}_{T-1}^{t}\left(\boldsymbol{\psi}_{\boldsymbol{\theta}(T-1)_{k}} \bullet\left(\boldsymbol{\psi}_{\boldsymbol{\theta}(T-1)_{k}}^{*}\right)^{-1 / 2}\right)
$$

em que $\boldsymbol{\psi}_{\boldsymbol{\theta}(T-1)_{k}}^{*}$ é dado em 4.16).

\section{Toeplitz Heterogênea}

- Passo 10 : Calcular a correlação populacional através de

$$
\rho_{\theta_{k}}=\left(\boldsymbol{\psi}_{\boldsymbol{\theta}(T-1)_{k}} \bullet\left(\boldsymbol{\psi}_{\boldsymbol{\theta}(T-1)_{k}}^{*}\right)^{-1 / 2}\right)_{(1 \times 1)},
$$

em que $\boldsymbol{A}_{(1 \times 1)}$ denota o elemento da primeira linha e primeira coluna da matriz (vetor) $\boldsymbol{A}$ e $\boldsymbol{\psi}_{\boldsymbol{\theta}(T-1)_{k}}^{*}$ é dado em (4.16).

\section{Hankel}

- Passo 10 : Calcular a covariância populacional através de

$$
\rho_{\theta_{k}}=\frac{1}{T-1} \mathbf{1}_{T-1}^{t}\left(\boldsymbol{\psi}_{\boldsymbol{\theta}(T-1)_{k}}\right)
$$

\section{4. $\operatorname{ARH}(\mathbf{1})$}

- Passo 10 : Calcular o parâmetro de média móvel $\gamma_{\theta_{k}}$ (a correlação entre instantes adjacentes) através de

$$
\gamma_{\theta_{k}}=\left(\boldsymbol{\psi}_{\boldsymbol{\theta}(T-1)_{k}} \bullet\left(\boldsymbol{\psi}_{\boldsymbol{\theta}(T-1)_{k}}^{*}\right)^{-1 / 2}\right)_{(1 \times 1)}
$$

- Passo 11 : Calcular o parâmetro de correlação $\rho_{\theta_{k}}$, através de

$$
\rho_{\theta_{k}}=\frac{1}{T-2} \mathbf{1}_{T-2}^{t}\left(\boldsymbol{\psi}_{\boldsymbol{\theta}(T-1)_{k}} \bullet\left(\boldsymbol{\psi}_{\boldsymbol{\theta}(T-1)_{k}}^{*}\right)^{-1 / 2}\right)_{(T-2)} .
$$

em que $\boldsymbol{A}_{T}$ representa o subvertor composto das $T$ últimas componentes do vetor $\boldsymbol{A}$.

Azevedo, Caio L. N.

IME/USP 


\section{Ante-dependência}

- Passo 10 : Calcular os parâmetros de correlação $\boldsymbol{\rho}_{\theta_{k}}$ através de

$$
\rho_{\theta_{k 1}}=\left(\boldsymbol{\psi}_{\boldsymbol{\theta}(T-1)_{k}} \bullet\left(\boldsymbol{\psi}_{\boldsymbol{\theta}(T-1)_{k}}^{*}\right)^{-1 / 2}\right)_{1 \times 1},
$$

e para $t=2, \ldots, T$

$$
\rho_{\theta_{k t}}=\frac{\left(\boldsymbol{\psi}_{\boldsymbol{\theta}(T-1)_{k}} \bullet\left(\boldsymbol{\psi}_{\boldsymbol{\theta}(T-1)_{k}}^{*}\right)^{-1 / 2}\right)_{t \times 1}}{\prod_{t^{\prime}=1}^{t} \rho_{\theta_{k t^{\prime}}}} .
$$

\subsection{Seleção de estruturas de covariância via RJMCMC}

Como dito anteriomente, uma das etapas mais importantes na análise de dados longitudinais é a escolha da matriz de covariâncias mais adequada para representar a estrutura de dependência entre as medidas repetidas, veja Diggle et al. (2002). Uma forma descritiva consiste no estudo dos valores observados das medidas repetidas. Contudo, uma vez que a estrutura de correlação é admitida para os traços latentes e estes, por sua vez, não são observáveis diretamente, tal processo torna-se um tanto quanto mais complicado. O ajuste de um MGM, ou seja, de um modelo sob a suposição de independência, e a posterior utilização de técnicas conhecidas, nos traços latentes preditos, pode fornecer indícios a respeito de (famílias) de matrizes de covariância adequadas. Contudo, a metodologia descrita no Resultado 3.5.1. fornece indícios a respeito da matriz de covariâncias verdadeira, uma vez que considera a estimação de $\boldsymbol{\Psi}_{\boldsymbol{\theta}}$ sem impô-la nenhuma restrição (a menos daquela correspondente a identificabilidade).

Por outro lado, a utilização de metodologias inferenciais, como o uso de estatística de ajuste (AIC e o BIC, por exemplo), tornam-se ainda mais problemáticas, em nosso caso. Isso ocorre, pois uma vez que os algoritmos MCMC tendem a demandar muito tempo (e/ou muitas iterações) para fornecer as estimativas, pode-se tornar proibitivo o ajuste de muitos modelos para a escolha a posteriori do mais conveniente. Uma metodologia de seleção de modelos bastante útil quando se considera algoritmos do tipo MCMC é a utilização de sua variante conhecida como algoritmos de Monte Carlo via cadeias de Markov de saltos reversíveis (RJMCMC), veja Green (1995). Tal procedimento consiste na simulação de cadeias de Markov que transitam não só entre valores dos espaços paramétricos mas também entre modelos candidatos. Em outras palavras, em cada ciclo do algoritmo simulamos não só valores para os parâmetros do modelo mas também escolhemos o modelo a ser usado no passo seguinte. Sucintamente o algoritmo RJMCMC pode ser descrito comf $f^{\dagger}$ : Considere dois

* Sigla que representa a expressão em inglês Reversible Jump Monte Carlo Markov Chain

$\dagger$ Tal descrição foi adptada de Ehlers (2005)

Azevedo, Caio L. N.

IME/USP 
modelos $M_{1}$ e $M_{2}$, em que cada um representa o mesmo MRI como descrito em (4.1) e (4.2), com estruturas de covariância diferentes. Suponha que o estado atual da cadeia seja $\left(M_{1}, \boldsymbol{\vartheta}_{1}\right)$, em que $\boldsymbol{\vartheta}_{m}$ denota os parâmetros associados ao modelo $M_{m}$, e o modelo $M_{2}$ com parâmetros $\boldsymbol{\vartheta}_{2}$, seja proposto com probabilidade $r_{\left(M_{1}, M_{2}\right)}$. Isto pode significar alterar ou não o número de parâmetros. Vamos supor que o número de parâmetros do modelo $1\left(n_{p 1}\right)$ é menor do que do modelo $2\left(n_{p 2}\right)$. Seja $g$ uma função determinística de sorte que $\boldsymbol{\vartheta}_{2}=g\left(\boldsymbol{\vartheta}_{1}, \boldsymbol{u}\right), \boldsymbol{u}$ um vetor aleatório de dimensão $n_{p 2}-n_{p 1}$ tal que $\boldsymbol{u} \sim q(\boldsymbol{u})$ e que $q$ é uma densidade conhecida e conveniente. Então o seguinte algoritmo é considerado:

- Proponha $\left(M_{1}, \boldsymbol{\vartheta}_{1}\right) \rightarrow\left(M_{2}, \boldsymbol{\vartheta}_{2}\right)$, com probabilidade $r_{\left(M_{1}, M_{2}\right)}$,

- Gere $\boldsymbol{u} \sim q(\boldsymbol{u})$ com dimensão $n_{p 2}-n_{p 1}$,

- Faça $\boldsymbol{\vartheta}_{2}=g\left(\boldsymbol{\vartheta}_{1}, \boldsymbol{u}\right)$,

- Aceita $\left(M_{2}, \boldsymbol{\vartheta}_{2}\right)$ com probabilidade $\min \left(1, R_{\left(M_{1}, M_{2}\right)}\right)$, em que:

$$
R_{\left(M_{1}, M_{2}\right)}=\frac{p\left(M_{2}, \boldsymbol{\vartheta}_{2}\right)}{p\left(M_{1}, \boldsymbol{\vartheta}_{1}\right)} \times \frac{r_{\left(M_{1}, M_{2}\right)}}{r_{\left(M_{2}, M_{1}\right)} q(\boldsymbol{u})} \times\left|\frac{\partial g\left(\boldsymbol{\vartheta}_{1}, \boldsymbol{u}\right)}{\partial\left(\boldsymbol{\vartheta}_{1}, \boldsymbol{u}\right)}\right|
$$

e $p\left(M_{m}, \boldsymbol{\vartheta}_{m}\right)$ é a distribuição a posteriori relacionada ao modelo $M_{m}, m=1,2$.

Podemos notar que, de uma forma geral, teremos que adicionar um passo aos algoritmos de estimação propostos, correspondente a um salto de Metropolis-Hastings o qual define a transição entre os modelos propostos. Em cada iteração, selecionado um modelo, a simulação dos parâmetros inerentes àquele segue a estrutura descrita no Resultado 4.5.1, de acordo com a matriz de covariâncias selecionada. A Figura 4.1 ilustra o esquema de simulação considerando apenas dois modelos. Podemos notar que a etapa de escolha de modelos se constitui em passo adicional na simulação MCMC.

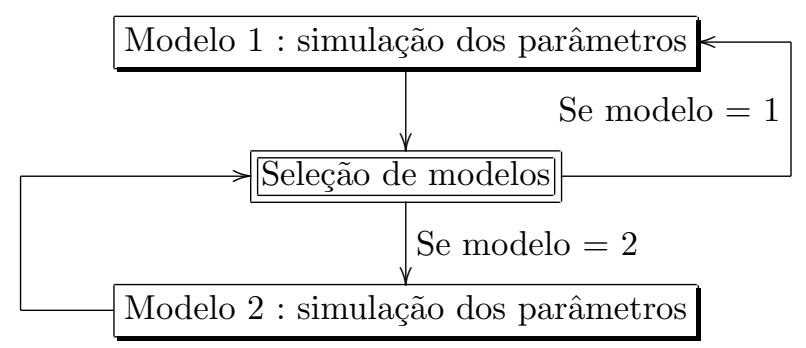

Figura 4.1: Esquema do algoritmo RJMCMC considerando dois modelos

Azevedo, Caio L. N.

IME/USP 
Os desenvolvimentos que se seguem dizem respeito a um estudo longitudinal de grupos múltiplos. Para exemplificar considere o caso de um estudo longitudinal com uma única população em que desejamos escolher entre os modelos ARH(1) e ARMAH(1,1) como o mais apropriado. O modelo 1 será o ARH(1) e, conseqüentemente, o modelo 2 será o ARMAH(1,1). Como exposto no Capítulo 3, consideramos a estimação das matrizes de covariância e dela extrairemos os parâmetros de interesse. No entanto, por uma questão de simplicidade, utilizaremos diretamente os parâmetros de dependência na etapa correspondente à seleção de modelos. Isto torna a obtenção da taxa de aceitação, equação (4.17), bem mais simples. Denote por $\rho_{\theta_{k}(A R H)}$ e $\rho_{\theta_{k}(A R M A H)}$ os parâmetros de correlação estimados sob os modelos $\mathrm{ARH}(1)$ e $\mathrm{ARMAH}(1,1)$, da população $k$, respectivamente. Considere as seguintes prioris para os parâmetros $\left(\rho_{\theta_{k}(A R H)}, \rho_{\theta_{k}(A R M A H)}, \gamma_{\theta_{k}}\right)^{t}$ :

$$
\begin{aligned}
\rho_{\theta_{k}(A R H)} & \sim N\left(\mu_{\rho}, \psi_{\rho}\right) \\
\rho_{\theta_{k}(A R M A H)} & \sim N\left(\mu_{\rho}, \psi_{\rho}\right) \\
\gamma_{\theta_{k}} & \sim N\left(\mu_{\gamma}, \psi_{\gamma}\right) .
\end{aligned}
$$

Dessa forma, as etapas correspondentes ao passo de seleção estrutural associado ao Resultado 4.5.1, são dadas por

Resultado 4.6.1. Considerando as prioris (4.18), 4.19) e 4.20), as matrizes de covariância (4.9) e 4.13) $e$ a estrutura de simulação do Resultado 4.5 .1 as etapas de seleção estrutural utilizando RJMCMC, são dadas por :

1. Caso o modelo corrente seja ARH(1)

- Passo 1 Gerar $\gamma_{\theta_{k}}=u_{k} \sim U(0,1)$ e calcular $\rho_{\theta_{k}(A R M A H)}=\frac{\rho_{\theta_{k}(A R H)}+\gamma_{\theta_{k}}}{2}$.

- Passo 2 Gerar a matriz $\boldsymbol{\Psi}_{\boldsymbol{\theta}_{k}(A R M A H)}$ utilizando $\left(\rho_{\theta_{k}(A R M A H)}, \gamma_{\theta_{k}}\right)^{t}$ e $\boldsymbol{\psi}_{\boldsymbol{\theta}_{k}}$ (estimativa corrente do vetor de variâncias).

- Passo 3 Calcular a taxa de aceitação :

Azevedo, Caio L. N.

IME/USP 


$$
\begin{aligned}
R_{k(A R H, A R M A H)=}= & \frac{\exp \left\{-0.5 \sum_{j=1}^{n_{k}}\left(\boldsymbol{\theta}_{j k .}-\boldsymbol{\mu}_{\boldsymbol{\theta}_{k}}\right)^{t} \boldsymbol{\Psi}_{\boldsymbol{\theta}_{k}(A R M A H)}^{-1}\left(\boldsymbol{\theta}_{j k .}-\boldsymbol{\mu}_{\boldsymbol{\theta}_{k}}\right)\right\}}{\exp \left\{-0.5 \sum_{j=1}^{n_{k}}\left(\boldsymbol{\theta}_{j k .}-\boldsymbol{\mu}_{\boldsymbol{\theta}_{k}}\right)^{t} \boldsymbol{\Psi}_{\boldsymbol{\theta}_{k}(A R H)}^{-1}\left(\boldsymbol{\theta}_{j k .}-\boldsymbol{\mu}_{\boldsymbol{\theta}}\right)\right\}} \times \\
& \frac{\exp \left\{-\frac{0.5}{\psi_{\rho}}\left(\rho_{\theta_{k}(A R M A H)}-\mu_{\rho_{k}}\right)^{2}\right\} \exp \left\{-\frac{0.5}{\psi_{\gamma_{k}}}\left(\gamma_{\theta_{k}}-\mu_{\gamma_{k}}\right)^{2}\right\}}{\exp \left\{-\frac{0.5}{\psi_{\rho_{k}}}\left(\rho_{\theta_{k}(A R H)}-\mu_{\rho_{k}}\right)^{2}\right\}} \times \frac{1}{\sqrt{\pi \psi_{\gamma_{k}}}} \\
& \frac{\left|\boldsymbol{\Psi}_{\boldsymbol{\theta}_{k}(A R M A H)}\right|^{-n_{k} / 2}}{\left|\boldsymbol{\Psi}_{\boldsymbol{\theta}_{k}(A R H)}\right|^{-n_{k} / 2}} .
\end{aligned}
$$

Aceite o modelo ARMAH $(1,1)$ com probabilidade $\pi_{k(A R H, A R M A H)}=\min \left\{R_{k(A R H, A R M A H)}, 1\right\}$, caso contrário o modelo permanece $\mathrm{ARH}(1)$.

2. Caso o modelo corrente seja $\operatorname{ARMAH}(1,1)$

- Passo 1 Calcular $u_{k}=\gamma_{\theta_{k}}$ e $\rho_{\theta_{k}(A R H)}=2 \rho_{\theta_{k}(A R M A H)}-\gamma_{\theta_{k}}$.

- Passo 2 Gerar a matriz $\boldsymbol{\Psi}_{\boldsymbol{\theta}_{k}(A R H)}$ utilizando $\rho_{\theta_{k}(A R H)}$ e $\boldsymbol{\psi}_{\boldsymbol{\theta}_{k}}$ (estimativa corrente do vetor de variâncias).

- Passo 3 Calcular a taxa de aceitação :

$$
\begin{aligned}
& R_{k(A R M A H, A R H)=}=\frac{\exp \left\{-0.5 \sum_{j=1}^{n_{k}}\left(\boldsymbol{\theta}_{j k .}-\boldsymbol{\mu}_{\boldsymbol{\theta}_{k}}\right)^{t} \boldsymbol{\Psi}_{\boldsymbol{\theta}_{k}(A R H)}^{-1}\left(\boldsymbol{\theta}_{j k .}-\boldsymbol{\mu}_{\boldsymbol{\theta}_{k}}\right)\right\}}{\exp \left\{-0.5 \sum_{j=1}^{n_{k}}\left(\boldsymbol{\theta}_{j k .}-\boldsymbol{\mu}_{\boldsymbol{\theta}_{k}}\right)^{t} \boldsymbol{\Psi}_{\boldsymbol{\theta}_{k}(A R M A H)}^{-1}\left(\boldsymbol{\theta}_{j k .}-\boldsymbol{\mu}_{\boldsymbol{\theta}_{k}}\right)\right\}} \times \\
& \frac{\exp \left\{-\frac{0.5}{\psi_{\rho_{k}}}\left(\rho_{\theta_{k}(A R H)}-\mu_{\rho_{k}}\right)^{2}\right\}}{\exp \left\{-\frac{0.5}{\psi_{\rho_{k}}}\left(\rho_{\theta_{k}(A R M A H)}-\mu_{\rho_{k}}\right)^{2}\right\} \exp \left\{-\frac{0.5}{\psi_{\gamma_{k}}}\left(\gamma_{\theta_{k}}-\mu_{\gamma_{k}}\right)^{2}\right\}} \times \sqrt{\pi \psi_{\gamma_{k}}} \\
& \frac{\left|\boldsymbol{\Psi}_{\boldsymbol{\theta}_{k}(A R H)}\right|^{-n_{k} / 2}}{\left|\boldsymbol{\Psi}_{\boldsymbol{\theta}_{k}(A R M A H)}\right|^{-n_{k} / 2}}
\end{aligned}
$$

Aceite o modelo $\mathrm{ARH}(1)$ com probabilidade $\pi_{k(A R M A H, A R H)}=\min \left\{R_{k(A R M A H, A R H)}, 1\right\}$, caso contrário o modelo permanece $\operatorname{ARMAH}(1,1)$. 


\section{Demonstração do Resultado 4.6.1 :}

A demonstração do Resultado 4.6.1 segue diretamente da equação (4.17), das prioris 4.18, 4.19) e 4.20) e observando que o Jacobiano é igual a :

$$
\left|\frac{\partial g\left(\boldsymbol{\vartheta}_{1}, \boldsymbol{u}\right)}{\partial\left(\boldsymbol{\vartheta}_{1}, \boldsymbol{u}\right)}\right|=\frac{1}{2}
$$

Q.E.D.

Portanto, em cada iteração, escolhido o modelo, procedemos à simulação do conjunto de parâmetros associados, utilizando os passos descritos no Resultado 4.5.1.

Note-se que, como algoritmo de Gibbs não impõe estrutura alguma à matriz $\Psi_{\boldsymbol{\theta}}$, a etapa correspondente à simulação dos parâmetros independente do modelo selecinado na iteração corrente. O que difere é apenas que parâmetros se extraí da matriz simulada. Assim, nossa abordagem difere um pouco da proposta de Green (1995).

\subsection{Estudos de simulação}

Nesta seção exploraremos duas situações para avaliar as metodologias propostas, uma com relação à modelagem longitudinal de grupos múltiplos e outra concernente à seleção de modelos. As duas subseções seguintes tratam de cada uma delas em separado.

\subsubsection{Análise longitudinal com grupos múltiplos}

Nesta subseção exploraremos numericamente a modelagem e o método de estimação relacionados à situação em que temos um estudo longitudinal com grupos múltiplos. O estudo de simulação consiste no acompanhamento de duas populações independentes durante três condições de avaliação. Para a população 1 será considerada uma matriz de covariâncias Hankel com parâmetro de correlação igual à $\rho_{\theta}=0,6$, assegurando que a mesma seja positiva definida. Para a população 2 atribuiremos uma matriz ARMAH(1,1) cujos parâmetros são $\rho_{\theta}=0.8$ e $\gamma_{\theta}=0.88$. Estes valores sugerem uma correlação elevada entre os tempos. Teremos um teste para cada população/condição de avaliação. Os testes para a população 1, nos tempos 1, 2 e 3 são exatamente os mesmos apresentados na Seção 3.7 inclusive os valores dos parâmetros dos itens e itens comuns. Para a população 2, aplicaremos testes nos tempos 1,2 e 3, nomeada e respectivamente, Testes 4,5 e 6 . Consideramos 6 itens comuns aos Testes 4 e 5 e outros 6 comuns aos Testes 5 e 6 . Ademais, temos 6 itens comuns aos testes 1 e 4, outros 6 comuns aos testes 2 e 5 , e ainda outros 6 comuns aos testes 3 e 6 . Tal estrutura permite melhores resultados no processo de equalização haja vista a necessidade da existência de um número razoável de itens comuns para fazê-lo, veja Andrade et al. (2000). Os parâmetros dos itens se encontram na Tabela 4.1 .

Com os parâmetros definidos conduzimos um estudo de replicação com $\mathrm{R}=10$ réplicas, e utilizamos os 
valores médios das estimativas para avaliar o desempenho da metodologia. A Tabela 4.1 apresenta os resultados referentes as estimativas dos parâmetros dos itens. Apresentamos os valores dos parâmetros de dificuldade originais ao invés dos transformados por razões de interpretabilidade. Os erros-padrão dos parâmetros $b^{*}$ foram calculados utilizando o método delta, veja Sen and Singer (1994) e considerando que $\operatorname{cov}(a, b)=0$, para detalhes veja o Apêndice A. Isto foi feito pois calcular IC's e HPD's demanda muito tempo de processamento. Os resultados indicam que as estimativas estão bem próximas dos verdadeiros valores e os erros-padrão com magnitudes razoáveis, no sentido de serem pequenos com relação aos valores das estimativas. A Figura 4.2 ilustra a proximidade entre as estimativas e os verdadeiros valores, inclusive para os traços latentes. A Tabela 4.2 apresentam algumas estatísticas relativas à estimação dos traços latentes e parâmetros dos itens. Percebemos que as correlações são bem altas, que as médias das estimativas são próximas dos verdadeiros valores e que a variabilidade entre as estimativas é pequena. Dessa forma, podemos concluir que as estimativas, em média, possuem vício desprezível e variam muito pouco em torno dos verdadeiros valores. A Tabela 4.3 apresenta alguns resultados inerentes à estimação dos parâmetros populacionais. Percebemos que todos os parâmetros foram bem estimados à exceção das variâncias do tempo 3, para a população 1, e as variâncias dos tempos 2 e 3 para a população 2. Todas elas foram ligeiramente superestimadas. Entretanto, as diferenças, entre as estimativas e os verdadeiros valores, tendem a diminur quando se considera o desvio-padrão, medida essa mais utilizada que a variância para medir variabilidade. Alguns fatores que podem contribuir para isso são : tamanho da amostra e número de itens (razão entre número de indíviduos e itens), número de replicações, quantidade de itens comuns, número de testes com itens comuns, dentre outros. Por exemplo, o trabalho de Hulin et al. (1982), sugere que estimativas razoáveis são obtidas com mais de 1000 indivíduos e pelo menos 60 itens. Lord (1968) sugere que pelo menos 1000 indivíduos e 50 itens são necessários para se obter boas estimativas dos parâmetros de discriminação. Ree and Jensen (1980) também advogam a necessidade de um tamanho de amostra e número de itens razoáveis para se obter boas estimativas. Eles afirmam que : "a stable and accurate estimate of the $a$ and $b$ parameters requires large numbers of subjects over a broad range of ability (pag. 227)". Usando testes simulados de comprimento $I=80$ itens, eles descobriram erros de estimação associados ao parâmetro $a$ de elevada magnitude para tamanhos amostrais menores que $n=1000$. Apesar de alguns desses trabalhos considerarem o modelo logístico de 3 parâmetros, que é mais complicado de se ajustar que o modelo de 2 parâmetros, a idéia de tamanho de amostra continua válida uma vez que os modelos do presente trabalho são mais complexos do que aqueles abordadados nos referidos trabalhos. Além disso a estimação das variâncias é complicada, uma vez que estas dependem dos traços latentes e das médias deles.

Azevedo, Caio L. N.

IME/USP 
Tabela 4.1: Parâmetros dos itens e estimativas para o estudo longitudinal de grupos múltiplos

\begin{tabular}{|c|c|c|c|c|c|c|c|}
\hline \multirow[t]{3}{*}{ Teste } & \multirow[t]{3}{*}{ Item } & \multicolumn{2}{|c|}{ Val. verd. } & \multicolumn{4}{|c|}{ Estimativas } \\
\hline & & \multirow[t]{2}{*}{$\mathbf{a}$} & \multirow[t]{2}{*}{$b^{*}$} & \multicolumn{2}{|c|}{$\mathbf{a}$} & \multicolumn{2}{|c|}{$b^{*}$} \\
\hline & & & & Est. & $\mathbf{E P}$ & Est. & EP \\
\hline $1-4$ & 1 & 0,800 & $-2,000$ & 0,806 & 0,063 & $-2,005$ & 0,147 \\
\hline 1 & 2 & 1,100 & $-1,800$ & 1,062 & 0,113 & $-1,844$ & 0,238 \\
\hline 1 & 3 & 1,400 & $-1,600$ & 1,417 & 0,142 & $-1,580$ & 0,249 \\
\hline 1 & 4 & 0,810 & $-1,400$ & 0,797 & 0,070 & $-1,415$ & 0,125 \\
\hline 1 & 5 & 1,110 & $-1,200$ & 1,114 & 0,091 & $-1,206$ & 0,131 \\
\hline $1-4$ & 6 & 1,410 & $-1,000$ & 1,479 & 0,089 & $-0,976$ & 0,099 \\
\hline 1 & 7 & 0,820 & $-0,800$ & 0,832 & 0,063 & $-0,785$ & 0,079 \\
\hline 1 & 8 & 1,090 & $-0,600$ & 1,087 & 0,077 & $-0,580$ & 0,067 \\
\hline 1 & 9 & 1,390 & $-0,400$ & 1,444 & 0,102 & $-0,379$ & 0,055 \\
\hline $1-4$ & 10 & 0,830 & $-0,100$ & 0,831 & 0,045 & $-0,114$ & 0,040 \\
\hline $1-4$ & 11 & 0,900 & 1,000 & 0,911 & 0,050 & 0,982 & 0,068 \\
\hline 1 & 12 & 1,200 & 1,200 & 1,292 & 0,104 & 1,151 & 0,139 \\
\hline 1 & 13 & 1,380 & 1,400 & 1,393 & 0,128 & 1,406 & 0,204 \\
\hline 1 & 14 & 0,950 & 1,600 & 0,933 & 0,084 & 1,644 & 0,165 \\
\hline 1 & 15 & 1,050 & 1,800 & 1,057 & 0,103 & 1,785 & 0,211 \\
\hline 1 & 16 & 1,350 & 2,000 & 1,309 & 0,109 & 2,004 & 0,245 \\
\hline 1 & 17 & 0,850 & 0,800 & 0,882 & 0,065 & 0,793 & 0,078 \\
\hline 1 & 18 & 1,050 & 0,000 & 1,059 & 0,053 & 0,012 & 0,034 \\
\hline $1-2$ & 19 & 1,350 & 0,000 & 1,384 & 0,065 & $-0,007$ & 0,031 \\
\hline $1-2$ & 20 & 0,820 & 0,200 & 0,819 & 0,040 & 0,174 & 0,044 \\
\hline $1-2$ & 21 & 1,120 & 0,400 & 1,161 & 0,056 & 0,401 & 0,044 \\
\hline $1-2$ & 22 & 1,420 & 0,600 & 1,422 & 0,071 & 0,581 & 0,056 \\
\hline $1-2$ & 23 & 0,900 & 0,800 & 0,912 & 0,046 & 0,796 & 0,061 \\
\hline $1-2$ & 24 & 1,200 & 1,000 & 1,243 & 0,062 & 0,973 & 0,077 \\
\hline $2-4$ & 25 & 1,300 & $-0,800$ & 1,316 & 0,115 & $-0,817$ & 0,108 \\
\hline 2 & 26 & 0,880 & $-0,600$ & 0,923 & 0,091 & $-0,615$ & 0,096 \\
\hline $2-4$ & 27 & 1,180 & $-0,400$ & 1,218 & 0,089 & $-0,414$ & 0,063 \\
\hline $2-4$ & 28 & 1,320 & $-0,200$ & 1,318 & 0,088 & $-0,244$ & 0,052 \\
\hline $2-4$ & 29 & 1,000 & 0,000 & 0,986 & 0,060 & $-0,024$ & 0,057 \\
\hline $2-4$ & 30 & 1,200 & 2,000 & 1,212 & 0,071 & 1,977 & 0,167 \\
\hline 2 & 31 & 1,300 & 2,200 & 1,325 & 0,112 & 2,198 & 0,285 \\
\hline 2 & 32 & 0,950 & 2,400 & 0,937 & 0,085 & 2,399 & 0,252 \\
\hline 2 & 33 & 1,250 & 0,800 & 1,260 & 0,089 & 0,781 & 0,100 \\
\hline $2-4$ & 34 & 1,150 & 1,000 & 1,144 & 0,061 & 0,976 & 0,086 \\
\hline 2 & 35 & 1,000 & 1,200 & 1,002 & 0,073 & 1,187 & 0,124 \\
\hline 2 & 36 & 1,100 & 1,100 & 1,145 & 0,082 & 1,089 & 0,121 \\
\hline $2-3$ & 37 & 1,200 & 1,300 & 1,167 & 0,063 & 1,266 & 0,110 \\
\hline $2-3$ & 38 & 1,300 & 1,400 & 1,267 & 0,070 & 1,379 & 0,123 \\
\hline $2-3$ & 39 & 1,400 & 1,600 & 1,379 & 0,075 & 1,567 & 0,142 \\
\hline $2-3$ & 40 & 0,800 & 1,800 & 0,802 & 0,046 & 1,768 & 0,124 \\
\hline $2-3$ & 41 & 1,100 & 2,000 & 1,088 & 0,061 & 1,976 & 0,152 \\
\hline $2-3$ & 42 & 1,400 & 2,100 & 1,365 & 0,079 & 2,096 & 0,196 \\
\hline $3-6$ & 43 & 1,300 & 0,000 & 1,339 & 0,126 & 0,000 & 0,114 \\
\hline 3 & 44 & 1,000 & 0,200 & 1,029 & 0,110 & 0,175 & 0,146 \\
\hline 3 & 45 & 1,100 & 0,400 & 1,084 & 0,110 & 0,352 & 0,146 \\
\hline 3 & 46 & 1,200 & 0,600 & 1,159 & 0,111 & 0,520 & 0,146 \\
\hline 3 & 47 & 1,300 & 0,800 & 1,289 & 0,113 & 0,791 & 0,153 \\
\hline
\end{tabular}

Azevedo, Caio L. N. 
Continuação da Tabela 4.1

\begin{tabular}{|c|c|c|c|c|c|c|c|}
\hline \multirow[t]{3}{*}{ Teste } & \multirow[t]{3}{*}{ Item } & \multicolumn{2}{|c|}{ Val. verd. } & \multicolumn{4}{|c|}{ Estimativas } \\
\hline & & \multirow[t]{2}{*}{$\mathbf{a}$} & \multirow[t]{2}{*}{$b^{*}$} & \multicolumn{2}{|c|}{$\mathbf{a}$} & \multicolumn{2}{|c|}{ b } \\
\hline & & & & Est. & EP & Est. & EP \\
\hline $3-6$ & 48 & 1,400 & 1,000 & 1,362 & 0,093 & 0,984 & 0,140 \\
\hline $3-6$ & 49 & 0,900 & 1,200 & 0,878 & 0,058 & 1,158 & 0,137 \\
\hline 3 & 50 & 1,000 & 1,400 & 1,011 & 0,080 & 1,397 & 0,180 \\
\hline $3-6$ & 51 & 1,100 & 1,600 & 1,077 & 0,065 & 1,570 & 0,151 \\
\hline 3 & 52 & 1,200 & 1,800 & 1,201 & 0,090 & 1,755 & 0,210 \\
\hline 3 & 53 & 0,800 & 3,400 & 0,796 & 0,073 & 3,358 & 0,332 \\
\hline 3 & 54 & 1,100 & 2,200 & 1,050 & 0,080 & 2,208 & 0,236 \\
\hline $3-6$ & 55 & 1,400 & 2,100 & 1,329 & 0,077 & 2,108 & 0,198 \\
\hline 3 & 56 & 0,900 & 2,300 & 0,894 & 0,072 & 2,307 & 0,236 \\
\hline 3 & 57 & 1,200 & 3,000 & 1,162 & 0,100 & 3,011 & 0,366 \\
\hline 3 & 58 & 1,300 & 2,600 & 1,274 & 0,100 & 2,608 & 0,316 \\
\hline 3 & 59 & 1,100 & 2,800 & 1,077 & 0,087 & 2,789 & 0,305 \\
\hline $3-6$ & 60 & 1,400 & 3,800 & 1,287 & 0,105 & 3,866 & 0,473 \\
\hline 4 & 61 & 1,100 & $-1,800$ & 1,176 & 0,135 & $-1,745$ & 0,262 \\
\hline 4 & 62 & 1,400 & $-1,600$ & 1,515 & 0,178 & $-1,565$ & 0,303 \\
\hline 4 & 63 & 0,810 & $-1,400$ & 0,852 & 0,080 & $-1,342$ & 0,133 \\
\hline 4 & 64 & 1,110 & $-1,200$ & 1,153 & 0,106 & $-1,161$ & 0,142 \\
\hline 4 & 65 & 0,820 & $-0,800$ & 0,893 & 0,074 & $-0,759$ & 0,083 \\
\hline 4 & 66 & 1,090 & $-0,600$ & 1,114 & 0,085 & $-0,601$ & 0,075 \\
\hline 4 & 67 & 1,390 & $-0,400$ & 1,440 & 0,107 & $-0,407$ & 0,063 \\
\hline 4 & 68 & 1,200 & 1,200 & 1,223 & 0,099 & 1,184 & 0,140 \\
\hline 4 & 69 & 1,380 & 1,400 & 1,371 & 0,122 & 1,359 & 0,189 \\
\hline 4 & 70 & 0,950 & 1,600 & 0,964 & 0,090 & 1,584 & 0,170 \\
\hline 4 & 71 & 1,050 & 1,800 & 1,009 & 0,100 & 1,808 & 0,212 \\
\hline 4 & 72 & 0,850 & 0,800 & 0,882 & 0,068 & 0,787 & 0,084 \\
\hline $4-5$ & 73 & 1,350 & 0,000 & 1,383 & 0,072 & $-0,023$ & 0,039 \\
\hline $4-5$ & 74 & 0,820 & 0,200 & 0,808 & 0,043 & 0,182 & 0,054 \\
\hline $4-5$ & 75 & 1,120 & 0,400 & 1,142 & 0,057 & 0,373 & 0,050 \\
\hline $4-5$ & 76 & 1,420 & 0,600 & 1,430 & 0,071 & 0,569 & 0,061 \\
\hline $4-5$ & 77 & 0,900 & 0,800 & 0,888 & 0,047 & 0,801 & 0,068 \\
\hline $4-5$ & 78 & 1,200 & 1,000 & 1,206 & 0,061 & 0,994 & 0,083 \\
\hline 5 & 79 & 0,880 & $-0,600$ & 0,881 & 0,094 & $-0,623$ & 0,119 \\
\hline 5 & 80 & 1,300 & 2,200 & 1,271 & 0,101 & 2,174 & 0,261 \\
\hline 5 & 81 & 0,950 & 2,400 & 0,916 & 0,080 & 2,409 & 0,246 \\
\hline 5 & 82 & 1,250 & 0,800 & 1,274 & 0,092 & 0,779 & 0,111 \\
\hline 5 & 83 & 1,000 & 1,200 & 0,965 & 0,073 & 1,174 & 0,135 \\
\hline 5 & 84 & 1,100 & 1,100 & 1,095 & 0,078 & 1,058 & 0,125 \\
\hline 5-6 & 85 & 1,200 & 1,300 & 1,214 & 0,066 & 1,279 & 0,119 \\
\hline 5-6 & 86 & 1,300 & 1,400 & 1,288 & 0,071 & 1,377 & 0,128 \\
\hline 5-6 & 87 & 1,400 & 1,600 & 1,374 & 0,076 & 1,595 & 0,151 \\
\hline 5-6 & 88 & 0,800 & 1,800 & 0,791 & 0,045 & 1,799 & 0,133 \\
\hline 5-6 & 89 & 1,100 & 2,000 & 1,073 & 0,059 & 1,997 & 0,155 \\
\hline 5-6 & 90 & 1,400 & 2,100 & 1,383 & 0,078 & 2,106 & 0,196 \\
\hline 6 & 91 & 1,000 & 0,200 & 0,975 & 0,128 & 0,131 & 0,220 \\
\hline 6 & 92 & 1,100 & 0,400 & 1,164 & 0,149 & 0,348 & 0,202 \\
\hline 6 & 93 & 1,200 & 0,600 & 1,234 & 0,141 & 0,596 & 0,202 \\
\hline 6 & 94 & 1,300 & 0,800 & 1,274 & 0,134 & 0,789 & 0,205 \\
\hline 6 & 95 & 1,000 & 1,400 & 1,000 & 0,088 & 1,382 & 0,220 \\
\hline 6 & 96 & 1,200 & 1,800 & 1,169 & 0,095 & 1,800 & 0,241 \\
\hline 6 & 97 & 0,800 & 3,400 & 0,778 & 0,070 & 3,424 & 0,342 \\
\hline 6 & 98 & 1,100 & 2,200 & 1,074 & 0,084 & 2,196 & 0,255 \\
\hline 6 & 99 & 0,900 & 2,300 & 0,853 & 0,073 & 2,300 & 0,261 \\
\hline 6 & 100 & 1,200 & 3,000 & 1,154 & 0,093 & 3,016 & 0,351 \\
\hline 6 & 101 & 1,300 & 2,600 & 1,216 & 0,091 & 2,627 & 0,301 \\
\hline 6 & 102 & 1,100 & 2,800 & 1,028 & 0,081 & 2,811 & 0,299 \\
\hline
\end{tabular}

Azevedo, Caio L. N. 
Tabela 4.2: Resultados da estimação dos traços latentes e dos parâmetros dos itens : estudo de replicação longitudinal de grupos múltiplos

\begin{tabular}{lccccr}
\hline \hline \multirow{2}{*}{ Parâmetro } & \multicolumn{5}{c}{ Estatística } \\
\cline { 2 - 6 } & Corr & MEP & VQ & Var & REQM \\
\hline Traço latente & 0,994 & 0,276 & 0,020 & 0,079 & 0,313 \\
Discriminação & 0,983 & 0,085 & 0,001 & 0,008 & 0,096 \\
Dificuldade & 0,999 & 0,116 & 0,004 & 0,017 & 0,146 \\
\hline \hline
\end{tabular}

Tabela 4.3: Resultados da estimação dos parâmetros populacionais (média e variância) : estudo de replicação para seleção de modelos

\begin{tabular}{clrrrrrr}
\hline \hline População & Parâmetro & Valor & M.est. & MEP & VQ & Var & REQM \\
\hline \multirow{2}{*}{1} & $\mu_{\theta_{2}}$ & 1,000 & 0,983 & 0,042 & $<0,000$ & $<0,000$ & 0,028 \\
& $\mu_{\theta_{3}}$ & 2,000 & 1,984 & 0,063 & $<0,000$ & 0,001 & 0,039 \\
& $\psi_{\theta_{2}}$ & 0,900 & 0,918 & 0,067 & $<0,000$ & 0,002 & 0,044 \\
& $\psi_{\theta_{3}}$ & 0,950 & 1,002 & 0,090 & 0,003 & 0,002 & 0,070 \\
& $\rho_{\theta}$ & 0,600 & 0,593 & 0,024 & $<0,000$ & $<0,000$ & 0,015 \\
\hline \multirow{2}{*}{2} & $\mu_{\theta_{1}}$ & 0,200 & 0,189 & 0,040 & $<0,000$ & 0,001 & 0,034 \\
& $\mu_{\theta_{2}}$ & 1,300 & 1,287 & 0,048 & $<0,000$ & 0,001 & 0,034 \\
& $\mu_{\theta_{3}}$ & 2,500 & 2,514 & 0,075 & $<0,000$ & 0,002 & 0,045 \\
& $\psi_{\theta_{1}}$ & 0,900 & 0,894 & 0,065 & $<0,000$ & 0,001 & 0,031 \\
& $\psi_{\theta_{2}}$ & 0,800 & 0,856 & 0,066 & 0,003 & 0,003 & 0,079 \\
& $\psi_{\theta_{3}}$ & 0,850 & 0,911 & 0,084 & 0,004 & 0,002 & 0,073 \\
& $\rho_{\theta}$ & 0,800 & 0,805 & 0,019 & $<0,000$ & $<0,000$ & 0,009 \\
& $\gamma_{\theta}$ & 0,880 & 0,872 & 0,011 & $<0,000$ & $<0,000$ & 0,010 \\
\hline \hline
\end{tabular}

Azevedo, Caio L. N. 

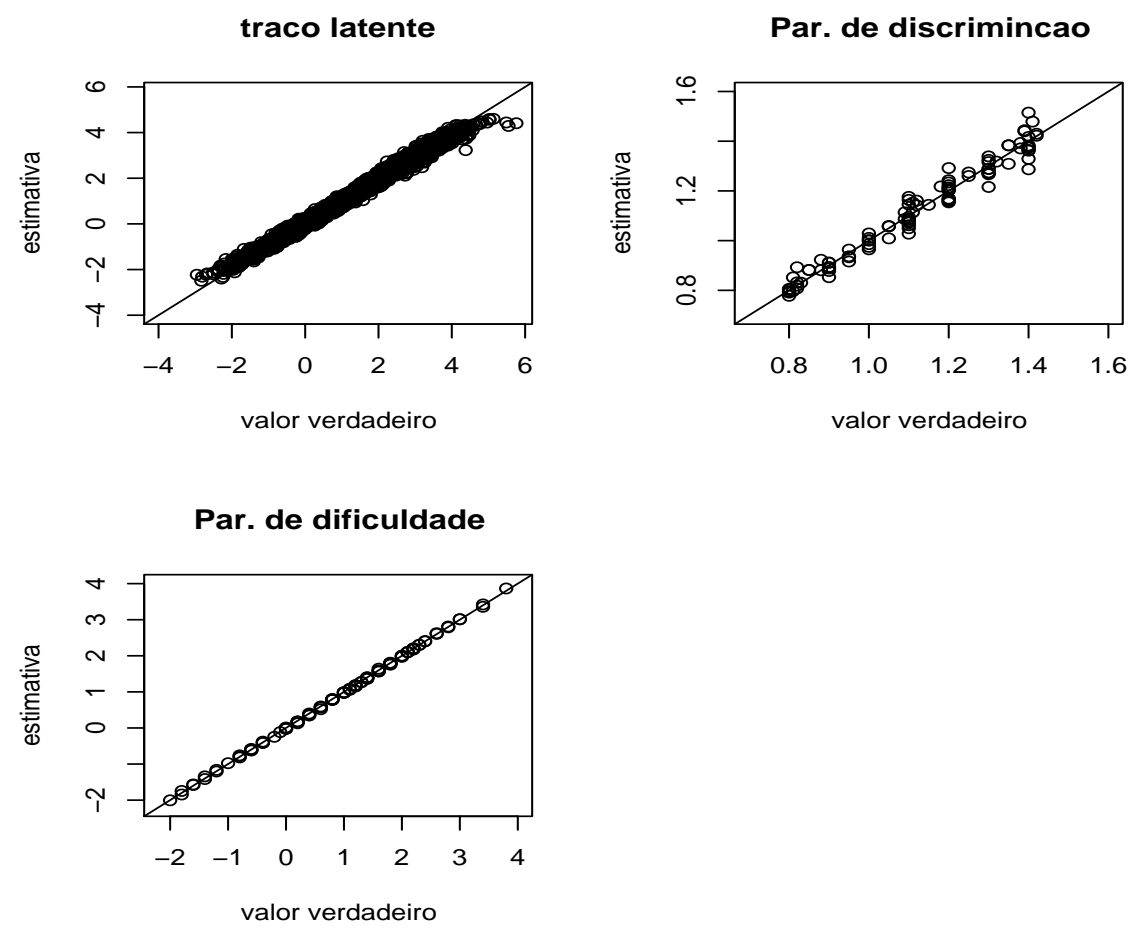

Figura 4.2: Estimativas do estudo de replicação : estudo longitudinal de grupos múltiplos 


\subsubsection{Estudo de seleção de modelos através da metodologia RJMCMC}

Nesta parte conduziremos estudos de simualação para avaliar o comportamento da metodologia de seleção de modelos via RJMCMC. Consideraremos uma única população acompanhada em três instantes de avaliação. Os valores escolhidos para todos os parâmetros, a exceção do parâmetro de correlação, e também com relação as prioris para calcular as taxas de aceitação, equações de 4.18) a 4.20), são exatamente aqueles definidos na Seção 3.7. Mais especificamente, no que diz respeito as estruturas de covariância, consideraremos três situações a saber :

1. matriz de covariâncias verdadeira : $\operatorname{ARH}(1), \operatorname{com} \rho_{\theta(A R H)}=0,80$.

2. matriz de covariâncias verdadeira : $\operatorname{ARMAH}(1,1), \operatorname{com} \rho_{\theta(A R M A H)}=0,80$ e $\gamma_{\theta}=0,80$.

3. matriz de covariâncias verdadeira : $\operatorname{ARMAH}(1,1), \operatorname{com} \rho_{\theta(A R M A H)}=0,80$ e $\gamma_{\theta}=0,88$.

Podemos notar que a segunda situação é equivalente a se considerar uma estrutrua ARH(1) com

$$
\rho_{\theta_{k}(A R H)}=\rho_{\theta_{k}(A R M A H)} \gamma_{\theta_{k}} .
$$

Com efeito a matriz ARH(1) é um caso particular da estrutura $\operatorname{ARMAH}(1,1)$ em que a equação (4.21) se verifica.

Para avaliar o desempenho da metodologia conduzimos um estudo de replicação com $\mathrm{R}=10$ réplicas, utilizando as prioris descritas, para cada uma das três situações consideradas. Em cada um dos casos, a estrutura de seleção escolhida foi aquele visitada em uma maior número de vezes. Ou seja, aquela cuja proporção de visitas foi maior que 0,50. Sendo assim, apresentaremos apenas as estimativas referentes aos modelos escolhidos.

A Tabela 4.4 apresenta a proporção de vezes que cada modelo foi visitado em cada uma das situações consideradas. As proporções foram bastante similares e altamente favoráveis aos verdadeiros modelos. Como era de se esperar, na situação 2 o modelo escolhido foi o ARH(1). Isso ocorreu devido a equivalência entre os modelos ARMAH(1,1) e ARH(1) anteriormente mencionada. Os resultados ilustram a capacidade da metodologia em selecionar o modelo mais adequado.

A Tabela 4.5 apresenta os resultados relacionados as estimativas dos traços latentes e dos parâmetros dos itens. Podemos observar que eles estão bem próximos entre si, para cada situação. Ou seja, a metodologia parece ter apresentado desempenho semelhante entre as situações de seleção de modelos. Além disso, os resultados estão bem próximos daqueles da Tabela 3.5, que correspondem ao ajuste de um modelo longitudinal utilizando a correta estrutura de covariância. No entanto, uma leve vantagem é perceptível para o caso em que se utiliza a verdadeira matriz, o que é esperado. 
A Tabela 4.6 apresenta os resultados relacionados aos parâmetros populacionais. Estes indicam que, com relação às médias e as variâncias, a situação em que o verdadeiro modelo é ARMAH(1,1) apresenta os melhores resultados. Isto possivelmente se deve ao fato de que, em algumas réplicas, após o aquecimento da cadeia, o verdadeiro modelo foi visitado em $100 \%$ das iterações. Dessa forma, as estimativas obtidas são bem mais próximas dos verdadeiros valores nestas circunstâncias. Além disso, tais estimativas são mais precisas pois se utilizam de uma maior número de valores simulados das respectivas distribuições a posteriori. Em geral, as melhores estimativas estão relacionadas aos parâmetros de correlação. Isto se deve, provavelmente, ao fato de que utiliza-se as informações referentes a todos os instantes, na estimação dos referidos parâmetros.

As Figuras $4.3,4.4$ e 4.5 apresentam os gráficos de dispersão entre as estimativas e os verdadeiros valores, dos traços latentes e parâmetros dos itens, para as situações 1, 2 e 3 respectivamente.

Tabela 4.4: Proporção de visitas a cada modelo

\begin{tabular}{lrr}
\hline \hline Situação & \multicolumn{2}{c}{ Modelo } \\
\cline { 2 - 3 } & ARH1 & \multicolumn{1}{c}{ ARMAH(1,1) } \\
\hline 1 & 0,979 & 0,021 \\
2 & 0,966 & 0,034 \\
3 & 0,034 & 0,966 \\
\hline \hline
\end{tabular}

Tabela 4.5: Resultados da estimação dos traços latentes e dos parâmetros dos itens : estudo de replicação para seleção de modelos

\begin{tabular}{lcccccr}
\hline \hline \multirow{2}{*}{ Parâmetro } & Situação & \multicolumn{5}{c}{ Estatística } \\
\cline { 2 - 7 } & & Corr & MEP & VQ & Var & REQM \\
\hline Traço latente & 1 & 0,994 & 0,276 & 0,023 & 0,078 & 0,317 \\
& 2 & 0,976 & 0,280 & 0,022 & 0,080 & 0,319 \\
& 3 & 0,979 & 0,267 & 0,019 & 0,073 & 0,303 \\
\hline Discriminação & 1 & 0,977 & 0,094 & 0,002 & 0,010 & 0,107 \\
& 2 & 0,984 & 0,092 & 0,001 & 0,018 & 0,140 \\
& 3 & 0,983 & 0,092 & 0,001 & 0,009 & 0,103 \\
\hline Dific & 1 & 0,999 & 0,119 & 0,005 & 0,019 & 0,156 \\
& 2 & 0,999 & 0,117 & 0,008 & 0,018 & 0,163 \\
& 3 & 0,999 & 0,119 & 0,005 & 0,019 & 0,155 \\
\hline \hline
\end{tabular}

Azevedo, Caio L. N.

IME/USP 
Tabela 4.6: Resultados da estimação dos parâmetros populacionais : estudo de replicação para seleção de modelos

\begin{tabular}{|c|c|c|c|c|c|c|c|}
\hline Situação & Tempo & Parâmetro & M. est. & MEP & VQ & Var & REQM \\
\hline \multicolumn{8}{|c|}{$\mu_{\theta}$} \\
\hline \multirow[t]{2}{*}{1} & 2 & 1,00 & 0,962 & 0,044 & 0,001 & 0,001 & 0,053 \\
\hline & 3 & 2,00 & 1,950 & 0,073 & 0,003 & 0,003 & 0,077 \\
\hline \multirow[t]{2}{*}{2} & 2 & 1,00 & 0,965 & 0,045 & 0,001 & 0,001 & 0,046 \\
\hline & 3 & 2,00 & 1,963 & 0,074 & 0,001 & 0,002 & 0,056 \\
\hline \multirow[t]{3}{*}{3} & 2 & 1,00 & 0,980 & 0,047 & $<0,000$ & $<0,000$ & 0,023 \\
\hline & 3 & 2,00 & 1,996 & 0,076 & 0,000 & 0,001 & 0,038 \\
\hline & & & & $\psi_{\boldsymbol{\theta}}$ & & & \\
\hline \multirow[t]{2}{*}{1} & 2 & 0,90 & 0,867 & 0,073 & 0,001 & 0,004 & 0,075 \\
\hline & 3 & 0,95 & 0,966 & 0,105 & $<0,000$ & 0,007 & 0,085 \\
\hline \multirow[t]{2}{*}{2} & 2 & 0,90 & 0,921 & 0,079 & $<0,000$ & 0,002 & 0,050 \\
\hline & 3 & 0,95 & 1,005 & 0,108 & 0,003 & 0,004 & 0,083 \\
\hline \multirow[t]{3}{*}{3} & 2 & 0,90 & 0,913 & 0,076 & $<0,000$ & 0,002 & 0,050 \\
\hline & 3 & 0,95 & 1,041 & 0,109 & 0,008 & 0,002 & 0,103 \\
\hline & & \multicolumn{6}{|c|}{$\rho_{\theta}$} \\
\hline 1 & - & 0,8 & 0,794 & 0,012 & $<0,000$ & $<0,000$ & 0,008 \\
\hline 2 & - & 0,8 & 0,798 & 0,013 & $<0,000$ & $<0,000$ & 0,006 \\
\hline \multirow[t]{2}{*}{3} & - & 0,8 & 0,802 & 0,019 & $<0,000$ & $<0,000$ & 0,002 \\
\hline & & & & $\gamma_{\boldsymbol{\theta}}$ & & & \\
\hline 3 & - & 0,85 & 0,875 & 0,011 & 0,001 & $<0,000$ & 0,025 \\
\hline
\end{tabular}



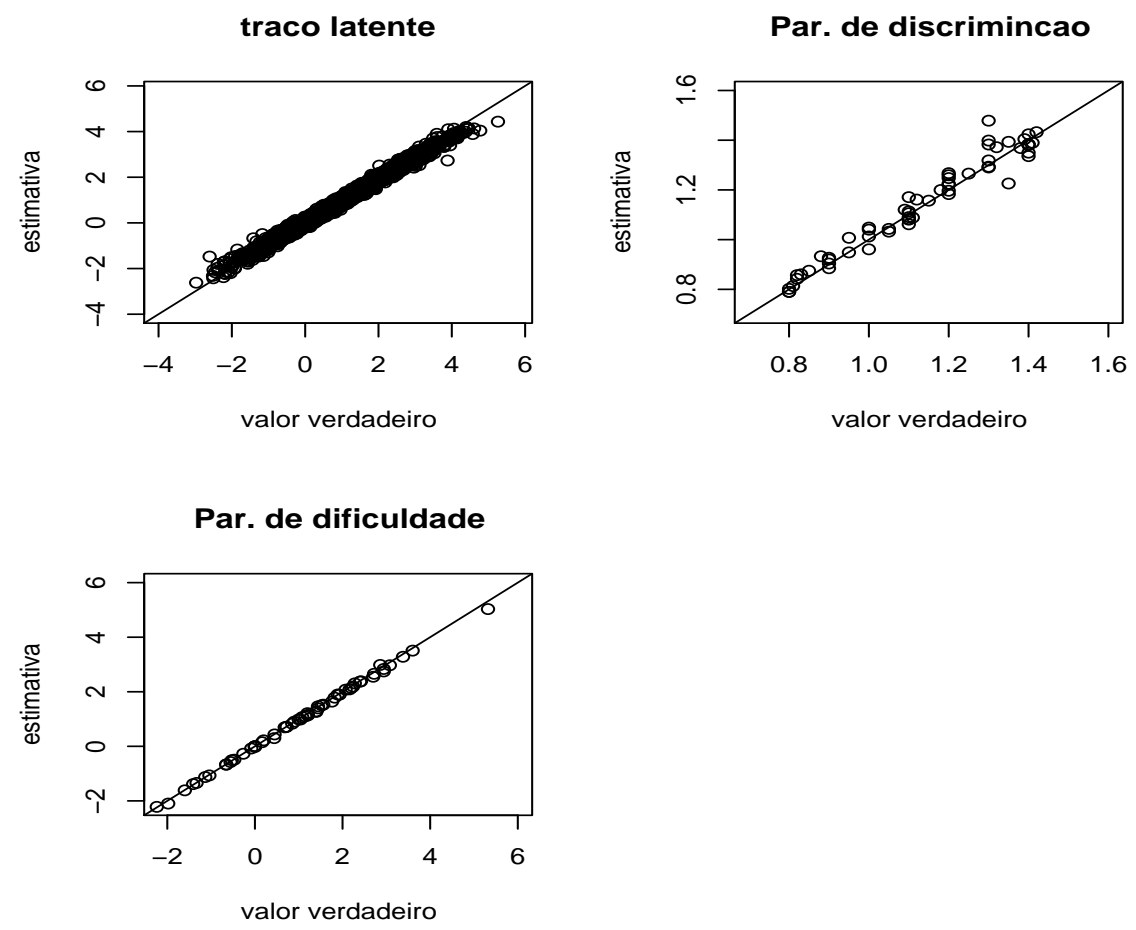

Figura 4.3: Estimativas do estudo de replicação : situação 1 

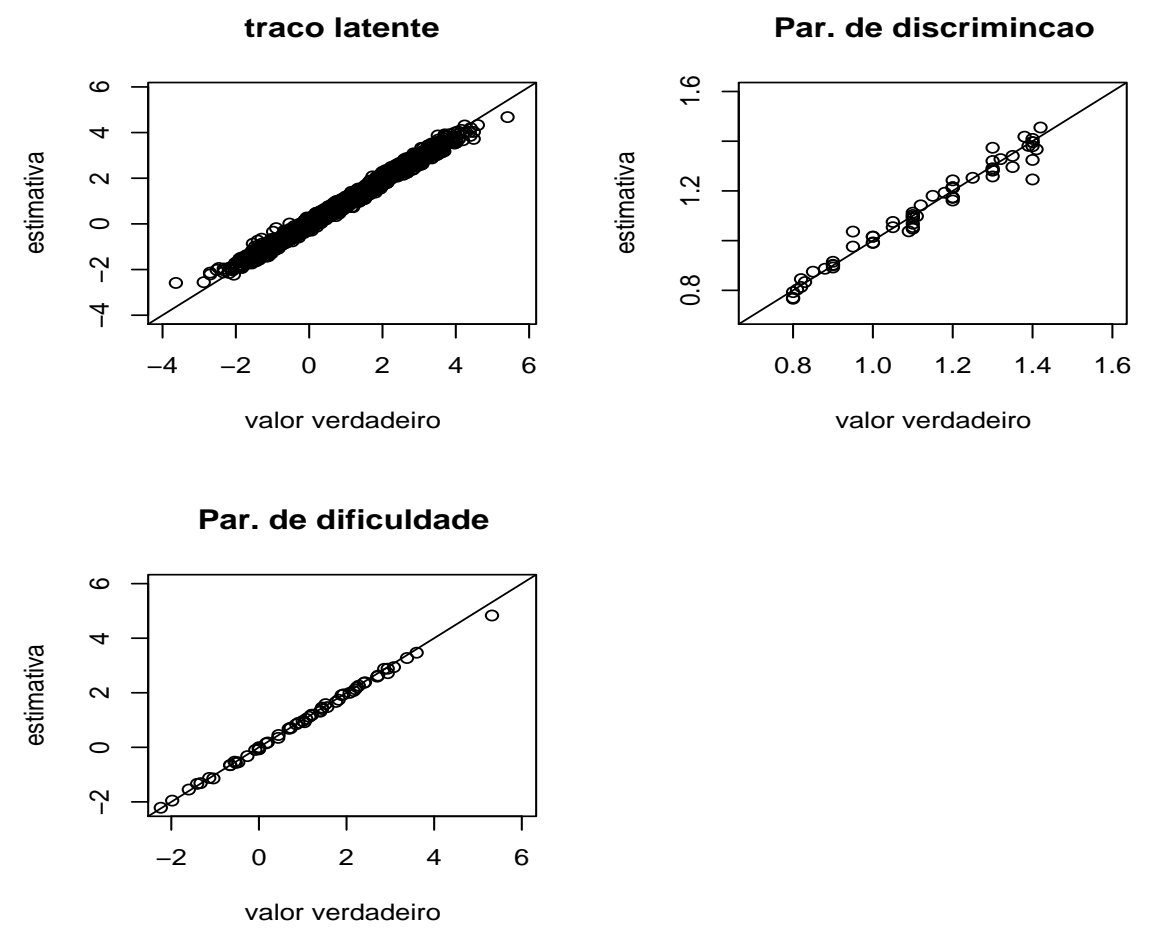

Figura 4.4: Estimativas do estudo de replicação : situação 2 

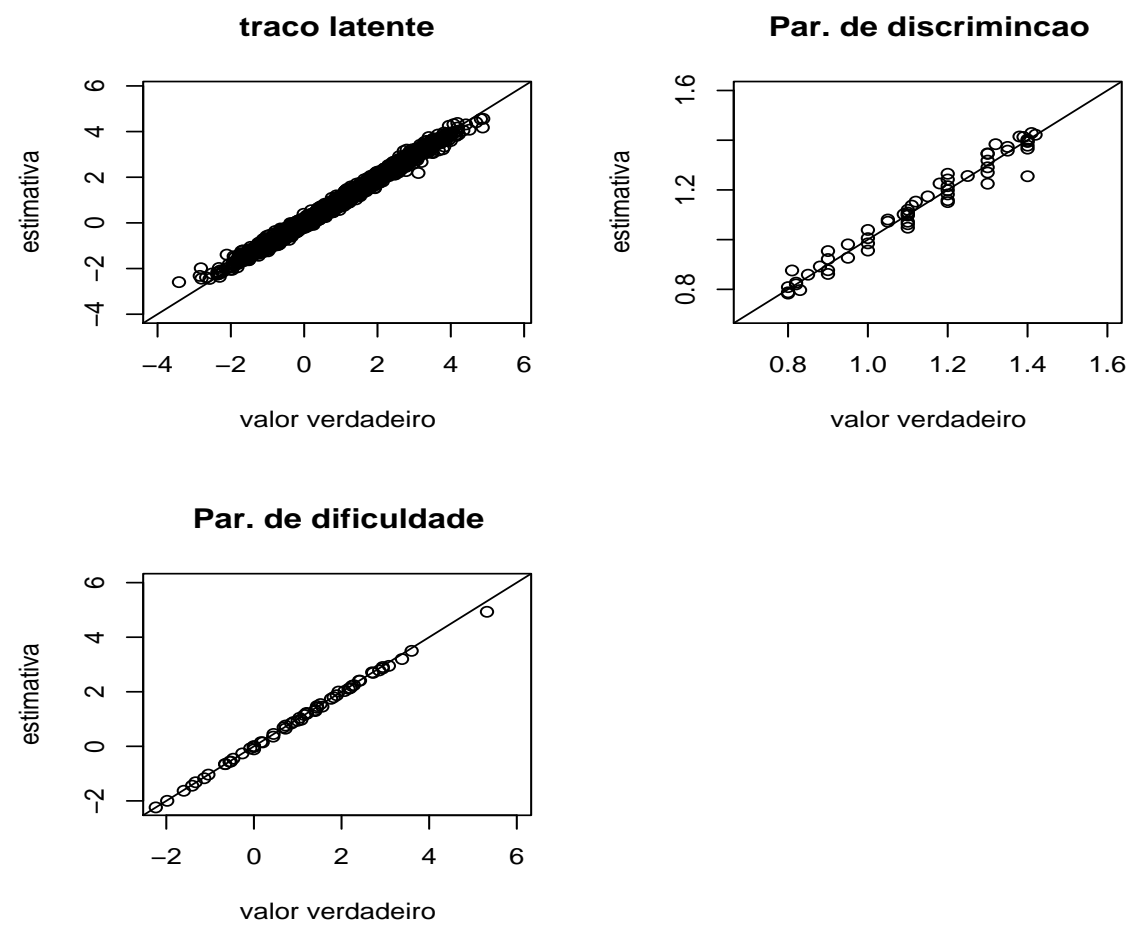

Figura 4.5: Estimativas do estudo de replicação : situação 3 


\subsection{Análise de dados reais}

Nesta subseção analisaremos o conjunto de dados reais considerando a seleção entre as estruturas ARH(1) e ARMAH(1,1). Novamente, as prioris utilizadas bem como toda estrutura MCMC é a mesma descrita na subseção 3.8. Por questões de simplicidade, os intervalos de credibilidade e HPD's não foram calculados. Apresentaremos apenas as estimativas pontuais e respectivos erros-padrão associados aos modelo escolhido.

A proporção de vezes em que o modelo $\mathrm{ARH}(1)$ foi vistitado é 0,620. Dessa forma adotou-se tal estrutura. A Tabela 4.7 apresenta as estimativas dos parâmetros dos itens. É digno de nota que, por uma questão de praticidade, os erros-padrão dos parâmetros de dificuldade originais foram calculadas usando o método Delta, veja Sen and Singer (1994) e Apêndice A, considerando nula a covariância entre os parâmetros $(a, b)$. A Figura 4.6 apresenta o gráfico de dispersão entre as estimativas e os respectivos erros-padrão obtidos com e sem RJMCMC. As estimativas pontuais apresentam-se bem próximas entre si. Entretanto, os erros-padrão, considerando-se a seleção de modelos no procedimento MCMC, apresenta maiores valores do que ao se utilizar a verdadeira matriz de covariâncias. Isso se deve ao fato de que, além de se estar utilizando o método Delta, a incerteza a respeito do verdadeiro modelo torna as estimativas mais imprecisas. Esse é o custo de se ignorar a verdadeira estrutura de covariância.

Azevedo, Caio L. N. 
Tabela 4.7: Estimativas dos parâmetros dos itens via RJMCMC

\begin{tabular}{|c|c|c|c|c|c|}
\hline \multirow[t]{3}{*}{ Teste } & \multirow[t]{3}{*}{ Item } & \multicolumn{4}{|c|}{ Estimativas } \\
\hline & & \multicolumn{2}{|c|}{$\mathbf{a}$} & \multicolumn{2}{|c|}{$\mathbf{b}^{*}$} \\
\hline & & Est. & $\mathbf{E P}$ & Est. & EP \\
\hline 1 & 101 & 0,412 & 0,039 & $-0,442$ & 0,095 \\
\hline 1 & 102 & 0,440 & 0,042 & $-0,882$ & 0,116 \\
\hline 1 & 103 & 0,644 & 0,047 & $-0,900$ & 0,089 \\
\hline $1-2$ & 104 & 0,565 & 0,033 & $-0,608$ & 0,060 \\
\hline 1 & 106 & 0,421 & 0,042 & $-1,405$ & 0,160 \\
\hline 1 & 108 & 0,417 & 0,044 & $-1,714$ & 0,205 \\
\hline $1-2-3$ & 109 & 0,782 & 0,038 & $-0,837$ & 0,055 \\
\hline $1-2$ & 110 & 0,692 & 0,041 & $-0,432$ & 0,046 \\
\hline 1 & 111 & 0,561 & 0,050 & $-1,511$ & 0,151 \\
\hline $1-2-3$ & 114 & 0,548 & 0,028 & $-0,403$ & 0,045 \\
\hline 1 & 116 & 0,727 & 0,056 & $-1,026$ & 0,100 \\
\hline 1 & 117 & 0,519 & 0,042 & 0,047 & 0,061 \\
\hline $1-2-3$ & 118 & 0,549 & 0,044 & $-0,532$ & 0,078 \\
\hline 1 & 119 & 0,449 & 0,031 & $-0,794$ & 0,074 \\
\hline 1 & 120 & 0,424 & 0,040 & $-0,648$ & 0,103 \\
\hline $1-2$ & 121 & 0,492 & 0,048 & $-1,850$ & 0,197 \\
\hline $1-2-3$ & 122 & 0,684 & 0,035 & 0,258 & 0,044 \\
\hline 1 & 124 & 0,711 & 0,035 & $-0,003$ & 0,037 \\
\hline $1-2$ & 125 & 0,757 & 0,060 & $-1,023$ & 0,097 \\
\hline 1 & 126 & 0,746 & 0,038 & $-0,376$ & 0,039 \\
\hline $1-2-3$ & 127 & 0,592 & 0,043 & 0,036 & 0,059 \\
\hline 1 & 128 & 0,720 & 0,035 & 0,043 & 0,036 \\
\hline 1 & 129 & 0,775 & 0,050 & $-0,168$ & 0,051 \\
\hline 1 & 132 & 0,504 & 0,041 & $-0,013$ & 0,069 \\
\hline $1-2$ & 134 & 0,573 & 0,044 & $-1,825$ & 0,152 \\
\hline 1 & 135 & 0,894 & 0,057 & $-0,561$ & 0,057 \\
\hline 1 & 136 & 0,427 & 0,040 & $-0,281$ & 0,084 \\
\hline 2 & 203 & 0,541 & 0,052 & $-0,035$ & 0,075 \\
\hline $2-3$ & 204 & 0,426 & 0,038 & $-1,524$ & 0,154 \\
\hline 2 & 207 & 0,741 & 0,062 & 0,070 & 0,062 \\
\hline 2 & 208 & 0,675 & 0,062 & 1,372 & 0,147 \\
\hline 2 & 209 & 0,672 & 0,067 & $-1,023$ & 0,123 \\
\hline 2 & 210 & 0,612 & 0,057 & $-0,266$ & 0,070 \\
\hline 2 & 214 & 0,502 & 0,052 & 1,655 & 0,192 \\
\hline 2 & 215 & 0,446 & 0,049 & 1,263 & 0,163 \\
\hline 2 & 216 & 0,632 & 0,068 & $-1,920$ & 0,226 \\
\hline $2-3$ & 218 & 0,708 & 0,051 & $-1,009$ & 0,088 \\
\hline $2-3$ & 219 & 0,539 & 0,041 & $-0,135$ & 0,059 \\
\hline 2 & 220 & 0,443 & 0,049 & 1,446 & 0,187 \\
\hline 2 & 221 & 0,536 & 0,054 & $-0,098$ & 0,075 \\
\hline 2 & 222 & 0,734 & 0,074 & $-1,466$ & 0,164 \\
\hline $2-3$ & 223 & 0,783 & 0,049 & 0,455 & 0,057 \\
\hline 2 & 225 & 0,722 & 0,072 & $-1,638$ & 0,180 \\
\hline 2 & 226 & 0,479 & 0,049 & $-0,472$ & 0,095 \\
\hline 2 & 227 & 0,453 & 0,050 & 1,000 & 0,143 \\
\hline 2 & 228 & 0,653 & 0,059 & 0,558 & 0,084 \\
\hline 2 & 229 & 0,865 & 0,090 & $-1,512$ & 0,172 \\
\hline 2 & 233 & 0,569 & 0,054 & $-0,589$ & 0,088 \\
\hline 2 & 234 & 0,959 & 0,076 & $-0,414$ & 0,060 \\
\hline 2 & 236 & 0,737 & 0,066 & $-0,865$ & 0,103 \\
\hline 2 & 240 & 0,569 & 0,056 & $-0,950$ & 0,121 \\
\hline
\end{tabular}

Azevedo, Caio L. N. 
Continuação da Tabela 4.7

\begin{tabular}{lcrrrr}
\hline \multirow{2}{*}{ Teste } & \multirow{2}{*}{ Item } & \multicolumn{4}{c}{ Estimativas } \\
\cline { 3 - 6 } & & \multicolumn{3}{c}{$\mathbf{a}$} & \multicolumn{3}{c}{$\mathbf{b}^{*}$} \\
\cline { 3 - 6 } & & Est. & EP & \multicolumn{1}{c}{ Est. } & EP \\
\hline 3 & 303 & 0,481 & 0,056 & $-1,016$ & 0,153 \\
3 & 308 & 0,509 & 0,048 & 1,198 & 0,157 \\
3 & 309 & 0,562 & 0,057 & $-0,675$ & 0,106 \\
3 & 312 & 0,496 & 0,049 & 0,194 & 0,096 \\
3 & 315 & 0,521 & 0,049 & 0,872 & 0,128 \\
3 & 316 & 0,894 & 0,083 & $-0,768$ & 0,095 \\
3 & 317 & 0,585 & 0,051 & 0,619 & 0,102 \\
3 & 318 & 0,425 & 0,045 & 0,882 & 0,145 \\
3 & 319 & 0,572 & 0,050 & 0,801 & 0,114 \\
3 & 324 & 0,670 & 0,061 & $-0,296$ & 0,075 \\
3 & 326 & 0,495 & 0,051 & $-0,147$ & 0,094 \\
3 & 330 & 0,516 & 0,048 & 0,668 & 0,112 \\
3 & 331 & 0,526 & 0,053 & $-0,586$ & 0,103 \\
3 & 332 & 0,659 & 0,058 & 0,469 & 0,087 \\
3 & 334 & 0,506 & 0,052 & $-0,375$ & 0,100 \\
3 & 335 & 0,639 & 0,056 & 0,489 & 0,085 \\
3 & 336 & 0,447 & 0,047 & 0,470 & 0,115 \\
3 & 337 & 0,656 & 0,055 & 1,211 & 0,133 \\
3 & 338 & 0,619 & 0,057 & $-0,010$ & 0,076 \\
3 & 339 & 0,654 & 0,056 & 0,693 & 0,100 \\
3 & 340 & 0,393 & 0,044 & 1,267 & 0,180 \\
\hline \hline
\end{tabular}

Est. Par. de discrimincao

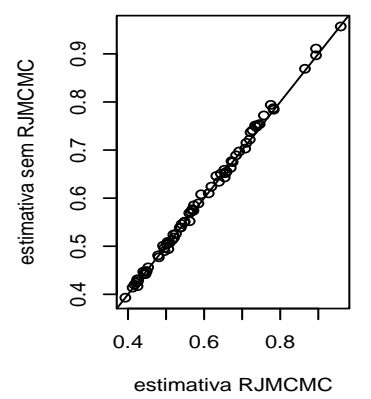

EP. Par. de dific. orig.

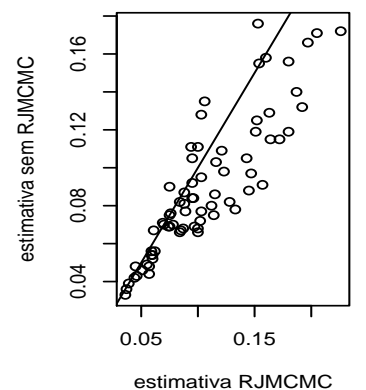

EP. Par. de discrimincao

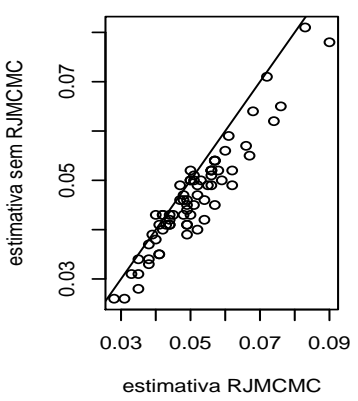

Est. traco latente

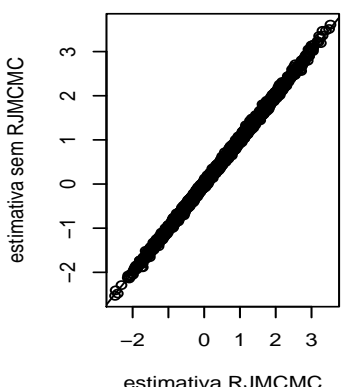

Est. Par. de dific. orig.

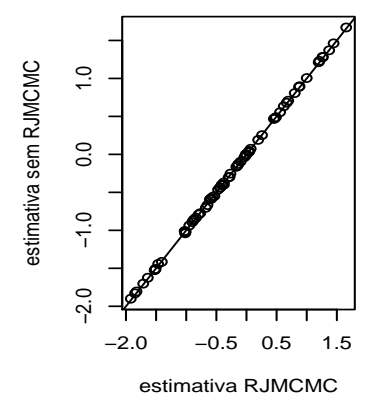

EP. traco latente

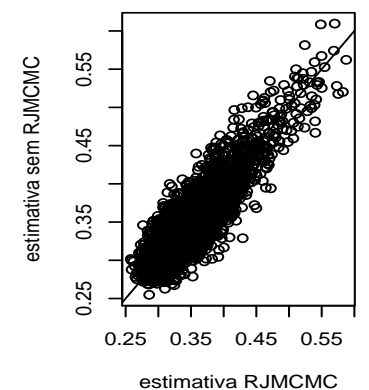

Figura 4.6: Estimativas dos parâmetros dos itens via RJMCMC e sem RJMCMC : dados reais 


\subsection{Comentários}

No presente capítulo estendemos as modelagens propostas nos Capítulos 2 e 3 no sentido de unificá-las. Este expediente permite obter resultados melhores do que em se analisando as populações de modo independente, principalmente quando os testes apresentados possuem itens em comum (com relação as populações). Desenvolvemos um procedimento de estimação de MCMC através do algoritmo de Gibbs. Mostramos como diferentes estruturas de covariância podem ser facilmente acomodadas através de simples adaptações do algoritmo de estimação proposto. Além disso, desenvolvemos uma metodologia de seleção de estruturas de covariância baseada no algoritmo de simulação RJMCMC. Este expediente, unido a utilização do MGM, o qual supõe independência entre os traços latentes, constituem ferramentas bastante úteis na escolha de estruturas de covariância mais adequadas. Apesar de não ter sido apresentado, a metodologia de diagnóstico proposta nos capítulos anteriores, pode ser estendida para a estrutura desenvolvida no presente capítulo. Os estudos de simulação indicam que a modelagem e o método de estimação desenvolvidos produzem resultados bastante satisfatórios, apesar de que alguns parâmetros não foram muito bem estimados. A análise de dados reais ilustra o potencial da metodologia desenvolvida.

Azevedo, Caio L. N. 



\section{Capítulo 5}

\section{Modelo longidutinal com grupos múltiplos : estrutura multinível bayesiana}

\subsection{Introducão}

Em muitos campos de pesquisa, como na área educacional, biologia e ciências do comportamento, é muito comum a existência de dados que apresentam algum tipo de estrutura hierárquica. Tal estrutura se caracteriza quando as unidades amostrais estão agrupadas em diferentes níveis. Ou seja, quando unidades amostrais pertencer a diferentes grupos e estes, por sua vez, podem pertencem ou não a outros tipos de grupos. Um exemplo na área educacional é a estrutura em que alunos se encontram agrupados em escolas, e escolas estão agrupadas em delegacias de ensino. Neste caso espera-se que unidades pertencentes a mesmos grupos sejam mais similares entre si do que unidades pertencentes à diferentes grupos. Isto ocorre pois é bastante frequente que unidades pertencentes a um mesmo grupo partilhem características comuns. Em termos do processo inferencial, é muito importante levar em consideração tais similaridades. Do contrário, pode-se obter estimativas viesadas, tanto pontuais quanto intervalares.

Os modelos de regressão usuais não permitem incorporar tais características. Dessa forma é necessário a utilização de uma modelagem mais apropriada que permita levar em consideração estruturas de dependência e diferentes fontes de variabilidade induzidas pela estrutura hierárquica. Os modelos que permitem considerar tal comportamento são chamados de modelos multiníveis ou modelos hierárquicos. Existe uma vasta literatura a respeito de dados hierárquicos e dos modelos multiníveis. Importantes referências são Goldstein (2003), Kreft and de Leeuw (1998), Kreft and de Leeuw (1999) e Bryk and Raudenbush (1987), dentre outros. Uma importante referência dentro da TRI é o trabalho de Fox (2001), que propôs uma estrutura multinível para o traço latente com o intuito de incorporar dependências entre indivíduos.

Uma outra utilidade da modelagem multinível é a representação de estruturas de dependência em dados longitudinais, veja Laird and Ware (1982) ou Snijders (1996). Isto se deve ao fato de que as condições de avaliação estão aninhadas, isto é, formam grupos de observações intra indivíduos. Dessa forma, espera-se que medidas feitas no mesmo indivíduo sejam mais similares entre si do que medidas tomadas em diferentes indivíduos. 
Sendo assim, é possível utilizar modelos multiníveis para representar diferentes estruturas de dependência longitudinal, veja Rochon (1992), por exemplo.

Os Capítulos 2, 3 e 4 apresentam estruturas hierárquicas. No Capítulo 2 temos indivíduos dentro de grupos. No Capítulo 3 temos instantes de avaliação dentro de indivíduos e no Capítulo 4 temos instantes de avaliação dentro de indivíduos, e indivíduos dentro de grupos. Estes dados são exemplos de estruturas hierárquicas de dois, dois e três níveis, respectivamente.

Um outro expediente igualmente útil para representar dados longitudinais é a utilização os modelos de efeitos aleatórios, veja Laird and Ware (1982) por exemplo, com estruturas de séries temporais, vide Goldstein et al. (1994) e Snijders (1996). Estes tipos de modelos são bastante úteis para representar correlações seriais, ou seja, correlações que diminuem com o aumento da distâncias temporais entre as medidas.

O objetivo deste capítulo é propor estruturas multiníveis e de efeitos aleatórios com séries temporais para representar as matrizes de covariância apresentadas no Capítulo 4. A partir da modelagem proposta desenvolvemos algoritmos de estimação via MCMC e também discutimos alguns aspectos relacionados à medidas de diagnóstico. Salientamos que as notações utilizadas neste capítulo, especificamente com relação as matrizes de covariância, serão um pouco diferentes daquelas definidas no Capítulo 4. Eventualmente, as letras gregas utilizadas representarão parâmetros diferentes daqueles definidos por tais letras no referido capítulo.

Na Seção 5.1 apresentamos alguns aspectos da modelagem multinível e o objetivo geral do presente capítulo. $\mathrm{Na}$ Seção 5.2 apresentaremos modelos multiníveis homocedásticos para representar algumas matrizes de covariância. Na Seção 5.3 estudaremos modelos de séries temporais estacionárias para representar outras matrizes. Nas Seções 5.4 e 5.5 apresentaremos, respectivamente, modelos multiníveis heterocedásticos e para séries temporais não estacionárias com o intuito de gerar as matrizes de covariância estudadas no presente trabalho. Na Seção 5.6 discutiremos a construção de uma estrutura geral para a verossimilhança de dados aumentados. A Seção 5.7 trata do procedimento de estimação MCMC para os modelos das Seções 5.2 e 5.3 , enquanto que a Seção 5.8 aborda o mesmo tema referente aos modelos das Seções 5.4 e 5.5. Na Seção 5.9 conduziremos um estudo de simulação para ilustrar parte da metodologia desenvolvida neste capítulo, enquanto que na seção 5.10 conduziremos uma análise de dados reais. Finalmente, na Seção 5.11, teceremos alguns comentários pertinentes.

As contribuições do presente capítulo são :

1. Desenvolvimento da modelagem multinível para representar as matrizes de covariância estudadas no Capítulo 4.

2. Desenvolvimento da modelagem de efeitos aleatórios com séries temporais para representar as matrizes de covariância estudadas no Capítulo 4.

Azevedo, Caio L. N.

IME/USP 
3. Desenvolvimento da abordagem de dados aumentados para o modelo probito de 2 parâmetros longitudinal de grupos múltiplos, sob as estruturas descritas nos itens 1) e 2).

4. Desenvolvimento e implementação computacional do amostrador de Gibbs para os modelos descritos no item 3).

5. Estudo e implementação de algumas medidas de diagnóstico para os modelos descritos no item 3).

6. Estudo de simulação :

(a) Consistência dos estimadores para a matriz de Hankel.

7. Aplicação da metodologia a um conjunto de dados reais.

\subsection{Modelos multiníveis homocedásticos}

Dentro do contexto da análise de dados longitudinais com resposta normal, a abordagem multivariada para dados longitudinais, proposta nos Capítulos 3 e 4, é apropriada para modelar uma grande variedade de estruturas de covariância. Entretanto, quando o número de condições de avaliação aumenta, os modelos multivariados tendem a apresentar alguns problemas, como no processo de estimação, veja Laird and Ware (1982). Além disso a interpretação e inclusão de informações adicionais, como covariáveis, se tornam mais complicadas.

Por outro lado, a modelagem multinível permite representar algumas estruturas de covariância através de distribuições condicionalmente independentes e univariadas, veja Laird and Ware (1982). Também, as interpretações dos modelos, procedimentos de estimação e inclusão de informações adicionais, como covariáveis, tornam-se mais simples. Um outro aspecto diz respeito a utilização de medidas de diagnóstico. A avaliação da qualidade de ajuste do modelo é menos complicada no contexto univariado do que no contexto multivariado, veja Fahrmeir et al. (2001) e Skrondal and Rabe-Hesketh (2004), por exemplo.

De uma forma geral, a abordagem multinível permite de forma mais simples :

- Utilizar métodos de estimação mais apropriados, veja Laird and Ware (1982).

- Incluir covariáveis constantes e dependentes no tempo, veja Snijders (1996).

- Separar diferentes fontes de variabilidade, e assim representar diferentes matrizes (estruturas) de covariância (dependência) veja Littell et al. (2000).

- Construir medidas de diagnósticos para a verificação do ajuste do modelo como um todo e o afastamento de suposições específicas, veja Skrondal and Rabe-Hesketh (2004).

Azevedo, Caio L. N.

IME/USP 
Na presente seção exploraremos estruturas multiníveis para representar as versões homocedásticas das matrizes UH e Hankel, no contexto de grupos múltiplos. Ou seja, consideraremos que as variâncias são constantes ao longo do tempo. Note que, neste caso, temos uma estrutura hierárquica de três níveis em que os instantes de avaliação estão agrupados dentro dos indivíduos e estes, por sua vez, encontram-se aninhados nos grupos. Esse padrão de comportamento é encontrado em algumas situações, veja Goldstein (2003).

\subsubsection{Matrizes uniforme e Hankel}

O primeiro importante detalhe a ser notado é que, quando se considera homocedasticidade, as matrizes Uniforme e Hankel são exatamente as mesmas. Por isso os desenvolvimentos dessa subseção se aplicam a ambas. As versões, respectivamente das matrizes de covariância e de correlação que assumem variâncias iguais, das referidas matrizes são:

$$
\boldsymbol{\Psi}_{\boldsymbol{\theta}_{k}}=\psi_{\theta_{k}}\left[\begin{array}{ccccc}
1 & \rho_{\theta_{k}} & \rho_{\theta_{k}} & \ldots & \rho_{\theta_{k}} \\
\rho_{\theta_{k}} & 1 & \rho_{\theta_{k}} & \ldots & \rho_{\theta_{k}} \\
\rho_{\theta} & \rho_{\theta_{k}} & 1 & \ldots & \rho_{\theta_{k}} \\
\vdots & \vdots & \vdots & \ddots & \vdots \\
\rho_{\theta_{k}} & \rho_{\theta_{k}} & \rho_{\theta_{k}} & \ldots & 1
\end{array}\right],
$$

e,

$$
\boldsymbol{\Omega}_{\boldsymbol{\theta}_{k}}=\left[\begin{array}{ccccc}
1 & \rho_{\theta_{k}} & \rho_{\theta_{k}} & \ldots & \rho_{\theta_{k}} \\
\rho_{\theta_{k}} & 1 & \rho_{\theta_{k}} & \ldots & \rho_{\theta_{k}} \\
\rho_{\theta} & \rho_{\theta_{k}} & 1 & \ldots & \rho_{\theta_{k}} \\
\vdots & \vdots & \vdots & \ddots & \vdots \\
\rho_{\theta_{k}} & \rho_{\theta_{k}} & \rho_{\theta_{k}} & \ldots & 1
\end{array}\right]
$$

Este é um padrão de comportamento muito utilizado para representar certos tipo de dados hierárquicos, veja Goldstein (2003). Nessa situação, os indivíduos estão agrupados em diferentes "clusters". Dessa forma, esperase observar algum tipo de correlação entre indivíduos pertencentes a um mesmo grupo. Uma suposição usual é a de homedasticidade nos efeitos aleatórios dos indivíduos, veja Goldstein (2003). Isto implica que a correlação entre qualquer par de indivíduos é a mesma dentro de cada grupo e que aquela não difere entre entre estes. No contexto longitudinal os instantes de avaliação estão agrupados nos indivíduos e as correlações entre dois instantes quaisquer é a mesma. Entretanto, temos um terceiro nível, que são os grupos. E, assim, consideramos que tais correlações podem ser diferentes entre eles. Note que grupo no contexto hierárquico equivale a indivíduo 
no contexto longitudinal. Para levar em consideração tal estrutura, um modelo apropriado é, veja Littell et al. (2000) :

$$
\begin{aligned}
\theta_{j k t} & =\mu_{\theta_{k t}}+\tau_{j k}+\xi_{j k t} \\
\tau_{j k} & \sim N\left(0, \sigma_{\theta_{k}}^{2}\right) \\
\xi_{j k t} & \sim N\left(0, \psi_{\theta_{k}}\right),
\end{aligned}
$$

em que $\tau_{j k}$ and $\xi_{j k t}$ são mutuamente independentes $\forall j, k, t$. De acordo com esta estrutura temos que

$$
\begin{gathered}
\mathbb{E}\left(\theta_{j k t}\right)=\mu_{\theta_{k t}}, \\
\operatorname{Cov}\left(\theta_{j k t}, \theta_{j^{\prime} k^{\prime} t^{\prime}}\right)= \begin{cases}0, & \text { if, } j \neq j^{\prime}, \text { e } / \text { ou } k \neq k^{\prime} \\
\sigma_{\theta_{k}}^{2}+\psi_{\theta_{k}}, & \text { se } j=j^{\prime}, k=k^{\prime} \text { e } t=t^{\prime} \\
\sigma_{\theta_{k}}^{2}, & \text { if } j=j^{\prime}, k=k^{\prime} \text { e } t \neq t^{\prime},\end{cases}
\end{gathered}
$$

e

$$
\operatorname{Corr}\left(\theta_{j k t}, \theta_{j^{\prime} k^{\prime} t^{\prime}}\right)= \begin{cases}0, & \text { se } j \neq j^{\prime}, \text { e } / \text { ou } k \neq k^{\prime} \\ 1, & \text { se } j=j^{\prime}, k=k^{\prime} \text { e } t=t^{\prime} \\ \frac{\sigma_{\theta_{k}}^{2}}{\sigma_{\theta_{k}}^{2}+\psi_{\theta_{k}}}, & \text { se } j=j^{\prime}, k=k^{\prime} \text { e } t \neq t^{\prime}\end{cases}
$$

Em termos matriciais temos que

$$
\boldsymbol{\Psi}_{\boldsymbol{\theta}_{k}}=\left[\begin{array}{ccccc}
\sigma_{\theta_{k}}^{2}+\psi_{\theta_{k}} & \sigma_{\theta_{k}}^{2} & \sigma_{\theta_{k}}^{2} & \ldots & \sigma_{\theta_{k}}^{2} \\
\sigma_{\theta_{k}}^{2} & \sigma_{\theta_{k}}^{2}+\psi_{\theta_{k}} & \sigma_{\theta_{k}}^{2} & \ldots & \sigma_{\theta_{k}}^{2} \\
\sigma_{\theta_{k}}^{2} & \sigma_{\theta_{k}}^{2} & \sigma_{\theta_{k}}^{2}+\psi_{\theta_{k}} & \ldots & \sigma_{\theta_{k}}^{2} \\
\vdots & \vdots & \vdots & \ddots & \vdots \\
\sigma_{\theta_{k}}^{2} & \sigma_{\theta_{k}}^{2} & \sigma_{\theta_{k}}^{2} & \ldots & \sigma_{\theta_{k}}^{2}+\psi_{\theta_{k}}
\end{array}\right]
$$

Azevedo, Caio L. N.

IME/USP 


$$
\boldsymbol{\Omega}_{\theta_{k}}=\left[\begin{array}{ccccc}
1 & \frac{\sigma_{\theta_{k}}^{2}}{\sigma_{\theta_{k}}^{2}+\psi_{\theta_{k}}} & \frac{\sigma_{\theta_{k}}^{2}}{\sigma_{\theta_{k}}^{2}+\psi_{\theta_{k}}} & \cdots & \frac{\sigma_{\theta_{k}}^{2}}{\sigma_{\theta_{k}}^{2}+\psi_{\theta_{k}}} \\
& 1 & \frac{\sigma_{\theta_{k}}^{2}}{\sigma_{\theta_{k}}^{2}+\psi_{\theta_{k}}} & \cdots & \frac{\sigma_{\theta_{k}}^{2}}{\sigma_{\theta_{k}}^{2}+\psi_{\theta_{k}}} \\
\frac{\sigma_{\theta_{k}}^{2}}{\sigma_{\theta_{k}}^{2}+\psi_{\theta_{k}}} & \frac{\sigma_{\theta_{k}}^{2}}{\sigma_{\theta_{k}}^{2}+\psi_{\theta_{k}}} & 1 & \cdots & \frac{\sigma_{\theta_{k}}^{2}}{\sigma_{\theta_{k}}^{2}+\psi_{\theta_{k}}} \\
\vdots & \vdots & \vdots & \ddots & \vdots \\
\frac{\sigma_{\theta_{k}}^{2}}{\sigma_{\theta_{k}}^{2}+\psi_{\theta_{k}}} & \frac{\sigma_{\theta_{k}}^{2}}{\sigma_{\theta_{k}}^{2}+\psi_{\theta_{k}}} & \frac{\sigma_{\theta_{k}}^{2}}{\sigma_{\theta_{k}}^{2}+\psi_{\theta_{k}}} & \cdots & 1
\end{array}\right] .
$$

Então, o modelo (5.3) gera o mesmo tipo de estrutura de dependência dada por $(5.1)$ e $(5.2)$ em que $\psi_{\theta_{k}}^{*}=\sigma_{\theta_{k}}^{2}+\psi_{\theta_{k}}$ e $\rho_{\theta_{k}}=\frac{\sigma_{\theta_{k}}^{2}}{\sigma_{\theta_{k}}^{2}+\psi_{\theta_{k}}}$, são as covariâncias e as correlações, respectivamente. Em outras palavras, a estrutura de dependência é a mesma, embora ela seja induzida por uma outra parametrização. Além disso, os traços latentes são mutuamente independentes, condicionados aos efeitos aleatórios $\tau_{j k}$. No entanto, a independência entre grupos permanece. Note que esta independência também é válida para a estrutura multivariada. Entretanto, a independência condicional intra indivíduos ocorre apenas para a modelagem multinível. Um outro aspecto é que a modelagem multinível possui uma interpretação mais simples. Os efeitos aleatórios $\tau_{j k}$ representam a diferença entre cada indivíduo e a média geral $\mu_{\theta_{k t}}$. Além disso, $\tau_{j k}$ representa a variação entre indivíduos enquanto que $\xi_{j k t}$ representa a variação intra indivíduos. Em outras palavras, enquanto $\tau_{j k}$ representa a variabilidade devida ao processo de amostragem $\xi_{j k t}$ representa a variabilidade oriunda do planejamento longitudinal.

\subsection{Modelos para séries temporais estacionárias}

A análise de séries temporais (AST) compreende o estudo de observações realizadas ao longo do tempo, veja Hamilton (1994). Diferentemente dos estudos longitudinais, na AST poucos unidades amostrais são acompanhadas ao longo de muitos instantes de observação. Neste tipo de estudo é esperado que observações tomadas em instantes mais próximos sejam mais correlacionadas do que observações mais distantes. Este tipo de dependência é conhecida como correlação serial, veja Bhargava et al. (1982), por exemplo. Nas últimas décadas muitos modelos têm sido propostos para representar diversos tipos de séries temporais. Tais modelos são conhecidos como modelos de séries temporais (MST). Algumas referências importantes, utilizadas nesse trabalho, são Hamilton (1994) e Morettin and Toloi (2006). Uma classe bastante utilizada de MST são aqueles relacionados à séries temporais estacionárias. Esses modelos são conhecidos como modelos de séries temporais estacionárias (MSTE). Tais séries se caracterizam quando as médias e as variâncias são constantes ao longo do tempo. Além disso, as correlações dependem apenas da distância entre as observações e não dos instantes propriamente.

Azevedo, Caio L. N.

IME/USP 
Por outro lado, é esperado observar algum tipo de correlação serial em estudos longitudinais, nos quais a condição de avaliação é o tempo. No caso de estudos longitudinais com comportamento estacionário, alguns modelos têm sido propostos, assumindo resposta com distribuição normal. Dentre eles citamos Littell et al. (2000), Rochon and Helms (1989) e Jones (1990). Apesar de que o número de condições de avaliação em estudos longitudinais tende a ser pequeno, em geral, tem-se muitos indivíduos em cada instante. Dessa forma, as autocorrelações podem ser satisfatoriamente estimadas ainda que o número de condições de avaliação seja pequeno. Com efeito, os modelos de séries temporais para dados longitudinais podem ser vistos como uma variante dos modelos dinâmicos, veja West and Harrison (1999), ou mesmo dos modelos com erros nas variáveis, veja Carrol et al. (2005).

Antes de estudarmos os modelos, apresentaremos as versões homocedásticas das matrizes ARH(1), TH e ARMAH(1,1). Observemos ainda que a estrutura AD é não estacionária, mesmo na sua versão homocedástica, veja Nunez-Anton and Zimmerman (2000). Sendo assim, ela só será estudada na Seção 5.5. As referidas estruturas são dadas, respectivamente, por

$\operatorname{AR}(1)$

$$
\boldsymbol{\Psi}_{\boldsymbol{\theta}_{k}}=\psi_{\theta_{k}}\left[\begin{array}{ccccc}
1 & \rho_{\theta_{k}} & \rho_{\theta_{k}}^{2} & \ldots & \rho_{\theta_{k}}^{T-1} \\
\rho_{\theta_{k}} & 1 & \rho_{\theta_{k}} & \ldots & \rho_{\theta_{k}}^{T-2} \\
\rho_{\theta}^{2} & \rho_{\theta_{k}} & 1 & \ldots & \rho_{\theta_{k}}^{T-3} \\
\vdots & \vdots & \vdots & \ddots & \vdots \\
\rho_{\theta_{k}}^{T-1} & \rho_{\theta_{k}}^{T-2} & \rho_{\theta_{k}}^{T-3} & \ldots & 1
\end{array}\right]
$$

Toeplitz

$$
\boldsymbol{\Psi}_{\boldsymbol{\theta}_{k}}=\psi_{\theta_{k}}\left[\begin{array}{ccccc}
1 & \rho_{\theta_{k}} & 0 & \ldots & 0 \\
\rho_{\theta_{k}} & 1 & \rho_{\theta_{k}} & \ldots & 0 \\
0 & \rho_{\theta_{k}} & 1 & \ldots & 0 \\
\vdots & \vdots & \vdots & \ddots & \vdots \\
0 & 0 & 0 & \ldots & 1
\end{array}\right]
$$

Azevedo, Caio L. N. 
$\operatorname{ARMA}(1,1)$

$$
\boldsymbol{\Psi}_{\boldsymbol{\theta}_{k}}=\psi_{\theta_{k}}\left[\begin{array}{ccccc}
1 & \gamma_{\theta_{k}} & \gamma_{\theta_{k}} \rho_{\theta_{k}} & \ldots & \gamma_{\theta_{k}} \rho_{\theta_{k}}^{T-2} \\
\gamma_{\theta_{k}} & 1 & \gamma_{\theta_{k}} & \ldots & \gamma_{\theta_{k}} \rho_{\theta_{k}}^{T-2} \\
\gamma_{\theta_{k}} \rho_{\theta} & \gamma_{\theta_{k}} & 1 & \ldots & \gamma_{\theta_{k}} \rho_{\theta_{k}}^{T-4} \\
\vdots & \vdots & \vdots & \ddots & \vdots \\
\gamma_{\theta_{k}} \rho_{\theta_{k}}^{T-2} & \gamma_{\theta_{k}} \rho_{\theta_{k}}^{T-3} & \gamma_{\theta_{k}} \rho_{\theta_{k}}^{T-4} & \ldots & 1
\end{array}\right],
$$

as matrizes de correlação são exatamente as mesmas dadas em (5.4), (5.5) e (5.6), desconsiderando-se o termo $\psi_{\theta_{k}}$. Note que a suposição de homocedasticidade não garante a estacionariedade dos traços latentes, uma vez que $\mathbb{E}\left(\theta_{j k t}\right)=\mu_{\theta_{k t}}$. No entanto, isto pode ser facilmente contornado considerando-se a seguinte transformação:

$$
\boldsymbol{\theta}_{j .}^{*}=\boldsymbol{\theta}_{j k .}-\boldsymbol{\mu}_{\boldsymbol{\theta}_{k}} \sim N_{T}\left(\mathbf{0}_{k}, \mathbf{\Psi}_{\boldsymbol{\theta}_{k}}\right)
$$

Note que a transformação definida em 5.7, não modifica as matrizes 5.4, 5.5 e 5.6. Portanto, a estrutura proposta implica que

$$
\begin{aligned}
\mathbb{E}\left(\theta_{j k t}^{*}\right) & =0 \\
\operatorname{Var}\left(\theta_{j k t}^{*}\right) & =\psi_{\theta_{k}} \\
\operatorname{Cov}\left(\theta_{j k t}^{*}, \theta_{j k t^{\prime}}^{*}\right) & =\psi_{\theta_{k\left|t-t^{\prime}\right|}} .
\end{aligned}
$$

Em outras palavras a série temporal definida por $\theta_{j k t}^{*}, t=1,2, \ldots$; é estacionária e portanto, podemos utilizar a metodologia de estudos longitudinais estacionários.

\subsection{1 $\operatorname{AR}(1)$}

Neste caso assume-se que a correlação diminui exponencialmente como uma função do tempo, padrão este bastante comum em séries temporais. Dessa forma temos que os traços latentes, de um mesmo indivíduo, medidos em tempos próximos, possuem maior correlação do que aqueles medidos em tempos mais distantes. Alguns trabalhos que estudam MSTE aplicados à dados longitudinais são: Jones (1990), Bhargava et al. (1982), Goldstein et al. (1994), Jones and Boadi-Boateng (1991), Diggle (1988), Geary (1989), Chi and Reinsel (1989) e Mansour et al. (1985). Estes trabalhos discutem como estruturas AR(r), em que $r$ denota a defasagem da série,

Azevedo, Caio L. N.

IME/USP 
podem ser convenientemente modeladas através de MSTE. Particularmente, a estrutura AR(1) definida neste trabalho, pode ser convenientemente representada através de um processo AR(1) estacionário, veja Mansour et al. (1985), isto é,

$$
\begin{aligned}
\theta_{j k t}^{*} & =\rho_{\theta_{k}} \theta_{j k(t-1)}^{*}+\xi_{j k t} \\
\xi_{j k t} & \sim N\left(0, \psi_{\theta_{k}}\right),
\end{aligned}
$$

em que $\left|\rho_{\theta_{k}}\right|<1, \forall k$ para garantir a estacionariedade, veja Hamilton (1994). Note que a estrutura definida por (5.11) e 5.12 implica que

$$
\begin{aligned}
\operatorname{Var}\left(\theta_{j k t}^{*}\right) & =\frac{\psi_{\theta_{k}}}{1-\rho_{\theta_{k}}^{2}}=\psi_{\theta_{k}}^{*} \\
\operatorname{Corr}\left(\theta_{j k t}^{*}, \theta_{j k\left(t-t^{\prime}\right)}^{*}\right) & =\rho_{\theta_{k}}^{\left|t^{\prime}\right|},
\end{aligned}
$$

em que $\xi_{j k t^{\prime}}$ são mutuamente independentes e independentes de $\theta_{j k t}^{*}, t^{\prime}=1,2, \ldots, t-1, \forall t$. A demonstração é dada no Apêndice B.1. Dessa forma, notemos que a matriz de covariâncias (e também a respectiva matriz de correlações) gerada pelo modelo definido por (5.11) e (5.12), é exatamente a mesma dada por (5.4) em que $\psi_{\theta_{k}}$ é substituído por $\psi_{\theta_{k}}^{*}$. Note também que a estrutura definida por (5.11) e 5.12) pode ser vista como um modelo de regressão usual homocedástico, condicionado a $\theta_{j k(t-1)}^{*}$ com intercepto nulo e coeficiente de regressão $\rho_{\theta_{k}}$.

\subsubsection{Toeplitz}

A classe de estruturas Toeplitz é bastante usada em estudos longitudinais quando as correlações decaem muito rapidamente. Principalmente em sua forma mais geral, ou seja, com correlações não necessariamente nulas para tempos não adjacentes, é bastante flexível, pois permite que as correlações sejam diferentes, seguindo, apenas, a estacionariedade, veja Akaike (1973). Na AST algumas situações são modeladas considerando-se uma matriz estacionária Toeplitz de ordem 1, o qual possui a mesma estrutura de (5.5). Sob esta estrutura, apenas as medidas tomadas em tempos consecutivos possuem correlação não-nula. Discussões gerais e aplicações podem ser encontradas em Littell et al. (2000), Wolfinger (1993) and Wolfinger (1996). Um MSTE conveniente para representar a matriz Toeplitz é definido por um processo de média móvel de ordem 1, nomeadamente MA(1), veja Hamilton (1994), pág. 46, isto é

Azevedo, Caio L. N.

IME/USP 


$$
\begin{aligned}
\theta_{j k t}^{*} & =\gamma_{\theta_{k}} \xi_{j k(t-1)}+\xi_{j k t} \\
\xi_{j k t} & \sim N\left(0, \psi_{\theta_{k}}\right),
\end{aligned}
$$

em que $\xi_{j k t}$ são mutuamente independentes e $\left|\gamma_{\theta_{k}}\right|<1, \forall k$ para garantir a estacionariedade, veja Hamilton (1994). Este parâmetro modela a média móvel. O modelo definido por (5.15) e (5.16) implica que

$$
\begin{gathered}
\operatorname{Var}\left(\theta_{j k t}^{*}\right)=\psi_{\theta_{k}}\left(1+\gamma_{\theta_{k}}^{2}\right)=\psi_{\theta_{k}}^{*}, \\
\operatorname{Cov}\left(\theta_{j k t}, \theta_{j k\left(t-t^{\prime}\right)}\right)= \begin{cases}\gamma_{\theta_{k}} \psi_{\theta_{k}}, & \text { se } t^{\prime}=1 \\
0, & \text { se } t^{\prime} \geq 2,\end{cases}
\end{gathered}
$$

$$
\operatorname{Corr}\left(\theta_{j k t}, \theta_{j k\left(t-t^{\prime}\right)}\right)= \begin{cases}1, & \text { se } t^{\prime}=0 \\ \frac{\gamma_{\theta_{k}}}{1+\gamma_{\theta_{k}}^{2}}=\rho_{\theta_{k}} & \text { se } t^{\prime}=1 \\ 0, & \text { se } t^{\prime} \geq 2\end{cases}
$$

A prova é dada no Apêndice B.2 Então (5.15) e (5.16) geram a matriz dada por (5.5) e também a correspondente matriz de correlações em que $\psi_{\theta_{k}}$ é substituído por $\psi_{\theta_{k}}^{*}$ e $\rho_{\theta_{k}}=\sigma_{\theta_{k}}^{2} /\left(1+\sigma_{\theta+k}^{2}\right)$. Note que, assim como no modelo $\mathrm{AR}(1)$, as equações (5.15) e (5.16) definem um modelo de regressão, condicionado a $\xi_{j k(t-1)}$, com intercepto nulo, em que $\xi_{j k(t-1)}$, são as variáveis explicativas e $\gamma_{\theta_{k}}$ é o coeficiente angular.

\subsubsection{ARMA $(1,1)$}

A estrutura ARMA(1,1) pode ser vista como a união ente as estruturas AR(1) e MA(1), veja Hamilton (1994). Dessa forma é possível modelar concomitantemente tanto a correlação serial quanto a média móvel. Além disso a modelagem dos valores das correlações se torna mais flexível devido a inserção do parâmetro $\gamma_{\theta_{k}}$. Para mais detalhes veja Rochon (1992), Rochon and Helms (1989), Jones (1980), Jones and Ackerson (1990) e Yao and Brockwell (2006). Esta matriz pode ser modelada apropriadamente por um processo temporal autoregressivo com média móvel de ordem 1 (ARMA(1,1)), veja Hamilton (1994). Isto é, 


$$
\begin{aligned}
\theta_{j k t}^{*} & =\rho_{\theta_{k}} \theta_{j k(t-1)}^{*}+\gamma_{\theta_{k}} \xi_{j k(t-1)}+\xi_{j k t} \\
\xi_{j k t} & \sim N\left(0, \psi_{\theta_{k}}\right)
\end{aligned}
$$

em que $\xi_{j k t^{\prime}}$ são mutuamente independentes e independentes de $\theta_{j k t}, t^{\prime}=1, \ldots, t-2, \forall t,\left|\rho_{\theta_{k}}\right|<1, \forall k$, o que garante a estacionariedade e nenhuma restrição é imposta a $\gamma_{\theta_{k}}$. Este modelo implica que, veja ApêndiceB.3.

$$
\begin{aligned}
\operatorname{Var}\left(\theta_{j k t}\right) & =\psi_{\theta_{k}}^{*} \gamma_{\theta_{k}}^{*} \\
\operatorname{Cov}\left(\theta_{j k t}, \theta_{j k(t-1)}\right) & =\psi_{\theta_{k}}^{*} \rho_{\theta_{k}}^{*}, \\
\operatorname{Corr}\left(\theta_{j k t}, \theta_{j k(t-1)}\right) & =\frac{\rho_{\theta_{k}}^{*}}{\gamma_{\theta_{k}}^{*}},
\end{aligned}
$$

em que

$$
\begin{aligned}
\psi_{\theta_{k}}^{*} & =\frac{\psi_{\theta_{k}}}{1-\rho_{\theta_{k}}^{2}} \\
\gamma_{\theta_{k}}^{*} & =\left(1+2 \gamma_{\theta_{k}} \rho_{\theta_{k}}+\gamma_{\theta_{k}}^{2}\right) \\
\rho_{\theta_{k}}^{*} & =\left(\rho_{\theta_{k}}+\gamma_{\theta_{k}}\right)\left(1+\rho_{\theta_{k}} \gamma_{\theta_{k}}\right) .
\end{aligned}
$$

Por se tratar de uma séries estacionária, note que é possível obter todas as outras covariâncias e correlações através de

$$
\begin{aligned}
\operatorname{Cov}\left(\theta_{j k t}, \theta_{j k\left(t-t^{\prime}\right)}\right) & =\rho_{\theta_{k}} \operatorname{Cov}\left(\theta_{j k t}, \theta_{j k\left(t-t^{\prime}-1\right)}\right) \\
\operatorname{Corr}\left(\theta_{j k t}, \theta_{j k\left(t-t^{\prime}\right)}\right) & =\rho_{\theta_{k}} \operatorname{Corr}\left(\theta_{j k t}, \theta_{j k\left(t-t^{\prime}-1\right)}\right) .
\end{aligned}
$$

Então, a estrutura dada por (5.22), (5.23) e (5.24), reproduz a matriz (5.6), em que $\psi_{\theta_{k}}$ e $\rho_{\theta_{k}}$ são substituídos por $\psi_{\theta_{k}}^{*}$ e $\rho_{\theta_{k}}^{*}$. Note que a estrutura dada por (5.20) e (5.21) define um modelo de regressão condicional à $\theta_{j k(t-1)}^{*}$ e $\xi_{j k(t-1)}$, de intercepto nulo, em que $\theta_{j k(t-1)}^{*}$ e $\xi_{j k(t-1)}$ são as variáveis explicativas e $\rho_{\theta_{k}}$ e $\gamma_{\theta_{k}}$ são os coeficientes de regressão.

Um detalhe importante a ser considerado é o fato de que estamos assumindo que os instantes de avaliação são igualmente espaçados. Ou, pelo menos, podem ser considerados como tal. Isso vale para todas as 
matrizes estudadas. Esta suposição é muito importante para se considerar processos AR1 e ARMA(1,1) discretos, veja Rochon (1992) e Rochon and Helms (1989). Quando os instantes não são igualmente espaçados, uma abordagem mais apropriada é considerar processos temporais contínuos, veja Jones and Boadi-Boateng (1991), Jones and Ackerson (1990) e Goldstein et al. (1994). Neste caso, as correlações seriam apropriadamente modeladas por funções não-lineares. Entretanto, não consideraremos tal abordagem em nosso trabalho por não contemplar os objetivos do mesmo.

\subsection{Modelos multiníveis heterocedásticos}

Uma das suposições mais importantes nos modelos multiníveis é considerar a mesma variância entre as unidades do nível 1 e a mesma variância entre as unidades do nível 2. No caso dos estudos longitudinais abordados neste trabalho, isso equivale a considerar que as variâncias $\sigma_{\theta_{k}}^{2}$ e $\psi_{\theta_{k}}$, no modelo 5.3 , não dependem do tempo.

Entretanto, em muitos estudos longitudinais, a suposição de homocedasticidade não é válida, veja Rochon (1992) e Nunez-Anton and Zimmerman (2000). Dessa forma, o modelo 5.3 não seria apropriado. Uma das formas de se introduzir heterocedasticidade em um modelo multinível é permitir que a variância dependa, diretamente, de alguma covariável. Um outro modo é introduzir um coeficiente angular associado a alguma covariável, veja Fox (2001). De qualquer forma, essas duas alternativas não permitem uma modelagem muito flexível da estrutura de variabilidade. Além disso, ela depende muito da fidedignidade da informação relativa a tais variáveis explicativas. Em nosso caso consideraremos que os parâmetros $\psi_{\theta_{k}}$ dependem do tempo. Ou seja, definiremos uma variância para cada instante. Tal abordagem é justificável na medida em que estamos considerando um estudo com um número razoável de indivíduos. Isso faz com que tenhamos um quantidade razoável de informação entre e intra indivíduos. Este fato, por sua vez, é muito importante, haja vista que os indivíduos, no estudo longitudinal, fazem o papel do grupo, referente à modelagem multinível.

É importante notar que, os modelos Hankel e Uniforme não são mais equivalente da forma que o são quando da suposição de homocedasticidade. Portanto, se faz necessário considerar um modelo para cada matriz.

\subsubsection{Matriz Hankel}

Um modelo multinível conveniente para representar a estrutura Hankel é uma extensão natural do modelo (5.3), em outras palavras:

$$
\begin{aligned}
\theta_{j k t} & =\mu_{\theta_{k t}}+\tau_{j k}+\xi_{j k t} \\
\tau_{j k} & \sim N\left(0, \sigma_{\theta_{k}}^{2}\right) \\
\xi_{j k t} & \sim N\left(0, \psi_{\theta_{k t}}\right)
\end{aligned}
$$

Azevedo, Caio L. N.

IME/USP 
em que $\tau_{j k}$ e $\xi_{j k t}$ são mutuamente independentes $\forall j, k, t$. De acordo com esta estrutura temos que

$$
\operatorname{Cov}\left(\theta_{j k t}, \theta_{j^{\prime} k^{\prime} t^{\prime}}\right)= \begin{cases}0, & \text { se } j \neq j^{\prime}, \text { e } / \text { ou } k \neq k^{\prime} \\ \sigma_{\theta_{k}}^{2}+\psi_{\theta_{k t}}, & \text { se } j=j^{\prime}, k=k^{\prime} \text { e } t=t^{\prime} \\ \sigma_{\theta_{k}}^{2}, & \text { se } j=j^{\prime}, k=k^{\prime} \text { e } t \neq t^{\prime} .\end{cases}
$$

e

$$
\operatorname{Corr}\left(\theta_{j k t}, \theta_{j^{\prime} k^{\prime} t^{\prime}}\right)= \begin{cases}0, & \text { se } j \neq j^{\prime}, \text { e } / \text { ou } k \neq k^{\prime} \\ 1, & \text { se } j=j^{\prime}, k=k^{\prime} \text { e } t=t^{\prime} \\ \frac{\sigma_{\theta_{k}}^{2}}{\sigma_{\theta_{k}}^{2}+\psi_{\theta_{k t}}}, & \text { se } j=j^{\prime}, k=k^{\prime} \text { e } t \neq t^{\prime}\end{cases}
$$

Percebemos então que embora a estrutura seja heterocedástica, as covariâncias iguais permanecem. Portanto, o modelo definido por 5.25 gera uma matriz equivalente à 4.12 .

\subsubsection{Matriz uniforme}

O modelo para representar a estrutura UH é uma pequena modificação da equação 5.25 . Mais concretamente, temos que

$$
\begin{aligned}
\theta_{j k t} & =\mu_{\theta_{k t}}+\sqrt{\psi_{\theta_{k t}}} \tau_{j k}+\xi_{j k t} \\
\tau_{j k} & \sim N\left(0, \sigma_{\theta_{k}}^{2}\right) \\
\xi_{j k t} & \sim N\left(0, \psi_{\theta_{k t}}\right),
\end{aligned}
$$

o que implica que,

$$
\operatorname{Cov}\left(\theta_{j k t}, \theta_{j^{\prime} k^{\prime} t^{\prime}}\right)= \begin{cases}0, & \text { se } j \neq j^{\prime}, \text { e } / \text { ou } k \neq k^{\prime} \\ \psi_{\theta_{k t}}\left(1+\sigma_{\theta_{k}}^{2}\right), & \text { se } j=j^{\prime}, k=k^{\prime} \text { e } t=t^{\prime} \\ \sqrt{\psi_{\theta_{k t}}} \sigma_{\theta_{k}}^{2}, & \text { se } j=j^{\prime}, k=k^{\prime} \text { e } t \neq t^{\prime}\end{cases}
$$

e

Azevedo, Caio L. N.

IME/USP 


$$
\operatorname{Corr}\left(\theta_{j k t}, \theta_{j^{\prime} k^{\prime} t^{\prime}}\right)= \begin{cases}0, & \text { se } j \neq j^{\prime}, \text { e } / \text { ou } k \neq k^{\prime} \\ 1, & \text { se } j=j^{\prime}, k=k^{\prime} \text { e } t=t^{\prime} \\ \frac{\sigma_{\theta_{k}}^{2}}{1+\sigma_{\theta_{k}}^{2}}, & \text { se } j=j^{\prime}, k=k^{\prime} \text { e } t \neq t^{\prime}\end{cases}
$$

Dessa forma, a estrutura definida pelo modelo (5.26), gera uma matriz equivalente à (4.10).

\subsection{Modelos de séries temporais não estacionários}

Em estudos longitudinais que apresentam correlação serial é bastante frequente encontrar variâncias que dependem do tempo, veja Rochon (1992) e Nunez-Anton and Zimmerman (2000), por exemplo. Dessa forma é necessário a utilização de modelos de séries temporais não estacionários (MSTNE), ou seja modelos que representem séries temporais com tal comportamento. Existe uma literatura ampla com relação à alguns modelos que permitem variâncias ou mesmo correlações dependentes do tempo. Exemplo são os modelos ARCH e GARCH, veja Hamilton (1994). Entretanto, utilizaremos a proposta de Rochon (1992), que permite representar uma ampla família de modelos ARMA(r,s), consequentemente famílias AR(r) e MA(s), no contexto longitudinal, de uma forma razoavelmente simples. Com efeito, tal abordagem é uma extensão direta dos desenvolvimentos apresentados na Subseção 5.3. Dessa forma apresentaremos nesta parte apenas o necessário para o entendimento da metodologia. As suposições acerca dos parâmetros $\left(\rho_{\theta_{k}}, \gamma_{\theta_{k}}\right)$ são as mesmas consideradas na referida seção.

Sucintamente, para a modelagem das estruturas ARH(1), Toeplitz e ARMAH(1,1), propostas no presente trabalho, a abordagem de Rochon (1992) se traduz em

$$
\begin{aligned}
\theta_{j k t} & =\mu_{\theta_{k t}}+\sqrt{\psi_{\theta_{k t}}} \xi_{j k t} \\
\xi_{j k t} & \sim \operatorname{MSTE}\left(\rho_{\theta_{k}}, \gamma_{\theta_{k}}\right),
\end{aligned}
$$

em que $\xi_{j k t} \sim \operatorname{MSTE}\left(\rho_{\theta_{k}}, \gamma_{\theta_{k}}\right)$ significa que a variável aleatória segue um processo estacionário de séries temporais, indexado pelo vetor de parâmetros $\left(\psi_{\theta_{k}}, \gamma_{\theta_{k}}\right)^{t}$.

Azevedo, Caio L. N.

IME/USP 


\subsubsection{ARH(1)}

O modelo (5.27), para a estrutura $\mathrm{ARH}(1)$ se traduz em

$$
\begin{aligned}
\theta_{j k t} & =\mu_{\theta_{k t}}+\sqrt{\psi_{\theta_{k t}}} \xi_{j k t} \\
\xi_{j k t} & =\rho_{\theta_{k}} \xi_{j k(t-1)}+\epsilon_{j k t} \\
\epsilon_{j k t} & \sim N(0,1)
\end{aligned}
$$

em que $\epsilon_{j k t}$ são mutuamente independentes $\forall j, k, t$. Dessa forma, temos que

$$
\begin{aligned}
\operatorname{Var}\left(\theta_{j k t}\right) & =\frac{\psi_{\theta_{k t}}}{1-\rho_{\theta_{k}}^{2}}=\psi_{\theta_{k t}}^{*} \\
\operatorname{Corr}\left(\theta_{j k t}, \theta_{j k\left(t-t^{\prime}\right)}\right) & =\rho_{\theta_{k}}^{\left|t^{\prime}\right|} .
\end{aligned}
$$

Portanto, o modelo definido por (5.28), (5.29) e (5.30), induz uma estrutura de dependência tal como aquela dada em 4.9), veja Apêndice C.1 para outros detalhes.

\subsubsection{Toeplitz}

Para esta estrutura temos que um modelo apropriado é dado por

$$
\begin{aligned}
\theta_{j k t} & =\mu_{\theta_{k t}}+\sqrt{\psi_{\theta_{k t}}} \xi_{j k t} \\
\xi_{j k t} & =\gamma_{\theta_{k}} \epsilon_{j k(t-1)}+\epsilon_{j k t} \\
\epsilon_{j k t} & \sim N(0,1),
\end{aligned}
$$

em que $\epsilon_{j k t}$ são mutuamente independentes $\forall j, k, t$. Dessa forma, temos que

$$
\operatorname{Var}\left(\theta_{j k t}^{*}\right)=\psi_{\theta_{k t}}\left(1+\gamma_{\theta_{k}}^{2}\right)=\psi_{\theta_{k}}^{*}
$$

Azevedo, Caio L. N. 


$$
\operatorname{Cov}\left(\theta_{j k t}, \theta_{j k\left(t-t^{\prime}\right)}\right)= \begin{cases}\gamma_{\theta_{k}} \sqrt{\psi_{\theta_{k t}}} \sqrt{\psi_{\theta_{k t^{\prime}}}}, & \text { se, } t^{\prime}=1 \\ 0, & \text { se } t^{\prime} \geq 2\end{cases}
$$

e

$$
\operatorname{Corr}\left(\theta_{j k t}, \theta_{j k\left(t-t^{\prime}\right)}\right)= \begin{cases}1, & \text { se, } t^{\prime}=0 \\ \frac{\gamma_{\theta_{k}}}{1+\gamma_{\theta_{k}}^{2}}=\rho_{\theta_{k}} & \text { se, } t^{\prime}=1 \\ 0, & \text { se } t^{\prime} \geq 2\end{cases}
$$

O modelo definido por (5.31), 5.32) e (5.33), induz uma estrutura de dependência tal como a matriz (4.11). Para outros detalhes, veja Apêndice C.2.

\subsubsection{ARMAH(1,1)}

A estrutura $\operatorname{ARMAH}(1,1)$ é cabalmente representada por

$$
\begin{aligned}
\theta_{j k t} & =\mu_{\theta_{k t}}+\sqrt{\psi_{\theta_{k t}}} \xi_{j k t} \\
\xi_{j k t} & =\rho_{\theta_{k}} \xi_{j k(t-1)}+\gamma_{\theta_{k}} \epsilon_{j k(t-1)}+\epsilon_{j k t} \\
\epsilon_{j k t} & \sim N(0,1),
\end{aligned}
$$

em que $\epsilon_{j k t}$ são mutuamente independentes, $\forall j, k, t$ e $\xi_{j k t^{\prime}} \perp \theta_{j k t}, \forall j, k, t$ e $t^{\prime}=1,2, \ldots, t-1$. Dessa forma, vem que

$$
\begin{aligned}
\operatorname{Var}\left(\theta_{j k t}\right) & =\psi_{\theta_{k t}}^{*} \gamma_{\theta_{k}}^{*} \\
\operatorname{Cov}\left(\theta_{j k t}, \theta_{j k(t-1)}\right) & =\psi_{\theta_{k t}}^{*} \rho_{\theta_{k}}^{*}, \\
\operatorname{Corr}\left(\theta_{j k t}, \theta_{j k(t-1)}\right) & =\frac{\rho_{\theta_{k}}^{*}}{\gamma_{\theta_{k}}^{*}},
\end{aligned}
$$

em que

Azevedo, Caio L. N.

IME/USP 


$$
\begin{aligned}
\psi_{\theta_{k t}}^{*} & =\frac{\psi_{\theta_{k t}}}{1-\rho_{\theta_{k}}^{2}} \\
\gamma_{\theta_{k}}^{*} & =\left(1+2 \gamma_{\theta_{k}} \rho_{\theta_{k}}+\gamma_{\theta_{k}}^{2}\right) \\
\rho_{\theta_{k}}^{*} & =\left(\rho_{\theta_{k}}+\gamma_{\theta_{k}}\right)\left(1+\rho_{\theta_{k}} \gamma_{\theta_{k}}\right) .
\end{aligned}
$$

Note que é possível obter todas as outras covariâncias e correlações através de

$$
\begin{aligned}
\operatorname{Cov}\left(\theta_{j k t}, \theta_{j k\left(t-t^{\prime}\right)}\right) & =\sqrt{\psi_{\theta_{k t}}} \sqrt{\psi_{\theta_{k\left(t-t^{\prime}\right)}}} \rho_{\theta_{k}} \operatorname{Cov}\left(\theta_{j k t}, \theta_{j k\left(t-t^{\prime}-1\right)}\right) \\
\operatorname{Corr}\left(\theta_{j k t}, \theta_{j k\left(t-t^{\prime}\right)}\right) & =\rho_{\theta_{k}} \operatorname{Corr}\left(\theta_{j k t}, \theta_{j k\left(t-t^{\prime}-1\right)}\right) .
\end{aligned}
$$

O modelo definido por (5.34, 5.35) e 55.36) induz uma estrutura de dependência tal como a matriz (4.13). Para outros detalhes, detalhes veja Apêndice C.3.

\subsubsection{AD}

A família de matrizes de Ante-dependência é intrinsicamente não estacionária. Ela permite que variâncias, covariâncias e correlações dependam do tempo, embora o padrão serial se mantenha. Esta estrutura é aplicável em estudos cujos instantes de avaliação não são igualmente espaçados, que apresentam heterocedasticidade e correlação serial. Um modelo parcimonioso para a estrutura AD, é uma adaptação da abordagem de NunezAnton and Zimmerman (2000). Mais concretamente, temos que

$$
\begin{aligned}
\theta_{j k t} & =\mu_{\theta_{k t}}+\phi_{k(t-1)} \theta_{j k(t-1)}+\xi_{j k t} \\
\xi_{j k t} & \sim N\left(0, \psi_{\theta_{k t}}\right) .
\end{aligned}
$$

A modelagem definida por (5.38) e (5.39), implica que

$$
\mathbb{E}\left(\theta_{j k t}\right)=\mu_{\theta_{k t}},
$$

Azevedo, Caio L. N. 


$$
\operatorname{Cov}\left(\theta_{j k t}, \theta_{j k\left(t-t^{\prime}\right)}\right)= \begin{cases}\psi_{\theta_{k t}}^{*}, & \text { se, } t^{\prime}=0 \\ \left(\prod_{l=1}^{t^{\prime}} \phi_{k(t-l)}\right) \psi_{\theta_{k\left(t-t^{\prime}\right)}^{*}}^{*}=\left(\prod_{l=1}^{t^{\prime}} \rho_{\theta_{k(t-l)}}\right) \psi_{\theta_{k\left(t-t^{\prime}\right)}}^{*} \psi_{\theta_{k t}}^{*}, & \text { se } 1 \leq t^{\prime} \leq t-1,\end{cases}
$$

e

$$
\operatorname{Corr}\left(\theta_{j k t}, \theta_{j k\left(t-t^{\prime}\right)}\right)= \begin{cases}1, & \text { se, } t^{\prime}=0 \\ \left(\prod_{l=1}^{t^{\prime}} \rho_{\theta_{k(t-l)}}\right) \frac{\psi_{\theta_{k\left(t-t^{\prime}\right)}}^{*} \psi_{\theta_{k t}}^{*}}{\sqrt{\psi_{\theta_{k\left(t-t^{\prime}\right)}^{*}}^{*} \sqrt{\psi_{\theta_{k t}}^{*}}}}= & \\ \left(\prod_{l=1}^{t^{\prime}} \rho_{\theta_{k(t-l)}}\right) \sqrt{\psi_{\theta_{k}}^{*}} \sqrt{\psi_{\theta_{k\left(t-t^{\prime}\right)}}^{*}}, & \text { se } 1 \leq t^{\prime} \leq t-1,\end{cases}
$$

em que

$$
\begin{aligned}
\psi_{\theta_{k t}}^{*} & =\sum_{t^{\prime}=1}^{t}\left(\prod_{l=t-t^{\prime}+1}^{t} \phi_{l}^{2} \psi_{\theta_{k l}}\right)+\psi_{\theta_{k t}}, \\
\rho_{\theta_{k(t-l)}} & =\frac{\phi_{k(t-l)}}{\psi_{\theta_{k t}}^{*}} .
\end{aligned}
$$

Dessa forma, o modelo estabelecido por (5.38) e (5.39) define uma matriz de Ante-dependência bastante semelhante à estrutura 4.14, em que $\psi_{\theta_{k t}}=\psi_{\theta_{k t}}^{*}$ e $\rho_{\theta_{k(t-l)}}=\phi_{k(t-l)} / \psi_{\theta_{k t}}^{*}$. A diferença, essencialmente, reside na correlação. Contudo a estrutura de correlações que dependem não só da distância, mas também do tempo, é preservada. Salientamos o fato de que não encontramos na literatura uma representação que nos levasse à uma matriz igual à (4.14, a menos de uma reparametrização apenas. Mais concretamente, embora ambas abordagens, multivariada e multinível, definam famílias de matrizes AD, elas não são as mesmas, ainda que se considere alguma reparametrização. Para outros detalhes, veja Apêndice C.4.

Podemos notar que as equações de (5.28) a (5.30), de (5.31) a (5.33) e de (5.34) a (5.35), são adaptações dos modelos (5.11), 5.15) e 5.20), respectivamente. Dessa forma, a estrutura que modela a não estacionariedade em dados longitudinais incorpora a estrura estacionária. Tal modelo permite, como veremos mais adiante, desenvolver uma processo de simulação de MCMC através do algoritmo de Gibbs. Ou seja, com todas as distribuições condicionais completas com forma conhecida.

Todos os modelos apresentados anteriormente são um caso particular de uma estrutura mais geral, conhecida como modelo de efeitos aleatórios, veja Laird and Ware (1982). Tal estrutura se traduz em

Azevedo, Caio L. N.

$\mathrm{IME} / \mathrm{USP}$ 


$$
\begin{aligned}
\boldsymbol{\theta}_{j k .} & =\boldsymbol{X}_{j k .} \boldsymbol{\beta}_{k}+\boldsymbol{W}_{j k .} \boldsymbol{u}_{j k .}+\boldsymbol{\xi}_{j k .} . \\
\boldsymbol{u}_{j k .} & \sim N_{Q}(\mathbf{0}, \Lambda) \\
\boldsymbol{\xi}_{j k .} & \sim N_{T}\left(\mathbf{0}, \Omega_{\boldsymbol{\theta}}\right) \\
\boldsymbol{u}_{j k .} & \perp \boldsymbol{\xi}_{j k .}, \forall j, k,
\end{aligned}
$$

em que $\boldsymbol{X}_{j k}$. e $\boldsymbol{W}_{j k}$. são matrizes de planejamento conhecidas de posto coluna completo, $\boldsymbol{\beta}_{k}$ é um vetor de efeitos fixos desconhecido, $\boldsymbol{u}_{j k}$. é um vetor de efeitos aleatórios desconhecidos e $\boldsymbol{\xi}_{j k}$. é um vetor de resíduos não observáveis.

\subsection{Verossimilhança de dados aumentados}

Nesta seção apresentaremos a verossimilhança para os modelos multiníveis discutidos nas seções anteriores. As suposições são essencialmente aquelas estabelecidas na Seção 2.5 para o modelo MGM. Adicione-se à elas as suposições de independência condicional dos traços latentes e dos efeitos aleatórios. A construção dos dados aumentados, tanto para as respostas observadas quanto para os indicadores de resposta, é exatamente a mesma dada em 4.3) e 4.4, respectivamente.

Posto isso e os modelos multiníveis apresentados, a estrutura geral da verossimilhança de dados aumentados é dada por:

$$
\begin{aligned}
& L\left(\boldsymbol{\theta}_{\ldots,}, \boldsymbol{\xi}_{\ldots}, \boldsymbol{\epsilon} \ldots, \boldsymbol{\zeta}, \boldsymbol{\eta}_{\boldsymbol{\theta}}, \boldsymbol{\delta} \mid \boldsymbol{z}_{\ldots,}, \boldsymbol{y}_{\ldots .}, \boldsymbol{v}_{\ldots}\right) \propto p\left(\boldsymbol{v}_{\ldots,}, \boldsymbol{z}_{\ldots .} \mid \boldsymbol{\theta}_{\ldots,}, \boldsymbol{\xi}_{\ldots}, \boldsymbol{\epsilon} \ldots, \boldsymbol{\zeta}, \boldsymbol{\eta}_{\boldsymbol{\theta}}, \boldsymbol{\delta}, \boldsymbol{y}_{\ldots}\right) \\
& =p\left(\boldsymbol{v}_{\ldots .} \mid \boldsymbol{z}_{\ldots,}, \boldsymbol{\theta}_{\ldots,}, \boldsymbol{\xi}_{\ldots}, \boldsymbol{\epsilon} \ldots, \boldsymbol{\zeta}, \boldsymbol{\eta}_{\boldsymbol{\theta}}, \boldsymbol{\delta}, \boldsymbol{y}_{\ldots .}\right) \\
& \times p\left(\boldsymbol{z}_{\ldots} \mid \boldsymbol{\theta}_{\ldots,}, \boldsymbol{\xi}_{\ldots,}, \boldsymbol{\epsilon}, \boldsymbol{\zeta}, \boldsymbol{\eta}_{\boldsymbol{\theta}}, \boldsymbol{\delta}, \boldsymbol{y}_{\ldots}\right) \\
& =p\left(\boldsymbol{v}_{\ldots} \mid \boldsymbol{\delta}\right) p\left(\boldsymbol{z}_{\ldots .} \mid \boldsymbol{\theta} \ldots, \boldsymbol{\zeta}, \boldsymbol{y}_{\ldots .}\right) \\
& \propto p\left(\boldsymbol{z}_{\ldots .} \mid \boldsymbol{\theta}_{\ldots,}, \boldsymbol{\zeta}, \boldsymbol{y}_{\ldots .}\right) \\
& \propto \prod_{k=1}^{K} \prod_{t=1}^{T} \prod_{j=1}^{n_{k}} \prod_{i \in I_{j k t}}\left\{\exp \left\{-0.5\left(z_{i j k t}-a_{i} \theta_{j k t}+b_{i}\right)^{2}\right\}\right. \\
& \left.\times \mathbb{1}_{\left(z_{i j k t}, y_{i j k t}\right)}\right\} \text {, }
\end{aligned}
$$

em que $I_{j k t}$ representa o conjunto de itens apresentados ao indivíduo $j$, da população $k$ no instante $t$. A parte 5.40 segue do fato de que $\boldsymbol{\eta}_{\boldsymbol{\theta}}$ e $\left(\boldsymbol{\xi} \ldots, \boldsymbol{\epsilon}_{\ldots}\right)^{t}$ dependem apenas da distribuição de $\boldsymbol{\theta} \ldots$ e 5.41 vem do fato de que $\boldsymbol{V}$... segue um processo MAR.

Azevedo, Caio L. N.

IME/USP 


\subsection{Estimação MCMC para modelos multiníveis homocedásticos e estacionários}

Nesta seção apresentaremos um algoritmo de Gibbs para os modelos homocedásticos e estacionários desenvolvidos nas Seções 5.2 e 5.3 respectivamente. As únicas diferenças entre os modelos apresentados nos capítulos anteriores e os desenvolvidos do presente capítulo diz respeito a estrutura dos traços latentes, e consequentemente, dos parâmetros populacionais. Portanto, os algoritmos MCMC apenas diferirão nos passos relacionados a tais parâmetros. Devido a estrutura univariada induzida pela modelagem multinível, o procedimento de estimação desenvolvido na Seção 2.7, ou seja, o Resultado 2.7.1 será utilizado como base nos algoritmos de estimação para tal modelagem. Mais especificamente, somente os Passos 2, 4 e 5 serão modificados. Devido a parâmetros adicionais relacionados à estrutura de dependência, alguns passos serão incluídos para contemplar a existência dos referidos parâmetros. Os demais passos precisam apenas serem modificados de modo a incluir os índices de tempo. Dessa forma, eles serão omitidos.

O uso de métodos de MCMC para ajustar modelos multiníveis e de séries temporais têm sido bastante estudados nos últimos anos. Uma referência importante que apresenta uma ampla discussão relacionada à aplicação da metodologia MCMC em modelos multiníveis é Browne (1998a). Em sua Tese de Doutorado o autor estudou diferentes algoritmos de MCMC aplicados a diversos modelos multiníveis. Ele discute a respeito da escolha de densidades de transição e a priori, veja Chib and Greenberg (1995), e também faz alguns comentários a respeito de aspectos relacionados a convergência. Browne et al. (2002) compara uma abordagem via máxima verossimilhança e métodos de MCMC para ajustar modelos multiníveis. Um outra comparação entre esses métodos e que também apresenta uma interesante discussão a respeito, pode ser encontrada em Browne and Draper (2006). Ansari and Jadidi (2000) apresentam um esquema de simulação MCMC para modelos multiníveis com resposta binária, através de uma abordagem de dados aumentados, discutindo sensibilidade à escolha de prioris e adequabilidade do modelo. Um estudo a respeito dos efeitos do tamanho amostral e modelagem de dados faltantes pode ser encontrado em Browne (1998b). Gelman (2006) analisa a influência da escolha da distribuições a priori para as variâncias (do níveis 1 e 2) nos resultados, propondo uma nova classe de distribuições robusta para tais parâmetros.

No contexto da TRI, Fox and Glas (2001) desenvolveram uma abordagem via algoritmo de Gibbs para ajustar um modelo multinível e dois níveis para os traços latentes e também discute alguns aspectos relacionados a qualidade do ajuste do modelo. Fox and Glas (2003) mostram como considerar varáveis com erros de medida no modelo apresentado por Fox and Glas (2001). Para modelos de resposta policotômica Fox (2005) desenvolveu uma abordagem de estimação via MCMC.

Em geral, no contexto da TRI ou fora dele, os trabalhos citados acima indicam que o tamanho da amostra, nos níveis 1 e 2, escolha das prioris para as variâncias e natureza da variável resposta podem influenciar de maneira considerável os resultados. Especialmente, prioris impróprias para as variâncias de ambos os níveis, com tamanhos de amostras pequenos, podem levar à instabilidade do processo de simulação MCMC produzindo

Azevedo, Caio L. N.

IME/USP 
estimativas viesadas. Todos esses aspectos devem ser levados em consideração quando da utilização de métodos MCMC no ajuste de modelos multiníveis de qualquer natureza.

Para a construção dos algoritmos de Gibbs consideraremos as seguintes prioris adicionais

$$
\begin{aligned}
\rho_{\theta_{k}} & \sim N\left(\mu_{\rho}, \psi_{\rho}\right) \\
\sigma_{\theta_{k}}^{2} & \sim I G\left(v_{1}, \kappa_{1}\right) .
\end{aligned}
$$

Considerando a verossimilhança dada em (5.42), as prioris (5.43) e (5.44), as prioris do Resultado 2.7.1 e as estruturas dadas nas Seções 5.2 e 5.3 temos que as posterioris relacionadas a cada um do modelos estudadas são dadas por:

\section{Uniforme e Hankel}

$$
\begin{aligned}
p\left(\boldsymbol{z}_{\ldots, \ldots}, \boldsymbol{\theta} \ldots, \boldsymbol{\zeta}, \boldsymbol{\tau}_{. .,}, \boldsymbol{\mu}_{\boldsymbol{\theta}}, \psi_{\theta}, \boldsymbol{\sigma}_{\theta}^{2}\right) & \propto\left\{\prod_{k=1}^{K} \prod_{t=1}^{T} \prod_{j=1}^{n_{k}} \prod_{i \in I_{j k t}} \exp \left\{-0.5\left(z_{i j k t}-a_{i} \theta_{j k t}+b_{i}\right)^{2}\right\} \mathbb{1}_{\left(z_{i j k t}, y_{i j k t}\right)}\right\} \\
& \times\left\{\prod_{k=1}^{K} \prod_{j=1}^{n_{k}} \prod_{t=1}^{T} \exp \left\{-\frac{1}{\psi_{\theta_{k}}}\left(\theta_{j k t}-\mu_{\theta_{k t}}-\tau_{j k}\right)^{2}\right\}\right\}\left\{\prod_{k=1}^{K} \psi_{\theta_{k}}^{-n_{k} T / 2}\right\} \\
& \times\left\{\prod_{k=1}^{K} \prod_{j=1}^{n_{k}} \exp \left\{-\frac{\tau_{j k}^{2}}{2 \sigma_{\theta_{k}}^{2}}\right\}\right\}\left\{\prod_{k=1}^{K} \sigma_{\theta_{k}}^{-n_{k} / 2}\right\} \\
& \times \prod_{k=1}^{K} \prod_{t=1}^{T} \exp \left\{-\frac{1}{\psi_{\theta_{0}}}\left(\mu_{\theta_{k t}}-\mu_{0}\right)^{2}\right\} \\
& \times \prod_{k=1}^{K} \psi_{\theta_{k}}^{-v_{0} / 2-1} \exp \left(-\frac{\kappa_{0}}{2 \psi_{\theta_{k}}}\right) \\
& \times \prod_{k=1}^{K}\left(\sigma_{\theta_{k}}^{2}\right)^{-v_{1} / 2-1} \exp \left(-\frac{\kappa_{1}}{2 \sigma_{\theta_{k}}^{2}}\right) \\
& \times \prod_{i=1}^{I} \exp \left\{-0.5\left(\boldsymbol{\zeta}_{i}-\boldsymbol{\mu}_{\boldsymbol{\zeta}}\right)^{t} \boldsymbol{\Psi}_{\boldsymbol{\zeta}}^{-1}\left(\boldsymbol{\zeta}_{i}-\boldsymbol{\mu}_{\boldsymbol{\zeta}}\right)\right\} \mathbb{1}_{\left(a_{i}>0\right)} .
\end{aligned}
$$


$\operatorname{AR}(1)$

$$
\begin{aligned}
p\left(\boldsymbol{z}_{\ldots .}, \boldsymbol{\theta} \ldots, \boldsymbol{\zeta}, \boldsymbol{\mu}_{\boldsymbol{\theta}}, \psi_{\theta}, \boldsymbol{\rho}_{\theta}\right) & \propto\left\{\prod_{k=1}^{K} \prod_{t=1}^{T} \prod_{j=1}^{n_{k}} \prod_{i \in I_{j k t}} \exp \left\{-0.5\left(z_{i j k t}-a_{i} \theta_{j k t}+b_{i}\right)^{2}\right\} \mathbb{1}_{\left(z_{i j k t}, y_{i j k t}\right)}\right\} \\
& \times\left\{\prod_{k=1}^{K} \prod_{j=1}^{n_{k}} \prod_{t=2}^{T} \exp \left\{-\frac{1}{\psi_{\theta_{k}}}\left(\theta_{j k t}-\mu_{\theta_{k t}}-\rho_{\theta_{k}} \theta_{j k(t-1)}\right)^{2}\right\}\right\}\left\{\prod_{k=1}^{K} \psi_{\theta_{k}}^{-n_{k} T / 2}\right\} \\
& \times\left\{\prod_{k=1}^{K} \prod_{j=1}^{n_{k}} \exp \left\{-\frac{1}{\psi_{\theta_{k}}}\left(\theta_{j k 1}-\mu_{\theta_{k 1}}\right)^{2}\right\}\right\}\left\{\prod_{k=1}^{K} \prod_{t=1}^{T} \exp \left\{-\frac{1}{\psi_{\theta_{0}}}\left(\mu_{\theta_{k t}}-\mu_{0}\right)^{2}\right\}\right\} \\
& \times\left\{\prod_{k=1}^{K} \psi_{\theta_{k}}^{-v_{0} / 2-1} \exp \left(-\frac{\kappa_{0}}{2 \psi_{\theta_{k}}}\right)\right\}\left\{\prod_{k=1}^{K} \exp \left\{-\frac{1}{2 \psi_{\rho}}\left(\rho_{\theta_{k}}-\mu_{\rho}\right)^{2}\right\}\right\} \\
& \times \prod_{i=1}^{I} \exp \left\{-0.5\left(\boldsymbol{\zeta}_{i}-\boldsymbol{\mu}_{\boldsymbol{\zeta}}\right)^{t} \boldsymbol{\Psi}_{\boldsymbol{\zeta}}^{-1}\left(\boldsymbol{\zeta}_{i}-\boldsymbol{\mu}_{\boldsymbol{\zeta}}\right)\right\} \mathbb{1}_{\left(a_{i}>0\right)} .
\end{aligned}
$$

Toeplitz

$$
\begin{aligned}
p\left(\boldsymbol{z}_{\ldots .}, \boldsymbol{\theta} \ldots, \boldsymbol{\epsilon}_{\ldots, \ldots}, \boldsymbol{\zeta}, \boldsymbol{\mu}_{\boldsymbol{\theta}}, \psi_{\theta}, \boldsymbol{\gamma}_{\theta}\right) & \propto\left\{\prod_{k=1}^{K} \prod_{t=1}^{T} \prod_{j=1}^{n_{k}} \prod_{i \in I_{j k t}} \exp \left\{-0.5\left(z_{i j k t}-a_{i} \theta_{j k t}+b_{i}\right)^{2}\right\} \mathbb{1}_{\left(z_{i j k t}, y_{i j k t}\right)}\right\} \\
\times & \left\{\prod_{k=1}^{K} \prod_{j=1}^{n_{k}} \prod_{t=2}^{T} \exp \left\{-\frac{1}{\psi_{\theta_{k}}}\left(\theta_{j k t}-\mu_{\theta_{k t}}-\gamma_{\theta_{k}} \epsilon_{j k(t-1)}\right)^{2}\right\}\right\} \\
\times & \left.\times \prod_{k=1}^{K} \psi_{\theta_{k}}^{-n_{k} T / 2}\right\}\left\{\prod_{k=1}^{K} \prod_{j=1}^{n_{k}} \exp \left\{-\frac{1}{\psi_{\theta_{k}}}\left(\theta_{j k 1}-\mu_{\theta_{k 1}}\right)^{2}\right\}\right\} \\
\times & \left\{\prod_{k=1}^{K} \prod_{j=1}^{n_{k}} \prod_{t=1}^{T} \exp \left\{-\frac{\epsilon_{j k t}^{2}}{2}\right\}\right\}\left\{\prod_{k=1}^{K} \prod_{t=1}^{T} \exp \left\{-\frac{1}{\psi_{\theta_{0}}}\left(\mu_{\theta_{k t}}-\mu_{0}\right)^{2}\right\}\right\} \\
\times & \left\{\prod_{k=1}^{K} \psi_{\theta_{k}}^{-v_{0} / 2-1} \exp \left(-\frac{\kappa_{0}}{2 \psi_{\theta_{k}}}\right)\right\}\left\{\prod_{k=1}^{K} \exp \left\{-\frac{1}{2 \psi_{\gamma}}\left(\gamma_{\theta_{k}}-\mu_{\gamma}\right)^{2}\right\}\right\} \\
\times & \prod_{i=1}^{I} \exp \left\{-0.5\left(\boldsymbol{\zeta}_{i}-\boldsymbol{\mu}_{\boldsymbol{\zeta}}\right)^{t} \boldsymbol{\Psi}_{\boldsymbol{\zeta}}^{-1}\left(\boldsymbol{\zeta}_{i}-\boldsymbol{\mu}_{\boldsymbol{\zeta}}\right)\right\} \mathbb{1}_{\left(a_{i}>0\right)} .
\end{aligned}
$$

Azevedo, Caio L. N.

IME/USP 
$\operatorname{ARMA}(1,1)$

$$
\begin{aligned}
p\left(\boldsymbol{z}_{\ldots .}, \boldsymbol{\theta} \ldots, \boldsymbol{\epsilon}_{\ldots,}, \boldsymbol{\zeta}, \boldsymbol{\mu}_{\boldsymbol{\theta}}, \psi_{\theta}, \boldsymbol{\rho}_{\theta}, \boldsymbol{\gamma}_{\theta_{k}}\right) & \propto\left\{\prod_{k=1}^{K} \prod_{t=1}^{T} \prod_{j=1}^{n_{k}} \prod_{i \in I_{j k t}} \exp \left\{-0.5\left(z_{i j k t}-a_{i} \theta_{j k t}+b_{i}\right)^{2}\right\} \mathbb{1}_{\left(z_{i j k t}, y_{i j k t}\right)}\right\} \\
& \times\left\{\prod_{k=1}^{K} \prod_{j=1}^{n_{k}} \prod_{t=2}^{T} \exp \left\{-\frac{1}{\psi_{\theta_{k}}}\left(\theta_{j k t}-\mu_{\theta_{k t}}-\rho_{\theta_{k}} \theta_{j k(t-1)}\right)^{2}\right\}\right\} \\
& \times\left\{\prod_{k=1}^{K} \psi_{\theta_{k}}^{-n_{k} T / 2}\right\}\left\{\prod_{k=1}^{K} \prod_{j=1}^{n_{k}} \exp \left\{-\frac{1}{\psi_{\theta_{k}}}\left(\theta_{j k 1}-\mu_{\theta_{k 1}}\right)^{2}\right\}\right\} \\
& \times\left\{\prod_{k=1}^{K} \prod_{j=1}^{n_{k}} \prod_{t=1}^{T} \exp \left\{-\frac{\epsilon_{j k t}^{2}}{2}\right\}\right\}\left\{\prod_{k=1}^{K} \prod_{t=1}^{T} \exp \left\{-\frac{1}{\psi_{\theta_{0}}}\left(\mu_{\theta_{k t}}-\mu_{0}\right)^{2}\right\}\right\} \\
& \times\left\{\prod_{k=1}^{K} \psi_{\theta_{k}}^{-v_{0} / 2-1} \exp \left(-\frac{\kappa_{0}}{2 \psi_{\theta_{k}}}\right)\right\}\left\{\prod_{k=1}^{K} \exp \left\{-\frac{1}{2 \psi_{\gamma}}\left(\gamma_{\theta_{k}}-\mu_{\gamma}\right)^{2}\right\}\right\} \\
& \times\left\{\prod_{k=1}^{K} \exp \left\{-\frac{1}{2 \psi_{\rho}}\left(\rho_{\theta_{k}}-\mu_{\rho}\right)^{2}\right\}\right\} \\
& \times \prod_{i=1}^{I} \exp \left\{-0.5\left(\boldsymbol{\zeta}_{i}-\boldsymbol{\mu}_{\boldsymbol{\zeta}}\right)^{t} \boldsymbol{\Psi}_{\boldsymbol{\zeta}}^{-1}\left(\boldsymbol{\zeta}_{i}-\boldsymbol{\mu}_{\zeta}\right)\right\} \mathbb{1}_{\left(a_{i}>0\right)} .
\end{aligned}
$$

A seguir apresentaremos a estrutura de simulação MCMC para cada um dos modelos em separado.

Azevedo, Caio L. N.

IME/USP 
Resultado 5.7.1. Considerando as posterioris definidas em (5.45), (5.46), (5.47) e (5.48) e denotando por (.) o conjunto de todos os outros parâmetros os passos para amostragem de Gibbs para os modelos multníveis saõ dados por:

Para a população $\mathbf{k}, k=1, \ldots, K$, de modo mutuamente independente, execute os seguintes passos :

\section{Matrizes Hankel e Uniforme}

- Passo 2: Simular, de forma mutuamente independente os traços latentes através de $\theta_{j k t} \mid(.) \sim N\left(\widehat{\psi}_{\theta_{j k t}} \widehat{\theta}_{j k t}, \widehat{\psi}_{\theta_{j k t}}\right)$, em que

$$
\begin{aligned}
\widehat{\theta}_{j k t} & =\sum_{i \in I_{j k t}} z_{i j k t} a_{i}+\sum_{i \in I_{j k t}} a_{i} b_{i}+\frac{\mu_{\theta_{k t}}+\tau_{j k}}{\psi_{\theta_{k}}} \\
\widehat{\psi}_{\theta_{j k t}} & =\left(\frac{1}{\psi_{\theta_{k}}}+\sum_{i \in I_{j k t}} a_{i}^{2}\right)^{-1} .
\end{aligned}
$$

- Passo 4: Simular, de forma mutuamente independente, as médias populacionais através de $\mu_{\theta_{k t}} \mid(.) \sim$ $N\left(\widehat{\psi}_{\mu_{k}} \widehat{\mu}_{\theta_{k t}}, \widehat{\psi}_{\mu_{k}}\right)$, em que

$$
\begin{aligned}
& \widehat{\mu}_{\theta_{k}}=\sum_{j=1}^{n_{k}} \frac{\left(\theta_{j k t}-\tau_{j k}\right)}{\psi_{\theta_{k}}}+\frac{\mu_{0}}{\psi_{0}} \\
& \widehat{\psi}_{\mu_{k}}=\left(\frac{n_{k}}{\psi_{\theta_{k}}}+\frac{1}{\psi_{0}}\right)^{-1} .
\end{aligned}
$$

- Passo 5: Simular, de forma mutuamente independente, as variâncias populacionais através de $\psi_{\theta_{k}} \mid(.) \sim$ $I G\left(\widehat{v}_{k}, \widehat{\kappa}_{k}\right)$, em que

$$
\begin{aligned}
\widehat{v}_{k} & =\frac{n_{k}+v_{0}}{2} \\
\widehat{\kappa}_{k} & =\frac{1}{2}\left(\sum_{t=1}^{T} \sum_{j=1}^{n_{k}}\left(\theta_{j k t}-\mu_{\theta_{k t}}-\tau_{j k}\right)^{2}+\kappa_{0}\right) .
\end{aligned}
$$

- Passo 6: Simular, de forma mutuamente independente, os efeitos aleatórios através de $\tau_{j k} \mid(.) \sim N\left(\widehat{\sigma}_{k}^{2} \widehat{\tau}_{j k}, \widehat{\sigma}_{k}^{2}\right)$, em que 


$$
\begin{aligned}
\widehat{\tau}_{j k} & =\sum_{t=1}^{T}\left(\theta_{j k t}-\mu_{\theta_{k t}}\right) \\
\widehat{\sigma}_{k}^{2} & =\left(\frac{T}{\psi_{\theta_{k}}}+\frac{1}{\sigma_{\theta_{k}}^{2}}\right)^{-1} .
\end{aligned}
$$

- Passo 7: Simular, de forma mutuamente independente, as variâncias dos efeitos aleatórios de $\sigma_{k}^{2} \mid(.) \sim$ $I G\left(\widehat{v}_{k_{1}}, \widehat{\kappa}_{k_{1}}\right)$, em que

$$
\begin{aligned}
\widehat{v}_{k_{1}} & =\frac{n_{k}+v_{1}}{2} \\
\widehat{\kappa}_{k_{1}} & =\frac{1}{2}\left(\sum_{j=1}^{n_{k}} \tau_{j k}^{2}+\kappa_{1}\right) .
\end{aligned}
$$

\section{Matriz AR(1)}

- Passo 2: Simular, de forma mutuamente independente os traços latentes através de $\theta_{j k t} \mid(.) \sim N\left(\widehat{\psi}_{\theta_{j k t}} \widehat{\theta}_{j k t}, \widehat{\psi}_{\theta_{j k t}}\right)$, em que

$$
\begin{aligned}
& \widehat{\theta}_{j k t}=\left\{\begin{array}{l}
\sum_{i \in I_{j k t}} z_{i j k t} a_{i}+\sum_{i \in I_{j k t}} a_{i} b_{i}+\frac{\mu_{\theta_{k t}}}{\psi_{\theta_{k}}}, \text { se } t=1 \\
\sum_{i \in I_{j k t}} z_{i j k t} a_{i}+\sum_{i \in I_{j k t}} a_{i} b_{i}+\frac{\mu_{\theta_{k t}}+\rho_{\theta_{k}} \theta_{j k(t-1)}^{*}}{\psi_{\theta_{k}}}, \text { se } t \geq 2 .
\end{array}\right. \\
& \widehat{\psi}_{\theta_{j k t}}=\left(\frac{1}{\psi_{\theta_{k}}}+\sum_{i \in I_{j k t}} a_{i}^{2}\right)^{-1} .
\end{aligned}
$$

- Passo 4: Simular, de forma mutuamente independente, as médias populacionais através de $\mu_{\theta_{k t}} \mid(.) \sim$ $N\left(\widehat{\psi}_{\mu_{k}} \widehat{\mu}_{\theta_{k t}}, \widehat{\psi}_{\mu_{k}}\right)$, em que 


$$
\begin{aligned}
& \widehat{\mu}_{\theta_{k t}}=\left\{\begin{array}{l}
\sum_{j=1}^{n_{k}} \frac{\theta_{j k t}}{\psi_{\theta_{k}}}+\frac{\mu_{0}}{\psi_{0}}, \text { se } t=1 \\
\sum_{j=1}^{n_{k}} \frac{\theta_{j k t}-\rho_{\theta_{k}} \theta_{j k(t-1)}^{*}}{\psi_{\theta_{k}}}+\frac{\mu_{0}}{\psi_{0}}, \text { se } t \geq 2 .
\end{array}\right. \\
& \widehat{\psi}_{\mu_{k}}=\left(\frac{n_{k}}{\psi_{\theta_{k}}}+\frac{1}{\psi_{0}}\right)^{-1} .
\end{aligned}
$$

- Passo 5: Simular, de forma mutuamente independente, as variâncias populacionais através de $\psi_{\theta_{k}} \mid(.) \sim$ $I G\left(\widehat{v}_{k}, \widehat{\kappa}_{k}\right)$, em que

$$
\begin{aligned}
\widehat{v}_{k} & =\frac{n_{k}+v_{0}}{2} \\
\widehat{\kappa}_{k} & =\frac{1}{2}\left(\sum_{t=2}^{T} \sum_{j=1}^{n_{k}}\left(\theta_{j k t}^{*}-\rho_{\theta_{k}} \theta_{j k(t-1)}^{*}\right)^{2}+\sum_{j=1}^{n_{k}}\left(\theta_{j k 1}^{*}\right)^{2}+\kappa_{0}\right) .
\end{aligned}
$$

- Passo 6: Simular, de forma mutuamente independente, os parâmetros de correlação através de através de $\rho_{\theta_{k}} \mid(.) \sim N\left(\widehat{\psi}_{\rho_{k}} \widehat{\rho}_{k}, \widehat{\psi}_{\rho_{k}}\right)$, em que

$$
\begin{aligned}
\widehat{\rho}_{\theta_{k}} & =\sum_{j=1}^{n_{k}} \sum_{t=2}^{T} \theta_{j k(t-1)}^{*}\left(\theta_{j k t}^{*}\right) \\
\widehat{\psi}_{\rho_{k}} & =\frac{\psi_{\theta_{k}}}{\sum_{j=1}^{n_{k}} \sum_{t=2}^{T}\left(\theta_{j k t}^{*}\right)^{2}} .
\end{aligned}
$$

Azevedo, Caio L. N. 


\section{Matriz Toeplitz}

- Passo 2 : Simular, de forma mutuamente independente os traços latentes através de $\theta_{j k t} \mid(.) \sim N\left(\widehat{\psi}_{\theta_{j k t}} \widehat{\theta}_{j k t}, \widehat{\psi}_{\theta_{j k t}}\right)$, em que

$$
\begin{aligned}
& \widehat{\theta}_{j k t}=\left\{\begin{array}{l}
\sum_{i \in I_{j k t}} z_{i j k t} a_{i}+\sum_{i \in I_{j k t}} a_{i} b_{i}+\frac{\mu_{\theta_{k t}}}{\psi_{\theta_{k}}}, \text { se } t=1 \\
\sum_{i \in I_{j k t}} z_{i j k t} a_{i}+\sum_{i \in I_{j k t}} a_{i} b_{i}+\frac{\mu_{\theta_{k t}}+\gamma_{\theta_{k}} \xi_{j k(t-1)}}{\psi_{\theta_{k}}}, \text { se } t \geq 2 .
\end{array}\right. \\
& \widehat{\psi}_{\theta_{j k t}}=\left(\frac{1}{\psi_{\theta_{k}}}+\sum_{i \in I_{j k t}} a_{i}^{2}\right)^{-1}
\end{aligned}
$$

- Passo 4: Simular, de forma mutuamente independente, as médias populacionais através de $\mu_{\theta_{k t}} \mid(.) \sim$ $N\left(\widehat{\psi}_{\mu_{k}} \widehat{\mu}_{\theta_{k t}}, \widehat{\psi}_{\mu_{k}}\right)$, em que

$$
\begin{aligned}
& \widehat{\mu}_{\theta_{k t}}=\left\{\begin{array}{l}
\sum_{j=1}^{n_{k}} \frac{\theta_{j k t}}{\psi_{\theta_{k}}}+\frac{\mu_{0}}{\psi_{0}}, \text { se } t=1 \\
\sum_{j=1}^{n_{k}} \frac{\theta_{j k t}-\gamma_{\theta_{k}} \xi_{j k(t-1)}}{\psi_{\theta_{k}}}+\frac{\mu_{0}}{\psi_{0}}, \text { se } t \geq 2 .
\end{array}\right. \\
& \widehat{\psi}_{\mu_{k}}=\left(\frac{n_{k}}{\psi_{\theta_{k}}}+\frac{1}{\psi_{0}}\right)^{-1} .
\end{aligned}
$$

- Passo 5: Simular, de forma mutuamente independente, as variâncias populacionais através de $\psi_{\theta_{k}} \mid(.) \sim$ $I G\left(\widehat{v}_{k}, \widehat{\kappa}_{k}\right)$, em que

$$
\begin{aligned}
\widehat{v}_{k} & =\frac{n_{k}+v_{0}}{2} \\
\widehat{\kappa}_{k} & =\frac{1}{2}\left(\sum_{t=2}^{T} \sum_{j=1}^{n_{k}}\left(\theta_{j k t}^{*}-\gamma_{\theta_{k}} \xi_{j k(t-1)}\right)^{2}+\sum_{j=1}^{n_{k}}\left(\theta_{j k 1}^{*}\right)+\kappa_{0}\right) .
\end{aligned}
$$

Azevedo, Caio L. N. 
- Passo 6: Simular, de forma mutuamente independente, para $t=1, \ldots, T-1$ os efeitos aleatórios através de $\xi_{j k t} \mid(.) \sim N\left(\widehat{\xi}_{j k(t-1)}, \widehat{\psi}_{k}\right)$, em que

$$
\begin{aligned}
\widehat{\xi}_{j k(t-1)} & =\frac{\theta_{j k t}^{*}}{1+\gamma_{\theta_{k}}^{2}} \\
\widehat{\psi}_{k} & =\frac{\psi_{\theta_{k}}}{1+\gamma_{\theta_{k}}^{2}}
\end{aligned}
$$

- Passo 7: Simular, de forma mutuamente independente, os parâmetros de médias móveis, através de $\gamma_{\theta_{k}} \mid(.) \sim N\left(\widehat{\psi}_{\gamma_{k}} \widehat{\gamma}_{\theta_{k}}, \widehat{\psi}_{\gamma_{k}}\right)$, em que

$$
\begin{aligned}
\widehat{\gamma}_{\theta_{k}} & =\frac{1}{\psi_{\theta_{k}}} \sum_{t=2}^{T} \sum_{j=1}^{n_{k}} \xi_{j k(t-1)} \theta_{j k t}^{*} \\
\widehat{\psi}_{\gamma_{k}} & =\frac{\psi_{\theta_{k}}}{\sum_{t=2}^{T} \sum_{j=1}^{n_{k}} \xi_{j k(t-1)}^{2}} .
\end{aligned}
$$

\section{Matriz ARMA(1,1)}

- Passo 2: Simular, de forma mutuamente independente os traços latentes através de $\theta_{j k t} \mid(.) \sim N\left(\widehat{\psi}_{\theta_{j k t}} \widehat{\theta}_{j k t}, \widehat{\psi}_{\theta_{j k t}}\right)$, em que

$$
\widehat{\theta}_{j k t}=\left\{\begin{array}{c}
\sum_{i \in I_{j k t}} z_{i j k t} a_{i}+\sum_{i \in I_{j k t}} a_{i} b_{i}+\frac{\mu_{\theta_{k t}}}{\psi_{\theta_{k}}}, \text { se } t=1 \\
\sum_{i \in I_{j k t}} z_{i j k t} a_{i}+\sum_{i \in I_{j k t}} a_{i} b_{i}+\frac{\left(\mu_{\theta_{k t}}+\rho_{\theta_{k}} \theta_{j k(t-1)}^{*}+\gamma_{\theta_{k}} \xi_{j k(t-1)}\right)}{\psi_{\theta_{k}}}, \text { se } t \geq 2 . \\
\widehat{\psi}_{\theta_{j k t}}=\left(\frac{1}{\psi_{\theta_{k}}}+\sum_{i \in I_{j k t}} a_{i}^{2}\right)^{-1} .
\end{array}\right.
$$

- Passo 4: Simular, de forma mutuamente independente, as médias populacionais através de $\mu_{\theta_{k t}} \mid(.) \sim$ $N\left(\widehat{\psi}_{\mu_{k}} \widehat{\mu}_{\theta_{k t}}, \widehat{\psi}_{\mu_{k}}\right)$, em que 


$$
\begin{aligned}
& \widehat{\mu}_{\theta_{k t}}=\left\{\begin{array}{l}
\sum_{j=1}^{n_{k}} \frac{\theta_{j k t}}{\psi_{\theta_{k}}}+\frac{\mu_{0}}{\psi_{0}}, \text { se } t=1 \\
\sum_{j=1}^{n_{k}} \frac{\theta_{j k t}-\rho_{\theta_{k}} \theta_{j k(t-1)}^{*}-\gamma_{\theta_{k}} \xi_{j k(t-1)}}{\psi_{\theta_{k}}}+\frac{\mu_{0}}{\psi_{0}}, \text { se } t \geq 2 .
\end{array}\right. \\
& \widehat{\psi}_{\mu_{k}}=\left(\frac{n_{k}}{\psi_{\theta_{k}}}+\frac{1}{\psi_{0}}\right)^{-1} .
\end{aligned}
$$

- Passo 5: Simular, de forma mutuamente independente, as variâncias populacionais através de $\psi_{\theta_{k}} \mid(.) \sim$ $I G\left(\widehat{v}_{k}, \widehat{\kappa}_{k}\right)$, em que

$$
\begin{aligned}
\widehat{v}_{k} & =\frac{n_{k}+v_{0}}{2} \\
\widehat{\kappa}_{k} & =\frac{1}{2}\left(\sum_{t=2}^{T} \sum_{j=1}^{n_{k}}\left(\theta_{j k t}^{*}-\rho_{\theta_{k}} \theta_{j k(t-1)}^{*}-\gamma_{\theta_{k}} \xi_{j k(t-1)}\right)^{2}+\sum_{j=1}^{n_{k}}\left(\theta_{j k 1}^{*}\right)^{2}+\kappa_{0}\right) .
\end{aligned}
$$

- Passo 6: Simular, de forma mutuamente independente, os parâmetros de correlação através de através de $\rho_{\theta_{k}} \mid(.) \sim N\left(\widehat{\psi}_{\rho_{k}} \widehat{\rho}_{k}, \widehat{\psi}_{\rho_{k}}\right)$, em que

$$
\begin{aligned}
\widehat{\rho}_{\theta_{k}} & =\sum_{j=1}^{n_{k}} \sum_{t=2}^{T} \theta_{j k(t-1)}^{*}\left(\theta_{j k t}^{*}-\gamma_{\theta_{k}} \xi_{j k(t-1)}\right) \\
\widehat{\psi}_{\rho_{k}} & =\frac{\psi_{\theta_{k}}}{\sum_{j=1}^{n_{k}} \sum_{t=2}^{T}\left(\theta_{j k t}^{*}\right)^{2}} .
\end{aligned}
$$

- Passo 7: Simular, de forma mutuamente independente, para $t=1, \ldots, T-1$ os efeitos aleatórios através de $\xi_{j k t} \mid(.) \sim N\left(\widehat{\xi}_{j k(t-1)}, \widehat{\psi}_{k}\right)$, em que

$$
\begin{aligned}
\widehat{\xi}_{j k(t-1)} & =\frac{\theta_{j k t}^{*}-\rho_{\theta_{k}} \theta_{j k t}^{*}}{1+\gamma_{\theta_{k}}^{2}} \\
\widehat{\psi}_{k} & =\frac{\psi_{\theta_{k}}}{1+\gamma_{\theta_{k}}^{2}} .
\end{aligned}
$$

Azevedo, Caio L. N.

IME/USP 
- Passo 8: Simular, de forma mutuamente independente, os parâmetros de médias móveis, através de $\gamma_{\theta_{k}} \mid(.) \sim N\left(\widehat{\psi}_{\gamma_{k}} \widehat{\gamma}_{\theta_{k}}, \widehat{\psi}_{\gamma_{k}}\right)$, em que

$$
\begin{aligned}
\widehat{\gamma}_{\theta_{k}} & =\frac{1}{\psi_{\theta_{k}}} \sum_{t=2}^{T} \sum_{j=1}^{n_{k}} \xi_{j k(t-1)}\left(\theta_{j k t}^{*}-\rho_{\theta_{k}} \theta_{j k t}^{*}\right) \\
\widehat{\psi}_{\gamma_{k}} & =\frac{\psi_{\theta_{k}}}{\sum_{t=2}^{T} \sum_{j=1}^{n_{k}} \xi_{j k(t-1)}^{2}} .
\end{aligned}
$$

\section{Demonstração do Resultado 5.7.1:}

A demonstração segue do Resultado 2.7.1 e das prioris 5.43 e 5.44. É necessário apenas mais alguns algebrismos para se chegar as distribuições condicionais completas de interesse.

Q.E.D.

\subsection{Estimação MCMC para modelos multiníveis heterocedásticos e não esta- cionários}

A estrutura dos modelos multiníveis heterocedásticos e não - estacionários é uma extensão daquela que supõe homocedasticidade. No entanto, a diferença reside não somente no aumento do número de variâncias do primeiro nível, mas também na necessidade de inclusão de efeitos aleatórios. Portanto, apresentaremos os passos referentes a todas essas modificações, no que diz respeito aos algoritmos de Gibbs, para o ajuste dos modelos heterocedásticos e não estacionários.

No modelo para a estrutura UH, equação (5.26), para ser possível construir o algoritmo de Gibbs (simular diretamente de todas as distribuições condicionais completas), consideraremos a seguinte reparametrização

$$
\varphi_{\theta_{k t}}=\sqrt{\psi_{\theta_{k t}}},
$$

com a seguinte priori

$$
\varphi_{\theta_{k t}} \sim N\left(\mu_{\varphi}, \psi_{\varphi}\right)
$$

Azevedo, Caio L. N.

IME/USP 
Adicionalmente, suponhamos que

$$
\phi_{k(t-1)} \sim N\left(\mu_{\phi}, \psi_{\phi}\right)
$$

Considerando a verossimilhança dada em (5.42), as prioris (5.43), 5.44), (5.49) e (5.50), as prioris do Resultado 2.7.1 e as estruturas dadas nas Seções 5.2 e 5.3

\section{Uniforme}

$$
\begin{aligned}
p\left(\boldsymbol{z}_{\ldots .}, \boldsymbol{\theta}_{\ldots, .}, \boldsymbol{\zeta}, \boldsymbol{\tau}_{. .}, \boldsymbol{\mu}_{\boldsymbol{\theta}}, \boldsymbol{\psi}_{\theta}, \boldsymbol{\sigma}_{\theta}^{2}, \boldsymbol{\varphi}_{\theta}\right) & \propto\left\{\prod_{k=1}^{K} \prod_{t=1}^{T} \prod_{j=1}^{n_{k}} \prod_{i \in I_{j k t}} \exp \left\{-0.5\left(z_{i j k t}-a_{i} \theta_{j k t}+b_{i}\right)^{2}\right\} \mathbb{1}_{\left(z_{i j k t}, y_{i j k t}\right)}\right\} \\
& \times\left\{\prod_{k=1}^{K} \prod_{j=1}^{n_{k}} \prod_{t=1}^{T} \exp \left\{-\frac{1}{\psi_{\theta_{k t}}}\left(\theta_{j k t}-\mu_{\theta_{k t}}-\tau_{j k}\right)^{2}\right\}\right\}\left\{\prod_{k=1}^{K} \prod_{t=1}^{T} \psi_{\theta_{k t}}^{-n_{k} / 2}\right\} \\
& \times\left\{\prod_{k=1}^{K} \prod_{j=1}^{n_{k}} \exp \left\{-\frac{\tau_{j k}^{2}}{2 \sigma_{\theta_{k}}^{2}}\right\}\right\}\left\{\prod_{k=1}^{K} \sigma_{\theta_{k}}^{-n_{k} / 2}\right\} \\
& \times\left\{\prod_{k=1}^{K} \prod_{t=1}^{T} \exp \left\{-\frac{1}{\psi_{\theta_{0}}}\left(\mu_{\theta_{k t}}-\mu_{0}\right)^{2}\right\}\right\}\left\{\prod_{k=1}^{K} \prod_{t=1}^{T} \psi_{\theta_{k t}}^{-v_{0} / 2-1} \exp \left(-\frac{\kappa_{0}}{2 \psi_{\theta_{k t}}}\right)\right\} \\
& \times\left\{\prod_{k=1}^{K}\left(\sigma_{\theta_{k}}^{2}\right)^{-v_{1} / 2-1} \exp \left(-\frac{\kappa_{1}}{2 \sigma_{\theta_{k}}^{2}}\right)\right\}\left\{\exp \left\{-\frac{1}{2 \psi_{\varphi}}\left(\varphi_{k t}-\mu_{\varphi}\right)^{2}\right\}\right\} \\
& \times \prod_{i=1}^{I} \exp \left\{-0.5\left(\boldsymbol{\zeta}_{i}-\boldsymbol{\mu}_{\boldsymbol{\zeta}}\right)^{t} \boldsymbol{\Psi}_{\boldsymbol{\zeta}}^{-1}\left(\boldsymbol{\zeta}_{i}-\boldsymbol{\mu}_{\boldsymbol{\zeta}}\right)\right\} \mathbb{1}_{\left(a_{i}>0\right)} .
\end{aligned}
$$


Hankel

$$
\begin{aligned}
p\left(\boldsymbol{z}_{\ldots .}, \boldsymbol{\theta} \ldots, \boldsymbol{\zeta}, \boldsymbol{\tau}_{. .,}, \boldsymbol{\mu}_{\boldsymbol{\theta}}, \boldsymbol{\psi}_{\theta}, \boldsymbol{\sigma}_{\theta}^{2}\right) & \propto\left\{\prod_{k=1}^{K} \prod_{t=1}^{T} \prod_{j=1}^{n_{k}} \prod_{i \in I_{j k t}} \exp \left\{-0.5\left(z_{i j k t}-a_{i} \theta_{j k t}+b_{i}\right)^{2}\right\} \mathbb{1}_{\left(z_{i j k t}, y_{i j k t}\right)}\right\} \\
\times & \left.\left\{\prod_{k=1}^{K} \prod_{j=1}^{n_{k}} \prod_{t=1}^{T} \exp \left\{-\frac{1}{\psi_{\theta_{k t}}}\left(\theta_{j k t}-\mu_{\theta_{k t}}-\tau_{j k}\right)^{2}\right\}\right\} \prod_{k=1}^{K} \prod_{t=1}^{T} \psi_{\theta_{k t}}^{-n_{k} / 2}\right\} \\
\times & \left\{\prod_{k=1}^{K} \prod_{j=1}^{n_{k}} \exp \left\{-\frac{\tau_{j k}^{2}}{2 \sigma_{\theta_{k}}^{2}}\right\}\right\}\left\{\prod_{k=1}^{K} \sigma_{\theta_{k}}^{-n_{k} / 2}\right\} \\
\times & \left\{\prod_{k=1}^{K} \prod_{t=1}^{T} \exp \left\{-\frac{1}{\psi_{\theta_{0}}}\left(\mu_{\theta_{k t}}-\mu_{0}\right)^{2}\right\}\right\}\left\{\prod_{k=1}^{K} \prod_{t=1}^{T} \psi_{\theta_{k t}}^{-v_{0} / 2-1} \exp \left(-\frac{\kappa_{0}}{2 \psi_{\theta_{k t}}}\right)\right\} \\
\times & \prod_{k=1}^{K}\left(\sigma_{\theta_{k}}^{2}\right)^{-v_{1} / 2-1} \exp \left(-\frac{\kappa_{1}}{2 \sigma_{\theta_{k}}^{2}}\right) \\
\times & \prod_{i=1}^{I} \exp \left\{-0.5\left(\boldsymbol{\zeta}_{i}-\boldsymbol{\mu}_{\boldsymbol{\zeta}}\right)^{t} \boldsymbol{\Psi}_{\boldsymbol{\zeta}}^{-1}\left(\boldsymbol{\zeta}_{i}-\boldsymbol{\mu}_{\boldsymbol{\zeta}}\right)\right\} \mathbb{1}_{\left(a_{i}>0\right)} .
\end{aligned}
$$

$\operatorname{ARH}(1)$

$$
\begin{aligned}
p\left(\boldsymbol{z}_{\ldots .}, \boldsymbol{\theta}_{\ldots, \ldots}, \boldsymbol{\xi}_{\ldots}, \boldsymbol{\zeta}, \boldsymbol{\mu}_{\boldsymbol{\theta}}, \boldsymbol{\psi}_{\theta}, \boldsymbol{\rho}_{\theta}\right) & \propto\left\{\prod_{k=1}^{K} \prod_{t=1}^{T} \prod_{j=1}^{n_{k}} \prod_{i \in I_{j k t}} \exp \left\{-0.5\left(z_{i j k t}-a_{i} \theta_{j k t}+b_{i}\right)^{2}\right\} \mathbb{1}_{\left(z_{i j k t}, y_{i j k t}\right)}\right\} \\
\times & \left\{\prod_{k=1}^{K} \prod_{j=1}^{n_{k}} \prod_{t=2}^{T} \exp \left\{-\frac{1}{\psi_{\theta_{k}}}\left(\theta_{j k t}-\mu_{\theta_{k t}}-\sqrt{\psi_{\theta_{k}}} \rho_{\theta_{k}} \xi_{j k(t-1)}\right)^{2}\right\}\right\}\left\{\prod_{k=1}^{K} \prod_{t=1}^{T} \psi_{\theta_{k t}}^{-n_{k} / 2}\right\} \\
\times & \left\{\prod_{k=1}^{K} \prod_{j=1}^{n_{k}} \prod_{t=2}^{T} \exp \left\{-0.5\left(\xi_{j k t}-\rho_{\theta_{k}} \xi_{j k(t-1)}\right)^{2}\right\}\right\}\left\{\prod_{k=1}^{K} \prod_{j=1}^{n_{k}} \exp \left\{-0.5\left(\xi_{j k 1}\right)^{2}\right\}\right\} \\
\times & \left\{\prod_{k=1}^{K} \prod_{j=1}^{n_{k}} \exp \left\{-\frac{1}{\psi_{\theta_{k}}}\left(\theta_{j k 1}-\mu_{\theta_{k 1}}\right)^{2}\right\}\right\}\left\{\prod_{k=1}^{K} \prod_{t=1}^{T} \exp \left\{-\frac{1}{\psi_{\theta_{0}}}\left(\mu_{\theta_{k t}}-\mu_{0}\right)^{2}\right\}\right\} \\
\times & \left\{\prod_{k=1}^{K} \prod_{t=1}^{T} \psi_{\theta_{k t}}^{-v_{0} / 2-1} \exp \left(-\frac{\kappa_{0}}{2 \psi_{\theta_{k t}}}\right)\right\}\left\{\prod_{k=1}^{K} \exp \left\{-\frac{1}{2 \psi_{\rho}}\left(\rho_{\theta_{k}}-\mu_{\rho}\right)^{2}\right\}\right\} \\
\times & \prod_{i=1}^{I} \exp \left\{-0.5\left(\boldsymbol{\zeta}_{i}-\boldsymbol{\mu}_{\zeta}\right)^{t} \boldsymbol{\Psi}_{\boldsymbol{\zeta}}^{-1}\left(\boldsymbol{\zeta}_{i}-\boldsymbol{\mu}_{\zeta}\right)\right\} \mathbb{1}_{\left(a_{i}>0\right)} .
\end{aligned}
$$




\section{Toeplitz}

$$
\begin{aligned}
p\left(\boldsymbol{z}_{\ldots, \ldots}, \boldsymbol{\theta}_{\ldots, \ldots}, \ldots, \boldsymbol{\zeta}, \boldsymbol{\mu}_{\boldsymbol{\theta}}, \boldsymbol{\psi}_{\theta}, \boldsymbol{\gamma}_{\theta}\right) & \propto\left\{\prod_{k=1}^{K} \prod_{t=1}^{T} \prod_{j=1}^{n_{k}} \prod_{i \in I_{j k t}} \exp \left\{-0.5\left(z_{i j k t}-a_{i} \theta_{j k t}+b_{i}\right)^{2}\right\} \mathbb{1}_{\left(z_{i j k t}, y_{i j k t}\right)}\right\} \\
\times & \left\{\prod_{k=1}^{K} \prod_{j=1}^{n_{k}} \prod_{t=2}^{T} \exp \left\{-\frac{1}{\psi_{\theta_{k}}}\left(\theta_{j k t}-\mu_{\theta_{k t}}-\sqrt{\psi_{\theta_{k}}} \gamma_{\theta_{k}} \epsilon_{j k(t-1)}\right)^{2}\right\}\right\} \\
\times & \left\{\prod_{k=1}^{K} \prod_{t=1}^{T} \psi_{\theta_{k t}}^{-n_{k} / 2}\right\} \\
\times & \left\{\prod_{k=1}^{K} \prod_{j=1}^{n_{k}} \prod_{t=1}^{T-1} \exp \left\{-0.5\left(\epsilon_{j k t}\right)^{2}\right\}\right\} \\
\times & \left\{\prod_{k=1}^{K} \prod_{j=1}^{n_{k}} \exp \left\{-\frac{1}{\psi_{\theta_{k}}}\left(\theta_{j k 1}-\mu_{\theta_{k 1}}\right)^{2}\right\}\right\}\left\{\prod_{k=1}^{K} \prod_{t=1}^{T} \exp \left\{-\frac{1}{\psi_{\theta_{0}}}\left(\mu_{\theta_{k t}}-\mu_{0}\right)^{2}\right\}\right\} \\
\times & \left\{\prod_{k=1}^{K} \prod_{t=1}^{T} \psi_{\theta_{k t}}^{-v_{0} / 2-1} \exp \left(-\frac{\kappa_{0}}{2 \psi_{\theta_{k t}}}\right)\right\}\left\{\prod_{k=1}^{K} \exp \left\{-\frac{1}{2 \psi_{\rho}}\left(\rho_{\theta_{k}}-\mu_{\rho}\right)^{2}\right\}\right\} \\
\times & \prod_{i=1}^{I} \exp \left\{-0.5\left(\boldsymbol{\zeta}_{i}-\boldsymbol{\mu}_{\boldsymbol{\zeta}}\right)^{t} \boldsymbol{\Psi}_{\boldsymbol{\zeta}}^{-1}\left(\boldsymbol{\zeta}_{i}-\boldsymbol{\mu}_{\boldsymbol{\zeta}}\right)\right\} \mathbb{1}_{\left(a_{i}>0\right)} .
\end{aligned}
$$


$\operatorname{ARMAH}(1,1)$

$$
\begin{aligned}
& p\left(\boldsymbol{z}_{\ldots .}, \boldsymbol{\theta}_{\ldots}, \boldsymbol{\xi}_{\ldots}, \epsilon_{\ldots}, \boldsymbol{\zeta}, \boldsymbol{\mu}_{\boldsymbol{\theta}}, \boldsymbol{\psi}_{\theta}, \boldsymbol{\rho}_{\theta}, \boldsymbol{\gamma}_{\theta}\right) \propto\left\{\prod_{k=1}^{K} \prod_{t=1}^{T} \prod_{j=1}^{n_{k}} \prod_{i \in I_{j k t}} \exp \left\{-0.5\left(z_{i j k t}-a_{i} \theta_{j k t}+b_{i}\right)^{2}\right\} \mathbb{1}_{\left(z_{i j k t}, y_{i j k t}\right)}\right\} \\
& \times\left\{\prod _ { k = 1 } ^ { K } \prod _ { j = 1 } ^ { n _ { k } } \prod _ { t = 2 } ^ { T } \operatorname { e x p } \left\{-\frac{1}{\psi_{\theta_{k}}}\left(\theta_{j k t}-\mu_{\theta_{k t}}-\sqrt{\psi_{\theta_{k}}}\left(\rho_{\theta_{k}} \xi_{j k(t-1)}+\right.\right.\right.\right. \\
& \left.\left.\left.\left.\times \quad \gamma_{\theta_{k}} \epsilon_{j k(t-1)}\right)\right)^{2}\right\}\right\} \\
& \times\left\{\prod_{k=1}^{K} \prod_{t=1}^{T} \psi_{\theta_{k t}}^{-n_{k} / 2}\right\} \\
& \times\left\{\prod_{k=1}^{K} \prod_{j=1}^{n_{k}} \prod_{t=2}^{T} \exp \left\{-0.5\left(\xi_{j k t}-\rho_{\theta_{k}} \xi_{j k(t-1)}-\gamma_{\theta_{k}} \epsilon_{j k(t-1)}\right)^{2}\right\}\right\} \\
& \times\left\{\prod_{k=1}^{K} \prod_{j=1}^{n_{k}} \exp \left\{-0.5\left(\xi_{j k 1}\right)^{2}\right\}\right\}\left\{\prod_{k=1}^{K} \prod_{j=1}^{n_{k}} \prod_{t=1}^{T-1} \exp \left\{-0.5\left(\epsilon_{j k t}\right)^{2}\right\}\right\} \\
& \times\left\{\prod_{k=1}^{K} \prod_{j=1}^{n_{k}} \exp \left\{-\frac{1}{\psi_{\theta_{k}}}\left(\theta_{j k 1}-\mu_{\theta_{k 1}}\right)^{2}\right\}\right\} \\
& \times\left\{\prod_{k=1}^{K} \prod_{t=1}^{T} \exp \left\{-\frac{1}{\psi_{\theta_{0}}}\left(\mu_{\theta_{k t}}-\mu_{0}\right)^{2}\right\}\right\} \\
& \times\left\{\prod_{k=1}^{K} \prod_{t=1}^{T} \psi_{\theta_{k t}}^{-v_{0} / 2-1} \exp \left(-\frac{\kappa_{0}}{2 \psi_{\theta_{k t}}}\right)\right\}\left\{\prod_{k=1}^{K} \exp \left\{-\frac{1}{2 \psi_{\rho}}\left(\rho_{\theta_{k}}-\mu_{\rho}\right)^{2}\right\}\right\} \\
& \times \prod_{i=1}^{I} \exp \left\{-0.5\left(\boldsymbol{\zeta}_{i}-\boldsymbol{\mu}_{\zeta}\right)^{t} \boldsymbol{\Psi}_{\boldsymbol{\zeta}}^{-1}\left(\boldsymbol{\zeta}_{i}-\boldsymbol{\mu}_{\zeta}\right)\right\} \mathbb{1}_{\left(a_{i}>0\right)} \text {. }
\end{aligned}
$$

Azevedo, Caio L. N. 


\section{Ante-dependência}

$$
\begin{aligned}
p\left(\boldsymbol{z}_{\ldots .}, \boldsymbol{\theta}_{\ldots,}, \boldsymbol{\xi}, \boldsymbol{\zeta}, \boldsymbol{\mu}_{\boldsymbol{\theta}}, \psi_{\theta}, \boldsymbol{\phi}_{\theta}\right) & \propto\left\{\prod_{k=1}^{K} \prod_{t=1}^{T} \prod_{j=1}^{n_{k}} \prod_{i \in I_{j k t}} \exp \left\{-0.5\left(z_{i j k t}-a_{i} \theta_{j k t}+b_{i}\right)^{2}\right\} \mathbb{1}_{\left(z_{i j k t}, y_{i j k t}\right)}\right\} \\
& \times\left\{\prod_{k=1}^{K} \prod_{j=1}^{n_{k}} \prod_{t=2}^{T} \exp \left\{-\frac{1}{\psi_{\theta_{k}}}\left(\theta_{j k t}-\mu_{\theta_{k t}}-\phi_{\theta_{k(t-1)}} \theta_{j k(t-1)}\right)^{2}\right\}\right\}\left\{\prod_{k=1}^{K} \prod_{t=1}^{T} \psi_{\theta_{k t}}^{-n_{k} / 2}\right\} \\
& \times\left\{\prod_{k=1}^{K} \prod_{j=1}^{n_{k}} \exp \left\{-\frac{1}{\psi_{\theta_{k}}}\left(\theta_{j k 1}-\mu_{\theta_{k 1}}\right)^{2}\right\}\left\{\prod_{k=1}^{K} \prod_{t=1}^{T} \exp \left\{-\frac{1}{\psi_{\theta_{0}}}\left(\mu_{\theta_{k t}}-\mu_{0}\right)^{2}\right\}\right\}\right. \\
& \times\left\{\prod_{k=1}^{K} \prod_{t=1}^{T} \psi_{\theta_{k t}}^{-v_{0} / 2-1} \exp \left(-\frac{\kappa_{0}}{2 \psi_{\theta_{k t}}}\right)\right\}\left\{\prod_{k=1}^{K} \prod_{t=1}^{T-1} \exp \left\{-\frac{1}{2 \psi_{\phi}}\left(\phi_{\theta_{k t}}-\mu_{\phi}\right)^{2}\right\}\right\} \\
& \times \prod_{i=1}^{I} \exp \left\{-0.5\left(\boldsymbol{\zeta}_{i}-\boldsymbol{\mu}_{\boldsymbol{\zeta}}\right)^{t} \boldsymbol{\Psi}_{\boldsymbol{\zeta}}^{-1}\left(\boldsymbol{\zeta}_{i}-\boldsymbol{\mu}_{\boldsymbol{\zeta}}\right)\right\} \mathbb{1}_{\left(a_{i}>0\right)} .
\end{aligned}
$$

O resultado seguinte apresenta os algoritmos de Gibbs para cada um dos modelos estudados.

Resultado 5.8.1. Considerando as distribuições a posteriori (5.51), (5.52), (5.53), 5.54), (5.55) e (5.56), os passos dos amostradores de Gibbs são:

Para a população $\mathrm{k}, k=1, \ldots, K$, de modo mutuamente independente, execute os seguintes passos:

\section{Matriz Hankel}

- Passo 2: Simular, de forma mutuamente independente os traços latentes através de $\theta_{j k t} \mid(.) \sim N\left(\widehat{\psi}_{\theta_{j k t}} \widehat{\theta}_{j k t}, \widehat{\psi}_{\theta_{j k t}}\right)$, em que

$$
\begin{aligned}
\widehat{\theta}_{j k t} & =\sum_{i \in I_{j k t}} z_{i j k t} a_{i}+\sum_{i \in I_{j k t}} a_{i} b_{i}+\frac{\mu_{\theta_{k t}}+\tau_{j k}}{\psi_{\theta_{k t}}} \\
\widehat{\psi}_{\theta_{j k t}} & =\left(\frac{1}{\psi_{\theta_{k t}}}+\sum_{i \in I_{j k t}} a_{i}^{2}\right)^{-1} .
\end{aligned}
$$

- Passo 4: Simular, de forma mutuamente independente, as médias populacionais através de $\mu_{\theta_{k t}} \mid(.) \sim$ $N\left(\widehat{\psi}_{\mu_{k t}} \widehat{\mu}_{\theta_{k t}}, \widehat{\psi}_{\mu_{k t}}\right)$, em que 


$$
\begin{aligned}
\widehat{\mu}_{\theta_{k}} & =\sum_{j=1}^{n_{k}} \frac{\left(\theta_{j k t}-\tau_{j k}\right)}{\psi_{\theta_{k t}}}+\frac{\mu_{0}}{\psi_{0}} \\
\widehat{\psi}_{\mu_{k t}} & =\left(\frac{n_{k}}{\psi_{\theta_{k t}}}+\frac{1}{\psi_{0}}\right)^{-1} .
\end{aligned}
$$

- Passo 5: Simular, de forma mutuamente independente, as variâncias populacionais através de $\psi_{\theta_{k t}} \mid(.) \sim$ $I G\left(\widehat{v}_{k}, \widehat{\kappa}_{k t}\right)$, em que

$$
\begin{aligned}
\widehat{v}_{k} & =\frac{n_{k}+v_{0}}{2} \\
\widehat{\kappa}_{k t} & =\frac{1}{2}\left(\sum_{j=1}^{n_{k}}\left(\theta_{j k t}-\mu_{\theta_{k t}}-\tau_{j k}\right)^{2}+\kappa_{0}\right) .
\end{aligned}
$$

- Passo 6: Simular, de forma mutuamente independente, os efeitos aleatórios através de $\tau_{j k} \mid(.) \sim N\left(\widehat{\psi}_{k} \widehat{\tau}_{j k}, \widehat{\psi}_{k}\right)$, em que

$$
\begin{aligned}
\widehat{\tau}_{j k} & =\sum_{t=1}^{T}\left(\theta_{j k t}-\mu_{\theta_{k t}}\right) \\
\widehat{\psi}_{k} & =\left(\frac{T}{\psi_{\theta_{k t}}}+\frac{1}{\sigma_{\theta_{k}}^{2}}\right)^{-1} .
\end{aligned}
$$

- Passo 7: Simular, de forma mutuamente independente as variâncias dos efeitos aleatórios de $\sigma_{\theta_{k}}^{2} \mid(.) \sim$ $I G\left(\widehat{v}_{k_{1}}, \widehat{\kappa}_{k_{1}}\right)$, em que

$$
\begin{aligned}
\widehat{v}_{k_{1}} & =\frac{n_{k}+v_{1}}{2} \\
\widehat{\kappa}_{k_{1}} & =\frac{1}{2}\left(\sum_{j=1}^{n_{k}} \tau_{j k}^{2}+\kappa_{1}\right) .
\end{aligned}
$$

Azevedo, Caio L. N. 


\section{Matriz Uniforme}

- Passo 2: Simular, de forma mutuamente independente os traços latentes através de $\theta_{j k t} \mid(.) \sim N\left(\widehat{\psi}_{\theta_{j k t}} \widehat{\theta}_{j k t}, \widehat{\psi}_{\theta_{j k t}}\right)$, em que

$$
\begin{aligned}
\widehat{\theta}_{j k t} & =\sum_{i \in I_{j k t}} z_{i j k t} a_{i}+\sum_{i \in I_{j k t}} a_{i} b_{i}+\frac{\mu_{\theta_{k t}}+\varphi_{k t} \tau_{j k}}{\psi_{\theta_{k t}}} \\
\widehat{\psi}_{\theta_{j k t}} & =\left(\frac{1}{\psi_{\theta_{k t}}}+\sum_{i \in I_{j k t}} a_{i}^{2}\right)^{-1} .
\end{aligned}
$$

- Passo 4: Simular, de forma mutuamente independente, as médias populacionais através de $\mu_{\theta_{k t}} \mid(.) \sim$ $N\left(\widehat{\psi}_{\mu_{k t}} \widehat{\mu}_{\theta_{k t}}, \widehat{\psi}_{\mu_{k t}}\right)$, em que

$$
\begin{aligned}
\widehat{\mu}_{\theta_{k}} & =\sum_{j=1}^{n_{k}} \frac{\left(\theta_{j k t}-\varphi_{\theta_{k t}} \tau_{j k}\right)}{\psi_{\theta_{k t}}}+\frac{\mu_{0}}{\psi_{0}} \\
\widehat{\psi}_{\mu_{k t}} & =\left(\frac{n_{k}}{\psi_{\theta_{k t}}}+\frac{1}{\psi_{0}}\right)^{-1} .
\end{aligned}
$$

- Passo 5: Simular, de forma mutuamente independente, as variâncias populacionais através de $\psi_{\theta_{k}} \mid(.) \sim$ $I G\left(\widehat{v}_{k}, \widehat{\kappa}_{k t}\right)$, em que

$$
\begin{aligned}
\widehat{v}_{k} & =\frac{n_{k}+v_{0}}{2}, \\
\widehat{\kappa}_{k t} & =\frac{1}{2}\left(\sum_{j=1}^{n_{k}}\left(\theta_{j k t}-\mu_{\theta_{k t}}-\varphi_{k t} \tau_{j k}\right)^{2}+\kappa_{0}\right) .
\end{aligned}
$$

- Passo 6: Simular, de forma mutuamente independente, os efeitos aleatórios através de $\tau_{j k} \mid(.) \sim N\left(\widehat{\psi}_{k} \widehat{\tau}_{j k}, \widehat{\psi}_{k}\right)$, em que 


$$
\begin{aligned}
\widehat{\tau}_{j k} & =\frac{1}{\psi_{\theta_{k t}}} \sum_{t=1}^{T} \varphi_{\theta_{k t}}\left(\theta_{j k t}-\mu_{\theta_{k t}}\right) \\
\widehat{\psi}_{k} & =\left(\sum_{t=1}^{T} \frac{\varphi_{\theta_{k t}}^{2}}{\psi_{\theta_{k t}}}+\frac{1}{\sigma_{\theta_{k}}^{2}}\right)^{-1} .
\end{aligned}
$$

- Passo 7: Simular, de forma mutuamente independente, os parâmetros de dependência, através de $\varphi_{\theta_{k t}} \sim$ $N\left(\widehat{\psi}_{k} \widehat{\varphi}_{\theta_{k t}}, \widehat{\psi}_{k}\right)$, em que

$$
\begin{aligned}
\widehat{\varphi}_{\theta_{k t}} & =\frac{1}{\psi_{\theta_{k t}}} \sum_{j=1}^{n_{k}} \tau_{j k}\left(\theta_{j k t}-\mu_{\theta_{k t}}\right)+\frac{\mu_{\varphi}}{\psi_{\varphi}} \\
\widehat{\psi}_{\varphi_{k}} & =\left(\sum_{j=1}^{n_{k}} \tau_{j k}^{2}+\frac{1}{\psi_{\varphi}}\right)^{-1} .
\end{aligned}
$$

- Passo 8: Simular, de forma mutuamente independente, as variâncias dos efeitos aleatórios de $\sigma_{k}^{2} \mid(.) \sim$ $I G\left(\widehat{v}_{k_{1}}, \widehat{\kappa}_{k_{1}}\right)$, em que

$$
\begin{aligned}
\widehat{v}_{k_{1}} & =\frac{n_{k}+v_{1}}{2} \\
\widehat{\kappa}_{k_{1}} & =\frac{1}{2}\left(\sum_{j=1}^{n_{k}} \tau_{j k}^{2}+\kappa_{1}\right) .
\end{aligned}
$$

Azevedo, Caio L. N. 


\section{Matriz ARH(1)}

- Passo 2: Simular, de forma mutuamente independente os traços latentes através de $\theta_{j k t} \mid(.) \sim N\left(\widehat{\psi}_{\theta_{j k t}} \widehat{\theta}_{j k t}, \widehat{\psi}_{\theta_{j k t}}\right)$, em que

$$
\widehat{\theta}_{j k t}=\left\{\begin{array}{l}
\sum_{i \in I_{j k t}} z_{i j k t} a_{i}+\sum_{i \in I_{j k t}} a_{i} b_{i}+\frac{\mu_{\theta_{k t}}}{\psi_{\theta_{k t}}}, \text { se } t=1 \\
\sum_{i \in I_{j k t}} z_{i j k t} a_{i}+\sum_{i \in I_{j k t}} a_{i} b_{i}+\frac{\mu_{\theta_{k t}}+\sqrt{\psi_{\theta_{k t}}} \rho_{\theta_{k}} \xi_{j k(t-1)}}{\psi_{\theta_{k t}}}, \text { se } t \geq 2 .
\end{array},\right.
$$

$\mathrm{e}$

$$
\widehat{\psi}_{\theta_{j k t}}=\left(\frac{1}{\psi_{\theta_{k t}}}+\sum_{i \in I_{j k t}} a_{i}^{2}\right)^{-1}
$$

- Passo 4: Simular, de forma mutuamente independente, as médias populacionais através de $\mu_{\theta_{k t}} \mid(.) \sim$ $N\left(\widehat{\psi}_{\mu_{k t}} \widehat{\mu}_{\theta_{k t}}, \widehat{\psi}_{\mu_{k t}}\right)$, em que

$$
\begin{aligned}
\widehat{\mu}_{\theta_{k t}} & =\sum_{j=1}^{n_{k}} \frac{\theta_{j k t}}{\psi_{\theta_{k}}}+\frac{\mu_{0}}{\psi_{0}} \\
\widehat{\psi}_{\mu_{k t}} & =\left(\frac{n_{k}}{\psi_{\theta_{k t}}}+\frac{1}{\psi_{0}}\right)^{-1} .
\end{aligned}
$$

- Passo 5: Simular, de forma mutuamente independente, as variâncias populacionais através de $\psi_{\theta_{k t}} \mid(.) \sim$ $I G\left(\widehat{v}_{k}, \widehat{\kappa}_{k t}\right)$, em que

$$
\begin{aligned}
\widehat{v}_{k} & =\frac{n_{k}+v_{0}}{2} \\
\widehat{\kappa}_{k} & =\frac{1}{2}\left(\sum_{j=1}^{n_{k}}\left(\theta_{j k t}-\mu_{\theta_{k t}}\right)^{2}+\kappa_{0}\right) .
\end{aligned}
$$

Azevedo, Caio L. N. 
- Passo 6: Simular, de forma mutuamente independente, para $t=1,2, \ldots, T$, os efeitos aleatórios através de $\xi_{j k(t-1)} \mid(.) \sim N\left(\widehat{\xi}_{j k(t-1)}, \widehat{\psi}_{k}\right)$, em que

$$
\begin{aligned}
\widehat{\xi}_{j k(t-1)} & =\frac{\rho_{\theta_{k}}}{1+\rho_{\theta_{k}}^{2}}\left[\frac{\theta_{j k t}-\mu_{\theta_{k t}}}{\sqrt{\psi_{\theta_{k t}}}}+\xi_{j k(t-2)}\right] \\
\xi_{j k 0} & \equiv 0 \\
\widehat{\psi}_{k} & =\frac{1}{1+\rho_{\theta_{k}}^{2}}
\end{aligned}
$$

- Passo 7: Simular, de forma mutuamente independente, os parâmetros de correlação através de através de $\rho_{\theta_{k}} \mid(.) \sim N\left(\widehat{\psi}_{\rho_{k}} \widehat{\rho}_{k}, \widehat{\psi}_{\rho_{k}}\right)$, em que

$$
\begin{aligned}
\widehat{\rho}_{\theta_{k}} & =\sum_{t=3}^{T} \sum_{j=1}^{n_{k}} \xi_{j k(t-1)} \xi_{j k(t-2)}+\frac{\mu_{\rho}}{\psi_{\rho}} \\
\widehat{\psi}_{\rho_{k}} & =\left(\frac{1}{\psi_{\rho}}+\sum_{t=3}^{T} \sum_{j=1}^{n_{k}} \xi_{j k(t-2)}^{2}\right)^{-1} .
\end{aligned}
$$

\section{Matriz TH}

- Passo 2: Simular, de forma mutuamente independente, os traços latentes através de $\theta_{j k t}(.) \sim N\left(\widehat{\psi}_{\theta_{j k t}} \widehat{\theta}_{j k t}, \widehat{\psi}_{\theta_{j k t}}\right)$, em que

$$
\begin{aligned}
& \widehat{\theta}_{j k t}=\left\{\begin{array}{l}
\sum_{i \in I_{j k t}} z_{i j k t} a_{i}+\sum_{i \in I_{j k t}} a_{i} b_{i}+\frac{\mu_{\theta_{k t}}}{\psi_{\theta_{k}}}, \text { se } t=1 \\
\sum_{i \in I_{j k t}} z_{i j k t} a_{i}+\sum_{i \in I_{j k t}} a_{i} b_{i}+\frac{\mu_{\theta_{k t}}+\sqrt{\psi_{k t}} \gamma_{\theta_{k}} \epsilon_{j k(t-1)}}{\psi_{\theta_{k t}}}, \text { se } t \geq 2 .
\end{array}\right. \\
& \widehat{\psi}_{\theta_{j k t}}=\left(\frac{1}{\psi_{\theta_{k t}}}+\sum_{i \in I_{j k t}} a_{i}^{2}\right)^{-1} .
\end{aligned}
$$

- Passo 4: Simular, de forma mutuamente independente, as médias populacionais através de $\mu_{\theta_{k t}} \mid(.) \sim$ $N\left(\widehat{\psi}_{\mu_{k t}} \widehat{\mu}_{\theta_{k t}}, \widehat{\psi}_{\mu_{k t}}\right)$, em que 


$$
\begin{aligned}
\widehat{\mu}_{\theta_{k t}} & =\sum_{j=1}^{n_{k}} \frac{\theta_{j k t}}{\psi_{\theta_{k t}}}+\frac{\mu_{0}}{\psi_{0}} \\
\widehat{\psi}_{\mu_{k t}} & =\left(\frac{n_{k}}{\psi_{\theta_{k t}}}+\frac{1}{\psi_{0}}\right)^{-1} .
\end{aligned}
$$

- Passo 5: Simular, de forma mutuamente independente, as variâncias populacionais através de $\psi_{\theta_{k t}} \mid(.) \sim$ $I G\left(\widehat{v}_{k}, \widehat{\kappa}_{k t}\right)$, em que

$$
\begin{aligned}
\widehat{v}_{k} & =\frac{n_{k}+v_{0}}{2} \\
\widehat{\kappa}_{k t} & =\frac{1}{2}\left(\sum_{j=1}^{n_{k}}\left(\theta_{j k t}-\mu_{\theta_{k t}}\right)^{2}+\kappa_{0}\right) .
\end{aligned}
$$

- Passo 6: Simular, de forma mutuamente independente, para $t=2, \ldots, T$ os efeitos aleatórios através de $\epsilon_{j k(t-1)} \mid(.) \sim N\left(\widehat{\epsilon}_{j k t}, \widehat{\psi}_{k t}^{2}\right)$, em que

$$
\begin{aligned}
\widehat{\epsilon}_{j k t} & =\frac{\left(\sqrt{\psi_{\theta_{k t}}} \gamma_{\theta_{k}}\right)\left(\theta_{j k t}-\mu_{k t}\right)}{1+\psi_{\theta_{k t}} \gamma_{\theta_{k}}^{2}} \\
\widehat{\psi}_{k t} & =\left(\frac{1}{1+\psi_{\theta_{k t}} \gamma_{\theta_{k}}^{2}}\right) .
\end{aligned}
$$

- Passo 7: Simular, de forma mutuamente independente, os parâmetros das médias móveis, através de $\gamma_{\theta_{k}} \mid(.) \sim N\left(\widehat{\psi}_{\gamma_{k}} \widehat{\gamma}_{\theta_{k}}, \widehat{\psi}_{\gamma_{k}}\right)$, em que

$$
\begin{aligned}
\widehat{\gamma}_{\theta_{k}} & =\frac{1}{\sqrt{\psi_{\theta_{k t}}}} \sum_{t=2}^{T} \sum_{j=1}^{n_{k}} \epsilon_{j k(t-1)}\left(\theta_{j k t}-\mu_{\theta_{k t}}\right)+\frac{\mu_{\gamma}}{\psi_{\gamma}} \\
\widehat{\psi}_{\gamma_{k}} & =\left(\sum_{t=2}^{T} \sum_{j=1}^{n_{k}} \epsilon_{j k(t-1)}^{2}+\frac{1}{\psi_{\gamma}}\right)^{-1} .
\end{aligned}
$$

Azevedo, Caio L. N. 


\section{Matriz ARMAH(1,1)}

- Passo 2: Simular, de forma mutuamente independente os traços latentes através de $\theta_{j k t} \mid(.) \sim N\left(\widehat{\psi}_{\theta_{j k t}} \widehat{\theta}_{j k t}, \widehat{\psi}_{\theta_{j k t}}\right)$, em que

$$
\begin{aligned}
& \widehat{\theta}_{j k t}=\left\{\begin{array}{l}
\sum_{i \in I_{j k t}} z_{i j k t} a_{i}+\sum_{i \in I_{j k t}} a_{i} b_{i}+\frac{\mu_{\theta_{k t}}}{\psi_{\theta_{k t}}}, \text { se } t=1 \\
\sum_{i \in I_{j k t}} z_{i j k t} a_{i}+\sum_{i \in I_{j k t}} a_{i} b_{i}+\frac{\mu_{\theta_{k t}}+\sqrt{\psi_{\theta_{k t}}}\left(\rho_{\theta_{k}} \xi_{j k(t-1)}+\gamma_{\theta_{k}} \epsilon_{j k(t-1)}\right)}{\psi_{\theta_{k t}}}, \text { se } t \geq 2 .
\end{array}\right. \\
& \widehat{\psi}_{\theta_{j k t}}=\left(\frac{1}{\psi_{\theta_{k t}}}+\sum_{i \in I_{j k t}} a_{i}^{2}\right)^{-1} .
\end{aligned}
$$

- Passo 4: Simular, de forma mutuamente independente, as médias populacionais através de $\mu_{\theta_{k t}} \mid(.) \sim$ $N\left(\widehat{\psi}_{\mu_{k t}} \widehat{\mu}_{\theta_{k t}}, \widehat{\psi}_{\mu_{k t}}\right)$, em que

$$
\begin{gathered}
\widehat{\mu}_{\theta_{k t}}=\sum_{j=1}^{n_{k}} \frac{\theta_{j k t}}{\psi_{\theta_{k t}}}+\frac{\mu_{0}}{\psi_{0}} \\
\widehat{\psi}_{\mu_{k t}}=\left(\frac{n_{k}}{\psi_{\theta_{k t}}}+\frac{1}{\psi_{0}}\right)^{-1} .
\end{gathered}
$$

- Passo 5: Simular, de forma mutuamente independente, as variâncias populacionais através de $\psi_{\theta_{k t}} \mid(.) \sim$ $I G\left(\widehat{v}_{k}, \widehat{\kappa}_{k t}\right)$, em que

$$
\begin{aligned}
\widehat{v}_{k} & =\frac{n_{k}+v_{0}}{2} \\
\widehat{\kappa}_{k t} & =\frac{1}{2}\left(\sum_{j=1}^{n_{k}}\left(\theta_{j k t}-\mu_{\theta_{k t}}\right)^{2}+\kappa_{0}\right) .
\end{aligned}
$$

- Passo 6: Simular, de forma mutuamente independente, para $t=2, \ldots, T$ os resíduos através de $\xi_{j k t} \mid(.) \sim$ $N\left(\widehat{\psi}_{k} \widehat{\xi}_{j k(t-1)}, \widehat{\psi}_{k)}\right)$, em que 


$$
\begin{aligned}
\widehat{\xi}_{j k(t-1)} & =\rho_{\theta_{k}} \frac{\left(\theta_{j k t}-\mu_{\theta_{k t}}+\rho_{k} \xi_{j k(t-2)}-\sqrt{\psi_{\theta_{k t}}} \gamma_{\theta_{k}} \epsilon_{j k(t-1)}\right)}{\sqrt{\psi_{\theta_{k t}}}} \\
\widehat{\psi}_{k} & =\left(\frac{1}{1+\rho_{\theta_{k}}^{2}}\right) .
\end{aligned}
$$

- Passo 7: Simular, de forma mutuamente independente, para $t \geq 2$ os efeitos aleatórios através de $\epsilon_{j k(t-1)} \mid(.) \sim N\left(\widehat{\psi}_{k} \widehat{\xi}_{j k(t-1)}, \widehat{\psi}_{k)}\right)$, em que

$$
\begin{aligned}
\widehat{\xi}_{j k(t-1)} & =\gamma_{\theta_{k}} \frac{\left(\theta_{j k t}-\mu_{\theta_{k t}}-\sqrt{\psi_{\theta_{k t}}} \rho_{\theta_{k}} \theta_{j k(t-1)}\right)}{\sqrt{\psi_{\theta_{k t}}}} \\
\widehat{\psi}_{k}^{2} & =\left(\frac{1}{1+\gamma_{\theta_{k}}^{2}}\right) .
\end{aligned}
$$

- Passo 8: Simular, de forma mutuamente independente, os parâmetros de correlação através de $\rho_{\theta_{k}} \mid(.) \sim$ $N\left(\widehat{\psi}_{\rho_{k}} \widehat{\rho}_{k}, \widehat{\psi}_{\rho_{k}}\right)$, em que

$$
\begin{aligned}
\widehat{\rho}_{\theta_{k}} & =\sum_{j=1}^{n_{k}} \sum_{t=2}^{T} \xi_{j k(t-1)}\left(\xi_{j k t}-\gamma_{\theta_{k}} \epsilon_{j k(t-1)}\right)+\frac{\mu_{\rho}}{\psi_{\rho}} \\
\widehat{\psi}_{\rho_{k}} & =\frac{1}{\sum_{j=1}^{n_{k}} \sum_{t=2}^{T}\left(\xi_{j k t}\right)^{2}+\psi_{\rho}^{-1}} .
\end{aligned}
$$

- Passo 9: Simular, de forma mutuamente independente, os parâmetros de médias móveis, através de $\gamma_{\theta_{k}} \mid(.) \sim N\left(\widehat{\psi}_{\gamma_{k}} \widehat{\gamma}_{\theta_{k}}, \widehat{\psi}_{\gamma_{k}}\right)$, em que

$$
\begin{aligned}
\widehat{\gamma}_{\theta_{k}} & =\sum_{t=2}^{T} \sum_{j=1}^{n_{k}} \epsilon_{j k(t-1)}\left(\xi_{j k t}-\rho_{\theta_{k}} \xi_{j k(t-1)}\right)+\frac{\mu_{\gamma}}{\psi_{\gamma}} \\
\widehat{\psi}_{\gamma_{k}} & =\frac{1}{\sum_{t=2}^{T} \sum_{j=1}^{n_{k}} \epsilon_{j k(t-1)}^{2}+\psi_{\gamma}^{-1}} .
\end{aligned}
$$

Azevedo, Caio L. N. 


\section{Matriz AD}

- Passo 2: Simular, de forma mutuamente independente, os traços latentes através de $\theta_{j k t} \mid(.) \sim N\left(\widehat{\psi}_{\theta_{j k t}} \widehat{\theta}_{j k t}, \widehat{\psi}_{\theta_{j k t}}\right)$, em que

$$
\begin{aligned}
& \widehat{\theta}_{j k t}=\left\{\begin{array}{l}
\sum_{i \in I_{j k t}} z_{i j k t} a_{i}+\sum_{i \in I_{j k t}} a_{i} b_{i}+\frac{\mu_{\theta_{k t}}}{\psi_{\theta_{k t}}}, \text { se } t=1 \\
\sum_{i \in I_{j k t}} z_{i j k t} a_{i}+\sum_{i \in I_{j k t}} a_{i} b_{i}+\frac{\mu_{\theta_{k t}}+\phi_{k(t-1)} \theta_{j k(t-1)}}{\psi_{\theta_{k t}}}, \text { se } t \geq 2 .
\end{array},\right. \\
& \widehat{\psi}_{\theta_{j k t}}=\left(\frac{1}{\psi_{\theta_{k t}}}+\sum_{i \in I_{j k t}} a_{i}^{2}\right)^{-1} .
\end{aligned}
$$

- Passo 4: Simular, de forma mutuamente independente, as médias populacionais através de $\mu_{\theta_{k t}} \mid(.) \sim$ $N\left(\widehat{\psi}_{\mu_{k t}} \widehat{\mu}_{\theta_{k t}}, \widehat{\psi}_{\mu_{k t}}\right)$, em que

$$
\widehat{\mu}_{\theta_{k t}}=\left\{\begin{array}{c}
\sum_{j=1}^{n_{k}} \frac{\theta_{j k t}}{\psi_{\theta_{k t}}}+\frac{\mu_{0}}{\psi_{0}}, \text { se } t=1 \\
\sum_{j=1}^{n_{k}} \frac{\theta_{j k t}-\phi_{k(t-1)} \theta_{j k(t-1)}}{\psi_{\theta_{k t}}}+\frac{\mu_{0}}{\psi_{0}}, \text { se } t \geq 2 . \\
\widehat{\psi}_{\mu_{k t}}=\left(\frac{n_{k}}{\psi_{\theta_{k t}}}+\frac{1}{\psi_{0}}\right)^{-1} .
\end{array}\right.
$$

- Passo 5: Simular, de forma mutuamente independente, as variâncias populacionais através de $\psi_{\theta_{k t}} \mid(.) \sim$ $I G\left(\widehat{v}_{k}, \widehat{\kappa}_{k t}\right)$, em que

$$
\begin{aligned}
\widehat{v}_{k} & =\frac{n_{k}+v_{0}}{2} \\
\widehat{\kappa}_{k t} & =\frac{1}{2}\left(\sum_{j=2}^{n_{k}}\left(\theta_{j k t}-\mu_{\theta_{k t}}-\phi_{k(t-1)} \theta_{j k(t-1)}\right)^{2}+\left(\theta_{j k 1}-\mu_{\theta_{k 1}}\right)^{2} \kappa_{0}\right) .
\end{aligned}
$$

Azevedo, Caio L. N. 
- Passo 6: Simular, de forma mutuamente independente, os parâmetros de correlação através de $\phi_{k(t-1)} \mid(.) \sim$ $N\left(\widehat{\psi}_{k(t-1)} \widehat{\phi}_{k(t-1)}, \widehat{\psi}_{k(t-1)}\right)$, em que

$$
\begin{aligned}
\widehat{\phi}_{k(t-1)} & =\sum_{j=1}^{n_{k}} \sum_{t=2}^{T} \theta_{j k(t-1)}\left(\theta_{j k t}-\mu_{\theta_{k t}}\right)+\frac{\mu_{\phi}}{\psi_{\phi}} \\
\widehat{\psi}_{k(t-1)} & =\frac{1}{\sum_{j=1}^{n_{k}} \sum_{t=2}^{T}\left(\theta_{j k t}\right)^{2}+\psi_{\phi}^{-1}} .
\end{aligned}
$$

\section{Demonstração do Resultado 5.8.1:}

A demonstração segue do Resultado 2.7.1 do Resultado 5.7.1 e das prioris estabelecidas no Resultado 5.8.1. É necessário apenas mais alguns algebrismos para se chegar as distribuições condicionais completas de interesse.

Q.E.D.

\subsection{Estudos de simulação}

Neste seção conduziremos um estudo de simulação, baseado em réplicas de Monte Carlo, com o intuito de avaliar parte da metodologia desenvolvida no presente capítulo. Mais especificamente, consideraremos o modelo que representa a forma heterocedástica da matriz Hankel em 3 condições de avaliação e uma única população. Os valores adotados para os parâmetros de variabilidade foram : $\left(\psi_{\theta_{1}} ; \psi_{\theta_{2}} ; \psi_{\theta_{3}}\right)^{t}=(0,20 ; 0,10 ; 0,15)$ (variâncias residuais) e $\sigma_{\theta}^{2}=0,80$ (variância dos efeitos aleatórios). Isso gera as seguintes variâncias populacionais $\operatorname{Var}\left(\theta_{1}\right)=1,00 ; \operatorname{Var}\left(\theta_{2}\right)=0,90$ e $\operatorname{Var}\left(\theta_{3}\right)=0,95$. Os hiperparâmetros para as prioris dos referidos parâmetros foram : $v_{0}=v_{1}=2,2$ e $\kappa_{0}=\kappa_{1}=4,2$, respectivamente, seguindo os resultados da Subseção 2.10 .2 Todos os demais valores são como descrito na Seção 3.7

A Tabela 5.1 apresenta algumas estatísticas relacionadas à estimação dos parâmetros, incluindos os efeitos aleatórios. Percebemos que, em geral, as estimativas foram bem próximas dos verdadeiros valores com uma baixa variabilidade entre si. Os efeitos aleatórios $\tau_{j k}$ apresentaram o desempenho menos favorável. Isto se deve, possivelmente, ao fato de que os efeitos aleatórios são estimados com base nos traços latentes, os quais, por sua vez, são desconhecidos e precisam ser estimados (preditos). Este fato induz uma imprecisão maior nas estimativas dos efeitos aleatórios. A Figura 5.1 ilustra os comentários anteriores. De qualquer forma, o desempenho do procedimento de estimação se mostrou bem satisfatório.

A Tabela 5.2 apresenta as estimativas relacionadas aos parâmetros populacionais. Elas sugerem que o procedimento de estimação teve um comportamento bastante satisfatório. As médias das estimativas se mostram bem próximas dos verdadeiros valores. Além disso apresentam uma variabilidade pequena. Um outro aspecto 
diz respetio à estimação das variâncias dos traços latentes. Utilizando os valores médios dos parâmetros $\psi_{\theta_{i}} \mathrm{e}$ $\sigma_{\theta}^{2}$, obtemos os seguintes valores para as variâncias dos tempos 2 e $\left.3: \widehat{\operatorname{Var}\left(\theta_{2}\right.}\right)=0,935$ e $\left.\widehat{\operatorname{Var}\left(\theta_{3}\right.}\right)=0,989$. Em relação aos resultados da estimação via abordagem multivariada, a variância do tempo 2 foi pior estimada, ocorrendo o contrário para a variância do tempo 3. Contudo, as estimativas obtidas via modelagem multinível foram melhores. Acreditamos que, decompor a variabilidade trouxe benefícios no procedimento de estimação. Provavelmente, se aumentarmos o número de instantes de avaliação, a modelagem multinível será ainda mais vantajosa.

Tabela 5.1: Resultados da estimação dos traços latentes e dos parâmetros dos itens : estudo de replicação

\begin{tabular}{lccccr}
\hline \hline \multirow{2}{*}{ Parâmetro } & \multicolumn{5}{c}{ Estatística } \\
\cline { 2 - 6 } & Corr & MEP & Vq & Var & REQM \\
\hline Traço latente & 0,993 & 0,270 & 0,022 & 0,056 & 0,307 \\
Discriminação & 0,973 & 0,085 & 0,003 & 0,007 & 0,103 \\
Dificuldade & 0,998 & 0,115 & 0,011 & 0,014 & 0,167 \\
Efeito aleatório & 0,968 & 0,279 & 0,050 & 0,028 & 0,358 \\
\hline \hline
\end{tabular}

Tabela 5.2: Resultados da estimação dos parâmetros populacionais : estudo de replicação

\begin{tabular}{ccrrr}
\hline \hline Parâmetro & Parâmetro & Média est. & Média EP & Var. Est. \\
\hline$\mu_{\theta_{2}}$ & 1,000 & 1,012 & 0,042 & 0,001 \\
$\mu_{\theta_{3}}$ & 2,000 & 2,035 & 0,058 & 0,002 \\
$\psi_{\theta_{1}}$ & 0,200 & 0,196 & 0,018 & $<0,001$ \\
$\psi_{\theta_{2}}$ & 0,100 & 0,117 & 0,016 & $<0,001$ \\
$\psi_{\theta_{3}}$ & 0,150 & 0,171 & 0,021 & $<0,001$ \\
$\sigma_{\theta}^{2}$ & 0,800 & 0,818 & 0,045 & $<0,001$ \\
\hline \hline
\end{tabular}

Azevedo, Caio L. N. 

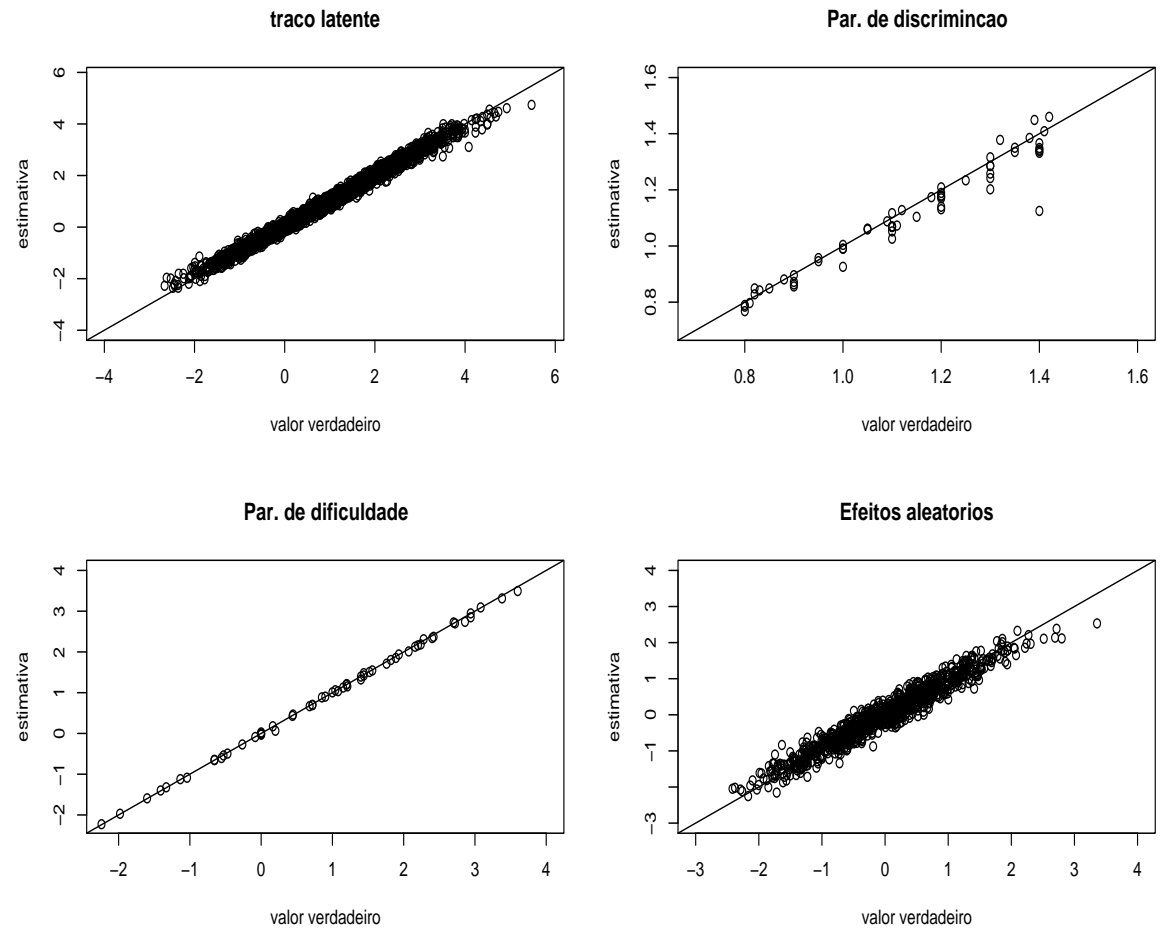

Figura 5.1: Médias das estimativas do estudo de replicação 


\subsection{Análise de dados reais}

Neste seção analisaremos o conjunto de dados descrito na Seção 2.11. Como o objetivo principal é o de ilustrar a metodologia e não avaliar o teste, propriamente, consideraremos na análise os itens selecionados na referida seção. Todas as escolhas com relação a prioris, aquecimento da cadeia e demais pontos são exatamente aqueles descritos na seção anterior.

O p-valor bayesiano para o ajuste do modelo foi $\mathrm{p}=0,4575$ o que indica um ajuste bastante razoável do modelo. Este valor é bom próximo daqueles encontrados nos ajuste no MGM e no MLONG com estrutura $\mathrm{ARH}(1)$, respectivamente, $\mathrm{p}=0,4611 \mathrm{e} \mathrm{p}=0,4281$. É digno de nota que o p-valor calculado como descrito no Capítulo 2 tende a ser conservativo. Ou seja, tende a indicar um bom ajuste do modelo. Lembramos ainda que este p-valor é uma medida da qualidade do ajuste global e não do afastamento de suposições específicas.

A Figura 5.2 apresenta as distribuições dos escores preditos e observados e o respectivos intervalos de credibilidade de $95 \%$. O comportamento deles é bastante semelhante as figuras equivalentes dos Capítulos 2 e 3. Vemos que a grande maioria dos escores observados encontra-se dentro dos limites dos intervalos e próximos dos escores preditos. Isto indica um ajuste satisfatório do modelo.

As Figuras 5.3 e 5.4 apresentam os resíduos preditos para os traços latentes e os respectivos gráficos de quantis normal-normal. Percebemos que não há indícios de afastamento da suposição de normalidade.

A Tabela 5.3 apresenta as estimativas para os parâmetros dos itens, incluindo IC's e HPD's de 95\%, estes calculados utilizando a metodologia proposta por Chen and Shao (1999). Os resultados estão bem próximos daqueles obtidos nos Capítulos 2 e 3. Em outras palavras, concluímos que o teste não possui razoável poder de discriminação e apresenta-se relativamente fácil para a população envolvida no estudo, veja Tabela 5.4 . Entretanto os valores dos parâmetros de dificuldade apresentam-se bem heterogêneos, veja o CV na Tabela 5.4. o que é uma boa característica para o teste.

A Tabela 5.5 apresenta os resultados referentes aos parâmetros populacionais. Eles indicam que existe uma tendência significativamente crescente nas médias e variâncias iguais. Além disso notamos que as correlações apresentam um comportamento serial não estacionário, ou seja, elas descrescem com o aumento da distância entre as medidas e seus valores dependem dos tempos em si e não somente da distância entre os eles, veja também Figura 5.6. Sendo assim, um modelo que leve em conta tal estrutura de covariância poderia apresentar um melhor ajuste. Com efeito sugerimos uma futura exploração considerando tal estrutura de covariância como o modelo de 3 parâmetros ou de resposta nominal, veja Baker and Kim (2004). As matrizes de covariância AD e Toeplitz de ordem 2, em suas versões homocedásticas, poderiam ser alternativas bem interessantes.

Azevedo, Caio L. N.

IME/USP 

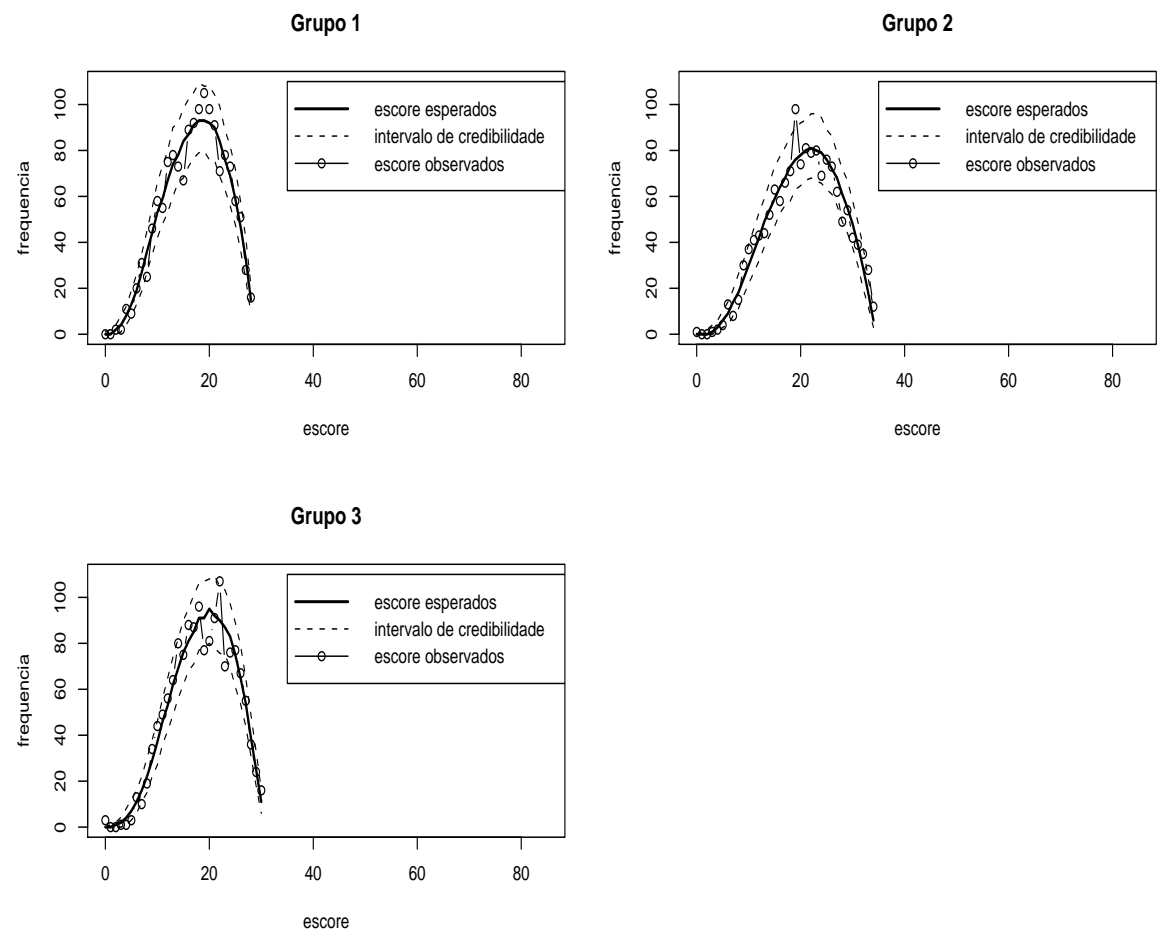

Figura 5.2: Escores preditos, observados e respectivos IC's simétricos de $95 \%$

Azevedo, Caio L. N. 

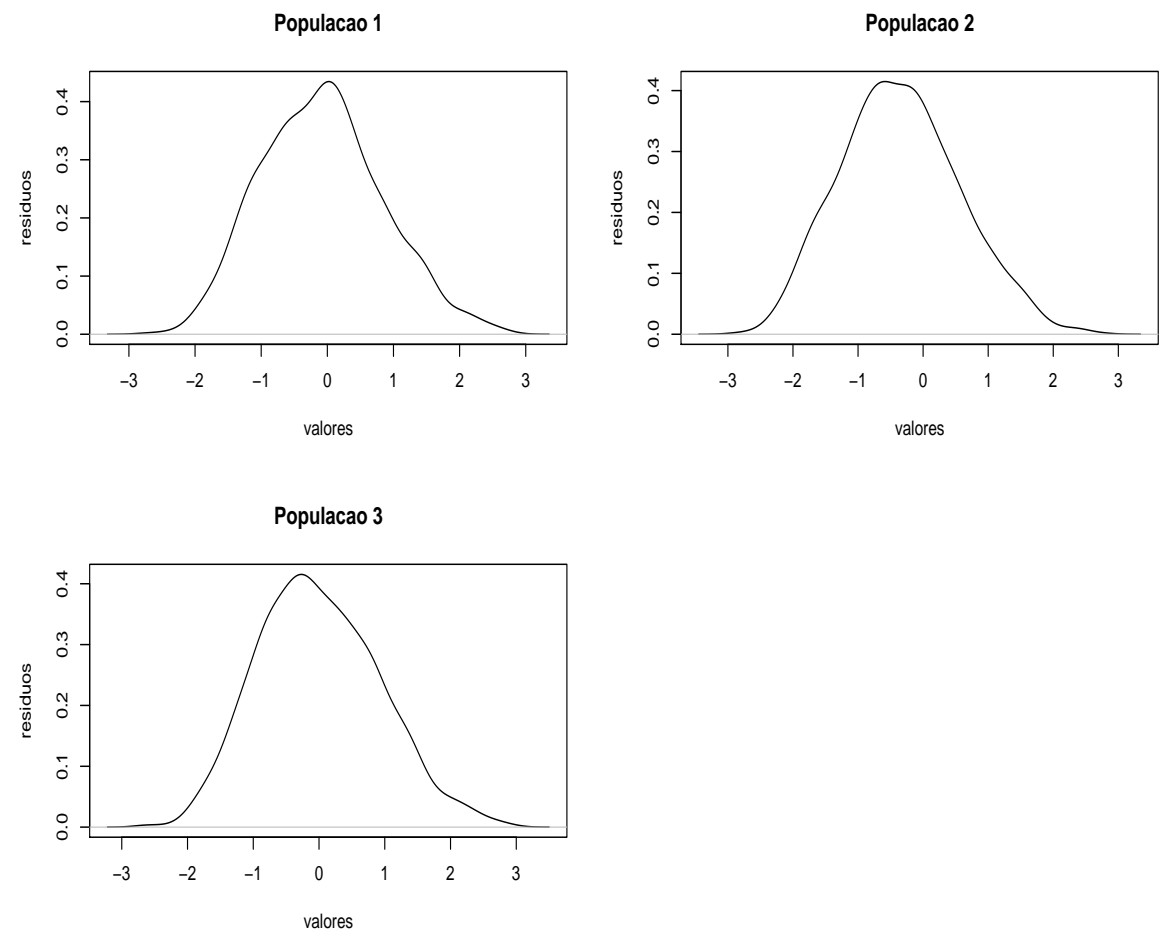

Figura 5.3: Densidade dos resíduos dos traços latentes

Azevedo, Caio L. N. 

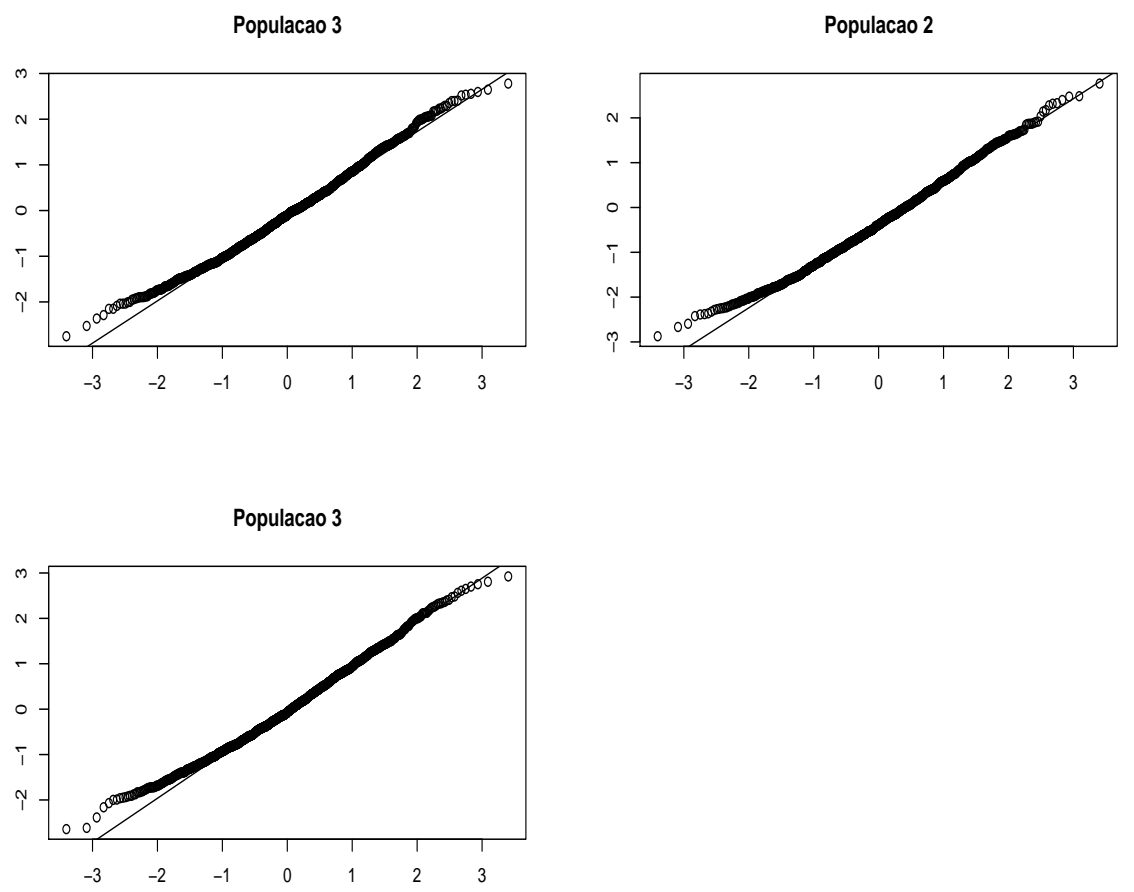

Figura 5.4: Gráfico de quantis normal-normal dos resíduos dos traços latentes

Azevedo, Caio L. N. 
Tabela 5.3: Resultados dos parâmetros dos itens : análise de dados reais

\begin{tabular}{|c|c|c|c|c|c|c|c|c|c|}
\hline \multirow[t]{3}{*}{ Teste } & \multirow[t]{3}{*}{ Item } & \multicolumn{8}{|c|}{ Estimativas } \\
\hline & & \multicolumn{4}{|c|}{$\mathbf{a}$} & \multicolumn{4}{|c|}{$\mathbf{b}^{*}$} \\
\hline & & Est. & EP & CI (95\%) & HPD(95\%) & Est. & EP & CI $(95 \%)$ & HPD(95\%) \\
\hline 1 & 101 & 0,418 & 0,038 & 0,$351 ; 0,493$ & 0,$351 ; 0,493$ & $-0,440$ & 0,086 & {$[-0,628 ;-0,288$} & {$[-0,616 ;-0,281$} \\
\hline 1 & 102 & 0,440 & 0,044 & 0,$346 ; 0,525$ & 0,$364 ; 0,534$ & $-0,892$ & 0,115 & {$[-1,125 ;-0,690$} & $-1,119 ;-0,688$ \\
\hline 1 & 103 & 0,652 & 0,045 & 0,$561 ; 0,736$ & 0,$554 ; 0,724$ & $-0,887$ & 0,072 & $-1,029 ;-0,751$ & $-1,011 ;-0,745$ \\
\hline $1-2$ & 104 & 0,572 & 0,031 & 0,$519 ; 0,632$ & 0,$517 ; 0,629$ & $-0,588$ & 0,051 & $-0,684 ;-0,492$ & $-0,684 ;-0,492$ \\
\hline 1 & 106 & 0,423 & 0,041 & 0,$346 ; 0,508$ & 0,$342 ; 0,497$ & $-1,414$ & 0,153 & $-1,713 ;-1,126$ & $-1,700 ;-1,114$ \\
\hline 1 & 108 & 0,423 & 0,045 & 0,$344 ; 0,512$ & 0,$341 ; 0,507$ & $-1,698$ & 0,183 & $-2,123 ;-1,399$ & $-2,061 ;-1,357$ \\
\hline $1-2-3$ & 109 & 0,778 & 0,033 & 0,$718 ; 0,839$ & 0,$717 ; 0,838$ & $-0,838$ & 0,046 & $-0,937 ;-0,757$ & $-0,930 ;-0,754$ \\
\hline $1-2$ & 110 & 0,701 & 0,035 & 0,$631 ; 0,768$ & 0,$637 ; 0,771$ & $-0,429$ & 0,042 & $-0,512 ;-0,348$ & $-0,515 ;-0,356$ \\
\hline 1 & 111 & 0,567 & 0,049 & 0,$468 ; 0,663$ & 0,$455 ; 0,649$ & $-1,513$ & 0,122 & $-1,785 ;-1,290$ & $-1,715 ;-1,239$ \\
\hline $1-2-3$ & 114 & 0,539 & 0,024 & 0,$487 ; 0,590$ & 0,$482 ; 0,578$ & $-0,400$ & 0,049 & $-0,493 ;-0,305$ & $-0,485 ;-0,302$ \\
\hline 1 & 116 & 0,742 & 0,057 & 0,$634 ; 0,857$ & 0,$630 ; 0,841$ & $-1,014$ & 0,074 & {$[-1,173 ;-0,881$} & $-1,182 ;-0,893$ \\
\hline 1 & 117 & 0,530 & 0,040 & 0,$462 ; 0,614$ & 0,$462 ; 0,614$ & 0,049 & 0,069 & {$[-0,073 ; 0,189$} & {$[-0,084 ; 0,177$} \\
\hline 1 & 118 & 0,552 & 0,043 & 0,$481 ; 0,642$ & 0,$476 ; 0,630$ & $-0,532$ & 0,070 & {$[-0,661 ;-0,400$} & $-0,661 ;-0,400$ \\
\hline $1-2-3$ & 119 & 0,436 & 0,025 & 0,$392 ; 0,484$ & 0,$392 ; 0,484$ & $-0,806$ & 0,074 & $-0,962 ;-0,689$ & $-0,948 ;-0,687$ \\
\hline 1 & 120 & 0,430 & 0,041 & 0,$345 ; 0,519$ & 0,$335 ; 0,498$ & $-0,660$ & 0,095 & {$[-0,862 ;-0,486$} & $-0,838 ;-0,472$ \\
\hline 1 & 121 & 0,506 & 0,046 & 0,$416 ; 0,598$ & 0,$428 ; 0,601$ & $-1,813$ & 0,154 & $-2,131 ;-1,552$ & $-2,091 ;-1,532$ \\
\hline $1-2$ & 122 & 0,695 & 0,033 & 0,$632 ; 0,761$ & 0,$624 ; 0,750$ & 0,254 & 0,036 & {$[0,188 ; 0,325$} & {$[0,187 ; 0,322$} \\
\hline $1-2-3$ & 124 & 0,707 & 0,027 & 0,$657 ; 0,758$ & 0,$657 ; 0,757$ & 0,005 & 0,033 & {$[-0,063 ; 0,069$} & {$[-0,059 ; 0,070$} \\
\hline 1 & 125 & 0,761 & 0,053 & 0,$661 ; 0,865$ & 0,$652 ; 0,849$ & $-1,028$ & 0,072 & {$[-1,187 ;-0,893$} & $-1,139 ;-0,877$ \\
\hline $1-2$ & 126 & 0,757 & 0,035 & 0,$689 ; 0,821$ & 0,$689 ; 0,821$ & $-0,369$ & 0,038 & {$[-0,445 ;-0,306$} & $-0,445 ;-0,306$ \\
\hline 1 & 127 & 0,604 & 0,044 & 0,$512 ; 0,688$ & 0,$529 ; 0,698$ & 0,035 & 0,058 & {$[-0,081 ; 0,150$} & {$[-0,066 ; 0,159$} \\
\hline $1-2-3$ & 128 & 0,716 & 0,029 & 0,$654 ; 0,774$ & 0,$664 ; 0,776$ & 0,053 & 0,034 & {$[-0,008 ; 0,126$} & {$[-0,008 ; 0,126$} \\
\hline 1 & 129 & 0,802 & 0,047 & 0,$716 ; 0,887$ & 0,$716 ; 0,887$ & $-0,166$ & 0,048 & {$[-0,258 ;-0,076$} & $-0,259 ;-0,079$ \\
\hline 1 & 130 & 0,387 & 0,037 & 0,$315 ; 0,458$ & 0,$325 ; 0,459$ & $-0,137$ & 0,089 & {$[-0,314 ; 0,042$} & {$[-0,292 ; 0,057$} \\
\hline 1 & 132 & 0,509 & 0,037 & 0,$435 ; 0,583$ & 0,$440 ; 0,584$ & $-0,007$ & 0,067 & {$[-0,138 ; 0,127$} & {$[-0,144 ; 0,118$} \\
\hline $1-2$ & 134 & 0,592 & 0,036 & 0,$522 ; 0,662$ & 0,$530 ; 0,667$ & $-1,782$ & 0,105 & {$[-2,012 ;-1,577$} & $-2,030 ;-1,609$ \\
\hline 1 & 135 & 0,918 & 0,057 & 0,$816 ; 1,024$ & 0,$816 ; 1,023$ & $-0,561$ & 0,045 & $-0,640 ;-0,465$ & $-0,649 ;-0,483$ \\
\hline 1 & 136 & 0,427 & 0,039 & 0,$350 ; 0,510$ & 0,$348 ; 0,504$ & $-0,306$ & 0,089 & {$[-0,496 ;-0,124$} & $-0,518 ;-0,159$ \\
\hline 2 & 203 & 0,553 & 0,042 & 0,$474 ; 0,647$ & 0,$485 ; 0,654$ & $-0,027$ & 0,071 & {$[-0,165 ; 0,112$} & {$[-0,168 ; 0,095$} \\
\hline $2-3$ & 204 & 0,413 & 0,029 & 0,$356 ; 0,466$ & 0,$356 ; 0,467$ & $-1,568$ & 0,139 & {$[-1,871 ;-1,336$} & $-1,868 ;-1,335$ \\
\hline 2 & 207 & 0,760 & 0,048 & 0,$670 ; 0,847$ & 0,$670 ; 0,847$ & 0,073 & 0,055 & {$[-0,038 ; 0,177$} & {$[-0,031 ; 0,180$} \\
\hline 2 & 208 & 0,682 & 0,050 & 0,$595 ; 0,779$ & 0,$595 ; 0,776$ & 1,365 & 0,090 & {$[1,189 ; 1,552$} & {$[1,208 ; 1,562$} \\
\hline 2 & 209 & 0,677 & 0,056 & 0,$575 ; 0,792$ & 0,$581 ; 0,795$ & $-1,013$ & 0,100 & {$[-1,228 ;-0,830$} & $-1,233 ;-0,848$ \\
\hline 2 & 210 & 0,619 & 0,041 & 0,$540 ; 0,696$ & 0,$538 ; 0,694$ & $-0,249$ & 0,063 & {$[-0,367 ;-0,123$} & $-0,374 ;-0,132$ \\
\hline 2 & 214 & 0,511 & 0,044 & 0,$428 ; 0,597$ & 0,$418 ; 0,585$ & 1,658 & 0,140 & {$[1,418 ; 1,963$} & {$[1,418 ; 1,963$} \\
\hline 2 & 215 & 0,452 & 0,040 & 0,$373 ; 0,533$ & 0,$383 ; 0,539$ & 1,259 & 0,120 & {$[1,055 ; 1,506$} & {$[1,044 ; 1,478$} \\
\hline 2 & 216 & 0,651 & 0,064 & 0,$534 ; 0,771$ & 0,$538 ; 0,771$ & $-1,876$ & 0,182 & $-2,253 ;-1,564$ & $-2,212 ;-1,550$ \\
\hline $2-3$ & 218 & 0,683 & 0,039 & 0,$604 ; 0,759$ & 0,$610 ; 0,762$ & $-1,036$ & 0,074 & {$[-1,198 ;-0,898$} & $-1,177 ;-0,891$ \\
\hline $2-3$ & 219 & 0,530 & 0,030 & 0,$472 ; 0,591$ & 0,$475 ; 0,592$ & $-0,127$ & 0,058 & {$[-0,249 ;-0,013$} & $-0,250 ;-0,015$ \\
\hline 2 & 220 & 0,451 & 0,041 & 0,$369 ; 0,526$ & 0,$374 ; 0,528$ & 1,442 & 0,123 & {$[1,225 ; 1,691$} & {$[1,237 ; 1,702$} \\
\hline 2 & 221 & 0,543 & 0,041 & 0,$462 ; 0,635$ & 0,$457 ; 0,616$ & $-0,090$ & 0,066 & {$[-0,222 ; 0,038$} & {$[-0,225 ; 0,034$} \\
\hline 2 & 222 & 0,761 & 0,061 & 0,$645 ; 0,875$ & 0,$637 ; 0,861$ & $-1,413$ & 0,113 & {$[-1,656 ;-1,209$} & $-1,622 ;-1,197$ \\
\hline $2-3$ & 223 & 0,766 & 0,034 & 0,$701 ; 0,826$ & 0,$699 ; 0,824$ & 0,481 & 0,043 & {$[0,387 ; 0,567$} & {$[0,403 ; 0,578$} \\
\hline 2 & 225 & 0,747 & 0,066 & 0,$626 ; 0,890$ & 0,$634 ; 0,892$ & $-1,592$ & 0,134 & {$[-1,912 ;-1,347$} & $-1,845 ;-1,291$ \\
\hline 2 & 226 & 0,495 & 0,042 & 0,$423 ; 0,577$ & 0,$421 ; 0,575$ & $-0,448$ & 0,098 & {$[-0,663 ;-0,271$} & $-0,649 ;-0,267$ \\
\hline 2 & 227 & 0,461 & 0,039 & 0,$381 ; 0,534$ & 0,$391 ; 0,541$ & 0,982 & 0,093 & {$[0,821 ; 1,171$} & {$[0,827 ; 1,173$} \\
\hline 2 & 228 & 0,664 & 0,046 & 0,$581 ; 0,762$ & 0,$579 ; 0,755$ & 0,560 & 0,058 & {$[0,454 ; 0,685$} & {$[0,438 ; 0,661$} \\
\hline 2 & 229 & 0,893 & 0,083 & 0,$736 ; 1,064$ & 0,$748 ; 1,067$ & $-1,472$ & 0,119 & {$[-1,741 ;-1,258$} & {$[-1,721 ;-1,253$} \\
\hline 2 & 233 & 0,582 & 0,047 & 0,$488 ; 0,668$ & 0,$486 ; 0,665$ & $-0,574$ & 0,077 & $-0,722 ;-0,438$ & $-0,716 ;-0,436$ \\
\hline 2 & 234 & 0,969 & 0,063 & 0,$864 ; 1,106$ & 0,$862 ; 1,094$ & $-0,396$ & 0,050 & $-0,487 ;-0,304$ & $-0,483 ;-0,302$ \\
\hline 2 & 236 & 0,766 & 0,056 & 0,$662 ; 0,874$ & 0,$664 ; 0,875$ & $-0,834$ & 0,082 & {$[-0,985 ;-0,679$} & $-0,985 ;-0,679$ \\
\hline 2 & 240 & 0,591 & 0,047 & 0,$493 ; 0,687$ & 0,$517 ; 0,706$ & $-0,914$ & 0,098 & {$[-1,123 ;-0,739$} & $-1,106 ;-0,732$ \\
\hline
\end{tabular}

Azevedo, Caio L. N. 
Continuação da Tabela 5.3

\begin{tabular}{|c|c|c|c|c|c|c|c|c|c|}
\hline \multirow[t]{3}{*}{ Teste } & \multirow[t]{3}{*}{ Item } & \multicolumn{8}{|c|}{ Estimativas } \\
\hline & & \multicolumn{4}{|c|}{$\mathbf{a}$} & \multicolumn{4}{|c|}{$b^{*}$} \\
\hline & & Est. & $\overline{E P}$ & CI (95\%) & HPD(95\%) & Est. & EP & CI (95\%) & HPD(95\%) \\
\hline 3 & 303 & 0,447 & 0,041 & 0,$363 ; 0,534$ & 0,$374 ; 0,539$ & $-1,121$ & 0,173 & {$[-1,477 ;-0,780]$} & {$[-1,480 ;-0,796$} \\
\hline 3 & 308 & 0,471 & 0,038 & 0,$394 ; 0,550$ & 0,$404 ; 0,553$ & 1,291 & 0,087 & {$[1,140 ; 1,477$} & {$[1,140 ; 1,477$} \\
\hline 3 & 309 & 0,523 & 0,048 & 0,$430 ; 0,621$ & 0,$410 ; 0,595$ & $-0,748$ & 0,137 & $-1,087 ;-0,516$ & {$[-0,991 ;-0,478$} \\
\hline 3 & 312 & 0,461 & 0,040 & 0,$381 ; 0,531$ & 0,$387 ; 0,534$ & 0,191 & 0,096 & {$[-0,015 ; 0,370$} & {$[-0,023 ; 0,352$} \\
\hline 3 & 315 & 0,478 & 0,041 & 0,$397 ; 0,565$ & 0,$384 ; 0,550$ & 0,930 & 0,075 & {$[0,776 ; 1,083$} & {$[0,797 ; 1,085$} \\
\hline 3 & 316 & 0,837 & 0,076 & 0,$687 ; 0,990$ & 0,$676 ; 0,970$ & $-0,852$ & 0,116 & {$[-1,114 ;-0,661$} & {$[-1,115 ;-0,662$} \\
\hline 3 & 317 & 0,547 & 0,042 & 0,$473 ; 0,640$ & 0,$480 ; 0,643$ & 0,648 & 0,073 & {$[0,503 ; 0,789$} & {$[0,512 ; 0,793$} \\
\hline 3 & 318 & 0,391 & 0,037 & 0,$326 ; 0,458$ & 0,$325 ; 0,457$ & 0,945 & 0,098 & 0,$750 ; 1,158$ & 0,$745 ; 1,132$ \\
\hline 3 & 319 & 0,536 & 0,040 & 0,$460 ; 0,602$ & 0,$459 ; 0,600$ & 0,856 & 0,066 & {$[0,724 ; 0,988$} & {$[0,711 ; 0,972$} \\
\hline 3 & 324 & 0,616 & 0,048 & 0,$526 ; 0,709$ & 0,$535 ; 0,716$ & $-0,345$ & 0,094 & {$[-0,544 ;-0,189$} & $-0,535 ;-0,182$ \\
\hline 3 & 326 & 0,458 & 0,040 & 0,$388 ; 0,548$ & 0,$379 ; 0,531$ & $-0,180$ & 0,111 & {$[-0,389 ; 0,011$} & {$[-0,389 ; 0,011$} \\
\hline 3 & 330 & 0,476 & 0,038 & 0,$402 ; 0,551$ & 0,$402 ; 0,551$ & 0,704 & 0,082 & {$[0,533 ; 0,865$} & {$[0,546 ; 0,870$} \\
\hline 3 & 331 & 0,488 & 0,044 & 0,$398 ; 0,573$ & 0,$394 ; 0,561$ & $-0,663$ & 0,133 & {$[-0,969 ;-0,424$} & {$[-0,919 ;-0,391$} \\
\hline 3 & 332 & 0,609 & 0,045 & 0,$524 ; 0,689$ & 0,$524 ; 0,689$ & 0,487 & 0,065 & {$[0,362 ; 0,623$} & {$[0,354 ; 0,608$} \\
\hline 3 & 334 & 0,466 & 0,039 & 0,$384 ; 0,538$ & 0,$399 ; 0,546$ & $-0,433$ & 0,125 & {$[-0,729 ;-0,208$} & {$[-0,676 ;-0,197$} \\
\hline 3 & 335 & 0,593 & 0,045 & 0,$509 ; 0,675$ & 0,$510 ; 0,676$ & 0,505 & 0,071 & {$[0,357 ; 0,648$} & {$[0,395 ; 0,681$} \\
\hline 3 & 336 & 0,414 & 0,038 & 0,$344 ; 0,493$ & 0,$347 ; 0,494$ & 0,499 & 0,095 & 0,$307 ; 0,678$ & 0,$307 ; 0,678$ \\
\hline 3 & 337 & 0,608 & 0,045 & 0,$515 ; 0,705$ & 0,$513 ; 0,692$ & 1,297 & 0,076 & 1,$154 ; 1,441$ & {$[1,154 ; 1,441$} \\
\hline 3 & 338 & 0,579 & 0,048 & 0,$483 ; 0,666$ & 0,$482 ; 0,659$ & $-0,032$ & 0,088 & {$[-0,243 ; 0,122$} & {$[-0,191 ; 0,155$} \\
\hline 3 & 339 & 0,597 & 0,044 & 0,$503 ; 0,670$ & 0,$511 ; 0,671$ & 0,733 & 0,072 & {$[0,588 ; 0,870$} & {$[0,591 ; 0,871$} \\
\hline 3 & 340 & 0,365 & 0,036 & 0,$285 ; 0,440$ & 0,$275 ; 0,423$ & 1,367 & 0,117 & 1,$157 ; 1,614$ & 1,$139 ; 1,586$ \\
\hline
\end{tabular}

Tabela 5.4: Estatística descritivas das estimativas dos parâmetros dos itens

\begin{tabular}{lrr}
\hline \hline Estatística & Disc. (a) & Dif. Ori. $\left(\mathbf{b}^{*}\right)$ \\
\hline Média & 0,586 & $-0,241$ \\
Mediana & 0,567 & $-0,345$ \\
Desvio padrão & 0,140 & 0,888 \\
CV & 23,878 & 368,248 \\
Assimetria & 0,623 & 0,209 \\
Mínimo & 0,365 & $-1,875$ \\
Máximo & 0,969 & 1,659 \\
\hline \hline
\end{tabular}

Azevedo, Caio L. N.

IME/USP 
Tabela 5.5: Resultados das estimativas dos parâmetros populacionais : análise de dados reais

\begin{tabular}{lcccc}
\hline \hline Parâmetro & Est. & EP & $\mathbf{I C ( 9 5 \% )}$ & $\mathbf{H P D}(\mathbf{9 5 \%})$ \\
\hline$\mu_{\theta_{2}}$ & 0,240 & 0,035 & {$[0,172 ; 0,306]$} & {$[0,170 ; 0,305]$} \\
$\mu_{\theta_{3}}$ & 0,791 & 0,044 & {$[0,714 ; 0,885]$} & {$[0,712 ; 0,879]$} \\
$\psi_{\theta_{1}}$ & 0,174 & 0,018 & {$[0,138 ; 0,210]$} & {$[0,134 ; 0,205]$} \\
$\psi_{\theta_{2}}$ & 0,139 & 0,020 & {$[0,102 ; 0,178]$} & {$[0,102 ; 0,179]$} \\
$\psi_{\theta_{3}}$ & 0,291 & 0,029 & {$[0,236 ; 0,359]$} & {$[0,234 ; 0,350]$} \\
$\sigma_{\theta}^{2}$ & 0,840 & 0,037 & {$[0,777 ; 0,919]$} & {$[0,777 ; 0,919]$} \\
$\operatorname{Var}\left(\theta_{1}\right)$ & 1,014 & 0,035 & {$[0,954 ; 1,091]$} & {$[0,964 ; 1,096]$} \\
$\operatorname{Var}\left(\theta_{2}\right)$ & 0,979 & 0,045 & {$[0,898 ; 1,068]$} & {$[0,902 ; 1,068]$} \\
$\operatorname{Var}\left(\theta_{3}\right)$ & 1,131 & 0,050 & {$[1,041 ; 1,228]$} & {$[1,039 ; 1,223]$} \\
$\operatorname{Corr}\left(\theta_{1}, \theta_{2}\right)$ & 0,828 & 0,018 & {$[0,794 ; 0,863]$} & {$[0,799 ; 0,865]$} \\
$\operatorname{Corr}\left(\theta_{1}, \theta_{3}\right)$ & 0,859 & 0,017 & {$[0,825 ; 0,893]$} & {$[0,825 ; 0,892]$} \\
$\operatorname{Corr}\left(\theta_{2}, \theta_{3}\right)$ & 0,743 & 0,019 & {$[0,699 ; 0,781]$} & {$[0,697 ; 0,776]$} \\
\hline \hline
\end{tabular}
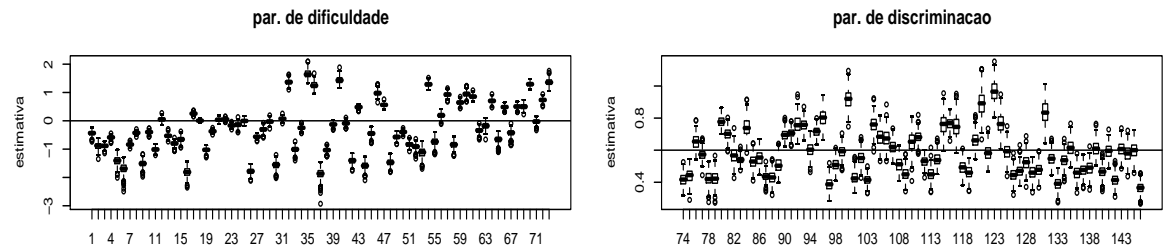

item
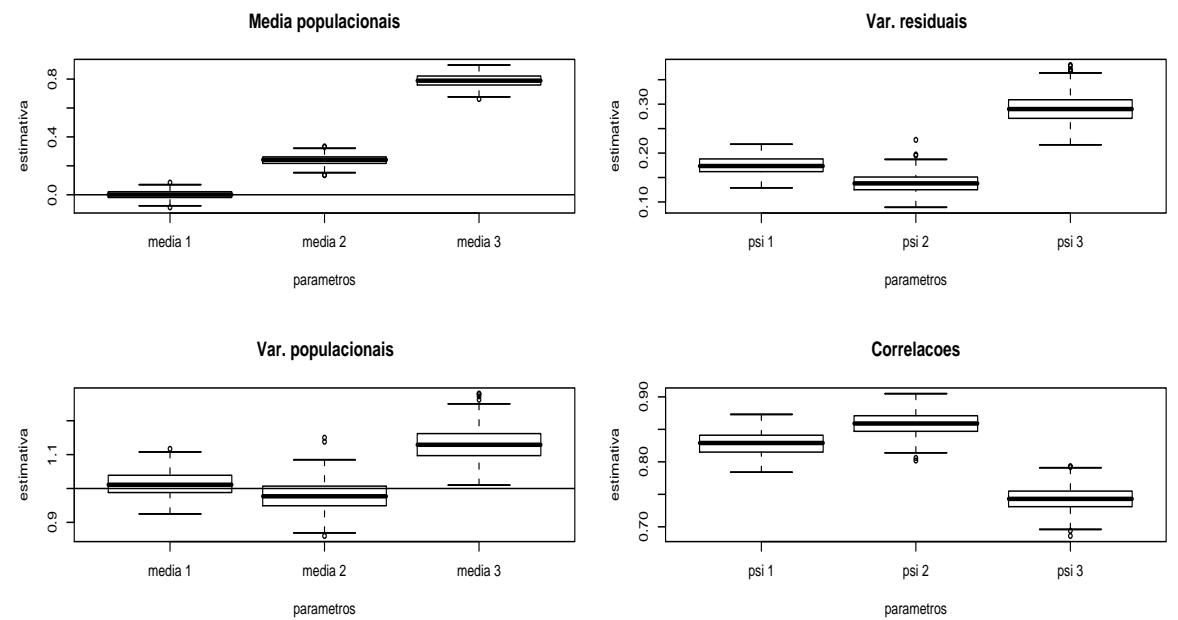

Figura 5.5: Box-plot das estimativas dos parâmetros dos itens e populacionais

Azevedo, Caio L. N.

IME/USP 

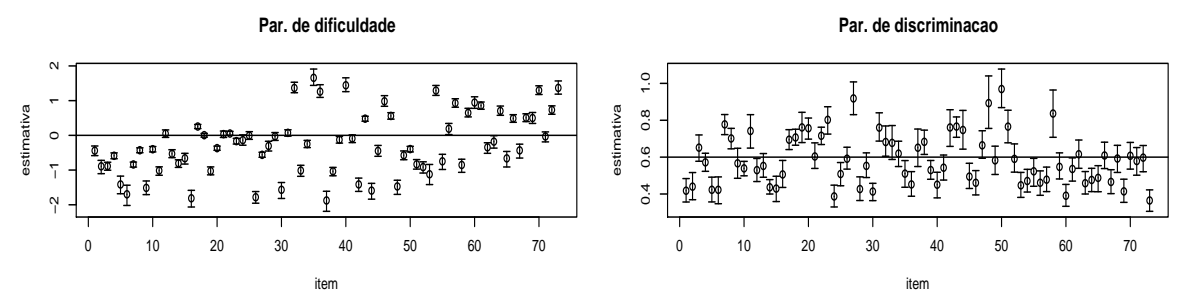

Medias populacionais

Var. residuais
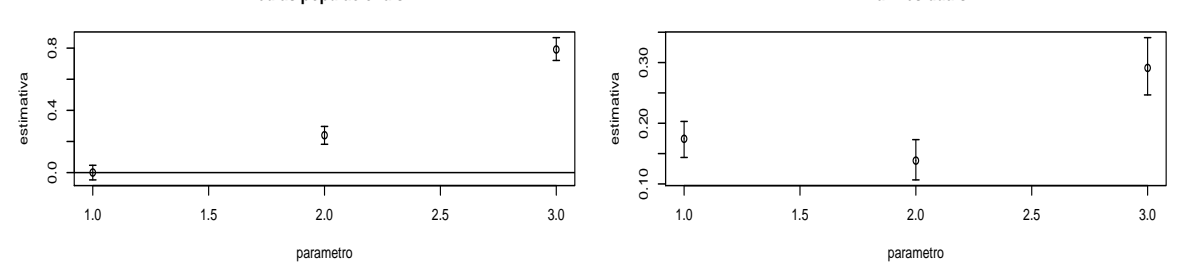

Var. populacionais

Corre. populacionais
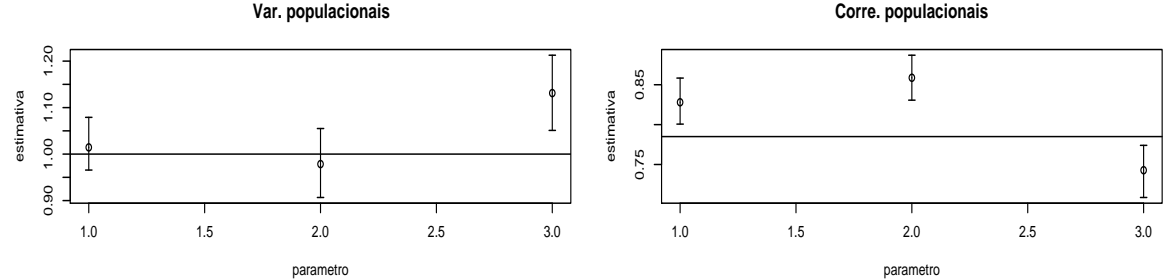

Figura 5.6: Estimativas e IC's de $95 \%$ dos parâmetros dos itens e populacionais 


\subsection{Comentários}

No presente capítulo apresentamos modelagens multiníveis e de séries temporais para representar a dependência longitudinal em estudos com medidas repetidas na presença de múltiplos grupos. Mostramos como as diferentes matrizes de dependência podem ser representadas por modelos univariados. Isto torna a interpretação dos modelos, utilização de métodos de estimação e de diagnóstico bem mais simples. Além disso, informações adicionais, como covariáveis, curvas de crescimento e estruturas de covariância para estudos com instantes não igualmente espaçados, podem ser cabalmente consideradas. Gostaríamos de salientar que, embora o amostrador de Gibbs seja computacionalmente simples, as vezes, utilizar algoritmos auxiliares como o Metropolis-Hastings ou Amostragem por corte, veja Gamerman and Lopes (2006), pode gerar cadeias com autocorrelações menores.

Tabela 5.6: Comparação entre as abordagens multinível e multivariada

\begin{tabular}{|c|c|c|}
\hline Metodologia & Vantagem & Desvantagem \\
\hline Multinível & $\begin{array}{l}\text { - Condicionais completas mais sim- } \\
\text { ples. } \\
\text { - Facilidade na inclusão de in- } \\
\text { formações adicionais. } \\
\text { - Interpretação direta. } \\
\text { - Ajuste e validação do modelo } \\
\text { tornam-se mais simples. } \\
\text { - Herda estruturas do MGM. }\end{array}$ & $\begin{array}{l}\text { - Útil na presença de pelo menos } \\
\text { três condições de avaliação. } \\
\text { - Um modelo para cada estrutura. }\end{array}$ \\
\hline Multivariada & $\begin{array}{l}\text { - Flexibilidade na utilização de es- } \\
\text { truturas de covariância. } \\
\text { - Os algoritmos de estimação se di- } \\
\text { ferenciam apenas na etapa referente } \\
\text { aos parâmetros de dependência. }\end{array}$ & $\begin{array}{l}\text { - Ajuste e validação dos modelos } \\
\text { tornam-se mais complicadas } \\
\text {-Interpretação do modelo é menos } \\
\text { simples. } \\
\text { - Dificuldade na inclusão de in- } \\
\text { formações adicionais. } \\
\text { - Dificuldade na inclusão de estru- } \\
\text { turas de assimetria. }\end{array}$ \\
\hline
\end{tabular}

Azevedo, Caio L. N.

IME/USP 


\section{Capítulo 6}

\section{Comentários e sugestões para futuras pesquisas}

Neste capítulo apresentaremos alguns comentários e sugestões para futuras pesquisas relacionados aos desenvolvimentos do presente trabalho.

\subsection{Comentários}

Os desenvolvimentos da Tese permitem analisar um grande número de situações reais sob uma perspectiva bayesiana plena. Ou seja, calculando todas as distribuições a posteriori de interesse, marginais ou conjuntas. A metodologia desenvolvida fornece mecanismos de ajuste, diagnóstico e seleção de modelos. Contudo, alguns aspectos que não foram abordados no presente trabalho merecem atenção, inclusive, algumas extensões de interesse.

\subsection{Sugestões para futuras pesquisas}

\subsubsection{Inclusão do parâmetro de acerto casual}

A FRI considerada no trabalho, o modelo probito de 2 parâmetros, não representa de modo satisfatório a probabilidade de acerto de indivíduos com habilidade muito baixa, em itens em que o acerto ao acaso é possível. Uma abordagem mais apropriada é a utilização do modelo probito de 3 parâmetros. Mecanismos de dados aumentados, para tal modelo, encontram-se desenvolvidos em Sahu (2002) e Béguin and Glas (2001). Uma extensão importante da metodologia adotada seria a inclusão do parâmetro de acerto ao acaso na FRI, ou seja, da utilização do modelo de 3 parâmetros via abordagem de dados aumentados.

\subsubsection{Outras FRI's}

Em testes com itens de múltipla escolha, construíduos a partir da escala de Likert, veja Garland (1991), ou dissertativos, pode ser mais apropriado utilizar modelos de resposta policotômicas. Ou seja, FRI's que contemplam a probabilidade de escolha de cada categoria, sejam elas nominais ou ordinais. A utilização do modelo de resposta nominal ou do modelo de resposta gradual, veja Baker and Kim (2004), são alternativas, 
aos modelos de 2 e 3 parâmetros, bastante importantes a serem exploradas, uma vez que utilizam a informação de todas as alternativas e não somente se o item foi respondido corretamente ou não.

Um outro tipo de FRI bastante útil é aquele baseado em funções de distribuição acumulada assimétrica. Bazán (2005) propôs uma família de FRI baseada na distribuição normal assimétrica, veja Genton (2004), para o modelo de 2 parâmetros com uma única população. A utilização desta e de outras famílias de FRI's assimétricas seria uma extensão bastante útil.

\subsubsection{Distribuições assimétricas}

Em estudos de grupos múltiplos, é esperado observar comportamentos diferentes entre as distribuições dos traços latentes. Muitas vezes, observa-se assimetria, ou seja, concentração de indivíduos em uma das caudas da distribuição. Isso ocorre, muitas vezes, quando os indivíduos são selecionados de acordo com resultados de pré-testes, veja Genton (2004), ou quando são submetidos à diferentes programas de ensino, por exemplo. Em estudos longitudinais, onde pode ocorrer eliminação ou inserção de indivíduos, a distribuição dos traços latentes pode se alterar ao longo do tempo. Dessa forma, considerar distribuições assimétricas, com a normal ou a $t$ assimétricas, veja Genton (2004), flexibiliza a utilização da metodologia desenvolvida no presente trabalho. Extensões nesse sentido são de grande valia na análise de testes, haja vista que possibilitam a obtenção de resultados mais fidedignos, vide Azevedo and Andrade (2008a) e Azevedo and Andrade (2008b).

\subsubsection{Distribuições não-paramétricas}

Uma abordagem mais geral do que considerar assimetria para os traços latentes consiste em representálos através de uma estrutura não paramétrica. Dessa forma, multimodalidade, caudas pesadas, assimetria e outras características são acomodadas de uma forma mais geral. Através da estrutura de estimação via MCMC poder-se-ía considerar distribuições não-paramétricas tal como no trabalho de Kleinman and Ibrahim (1998).

\subsubsection{Outros métodos de estimação}

Apesar dos algoritmos MCMC constituirem uma ferramenta poderosa na utilização da inferência bayesiana e na validação de modelos, outros métodos de estimação podem ser utilizados. Uma alternativa bem interessante seria a utilização do algoritmo EM condicional de dados aumentados proposto por Azevedo and Andrade (2007). Este procedimento é uma variante do algoritmo EM que permite ajustar modelos complexos de uma forma razoavelmente simples com baixo custo de processamento computacional. Esta metodologia pode ser extendida de modo a contemplar assimetria dos traços latentes ou estruturas de dependência longitudinal. Uma outra variante do algoritmo EM, também interessante, é o algoritmo EM estocástico, veja Celeux and Diebolt (1985). Este método também consome menos tempo do que o algoritmo de Gibbs e possui igual flexibilidade.

Azevedo, Caio L. N.

IME/USP 


\subsubsection{Medidas de diagnóstico}

Apesar de algumas medidas de diagnóstico bem úteis terem sido adaptadas, como o p-valor bayesiano e os escore preditos, outras medidas podem ser exploradas. Dentre elas destacamos os escores preditos por item, os resíduos bayesianos latentes e os resíduos bayesianos latentes "Rao-Blackwellalisados". Para a verificação do afastamento de suposições específicas, como a unidimensionalidade, poderia ser utilizado o logaritmo da razão de chances, por exemplo. Para detalhes veja Sinharay et al. (2006) e Sinharay $(2006)$.

\subsubsection{Construção de testes de hipótese}

Testes de hiopótese possuem grande importância na verificação das suposições do modelo e na consequente escolha do mais apropriado. Uma aspecto interessante é a utilização de testes de hipótese dentro da modelagem e da estrutura de estimação propostas. Nesse contexto, a utilização do teste de significância genuinamente bayesiano (FBST ${ }^{*}$ ), veja Pereira and Stern (2003), seria de grande utilidade. Póder-se-ía propor testes para verificar simetria dos traços latentes, presença de DIF e DRIFT, o ajuste da FRI, dentre outras hipóteses.

\subsubsection{Utilização de estruturas dos modelos dinâmicos e modelos com erros nas variáveis}

Com dito anteriormente, os modelos multiníveis e de séries temporais, desenvolvidos para os traços latentes podem ser vistos como modelos dinâmicos ou modelos com erros nas variáveis, veja West and Harrison (1999) e Carrol et al. (2005). A utilização dessas duas classes para representar os traços latentes pode ser bastante útil, uma vez que existe toda uma teoria desenvolvida para tais modelos.

\subsubsection{Comparação da abordagem multivariada com a multinível para o modelo longitudinal}

Apesar de algumas comparações terem sido feitas entre as abordagens multivariada (Capítulos 3 e 4 ) e multinível (Capítulo 5), para o modelo longitudinal, muito ainda pode ser feito. Estudos de simulação para avaliar a qualidade das estimativas e o desempenho de métodos de diagnóstico seriam de grande importância. Tais comparações ajudariam a avaliar em que situações e em quais aspectos uma modelagem é mais conveniente do que a outra. Estudos considerando várias matrizes de covariância e número de condições de avaliação, poderiam ser conduzidos com esse intuito.

\subsubsection{Comparação do modelo longitudinal com o modelo de grupos múltiplos}

Não foi considerada nenhuma comparação, em termos de simulação, entre o MGM e o MLONG. Estudos quantificando o ganho em se considerar estruturas de dependência em detrimento à suposição de independência seriam bastante úteis. Os indícios apresentados no trabalho indicam que é vantajoso utilizar o modelo longitudinal. Em concordância com o trabalho de Mislevy (1991), os resultados sugerem que a correlação estimada

* Sigla que representa a expressão em inglês Full Bayesian Significance Test

Azevedo, Caio L. N.

IME/USP 
via MGM, utilizando os traços latentes preditos, é diferente daquela estimada via modelo longitudinal. Uma investigação mais profunda permitiria obter conclusões mais amplas.

\subsubsection{Modelos multiníveis com dependência intra grupos}

Em muitas situações é esperado observar uma maior similaridade entre indivíduos que pertencem à um mesmo grupo do que indivíduos oriundos de grupos diferentes. Uma extensão interessante seria utilizar a abordagem multinível para modelar não só a dependência intra indivíduos mas também a dependência entre indivíduos (do mesmo grupo). Dessa forma, estudos longitudinais que envolvessem muitas escolas (aqui representando os grupos) seriam melhor analisados.

\subsubsection{Modelos de curvas de crescimento}

Em nosso trabalho não consideramos regressores que dependessem de covariáveis. Atribuir estruturas lineares e não-lineares para representar as médias permitem incluir informações importantes e considerar modelos mais parcimoniosos. Curvas de crescimento, no caso longitudinal, possibilitam representar as médias de uma forma bem flexível, haja vista a quantidade de modelos disponíveis na literatura, veja Geisser (1980) e Bock and du Toit (2004), por exemplo. Extensões nesse sentido, através da modelagem multinível, permitem gerar classes mais amplas de modelos.

\subsubsection{Outras matrizes de covariância}

Consideramos no presente trabalho matrizes de covariância importantes e bastante utilizadas na análise de dados. Entretanto, outras estruturas como ARIMA, ARCH, GARCH, Toeplitz de ordem $s$, ARH de ordem $r$, ARMAH de ordem $(r, s)$, Ante dependência de ordem $r$ e não-estruturada, podem ser consideradas. $\mathrm{O}$ procedimento de estimação desenvolvido no Capítulo 3 pode ser utilizado para considerar qualquer uma das matrizes supracitadas. Todavia, dada a importância da abordagem proposta no Capítulo 5, modelos multiníveis que representam tais estruturas são úteis e constituem interssante ponto de pesquisa. Além disso, seleção de modelos para tais estruturas e estudos de simulação para avaliar o desempenho dos métodos de estimação são de relevante importância. Estruturas que consideram instantes desigualmente espaçados também são de grande interesse e devem ser estudadas.

\subsubsection{Recursos computacionais}

A utilização da TRI na análise de dados passa, necessariamente, pela disponibilidade de ferramentes computacionais apropriadas. A construção de programas com versão amigável ao usuário, diversas opções de análise e alta velocidade de processamento é imprescindível para a difusão de novas metodologias desenvolvidas. Um tópico de estudo é a utilização da linguagem $C++\AA$ com o programa $R \AA$ a fim de desenvolver rotinas, gratuitas e de código aberto, que contemplem tais características.

Azevedo, Caio L. N.

IME/USP 


\section{Apêndice A}

\section{Detalhes sobre o método Delta utilizado no Capítulo 4}

Primeiramente, denote por $\widehat{\boldsymbol{\Psi}}_{\zeta_{i}}$ a matriz de covariância baseada na distribuição a posteriori dos parâmetros do item $i$, calculada via MCMC, e assuma que

$$
\widehat{\boldsymbol{\Psi}}_{\zeta_{i}}=\left[\begin{array}{cc}
\widehat{\psi}_{a_{i}} & 0 \\
0 & \widehat{\psi}_{b_{i}}
\end{array}\right] .
$$

Denote por $\widehat{\mathbf{\Psi}}_{\zeta_{i}^{*}}$ a matriz de covariância entre $\left(a_{i}^{*}=a_{i}, b_{i}^{*}=b_{i} / a_{i}\right)$, calculada a partir da sua distribuição a posteriori via MCMC. Utilizando o método delta, temos que

$$
\widehat{\Psi}_{\zeta_{i}^{*}} \approx \boldsymbol{H}_{\zeta_{i}^{*}} \widehat{\Psi}_{\zeta_{i}} \boldsymbol{H}_{\zeta_{i}^{*}}^{t}
$$

em que

$$
\boldsymbol{H}_{\zeta_{i}^{*}}=\left[\begin{array}{cc}
1 & 0 \\
-\frac{b_{i}}{a_{i}^{2}} & \frac{1}{a_{i}}
\end{array}\right]
$$

Dessa forma, o resultado segue. 



\section{Apêndice B}

\section{Desenvolvimentos relacionados aos modelos de séries temporais estacionárias}

\section{B.1 Estrutura AR1}

Para demonstrar (5.13), note que de (5.11) e (5.12) temos que

$$
\operatorname{Var}\left(\theta_{j k t}^{*}\right)=\rho_{\theta_{k}}^{2} \operatorname{Var}\left(\theta_{j k(t-1)}^{*}\right)+\operatorname{Var}\left(\xi_{j k t}\right)
$$

uma vez que o processo é estacionário temos que $\operatorname{Var}\left(\theta_{j k t}^{*}\right)=\operatorname{Var}\left(\theta_{j k(t-1)}^{*}\right), \forall t$, então

$$
\begin{aligned}
\operatorname{Var}\left(\theta_{j k t}^{*}\right) & =\rho_{\theta}^{2} \operatorname{Var}\left(\theta_{j k t}^{*}\right)+\psi_{\theta_{k}} \\
\Rightarrow \operatorname{Var}\left(\theta_{j k t}^{*}\right) & =\frac{\psi_{\theta_{k}}}{1-\rho_{\theta_{k}}^{2}} .
\end{aligned}
$$

Para provar 5.14, considerando 5.11) e (5.12) tem-se que

$$
\operatorname{Cov}\left(\theta_{j k t}^{*}, \theta_{j k\left(t-t^{\prime}\right)}^{*}\right):=\mathbb{E}\left(\theta_{j k t}^{*} \theta_{j k\left(t-t^{\prime}\right)}^{*}\right)-\underbrace{\mathbb{E}\left(\theta_{j k t}^{*}\right)}_{0}, \underbrace{\mathbb{E}\left(\theta_{j k\left(t-t^{\prime}\right)}^{*}\right)}_{0}
$$

Multiplicando ambos os lados de 5.11 por $\theta_{j k\left(t-t^{\prime}\right)}^{*}$ e tomando a esperança condicional com relação a distribuição dos traços latentes, obtemos 


$$
\begin{aligned}
\mathbb{E}\left(\theta_{j k t}^{*} \theta_{j k\left(t-t^{\prime}\right)}^{*}\right) & =\rho_{\theta_{k}} \mathbb{E}\left(\theta_{j k(t-1)}^{*} \theta_{j k\left(t-t^{\prime}\right)}^{*}\right)+\mathbb{E}\left(\xi_{j k t} \theta_{j k\left(t-t^{\prime}\right)}^{*}\right) \\
& =\rho_{\theta_{k}} \mathbb{E}\left(\theta_{j k(t-1)}^{*} \theta_{j k\left(t-t^{\prime}\right)}^{*}\right)+\underbrace{\mathbb{E}\left(\xi_{j k t}\right)}_{0} \underbrace{\mathbb{E}\left(\theta_{j k\left(t-t^{\prime}\right)}^{*}\right)}_{0} \\
& =\rho_{\theta_{k}} \mathbb{E}\left(\theta_{j k(t-1)}^{*} \theta_{j k\left(t-t^{\prime}\right)}^{*}\right)
\end{aligned}
$$

Então, de (B.1) e B.2, vem que

$$
\begin{aligned}
\operatorname{Cov}\left(\theta_{j k t}^{*}, \theta_{j k\left(t-t^{\prime}\right)}^{*}\right) & =\rho_{\theta_{k}} \operatorname{Cov}\left(\theta_{j k(t-1)}^{*}, \theta_{j k\left(t-t^{\prime}\right)}^{*}\right) \\
& =\rho_{\theta_{k}}^{2} \operatorname{Cov}\left(\theta_{j k(t-2)}^{*}, \theta_{j k\left(t-t^{\prime}\right)}^{*}\right) \\
& =\vdots \\
& =\rho_{\theta_{k}}^{t^{\prime}} \operatorname{Cov}\left(\theta_{j k\left(t-t^{\prime}\right)}^{*}, \theta_{j k\left(t-t^{\prime}\right)}^{*}\right)=\rho_{\theta_{k}}^{t^{\prime}} \psi_{\theta_{k}},
\end{aligned}
$$

em que (B.3) segue da estacionariedade do processo. Finalmente, de (5.13) e (B.3), a equação (5.14) segue.

\section{B.2 Estrutura Toeplitz}

Para provar 5.17), note que, de 5.15) e 5.16), vem que

$$
\operatorname{Var}\left(\theta_{j k t}^{*}\right)=\psi_{\theta_{k}}+\gamma_{\theta_{k}}^{2} \psi_{\theta_{k}}=\psi_{\theta_{k}}\left(1+\gamma_{\theta_{k}}^{2}\right)=\psi_{\theta_{k}}^{*}
$$

Considerando 5.18 podemos notar que de 5.15 e 5.16 , tem-se

$$
\begin{aligned}
\operatorname{Cov}\left(\theta_{j k t}, \theta_{j k\left(t-t^{\prime}\right)}\right)= & \operatorname{Cov}\left(\xi_{j k t}+\gamma_{\theta_{k}} \xi_{j k(t-1)}, \xi_{j k\left(t-t^{\prime}\right)}+\gamma_{\theta_{k}} \xi_{j k\left(t-t^{\prime}-1\right)}\right) \\
= & \operatorname{Cov}\left(\xi_{j k t}, \xi_{j k\left(t-t^{\prime}\right)}\right)+\gamma_{\theta_{k}} \operatorname{Cov}\left(\xi_{j k t}, \xi_{j k\left(t-t^{\prime}-1\right)}\right)+\gamma_{\theta_{k}} \operatorname{Cov}\left(\xi_{j k(t-1)}, \xi_{j k\left(t-t^{\prime}\right)}\right) \\
& +\gamma_{\theta_{k}}^{2} \operatorname{Cov}\left(\xi_{j k t}, \xi_{j k\left(t-t^{\prime}-1\right)}\right)
\end{aligned}
$$

Azevedo, Caio L. N.

IME/USP 
Uma vez que $\xi_{j k t}$ são mutuamente independentes então $\operatorname{Cov}\left(\xi_{j k t}, \xi_{j k\left(t-t^{\prime}\right)}\right)=0, \forall t^{\prime} \neq t$. Dessa forma o resultado segue.

\section{B.3 Estrutura ARMA(1,1)}

Primeiramente definamos,

$$
\begin{aligned}
\lambda_{k\left(t^{\prime}\right)} & =\operatorname{Cov}\left(\theta_{j k t}^{*}, \theta_{j k\left(t-t^{\prime}\right)}^{*}\right) \\
\lambda_{k \xi\left(t^{\prime}\right)} & =\operatorname{Cov}\left(\theta_{j k t}^{*}, \xi_{j k\left(t-t^{\prime}\right)}^{*}\right) .
\end{aligned}
$$

Note que, devido a estacionariedade da série tem-se, $\forall t$, que

$$
\lambda_{k\left(t^{\prime}\right)}=\lambda_{k\left(-t^{\prime}\right)}
$$

Multiplicando ambos os lados de 5.20 por $\xi_{j k t}$ e tomando-se o valor esperado, vem que

$$
\begin{aligned}
\mathbb{E}\left(\theta_{j k t}^{*} \xi_{j k t}\right) & =\rho_{\theta_{k}} \mathbb{E}\left(\theta_{j k(t-1)}^{*} \xi_{j k t}\right)+\gamma_{\theta_{k}} \mathbb{E}\left(\xi_{j k t} \xi_{j k(t-1)}\right)+\underbrace{\mathbb{E}\left(\xi_{j k t}^{2}\right)}_{\psi_{\theta_{k}}} \\
& =\rho_{\theta_{k}} \underbrace{\mathbb{E}\left(\theta_{j k(t-1)}^{*}\right)}_{0} \underbrace{\mathbb{E}\left(\xi_{j k t}\right)}_{0}+\gamma_{\theta_{k}} \underbrace{\mathbb{E}\left(\xi_{j k t}\right)}_{0} \underbrace{\mathbb{E}\left(\xi_{j k(t-1)}\right)}_{0}+\psi_{\theta_{k}} \\
& =\psi_{\theta_{k}}, \forall t .
\end{aligned}
$$

Multiplicando ambos os lados de $\sqrt{5.20}$ por $\xi_{j k(t-1)}$ e tomando-se o valor esperado, vem que

$$
\begin{aligned}
\mathbb{E}\left(\theta_{j k t}^{*} \xi_{j k(t-1)}\right) & =\rho_{\theta_{k}} \underbrace{\mathbb{E}\left(\theta_{j k t}^{*} \xi_{j k(t-1)}\right)}_{\psi_{\theta_{k}}}+\gamma_{\theta_{k}} \underbrace{\mathbb{E}\left(\xi_{j k(t-1)}^{2}\right)}_{\psi_{\theta_{k}}}+\underbrace{\mathbb{E}\left(\xi_{j k(t-1)}\right)}_{0} \underbrace{\mathbb{E}\left(\xi_{j k t}\right)}_{0} \\
\lambda_{k \xi(-1)} & =\psi_{\theta_{k}}\left(\rho_{\theta_{k}}+\gamma_{\theta_{k}}\right) .
\end{aligned}
$$

Multiplicando ambos os lados de $\sqrt[5.20]{ }$ por $\theta_{j k t}^{*}$ e tomando-se o valor esperado, vem que

Azevedo, Caio L. N.

IME/USP 


$$
\begin{aligned}
\mathbb{E}\left(\theta_{j k t}^{*} \theta_{j k t}^{*}\right) & =\rho_{\theta_{k}} \underbrace{\mathbb{E}\left(\theta_{j k t}^{*} \theta_{j k(t-1)}^{*}\right)}_{\lambda_{k(-1)}}+\gamma_{\theta_{k}} \underbrace{\mathbb{E}\left(\theta_{j k t}^{*} \xi_{j k(t-1)}\right)}_{\lambda_{k \xi(-1)}}+\underbrace{\mathbb{E}\left(\theta_{j k t}^{*} \xi_{j k t}\right)}_{\psi_{\theta_{k}}} \\
\Rightarrow \lambda_{k(0)} & =\rho_{\theta_{k}} \lambda_{k(-1)}+\gamma_{\theta_{k}} \lambda_{k \xi(-1)}+\psi_{\theta_{k}} .
\end{aligned}
$$

Por outro lado, multiplicando ambos os lados de 5.20 por $\theta_{j k(t-1)}^{*}$ e tomando-se o valor esperado, vem que

$$
\begin{aligned}
\mathbb{E}\left(\theta_{j k t}^{*} \theta_{j k(t-1)}^{*}\right) & =\rho_{\theta_{k}} \underbrace{\mathbb{E}\left(\left(\theta_{j k(t-1)}^{*}\right)^{2}\right)}_{\lambda_{k(0)}}+\gamma_{\theta_{k}} \underbrace{\mathbb{E}\left(\theta_{j k(t-1)}^{*} \xi_{j k(t-1)}\right)}_{\psi_{\theta_{k}}}+\underbrace{\mathbb{E}\left(\theta_{j k(t-1)}^{*}\right)}_{0} \underbrace{\xi_{j k t}}_{0} \\
\Rightarrow \lambda_{k(-1)} & =\rho_{\theta_{k}} \lambda_{k(0)}+\gamma_{\theta_{k}} \psi_{\theta_{k}} .
\end{aligned}
$$

De (B.6), (B.7), (B.8) e (B.4), vem que,

$$
\left\{\begin{array}{l}
\lambda_{k(0)}=\rho_{\theta_{k}} \lambda_{k(1)}+\psi_{\theta_{k}}\left(\rho_{\theta_{k}}+\gamma_{\theta_{k}}\right)+\psi_{\theta_{k}}(1) \\
\lambda_{k(1)}=\rho_{\theta_{k}} \lambda_{k(0)}+\gamma_{\theta_{k}} \psi_{\theta_{k}}(2)
\end{array}\right.
$$

De $\overline{B .9}(2))$ em $(B .9(1))$, vem que

$$
\begin{aligned}
\lambda_{k(0)} & =\rho_{\theta_{k}}\left(\rho_{\theta_{k}} \lambda_{k(0)}+\gamma_{\theta_{k}} \psi_{\theta_{k}}\right)+\gamma_{\theta_{k}} \psi_{\theta_{k}}\left(\rho_{\theta_{k}}+\gamma_{\theta_{k}}\right)+\psi_{\theta_{k}} \\
\Rightarrow \lambda_{k(0)} & =\underbrace{\frac{\psi_{\theta_{k}}}{1-\rho_{\theta_{k}}^{2}} \underbrace{\left(1+2 \gamma_{\theta_{k}} \rho_{\theta_{k}}+\gamma_{\theta_{k}}^{2}\right)}_{\gamma_{\theta_{k}}^{*}}}_{\psi_{\theta_{k}}^{*}} \\
& =\psi_{\theta_{k}}^{*} \gamma_{\theta_{k}}^{*}
\end{aligned}
$$

Com relação a covariância, de (B.9), note que 


$$
\begin{aligned}
\lambda_{k(1)} & =\frac{\rho_{\theta_{k}} \psi_{\theta_{k}}}{1-\rho_{\theta_{k}}^{2}}\left(1+2 \rho_{\theta_{k}} \gamma_{\theta_{k}}+\gamma_{\theta_{k}}^{2}\right)+\gamma_{\theta_{k}} \psi_{\theta_{k}} \\
& =\frac{\psi_{\theta_{k}}}{1-\rho_{\theta_{k}}^{2}} \underbrace{\left(\rho_{\theta_{k}}+\gamma_{\theta_{k}}\right)\left(1+\rho_{\theta_{k}} \gamma_{\theta_{k}}\right)}_{\rho_{\theta_{k}}^{*}} \\
& =\psi_{\theta_{k}}^{*} \rho_{\theta_{k}}^{*}
\end{aligned}
$$

Para a calcular a correlação, de (B.10) e (B.11), temos que

$$
\operatorname{Corr}\left(\theta_{j k t}, \theta_{j k(t-1)}\right)=\frac{\psi_{\theta_{k}}^{*} \rho_{\theta_{k}}^{*}}{\psi_{\theta_{k}}^{*}}=\frac{\rho_{\theta_{k}}^{*}}{\gamma_{\theta_{k}}^{*}}=\frac{\left(\rho_{\theta_{k}}+\gamma_{\theta_{k}}\right)\left(1+\rho_{\theta_{k}} \gamma_{\theta_{k}}\right)}{1+2 \gamma_{\theta_{k}} \rho_{\theta_{k}}+\gamma_{\theta_{k}}^{2}}
$$





\section{Apêndice C}

\section{Desenvolvimentos relacionados aos modelos de séries temporais não estacionárias}

\section{C.1 Estruturas $\operatorname{ARH}(1)$}

Para demonstrar as propriedades do modelo (5.28), basta notar que

$$
\begin{aligned}
\operatorname{Var}\left(\theta_{j k t}\right) & =\psi_{\theta_{k t}} \operatorname{Var}\left(\xi_{j k t}\right) \\
\operatorname{Cov}\left(\theta_{j k t}, \theta_{j k\left(t-t^{\prime}\right)}\right) & =\sqrt{\psi_{\theta_{k t}}} \sqrt{\psi_{\theta_{k\left(t-t^{\prime}\right)}}} \operatorname{Cov}\left(\xi_{j k t}, \xi_{j k\left(t-t^{\prime}\right)}\right) \\
\operatorname{Corr}\left(\theta_{j k t}, \theta_{j k\left(t-t^{\prime}\right)}\right) & =\operatorname{Corr}\left(\xi_{j k t}, \xi_{j k\left(t-t^{\prime}\right)}\right) .
\end{aligned}
$$

Lembrando que $\xi_{j k t}$ segue um modelo estacionário, considerando as equações acima e utilizando os resultados da Seção B.1. os resultados seguem.

\section{C.2 Estrutura TH}

Para verificar os resultados relacionados ao modelo (5.31), a demonstração é análoga à da Seção C.1, considerando também os resultados da Seção B.2.

\section{C.3 Estrutura ARMAH(1,1)}

À semelhança da seção anterior, devemos utilizar os resultados da Seção B.3 e C.1.

\section{C.4 Estrutura AD}

Para demonstrar os resultados associados ao modelo (5.38), notemos que a partir dessa equação e de (5.39), vem que 


$$
\begin{aligned}
\operatorname{Var}\left(\theta_{j k 2}\right) & =\phi_{k 1}^{2} \psi_{\theta_{k 1}}+\psi_{\theta_{k 2}} \\
\operatorname{Var}\left(\theta_{j k 3}\right) & =\phi_{k 1}^{2} \phi_{k 2}^{2} \psi_{\theta_{k 1}}+\phi_{k 2}^{2} \psi_{\theta_{k 2}}+\psi_{\theta_{k 3}} \\
& \vdots \\
\operatorname{Var}\left(\theta_{j k t}\right) & =\sum_{t^{\prime}=1}^{t}\left(\prod_{l=t-t^{\prime}+1}^{t} \phi_{l}^{2} \psi_{\theta_{k l}}\right)+\psi_{\theta_{k t}} .
\end{aligned}
$$

De forma análoga, temos que

$$
\begin{aligned}
\operatorname{Cov}\left(\theta_{j k t}, \theta_{j k(t-1)}\right) & =\psi_{\theta_{k(t-1)}} \psi_{\theta_{k(t-1)}}^{*} \\
\operatorname{Cov}\left(\theta_{j k t}, \theta_{j k(t-2)}\right) & =\psi_{\theta_{k(t-1)}} \psi_{\theta_{k(t-2)}} \psi_{\theta_{k(t-2)}}^{*} \\
& \ldots \\
\operatorname{Cov}\left(\theta_{j k t}, \theta_{j k\left(t-t^{\prime}\right)}\right) & =\left(\prod_{l=1}^{t^{\prime}} \phi_{t-l}\right) \psi_{\theta_{k\left(t-t^{\prime}\right)}^{*}}^{*}
\end{aligned}
$$

Portanto, de C.1 e C.2 , os resultados seguem.

Azevedo, Caio L. N. 


\section{Referências Bibliográficas}

H. Akaike. Block toeplitz matrix inversion. SIAM Journal on Applied Mathematics, 24(2):234-241, 1973. 159

J. Albert. Bayesian estimation of normal ogive item response curves using gibbs sampling. Journal of educational statistics, 17(3):251-269, 1992. 8, 15, 18, 19, 20,65

J. Albert and M. Ghosh. Item response modelling, in Generalized Linear models : a bayesian perspective. D. K. Dey, S. K. Ghosh and B. K. Mallick eds, Marcel Dekker, New York, NY, first edition, 2000. 23, 37

J. H. Albert and S. Chib. Bayesian residual analysis for binary response regression models. Biometrika, 82(4): 747-759, 1995. 4

D. F. Andrade. Comparando o Desempenho de Grupos (Populações) de Respondentes Através da Teoria da Resposta ao Item. Tese apresentada ao Departamento de Estatística e Matemática Aplicada da UFC para o concurso de professor titular, 1999. 14, 116

D. F. Andrade and H. R. Tavares. Item response theory for longitudinal data : population parameter estimation. Journal of Multivariate Analysis, 95(1):1-22, 2005. 6, 8, 23, 120

D. F. Andrade, H. R. Tavares, and R. C. Valle. Teoria da Resposta ao Item : Conceitos e aplicações. $14^{0}$ SINAPE, ABE, primeira edition, 2000. 1, 14, 16, 18, 23, 30, 31, 35, 56, 68, 134

A. Ansari and K. Jadidi. Bayesian factor analysis for multilevel binary observations. Psychometrika, 65(4): 475-496, 2000. 170

A. Atkinson and M. Riani. Robust Diagnostic Regression Analysis. Springer-Verlarg, New York, first edition, 2000. 36

C. L. N. Azevedo. Métodos de estimação na Teoria da Resposta ao Item. Dissertação de Mestrado, IME-USP, 2003. 4. 17

C. L. N. Azevedo and D. F. Andrade. Bayesian Estimation in hierarchical latent $t \dot{z}$ distribution Rasch $\dot{z}$ Model. Trabalho apresentado no $56^{\text {th }}$ sessão do isi, lisboa edition, 2007. 17, 208

C. L. N. Azevedo and D. F. Andrade. Asymmetric nominal response model : an investigation of latent trait recovery and a comparasion of mcmc with non mcmc methods. submetido ao Brazilian Journal of probability and statistics, 2008a. 208

C. L. N. Azevedo and D. F. Andrade. An investigation of item parameter and latent trait recovery in the asymmetric nominal response model : a comparasion of mcmc with marginal methods. Artigo em preparação, 2008b. 208 
F. B. Baker. Some observations on the metric of pc-bilog results. Applied Psychological Measurement, 14(2): 139-150, 1990. 31, 36

F. B. Baker. An investigation of the item parameter recovery characteristcs of a gibbs sampling procedure. Psychometrika, 22(2):153-169, 1998. 22, 38

F. B. Baker and Seock-Ho Kim. Item response theory : Parameter Estimation Techniques. Marcel Dekker, Inc, New York, NY, second edition, 2004. 4, 17, 18, 22, 23, 31, 56, 105, 198, 207

D. J. Bartholomew and M. Knott. Latent Variable Models and Factor Analysis. Kendall's Library of Statistics, first edition, 1980. 1

J. L. Bazán. Uma familia de modelos de resposta ao item normal asimétrica. Tese de Doutorado, IME-USP, 2005. 5, 17, $19,23,208$

J. L. Bazán, H. Bolfarine, and R. A. Leandro. Bayesian estimation via mcmc for probit-normal model in item response theory. Technical report, University of São Paulo, (15), 2004. 1

A. A. Béguin and C. A. W. Glas. Mcmc estimation and some model-fit analysis of multidimensional irt models. Psychometrika, 66(4):541-561, 2001. 14, 19, 33, 34, 65, 207

J. Berkhof, I. van Mechelen, and H. Hoijtink. Posterior predictive assessment of item response theory models. Applied Psychological Measurement, 15:337-354, 2001. 34

J. M. Bernardo and A. F. M. Smith. Bayesian Theory. John Wiley \& Sons, England, first edition, 2000. 22, 23

A. Bhargava, L. Franzini, and W. Narendranathan. Serial correlation and the fixed effects model. The review of economic studies, 49(4):533-549, 1982. 156, 158

D. R. Bock and S. H. C. du Toit. Parameter estimation in the context of nonlinear longitudinal growth models, in Methods in human growth research. R. C. Hauspie, N. Cameron and L. Molinari eds, Cambridge Univesity press, Cambridge, first edition, 2004. 210

D. R. Bock and M. Lieberman. Fitting a response model for dichotomously scored items. Psychometrika, 35 (2):179-197, 1970. 18

D. R. Bock and M. F. Zimowski. The Multiple Groups IRT, in Handbook of modern Item Response Theory. Wim J. van der Linden and Ronald K. Hambleton eds, Springer-Verlag, New York, NY, first edition, 1997. 2, 3, 13, 14, 115

R. D. Bock and M. Aitkin. Marginal maximum likelihood estimation of item parameters: An application of an em algorithm. Psychometrika, 46(4):433-459, 1981. 4, 6, 14, 17, 18,88

R. D. Bock, E. Muraki, and W. Pfeiffenberger. Item pool maintenance in the presence of item parameter drift. Journal of Educational Measurement, 25(4):275-285, 1998. 3. 88

W. J. Browne. Applying MCMC Methods to Multi-level Models, PhD Thesis. University of Bath, 1998a. 170

W. J. Browne. Multilevel factor analysis modelling using markov chain monte carlo estimation, in Latent Variable and Latent Structure Models. G. A. Marcoulides and I. Moustaki eds, Lawrence Erlbaum Associates, Mahwah, NJ, firs edition, 1998b. 170

Azevedo, Caio L. N.

IME/USP 
W. J. Browne, D. Draper, H. Goldstein, and J. Rasbash. Bayesian and likelihood methods for fitting multilevel models with complex level-1 variation. Computational Statistics \& Data Analysis, 39(2):203-225, 2002. 170

W. J. Browne and David Draper. A comparison of bayesia and likelihood-base methods for fitting multilevel models. Bayesian analysis, 1(3):473-514, 2006. 170

A. S. Bryk and S. W. Raudenbush. Apllying the hierarchical linear model to measurement of change problems. Psychological Bulletin, 101(1):147-158, 1987. 151

F. B. Gonçalves. Análise Bayesiana da Teoria de Resposta ao Item: Uma Abordagem Generalizada. Dissertação de Mestrado, DME-UFRJ, 2006. 3

R. J. Carrol, D. Ruppert, and L. A. Stefanski. Measurement error in nonlinear models. London. Chapman \& Hall, London, second edition, 2005. 157, 209

G. Celeux and J. Diebolt. The sem algorithm : a probabilistic teacher algorithm derived from the em algorithm for the mixture problem. Computational statistics quarterly, 2:73-82, 1985. 7. 208

K. Chaloner and R. Brant. A bayesian approach to outlier detection and residual analysis. Biometrika, 75(4): 651-659, 1988. 4

M.-H. Chen and Q.-M. Shao. Monte carlo estimation of bayesian credible and hpd intervals. Journal of computational and graphical statistics, 8(1):69-92, 1999. 47, 198

Ming-Hui Chen, Qi-Man Shao, and J. G. Ibrahim. Monte Carlo Methods in Bayesian Computation. SpringVerlag, New York, first edition, 2000. 31, 32, 87

E. M. Chi and G. C. Reinsel. Models for longitudinal data with random effects and ar(1) errors. Journal of the American Statistical Association, 84(406):452 - 459, 1989. 158

S. Chib and B. P. Carlin. On mcmc sampling in hierarchical longitudinal models. Statistics and Computing, 9(1):17-26, 1999. 76

S. Chib and E. Greenberg. Understanding the metropolis-hastings algorithm. The American Statistician, 49 (4):327-335, 1995. 6, 170

S. Chib and E. Greenberg. Analysis of multivariate probit models. Biometrika, 85(2):347-361, 1998. 76

W. G. Cochran. Sampling Techniques. Wiley Series, New York, third edition, 2001. 15

M. R. Conoway. A random effects model for binary data. Biometrics, 46(2):317-328, 1990. 6

G. M. Cordeiro. Introdução à Teoria de Verossimilhança. $2^{0}$ SINAPE, ABE, 1992. 19

M. K. Cowles and B. P. Carlin. Markov chain monte carlo convergence diagnostics : a comparative review. Journal of the american statistical association, 91(434):883-904, 1996. 32

D. R. Cox. Regression models and life-tables. Journal of the Royal Statistical Society, B, 39(2):1-38, 1972. 6

F. M. M. da Rocha. Seleção de estruturas de covariância para dados com medidas repetidas, Dissertação de Mestrado. IME-USP, São Paulo, SP, 2004. 68, 72, 73, 77, 120

Azevedo, Caio L. N.

IME/USP 
M. Davidian and D. M. Giltinam. Nonlinear Models for repeated measurement. Chapman \& Hall, London, first edition, 1995. 2

J. A. de Araújo. Análise do rendimento em habilidade matemática via Teoria da Resposta ao Item. Monografia de especialização, UFPA, 2003. 55

C. E. DeMars. Sample size and the recovery of nominal response model item parameters. Applied Psychological Measurement, 27(4):275-288, 2003. 36

A. P. Dempster, N. M. Laird, and D. B. Rubin. Maximum likelihood from incomplete data via the em algorithm (with discussion). Journal of the Royal Statistical Society B, 39(1):1-38, 1977. 13,18

P. Diggle, K. Liang, and S. L. Zeger. Analysis of longitudinal data. Oxford:Clarendo press, Oxford, England, first edition, 2002. 72, 120, 130

P. J. Diggle. An approach to the analysis of repeated measurements. Biometrics, 44(4):959-971, 1988. 158

J. A. Douglas. Item response models for longitudinal quality of life data in clinical trials. Statistics In Medicine, 18(21):2917-2931, 1999. 1, 6, 84,88

B. Efron. Missing data, imputation, and the bootstrap. Journal of the American Statistical Association, 89 (426):463-475, 1994. 86

R. S. Ehlers. Introdução à Inferência bayesiana. Departamento de estatística, UFPR, Disponível em http://leg.ufpr.br/ ehlers/notas/bayes.pdf, acesso em 18/12/2007, 2005. 130

M. Eid. Longitudinal confirmatory factor analysis for polytomous item responses : Model definition and model selection on the basis of stochastic measurement theory. Methods of Psychological Research Online, 1(4): $65-85,1996.6$

L. Fahrmeir, G. Tutz, and W. Hennevogl. Multivariate Statistical Modelling Based on Generalized Linear Models. Springer-Verlag, New York, first edition, 2001. 153

J. P. Fox. Multilevel IRT : A bayesian perspective on estimating paramaters and testing statistical hypothesis. Unpublished PhD Thesis, OMD-University of Twente, 2001. 2, 4, 6, 7, 16, 20, 29, 31, 34, 151, 162

J. P. Fox. Stochastic em for estimating the parameters of a multilevel irt model. British Journal of Mathematical and Statistical Psychology, 56(1):65-81, 2003. 7

J. P. Fox. Multilevel IRT assessment, in New Developments in Categorical Data Analysis for the Social and Behavioral Sciences. van der Ark, Croon and Sijtsma eds, Lawrence Erlbaum Associates, Inc., London, first edition, 2004. 33, 35

J. P. Fox. Multilevel irt using dichotomous and polytomous response data. Psychometrika, 58(1):145-172, 2005. 7, 170

J. P. Fox and C. A. W. Glas. Bayesian estimation of a multilevel irt model using gibbs sampling. Psychometrika, 66(2):269-286, 2001. 7, 19,170

J. P. Fox and C. A. W. Glas. Bayesian modeling of measurement error in predictor variables using item response theory. Psychometrika, 68(2):169-191, 2003. 7, 19,170

Azevedo, Caio L. N.

IME/USP 
J.-P. Fox and C. A. W. Glas. Bayesian modification indices for irt models. Statistica neerlendica, 59:95-106, 2005. 35

D. A. Fraser and N. Reid. Adjustment of profile likelihood. Biometrika, 76(3):477-488, 1989. 18

D. Gamerman and H. F. Lopes. Markov Chain Monte Carlo : Stochastic simulation for bayesian inference. Chapman \& Hall/CRC, London, second edition, 2006. 19, 27, 32, 87, 206

W. Gander and W. Gautschi. Adaptive quadrature revisited. BIT Numerical Mathematics, 40(1):84-101, 2000. 18

R. Garland. Mid-point on a rating scale : Is it desirable ? Marketing bulletin, (2):66-70, 1991. 207

D. N. Geary. Modelling the covariance strucutre of repeated measurements. Biometrics, 45(4):1183-1195, 1989. 158

S. Geisser. Growth curves analysis, in Handbook of Statistics, 1. P. K. Sen and C. R. Rao eds., Elsevier, The Netherlands, 1980. 68, 210

A. Gelman. Prior distribution for variance parameters in hierarchical models. Bayesian Analysis, 1(3):515-533, 2006. 23, 26, 78, 170

A. Gelman, J. B. Carlin, H. S. Stern, and D. B. Rubin. Bayesian data analysis. Chapman \& Hall, London, second edition, 2004. 5, 22, 25, 26, 36, 77, 78, 83

S. Geman, D. Geman, K. Abend, T. J. Harley, and L. N. Kanal. Stochastic relaxation, gibbs distributions and the bayesian restoration of images. Journal of Applied Statistics, 20(5):25-62, 1993. 27, 68

M. Genton. Skew-Elliptical Distributions and Their Applications: A Journey Beyond Normality. Chapman \& Hall, London, first edition, 2004. 208

M. Ghosh, A. Ghosh, Ming-Hui Chen, and A. Agresti. Noninformative priors for one-parameter item response models. Journal of Statistical Planning and Inference, 88(1):99-115, 2002. 23

R. D. Gibbons and D. Hedeker. Random effects probit and logistic regression models for three-level data. Biometrics, 53(4):1527-1537, 1997. 4

J. A. Gifford and H. Swaminathan. Bias and the effect of priors in bayesian estimation of parameters of item response models. Applied Psychological Measurement, 14(1):33-43, 1990. 22

W. R. Gilks, S. Richardson, and D. J. Spiegelhalter. Markov Chain Monte Carlo in practice. Chapman \& Hall, London, first edition, 1996. 4, 18, 27, 32

H. Goldstein. Multilevel Statistical Models. Kendall library of Statistics 3, 2003. 7, 151, 154

H. Goldstein, M. J. R. Healy, and J. Rasbash. Multilevel time series models with applications to repeated measures data. Statistics in Medicine, 13(16):1643-1655, 1994. 152, 158, 162

F. A. Graybill. Matrices with Applications in Statistics. duxburry classic series, first edition, 2001. 122

P. J. Green. Reversible jump markov chain monte carlo computation and bayesian model determination. Biometrika, 82(4):711-732, 1995. 130,134 
R. K. Hambleton and H. Swaminathan. Item Response Theory : Principles and Applications. Kluwer Academic Publishers, Boston, first edition, 1985. 1

R. K. Hambleton, H. Swaminathan, and H. J. Rogers. Fundamentals of Item Response Theory. Newburry Park : Sage publications, first edition, 1991. 1

J. D. Hamilton. Time series analysis. Princeton University, Princeton, New Jersey, first edition, 1994. 68, $104,156,159,160,164$

M. R. Harwell, F. B. Baker, and M. Zwarts. Item parameter estimation via marginal maximum likelihood and an em algorithm: A didactic. Journal of Educational Statistics, 13(3):243-271, 1988. 17

M. R. Harwell and J. E. Janosky. An empirical study of the effects of small datasets and varying prior variances on item parameter estimation in bilog. Applied Psychological Measurement, 15(3):279-291, 1991. 22

Michael Harwell, Clement A. Stone, Tse-Chi Hsu, and Levent Kirisci. Monte carlo studies in item response theory. Applied Psychological Measurement, 20(2):101-125, 1996. 42

D. Hedeker and R. D. Gibbons. Longitudinal data analysis. Wiley Series, New York, first edition, 2006. 68, 72

M. S. Hendryx, M. G. Haviland, R. D. Gibbons, and D. C. Clark. An application of item response theory to alexithymia assessment among abstinent alcoholics. Journal of Personality Assessment, 58(3):506-515, 1992. 1

H. Hoijtink and I. W. Molenaar. A multidimensional item response model : constrained latent class analysis using gibbs sampler and posterior checks. Psychometrika, 62(2):171-190, 1997. 33

R. A. Horn and C. R. Johnson. Topics in Matrix Analysis. Cambridge university press, United Kingdom, first edition, 1991. 28

J. De La Horra and M. T. Rodríguez-Bernal. The posterior predictive p-value for the problem of goodness of fit. Test, 8(1):117-128, 1999. 34

C. Huber-Carol, N. Balakrishnan, M. Nikulin, and M. Mesbah. Goodness-of-Fit Tests and Model Validity. Statistics for Industry and Technology, Birkhäuser, New York, first edition, 2002. 36

C. L. Hulin, R. I. Lissak, and F. Drasgow. Effect of sample size, number of biased items, and magnitude of bias on a two-stage item bias estimation method. Applied Psychological Measurement, 6(3):249-260, 1982. 135

K. Imai and D. A. van Dyk. A bayesian analysis of the multinomial probit model using marginal data augmentation. Journal of Econometrics, 124(2):311 - 334, 2005. 76

V. E. Johnson and J. H. Albert. Ordinal data modelling. Springer-Verlag, Inc, New York, NY, first edition, 1999. 18,37

R. H. Jones. Maximum likelihood fitting of arma models to time series with missing observations. Technometrics, 22(3):389-395, 1980. 160

R. H. Jones. Serial correlation or random subject effects ? Communications in statistics. Simulation and computation, 19(3):1105-1123, 1990. 157, 158

Azevedo, Caio L. N.

IME/USP 
R. H. Jones and L. M. Ackerson. Serial correlation in unequally spaced longitudinal data. Biometrika, 77(4): 721-731, 1990. 160,162

R. H. Jones and F. Boadi-Boateng. Unequally spaced longitudinal data with ar(1) serial correlation. Biometrics, 47(1):161-175, 1991. 158,162

A. Kamata. Some generalizations of the Rasch model by the hierarchical generalized linear model. Unpublished PhD Thesis, Michigan State University, 1998. 2

R. C. Kessler, G. Andrews, L. P. Colpe, D. K. Mroczek, Norman D. K., Walters S. L. T., and A. M. Zaslavsky. Short screening scales to monitor population prevalences and trends in non-specific psychological distress. Psychological Medicine, 32(6):959-976, 2002. 1

Seock-Ho Kim. An evaluation of a markov chain monte carlo method for the rasch model. Applied Psychological Measurement, 25(2):163-176, 2001. 38

Seock-Ho Kim, A. S. Cohen, F. B. Baker, M. J. Sobkoviak, and T. Leonard. An investigation of hierarchical bayes procedure in item response theory. Psychometrika, 59(3):405-421, 1994. 22

K. P. Kleinman and J. G. Ibrahim. A semi-parametric bayesian approach to generalized linear mixed models. Statistics in Medicine, 17(22):2579-2596, 1998. 208

M. J. Kolen and R. L. Brennan. Teste Equating - Methods and Pratices. Springer-verlarg, New York, second edition, 2004. 3, $14,69,115,116$

I. G. G. Kreft and J. de Leeuw. Introducing multilevel modeling. Sage Publications, London, first edition, 1998. 151

I. G. G. Kreft and J. de Leeuw. Multilevel analysis. Sage Publications, London, first edition, 1999. 151

N. M. Laird and J. H. Ware. Random-effects model for longitudinal data. Biometrics, 38:963-974, 1982. 151 . $152,153,168$

Y. Lee and J. A. Nelder. Hierarchical generalized linear models. Journal of the Royal statistical Society, B, 58 (4):619-678, 1996. 2

R. C. Littell, J. Pendergast, and R. Natarajan. Tutorial in biostatistics modelling covariance structure in the analysis of repeated measures data. Statistics in medicine, 19(13):1793-1819, 2000. 153, 155, 157, 159

R. J. Little and D. B. Rubin. Statistical analysis with missing data. John Wiley \& Sons, New Jersey, second edition, 2002. 19, 21, 74, 84, 86, 119

C. Liu. Missing data imputation using the multivariate t distribution. Journal of Multivariate Analysis, 53 (1):139 - 158, 1995. 86

L. C. Liu and D. Hedeker. A fixed-effects regression model for longitudinal multivariate ordinal data. Biometrics, 62(1):261-268, 2006. 6. 22

F. M. Lord. An analysis of the verbal scholastic aptitude test using birnbaums three-parameter logistic model. Educational and Psychological Measurement, 28:989-1020, 1968. 135

Azevedo, Caio L. N.

IME/USP 
F. M. Lord. Applications of Item Response Theory to Practical Testing Problems. Hillsdale : Lawrence Erlbaum Associates, Inc, first edition, 1980. 1

F. M. Lord. Maximum likelihood and bayesian parameter estimation in item response theory. Journal of Educational Measurement, 23(2):157-162, 1986. 18

F. M. Lord and M. R. Novick. Statistical Theories of Mental Test Scores. Reading, MA : Addison-Wesley, first edition, 1968. 1

J. R. Magnus and H. Neudecker. Matrix Differential Calculus with Applications in Statistics and Econometrics. Wiley Series, New York, revised edition edition, 1999. 71, 89

H. Mansour, E. V. Nordheim, and J. J. Rutledge. Maximum likelihood estimation of variance components in repeated measures designs assuming autoregressive errors. Biometrics, 41(1):387-294, 1985. 158, 159

G. S. Matos. Teoria da Resposta ao Item : Uma proposta de modelo multivariado. Dissertação de Mestrado, UFPE, 2001. 2, 3, 18,73

R. E. McCulloh, N. G. Polson, and P. E. Rossi. A bayesian analysis of the multinomial probit model with fully identified parameters. Journal of Econometrics, 99(1):173 - 193, 2000. 76, 89

R. P. McDonald. Normal-Ogive multidimensional model in Handbook of modern Item Response Theory. Wim J. van der Linden and Ronald K. Hambleton eds, Springer-Verlag, New York, NY, first edition, 1997. 5

G. J. Mellenbergh. A unidimensional latent trait model for continuous item responses. Multivariate Behavioral Research, 29(3):223-236, 1994. 5

R. J. Mislevy. Item response models for grouped data. Journal of Educational Statistics, 8(4):271-288, 1983. 13

R. J. Mislevy. Estimating latent distributions. Psychometrika, 49(3):359-381, 1984. 13,17

R. J. Mislevy. Estimation of latent group effects. Journal of the American Statistical Association, 80(392): 993-997, 1985. 13

R. J. Mislevy. Bayes modal estimation in item response models. Psychometrika, 51(2):177-195, 1986. 4, 17 , 18,22

R. J. Mislevy. Exploiting auxiliary information about examinees in the estimation of item parameters. Applied Psychological Measurement, 11(1):81-91, 1987. 6

R. J. Mislevy. Randomization-based inference about latent variables from complex samples. Psychometrika, 56(2):177-196, 1991. 14, 104, 209

R. J. Mislevy and M. L. Stocking. A consumer's guide to logist and bilog. Applied Psychological Measurement, 13(1):57-75, 1989. 18

G. Molenberghs and G. Verbeke. Models for discrete longitudinal data. 68

P. A. Morettin and C. M. C. Toloi. Análise de séries temporais. ABE, São Paulo, first edition, 2006. 156

Azevedo, Caio L. N.

IME/USP 
B. Muthén. LISCOMP: Analysis of linear structural equations with a comprehensive measurement model. Mooresville, IN: Scientific Software, second edition, 1988. 6

L. Nátis. Modelos lineares hierárquicos. Dissertação de Mestrado, IME-USP, 2000. 7

J. S. Nobre. Métodos de diagnóstico em Modelos Lineares Mistos. Dissertação de Mestrado, IME, 2004.68

R. T. Nojosa. Modelos multidimensionais na Teoria da Resposta ao Item. Dissertação de Mestrado, UFPE, 2001. 2

V. Nunez-Anton and D. L. Zimmerman. Modelinng nonstationary longitudinal data. Biometrics, 56(3):699705, 2000. 124, 157, 162, 164, 167

S. M. O'Brien and D. B. Dunson. Bayesian multivariate logistic regression. Biometrics, 60(3):739-746, 2004. 4

D. A. Pastor and S. N. Beretvas. Longitudinal rasch modeling in the context of psychoterapy outcomes assessment. Applied Psychological Measurement, 30(2):100-120, 2006. 4, 88

J. R. Patz and B. W. Junker. Applications and extensions of mcmc in irt: Multiple item types, missing data, and rated responses. Journal of Educational and Behavorial Statistics, 24(4):342-366, 1999a. 22

J. R. Patz and B. W. Junker. A straightforward approach to markov chain monte carlo methods for item response models. Journal of Educational and Behavorial Statistics, 24(2):146-178, 1999b. 4, 22

C. D. Paulino, A. A. Turkman, and B. Murteira. Estatística Bayesiana. Fundação Calouste Gulbenkian, Lisboa, primeira edition, 2003. 22, 34, 47, 93.

C. A. B. Pereira and J. M. Stern. Evidence and credibility: Full bayesian significance test for precise hypotheses. Entropy, (1):99-110, 2003. 209

S. W. Raudenbush and A. S. Bryk. Hierarchical Linear Models: Applications and Data Analysis Methods. Sage publications, London, second edition, 2001. 7

S. W. Raundebush, A. G. Bryk, Y. F. Cheong, and R. Congdon. HLM 6 :Hierarchical linear and nonlinear modeling [Computer software]. Scientific Software International., Chicago, 2004. 4, 88

M. J. Ree and H. E. Jensen. Effects of sample size on linear equating of item characteristic curve parameters. In D. J. Weiss (Ed.), Proceedings of the 1979 Computerized Adaptive Testing Conference, Minneapolis: University of Minnesota, Department of Psychology, Psychometric Methods Program, Computerized Adaptive Testing Laboratory, 1980. 135

A. C. Rencher. Methods of Multivariate Analysis. Wiley Series, New York, first edition, 2002. 77, 83

F. Rijmen, F. Tuerlinckx, P. De Boeck, and P. Kuppens. A nonlinear mixed model framework for item response theory. Psychological Methods, 8(2):185-205, 2003. 2

D. Rivers. Identification of multidimensional spatial voting models. Typescript, Department of political science, Stanford University, 2003. 115

C. P. Robert and G. Casella. Monte carlo statiscal methods. Chapman \& Hall/CRC, Springer-Verlag, second edition, 2005. 27, 32

Azevedo, Caio L. N.

IME/USP 
G. O. Roberts and S. K. Sahu. Updating schemes, correlation structure, blocking and parameterization for the gibbs sampler. Journal of the Royal Statistical Society, B, 59(2):291-317, 1997. 31.87

J. Rochon. Arma covariance structures with time heterocedasticity for repeated measures experiments. Journal of the American Statistical Association, 87(419):777-784, 1992. 152, 160, 162,164

J. Rochon and R. Helms. Maximum likelihood estimation for incomplete repeated-measures experiments under an arma covariance structure. Biometrics, 45(1):207-218, 1989. 157, 160,162

V. K. Rohatgi and A. K. Md. E. Saleh. An Introduction to Probability and Statistics. Wiley Series, New York, second edition, 1994. 57, 105

S. K. Sahu. Bayesian estimation and model choice in item response models. Journal of Statistical Computation and Simulation, 72(3):217-232, 2002. 19, 23, 207

F. A. Samejima. Estimation of latent ability using a response of graded scores. Psychometric Monograph, (17), 1969. 6

J. L. Schafer. Analysis of Incomplete Multivariate Data, Monographs on Statistics and Applied Probablity 72. Chapman \& Hall, London, first edition, 1997. 74, 119

S. Schilling and R. D. Bock. High-dimensional maximum marginal likelihood item factor analysis by adaptive quadrature. Psychometrika, 70(3):533-555, 2005. 18

P. K. Sen and J. M. Singer. Large Sample Methods in Statistics : An introduction with applications. Chapman \& Hall, London, first edition, 1994. 135, 146

J. M. Singer and D. F. Andrade. Analysis of longitudinal data, in Handbook of Statistics, 18. P. K. Sen and C. R. Rao eds., Elsevier, The Netherlands, 2000. 67, 68, 73, 120

S. Sinharay. A bayesian item fit analysis for unidimensional item response theory models. British journal of mathematical and statistical psychology, 59:429-449, 2006. 35, 209

S. Sinharay, M. S. Johnson, and H. Stern. Posterior predictive assessment of item response theory models. Applied Psychological Measurement, 30(4):298-321, 2006. 33, 35, 209

A. Skrondal and S. Rabe-Hesketh. Generalized Latent Variable Modeling: Multilevel, Longitudinal, and Structural Equation Models. Chapman \& Hall, London, first edition, 2004. 6] 153

T. Snijders. Analysis of longitudinal data using the hierarchical linear model. Quality and Quantity, 30(4): 405-426, 1996. 151, 152, 153

H. S. Stern and S. Sinharay. Bayesian model checking and Model Diagnostics, in Handbook of Statistics, 25, Bayesian Modelling, Thinking and Computation. Dipak K. Dey and C.R. Rao eds., Elsevier, The Netherlands, 2005. 35, 36

H. Swaminathan, R. K. Hambleton, S. G. Sireci, D. Xingi, and S. M. Rizavi. Small sample estimation in dichotomous item response models : effect of priors based on judgemental information on the accuracy of item parameter estimates. Psychometrika, 27(1):27-51, 2003. 22

M. A. Tanner and W. H. Wong. The calculation of posterior distributions by data augmentation. Journal of American Statistical Association, 82(398):5258-550, 1987. 18, 20

Azevedo, Caio L. N.

IME/USP 
H. R. Tavares. Teoria da Resposta ao Item para Dados Longitudinais. Tese de Doutorado, IME-USP, 2001.2 . 3, 8, 17, 18, 20, 30, 68, 74, 76, 88, 115, 122

H. R. Tavares and D. F. Andrade. Latent distribution parameter estimation and approximation. personal communication, 2006. 31.

H. R. Tavares, D. F. Andrade, and C. A. B. Pereira. Detection of determinant genes and diagnostic via item response theory. Genetics and Molecular Biology, 27(4):679-685, 2004. 1

G. C. Tiao and A. Zellner. On the bayesian estimation of multivariate regression. Journal of the Royal Statistical Society, B, 26(2):277-285, 1964. 68, 71, 78

L. R. Tucker. Maximum validity of a test with equivalent items. Psychometrika, 11(1):1-13, 1946. 31

R. C. Valle. Teoria da Resposta ao Item. Dissertação de Mestrado, IME-USP, 1999. 14

W. J. van der Linden and R. K. Hambleton. Handbook of Modern Item Response Theory. Springer-Verlag, New York, first edition, 1997. 5

H. M. Vianna. Testes em educação. IBRASA, São Paulo, SP, terceira edition, 1978. 1

M. West and J. Harrison. Bayesian Forecasting and Dynamic Models. Springer-Verlag, New York, first edition, 1999. 157, 209

R. D. Wolfinger. Covariance structure selection in general mixed models. Communications in Statistics Simulation and Computation, 22(4):1079-1106, 1993. 159

R. D. Wolfinger. Heterogeneous variance - covariance structures for repeated measures. Journal of Agricultural, Biological, and Environmental Statistics, 1(2):205-230, 1996. 159

J. A. Wollack, D. M. Bolt, A. S. Cohen, and Young-Sun Lee. Recovery of item parameters in the nominal response model: A comparison of marginal maximum likelihood estimation and markov chain monte carlo estimation. Applied Psychological Measurement, 26(3):339-352, 2002. 38

Q. Yao and O. J. Brockwell. Gaussian maximum likelihood estimation for arma models. i. time series. Journal of time series analysis, 27(6):857-875, 2006. 160

M. F. Zimowski, E. Muraki, R. J. Mislevy, and R. D. Bock. Bilog-MG : Multiple-group IRT analysis and test maintenance for binary items. SSI : Scientific Software, Chicago, 1996. 14, 18

Azevedo, Caio L. N.

$\mathrm{IME} / \mathrm{USP}$ 